Hexagon Series on Human and Environmental

Security and Peace VOL 9

Thanh-Dam Truong

Des Gasper

Jeff Handmaker

Sylvia I. Bergh Editors

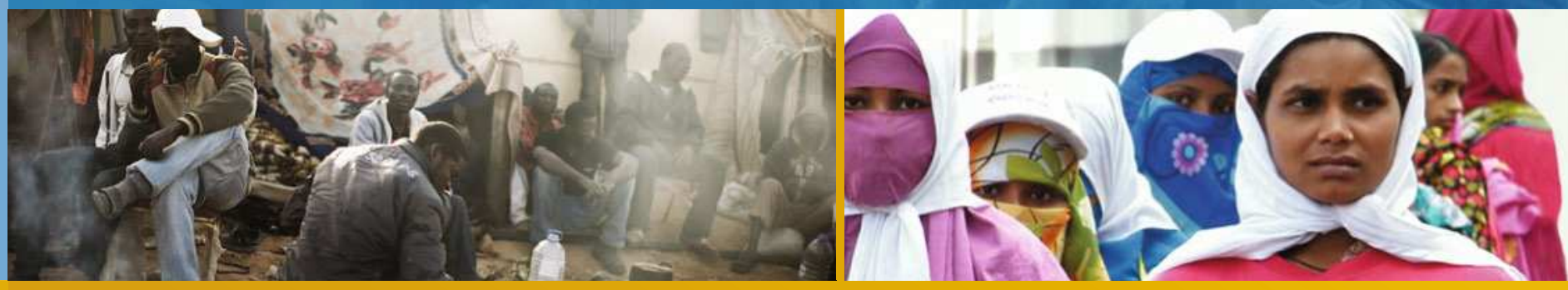

Migration, Gender

and Social Justice

Perspectives on Human Insecurity

Springer Open 
Hexagon Series on Human and Environmental Security and Peace Vol. 9

Series Editor: Hans Günter Brauch 

Thanh-Dam Truong, Des Gasper, Jeff Handmaker, Sylvia I. Bergh Editors

\section{Migration, Gender and Social Justice}

Perspectives on Human Insecurity

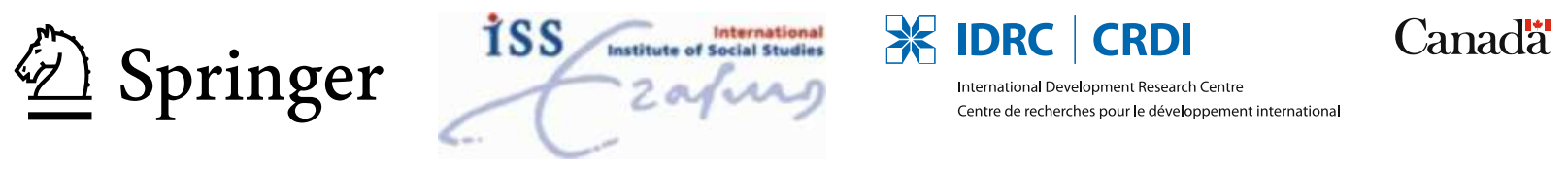


Editors

Dr. Thanh-Dam Truong, International Institute of Social Studies, Erasmus University Rotterdam, Kortenaerkade 12, The Hague, NL-2502 LT Netherlands.

Prof. Dr. Des Gasper, International Institute of Social Studies, Erasmus University Rotterdam, Kortenaerkade 12, The Hague, NL-2502 LT Netherlands.

Dr. Jeff Handmaker, International Institute of Social Studies, Erasmus University Rotterdam, Kortenaerkade 12, The Hague, NL-2502 LT Netherlands.

Dr. Sylvia I. Bergh, International Institute of Social Studies, Erasmus University Rotterdam, Kortenaerkade 12, The Hague, NL-2502 LT Netherlands.

ISSN 1865-5793

ISSN 1865-5807 (electronic)

ISBN 978-3-642-28011-5

ISBN 978-3-642-28012-2 (eBook)

DOI 10.1007/978-3-642-28012-2

Springer Heidelberg New York Dordrecht London

Library of Congress Control Number: 2013946205

(C) The Editor(s) and the Author(s) 2014. The book is published with open access at SpringerLink.com.

Open Access This book is distributed under the terms of the Creative Commons Attribution Noncommercial License which permits any noncommercial use, distribution, and reproduction in any medium, provided the original author(s) and source are credited.

All commercial rights are reserved by the Publisher, whether the whole or part of the material is concerned, specifically the rights of translation, reprinting, re-use of illustrations, recitation, broadcasting, reproduction on microfilms or in any other way, and storage in data banks. Duplication of this publication or parts thereof is permitted only under the provisions of the Copyright Law of the Publisher's location, in its current version, and permission for commercial use must always be obtained from Springer. Permissions for commercial use may be obtained through RightsLink at the Copyright Clearance Center. Violations are liable to prosecution under the respective Copyright Law.

The use of general descriptive names, registered names, trademarks, service marks, etc. in this publication does not imply, even in the absence of a specific statement, that such names are exempt from the relevant protective laws and regulations and therefore free for general use.

While the advice and information in this book are believed to be true and accurate at the date of publication, neither the authors nor the editors nor the publisher can accept any legal responsibility for any errors or omissions that may be made. The publisher makes no warranty, express or implied, with respect to the material contained herein.

Cover illustrations: The photograph of the Burmese women crossing the Moei River, also a border between Burma and Thailand, on their way to work in Mae Sot, North Eastern Thailand, was taken by Kyoko Kusakabe in 2007. The photograph of African migrant workers, living next to the airport in Tripoli, Libya hoping to fly home, was taken by Moises Saman in March 2011. The photograph of Bangladeshi returnee women migrant workers at a march to raise awareness about gender-based violence in migration, using the slogan "Safe Migration, Economic Development", was taken by Anindit Roy-Chowdhury for UN Women in 2011. All photographers granted their permission.

Copyediting: PD Dr. Hans Günter Brauch, AFES-PRESS e.V., Mosbach, Germany

Language editing: Michael Headon, Colwyn Bay, Wales, UK

Typesetting and layout: Thomas Bast, AFES-PRESS e.V., Mosbach, Germany

Printed on acid-free paper

Springer is part of Springer Science+Business Media (www.springer.com) 


\section{Contents}

Preface

Part I Introduction 1

1 Migration, Gender, Social Justice, and Human Insecurity 3

Thanh-Dam Truong, Des Gasper, and Jeff Handmaker

Part II Transformation of Social Reproduction Systems and Migration: Local-Global Interactions

2 From Breaking the Silence to Breaking the Chain of Social Injustice: Indonesian Women Migrant Domestic Workers in the United Arab Emirates

Sulistyowati Irianto and Thanh-Dam Truong

3 From Temporary Work in Agriculture to Irregular Status in Domestic Service: The Transition and Experiences of Senegalese Migrant Women in Spain Aly Tandian and Sylvia I. Bergh

4 Burmese Female Migrant Workers in Thailand: Managing Productive and Reproductive Responsibilities Kyoko Kusakabe and Ruth Pearson

5 Transnational Marriage Migration and the East Asian Family-Based Welfare Model: Social Reproduction in Vietnam, Taiwan, and South Korea Duong Bach Le, Thanh-Dam Truong, and Thu Hong Khuat

6 Masculinity at Work: Intersectionality and Identity Constructions of Migrant Domestic Workers in the Netherlands Aster Georgo Haile and Karin Astrid Siegmann

Part III The State and Female Internal Migration: Rights and Livelihood Security 121

7 Traversing Myriad Trails: Tracking Gender and Labour Migration across India Indrani Mazumdar and Indu Agnihotri

8 From 'Integration into Cities' to 'An Integrated Society':

Women Migrants' Needs and Rights in Fujian Province, China Yu Zhu and Liyue Lin 
9 Migration, Woodcarving, and Engendered Identities in

San Martín Tilcajete, Oaxaca, Mexico

Serena Eréndira Serrano Oswald

10 Strategic Invisibility as Everyday Politics for a Life with Dignity:

Guatemalan Women Migrants' Experiences of Insecurity at

Mexico's Southern Border

Martha Luz Rojas-Wiesner and Maria DeVargas

Part IV Complexity of Gender: Embodiment and Intersectionality

11 Masculinities and Intersectionality in Migration: Transnational Wolof Migrants Negotiating Manhood and Gendered Family Roles

Giulia Sinatti

12 Intersectionality, Structural Vulnerability, and Access to Sexual and Reproductive Health Services: Filipina Domestic Workers in

Hong Kong, Singapore, and Qatar

Thanh-Dam Truong, Maria Lourdes S. Marin, and

Amara Quesada-Bondad

13 Sub-Saharan Migrants' Masculinities: An Intersectional Analysis of Media Representations during the Libyan War 2011

Maria DeVargas and Stefania Donzelli

14 Complexity of Gender and Age in Precarious Lives: Malian Men, Women, and Girls in Communities of Blind Beggars in Senegal Codou Bop and Thanh-Dam Truong

Part V Liminal Legality, Citizenship and Migrant Rights Mobilization

15 Migrants' Citizenship and Rights: Limits and Potential for NGOs' Advocacy in Chile Claudia Mora and Jeff Handmaker

16 Diminished Civil Citizenship of Female Migrant Domestic Workers in Saudi Arabia and the United Arab Emirates Antoinette Vlieger

17 The Right to Education for Migrant Children in Thailand: Liminal Legality and the Educational Experience of Migrant Children in Samut Sakhon Kamowan Petchot

18 Challenges of Recognition, Participation, and Representation for the Legally Liminal: A Comment 
Part VI Migration Regimes, Gender Norms, and Public Action

19 Gender, Masculinity, and Safety in the Changing Lao-Thai Migration Landscape Roy Huijsmans

20 Public Social Science at Work: Contesting Hostility Towards Nicaraguan Migrants in Costa Rica Carlos Sandoval-García

Part VII Conclusion

21 'Women in Motion' in a World of Nation-States, Market Forces, and Gender Power Relations

Des Gasper and Thanh-Dam Truong

Abbreviations 



\section{Preface}

This book emerges from a collaborative effort between partners from Africa, Asia, Europe, and Latin America, funded by the International Development Research Centre (IDRC). The empirical data of the book originate mostly from the IDRC research programme on Women and Migration (2006-20II) that was funded as a component of the larger Women's Rights and Citizenship programme (WRC). Whereas previous support for research on gender by IDRC has been integrated into broader themes such as agriculture, health, social and economic policy, science and technology, the WRC programme has used the concept of citizenship as an entry point and sought to bring Southern voices more fully into current international debates in the field of gender and development. Built on the vision of a just world where women in the South are acknowledged to have a sense of self that is connected to the ideals of citizenship, the WRC programme has supported work directed at undoing social discrimination based on gender and enabling the realization of the full range of rights and freedoms for women.

With the support of IDRC, a team based at the International Institute of Social Studies (ISS) of Erasmus University Rotterdam has led the work of distillation and synthesis of the research findings of the Women and Migration research programme, by way of a sustained exchange of knowledge and practice between partners over a two-year period (2OII and 20I2). The synthesis project had the title Migration, Gender and Social Justice (MGSJ). It involved an opening workshop at ISS in The Hague in January 20II, followed by individual visits to The Hague for writing and discussion, and a concluding workshop at the Centre for Development Studies, Trivandrum (India) in February 20I3. The synthesis of research findings has aimed at promoting long-term collaboration based on reciprocal and selfreflexive learning between partners. It is hoped too that by connecting communities of research and practice the collaboration can contribute to a change in attitudes and views in order to bridge differences in the understanding of migration and thus improve policy interventions.

Against this background, the book is problem-oriented and multidisciplinary and connects the research results of international teams working across different research sites, with different emphases and on different scales of analysis. Given the diversity of research approaches, the richness of the findings, and the complex realities of rights claiming, the task of the MGSJ research project has been threefold.

1. The first task of the project has been to distil the research findings of WRC projects, and articulate commonalities and differences in the operation of different structures of power (gender, class, race/ethnicity, generation) and their interaction within the institutional domain of migration (with reference to organizational practices, legal regulations, circulation of material and ideational resources) which produce context-specific forms of social inequality.

2. The second task was to generate critical reflections on the intersection of the different power structures that circumscribe the space for migrants to claim rights, and to relate these perspectives with existing approaches to social justice. For this purpose additional contributions were solicited to cover core issues that had not been fully addressed by the WRC projects, including legal liminality and how the social construction of not only femininity but also masculinity affects all migrants and all women. 
3. The final task has been to jointly produce both an academic volume and a set of policy briefs ${ }^{1}$ from the perspective of the South that can be used in engagement with policymakers. Such an engagement can help identify connections between different forms of rights violation and accountability in different locations, in order to improve the styles and structures of the administration of migration.

We hope this book contributes to processes of change in the perceptions and values inscribed in the framing of policy, and those held by migrants and related actors, and will thereby contribute to improve inter-group interactions and respect for migrants' rights.

The Hague, February 2013

Thanh-Dam Truong, Des Gasper, Jeff Handmaker, and Sylvia I. Bergh

1 The policy briefs are available for free download at: 〈http://www.iss.nl/IDRC〉. 


\section{Acknowledgments}

We would like to acknowledge the contributions to the preparation of this book by many individuals and organizations.

First and foremost, the book rests on the work of a large number of researchers and research teams from many different countries. It has been a pleasure to work with them in presenting their findings and perspectives, and to help to interconnect these rich materials.

Secondly, the book would not have been possible without the initiative and generous support from the International Development Research Centre (IDRC) for the synthesis project Migration, Gender and Social Justice (MGSJ) coordinated by the International Institute of Social Studies (ISS) in The Hague, led by Thanh-Dam Truong. Among the IDRC staff, we thank especially Ramata Molo Thioune, who supervised the project with keen interest and a facilitating flexibility.

The IDRC project budget allowed us to host several contributors as visiting fellows and organize seminars at which early draft chapters were presented and discussed. It also enabled us, amongst other items, to conduct an inception workshop in The Hague, which brought together many of the contributors and ensured an invaluable discussion of the themes running through this book. Our appreciation is extended for the support of several ISS-EUR alumni in workshop logistics, especially Camilo Villa, Tamara Soukotta, and Sophie Conin.

Thirdly, during the workshop, and through the subsequent two years, we benefited from the involvement, administrative support, and intellectual contributions of colleagues at ISS and elsewhere, including Silke Heumann, Helen Hintjens, Roy Huijsmans, Rosalba Icaza, Mahmoud Messkoub, Linda McPhee, Karin Astrid Siegmann, Giulia Sinatti, Rene Spitz, and Joop de Wit. At the MGSJ panel organized on the occasion of the ISS's 6oth Lustrum festivities in October 20I2, we benefited from commentaries by Han Entzinger, Eleonore Kofman, Ruth Pearson, and Helen Schwenken.

Fourthly, we wish to thank the following peer-reviewers whose valuable comments greatly enhanced the quality of the various chapters: Fikret Adaman, Kif Augustine Adams, A. K. Bagchi, Beth Baker-Cristales, Magdalena Barros Nock, Amrita Chhachhi, Papa Demba Mahoumy Fall, Bina Fernandez, Arjan de Haan, Leo de Haan, Wendy Harcourt, María Hernández Carretero, Lan Anh Hoang, Jerrold Huguet, Roy Huijsmans, Rosalba Icaza, Majella Kilkey, Jonathan Klaaren, Mahmoud Messkoub, Sverre Molland, Ingrid Palmary, Emanuela Paoletti, Ruth Pearson, Doris Marie Provine, Louk de la Rive Box, Oscar Salemink, Helen Schwenken, Magueye Seck, Karin Astrid Siegmann, Giulia Sinatti, Massimiliano Trentin, Rolando Vasquez, Gustavo Verduzco Igartua, Sharuna Verghis, Sarah K. van Walsum, and Rekha Wazir.

Critically, the project could not have succeeded without the tireless efforts, efficiency, and human touch of our dear colleague Ms Maria DeVargas Ortiz, who has kept the editorial and administrative processes on track, ensured smooth communication with the authors and publisher, and contributed to the intellectual work. Appreciation is also extended to Paul Huber for his professional inputs in the preparation of the design of the project, David Wubs-Mrozewicz for taking charge of overseeing the project managerially, and Veronika Goussatchenko for her periodic project support. 
We would also like to thank the photographers who granted permission to use their photos for the front cover of this book, to the United Nations for permitting us to use a map, and to the College of the Southern Border of Mexico who designed another map of Mexico and its southern border with Guatemala specifically for the purpose of chapter Io.

The process of preparing the book has benefited throughout from the prompt and expert advice and support of Adj. Prof. Dr. Hans Günter Brauch, Editor of the Hexagon Series on Human and Environmental Security and Peace. Mike Headon and Thomas Bast are warmly acknowledged for their efficient language editing, and typesetting and indexing work, respectively.

We offer our thanks and our apologies to all those who have influenced this work and whom we have forgotten to cite by name. Despite our many debts to others, responsibility for any remaining errors remains ours alone.

Finally, we gratefully acknowledge the support of the IDRC grant as well as the ISS Open Access Fund to allow us to publish this book in Open Access, thereby greatly facilitating dissemination of an effort to present and understand something more about the situation of hundreds of millions of women migrants and their families, worldwide.

The Hague, February 2013

Thanh-Dam Truong, Des Gasper, Jeff Handmaker, and Sylvia I. Bergh 


\section{Part I Introduction}

Chapter 1 Migration, Gender, Social Justice, and Human Insecurity

Thanh-Dam Truong, Des Gasper, and

Jeff Handmaker 


\title{
1 Migration, Gender, Social Justice, and Human Insecurity
}

\author{
Thanh-Dam Truong, Des Gasper, and Jeff Handmaker
}

\subsection{Context of the Book}

This book examines the links between gender and migration and their implications for social justice thinking, both at the experiential and normative levels. It offers insights also into the uses of human security thinking as a framework for attention to social justice concerns, including in trans-border contexts, and to their intersectional complexity. The volume presents a diverse but selective set of empirical, theoretical, and methodological issues on gender in migration from migrant-centred and Southern perspectives. Its aim is to stimulate debate and discussion among migration scholars and professionals engaged in migration-related policy and to enable insights and enrich practices on gender and social justice.

The point of departure of the book is a recognition that the practice of governing migration as population flows has been closely connected with the rise of the modern nation-state, with the human sciences, and with the production of "knowledge about the population and individuals" (Foucault 2007). Such practices are to be understood as an interface between government and society, or what Foucault called 'governmentality' (Truong 2009, 20II). Central to this interface is the role of dominant forms of knowledge of society in shaping the regulation of socio-demographic processes, inclusive of gender relations, lifestyles, and their social forms. These forms of knowledge have created historically distinct regimes of discipline over individuals and their subject identities and self-regulation (Foucault 1995).

An understanding of the contemporary mode of governing migration in the depth that it deserves means tracing the different forms of knowledge and rationalities used by various actors (states, migrants, social networks, recruiting agencies). Each of these forms may be expressed differently, but together they buttress the relationships between specific interests and powers that define entitlements, rights, and obligations in migration, as well as the framings of 'gen- der' as a set of values linked to the identity of 'migrants' as social subjects.

Rethinking migration and social justice in the context of globalizing processes requires, firstly, challenging the dominant forms of knowledge that operate under the guise of neutrality, and revealing the hierarchies of power-to-interpret that undermine principles for a just world. Secondly, since the notion of belonging that underpins concepts of citizenship and rights is now polycentric and fluid in social terms, it must be located in society-centred practices of solidarity that seek to claim rights by emphasizing the interconnectedness and interdependence of rights, rather than defending them only on the basis of conventional hierarchies (i.e. civil and political over socio-economic and cultural) and delinking these legal rights from migrants' experiences and consciousness. Accordingly, social-justice-seeking strategies for migrants should directly challenge hegemonic understandings of human mobility produced by legal categorizations. Such categorizations can also be seen as sociopolitical constructs to be countered by an ascending approach to realizing rights. Gender hegemony (either male-centred or female-centred) must be subject to scrutiny in order to bring attention to the confluences of social relationships (gender, class, race, generation) that shape migrants' experiences and identities in ways that set the boundaries of their access to rights.

Taking off from the ideas of the feminist historian Joan Scott (I986), this book approaches 'gender' simultaneously as (I) a constitutive element of social relations built on the perceived differences between the sexes and (2) a signifier of power in a relationship often operating in conjunction with other types of power relations. This definition enables us to establish intersections of significant subsets of power relations that are specific in time and place and their social formations. Specifically, we note that in a changing environment of border controls, the institutional structures of the state, and knowledge about migration (internal and cross-border) are also changing. 
Rather than seeking wide empirical generalizations about the impact of migration on women's rights, this book essays empathetic and careful listening at many levels, presenting the research findings in ways that help bring to light a range of meanings of social justice. By situating notions of 'citizenship' and 'gender' in their contexts and problematizing their expression as a signifier of relational power, the book also takes on board the diverse ways in which femininities and masculinities are constructed and how they impact on the subject positions of migrants.

Distancing itself from the hegemonic treatment of the North and South as binary opposites of power and privilege, this book adopts a perspective on structural inequality and vulnerability as a phenomenon that cuts across countries, whether defined as belonging to the North or the South. In doing so, the authors open empirical and theoretical space for reflection on, and by, those groups of migrants (male or female) situated in vulnerable positions within the hierarchies of social power. Rather than a fixed state of being, vulnerability can be understood as a process of becoming while on the move. As Munck (2008) pointed out, adopting a Southern vantage point on migration in contrast to the Northern bias of the dominant discourses is a necessary step for moving towards a holistic global approach to the interlinked processes of migration and development, in order to develop a paradigm through which processes can be properly contextualized and placed in an adequate historical perspective.

This interpretation of the 'South' triggered our use of the United Nations' framework of Human Security (Commission on Human Security 2003) as one important point of reference for studying social justice in migration. Security, according to this framework, means the absence of, or freedom from, any threat to the core values of human dignity (including in particular physical survival, well-being, and identity with respect). The framework is based on the norms of human rights and human development and pays specific attention to population groups defined as 'people on the move', situated between different jurisdictions and rendered vulnerable by socially embedded forms of power operating at both the inter-group level and the level of states, including inter-state relations and citizen-state relations. With the exception of the work convened by the United Nations Educational, Scientific and Cultural Organization (UNESCO) (see Burgess 2007; Goucha/Crowley 2008), most work on human security has not done justice to the relationship between subjective identity and security as lived.
Though on various occasions the United Nations (UN) has emphasized the distinction between the meanings of 'state security' and 'human security', in practice the politics of securitization in different parts of the world demonstrates that the focus of practices called 'security' has mostly shifted from the security of those human beings on the move to 'border security' (Truong 20II). A variety of binary constructs - 'legal and illegal', 'regular and irregular', 'victim and agent' - have been utilized, and these have fuelled xenophobic sentiments and legitimized ever more stringent practices of control and discipline over migrants, including extraterritorial forms of control. From the perspective of the South, the notion of statehood has generally been subject to the impact of colonization and an artificial definition of the 'nation'. For this reason, in many cases the discursive apparatus that regulates migration cannot simply be read off from international models of codification. ${ }^{1}$ Identifying the discrepancy between the normative and the experiential helps to demonstrate the relationships between the categories of 'security', 'gender', and 'migration'. These are historically constituted by unequal political, economic, and social structures. New ways of realizing rights (through qualitative transformations in the relationships between people as well as with, and between, states and bureaucracies) are sorely needed.

This introductory chapter provides an overview of how different understandings of gender have influenced migration research and considers the values for policy of their various insights, especially when viewed from the perspective of migrants' experiences of human security. Section I.2 provides the theoretical context in which gender research on migration has emerged and the diverse ways in which the meanings of 'gender' have been applied, as well as the shortcomings and explanatory potentials of these meanings. Gendered forms of engagement with power should be analysed in contextual terms, contingent on the discourses and practices of migration and security in specific places. Finally, section I.3 presents a detailed overview of the chapters of the book and the studies it draws together.

1 Regular versus irregular; legal versus illegal; economic migrants versus asylum seekers; knowledge workers as subjects in trade in services versus migrant workers as subjects of immigration control; human trafficking versus human smuggling. 


\subsection{Concepts and Objectives}

Long dominated by a state-centric approach, models of analysis of migration have tended to favour the interests of states over people. In recent decades, new forms of analysis have emerged and new theoretical and empirical spaces have been opened up to address the multilayered phenomenon of migration. Alongside analyses that treat people's mobility as faceless and placeless flows, a wide range of perspectives now exist and these try to identify specific institutional domains where the specific causal relationships underlying certain types of flow and their human consequences may be located and explained.

Broadly, different conceptualizations of migration may be differentiated as follows: I) migration as an integral aspect of macro-changes (socio-demographic, economic, cultural, and political) in the longue durée (Braudel 1972; Castles/Miller 2003; Hatton/Williamson 2006; McKeown 2004; Hoerder 2002); 2) migration as a time- and space-bound phenomenon patterned by interactions between migration-related institutions and collective actors (household, labour markets, recruitment and employment agencies, migrants' organizations) (Brettell/Hollifield 2000; Faist 2000; Faist/Özveren 2004); 3) migration policy and practices as bounded by the ethos of nation-states, public opinion, and the politics of migrants' rights and identities (Thränhardt/Bommes 2008).

Migration research can thus be seen as being subject to two different ontological standpoints, static and interactive. The first limits the formation of migration systems to economic fundamentals (resources, population, exchange), while the second takes a more open approach to exploring the interactive dynamics capable of releasing non-actualized possibilities and unexercised powers within existing structures, and the conditions under which these produce legally and socially unanticipated migration systems, such as those formed by the confluence of human trafficking and smuggling practices (Kyle/Koslowski 20II; Truong 2008).

Feminist research on migration has been engaging with the power of cognition embedded in models of thinking on 'gender', human mobility, and migration. The key challenge has been to show how these models actually inform research and shape results, including how different understandings of gender influence the choice of sites of inquiry and methods (Mahler/ Pessar 2006; Silvey 2004a, 2004b). One striking issue is the emergence of the term 'feminization of migration' and its common usage in the last two decades.
Though popular in usage, so far the term refers mainly to the increasing statistical share of women in various migration streams (internal, cross-border, South-North, and South-South). In other words, the term conveys a representation of the empirical reality of migration based on a normative distinction between male and female migrants. Yet the evidence shows that the term can be extended to cover also the discursive codification of gender in (a) migration regimes that bear and/or promote distinct gendered values, norms, and characteristics, and (b) gendered forms of subjectivity and agency that emerge from the enactment of these regimes. Therefore, questioning why gender relations are constructed in the migration process as they are, and deciphering the logic of their operation and transformation, may help open a new space for conversations on the relationships between gender and migration and the implications for debates on the rights and human security of migrants.

\subsubsection{From International Migration to Transnational Mobility}

Migration scholarship has been traditionally influenced by a twofold methodological bias inherited from positivist sociology and its epistemological orientations. Until recently, this bias treated the nationstate and the individual as relatively fixed units of analysis and shaped a large core of theoretical explanations about contemporary patterns of internal and cross-border movements (Wimmers/Glick-Schiller 2002). The central focus of migration studies has been the monitoring of stocks and flows of migrants, later extended to their patterns of remittances and their capability of assimilation and social integration in host societies. Refugees have been handled as a separate category, through different procedures of status determination and classification, thus producing the field of refugee studies as a distinct entity. Migration research, by and large driven by policy concerns, is often structured more by ideas concerning what should be rather than what is actually happening and emerging. Assumptions that are disconnected from the social worlds of migration can obscure significant aspects of ongoing social transformations.

The intensification of various migratory flows since the I990s following the fall of the Berlin Wall and processes of economic liberalization worldwide has posed huge challenges for policymakers and researchers. In particular, the transformation of the state from society-led to market-led, coupled with the rise of social network theories and theories of the in- 
formation-driven post-industrial society, has exposed the limits of the assumption that the individual and the nation-state are relatively static entities.

The 'transnational' approach to migration offers an alternative perspective that sees the rise of nonstate actors in the globalizing processes as a force capable of curtailing the power of states to assume an increasing role in shaping cross-border migration; by implication these non-state actors also become capable of changing certain features of the societies of origin and destination (Smit/Guarnizo I999). Social network theories, as applied to the study of non-state actors, direct analytical attention to interactions between micro-, meso-, and macro-levels, and view individual migrants' decision-making as inseparable from influences at many levels (household, informal social groups, formal organizations and the community, and sometimes also nation-states).

Nowadays, the human dimensions omitted by the classical approach in migration studies are brought to the fore and integrated with the analysis of transnational migration as an aspect of identity formation within a plurality of intertwined life-worlds of migrants connecting the area/country of origin and of destination (Basch/Schiller/Szanton-Blanc I994). Flows of values and ideas play a central role in shaping migration patterns; wage differentials are not the only determinant. Portes and Sensenbrenner (I993) demonstrated the 'social embeddedness' of migration chains, and directed researchers to explore how migration is mediated through local structures of power and networks at both the sending and receiving ends. The 'circular and cumulative' characteristics of these chains have been noted, especially their certain degree of dependency on the paths laid down by earlier migrants (Massey/Arango/Hugo/Kouaouci/Pellegrino/ Taylor 2005). Furthermore, interactions between policy norms and the agency of migrants can change public opinion and so influence and alter the practices of states in migration management (Maas/Truong 20II; Irudaya Rajan/Varghese 20IO).

Turning to the literature that addresses specifically the links between migration and development, De Haas (2010) has shown that many of the discursive shifts in the migration and development debate may actually be seen as part of more general paradigm shifts in social and development theory. Furthermore, in view of the heterogeneous empirical evidence regarding the impacts that migration has on development, caution should be exercised against ideologically-driven positions. There is now a certain degree of consensus about the social and political world of migration being constituted by power relations that connect sending and receiving countries and areas. The detailed explanations of these relationships still vary according to the relative emphasis placed on different types of power, but generally migration (internal or cross-border) is becoming accepted as part and parcel of social transformations occurring on different scales. Migration research has now moved beyond the view of flows between fundamental building blocks (household, labour market, and nation-states) to cover also processes involving networks of relationships that are constantly changing, affecting individual migrants and affected by their actions. This has provided new empirical and theoretical spaces for gender analysis in migration research.

\subsubsection{Gender Equality and Women's Rights in Migration: Siting the Power of Denial}

The framing of women's rights in migration from the perspective of the South stemmed from the seminal work of Ester Boserup (1970) on women in processes of demographic transition and economic development. Women appeared in her work both as actors in migration and as bearers of the consequences of male migration. Her work played a prominent role in the UN-led campaigns in the I970s for women's rights in the development process and contributed to the framing of the policy debate on women's rights in terms of access to resources in countries categorized as 'underdeveloped' (Tinker 2006).

Migration research since then has included women as a category, and has generated a rich body of knowledge that refutes the view of the male migrant as always head of the family and instead regards women, analytically, as persons in their own right, whether migrating or staying behind. ${ }^{2}$ More than three decades of research on women as subjects of migration has generated a full critique of migration theories. Feminist research often begins with a perspective on social lives and uses plural methodologies, including historical, narrative, and case study approaches. Even those preoccupied with statistical

2 This has consequences for extant male-centred standards of measurement of the costs and benefits of migration (employment defined as paid economic activity; gains and risks defined in monetary terms; remittances and their impacts defined in monetary and investment terms; use of remittances for education, health, and food categorised as unproductive use; and so forth). 
analysis use these perspectives to challenge dominant representations.

Following Boserup, research that initially included women in dominant models of analysis of migration took off from the critique of state-generated demographic and socio-economic indicators that provided a 'view from above' which depicts men as being the central subjects. Chapter 7 by Mazumdar and Agnihotri provides an intensive example of such a critique. When women were included, their marital status was the main template used to infer their motivations. ${ }^{3}$ Scant attention was given to the unequal structures of power that govern their activities in migration as an entire process that connects sending and receiving ends, hence the silence on them as individual subjects of rights.

Phizacklea's edited volume (I983) focused on European countries and examined the place of migrant women in the labour market, the gender division of labour in factories, discrimination against second-generation migrant women in the workplace, and 'home working' as a pervasive form of employment at piece rates for migrant women. Studies on political and cultural identity have explored how second- and thirdgeneration women migrants still faced the boundaries of 'belonging' set by the societies of their residence, and exposed the links between gender, race, and class in the social construction of the 'nation' as 'community' (Anthias/Yuval Davis I992). By exposing the modern notion of the 'nation' as a false construct, this work laid the ground for exploring the distinctive social hierarchies (gender, race, class) built into it. Intersections of these hierarchies in white societies delimit the space for women of colour (who can be seen as migrants of different generations) to articulate their experiences of discrimination and non-belonging (Carby I999; Creenshaw I99I; Collins I986; I990). These studies were among the first to resist the liberal notions of women's rights and 'emancipation', and turn instead to issues of cultural representation as an

3 For example, Thadani and Todaro (1984) introduced a typology of women migrants that had been missing from earlier analyses, consisting of: (a) married women migrating in search of employment; (b) unmarried women migrating in search of employment; (c) unmarried women migrating for marriage reasons; and (d) married women engaged in associational migration with no thought of employment. The conceptualization of women's migration remained heavily influenced by views on the male-dominated heterosexual family as an institution. obstruction in a terrain of struggle for economic, political, and social rights.

Turning to the literature that has addressed the links between migration, gender, and development, Sassen-Koob (I984a) noted that export-oriented production and women's international migration since the 1970s have evolved into mechanisms that incorporate women from the South into wage labour in and for the North. Women migrants have filled emerging labour demands in the urban service sector in metropolitan centres that have acquired a global role (Sassen-Koob I984b). Research that integrated the household as an analytical sphere to account for decisionmaking and resource distribution has looked at links between rural-urban migration and poverty. Such studies demonstrated gender-differentiated motivations for, and the impacts of, migration, and how class and gender relations at the household and community levels have structured migratory processes (Phongpaichit I982; Chant I998; Wright I995). Phongpaichit's work on the migration of young women from rural Thailand to Bangkok to take up employment as masseuses demonstrated the gendered aspects of urban-rural linkages. Though she examined migration as an outcome of individual decisions, she also demonstrated its link with women's responsibilities as daughters. Their remittances not only sustained their rural households but also sustained cultural practices at the community level such as maintaining temples and village ceremonies. From this perspective, women's migration may be seen as integral to the intergenerational process of social and cultural reproduction, and as reflecting the relational nature of female agency.

Explaining the differentiated motivation of migration between men and women requires understanding the gendering of the household as a site of power where many activities and interests can be viewed as cooperative conflict (Sen I990) and where gender as cultural hegemony strongly influences behaviours and defends the legitimacy of gender norms (Kabeer 2000; Silvey 2004a, 2004b). These insights emphasize the contextual nature of 'gender' as power relations within the household defining the actors' cultural dispositions and their derived bargaining power. The labour market, social networks, and national policy and legislation also play an important role in making the motivation to migrate legitimate (Silvey 2007).

Gender equality strategies in migration that use a universal category of 'women' as subjects of rights without a complementary perspective on the social embeddedness of gender relations have encountered many difficulties related to the power of the state and 
its ethos on gender, which can operate as a doubleedged sword. On the one hand, this ethos can be used to define women's right to migrate for work and also impose restrictions on their mobility by drawing on the state's responsibility to 'protect' women, to the extent of 'infantilizing' them (Kapur 20IO). On the other hand, it can promote women's migration to join the global labour force, often in unregulated sectors such as domestic work and entertainment where they are excluded from civil, social, and political provisions for protection as workers.

\subsubsection{Gender as a Social Structure and Structuring Process}

The corpus of knowledge in feminist research that treats 'gender' as a property of the state, the economy, and social institutions has brought to the fore the significance of social reproduction, ignored by mainstream theories. Building on perspectives from feminist perspectives on political economy, Truong (1996; 2003; 2006) posits that the emergence of women's migration across borders as domestic helpers and sexual service providers constitutes a transfer of reproductive and sexual labour from one social group and nation to another. Parreñas (200I) has extended this idea and formulates the concept of the 'international division of reproductive labour' to cover the transfer of care duties between three groups of women: female employers in the receiving countries, migrant workers, and women in the countries of origin who care for those who stay behind. This form of analysis has exposed the chains of negative externalities by which an enhancement of care provision through labour import in some countries can lead to the denial of the entitlement to care of others who have stayed behind.

Contemporary migration chains in this 'intimate' side of the economy operate within a two-tiered system. Tier (I) consists of the care sector in which the chains have been formed by a combination of macroand institutional factors. These include the care deficit in major industrialized countries caused by ageing populations, structural reforms affecting the quality and coverage of care, and the growth of women's participation in the labour force without a corresponding rise in the range and intensity of men's 'domestic' participation. Tier (2) consists of the commercial sex sector, which has evolved with a different set of dynamics. These came about through the growth of tourism driven by the desire for foreign exchange earnings, combined with the political will to allow commercial sexual services to become the auxiliary of tourism (Truong I990; Moon 1997).

By treating movements in the care and sex sectors as integral to broader transformations in sending and receiving societies, a new area has opened up for theoretical reflection on the gender hegemony (in favour of men) in legal and policy frameworks that obliterate the reproductive side of societies and economies through the exclusion of domestic work and commercial sexual services as categories in the classification of occupations (Ehrenreich/Hochschild 2002; Yeates 20IO). This obliteration has produced ambiguous policy and social environments that have enabled the formation of distinct networks and pathways of movements of women across borders in search of employment in the care or sex sectors (Tyner 2004, Oishi 2005).

Migration chains in the care and commercial sexual services sectors show how a gender division of labour is an institution vested with power, and how we must treat gender as a resilient social structure. This power comes from the recursive and reiterative practices of individuals and groups who adhere to the notion of an asymmetrical gender order as 'natural', and from the neglect of the reproductive side of the economy. The following chapters in this book will illustrate this in detail - for example in the studies by $\mathrm{Ku}$ sakabe and Pearson (chapter 4); Duong, Truong, and Khuat (chapter 5); Haile and Siegmann (chapter 6); Serrano Oswald (chapter 9); Truong, Marin, and Quesada-Bondad (chapter I2). This neglect of social reproduction produces a hegemonic understanding of the law, of public morality about care as a moral duty, and of sex as intimacy, which refuses to recognize that the liberalization of economies and broadening market relations can free up a social and moral space for care and sexual services to become incorporated into (semi-industrial) labour relations.

Growing links between different national systems of social reproduction, now spanning most countries and regions, are being formed, and point to the formation of a new class of women based on their gender identity (female), their work (domestic helper, commercial sexual provider, foreign bride), and their unrecognized status in migration law (Truong 1996; Chin I998; Kojima 200I; Cheah 2009; Agustin 2003). The socio-legal space through which these migratory movements take place is ambiguous and therefore abuse is frequent and often without redress. The politics behind discursive constructions of gender, and of skills, work, and legislation regarding rights and entitlements, have become important areas of theorizing 
and empirical research regarding women's agency in migration.

By integrating macro-, meso-, and micro-perspectives, gender research on migration has produced new perspectives on (I) how migration systems evolve from gendered interactions between regulation and the actions of all those involved: migrants, employers, social networks, civic organizations, and law enforcement agents; (2) how the intersecting inequalities which shape the security-seeking actions of particular groups of migrants pose new challenges to justiceseeking actions. We will see this in detail in the chapters that follow. Gender is now approached as a matrix of power relationships operating at multiple levels: I) as a resilient structure expressed through the various social and cultural meanings of being male and female that are embedded in the ethos of the state; 2) as a set of relationships that have organized the social and cultural reproduction of society; and 3) as the formation of identities and the definition of subject positions in a given social order.

A key point of contention is whether the contemporary, economics-dominated framing of migration, and the diffusion of related practices of management, contain emancipatory potentials for marginalized migrants, or whether these have become another apparatus of power that has created new categories of gendered mobile subjects whose identities remain distant from the human rights framework based on citizenship as the main criterion of belonging. This has led to the exploration of the social construction of femininities and masculinities in migration. A small body of literature has now emerged on how transnational migration also impacts on masculine identities, norms, and conventions, and how men negotiate and reconstruct their identities as they encounter different gender regimes, rationalize their experience of racial discrimination, and find new lines of inter-group differentiation (Datta/McIlwaine/Herbert/Evans/May/ Wills 2008). Several chapters in this volume engage with those themes, including the studies by Haile and Siegmann (chapter 6), Sinatti (chapter II), and Huijsmans (chapter 20).

The use of 'gender' as a heuristic device in several disciplinary interfaces (political economy, law, sociology, and anthropology) in migration studies suggests that satisfactory treatments of the relationship between gender and human rights require insights and angles of multiple kinds. Aspirations for a genderequal world cannot avoid employing epistemic vigilance to discern where and which thinking about 'gender' is valid and how unjustifiable biases may be cor- rected. Beyond individual social attributes, the struggles for gender equality have different expressions, contingent on geography, history, and culture.

\subsubsection{From Citizenship and Legal Liminality to Acknowledging Multiple Scales of Social Justice}

A legacy of the Enlightenment in European history and philosophy, the concept of citizenship embodies the epistemological orientation discussed earlier: a focus on individuals within national boundaries and on defining the terms and conditions and benefits of membership in such a political community. Although membership of such a community on the basis of the idealized and seldom realized liberal notions of equal individual rights rarely guarantees social justice as lived, this formal membership remains an indispensable basis in the struggle for achieving rights for both internal and international migrants - men, women, and children.

Until very recently, the relationship between citizenship and migration has been debated mainly from the perspectives of receiving countries, using a variety of approaches to address the rights of 'strangers' in a framework of concentric circles of belonging. In the inner core, rights obtained either via jus soli (through territory) or jus sanguinis (through blood) define the ground for nationality. In the additional layers, the other legal principles that define criteria of belonging - for immigrants, foreign residents, or temporary visitors - vary according to particular histories, demographic concerns, and the particular concerns of migration policy at a given point in time, creating a hierarchy of statuses, as pointed out earlier in this introduction.

Debates on migration and citizenship in the United States of America (USA) and the European Union (EU) boomed during the I990s. Many contributions were from the perspective of cosmopolitanism, understood as a cognitive process essential in the recognition of 'strangers' and for overcoming the binary distinction between 'self' and 'others'. Bloemraad, Korteweg, and Yurdakul (2008) discern three main areas in the debates. These include: I) the legal foundations of citizenship and how particular conceptions of national belonging or institutional configurations can be linked to conceptions of citizenship as legal status or right; 2) how group rights and multiculturalism may or may not be realized, from the point of view of the normative political theory of citizenship, taking into account how the assimilation and integra- 
tion of immigrants and their descendants into receiving societies may also transform these societies culturally and socially; 3) equality of participation in a host country's economy, society, and political system.

From a socio-legal perspective, work on liminal legality in respect of migrants with an uncertain legal status (Menjivar 2006; Coutin 2002) is more ethnographically informed and provides a more grounded, albeit sombre picture. Centred on segmented integration, this body of work focuses on migrants whose social lives are situated in a zone of legal ambiguity and their ways of struggling for residency under tighter immigration policies based on an anti-immigration stance. Coutin (20II) especially highlights the trends in the USA towards a conflation of immigration and criminalization as a result of a process of securitization of the homeland following the attack of II September 200I. This perspective is applied and explored in Part $\mathrm{V}$ of the book.

Both bodies of literature show the need to approach the migrant populations as heterogeneous and amongst whom citizenship as entitlement to legal protection does not necessarily carry the same meanings and implications. Furthermore, this debate lacks a transnational perspective on citizenship that connects all moments of the migration process and the institutional accountabilities of the parties involved (sending, transit, and receiving states; third parties; and the migrants themselves). Chapter 2 by Irianto and Truong will offer such a perspective. Just as migration policy tries to control inflows, migrants themselves increasingly rely on third parties to adjust their trajectories from the ideal to the viable, and in so doing they enable the migration business to take root and expand, giving rise to multidirectional flows rather than the traditional bidirectional flows. Migrants' needs and aspirations are often adjusted to family circumstances as well as to legal and economic possibilities. The categories for the classification of migrants by 'place of origin' and 'place of destination' and as 'permanent', 'temporary', or 'return' migrants can nowadays be seen as policy constructs that have been outdated by the changing character of migration.

In a transnational context, liminal legality is also a reality for migrants whose struggle may not be about settlement but rather about legalizing their presence as a temporary or transient migrant in a long-term migration project. It is important to bring forward a perspective (such as that presented in the Irianto and Truong chapter) that connects forms of arbitrary treatment at different points in the migration process to provide a fuller picture of dysfunctions in particular migration systems operating within a national jurisdiction or across two or more jurisdictions. These forms may be locally rooted in the absence of protection measures or arise from the dysfunctional character of existing measures.

A perspective on transnational justice that adds insights into how global connections can demand additional responsibilities for social justice may help to keep states and relevant actors in check rather than allowing them to use discretionary powers to deflect their responsibilities. ${ }^{4}$ Such a perspective may help to develop notions of responsibility for social justice in an inductive way and contribute to an approach to realizing rights for migrants closer to their lived realities. The exercise of citizenship and entitlements in the transnational migration process is socially embedded at each phase; departure, work placement, and return. For the universal language of citizenship to become meaningful to migrants for whom existing systems of protection fail, preconceived ideas about their social positions must be challenged.

Nancy Fraser's (2009a) proposal for a reflexive and dialogical approach to social justice offers some interesting ideas for the field of migration. In her view, globalization has dramatically changed the terrain of social justice, clearly revealing the limitations of a statist model. Both the 'who' of justice as well as 'how' the 'who' should be determined are objects of struggle (Fraser 2009b: 283). Two existing stances on justice obligations are predicated on the notion of belonging, defined either by a political relationship (to the nation and/or state) or by an abstract notion of moral personhood (the humanity principle). These are not sufficient to address the requirements of what she calls transnational justice derived from cross-border social relations of interdependence. As acknowledged in chapter I5 $_{5}$ by Mora and Handmaker, the Westphalian stance carries the danger of discriminatory nationalisms, which can become aggressive, and of obscuring economic inequalities, hierarchies of status, and asymmetry of political power within a territory. The humanity stance offers a one-size-fits-all frame that does not fully take into account actual or historical social relations, and can foreclose the possibility that different issues require different frames or

4 For example, Young (2006) provides a model of political responsibility based on global connections, such as in the claims of the anti-sweatshop movement, or indeed, any claims of responsibility that members of a society might be said to have towards harm and injustices to distant strangers. 
scales of justice (Fraser 2009b: 290). A third approach to obligation to justice is what she calls the all-affected principle, which views the 'who' of justice as neither always national nor always global, and presents transnational injustice as contextually expressed.

What makes a group of people fellow subjects of justice is their objective co-imbrication in a web of causal relationships. Whoever is causally affected by a given action nexus has standing as a subject of justice in relation to it. Thus, the 'who' of justice is a function of the scale of social interaction. As the latter varies from case to case, so does the former....Unable to identify morally relevant social relations, it [the all-affected principle] treats every causal connection as equally significant (Fraser 2009b: 29I-292).

Fraser's solution is to address misframing as a problématique, by introducing the all-subjected principle, according to which "all those who are jointly subject to a given governance structure, which sets the ground rules that govern their interaction, have moral standing as subjects of justice in relation to it". To her, the structure of governance as a broad expression can encompass relations to powers of various types (states, inter-state, and non-state agencies that generate enforceable rules that structure important swathes of social interaction). The all-subjected principle affords a critical standard for assessing the (in)justice of frames; an issue is justly framed if, and only if, everyone subjected to the governance structures that regulate a given swathe of social interaction is accorded equal consideration (Fraser 2009: 293).

Applied to migration, the all-subjected principle is relevant in that it makes possible a critique of misframing migration caused by the epistemological biases that reproduce hierarchies of status and asymmetry of political power (e.g. knowledge migrants, labour migrants, asylum seekers, trafficked persons). Misframing can lead, and has led, to distinctive forms of economic and cultural injustice (as in the treatment of migrant domestic workers) and/or denial of equal standing within democratic deliberation (as in the case of asylum seekers and trafficked persons). In this respect the Global Forum on International Migration and Development and the associated events (Roldan/ Gasper 20II) and the World Social Forum which has taken up the theme of migration offer nascent political spaces for migrant organizations and socially engaged scholars to interact with each other to address meta-political injustice and its practical implications.

Bridging the discrepancy between the normative and the lived realities can help to reveal how the misframing of categories of 'security', 'gender', and 'migration' obscures the role of unequal political, eco- nomic, and social structures in determining migratory processes historically. It will help also in imagining new ways of realizing rights through qualitative transformations in significant social relationships underpinning these processes. This implies a new ethical responsibility among researchers and policymakers for sustained engagement in reciprocal and self-reflexive learning that values flexibility, diversity, and knowledge sharing in order to provide sharper analyses of the political practices and norms applied to social justice in migration. Co-responsibility and mutual respect are indispensable for innovations in thinking to resolve the tension between a notion of citizenship that is bounded by the nation-state as a determinant of legal and social belonging and the ongoing forces that are redefining territorial, cultural, political, social, and economic boundaries and, consequently, undermining traditional norms of belonging.

\subsubsection{From Human Security as Protection of People on the Move to Critical Studies of Borders and Belonging}

Human security analysis is a framework brought into prominence by the United Nations Development Programme (UNDP)'s Human Development Report of I994 (Gasper 2005, 20IO). It involves a pervasive concern for human vulnerability derived from all sources, including organized political violence, generalized deprivation caused by structural inequality, natural disasters, disease, and environmental degradation (Brauch/Scheffran 20I2). This concern matches and extends the two pillars of the UN Charter, the foundations of human rights instruments, "freedom from want" and "freedom from fear". Many disagreements are related to the stance on humanity at the meta-political level which can be used as the one-size-fits-all frame discussed in the previous section. Moreover, as Fukuda-Parr and Messineo (20I2) point out, its openendedness has made the concept vulnerable to political dynamics and to use for purposes unrelated to the original concern. These may include exaggerating new post-Cold-War security threats; locating these threats in the developing world; and facilitating shortterm policy-making in the absence of clear strategic foreign policy visions (Chandler 2008: 248).

In so far as migration is concerned, going by the reports made accessible by the human security gateway, ${ }^{5}$ policy intervention over "protection of people on the move" appears to be primarily directed at

5 See at: 〈http://www.humansecuritygateway.com/>. 
forms of movement caused by organized political violence (freedom from fear) and environmental stress. Much less attention is given by governments to those movements that are related to economic instability (freedom from want), though the unfolding economic crisis that is sweeping across the globe may well turn the tide towards even more stringent border control. Even for the responsibility to protect (RToP) individuals from large-scale and systematic violations of their human rights by states, in practice only nationals of those states are protected, whereas non-nationals who may be foreign workers tend to be left to fend for themselves or to be cared for by their own governments (see chapter I3 by DeVargas/Donzelli).

Furthermore, the term human security can be, and has been by some, retracted to the comfort zone of collective security, as in the case of the European Union, which has defined terrorism, proliferation of weapons of mass destruction, regional conflicts, state failure, and organized crime as the key threats to human security in Europe (Kaldor 2007). The impact of such a vision on migration is the securitization of borders that creates what Van Houtum (20I0) calls "the global apartheid of the EU's external border regime".

Debating social justice in migration requires awareness of the history shaping present circumstances and a perspective on human security that makes sense of migrants' own conceptions of 'security' and the relational aspects of their agency, as has been shown by Mushakoji (20II), Burgess (2007), and some of the national Human Development Reports (Jolly/Basu 2007). Integrating these aspects into critical analyses of the norms and politics of policy is an important task ahead. Being contingent on the operation of various power relations, the relationship between identity and security is subject to dynamics that can produce hybridized experiences of insecurity, as shown by the case of Libya (see DeVargas/Donzelli chapter ${ }^{3} 3$, as well as chapter 4 by Kusakabe/Pearson and chapter Io by Rojas).

For policymakers, this poses a major problem of assigning weight to and setting priorities for which content of identity is to be secured (with reference to gender, age, ethnicity, religious identity). For example, programmes for safe migration of young women tend to prioritize the prevention of human trafficking for sex work to protect a specific group of the population considered to be at risk, but are silent on the key aspects of gender relations in the everyday life of people who depend on migration as an opportunity for earning income. It is important to engage with the various representations of 'people on the move' which depict them as social problems and displace their position as subjects of rights. Showing how such representations can serve to deflect political responsibility at various levels necessitates interrogating the categories used in defining the subjects of human security by using migrants' experiences of insecurity as an indicator of the reality as lived, against which conventional hypotheses can be tested and new questions can be asked.

The coding of identities of 'people on the move' into standardized bureaucratic categories delimits the fields of their action and also those of border controllers as well as those of civic advocates for human rights. Spaces of legal ambiguity that have emerged from these forms of administrative coding of migrants have significant consequences for migrant workers, people fleeing from conflict situations, and people subject to human trafficking networks, in terms of their ability to make choices in the present and of their life chances in the future. Ensuring greater transparency in negotiating and honouring formal international commitments requires interrogating the categories used in defining the subjects of human security and understanding the power relations implicated in the applications of such categories through the perspectives of the migrants themselves. That is what this book attempts to do.

\subsection{Overview of the Chapters}

The chapters are grouped into five parts after this introduction and overview. They cover five continents, and address both intra-national and especially international migration, as well as both 'South-to-North' and 'South-to-South' migration. They illustrate the often shared issues across these categories and how such categorizations have become in many respects too crude.

\subsubsection{Social Reproduction, Gender, and Migration: Local-Global Interactions}

Part II opens with a chapter by Irianto and Truong (chapter 2), which sets the stage for critical reflections on social reproduction, gender and migration. It surveys the migration chains: from villages and townships all over the Indonesian archipelago, through various intermediate phases, locations, and agencies, in both Indonesia and the United Arab Emirates (UAE) - the weakly regulated private recruitment agencies, brokers and subcontractors at various levels in Indonesia, and the employment agencies and Government offices in 
the Emirates - through to homes in the UAE where Indonesian women domestic workers sustain the households and seek to save in order to support their own households seven to eight thousand kilometres away. Table 2.2 gives a valuable summary overview of the chain and the key aspects of structural dependency. Drawing on field research in Java and Abu Dhabi, as well as documentary research, Irianto and Truong report on every level of the chain, and the problems, misinformation, deceptions, and injustices that are common at each level. Some of the cases reported convey the appalling vulnerability of workers with no status in labour law and no powerful defenders. While including detailed treatment of common problems of employment in the UAE - paralleling the discussions in chapter I6 by Vlieger on Saudi Arabia and the UAE and by Truong, Marin, and Quesada (chapter I2) on Qatar - Irianto and Truong note that perhaps eighty per cent of the problems arise from shortcomings within Indonesia, and call for deficiencies there (in legislation, regulations and their enforcement, and in education, training, and supervision) to be addressed. Reflecting on this leads one back to their discussion of the ways in which domestic work and women workers are conventionally viewed, or ignored - framed or left out of the frame. Indonesian labour legislation itself, like the legislation in the UAE, does not recognize the category of domestic work.

Domestic worker migrants are very largely women, including in the case of Indonesia where they form by far the largest part of an emigrant labour force which, by 20I0, was sending remittances equal to eleven per cent of the country's gross domestic product. Rich countries increasingly depend for their social and family reproduction on migrant women's labour for a range of demanding or 'menial' tasks that their own populations are less willing to undertake: cleaning, cooking, childcare, and care of the sick and of the old. The large movement of women in rich and middle-income countries into paid employment, while the numbers of old people steeply rise, is based to a large extent on the ability to hire poorer women (and men) to undertake these tasks, whether women from their own country or - increasingly - women from poor countries who are drawn to richer locations by the low level of opportunities in their home places, the high expectations placed on them for support for family members, the hopes raised by successful examples, and the promises circulated by migration industry brokers. The social reproduction of rich countries (and rich people in middle- and low-income countries), in all the cycles of daily living and generational rise and fall, physical and emotional maintenance, is highly dependent on 'domestic workers' who are largely not recognized and protected as 'workers', and whose own physical and emotional maintenance is stressed and often violated. Illustrations of this recur in the later chapters by Tandian and Bergh (chapter 3), Truong, Marin, and Quesada (chapter I2), Vlieger (chapter I6), and Sandoval (chapter I9).

Highlighted by Irianto and Truong, the status of 'domestic work' as employment was finally acknowledged internationally in 20II, with the signing of the ILO Convention Concerning Decent Work for Domestic Workers. This 'breaks the silence' about domestic work, previously hidden behind use of euphemisms like 'guest' to excuse the absence of rights enforceable in law. The chapter engages with 'breaking the chain of social injustice' by re-crafting the links along the labour-supply chain (elaborating laws, spreading information to ensure laws are respected, and so on), rather than breaking the labour-supply chain itself.

Chapter 3 by Tandian and Bergh also extensively discusses domestic work, for that proved to be the main destination for the women workers brought to Spain for seasonal agricultural labour by a scheme initiated by the Spanish government and administered in cooperation with the Senegalese government. The scheme, intended to promote regulated seasonal temporary migration, facilitated the opposite: long-term 'irregular' in-migration, into personal care services and domestic work. Faced with a wide discrepancy between promised and actual living and working conditions, which in many other situations migrants have no alternative but to accept, in this case the migrants did have alternatives: many of them were well-educated, not merely the bearers of 'pairs of harvesting hands', and had networks in Spain or nearby (often, a husband or other close relative) and possibly in Senegal too (including potential access to persuadable or bribable public officials connected to the allocation of places in temporary migration schemes). Based on a set of 525 interviews with women migrants in Spain, the chapter also draws key insights from thirty-three supplementary in-depth qualitative interviews which allow it to explore more profoundly the women's lives, with attention not just to economic variables but to their whole economic and social situation in terms of their full range of rights as seen through their own eyes. While domestic work is a relatively easy entry sector, many interviews recount the advantage that some employers take of their 'irregular' employees, and how migrants may thus after a while move on 
again to less oppressive and humiliating work, if and when they see a possibility. Related to this they may seek to regularize their status. Undocumented migrants can fortunately already register with a municipality for access to health care and to schooling for children. But their options have become less and less favourable under the economic crisis in Spain. Overall, this sort of outcome of immigration appears unsatisfactory to both the Spanish state and to very many migrants. Tandian and Bergh comment on ways in which mutually more attractive arrangements might be established: Spain needs migrants' work contributions, while most Senegalese migrants may well aspire to dividing their time between Senegal and Spain, eventually returning permanently to Senegal; but the migrants will require more secure and respectful, rights-based, options for their employment in Spain than the sort of scheme that was examined in this chapter.

Chapter 2 by Irianto and Truong described the complex machinery of the multi-location migration system, and yet how much of it centres on the most intimate types of work, in homes; and those themes were echoed in chapter 3 by Tandian and Bergh. In contrast, Chapter 4 by Kusakabe and Pearson focuses on different types of work, in factories, and on intimate relations outside the workplace, in the homes of the women factory workers where they act as young mothers, and in their connections with their families in places of origin, in which they are daughters and providers. Kusakabe and Pearson's research concerns one of the larger cross-border migratory movements in the world: the possibly two million Burmese migrants in Thailand. They look at the export-oriented garment and textile factories concentrated in a number of cities just within Thailand along the border with Burma (Myanmar), which rely on the cheap labour of mostly young Burmese women; in particular the export factories located in Mae Sot. How have the (typically 'illegal' or 'registered irregular' or sometimes now registered as temporary) women factory workers combined their multiple responsibilities as workers, wives, mothers, household managers, daughters and economic supporters of their families who remain in (or exit from) crisis-ridden Burma? They are paid far below the official minimum wage, work extraordinarily long hours, and receive little or no support for the upbringing and education of their children from the Thai state, the Burmese state, or their employers. Instead they must rely on their own additional efforts and their networks of family and fellow migrants. Access to Thai schools, for example, re- quires a household registration, which is essentially inaccessible for these immigrants. Kusakabe and Pearson describe the struggles by and ingenuity of the women and their families, nuclear and wider, to maintain themselves on a daily basis and support the newborn, the young, the old, and the sick or disabled. Childcare is often sustained through frequent shifts of children or caretakers to and fro across the border. The chapter vividly conveys the contradiction between the Thai economy's hunger for cheap dependent Burmese labour and Thai society's predominant comprehensive hostility to the labourers and their families. Results from its ramifying investigation are reported in fuller detail in a book (Pearson/Kusakabe 2012).

Duong, Truong, and Khuat's chapter 5 continues the analysis of social reproduction, again with reference to both daily and generational processes. The emerging crisis of the East Asian family model has led to significant flows of both domestic workers and brides from South-East Asia to Japan, South Korea, Taiwan, and now also China, to compensate for a shortage of women in those countries, increasing longevity and female employment, and a growing unwillingness amongst some East Asian women to marry some categories of East Asian men and to follow the model's expectations, such as to care for a husband's parents. Foreign brides may be a solution for workingclass families who cannot afford the full-time hire of a foreign domestic worker and who continue to adhere to traditional gender norms. (So, for example, the recruited brides must proceed through the charade of a virginity check, which serves to assert masculine privilege and gender hierarchy rather than to actually check anything.) The chapter reports on a study of the movement of Vietnamese women to South Korea and Taiwan via commercially arranged marriages, and examines the contexts, pressures and motivations on both sides, and the brides' varied subsequent life paths. Research was undertaken in sending areas in rural Vietnam and in cities in Taiwan and Korea, amongst potential, actual and ex-brides, husbands, and others involved. The chapter employs Pearson (1997)'s concept of 'the reproductive bargain': the partly (re)negotiable arrangements that divide responsibilities for daily, generational, and social reproduction between different members of the household, and between households and the state and other agents. The cases studied here make it clear how the bargains today frequently span countries, and not just at the moment of marriage. The Vietnamese brides abroad are expected to function as the multi-duty pro- 
viders required in the Confucian family model but also, from their own side, as economic providers for their families of origin. If one or both of these aspects is not fulfilled the marriage becomes at risk of termination. But in any event, concludes the chapter, transnational marriages may only slightly postpone a crisis of social reproduction that is emerging in East Asia.

The final study in this part, by Haile and Siegmann (chapter 6), also concerns out-migration from South-East Asia that serves to fill gaps in domestic labour in rich countries. Like the Tandian and Bergh chapter 3 it examines migrants' work situation in the rich country, here with specific reference to Filipino and Filipina domestic workers who have irregular status in the Netherlands. Based on a far smaller-scale research project than the preceding studies, its distinctiveness lies in its main focus: men who are employed as domestic workers, an occupation that is seen as 'women's work' but which is the avenue most open to them. It complements a series of later chapters (by Sinatti [chapter II], Donzelli and DeVargas [chapter I3], and Huijsmans [chapter 20]) which likewise look at male migrants and ideas about masculinity, including about what is fitting work and suitable behaviour for men; and other chapters which explore predominant ideas about appropriate gender identities, such as the piece by Serrano Oswald (chapter 9). Like that chapter it applies ideas from Nancy Fraser $(2000,2007)$ about social recognition and distributive justice. The male domestic workers interviewed by Haile and Siegmann did not transcend beliefs that domestic work is feminine and of low status, but reconciled themselves to it as a route to fulfilling their manly role of material provisioning for family in the Philippines. Yet domestic work's multiple skills and essential role in social reproduction justify its own recognition as honourable and important, in addition to deserving inclusion in the regimes for worker protection.

\subsubsection{Women and Internal Migration: Visibility, Rights, and Livelihood Security}

The first three chapters in Part III are each the product of very large, though sharply contrasting, research projects that address different aspects of how migration within subcontinental-scale countries involves and affects women. The paper by Mazumdar and Agnihotri (chapter 7) covers women's work-related migration in the whole of India, and shows how it has grown enormously but has been conventionally misconceptualized and greatly under-recorded, including in the major government statistical publications. The paper by Zhu and Lin (chapter 8) looks at the current state of migration to the coastal province of Fujian in China, and to its capital city Fuzhou in particular; a part of the biggest migration in human history, to cities in the coastal regions of China during the past generation. It gives special attention to policy choices. The paper by Serrano Oswald (chapter 9), on a locality in Mexico, looks at the other side of massive outmigration: lives in the areas from which people have migrated but to which many wish to and do return, eventually or periodically. The three papers thus give special attention to, respectively: conceptualization, policy, and lived experiences; and each illustrates a special methodological depth of a distinctive type. In all the cases we see, first, how the very term 'migration', if it conveys an expectation of a once-for-all movement, fails to do justice to much of reality; and, second, that the greatest pressures arising from the multi-location lives which many families adopt, given their limited opportunities and their personal and cultural commitments, fall upon the shoulders of women.

Mazumdar and Agnihotri's chapter 7 addresses the enormous topic of women's employment-related migration in all of India, a country of over I.2 billion inhabitants. It is based on a correspondingly huge multi-year study that involved surveys in numerous parts of the country, both in places of origin and destination, complemented by other discussions and long-term literature review and critique. Even though women are officially recorded as the large majority of Indians who change their usual place of residence, due to their movement after marriage - and the recorded proportion of rural women who migrate for marriage has almost doubled since the early I990s women's migration has received little attention in research and policy on migration, since these moves are not seen as employment-related. Further, the criterion of change of usual place of residence leaves out the huge numbers of short-term migrants, which have grown enormously since the I990s and now contain a high proportion of women, as a result of the agrarian crisis in much of India and the marked decline in secure employment of women in most sectors in the era of market-led growth. "Armies of women [are] migrating in search of [seasonal] work", reported one observer cited in the chapter. But, due to a view of 'real' migration as meaning permanent transfer from rural to urban areas, short-term migrants only entered official figures as recently as $2007-2008$. Even then, those whose migratory cycles exceed six months are excluded; and the employment-related component in movements that are also for marriage is overlooked. 
Even so, the chapter takes such a component as secondary in importance and confines itself to the huge enough canvas of women's migration for the primary reason of paid employment. It aims to identify ways to better understand, support, and improve such employment.

By investigating what are the different modes of migration (including many that diverge from the stereotype picture - circulatory; short-term seasonal; irregular short-term; medium-term; daily or weekly longdistance commuters, including urban to rural; and migration for unpaid family care) and the different types of employment, the chapter gives a far deeper, richer picture than do the official statistics and associated analyses. It demonstrates, for example, the concentration of migrant women workers from the scheduled castes and tribes into the most marginal, poorly-remunerated, and physically arduous employment, especially in short-term and circulatory migration and particularly for work in agriculture and brickmaking. In general, the current patterns of female migration do not display a major shift of migrants into new types of employment that are more 'advanced'. Instead, the relatively fast-growing and higher-status urban service occupations are largely the preserve of urban uppercaste women; the women from outside the cities who enter such occupations are themselves in general of upper caste. Overall the study shows the desperate pressures on many poor women as the rural economy increasingly marginalizes some groups, groups who also have the least access to the relatively few formal sector jobs generated in the urban economy.

Zhu and Lin's chapter 8 on rural-to-urban migration in the economic boom province of Fujian in China presents a contrasting case, though again of a combination of economic structural transformation and yet continuity. The chapter preludes its empirical reportage with a detailed explanation of the welfare regime for migrants - the rights and actual access they have to housing, health and education services, insurance, and pensions. The Hukou household registration system has been the legal basis for social entitlements. The system has recently begun to evolve but large gaps remain. Social insurance has remained very largely place-bound: people who move on to another location cannot take all, or sometimes any, of the accumulated rights with them; hence most migrants choose not to participate in these insurance schemes or to withdraw from them. Drawing on a pair of large surveys, the chapter then maps the situation of migrants, in many dimensions. As in India, a large proportion of migrants are found not to be one-way trav- ellers, but to follow a circulatory pattern. Although in contrast to India women migrants are much more concentrated in manufacturing, sales, and service industries, they suffer from concentration in unstable, high-intensity, temporary, and relatively low-skilled types of work and enjoy very little formal welfare protection or upward occupational mobility. On the contrary, while popular with employers when young, women migrant workers 'are not wanted when they are over forty'.

Zhu and Lin return then to the policy issues arising from, and develop proposals to respond to, the tensions between, first, the enormous scale of migration, second, the restriction of socio-economic rights to people registered as belonging to an area, and third, the choice by very large numbers of people to spread their lives, loyalties, and resources across more than one location by circulating between their places of origin and destination and/or eventually returning permanently to the area of origin. Problems generated by the second factor, institutionalized in the bukou system, have been considerably reduced by recent policy changes that aim to extend the hukou-based, residence-based welfare system to cover in-migrants. But problems remain, including those due to the third factor: the choice by many migrants to maintain land, security, and family connections in their area of origin (not necessarily their exact birthplace) and/or some third location, both as insurance - given the limits and unreliability of demand for their labour in the cities where they are presently located - and out of family and regional loyalty. In addition to their parents and other relatives, often the migrants' children remain in the area of origin because of employment instability and the extra costs of urban residence. What is logically required to match the real nature of migration as not a once-for-all transfer but a fluctuating, risky, partial, long-term experimental process - is a nationalscale welfare regime rather than a place-based one. Rather than integration of migrants into urban areas, integration of the national society as a whole is required, to construct a welfare regime which has the same span as the economic system that it seeks to make whole. One can add that, eventually, the same logic may have to be acknowledged for the world as a whole.

After the colossal scale of the issues treated in the chapters on India and China, the next two chapters, both on Mexico, look at individual women's lives, though still with strong attention to bigger structures and processes. Serrano Oswald's chapter 9 focuses on the significance of migration for women who stay 
rather than for those who move. Migration studies that focus only on trajectories of departure and remittance do not capture many of the human implications and interconnections. She shows how large-scale migration to other parts of Mexico and especially to the USA brings major changes in a community of origin, especially for women, for they receive new and expanded duties; but that this occurs within an evolving continuity of tradition, male dominance, and female subordination. Based on years of research into an indigenous Zapotec locality in Oaxaca state in southern Mexico, her study looks at transformations and continuities in the local economy and society. Most migrants remain culturally rooted in their community of origin and intensely connected to it, maintaining frequent communication and revisiting regularly, often as the prelude to eventual return.

This pattern operates with particular intensity in the locality observed by Serrano Oswald because of the strength of indigenous identity and organization and the opportunities provided by tourism and the related growth of woodcarving, which have made seasonal international migration-and-return very common. The pattern has a special impact on women, who are expected to remain behind (or return and settle after they have children) and to maintain the community, the children, the culture, the elderly, the homes, the cherished agricultural base, and the local physical and organizational infrastructure, as well as to support the comings and goings of the migrants and the additional demands of the new economic activities, and often to bear a new child after a return visit home by their husband. The impact on the children of such migration is also intense, with an absent father and a severely loaded mother. Local women today work on average twenty to twenty-five hours extra per week when compared to their male counterparts, and the discrepancy is higher for women whose husband is away. Yet migrant men retain de jure authority and exercise it de facto, directly or through their blood relations. The role assigned to wives is as subordinates and as mothers, for whom all sacrifices for their family are mandatory.

In exploring this sort of social terrain, Serrano Oswald demonstrates the relevance of a combination of: first, critical ethnography, that allows local people to express and present themselves within long-term studies that provide space for the researcher to become aware of 'silences, omissions, and processes of invisibility'; second, social representation theory, which examines the systems of ideas used to define, characterize, and legitimate roles; and third, Nancy Fraser's theory of social justice, which distinguishes three aspects or types of justice, involving redistribution, recognition, and representation. Fraser (2009) argues the need for each of economic justice, political voice, and cultural respect, for each person and group; and in her own work has placed these issues in a global rather than solely national context (see Fernandez 2OII).

The remaining chapter in part IV, by Rojas-Wiesner and DeVargas (chapter Io), parallels the exploration of lived experiences of particular women seen in Serrano's chapter, and prefigures Section V's investigations of legal liminality. Rojas-Wiesner and DeVargas' study of long-term immigrants from Guatemala in south-eastern Mexico combines narratives gathered from in-depth interviews with a structural analysis. It shows the central importance of access to recognition and rights as a citizen, to be able to protest when one is a victim of injustice and excluded from basic services. In contrast, women of immigrant origin feel forced into invisibility, to avoid discrimination due to their origin or risk of being reported to the authorities and perhaps deported. This fear applies especially where networks and organizations that might protect them are too remote, geographically or socially. Increasingly restrictive immigration policies in the name of 'national security' keep migrant women powerless and vulnerable.

\subsubsection{Intersectionality in Migration and the Complexity of Gender}

The chapters in part IV articulate and apply the theme of intersectionality - the crucial significance of the combinations and interactions of factors that constitute a person's situation, including gender, economic class, ability, race and ethnicity, sexual orientation, religious and political affiliation, and more. Chapter II by Sinatti looks at transnational families, "families who maintain close relations and a sense of unity across geographic distances", as illustrated also in several other chapters. The definition has equal relevance to families spread across subcontinental-scale countries like India, China, and Mexico. Migration from Senegal is central to its society - a tenth of the population are outside at any one time - and its economy. The migrants are to a large extent young unmarried men, who carry high family expectations on their shoulders in addition to their individual dreams. Sinatti looks at the evolution of their ideas of gender roles, notably their constructions of masculinity, during the stressful years abroad, years in which they are 
separated from the comfortably familiar but may acquire great importance and higher status in their family as a provider of vital resources, while at the same time seeking to accumulate the resources to establish their own independent household. Typically the unmarried men eventually acquire a wife (or wives) during a trip (or trips) back to Senegal and subsequently live separated abroad while they seek to save for property at home. Sinatti's research on Senegalese migrants, in Italy and also when they are back in Senegal, reveals that while migration is seen as a path to increased status at home, including status as a serious man, it carries the price of years of low-status living abroad, without societal respect there, obliged to cook for oneself, and separated from the daily exercise of authority at home in Senegal and at risk of being treated only as the supplier of money. Some absent fathers maintain their family presence through carefully selected gifts. This is an example of how their role as man and father, which their emigration sought to ensure, is led to become something other than it would be if they were living at home.

The human right to health applies to migrants, to women, and not least to migrant women. In particular, migrant women have sexual and reproductive health (SRH) needs which are largely ignored by migration regimes, which frequently treat women as sexless units of labour to be used maximally and then discarded. Chapter I2, on "Intersectionality, Structural Vulnerability, and Access to Sexual and Reproductive Health Services" by Truong, Marin, and QuesadaBondad, shows the centrality of the issue of migrant workers' sexual and reproductive health. The Filipina women migrant domestic workers who were interviewed were largely in their child-bearing years, and most continued to have children during the cycle of their overseas employment. Older women too have SRH needs. The chapter thus transcends an abstraction that is convenient in the migration industry - an assumption that women workers are the equivalent of a washing machine or an electric iron, sexless production inputs, or that they must be rendered 'safe' through pregnancy prevention.

A holistic approach to the lives of real persons with real bodily and affective needs, in situations constituted by the intersection of multiple factors - cultural, psychological, biological, legal, financial - brings out migrants' human right to SRH, the constraints often encountered, and the need for cooperation between researchers and policymakers in the fields of health, migration, and gender. Foreign women domestics working in distant countries are physically and culturally isolated, typically not legally recognized as workers, and often culturally disempowered in such a way that they believe that sexual needs and many reproductive health issues are matters of shame that cannot be discussed. Truong et al. provide case studies of and from three of the financially richest countries in the world: Qatar, Singapore, and Hong Kong (Special Administrative Region of China). The chapter illustrates what is the truly shameful behaviour, that of employers who take advantage of vulnerable women to the maximum extent possible - working them without limit and in some cases abusing them physically, mentally, and/or sexually. The chapter also illustrates elements of good practice. Some non-governmental organizations (NGOs) try to build these workers' awareness, skills, self-image, and selfconfidence, to provide the bases for effective agency. Domestic workers' legal status in Hong Kong includes obligatory employment protection and health insurance, in contrast to the de facto situation in even Singapore, where only in $20 \mathrm{I} 2$ did migrant domestic workers receive the legal right to a rest day. In Qatar - the first- or second-ranked country in the world in many listings of real gross domestic product per capita - a 1963 Sponsorship Law still ties migrant workers to a single employer. Foreign workers are denied the legal protection given to Qatari workers and even their limited rights under the 1963 law are to a large extent not enforced, reflecting their marginal situation. In all three countries the health of the migrant domestic workers is largely dependent on the quality of their relationship with their employers. Financial wealth here appears something rather separate from human wealth.

The intersections examined in chapter 13 by $D e$ Vargas and Donzelli are those that structured the lives of foreign black sub-Saharan African male migrant workers in Libya during the war in 20II, and enabled the resulting extremes of insecurity, including armed attacks, that they faced as a group having multiple vulnerabilities. What the chapter distinctively adds is to show the importance of how these migrants were represented (and sometimes ignored) by the foreign media. This contributed to the allocation of attention and the processes of opinion formation amongst influential foreign publics and decision-makers, and in turn to the actions and inactions of the dominant foreign powers and the deaths of many migrants. Common in the representations of the diverse groups of black African male workers was that they were supposedly threats to some other actors, with an implication that their own protection and security had no pri- 
ority. In the background, argue DeVargas and Donzelli, amongst other notions (such as of proGaddafi black African mercenaries, an idea promoted by the anti-Gaddafi rebels) was often a Eurocentric presumption that the African workers in Libya were eventually headed for Europe and needed to be deterred, dispersed, and sent back southwards.

The chapter's analysis of a selection of reports during 20II in The New York Times, The Guardian, and Al Jazeera finds a shared and consistent set of themes: a picture of the events as a democratic revolution that advanced human rights; a mitigation of the violence against black Africans as being a product of a racist inheritance from the Gaddafi era and Gaddafi's perverse resistance, and as an unsurprising risk to be faced by rash illegal immigrants; and representations of masculinities that matched Connell (2005)'s categories: the hegemonic masterful controlled masculinity of the intervening Western powers; the imperfect complicit approximation by the anti-Gaddafi forces; and the inferior irrational and brutish masculinities of the Gaddafi regime and its desperate black African dependents. The chapter adds ideas on how to try to counter myth-making and marginalization, including by assertion of the right of those in insecure situations to specify what security signifies for them and what steps would improve their conditions.

The section concludes with a case study by Bop and Truong (chapter I4) of a particularly striking set of intersections. It concerns the migratory blind beggars, victims of river blindness, who move between Mali and Senegal, and the non-blind girls or young women who function as their guides or eyes. Rather than as individual migration, this form of migration is best understood through the lens of communities affected by an insidious illness, with sensitivity to the embeddedness of gender relations in the coping responses. The blind male migrants must deal with multiple conditions of disability to continue their role as the family providers. They are joined by non-blind boys and girls, but generally rely on the guidance of the girls and young women since boys mostly beg for themselves. A variety of social arrangements for guiding are in practice, including a modification of 'child fostering' as a tradition, biological kinship and marriage, and employment. Intersections between disability, gender, class, and age obliterate the visibility of the girl guides in the eyes of policymakers. Mutual dependency based on gender and age can be interwoven into layers of culturally defined intergenerational obligations, for which social justice strategies that are built only on the idea of the individual rights of women or children may not necessarily be appropriate.

The legal framework of human rights is understandably criticized as being too soft in its implementation and too individualistic in its orientation, approaching social justice and the advancement of minorities in terms of, for example, 'affirmative action' initiatives rather than by addressing the structural barriers faced by migrants. At the other extreme, efforts by states to administer migration policy regimes in a legal-technocratic manner have proved to be highly unsuccessful, as well as having negative consequences for migrants in terms of social justice. Whether framed by migrant advocates or government officials, narrow legalistic understandings of migrants' rights do not adequately address the social justice concerns of migrants. For example, relations of power as well as macro-economic policies tend to be much more significant for ensuring migrants' human security than the existence or non-existence of rights in law.

\subsubsection{Liminal Legality, Citizenship, and Migrant Rights Mobilization}

The chapters in part $\mathrm{V}$ explore the circumstances in which rights are denied to migrants by way of policy regimes and enforcement measures, illustrating what Menjivar (2006) has identified as a situation of liminal legality and which Coutin (2002) has described as legal non-existence. Chapter I5 by Mora and Handmaker on Peruvian migrants in Chile suggests that the main factors that structure the potential for advocacy, both by and on behalf of migrants, seem to be the presence of a vibrant civil society and the presence of democratic institutions that can serve as a reliable channel for rights claims. While acknowledging the potential for civic advocacy to protect migrants' rights, Mora and Handmaker elaborate the structural and institutional barriers faced by the Peruvian migrants, pointing out the consequences for the migrants and the specific challenges to be taken up by Chilean advocates. They argue that migrants and Chilean migrant advocacy organizations could make more productive use of Chilean state institutions than they have until now.

While migrant advocacy might hold much potential in Chile, the possibilities of invoking state institutions is substantially less possible in countries that highly restrict freedom of association, such as certain countries in the Gulf region, according to Vlieger in chapter I6. In a more extreme set of examples, she il- 
lustrates the appalling treatment of many women migrant domestic workers in Saudi Arabia and the United Arab Emirates, where the numerous protection efforts of migrant advocacy organizations, and in some cases by the states from which migrants have come, have proved highly insufficient. In addition to a range of restrictive laws, she vividly illustrates a range of social, structural, and institutional 'dysfunctions' faced by migrants working in the domestic service sector in both the United Arab Emirates and Saudi Arabia. Vlieger goes on to explain the various legal obligations owed by these states according to international law. In the light of the record of such widespread impunity, she concludes, rather depressingly, that there is, in fact, very little prospect for human rights to serve as a protective framework at all in either of these countries.

Similar difficulties in advocating for migrants' rights through state institutions exist in Thailand, as Petchot (chapter 17) observes in her chapter on Burmese children born in Thailand, but who lack citizenship and rights. Placing an emphasis on the duties of the receiving state, as Vlieger has done, she demonstrates that migrants pursue active transnational lives, with little if any official intervention, although the possibilities for migrants relying on state institutions to protect their human rights are far more limited than in Chile, but substantially easier than in Saudi Arabia. As in Chile, there appears to be at least some potential in Thailand for advocating social justice and human rights on behalf of migrants through appealing to law, media, and other social or state institutions. Petchot elaborates this further with reference to the specific institutional challenges that migrant children face in obtaining education in Thailand. Accordingly, she addresses the grey area between labour laws and migration laws in Thailand, and the consequences this has for migrant children's education. In doing so, Petchot reveals the structural opportunities for expanding migrants' rights in Thailand by exploiting the tensions between the labour laws and immigration laws.

The approaches adopted by the contributors in this section differ, although they cover similar case studies. For example, Vlieger and Petchot place greater emphasis on the receiving state and its institutions and less emphasis on the migrant herself. By contrast, Irianto and Truong, in chapter 2 at the outset of the book, adopt a more transnational perspective, accepting the inadequacies of the receiving state's institutions, but exploring the responsibility of the sending state, in this case Indonesia, as well as the scope for migrants wishing to exercise their agency and claim social justice, either on their own or through intermediary organizations.

Reflecting on these studies, Menjivar and Coutin's chapter I8 underlines the value of a socio-legal perspective and more particularly its potential to evaluate the limits of complex legal regimes to protect migrants or to serve as a reliable basis for policy implementation. As they make clear, in the absence of rights-based policies for the protection of migrants at the national level, migrants experience a situation of 'legal non-existence', or liminal legality, where the mere possession of legal status is of limited value, if at all. Liminal legality, they argue, is produced by national laws in receiving states that with increasing frequency grant new migrants nothing more than temporary statuses that limit their social rights and access to justice (e.g. 'registered irregulars'), thus enabling states to appear to satisfy both demands for rights and calls for restriction. Liminal legality is also produced through clashes between different legal orders or different agencies. It gives employers and the state itself greater power in relation to migrants while still using their labour when wished. In the precarious legal and social context experienced by migrants, the potential for violating their rights is high. Where states tend to resist the recognition, let alone realization of rights to migrants, the legal consciousness of stakeholders concerned with migration and its management becomes very important. Moreover, the consciousness that migrants have of their rights, that NGOs have of the possibilities for realizing those rights, and that government officials have in relation to state obligations towards migrants, plays a decisive role in mediating the liminal legal status of migrants.

In all of the preceding three case studies (Mora/ Handmaker [chapter 15]; Vlieger [chapter I6]; Petchot [chapter I7]), the socio-institutional factors make it extremely difficult for migrants to make a social justice claim, despite their 'entitlement' to a range of national, regional, and international rights. Even worse, conflating migration and crime, or crimmigration, can translate into highly restrictive policy and/or enforcement regimes (Welch 20I2; Stumpf 2006), including ethnic profiling by the police (Leun/Woude 20II). Systematic violation of migrants' rights can even be regarded as a form of structural violence, as opposed to 'direct violence', with the violence calculated in terms of the 'number of (life) years lost' (Galtung/Höivik 1979: 73). This could be a direct or indirect consequence of migration policies and/or enforcement measures, or other factors leading to mi- 
grants' social exclusion, especially where the possibilities for redress through public or official institutions are highly restricted. In short, both the tendency of states to resist rights, and of migrants and migrant advocacy organizations to resist oppressive state policies, can be measured. Barbara Oomen argues that "[i]n an empirical sense, this resistance can be understood as closely related to the constitutional pluralism that characterizes today's world". Looking beyond a strictly legal interpretation of this concept, as the authors in this section do, Oomen recognises that, from an anthropological perspective, interactions between these different normative orders often take place in a situation of "unequal power relations", where one system can "subvert, resist and evade the dominant legal order" (Oomen 20II: 2I).

The policy implication is that stakeholders involved in migrant advocacy - whether NGOs, state institutions, or international organizations - need to adopt a more nuanced and critical understanding of the dynamics of transnational migration and the realities of migrant life. Realizing social justice and migrant rights claims requires much more than a purely legalistic approach and must be intertwined with other, more grounded and migrant-centred strategies.

\subsubsection{Migration Regimes, Gender Norms, and Public Action}

Chapter I9 by Huijsmans in part VI is the last in the series of papers which pay particular attention to male migrants as gendered subjects. He does this within a perspective on the policy regime that governs migration from Laos to Thailand and in this respect the chapter figures also as the Janus partner to chapter 2 by Irianto and Truong. Haile and Siegmann (chapter 6) looked at male migrant workers with irregular status in domestic work; Sinatti (chapter II) discussed the role of notions of masculinity and how these are affected by the experience of international migration; DeVargas and Donzelli (chapter I3) considered the situation of African male migrants trapped in an armed conflict and stereotyped in ways that maximized their vulnerability; Bop and Truong (chapter I4) examined the multiple conditions of disability experienced by male beggars and their dependence on the support of young women and children; and here Huijsmans argues that the lack of attention to male migrant vulnerability in migration policy reflects hegemonic notions of masculinity which present hardship as something that real men must experience and overcome. His chapter looks at the rite of passage for young Lao men of spending some years away in Thailand, and examines how dominant gender notions mould the migration experiences of both men and women. In revisiting both the themes of migration regime and masculinity the paper highlights the link between two key elements in this book's analysis; the systemic subordination of women in migration regimes may only be overcome when the contributory ideas about not only femininity but also about masculinity are surfaced and reconsidered.

Although around sixty per cent of migrants from Laos (the Lao People's Democratic Republic) to Thailand have been women, a new migration policy regime formalizes the labour supply chain to Thailand by the insertion of authorized labour bureaus and is bringing an increase in the share of men. Migrants are supposed to enter only via the services of an authorized bureau. The new system is declared necessary in order to make migrants safer. But since undocumented migration remains predominant, due to the costs and inflexibility of the new formal system, and has become unsafe, migrant vulnerability has actually increased. The new bureaus are largely private migration-employment agencies that impose high charges and leave migrants uninformed and misinformed. Although their advance information is mostly misleading the bureaus do nothing when appealed to later by workers who are in difficulties. The high charges render most workers who use them indebted and hence insecure but tied to the agency and the assigned job. The system also has gender implications. First, prospective migrants using this channel are more dependent on parental approval and support in order to pay the charges, and so traditional gender notions often re-enter. The idea that women are more vulnerable, whereas men need a period abroad in order to grow as men, comes into play to reduce the share of women in migration. Second, domestic work is not recognized by the Lao state as an approved reason for migration; this serves as a way of asserting its honour in relation to its dominating neighbour Thailand. Women's migration into domestic work in Thailand continues as by far the largest migrant flow from Laos, given the limited domestic opportunities, but the women are forced to work irregularly in the eyes of the Lao state. Safety is not increased, while migration brokers reap gains. Policy functions as public theatre that fulfils objectives other than the ones declared.

The sequence of case studies concludes with a wide-ranging reflection by Sandoval (chapter 20) on the roles of migration research, researchers, and pol- 
icy campaigners, with reference to the case of Costa Rica. About ten per cent of Costa Rica's residents are immigrants; people from neighbouring Nicaragua comprise nearly seven per cent, a figure that is now growing only slowly. Nicaraguans play essential roles in the national economy but are widely stereotyped as a fast-growing horde of criminals and welfare-dependents, and this hostility is exacerbated now by a border dispute. Consistent with Michael Burawoy's call for "public sociology" (Burawoy 2005, 2007), Sandoval considers ways in which social scientists have contributed and could further contribute in this situation. So far these have ranged from seeking to clarify the real levels of immigrant population and its growth, through to involvement in taking up to the Supreme Court in 20II a writ of unconstitutionality against the State for new anti-immigrant legislation. Sandoval argues that international funders who fondly sponsor migration research, often on themes that have already been well studied, should spend rather more on supporting the necessary follow-up work of long-term policy advocacy and public education.

Much of the contribution by social scientists to public debate has pointed out how immigrants perform tasks that the local population no longer wishes to, notably heavy manual work in key export agriculture sectors and as domestic workers. Large numbers of Costa Rican women have joined paid employment because they can hire Nicaraguans to care for their children, homes, and older generations. But Sandoval finds Costa Rican society is not ready to acknowledge this fundamental interdependence; Nicaraguans are instead commonly represented as scroungers and 'Threatening Others'. Consequently, the next major type of social scientist involvement has been to try to counter unfounded stereotypes and their formation, for example the false claim that deterioration of public services under neo-liberalism is because of high demands placed on them by immigrants. In reality, predominantly working-age migrants require relatively little health care, for example.

A further type of involvement responds to the implicit overwhelming reliance on the nation-state as the basis for self-identification and collective identification in public debate. It tries to build on values of hospitality and solidarity, including on 'a social fabric of cosmopolitanism from below [that exists] around the eating establishments, clinics, or schools' in the binational communities where poorer Costa Ricans and Nicaraguan migrants co-reside. To articulate and convey this experience requires use of the methods of ethnography (as illustrated here in the chapters by
Tandian and Bergh [chapter 3] or Serrano [chapter 9], and the formats of popular culture, including music, film, videos, and novels. It requires also bridging the gap between abstracted policy advocates and analysts on the one hand, whose work remains in a vacuum when disconnected from popular discourses, and the community activists and practitioners on the other, who can connect well to these. A final, related, type of involvement has been trying to help migrant groups in their own organizations, participation, and self-projection, to help them make use of public spaces and connect to broader political actions and advocacy work.

Sandoval concludes how all of this implies the need for forms of social science training and organization that respect each of: skills in description and analysis, skills in critique and attempted change, and skills in listening and cooperation within coalitions of varied types of researcher and activist. His sentiments well reflect the spirit of this book as a whole.

The book's final chapter, by Gasper and Truong, steps back from the case studies, to draw out some of the underlying issues of social and political philosophy and political economy, including in regard to basic conceptions about migration, women, men and their roles. It also extends Sandoval's themes to a broader stage. The hundreds of millions of women nowadays who engage in migratory movement do so in settings that are structured by market forces, systems of nation-state authority and identity, and systems of gender identities and gender power relations. Market capitalist systems generate mobility; nationstate systems limit the rights and entitlements of migrants; and these systems combine in hybrid migration regimes to use and exploit migrant labour. A human rights and human security perspective adopts, in contrast, a global framework for according sympathetic attention and respect to all persons, as well as for understanding interconnections worldwide, including global-local and local-local. The book's set of studies contributes, we hope, to understanding and responding to the reality that the 'people on the move' are now often primarily women, who are typically subject to migration regimes that, in the terms we used earlier, bear and promote distinct gendered values, norms and characteristics. While women frequently already serve as social and economic 'shock absorbers', migrant women can be exposed to particular and particularly intense patterns of exploitation, at the intersection of multiple systems of power. Awareness of this remains insufficiently developed in work on migration and even in much work on human 
rights and human security, approaches which are often not explicitly or sufficiently gendered. The chapter considers ways to integrate insights from thinking about human rights, human security, feminist theory and migration studies, for studying the relationships between gender and migration, giving attention to relations of gender subordination but also to how the relationships are highly varied and may change. It reviews forms of 'invisibility' and misframing used in

\section{References}

Agústin, Laura, 2003: "A Migrant World of Services", in: International Journal of Social Politics, I0,3: 377-396.

Agústin, Laura, 2007: Sex at the Margins: Migration, Labour Markets and the Rescue Industry (London: Zed Books).

Anthias, Floya; Yuval-Davis, Nira, 1992: Racialized Boundaries: Race, Nation, Gender, Colour and Class and the Anti-racist Struggle (London: Routledge).

Basch, Linda; Glick Schiller, Nina; Szanton-Blanc, Cristina, 1994: Nations Unbound: Transnational Projects, Postcolonial Predicaments, and Deterritorialized NationStates (New York, NY: Gordon and Breach).

Bloemraad, Irene; Korteweg, Anna; Gokce, Yurdakul, 2008: "Citizenship and Immigration: Multiculturalism, Assimilation, and Challenges to the Nation-State", in: The Annual Review of Sociology, 34: 153-79.

Boserup, Ester, I970: Women's Role in Economic Development (London: Earthscan).

Bourdieu, Pierre, 1990: The Logic of Practice (Stanford: Stanford University).

Brauch, Hans Günter; Scheffran, Jurgen, 20I2: "Introduction: Climate Change, Human Security, and Violent Conflict in the Anthropocene”, in: Scheffran, Jürgen; Brzoska, Michael; Brauch, Hans Günter; Link, Peter Michael; Schilling, Janpeter (Eds.): Climate Change, Human Security and Violent Conflict: Challenges to Societal Stability (Heidelberg/Dordrecht/London/New York: Springer): 3-40.

Braudel, Fernand, 1972: The Mediterranean and the Mediterranean World in the Age of Philip II, 2 volumes (New York: Harper \& Row).

Brettell, Caroline; Hollifield, James Frank (Eds.) 2000: Migration Theory: Talking Across Disciplines (London/New York: Routledge).

Burawoy, Michael, 2005: "For Public Sociology", in: American Sociological Review, 70: 2-28.

Burawoy, Michael, 2007: "Public Sociology vs. the Market", in: Socio-Economic Review, 5,2: 356-367.

Burgess, J. Peter; Amicelle, Anthony; Bartels, Edien; Bellanova, Rocco; Cerami, Alfio; Eggum, Erik; Hoogensen, Gunhild; Kittelsen, Sonja; Knibbe, Kim; de Koning, Martijn; Koser, Khalid; Krause, Keith; Salemink, Oscar, 2007: Promoting Human Security: Ethical, Normative gendered migration regimes and directions for attempting to counter them. The chapter concludes with some indications for further work, including on South-South migration, the on-going transformations in the nature of borders, and portability of social protection, with attention in all these cases to differential impacts on various categories of women, men, children, and families.

and Educational Frameworks in Western Europe (Paris: UNESCO).

Carby, Hazel V., I999: Cultures in Babylon: Black Britain and African America (London: Verso).

Castles, Stephen; Miller, Mark J., 2003: The Age of Migration: International Population Movements in the Modern World (New York: Guilford Press).

Chandler, David, 2008: "Human Security: the dog that didn't bark" in: Security Dialogue 39,4: 427-438.

Chant, Sylvia; Radcliffe, Sarah A., I992: "Migration and development: the importance of gender", in Chant, Sylvia (Ed.): Gender and Migration in Developing Countries (London: Belhaven Press): I-29.

Cheah, Wui Ling, 2009: "Migrant Workers as Citizens Within the ASEAN Landscape: International Law and the Singapore Experiment", in: Chinese Journal of International Law, 8,I: 205-23I.

Chin, Christine B.N., I998 In Service and Servitude: Foreign Female Domestic Workers and the Malaysian 'Modernity' Project (New York: Columbia University Press).

Collins, Patricia H., 1986: "Learning From the Outsider Within: The Sociological Significance of Black Feminist Thought", in: Social Problems, 33,6: SI4-S32.

Collins, Patricia Hill, I990: Black Feminist Thought (New York: Routledge).

Commission on Human Security, 2003: Human Security Now (New York: United Nations).

Coutin, Susan, 2002: Legalizing Moves: Salvadoran Immigrants' Struggle for U.S. Residency (Ann Arbor: University of Michigan Press).

Coutin, Susan, 20II: "The Rights of Noncitizens in the United States", in: Annual Review of Law and Social Science, 7: 289-308.

Creenshaw, Kimberlé, I99I: "Mapping the Margins: Intersectionality, Identity Politics, and Violence Against Women of Color", in: Stanford Law Review, 43: I24II299.

Datta, Kavita; McIlwaine, Cathy; Herbert, Joanna; Evans, Yara; May, Jon; Wills, Jane, 2008: Mobile masculinities: Men, migration and low paid work in London (London: University of London, Queen Mary, Department of Geography).

De Haas, Hein, 20I0: "Migration and Development: A Theoretical Perspective", in: International Migration Review, 44,I: I-38. 
Ehrenreich, Barbara; Hochschild, Arlie Russell (Eds.), 2002: Global Woman: nannies, maids, and sex workers in the new economy (New York: Metropolitan Books).

Faist, Thomas, 2000: The Volume and Dynamics of International Migration and Transnational Social Spaces (Oxford: Oxford University Press).

Faist, Thomas; Ozveren, Eyüp (Eds), 2004: Transnational Social Spaces. Agents, Networks, Institutions (London/ Burlington, VT: Ashgate).

Fernandez, Bina, 20II: "Exploring the Relevance of Fraser's Ethical-Political Framework of Justice to the Analysis of Inequalities Faced by Migrant Workers", in: International Journal of Social Quality, I,2: 85-IOI.

Foucault, Michel, 1995: Discipline and Punish: The Birth of the Prison (New York: Vintage Books).

Foucault, Michel, 2007: Security, Territory, Population: Lectures at the College de France, I977-1978 (New York: Picador/Palgrave Macmillan).

Fraser, Nancy, 2000: "Rethinking Recognition", in: New Left Review, 3 (May-June): I07-I20.

Fraser, Nancy, 2007: “Transnationalizing the Public Sphere: On the Legitimacy and Efficacy of Public Opinion in a Post-Westphalian World”, in: Theory Culture \& Society, 24,4: 7-30.

Fraser, Nancy, 2009a: Scales of Justice: Reimagining Political Space in a Globalizing World (New York: Columbia University Press).

Fraser, Nancy, 2009b: "Who Counts? Dilemmas of Justice in a Postwestphalian World", in: Antipode, 4I,I: 28I-297.

Fukuda-Parr, Sakiko; Messineo, Carol, 20I2: "Human Security”, in: Brown, Graham; Langer, Arnim (Eds.): Elgar Handbook of Civil War and Fragile States (Cheltenham: Edward Elgar): 2I-38.

Galtung, Johan; Höivik, Tord, I979: "Structural and Direct Violence: A Note on Operationalization”, in: Journal of Peace Research, 8,1: 73-76.

Gasper, Des, 2005: "Securing Humanity - Situating 'Human Security' as Concept and Discourse”, in: Journal of Human Development, 6,2: 22I-245.

Gasper, Des, 20I0: “The Idea of Human Security", in: O’Brien, Karen; St. Clair, Asuncion Lera; Kristoffersen, Berit (Eds.): Climate Change, Ethics and Human Security (Cambridge: Cambridge University Press): 23-46.

Goucha, Moufida; Crowley, John; UNESCO, 2008: Rethinking Human Security (Malden, MA: Wiley-Blackwell).

Hatton, Timothy J.; Williamson, Jeffrey G., 2008: Global Migration and the World Economy: Two Centuries of Policy and Performance (Cambridge, MA: MIT Press).

Hoerder, Dirk, 2002: Cultures in Contact: World Migrations in the Second Millennium (Durham: Duke University Press).

Irudaya, Rajan S.; Varghese, V.J., 20I0: "Broadening Exchanges and Changing Institutions: Multiple Sites of Economic Transnationalism”, in: Faist, Thomas; Pirkko, Pitkänen; Gerdes, Jürgen; Reisenauer, Eveline (Eds.):
Transnationalisation and Institutional Transformations (Bielefeld: University of Bielefeld).

Jolly, Richard; Basu, Deepayan R., 2007: "Human SecurityNational Perspectives and Global Agendas: Insights from National Human Development Reports", in: Journal of International Development, 9,4: 457-472.

Kabeer, Naila, 2000: The Power to Choose: Bangladeshi Women and Labour Market Decisions in London and Dhaka (London: Verso).

Kaldor, Mary , 2007: Human Security : Reflections on Globalization and Intervention (Cambridge, UK/Malden, MA : Polity Press).

Kapur, Ratna, 20I0: Makeshift Migrants and Law: Gender, Belonging and the Legal Regulation of the Migrant (New Delhi: Routledge).

Kojima, Yu, 200I: "In the Business of Cultural Production: Theoretical Implications of the Mail-order-brides Phenomenon", in: Women's Studies International Forum, 24,2: 199-2IO.

Kyle, David; Koslowski, Rey, 20II: Global Human Smuggling: Comparative Perspectives (Baltimore: Johns Hopkins University Press).

Leun, Joanne; Woude, Maartje van der, 20II: "Ethnic Profiling in the Netherlands? A Reflection on Expanding Preventive Powers, Ethnic Profiling and a Changing Social and Political Context", in: Policing and Society, 21,4: 444-455.

Lutz, Helma, 2008: Migration and Domestic Work: A European Perspective on a Global Theme (Aldershot - Burlington, VT: Ashgate).

Maas, Wies; Truong, Thanh-Dam, 20II: "Europeanization and the Right to Seek Refugee Status: Reflections on Frontex”, in: Truong, Thanh-Dam; Gasper, Des (Eds.): Transnational Migration and Human Security: The Migration-Development-Security Nexus (Heidelberg Dordrecht - London - New York: Springer): 67-80.

Mahler, Sarah J.; Pessar, Patricia R., 2006: "Gender Matters: Ethnographers Bring Gender from the Periphery Toward the Core of Migration Studies", in: International Migration Review, 40,1: 27-63.

Massey, Douglas; Arango, Joaquín; Hugo, Graeme; Kouaouci, Ali; Pellegrino, Adela; Taylor, Edward J., 2005: Worlds in Motion: International Migration at the End of the Millennium (Oxford: Clarendon Press).

McKeown, Adam 2004: "Global Migration, I846-I940", in: Journal of Global History, 15,2: 155-89.

Menjivar, Cecilia, 2006: "Liminal Legality: Salvadoran and Guatemalan Immigrants' Lives in the United States”, in: American Journal of Sociology, III,4: 999-I037.

Moon, Katherine, 1997: Sex Among Allies: Military Prostitution in US-Korea Relations (New York, NY: Columbia University Press).

Munck, Robert, 2008: "Globalisation, Governance and Migration: An Introduction”, in: Third World Quarterly, 29,7: I227-I246.

Mushakoji, Kinhide, 20II: "State and Immigrant Diaspora Identity in Contemporary Japan: From a Developmen- 
talist Ethic Towards a Multicultural Ethic of Common Human Security", in: Truong, Thanh-Dam; Gasper, Des (Eds.): Transnational Migration and Human Security: The Migration-Development-Security Nexus (Heidelberg - Dordrecht - London - New York: Springer): 2973IO.

Oishi, Nana, 2005: Women in Motion : Globalization, State Policies, and Labor Migration in Asia (Stanford, CA: Stanford University Press).

Oomen, Barbara, 20II: "Small Places: The Homecoming of Human Rights in the Netherlands", Inaugural Lecture as Utrecht University Chair in the Sociology of Human Rights, Middelburg, short version delivered on the $2^{\text {nd }}$ of December 201 .

Parreñas, Rhacel S. 200I: Servants of Globalization: Women, Migration and Domestic Work (Stanford, CA: Stanford University Press).

Pearson, Ruth, 2007: "Gender, Globalisation and Development: Key Issues for the Asian Region in the 2Ist Century", Keynote Address, International Workshop, Beyond the Difference, at Ochanomizu University, I3-I4 January.

Pearson, Ruth; Kusakabe, Kyoko, 20I2: Thailand's Hidden Workforce: Burmese Women Factory Workers (London - New York : Zed Books - Palgrave Macmillan).

Phizacklea, Annie, 1987: One Way Ticket: Migration and Female Labour (London: Routledge).

Phongpaichit, Pasuk, 1982: From Peasant Girls to Bangkok Masseuses (Geneva: International Labour Office).

Piper, Nicola, 2008: New Perspectives on Gender and Migration: Livelihood, Rights and Entitlements (New York: Routledge).

Portes, Alejandro; Sensenbrenner, Julia, I993: "Embeddedness and Immigration: Notes on the Social Determinants of Economic Action", in: The American Journal of Sociology, 98,6: I320-I350.

Roldan, Bernice; Gasper, Des, 20II: "The Global Forum on Migration and Development: 'All talk and no action' or 'a chance to frame the issues in a way that allows you to move forward together?", in: Truong, Thanh-Dam; Gasper, Des (Eds.): Transnational Migration and Human Security: The Migration-Development-Security Nexus (Heidelberg- Dordrecht - London - New York: Springer): 239-256.

Sassen-Koob, Saskia, 1984a: "The New Labor Demand in Global Cities”, in: Smith, Michael Peter (Ed.): Cities in Transformation (Beverly Hills, CA: Sage): 139-72.

Sassen-Koob, Saskia, 1984b: "Notes on the Incorporation of Third World Women into Wage-Labor Through Immigration and Off-Shore Production", International Migration Review, I8,4: II44-II67.

Scott, Joan W., I986: "Gender: A Useful Category of Historical Analysis", in: The American Historical Review, 9I,5: I053-IO75.

Sen, Amartya Kumar, 1990: "Gender and Cooperative Conflicts”, in: Tinker, Irene (Ed.): Persistent Inequalities: Women and World Development (New York: Oxford University Press).
Silvey, Rachel, 2004a: "Transnational Migration and the Gender Politics of Scale: Indonesian Domestic Workers in Saudi Arabia, I997-2000", in: Singapore Journal of Tropical Geography, 25,2: I4I-I55.

Silvey, Rachel, 2004b: "Power, difference and mobility: feminist advances in migration studies" in: Progress in Human Geography, 28,4: I-I7.

Silvey, Rachel, 2007: "Mobilizing Piety: Gendered Morality and Indonesian-Saudi Transnational Migration”, in: Mobilities, 2,2: 219-229.

Smit, Michael P.; Guarnizo, Luis E., I999: Transnationalism from Below (New Brunswick, N.J.: Transaction Books).

Stumpf, Juliet, 2006: The Crimmigration Crisis: Immigrants, Crime and Sovereign Power, Bepress legal series working paper; at: <http://law.bepress.com/expresso/ eps> (27 July 20I2): I635.

Thadani, Veena N.; Todaro, Michael P., I984: "Female Migration: A Conceptual Framework", in: Fawcett, James T.; Siew-Ean Khoo, Siew-Ean; Smith, Peter Colin (Eds.): Women in the Cities of Asia: Migration and Urban Adaptation (Boulder, CO: Westview Press): 36-59.

Thränhardt, Dietrich; Bommes, Michael Dietrich (Eds.), 2008: National Paradigms of Migration Research (Gottingen: V\&R Unipress).

Tinker, Irene, 2006: "Boserup, Ester", in: Clark, David (Ed.): The Elgar Companion to Development Studies (Northampton, MA: Edward Elgar): 24-27.

Truong, Thanh-Dam, 1990: Sex, Money and Morality: Prostitution and Tourism in Southeast Asia (London: Zed Press).

Truong, Thanh-Dam, I996: “Gender, International Migration and Social Reproduction: Implications for Theory, Policy, Research and Networking”, in: Asian and Pacific Migration Journal, 5, I: 27-52.

Truong, Thanh-Dam, 2008: "Human Trafficking and New Patterns of Migration”, in: Gender, Technology and Development, I2,I: 5-8.

Truong, Thanh-Dam, 2009: "Human Security and the Governmentality of Neo-liberal Mobility: A Feminist Perspective”, in: Brauch, Hans Günter; Oswald Spring, Úrsula; Grin, John; Mesjasz, Czeslaw; Kameri-Mbote, Patricia; Chadha Behera, Navnita; Chourou, Béchir; Krummenacher, Heinz (Eds.): Facing Global Environmental Change: Environmental, Human, Energy, Food, Health and Water Security Concepts (Berlin Heidelberg: Springer): II83-II89.

Truong, Thanh-Dam, 20II: "The Governmentality of Transnational Migration and Human Security: The Making of a New Subaltern", in: Truong, Thanh-Dam; Gasper, Des (Eds.): Transnational Migration and Human Security: The Migration-Development-Security Nexus (Heidelberg- Dordrecht - London - New York: Springer): 2338 .

Tyner, James A., 2004: Made in the Philippines: Gendered Discourses and the Making of Migrants (London: Routledge). 
Van Houtum, Henk, 20I0: "Human Blacklisting: The Global Apartheid of the EU's External Border Regime”, in: Environment and Planning D: Society and Space, 28,6: 957-976.

Welch, Michael, 20I2: "The Sonics of Crimmigration in Australia: Wall of Noise and Quiet Manoeuvring”, in: British Journal of Criminology, 52,2: 324-344.

Wimmer, Andreas; Glick Schiller, Nina, 2002: "Methodological Nationalism and Beyond: Nation-state Building, Migration and the Social Sciences”, in: Global Networks, 2,4: 30I-334.
Wright, Caroline, 1995: "Gender Awareness in Migration Theory: Synthesizing Actor and Structure in Southern Africa", in: Development and Change, 26,4: 77I-792.

Yeates, Nicola 20I0: "The Globalisation of Paid Care Labour Migration: Policy Issues, Approaches and Responses", in: International Labour Review, I49,4: 423-440.

Young, Iris M., 2006: "Responsibility and Global Justice: A Social Connection Model", in: Social Philosophy and Policy, 23,I: IO2-I3O.

Open Access. This chapter is distributed under the terms of the Creative Commons Attribution Non-commercial License, which permits any noncommercial use, distribution, and reproduction in any medium, provided the original author(s) and source are credited. 


\section{Part II Transformation of Social Reproduction Systems and Migration: Local-Global Interactions}

Chapter 2 From Breaking the Silence to Breaking the Chain of Social Injustice: Indonesian Women Migrant Domestic Workers in the United Arab Emirates

Sulistyowati Irianto and Thanh-Dam Truong

Chapter 3 From Temporary Work in Agriculture to Irregular Status in Domestic Service: The Transition and Experiences of Senegalese Migrant Women in Spain Aly Tandian and Sylvia I. Bergh

Chapter 4 Burmese Female Migrant Workers in Thailand: Managing Productive and Reproductive Responsibilities

Kyoko Kusakabe and Ruth Pearson

Chapter 5 Transnational Marriage Migration and the East Asian Family-Based Welfare Model: Social Reproduction in Vietnam, Taiwan, and South Korea

Duong Bach Le, Thanh-Dam Truong, and Thu Hong Khuat

Chapter 6 Masculinity at Work: Intersectionality and Identity Constructions of Migrant Domestic Workers in the Netherlands Aster Georgo Haile and Karin Astrid Siegmann 


\title{
2 From Breaking the Silence to Breaking the Chain of Social Injustice: Indonesian Women Migrant Domestic Workers in the United Arab Emirates
}

\author{
Sulistyowati Irianto ${ }^{1}$ and Thanh-Dam Truong ${ }^{2}$
}

\begin{abstract}
$^{3}$
This chapter provides a perspective on the chain of social injustice faced by Indonesian migrant domestic workers in the United Arab Emirates (UAE). By using the lens of gender to connect practices within the Indonesian management system for labour migration with those guided by regulations governing the management of foreign labour in the UAE, the chapter reveals the consequences of the absence of a specific law governing the presence of domestic workers in both countries. Labour migration management systems are bounded by the nation state, whereas domestic workers must rely on transnational coordination between two systems. Where their work is not legally defined, they can become subject to arbitrary treatment at different points in their migration along a transnational chain of relations of structural dependency. They tend to bear the weight of institutional dysfunctions, often with dire consequences for their private lives. Learning from their experiences can help us draw lessons for future action towards achieving standards of decent work within a territory and standards of basic human security applicable to their transnational movement. Just as research into transnational migration has moved beyond methodological nationalism, so also labour migration policy needs to find frames of reference appropriate to context to ensure that workers' rights are protected in different places.
\end{abstract}

Keywords: domestic work, decent work, gender, migration, transnational, Indonesia, United Arab Emirates, social justice, human security.

\subsection{Introduction}

"We have broken the silence. We have yet to break our chains."

Ai-Jen Poo, a second-generation domestic worker and director of the National Domestic Workers Alliance in

1 Dr. Sulistyowati Irianto (Indonesia) is a Professor of the Anthropology of Law at the Faculty of Law, University of Indonesia

2 Dr. Thanh-Dam Truong is Associate Professor in Women/Gender and Development Studies at the Institute of Social Studies in The Hague (The Netherlands).

3 This chapter is based on a broader study entitled "Indonesian Women Domestic Migrant Workers in the United Arab Emirates" funded by IDRC, project number 105442. The research team members were: Sulistyowati Irianto, Titiek Kartika Hendrastiti, Liem Sing Meij, Vidhyandika, Tirtawening and Henky Irzan.

4 See at: <http://www.aflcio.org/Blog/Organizing-Bargaining/Domestic-Workers-We-Have-Broken-the-Silence.-WeHave-Yet-to-Break-Our-Chains> (accessed I9 March 20I2). the United States of America (USA), made this statement in June 2oII on her way home from the hundredth annual conference of the International Labour Office (ILO), which passed the Convention Concerning Decent Work for Domestic Workers. After decades of hard work, the Convention now recognizes the labour rights of persons engaged in domestic work under an employment relationship within a territory as well as when this relationship involves the movement of a person from one territory to another. The Convention is a victory for campaigners who have succeeded in breaking the wall of silence around domestic work. It has destabilized the hegemonic view that demarcates the limits of thinking about the value of domestic work and the status of persons engaged in it. It has recognized that, today, this service has become a subsector in a broader economy of care organized transnationally. ${ }^{5}$

Complex histories of labour-slavery, colonialism, and other forms of servitude-and their gendered understandings have indeed fostered a hegemonic view 
of domestic work as unproductive, i.e. 'non-work' and a 'private matter'. 6 This view underpins the rationale for the exclusion of domestic work from formal regulations concerning labour migration and their enforcement. The Convention, in fact, requires governments to take action by designing inter-state arrangements (bilateral, regional, or multilateral agreements) to govern in accordance with national laws, regulations, and practices the operation of private employment agencies that recruit or place domestic workers. As the human subject is the primary substance of labour as well as of migration, the dignity of a person is to be honoured and treatment of labour as a commodity forbidden. Many governments have yet to take steps towards realigning their national laws and moving towards ratification of the Convention.

Using the cases of Indonesia and the UAE, this chapter offers an insight into the prospects of realizing standards of 'decent work' for domestic workers in the absence of a specific national law governing the workers' presence in the receiving country. It highlights specific dysfunctional aspects of existing measures of rights protection in both countries and the implications for domestic workers. Indonesia is a striking case for a number of reasons. First, although women's rural-urban migration for domestic work is an old phenomenon, traceable at least to the early days of colonization, only since the I970s have Indonesians migrated overseas for employment in this sector (Silvey 2006). Second, there has been a remarkable rise in this migration since the financial crisis of I997 and the subsequent process of liberalization. According to IOM (20I0: 9), in I996 Indonesian women represented fifty-six per cent of the total flow of over half a million Indonesian workers deployed abroad, but by 2007 the figure had risen to seventy-eight per cent of a total of nearly seven hundred thousand. Being mainly of rural origins with low education and skills, these women migrants are deployed mainly in

5 For the full text of the Convention see at: <http:// www.ilo.org/wcmsp5/groups/public/--ed_norm/--relconf/documents/meetingdocument/wcms_I57836.pdf> (accessed 2I June 20I2).

6 Recent estimates reveal figures between 53 and Ioo million domestic workers worldwide (if hidden and unregistered people are taken into account). Around 83 per cent of these workers are women or girls and many are migrant workers (ILO 20IO). This confirms that women are the main cultural signifier of domestic labour globally, though men are also found in domestic work (Duffy 20II). domestic service. The major destinations are high-income countries in South-East Asia (Malaysia and Singapore), East Asia (Hong Kong Special Administrative of China and Taiwan), and West Asia, especially the countries of the Gulf Cooperation Council (GCC). Malaysia and Saudi Arabia are the major destination countries, accounting for more than seventy per cent of the total flow. In the GCC countries, since 1997 the UAE has become the most important destination after Saudi Arabia (IOM 20IO: I5). Third, the annual volume of financial remittance from Indonesian labour migrants has grown from US\$I.5 billion in 2002 to US\$7.I billion in 2010 - or about eleven per cent of the gross domestic product for that year (World Bank 20II: I39).

Seen from this perspective, Indonesia's growing labour exports seem to rely mainly on rural women's labour; there is no clear sign of diversification. Though financial earnings from remittances are growing, much of this still goes through informal channels. ${ }^{7}$ Sassen (2002) uses the term the "feminization of survival" to refer to the ways in which particular groups of women and their feminine gender roles are deeply implicated in sustaining national economic restructuring in a globalized world. In Indonesia, this view may be more relevant to local economic restructuring, given the country's decentralization policy. Together, deregulation and decentralization have enabled recruitment agencies in particular provinces to gain an important position in matching local supply with international demand for domestic workers. Workers depend entirely on cooperation between the recruitment agencies in Indonesia as the sending country and the employment agencies on the receiving end (Linquist 20IO). Where local practices of labour control are severe and archaic, many incidences of the violation of rights have been reported (Esim/Smith 2004).

Placing these issues in the context of the formation and transformation of the labour migration management system in the sending and receiving countries is helpful for understanding their individual operation as well as the interactions between them. Understanding how particular notions of 'gender' and 'work' are built into regulations and institutional practices that shape the organization of the migration of

7 The Bank of Indonesia has estimated that in 2006 more than ninety per cent of the total flow (nearly US $\$ 2.7$ billion) from Malaysia to Indonesia went through informal channels (Hernández-Coss/Brown/Buchori/Endo/ Todoroki/Naovalitha/Noor/March 2008). 
domestic workers may help to identify systemic dysfunctions that will carry negative consequences for the protection of the rights of domestic workers in different places. This seems to be the main challenge for future attempts to ensure standards of 'decent work' transnationally.

Section 2.2 reviews the debate on domestic work as an important concept in the gender politics of social equality, focusing on the contextual significance of its framing and the multi-scale implications for policy in today's reality. Section 2.3 discusses the main features of Indonesia's national regimes of labour migration and the UAE regulations affecting migrant domestic workers, highlighting how domestic work continues to be legally undefined. This has facilitated the formation of informal rules of governance concerning their presence in the Indonesian overseas workforce and in the UAE migrant workforce. Section 2.4 presents the outcomes of this socio-legal environment as seen in the operation of the migration business in Condet, Indonesia. It also discusses the effects on the lives of domestic workers in Abu Dhabi, who are known as 'runaways' in the local vernacular, and in legal terms as those who have 'absconded' from their employers. The narrations of the personal experiences of those who have sought protection in shelters set up by the Indonesian embassy facilitate an understanding of the practical meaning of being excluded from the law as workers, and an appreciation of the weight of inadequate national regimes of transnational labour migration on their lives. The conclusion points to the need for understanding of the social dynamics that has formed and transformed a national regime of transnational labour migration. This understanding can help shift such a regime towards a direction that can better address the specific aspects of the human security of domestic workers from a gender perspective. This would include (I) security of identity for those who join the transnational labour migration flows (legal identity, gender identity, and sexual identity); (2) security of regulations covering working conditions and wages; (3) protection when rights are violated prior to and during migration and on return. A law that governs the presence of domestic workers is the first step.

\subsection{Framing Domestic Labour from the Perspective of Gender Equality: Context, Issues, and Implications}

Housework, activities related to the maintenance of the home and the well-being of its members, is perennial, historically specific, and culturally defined. The framing and reframing of the definition of housework by different theoretical tendencies make manifest an ongoing struggle over the meaning of its economic, social, and cultural value. Since they are created by particular relatively powerful interest groups, value frameworks do play an important role in influencing public thinking and policy agendas. In the debate about housework - renamed as 'domestic labour' and 'domestic work' by various authors (see Kaluzynska 1980) - value frameworks are related to the wider debates about equal rights between men and women, and to the distribution of resources to ensure these rights. For this reason, value frameworks should be analytically treated as historical and cultural products. The following discussion presents the different framings of domestic labour on a broad canvas that can help capture the key aspects of people's engagement with, avoidance of, or resistance to domestic work and policy responses. Understanding domestic work through the perspective of the historical and cultural relationships between the state, men's and women's gender identities, and the family can help us to appreciate subtle differences regarding how rules concerning domestic work can be enforced, altered, reproduced, or reinvented at different levels and at specific points in time and space.

Within feminist debates in the Anglo-Saxon literature, housework as defined above has been variously framed, reflecting the historical transformation of the relations that organize domestic work. These frames are: the 'social factory'; the 'second shift'; the 'care deficit'; and the 'international division of reproductive labour'. Each category refers to an object of regulation and to the people being implicated, such as: I) a wage for housework for the housewife; 2) subsidized childcare for working parents; and 3 ) the intersections between care regimes and migration regimes and their consequences for regulating the migrant workforce in care work.

The term 'social factory' emerged in the context of post-World War II growth and the rise of the nuclear family in Western democracies, as perceived through the application of Marxist categories to human activities hitherto unanalysed by mainstream po- 
litical economy. Dalla Costa and James (1972) used the term to depict those working-class homes under state-led capitalism where women were toiling without recognition in physical isolation, resulting in their powerless position in the public domain. Though women's domestic work, as defined by the power holders, has no value, or only use value, it should be seen as effectively as productive as men's, and thus containing a surplus value. This argument was aimed at using economic value to justify women's class position in support of the campaign for a 'wage for housework'; housework was framed thus far as the 'labour of love'. An independent wage for women was seen as a means of freeing them from patriarchal bondage under a marriage contract.

However, both the absence of an employment relationship within the family applying to domestic work and its fragmented constitution posed many methodological problems for measurement and for discerning the embedded values - human and market. The debate about the use and exchange values was thus inconclusive. Himmelweit and Mohun (I977: 27) offered a compromise by acknowledging that domestic labour does reinforce women's subordination, but that this subordination is mainly due to the invisibility of domestic work and not necessarily due to profit. This had directed the campaign for gender equality towards making women's work - paid or unpaid, at home, in the labour market, in the community - visible to policymakers (Beneria I992).

Today, in view of the Convention on the Elimination of All Forms of Discrimination against Women (CEDAW) and the 1995 Beijing Plan of Action, a widely shared view of gender equality rests on the belief that a socially just democracy must create the conditions for women to earn their own income as a basic requirement for achieving their political rights (Molyneux/Razavi 2002). Yet, despite finely grained differences, the codification of women's work and wage as different from men's has historically been a stable system of practices and signification (Krais I993); the gender division of labour at home can be extended to the labour market, as shown in early industrialization periods when women entered waged work (Rowbotham 1975), and during a resurgence of this phenomenon in the I980s and I990s (Tzannatos 2008). In industrialized countries, the corresponding support through family policy for women's responsibilities for household maintenance and child-rearing has been found to be quite diverse owing to factors related to sociocultural and political values and circumstances (Gauthier I996).
The term "working women's 'second shift" offered by Hochschild (I989) from a perspective of social psychology tries to capture the gendered division of responsibilities in the domestic sphere, including not just the manual work of maintenance of the living unit but also the 'embodied labour' in the management of emotions and healthy lives for family members. Her perspective has provided the analytical space to also appreciate the discrete meanings of certain housework activities within kinship, rather than seeing them seamlessly as drudgery. The idea behind the second shift, it seems, was to reject the notion of 'social factory' as a mechanistic concept, and to acknowledge the diverse activities of domestic work, some of which may be closer to the notion of care in human relationships.

Care involves the human beings for whom care is being provided as well as the ones who provide care. Care needs can be mediated by different relationships on a continuum of moments of the life cycle, and these can take many different forms. From this perspective, Folbre (2002) proposes extending family values to society as a whole in order to increase the quality and recognition of care, using different measures such as tax credits for the provision of care services by men and women who should also be encouraged to share care duties in the family and community.

In the face of the advance of market liberalization since the I990s, intergenerational care (childcare and care for ageing people) has come under pressure in many countries. Generally, childcare arrangements to alleviate the 'second shift' for working parents, however modest, became no longer seen as an entitlement. Subsequently, national care regimes, within which domestic work is situated, have also been prised open to allow for the inflows of migrants workers (Lutz/Palenga-Möllenbeck 20II). Sevenhuijsen's (2003) study of the Dutch case directs attention to the shift of reasoning from the welfare to workfare regime and to how the politics of social policy have discursively relocated care from state to societal level by promoting practices of 'active citizenship'. At the same time, notions of relationality and interdependence have been used to justify the actual relocation of care responsibilities to families and communities. More generally, support for subsidized childcare in the I990s was soon replaced by private services with tax rebates, parental/care leave and nanny/au pair arrangements (Morgan/Zippel 2003; Lutz/Palenga-Möllenbeck 2OII).

From this position, Parreñas (2000) revises the concept of the international division of labour to 
make it applicable to her analysis of practices of allocating domestic and care responsibilities between working women. Her concept of the international division of reproductive labour tries to capture a reality that involves women in Italy and in the USA who are employed in the formal labour market and who informally hire undocumented foreign women as domestic workers and nannies to shoulder the burden of their second shift. In turn, these foreign women reallocate their own second shift to women in their countries of origin for payment, or through the mechanisms of extended kinship. Hochschild (2000) reconceptualized this phenomenon as links between people and labelled it the "global care chain", emphasizing its interpersonal aspects.

A variation of how households and family respond to women's entry into the labour market may be found in East and South-East Asian high-growth countries. In Japan and South Korea the organization of domestic work under rapid industrialization has gone through several phases. In the early phase of development the 'second shift' did not seem to affect women workers significantly because most entered waged work at a pre-marital age, and withdrew from employment when they reached childbearing age. Re-entry to the labour market at a later age through casual and part-time work allowed them to combine work and family duties (Brinton 1994). This scenario changes at the onset of globalization. Given the difficulty of balancing work and family, more women have been delaying marriage to continue their education in order to have a career and an independent life (Raymo 2003; Brinton 200I). In Taiwan, Hong Kong, Singapore, and Malaysia, where rapid economic development was also based on the massive entry of young women into the labour market, the presence of migrant domestic workers has become more visible as a public issue throughout the I990s and 2000s (Chin 1998; Cheng 2003; Lan 2008).

By contrast, the in-migration of domestic workers from Asia and Africa to the Gulf Cooperation Council (GCC) countries presents a different reality, which raises some doubts about the universal relevance of the concept of 'second shift' as originally defined. The GCC countries have been dependent on foreign labour since the beginning of the oil boom in the I970s. They have adopted indigenization policies in the last two decades to reduce this dependency and have implemented massive social development programmes that drew many women into the spheres of education, economics, and politics. Even so, the current proportion of females in the labour force varies from twelve per cent in the UAE to sixteen per cent in Saudi Arabia and forty-six per cent in Kuwait (Baldwin-Edwards 20II).

Here, gender-based barriers to participation in the labour force do not seem to be related to women's lack of education and skills but to a combination of factors, such as religious and cultural values that bar women from certain jobs, or socio-spatial rules that affect their mobility. The significant presence of domestic workers in this case seems to reflect the structure of families and living arrangements, lifestyle, and the maintenance of newly acquired social status (Anderson 2000; Sabban 2002: I2-I3). As has been suggested, the growing dependence of households on foreign domestic servants in the UAE may also be seen as part of the unspoken bargain between the modern state and the emerging civil society, by which the state provides a leisured life in exchange for complete political control, leading to what has been described by a local politician as the growth of an "unproductive family" (Sabban 2002: 13).

In this latest phase of the transformation of the relations that organize domestic work, there is a revision of the term 'second shift' into the 'care deficit', to emphasize 'care' as a public issue (Ehrenreich/ Hochschild 2004) that concerns young children and the ageing population as well as the health care system (Yeates 20IO).

In sum, the organization of domestic work, paid or unpaid, must be seen as contextual and nested in a mixture of care-related institutions within a broader policy framework concerning gender equality, the family, and women's economic participation in a nation state. The emerging intersection between care and migration as distinct national policy domains calls for analytical attention to the value frames applied in the interpretation of care and domestic work within the broader transnational economy of care. The place that care work (including domestic work) occupies in national law and policy regulating migration has consequences for how actors cooperate among themselves transnationally in order to move care and domestic workers as service providers across borders. Their modes of cooperation have implications for accountability that concern the protection of the rights of the workers who are being moved in order to deliver a service. 


\subsection{The Place of Domestic Work in Indonesian National Law on Labour Migration and the UAE Labour Law}

Qualitative gender research on women's labour migration from Indonesia to the GCC countries has produced important insights into the role of state policy in producing the domestication of women transnationally (Silvey 2004), and into how women's agency in joining the overseas workforce as domestic workers is also shaped by their gendered identity, personal conceptions of motherhood, and faith (Silvey 2006). ${ }^{8}$ Rudnyckyj's (2004) study of recruitment practices uses Foucault's concept of governmentality to dissect practices of the state and recruiting agencies, showing what she calls the "technology of servitude", or the production of the "maid" as a "docile subject" within a grid of power relations. Missing is a perspective that reveals what Rajan and Varghese (2010) call a "national regime of transnationalism" in labour migration that comprises specific administrative and policy frameworks, supported by discursive practices on national identity and interests in capturing transnational resource flows in migration. These provide the normative context within which transnational cooperation between institutions and private actors can take place in different localities. Situating Indonesian domestic workers in this perspective can help unpack the dense institutional context that regulates their migration and the connecting links with the receiving countries. Together these regulations and practices of relevant actors define the boundaries of women's agency in different places and at different stages of their migration.

Indonesia's Law No. 39/2004 on the Placement and Protection of Indonesian Manpower Abroad does not have a specific regulation governing domestic workers. UAE Federal Law No. 8 on labour excludes domestic workers, who are placed under immigration law where they are governed by the Kafala system (Esim/Smith 2004; Nisha 20II). Jointly, these laws leave domestic workers vulnerable to abuse without formal avenues for redress. Interpersonal relationships prevail over formal standards in rights protection.

8 Silvey (2006) shows how, as mothers and followers of Islam, in choosing to migrate for domestic work these women are also pursuing their desire to improve their children's social standing (through acquiring consumer goods such as motorbikes for their sons) as well as to improve their family status by visiting their Holy Land.
2.3.1

\section{Domestic Work Undefined in Migration Law in Indonesia}

Indonesia's Law No. 39/2004 is an extensive modern piece of legislation that provides guidelines for administering the country's labour migration policy and its decentralization. It has evolved since 1977 from previous regulations. ${ }^{9}$ According to Robinson (I99I; cited in Silvey 2004), the Indonesian government under Suharto's New Order had seen the prospects of gain from the export of labour to the Middle Eastern countries since 1983 , when it permitted private agents to recruit its nationals to work abroad through formal channels. From I984 to 1994 the majority of documented workers chose Saudi Arabia. Two-thirds of these workers were women, of whom some eighty per cent were estimated to be in domestic service; this was seen by the government as an emerging niche market (Silvey 2004: 250).

Under Suharto's New Order, state ideology concerning the family - built on the ideal of the middleclass nuclear family with a non-working wife - was altered to justify the active encouragement of low-income women to migrate overseas for work. These women were called upon to play the dual role of family maintenance and wage earning through migration "as long as their mobility did not interfere with their domestic duties...[and] for the sake of the "national' family's larger goal of economic development" (Silvey 2004: 253).

Following the financial crisis of 1997 and the fall of Suharto's New Order, deregulation and decentralization policies have generated a remarkable growth of licensed migration brokers operating within a certain geographical and cultural proximity (Malaysia and the GCC countries [IOM 20I0]). In 2002 Malaysia implemented the Immigration Act to limit migrant labour inflows, which resulted in the mass deportation of Indonesian migrant workers. Subsequently, migrant workers and migrant labour organizations intensified

9 Ministerial Decision No. 4/1970 on worker's deployment; Ministerial Decision No. I/1983 on private companies in charge of worker's deployment; Ministerial Decision No. 5/1988 on employment between countries, extended by Ministerial Decision No. I/I99I under the same name; Ministerial Decision No. 2/1994 on placement of workers inside and outside the country; Ministerial Decision No. 204/1999 on the placement of Indonesian workers overseas extended by Ministerial Decision No. I04/2000 and then extended again by Ministerial Decision No. IO4 A/2002 on the same issue. 
their demands on the Indonesian government for more protection (Ford 2004). This has prompted the introduction of Indonesian Law No. 39, 2004, a primary piece of legislation that provides the key legal principles for an extended system of administration under the Ministry of Manpower and Transmigration with an expanding numbers of affiliated Decrees in the last few years.

Law No. 39, 2004 makes no reference to 'domestic work' as a category, and mentions 'women' as a social group only once in Article 35, which refers to "female currently not pregnant" as a criterion of eligibility for employment overseas. It recognizes the presence of 'women' as a social group insofar as their state of pregnancy is concerned, and uses this as a barrier to entry. The character of the work they do in domestic service is left out. For this reason, this law cannot give women domestic workers the same protection it affords other workers. More significantly, it cannot include the category of domestic work until national labour legislation does.

Articles 33 and 34 of Labour Law No. I3/2003 differentiate between domestic employment and overseas employment. Supporters of a centralized approach to the management of transnational labour migration use these clauses to keep Law 39, 2004 on labour migration separate from labour law (Bachtiar 20II). The absence of an evidence-based discussion at the national level about legislation concerning domestic work, whether provided inside Indonesia or as part of the labour export programme, may reflect a deeply rooted ambiguity in society about gender relations generally, and domestic labour in particular. The tension between central and local government levels in interpreting responsibilities may also play a role.

In 200I, a Draft Law on Domestic Work was submitted by a non-governmental organization to the Provincial Parliament of Yogyakarta; but it was met with silence. Subsequent attempts were also made at the level of the City Government and the Regency Government of Yogyakarta (ILO 2006: I7). In 2010 a draft of the Domestic Workers' Protection Bill was placed on the national legislative agenda for debate, and again in 20II. In June 20I2, Parliamentary Commission IX decided to postpone the debate. According to Amnesty International, the lack of progress on the Bill is due to unresolved disputes between political parties. ${ }^{10}$ Though domestic work is not legally recognized, the risk of rape was included in Decree No.

10 See at: <http://www.amnesty.org.au/news/comments/ 25963/> (accessed I9 June 20I2).
PER-23/MEN/V/2006, removed in 2007 and reinstated in 2008 due to pressure from civil society organizations. Thus the law now recognizes the risk of rape in the workplace but is still reluctant to recognize labour abuse.

Without legal recognition of their presence, female domestic migrant workers are vulnerable to violations of rights committed by the staff of recruiting agencies, trainers, employers, or other actors in the migration business. The protection they may receive overseas by the representatives of their government is derived from their citizenship and not necessarily from their being recognized as a full member of the Indonesian overseas workforce.

Furthermore, there is a consensus among scholars and civil society organizations in Indonesia that Law No. 39, 2004 is weak on protection. Despite a number of additional Ministerial Decrees and central government regulations, the overall assessment is that the law puts far too much emphasis on work placement and pays insufficient attention to protection measures within Indonesia's territory and abroad. Among the Iog articles and sixteen chapters, there are only eight articles (Articles 77 to 84 ) that regulate protection, while the rest deal with the mechanisms for the placement of migrant workers. The articles on protection do not codify the specific rights for which an Indonesian migrant worker can enjoy legal protection, and do not comprehensively govern protection in the migration process across all stages.

Article 76 states that private recruiting agencies can charge the following costs: processing identity documents; health and psychological tests; job training and certificates; others. The category 'others' is spelled out in Decree No. PER.I4/MEN/X/20IO and covers: visas; food and accommodation during training; airfare; airport tax; local transport to the training centre; insurance premium; and agency service fees. Article 77 defines protection in phases: pre-placement, placement, and post-placement, and the rest of the provisions define placement in terms of the specific period during which the worker is deployed overseas.

Article 82 assigns private human resources companies to be in charge of recruitment and training; these are to be known as private recruitment agencies. The regulations covering education and training in the predeparture phase (Article 42, sub-point I) demonstrate the seriousness of the government in preparing the applicants for labour export programmes with knowledge of the law and an understanding of their rights in line with the requirements of their jobs in the destination country. As will be shown through the narra- 
tives of the migrant domestic workers in the UAE, this intent does not appear to have been taken seriously by private recruitment agencies, possibly due to cost factors and competition.

To obtain a licence, a private recruiting agency must have a work plan and sufficient capital requirements. The financial requirements for obtaining a placement licence consist of a deposit of Indonesian Rupiah 500 million (US\$50,000) and a working capital of the same amount (ILO 2006). There is no requirement for the work plan to specify protection measures for overseas workers, for example against extortion and overcharging. As Bachtiar notes (20II: I-9), eighty per cent of the problems facing migrant workers (identity fraud, extortion, and detention) occur on Indonesian territory. Yet there is no clause covering who supervises the recruiting agency and monitors overcharging. There is no penal sanction or punishment covering practices by a recruiting agency that violate the regulations regarding work contracts. Criticism has led to the introduction of Government Regulation No. 38/2007, which spells out the supervision of recruitment and outlines thirteen other responsibilities of local government, ${ }^{11}$ but it is unclear as to whether local governments have the resources to carry out these duties (Bachtiar 20II).

Articles 83 and 84 require the worker to pay a fee to cover assistance and protection overseas. Decree No. PER-23/MEN/V/2006 obliges workers to pay for their insurance prior to departure, yet there is no clear indication of what services are available when the worker encounters a legal problem or a misfortune while working overseas. Finally, the law also refers to the implicit or partial involvement of family members when a migrant worker dies at her or his workplace (Article 73, sub-points $2 \mathrm{~b}, \mathrm{~d}$, and e). It thereby places members of the family of migrant workers outside the

11 These responsibilities include: (i) information dissemination; (ii) registration of workers; (iii) selection of workers; (iv) supervision of recruitment; (v) facilitation of bilateral and multilateral agreement implementation; (vi) permit to establish a private recruitment agency branch office; (vii) recommendation for workers to obtain their passport; (viii) information and dissemination of information regarding opportunities in overseas employment in a computerized system and supervision of compliance by the migrant worker's application on payment of the required protection fee; (ix) socialization of the contents of placement and work contract; (x) assessment and validation of a placement contract; (xi) assistance, supervision, monitoring of placement, and protection of migrants; (xii) permit; (xiii) home return service. process of decision-making in migration, whereas the emigration rule concerning passport processing requires the formal approval of a family member.

In sum, the combination of the absence of a special law governing the presence of domestic workers in the country and as they join the overseas workforce and the weakness of Law No. 39, 2004 on protection may be regarded as a structural cause of their vulnerability in the migration process. In spite of their contributions to the economic development of the 'national family', migrant domestic workers in Indonesia are still waiting for the nation to act on reducing their structural vulnerability.

\subsubsection{Exclusion of the Category of Domestic Worker in the UAE's Federal Law No. 8 and the Role of the Kafala System}

In the last three decades the oil economy has helped the UAE to acquire a prominent international economic profile and a regional political profile as one of the most liberal countries in the GCC. With a relatively small indigenous labour force, large-scale inflows of low-skilled guest workers and highly skilled expatriates were required to ensure the transition from a traditional subsistence economy, characterized by herding, agriculture, fishing, pearling, and sea trade, into a modern economy under a federal state system. The foreign labour force now constitutes ninety per cent of the total labour force (Shah 2008: 20). Low-skilled workers are deployed primarily in construction (infrastructure and housing) and in cleaning and domestic services.

As in other GCC countries, the UAE's management of inflows of expatriates and foreign workers has been supported by what Longa (2005) calls the "ethnocratic politics" of governing, or a normative system of inclusion/exclusion. Under this system, the indigenous people - a minority from a demographic point of view - are politically dominant and benefit from generous state support in many spheres of life. Foreign workers are governed by Kafala - a sponsorship system based on a two-year, renewable contract and classified according to their region, nationality, ethnicity, and skills.

Shah (2008) notes that the UAE's structural dependency on migrant labour stems from two divergent tendencies. On the one hand, the strategic diversification of the industrial structure towards a post-oil economy has expanded activities such as manufacturing, construction, and services, some of which are labour-intensive and most of which are privately owned. 
On the other hand, nationals prefer employment in the public sector or to remain unemployed because of superior benefits. Attempts to solve this problem through the expansion of education and vocational training have achieved limited results. This has created not only a segmented labour market, but also spatially and socially divided societies, within which strong informal networks of care have been developing among the migrant populations across and also within ethnic, national, gender, and class categories (Ticku 2009; Kathiravelu 20I2).

The UAE Federal Law No. 8 on the Regulation of Labour Relations of 20 April I980 (with a consolidated version including amendments up to 200I) applies to foreign workers but excludes the category of domestic worker, locally referred to as a servant working in a private residence, though it is expected that changes will be made in view of the government support of the ILO convention on Decent Work for Domestic Workers. At the time of the research, the Immigration Department of the Ministry of Interior has jurisdiction over domestic workers. There is no other law governing their presence in the country; the employment contract is the only legal reference of their presence. $^{12}$ Under immigration law the following principles are binding:

1. A foreign national may stay in the UAE as a domestic worker so long as there is a sponsor (employer) willing to be her guarantor.

2. Prior to issuing a residence permit, the immigration office requires each employer and domestic employee to sign an employment agreement witnessed by an immigration official. The employment agreement contains provisions on the rights and responsibilities of both parties and the agreement will be a legal reference should there be any dispute in the future. In the event of a dispute concerning the content of the agreement, any party who feels a disadvantage may report the matter to

12 On 22 June 20II, the government of the UAE voted in favour of the the International Labour Organization's Convention 189 and Recommendation 20I on Decent Work for Domestic Workers. Before the convention comes into force, a two-stage ratification process must be completed: (I) the government must verify to what extent their existing laws meet the convention's requirements; (2) the government must then work to align themselves with the convention, if necessary. This may involve new legislation or amendments to existing law. See at: <http://www.thenational.ae/news/uae-news/uaevotes-for-new-charter-of-rights-for-domestic-workers> (accessed 9 March 20I2). the Unit for Handling Problems in the Immigration Office.

3. If a domestic worker runs away from her employer, the employer must report this to the Immigration Office and give the worker's passport to the Office.

4. A domestic worker who runs away loses all her rights as set forth in the contract and her residence permit will be revoked after the employer files a report to the Immigration office. No later than one week following that, the domestic worker must leave the UAE. Otherwise, she is declared to have violated the immigration regulations and her status is changed into overstayer and illegal, punishable by fine and imprisonment.

5. Every worker, including domestic workers wishing to leave the UAE, must first obtain clearance from the Immigration Office, who will issue his or her visa. Without clearance, a worker may not leave the UAE.

6. Under the sponsorship system (Kafala), a domestic worker does not have to obtain a labour card in order to be employed, nor does the employer need to seek the approval of the Ministry of Labour for their employment.

Rooted in Bedouin culture, the Kafala system is organized around the concept of 'guardianship' by which a 'guest' is given a place in the 'host' abode. The system operated as a custom of temporarily granting protection to strangers, and even affiliation into the tribe for specific purposes (Beagué I986; cited in Longva 1999: 78). It was adopted as the practice of labour organizations on the pearling dhows and now serves more broadly in the organization of migrant labour (Longva I999).

In its modern form, Kafala operates simultaneously as an employment and residence system, supporting a relationship of structural dependency that normalizes the practices of withholding migrant workers' passports and of socio-spatial control. These have given rise to practices such as guarded labour camps known 'bachelor cities' for male workers (Gardner 20II) and strict mobility control over live-in domestic workers. ${ }^{13}$ In some cases, the kafeel (sponsor) may take on the position of a guardian who holds the responsibility for potential cultural transgressions by foreign workers. This can also normalize and legiti-

13 See at: <http://www.ilo.org/public/english/region/arpro/ beirut/downloads/aef/migration_eng.pdf $>$ (accessed 1 April 20I2). 
mize control over the behaviour and social contacts of migrant workers. As Gardner (20IO, 20II) shows, relations of structural dependency can turn into structural violence, particularly when migrants abscond from untenable positions with their sponsors, thus abandoning the sole legal position under which they can be employed.

The risks for those who run away from their employers are serious. The employer can make a statement of absconding to the UAE migration office, which releases all obligations towards their domestic worker. Under the terms of the Employment Agreement for Domestic Workers and Sponsors, running away from the employer is perceived as illegal and punishable by UAE law. Runaways know that they are breaking the law and can be deported. Still, the risk of leaving an oppressive relationship is better for them than staying without a voice. Joining the illegal labour force is an option, especially for those who have heavy financial obligations at home (such as debts incurred in the pre-migration phase), or who simply wish to recoup their losses.

Data gathered from different sources, including discussions with the owner of an employment agency in the UAE, revealed some important issues embedded in the practices of signing contracts that might explain absconding. An employer first places an order for a domestic worker with an employment agency and pays general fees to the UAE government when the worker arrives. These include a residency visa, a refundable deposit, service fees, and a medical test and government health card. The cost can run to 9,000 Dirham or US\$2,450. In addition to this, a fee to the employment agency must also be paid, and this can be up to US\$398 (as of 2005; Shah 2008: I0). Upon the arrival of the domestic worker, the employment agency and employer sign a written agreement that sets out a warranty for a replacement of the domestic worker in the first three months (probation period). If the worker cannot continue working for specific reasons, the agency is obliged to replace her with another worker. This contract is important to prevent disputes between the agency and the domestic worker's employer.

It is important to note that the agency is the first party and the sponsor (employer) the second party to the contract. The name and nationality of the employer and the name and nationality of the domestic worker and the wage are stated in the contract, which also has to be signed by the migrant domestic worker as a third party. From the perspective of the migrant worker, before departure a contract written in English and Arabic, rather than Indonesian, must be signed a factor that contributes much to the clash of perspectives on wage and work conditions. Upon arrival, another contract, which assigns the worker to the position of the third part, must be signed.

Informants have reported cases in which the contract signed in Indonesia prior to departure specifies a monthly salary of 800 Dirham (US\$2I7), the official minimum wage in the UAE, while the one signed in the UAE states their salary as 600 (US\$163) or even 500 Dirham (US\$136). From this perspective, absconding by the worker means a lost investment for the employer and administrative and legal problems for the agency. For the worker, absconding can be the result of a system of multiple contracts, an anomaly arising from the involvement of several parties at different stages (recruitment and placement). It appears that the employment agency can make gains from both the employer and the worker, by charging a fee to the former, and deducting the salary of the latter.

Since monitoring by the UAE Immigration Office can neither reach the daily practices of signing a contract, nor deal with the volume of labour disputes, many domestic workers end up running away from their employers rather than going to the Immigration Office. Consistent complaints about absconding from employers, as well as from the representatives of the migrant workers in the sending countries, have led to the launch by the government of Dubai of an initiative to enforce specific requirements in the contract. The initiative was later adopted at the federal (state) level and eventually the provision in the contract related to 'domestic help' was passed on I April 2007. This provision includes the following standards: duration of the contract, salary and other benefits, accommodation, healthcare, working hours, paid leave, repatriation ticket, dispute settlement, recruitment fees, and coordination with the relevant embassies. Domestic migrant workers are now obliged to sign the contract upon arrival under the auspices of the UAE Immigration Office. The worker's passport has been declared a personal document not to be withheld by an employer or agency.

In sum, the structural dependency of households in the UAE on domestic workers also comes with a price tag for all sides. Inadequate pre-departure briefings and inadequate training on legal rights and obligations can lead to conflict at the workplace abroad. Placing domestic work outside the labour law and under immigration law in the receiving country puts the worker under constant threat of deportation while providing no room for negotiation over labour con- 
flict (perceived or real). Legally, the state is the sole protector of the rights of citizens, foreign residents, and workers. Yet governments on both the sending and receiving sides have allowed third parties to practise unfair contractual dealing regarding work.

\subsection{Recruitment and Placement as a Business: The View from Condet and the Voices of Women Domestic Workers in Abu Dhabi}

\subsubsection{Field Research Methodology}

The field research methodology tries to trace the articulation of standards of domestic work in practice, despite their absence in the law. Fieldwork in Indonesia was conducted in 2008 in Condet, a community that serves as a processing centre for labour migration. Observations aimed at mapping the socio-spatial aspects of recruitment, one-to-one interviews with several owners of local recruiting agencies, persons working with supporting facilities, and the relevant officials in the Ministry of Labour aimed at gaining insights into how Indonesian Law No. 39/2004 is implemented in the pre-departure phase, and at identifying the main legal and administrative problems that should be explored further in the UAE.

In the UAE, fieldwork was conducted in 2010 at the shelters set up by the Indonesian embassy in Abu Dhabi and the Indonesian consulate in Dubai, selected recruiting agencies and the Zayed Women's University. ${ }^{14}$ These shelters provide accommodation and assistance to Indonesian domestic workers who have absconded and are facing problems with the law of the host country. During the research visits, there were always approximately seventy women in the Abu Dhabi shelter and Ioo women in the Dubai shelter. Several focus group discussions (FGDs) were held in the Abu Dhabi shelter at different times. Between fifty-six and seventy women participated in the FGDs each time. Each FGD consisted of eight women, focusing on the extent to which they have a legal understanding of being a woman, a domestic worker, and a migrant, and how their status as a legal subject enables or prevents their access to legal assistance. Indepth interaction between the researchers and women migrant domestic workers took place mainly

14 Female students in this university employ domestic workers. in Abu Dhabi, as the main research location. Following Kaptani and Yuval-Davis (2008), a participatory theatre was adopted as a sociological research method to provide embodied, dialogical, and illustrative data and information on the articulation of the power relations in different phases of the migration process in the lived experience.

\subsubsection{Condet as a One-stop Service Centre}

Originally a small enclave for the indigenous people of Jakarta (the Betawi) and a conservation area (Budiati 1995), in the last three decades Condet has been absorbed by urban development and now serves as a business centre for labour recruiting and deployment overseas, especially to GCC countries. The community has undergone Islamic gentrification in terms of fashions and lifestyles after decades of pilgrimage to Saudi Arabia and labour migration to the GCC countries. Much of its spatial transformation has been driven by its new role as an important service centre where rural women undergo the 'initiation rites' to become a member of Indonesia's overseas workforce as domestic workers. This is the place where the implementation of Indonesia's Law No. 39/2004 on the Placement and Protection of Indonesian Manpower Abroad can be observed as practised and lived. Condet may be considered as a silent witness of women's entry into the 'social factory' that produces 'domestic workers' as labour for export, a mechanical process with little regard for the dignity of the person. ${ }^{15}$

For migrant applicants, the pre-departure phase is the most critical and involves much paperwork: an identity card; an education diploma; a birth certificate or a marriage certificate; a letter of permission from husband or wife or guardian; a passport; a medical certificate. Migrant applicants have to rely on a recruitment agency for many services. An important point to note is that because the financial ceiling required by Law No. 39/2004 for eligibility to set up a recruitment agency is too high, few entrepreneurs could comply. An unintended consequence is the rise of unlicensed agencies.

In Condet, a common practice among unlicensed agencies is to "borrow" a licence from a legal agency to run the business. The owner of the registered agency to which the licence belongs controls its use.

15 Women applicants must submit their bio-data, pictures, and other personal information to help recruitment agencies on the sending side and employment agencies on the receiving side find an appropriate match. 
The choice of which company's licence to borrow is governed by family relationships or friendship. Anyone can run a recruiting agency with a borrowed licence, as long as the owner of the licence is kept informed about the operation. Bribes and other informal arrangements to obtain required documents and clearances are common among unlicensed agencies.

Despite government prohibition of pseudo-recruiting agencies, many still operate with a borrowed licence. One way of "legalizing" a pseudo-business consists of a request from the pseudo-agency to the licensed company to issue a formal letter of appointment as its 'sub-division'. The 'sub-division' receives a verbally agreed share from the licensed company, ranging from Indonesian Rupiah 300,000 (US\$30) to Indonesian Rupiah 400,000 (US\$40) per worker sent. If any government official, such as those from the Ministry of Labour or police, come to inspect it is sufficient for the 'sub-division' to show the letter of appointment and to ensure that there is no signboard in front of the office. To maintain the flow of the business as a pseudo-agency, the owner must regularly pay protection money to the local police.

Apart from recruiting agencies and their 'sub-divisions', 'street hawker agencies' are those unlicensed actors who usually settle in rented houses away from the main road, some of them only tenements. Local residents of Condet explained that these are sub-let to women migrant worker applicants who need a transit place for three or four days during which they must go through the pre-departure process.

Another affiliated business is the medical service providing blood and urine tests and X-rays for migrant worker applicants before they can proceed with training and passport processing. In Condet, there are at least eight medical centres in operation. The tariffs of medical tests set by the government in 2007 range from Indonesian Rupiah 306,500 (US\$33) to Indonesian Rupiah 597,000 (US\$65), depending on the requirements of the destination countries. The aim of the tariff is to ensure the quality of the medical tests. A local informant reported that some medical centres were found to be providing sub-standard health certificates for migrant workers. They lowered their fees to Indonesian Rupiah 150,000 (US\$16) to attract clients and in consequence the tests were inaccurate, on one occasion leading to the return of about I,००० migrant workers.

Legally, every recruiting agency is required to provide training for migrant worker applicants. The training is to provide knowledge and understanding of work skills base on the type of work, situation, condition, culture, custom, religion, work risks, language of the destination country, and the rights and obligations of the workers. In Condet most training facilities for domestic workers were integrated in the shelter, with limited scope for effective learning. Furthermore, many recruiting agencies do not own a training facility; applicants who go through these channels did not undergo any training. The involvement of multiple stakeholders in Condet in providing services to aspirant migrants cannot be separated from the fact that migration has become a lucrative business.

Using the research data collected, the relationship between structural dependency and the costs of migration for the workers are summarized in the following tables.

Table 2.1: Recruitment Fees Breakdown: A Sample. Source: Morgan and Nolan (2011).

\begin{tabular}{|l|r|c|}
\hline Item & $\begin{array}{c}\text { Cost (in IND } \\
\text { Rupiah) }\end{array}$ & $\begin{array}{c}\text { Cost (in US } \\
\text { Dollars) }\end{array}$ \\
\hline Medical examination & 250,000 & 30 \\
\hline Insurance & 950,000 & 111 \\
\hline Passport processing* & 50,000 & 6 \\
\hline Airline ticket** & + - $5,000,000$ & 600 \\
\hline Labour tax on agency & 250,000 & 30 \\
\hline Agency fee & 500,000 & 60 \\
\hline Total & $6,950,000$ & 837 \\
\hline
\end{tabular}

* The government charges a fee of Indonesian Rupiah 50,000 to process passports for new and first-time migrant workers and Indonesian Rupiah 300,000 for passport renewals.

** This is the largest expense and the one which agencies try to manage most closely, given the inevitable uncertainties around price fluctuations. Urgent demands to fulfil job orders often increase this cost further and cut into agencies' margins. The cost of the air ticket is adjusted for Jakarta-Dubai.

To sum up, a major outcome of the absence of a law governing domestic workers within a territory as well as when they migrate for work in another territory, together with the privatization of the migration business, is the fostering of an environment in which migrant domestic workers are subject to successive relations of structural dependency that can reduce their status to 'labour-as-commodity', rather than persons with rights. 
Table 2.2: Recruitment and Placement: Successive Structural Dependency. Source: Compiled by the authors.

\author{
Recruitment, key actors, and pre- \\ financing \\ Village Broker: \\ - pre-finances cost for the aspirant \\ migrant to travel to urban areas to \\ apply for an overseas job. \\ Unlicensed company: \\ - works with a licensed human \\ resource company and receives a \\ share per worker sent.
}

Domestic Migrant Worker applicant under social and financial dependency:

- borrows money from the village broker (or other sources), who can be a member of the local elite, in order to get to the recruiting centre;

- if successful proceeds to the next step with a human resource company;

- if unsuccessful tries another company, usually unlicensed; pressure of debt and honour is a strong incentive to continue;

- faces more risks with an unlicensed company due to the lack of transparency and accountability.

\section{Processing and pre-departure preparation}

Human Resource Company (locally referred to as recruiting agency):

- liaises with unlicensed company to obtain qualified workers;

- works with brokers in destination countries to deliver them;

- income is based on the volume of employees placed in destination countries.

Successful Migrant Domestic Worker applicant under financial dependency

- receives an advance for ticket and other costs (fees, and pre-departure costs);

- pays back through wage deduction for the first few months;

- faces threat of deportation for noncompliance with employer's demands.
Work placement in the host country

Employment Agency:

- works with a human resource company in the country of origin of the migrant but has no incentives to investigate its practices;

- receives a fee from employer per worker allocated.

Migrant Domestic Worker under social and legal dependency

- depends on employment agency as the third party in the destination country to mediate problems with the employer;

- pays a portion of the monthly wage for this service;

- submits passport to agency or employer;

- in case of conflict with the employer goes to agency for mediation;

- faces unclear standards on grievance handling processes (can be threatened at this stage to be forced to return to work or be locked up, both as a means of harsh punishment and as 'storage' until the next employer can be found).

\subsubsection{The Weight of Dysfunctional Law and Policy on Domestic Workers: Voices from the Embassy's Shelters in Abu Dhabi and Dubai}

As mentioned in the previous section, at the pre-departure phase recruiting agencies are responsible for the education and training of the workers and there is no obligation on the part of the government to monitor the quality of the training. The dire consequences of the lack of monitoring are expressed by the absence of any consciousness of the legal implications of moving across borders among the majority of women who have run away from their employers. Many women did not properly understand the official migration procedures in Indonesia, much less the legal protection provided in the United Arab Emirates. Most significantly, they did not realize the importance of a passport as a legal document. At the time of the interviews, there was no single woman who had her own passport with her. Suspension of passport by their employers, or recruiting agencies, was considered to be a 'normal' practice.

When asked

"What do you know about the regulations in the United Arab Emirates which apply to domestic workers?",

a typical response was

"... law of the UAE requires a domestic worker to have important documents, which means that an Indonesian citizen who comes to the UAE must have an identity document from her country. A domestic worker must know the name of her agency in the UAE and the name of her employer, comply with the law and customs in the UAE, work properly as expected by the employer, sign the contract and keep to the contract while working in the workplace...”.

Another common response was

“... never heard...” or ".... don't know...” or “...never know...”. 
Only few of them knew that the employer must also comply with, and treat domestic workers in accordance with the applicable law as set forth in the working contract. They understood that during their stay in the UAE, they are entitled to insurance and can access hospital care whenever they are sick or injured. They knew that, when abused, they are entitled to have their case specifically handled by the police, and they can report to the Indonesian embassy to seek justice from the UAE government when they are in conflict with their employer.

When asked

"Who holds your passport while you are in the UAE?", "What is the content of the passport?", and "What happened to your passport when you ran away?",

a common response was that it was bound by the working contract, therefore must be held by the employer. If they cause trouble, the passport will move to another hand. If they went to the Immigration Office to try and settle their problem with their employer, then their passports would be held by the 'authority', cited as the employer, immigration office, agency, and the Indonesian embassy. None knew that since 2007 UAE law has prohibited employers and recruiters from withholding a migrant worker's passport.

Some of them mentioned that the Immigration Office in the UAE is the institution that issued their residence permit, and that a passport contains the status of a person in the UAE, i.e. the validity of their stay in the country and their status as 'domestic helper', and overstaying would make them subject to deportation.

"...A passport is the evidence that we have stayed for two years in the UAE because we are not citizens of the UAE...”.

The women workers also understood that if they practised takmim (absconding), their permit to stay in the UAE would expire. Some said that the employer should return the passport of the worker who ran away because, without a passport, the worker would not be able to return to her country. One woman shared her anxiety:

“... I cannot return to Indonesia yet and will stay longer in the shelter of the Indonesian embassy, because I have to wait until I get a ticket, while my employer kept my passport. If the employer does not return the passport, I will be put in prison or return to Indonesia using a 'temporary' passport. Some employers keep or burn their passport as an expression of their anger against workers who run away ... to make their status illegal ... it is hard to recover the unpaid salary or salary which is taken by the employer without a legal status...”.
These findings suggest that the training offered during the pre-departure stage, which should provide the migrant workers with legal knowledge, falls short of this duty. Training in the relevant laws seemed to be mixed with information about the working contract and the culture of the host country, and failed to impart systematically the knowledge of the law required when crossing national borders and the importance of the passport as a legal document. Training in knowledge of the relevant law is ultimately the responsibility of the government because it concerns the rights of migrant workers as citizens of Indonesia. Entrusting this task to recruiting agencies involves a conflict of interests, i.e. 'producing' obedient subjects to fulfil the employment contract smoothly versus imparting knowledge about the citizenship rights of workers deployed overseas by their government so that they can defend their rights.

Recruiting agencies in Indonesia are obliged by law to ensure their workers access to legal aid, covered by payment to the insurance consortium by the migrants before departure. In the event that migrant workers face a legal problem in the receiving country, the insurance consortium would cooperate with local lawyers or with the institution that handles legal protection for foreign workers. A gender-specific issue for migrant women domestic workers concerns the risk of rape. Despite the fact that the law covers the risk of being raped, this coverage is far removed from reality.

A runaway domestic worker shared her experience of being raped by her male employer as follows. After the incident, she reported to her female employer (the wife), who settled the matter with the placement agency and gave the agency 2,I00 Dirham (US\$573). The amount covered the salary owed to her, minus the cost of the flight ticket. The female employer told the victim to go to the employment agency to claim her entitlement. She proceeded with these instructions and was confined on the sixth floor of an office building where the agency is located for one month and four days, having to endure physical punishment, denial of food, and the threat of being sold to someone in Oman. She absconded from the employment agency with the help of co-workers (Indonesian, Filipino, and Indian women trapped in the same situation) to reach her embassy. At the embassy, she received protection but faced problems in processing her insurance claim due to the clauses that oblige claimants to attach a report from a medical doctor, a letter from the local police, specific medication and 
treatment from the hospital, and/or a letter from the representative of Indonesia in the host country.

Even if these conditions are fulfilled, the prevailing practice of allowing the insurance company to appoint lawyers can create a conflict of interest because insurance companies are business-oriented entities, and therefore must minimize the scope of being the party who ends up paying the settlement (ILO 2006: 25). In fact, the insurance coverage for the risk of acts of violence, including rape, during the employment phase can offer protection on paper only.

Running away from a situation of abuse is a right. Because of the legal implication of absconding, running away is seen as a crime. The consequence of staying in the shelter is that they have to undergo the required process in the embassy, and they have to accept whatever decisions are taken for them. For those women facing a lawsuit due to charges such as adultery, theft, and child abuse, providing legal consultancy and aid has become the most important task of the Indonesian embassy.

The Indonesian government set up a labour attaché in 2005 in five host countries, including the UAE. Help mechanisms as of 2010 include: (a) sheltering; (b) reaching agreements with recruiting agencies to guarantee protection for domestic workers; (c) endorsing self-regulation by hosting regular meetings with recruiting agencies from across the UAE, determining the minimum salary standard for non-Emirati employees, and blacklisting unethical recruiting agencies; (d) facilitating dispute settlement (providing legal consultancy, legal service, and mediation). ${ }^{16}$ However, because of the different legal jurisdictions only local lawyers are allowed to handle cases in the UAE. The involvement of Indonesian government representatives is limited to escorting the victim of an abuse to report her case at the police office. The alternative possibility is to build a partnership between the Indonesian representative and local Emirati lawyers, but this is not affordable for the Indonesian representatives because of very high fees, in addition to the costs of running the shelters.

Taken together, the experiences of domestic workers who have absconded and sought protection in the

16 Facilitating dispute settlements was not allowed by the UAE government as of 2007 . The year 2010 was the first year that the Indonesian embassy hired a local team of lawyers to provide legal aid in fifteen cases, due to a change of policy by the UAE government, authorizing the representation of countries of origin to provide legal aid to migrant workers.
Indonesian embassy's shelters reveal a dysfunctional system of migration management that has allowed space for the circumvention of legal and administrative standards, which in themselves are already weak on protection and strong on fees to be paid by the workers. Ensuring the standards of 'decent work' for domestic workers deployed overseas will require an institutional transformation at many levels, with a special law governing domestic workers as the first step.

\subsection{Conclusion}

This chapter has shown how the absence of a specific law governing the presence of domestic workers in Indonesia's overseas workforce and the UAE's migrant workforce combined with deregulation of labour and migration-related services has fostered national regimes of labour migration that generate the conditions of structural dependency for domestic migrant workers. These occur at several places in the process of their migration and are interlinked. Within a larger policy environment that does not recognize domestic work as work to begin with, it is easier for the unethical practices adopted by mediating institutions to be diffused, allowing the framework of reasoning about the transnational migration of domestic workers to become tilted towards economic gains rather than the protection of rights. Understanding the social dynamics that have formed, and can transform, a national regime of transnational labour migration into a domestic service can better address the specific aspects of human security faced by domestic migrant workers in different places.

Domestic workers who have absconded and sought protection in the shelter of the Indonesian embassy in Abu Dhabi and Dubai may be considered as a prototype of the justice seeker in the transnational economy of domestic service between Indonesia and the UAE. Finding ways to enforce standards of decent work and fair dealing is a longer journey that requires a political space for domestic workers to organize nationally and transnationally for their rights. At the broader level, socializing standards of domestic work as work - paid or unpaid - helps ensure the recognition of the dignity of the person doing such work, whether within the family or cohabitation relationships, or in employment relationships. Such standards are crucial in forming a shared understanding of decency about a form of work perennially essential to human life and society, yet so misrecognized and misplaced in the value frameworks that govern society. 


\section{References}

Anderson, Bridget, 2000: Doing the Dirty Work: the Global Politics of Domestic Labour (London: Zed Press).

Bachtiar, Palmira P., 20II: The Governance of Indonesian Overseas Employment in the Context of Decentralization (Jakarta: The SMERU Research Institute).

Baldwin-Edwards, Martin, 20II: Labour Immigration and Labour Markets in the GCC Countries: National Patterns and Trends (London: London School of Economics and Political Science).

Beneria, Lourdes, I992: "Accounting for women's work: the progress of two decades", in: World Development, 20,II: I547-I560.

Brinton, Mary, 200I: Women's Working Lives in East Asia (Stanford: Stanford University Press)

Brinton, Mary, 1994: Women and the Economic Miracle: Gender and Work in Postwar Japan (Berkeley: University of California Press).

Budiati, Tinia, 1995: Condet viewed from the changing of social cultural aspect. (Leiden: University of Leiden, Centre for Non-Western Sociology).

Cheng, Shu-Ju A., 2003: "Rethinking the globalization of domestic service: Foreign domestics, state control, and the politics of identity in Taiwan", in: Gender and Society, I7,2: I66-I86.

Chin, Christine B.N., I998: In service and servitude: foreign female domestic workers and the Malaysian Modernity project (New York: Columbia University Press).

Dalla Costa, Maria; James Selma, 1972: The power of women and the subversion of the community (Bristol: Falling Wall Press Ltd).

Duffy, Mignon, 20II: Making care count: A century of gender, race, and paid care work (New Brunswick, N.J.: Rutgers University Press).

Ehrenreich, Barbara; Hochschild, Arlie R., 2004: Global woman: nannies, maids, and sex workers in the new economy (New York: Metropolitan/Owl Books).

Esim, Simel; Smith, Monica, 2004: Gender and Migration in Arab States: The Case of Domestic Workers (Beirut: International Labour Organization, Regional Office for Arab States).

Folbre, Nancy, 200I: The invisible heart: economics and family values (New York: New Press).

Ford, Michele T., 2004: "Organizing the onorganizable: unions, NGOs, and Indonesian Migrant Labour”, in: International Migration, 42,5: 99-II7.

Gardner, Andrew, 20I0: City of strangers : Gulf migration and the Indian community in Bahrain (Ithaca : ILR Press).

Gardner, Andrew, 20II: "Gulf Migration and the Family", in: Journal of Arabian Studies: Arabia, the Gulf, and the Red Sea, I,I: 3-25.

Gauthier, Anne H., 1996: The state and the family: A Comparative analysis of family policies in industrialized countries (Oxford: Clarendon Press).
Hartmann, Heidi, I979: "The unhappy marriage of Marxism and Feminism: Towards a more progressive union", in: Capital and Class, 3,2: I-33.

Hernández-Coss, Raúl; Brown, Gillian; Buchori, Chitrawati; Endo, Isaku; Todoroki, Emiko; Naovalitha, Tita; Noor, Wameek; Mar, Cynthia, 2008:

Himmelweit, Susan; Mohun, Simon, I977: "Domestic Labour and Capital", in: Cambridge Journal of Economics, I,I: I5-3I.

Hochschild, Arlie, R., I989: The Second Shift: Working Parents and the Revolution at Home (New York, N.Y.: Viking).

Hochschild, Arlie, R., 2000: "The Nanny Chain”, in: The American Prospect, 3: 32-36.

ILO (International Labour Office), 2006: Using Indonesian Law to Protect and Empower Indonesian Migrant Workers: Some Lessons from the Philippines (Jakarta: ILO).

ILO (International Labour Office), 20IO: Decent work for domestic worker. Report IV(I) International Labour Conference, 99th Session (Geneva: ILO).

IOM (International Organization for Migration), 20IO: Labour migration from Indonesia: An overview of Indonesian labour to selected countries in Asia and the Middle East (Jakarta: IOM).

Janssens, Angélique, 1997: "The Rise and decline of the male breadwinner family? An overview of the debate", in: International Review of Social History, 42, Supplement S5: I-23.

Kaluzynska, Eva, I980: "Wiping the Floor with Theory: a survey of writings on housework", in: Feminist Review, 6: $27-54$

Kaptani, Erene; and Yuval-Davis, Nira, 2008: "Participatory Theatre as a Research Methodology: Identity, Performance and Social Action Among Refugees", in: Sociological Research Online, 13,5; at: <http://www.socresonline.org.uk/I3/5/2. html>.

Kathiravelu, Laavanya, 20I2: "Social Networks in Dubai: Informal Solidarities in an Uncaring State”, in: Journal of Intercultural Studies, 33,I: IO3-II9.

Krais, Beate, I993: "Gender and Symbolic Violence: Female Oppression in the Light of Pierre Bourdieu's Theory of Social Practice", in: Calhoun, Craig; LiPuma, Edward; Postone, Moishe (Eds.): Bourdieu: Critical Perspectives. Calhoun, Craig; LiPuma, Edward; Postone, Moishe, Eds. (Cambridge: Polity Press): I56-I77.

Kuptsch, Christiane, 2006: Merchants of Labour (Geneva: International Labour Office).

Lan, Pei-Chei, 2008: “Migrant Women's Bodies as Boundary Markers: Reproductive Crisis and Sexual Control in the Ethnic Frontiers of Taiwan", in: Signs: Journal of Women in Culture and Society, 33,4: 833-961.

Linquist, Johan, 20I0: "Labour Recruitment, Circuits of Capital, and Gendered Mobility: Reconceptualizing the Indonesian Migration Industry", in: Pacific Affairs, 83,1: II5-I32. 
Longva, Anh Nga, 1999: Keeping migrants in check. MERIP (Middle East Research and Information Project): 2II.

Longva, Anh Nga, 2005: "Neither autocracy nor democracy but ethnocracy: Citizens, expatriates, and the sociopolitical regime in Kuwait”, in: Dresch, Paul; Piscatori, James (Eds.): Monarchies and Nations - Globalization and Identity in the Arab States of the Gulf (London: I.B. Tauris): II4-I35.

Lutz, Helma; Palenga-Möllenbeck, Ewa, 20II: "Care, Gender and Migration: Towards a Theory of Transnational Domestic Work Migration in Europe", in: Journal of Contemporary European Studies, 19,3: 349-364.

Molyneux, Maxine; Razavi, Shahra, 2002: Gender Justice, Development, and Rights (Oxford: Oxford University Press).

Morgan, Kimberly J.; Zippel, Kathrin, 2003: "Paid to Care: The Origins and Effects of Care Leave Policies in Western Europe", in: Social Politics, IO,I: 49-85.

Morgan, Guy; Nolan, Chris, 20II: Step Up: Improving the Recruitment of Migrant Workers in Indonesia (BSRMigration Linkages); at: <http://www.bsr.org/reports/ Improving_Migrant_Worker_Recruitment_in_Indonesi a.pdf>

Parreñas, Rhacel , S., 2000: "Migrant Filipinas domestic workers and in international division of reproductive labour", in: Gender and Society, I4,4: 560-580.

Rajan, Irudaya S.; Varghese, V.J., (20I0): "Broadening Exchanges and Changing Institutions: Multiple Sites of Economic Transnationalism”, in: Faist, Thomas; Pirkko, Pitkänen; Gerdes, Jürgen; Reisenauer, Eveline (Eds.): Transnationalisationisation and Institutional Transformations (Bielefeld: University of Bielefeld): 93-II3.

Raymo, James M., 2003: "Educational attainment and the transition to first marriage among Japanese women", in: Demography, 40: 83-I03.

Robinson, Kathryn I99I: "Housemaids: The Effects of Gender and Culture on the Internal and International Migration of Indonesian Women", in: Bottomley, Gillian; Lepervanche, Marie de; Martin, Jeannie (Eds.): Intersexions: Gender, Class, Culture, Ethnicity (Sydney: Allen \& Unwin): 33-5I.

Rowbotham, Sheila, 1975: Hidden from History: 300 Years of Women's Oppression and the Fight Against It (London: Pluto Press).
Rudnyckyi, Daromir, 2004: "Technologies of Servitude: Governmentality and Indonesian Transnational Labour Migration”, in: Anthropological Quarterly, 77,3: 407434 .

Sabban, Rima 2002: Migrant Women in the United Arab Emirates: The Case of Female Domestic Workers (Geneva: International Labour Office - Gender Promotion Programme).

Sassen, Saskia, 2002: "Women's Burden: Counter-Geographies of Globalization and the Feminization of Survival", in: Nordic Journal of International Law, 71,2: 255-274.

Sevenhuijsen, Selma, 2003: "The Place of Care: The Relevance of the Feminist Ethic of Care for Social Policy", in: Feminist Theory, 4,2: 179-197.

Shah, Nasra, M., 2008: Recent Labour Immigration Policies in the Oil-Rich Gulf: How Effective are they likely to be?. ILO Asian Regional Programme on Governance of Labour Migration Working Paper No 3 (Bangkok: International Labour Office).

Silvey, Rachel, 2004: "Transnational Domestication: State Power and Indonesian Migrant Women in Saudi Arabia”, in: Political Geography, 24: 245-264.

Silvey, Rachel, 2006: "Consuming the Transnational Family: Indonesian Migrant Domestic Workers to Saudi Arabia”, in: Global Networks, 6,I: 23-40.

Ticku, Alisha, 2009: "Dubai Dreams: Exploring National Constructions of 'Citizen' and 'Migrant-Other' in the UAE”, in: Fynn, Veronica P. (Ed.): Documenting the Undocumented: Redefining Refugee Status (Boca Raton: Universal Publishers): 77-90.

Tzannatos, Zafiris, 2008: "Monitoring Progress in Gender Equality in the Labour Market", in: BuvinicÏ, Mayra; Morrison, R. Andrew; Ofosu-Amaah, A. Wafaas; Sjoblom, Mirja (Eds.): Equality for women: where do we stand on Millennium Development Goal 3? (Washington: D.C.: The World Bank).

World Bank, 20II: Migration and Remittances Factbook (Washington DC: World Bank).

Yeates, Nicola, 20I0: "The globalisation of nurse migration: policy issues and responses", in: International Labour Review, I49,4: 423-440.

Open Access. This chapter is distributed under the terms of the Creative Commons Attribution Non-commercial License, which permits any noncommercial use, distribution, and reproduction in any medium, provided the original author(s) and source are credited. 


\title{
3 From Temporary Work in Agriculture to Irregular Status in Domestic Service: The Transition and Experiences of Senegalese Migrant Women in Spain
}

\author{
Aly Tandian ${ }^{1}$ and Sylvia I. Bergh ${ }^{2}$
}

\begin{abstract}
$^{3}$
Amid increasing irregular flows of Senegalese migrants to Spanish territories, the two countries entered into a bilateral agreement in 2007 for a temporary work scheme that ultimately saw the migration of more than 700 Senegalese women for work in the agricultural sector in Spain. Due to a number of factors, including weaknesses in the recruitment process on the sending side and the nature of the work on the receiving side, many of the women subsequently abandoned their posts in search of domestic work or jobs in personal services in Spanish cities, thus transitioning to irregular status. Using data collected from 525 of these Senegalese migrant women, this chapter examines how they came to form this unintended cohort of unauthorized migrants and their experiences as they strive to live, work, and access various social rights in the context of the current Spanish labour market and economic crisis. Some measures are suggested to strengthen the management of future temporary work schemes and protect Senegalese women migrants in Spain.
\end{abstract}

Keywords: Agriculture, domestic work, gender, labour market, migration, Senegal, social justice, Spain, women.

\subsection{Introduction}

This chapter focuses on Senegalese women migrants' economic and social situation (including access to social protection) in Spain, largely as presented through their own eyes. These women first came to Spain in 2007 as part of a temporary agricultural work scheme which they abandoned for various reasons, and then ended up as migrants with irregular immigration sta-

1 Aly Tandian is Director of the 'Groupe d'Etudes et de Recherches sur les Migrations \& Faits de Sociétés', Université Gaston Berger de Saint-Louis, Senegal.

2 Sylvia I. Bergh is Senior Lecturer in Development Management and Governance at the International Institute of Social Studies, Erasmus University Rotterdam, The Netherlands.

3 We would like to thank the Groupe d'Etudes et de Recherches sur les Migrations \&o Faits de Sociétés (GERM) \& Faits de Sociétés, the two anonymous reviewers, Giulia Sinatti, Thanh-Dam Truong, and Des Gasper for their valuable support and comments. We would also like to thank Marianne Dobner and Simone Tappert for sharing their unpublished work with us. tus $^{4}$ in a variety of occupations in the care sector, especially in domestic work.

So far, research on Senegalese migration has focused on three main areas. First, Senegalese international (and especially intercontinental) migration is the object of a large corpus of research, though this has traditionally been conducted from a strictly global economic angle, with an emphasis on men and therefore without specifying the situation of women (Garreta Bochaca 200I). ${ }^{5}$ Second, research using the transnational approach in particular has focused significantly on non-economic aspects of this migration.

4 Following the United Nations Educational, Scientific and Cultural Organization (UNESCO 2008: 15), "persons with irregular immigration status" refers to persons "entering, travelling through or residing in a country without the necessary documents or permits".

5 See also the Migrations between Africa and Europe (MAFE) research project publications on Senegal, including Lessault and Mezger (20IO) and González-Ferrer and Graus (20I2). See <http://www.mafeproject. $\mathrm{com} />$. For an overview of Senegalese migration flows, see Wabgou (2008). 
However, while transnationality is now one of the most popular concepts in migration research, the processes of immigrants' dynamics in destination countries such as their moves across sectors have not been the focus of much scholarly attention (Van Nieuwenhuyze 2009: 16, 30). Third, research covering the migration of women to Spain and other European countries is widespread (e.g. Gutiérrez-Rodríguez 20IO; Lutz 20II). Yet despite feminization trends being on the rise in Senegalese migration and women having entered the debate on labour migration management (e.g. seasonal migration schemes), most academic research treats them as wives or as independent, self-employed merchants (commerce de valise) (e.g. Rosander 2005; Babou 2008; Blanchard 20I2). Research focusing on female migration to Spain or Europe has further been limited to issues involving migrant remittances to Senegal and family reunification, and not much has been written about their economic and social rights (the right to decent work, the right to adequate housing, the right to social protection, the right to adequate health care, among others; Apap 200I; Sow 2006; Coulibaly-Tandian 2008). Similarly, the process of becoming a migrant with irregular status' after having entered a country legally has rarely been the focus of research.

This chapter therefore contributes to our knowledge by focusing on the independent migration of women as labour migrants, which can be empowering for them, but also on the patterns of exclusion that they face in the country of immigration (Spain, in this case). The main research question to be addressed here is: why and how do initially legal temporary women labour migrants (in the agricultural sector) acquire 'irregular' status in Spain, and how do they fare as such in the domestic work sector?

Migrants with 'irregular status' or 'undocumented' or even 'illegal' migrants, as they are also often referred to, have become increasingly a pressing policy issue at the core of the migration debate, as undocumented migrants by definition challenge the system, break laws and rules, and compete with legal migrants and citizens for job opportunities, while living at the core of many European societies and performing much-needed services (Van Nieuwenhuyze 2009: 36-37).

There is thus an urgent need for a comprehensive understanding of the integration of Senegalese women migrants in the (formal and informal) labour market, with an emphasis on social protection for workers in sectors such as agriculture and domestic services where individual migrants appear to be ex- posed to health risks and social costs such as poisoning, food shortages, low wages, overwork, etc. According to the International Labour Organization (ILO), these issues are crucial to the fundamental rights of migrants, in particular with reference to the Decent Work Agenda. ${ }^{6}$

The findings presented here are also of considerable policy relevance, given that the EU and its member states are considering increasing temporary/seasonal labour schemes in the agricultural sector. Policymakers are thus invited to learn from the Senegal experience how schemes and access to rights can be improved.

The rest of the chapter is structured as follows. The next section will discuss the research methodology. This is followed by a brief review of Senegalese migration to the EU and Spain and its legal framework, setting the context for the research findings. These are presented in two main parts: one dealing with the temporary agricultural work migration scheme, and another, more substantive one on the process of becoming irregular migrants employed in the domestic work sector in Spain. This is followed by a discussion of the legal and social implications of migrant workers' 'invisibility'. The chapter ends with a brief assessment of migrant workers' attempts at claiming social protection and some conclusions focusing on the implications of the findings for migration policy.

\subsection{Methodology}

This chapter is based on a research project that focused on the social protection of Senegalese women migrants operating in agricultural activities and personal care/domestic work in Spain. ${ }^{7}$ Given the main research question mentioned above, the methodology was designed to elicit insights from the women migrants themselves as much as possible. A survey was conducted among Senegalese women who were part of a temporary migration scheme set up by the governments of Senegal and Spain in the agricultural sector, specifically strawberry picking, as well as migrants who had already arrived in Spain earlier. The majority of women were workers with an irregular status who had become such after abandoning agricultural activities to work as domestic workers. Many of them

6 See <http://www.ilo.org/global/about-the-ilo/decentwork-agenda/social-protection/lang-en/index.htm> 30 October 20I2). 
(though it is hard to give exact figures as the women interviewed mostly did not want to share this information) came to Spain on the agricultural work scheme while their husbands were already in Spain. The husbands did not fulfil the conditions to allow their wives to join them under family reunification rules (due to insufficient funds to pay for a large apartment or social security dues) and some of them instead preferred to send them money to bribe the Senegalese officials in order to be selected for the temporary work scheme (see discussion below). Other women interviewed were in a legally irregular situation because they had stayed in Spain and worked without a permit and therefore had not paid their social security contributions. This situation is an obstruction to attempts to renew their residence permit in Spain.

In total, 525 Senegalese women migrants in Spain were surveyed during the period March 2010 to October 20II. The questionnaire included closed and scaled as well as open questions and focused on their migration histories, life and work conditions, and economic and social situation. ${ }^{8}$ In addition, semi-structured interviews were held at both workplaces and homes with a sub-sample of thirty-three women with relevant experiences in order to deepen some insights gained from the survey data, notably the challenges they face in accessing and/or ensuring respect for their social protection rights. The meetings with the respondents were made possible largely through mi-

7 "La protection sociale des migrantes Sénégalaises évoluant dans les activités agricoles et les services aux particuliers en Espagne" (translated as "Social and Health Protection of Women Migrants from Senegal in Agricultural Activity and the Personal Care Industry in Spain”), research conducted by Le Groupe d'Etudes et de Recherches sur les Migrations (GERM), Université Gaston Berger de Saint-Louis (Senegal), funded by the International Development Research Centre (IDRC), project number I05463-OOI. For the final research report, see Tandian, Coulibaly, Sow, Tall, Wade, Dioh, Dime, Ba, Badji, Gueye, Mbaye, Tandia, Diallo, Diagne, Mbengue, Vasquez, Seron, Kebe, Sane, Thiakh, Thioye, Gueye, Niang, and Ciss. (20II). See also <http://www.germ.sn/ index.php? option $=$ com_content $\&$ view $=$ article $\& i d=39 \&$ Itemid=IO6> (30 October 20I2). The data collection team consisted of Senegalese who had lived in Spain for at least a decade. Some team members were or are enrolled in the Ph.D. programme at the Complutense University of Madrid and at Barcelona University.

8 The total number of questions was 26I, of which 18 addressed sociological identification, 36 previous activities and migration patterns, 36 marital and family status, 45 living conditions, II5 working conditions, and I2 the economic and social situation of migrant women. grant associations and their networks. At the start of the research, a database was constructed with fiftyone Senegalese migrant associations in Spain.

The sampling of the respondents was carried out by the snowball technique in various Spanish cities (Barcelona, Lerida, Valencia, Madrid, Murcia, Huelva, Granada, Malaga, Seville, Almeria, and the Canary Islands). Snowball sampling was necessary because of the lack of detailed official data on Senegalese women migrants in Spain that would have allowed for choosing a representative sample based on socio-professional and socio-demographic variables. Selection criteria of the snowball sample included: gender (female), profession (working in the agricultural and personal care sectors), length of stay (having lived in Spain for at least six months), and length of working in the same sector (at least three months). For the survey, an additional selection criterion for choosing the cities was the density of the Senegalese male and female migrant population (on this, official data exists $\left.^{9}\right)$. As for their educational status, thirty-three per cent of the women in the sample have completed primary education, thirty-six per cent have completed secondary education, and only two per cent have no education at all.

In the pre-fieldwork phase, interviews were held in Senegal with officials at the Labour Directorate, the National Youth Employment Agency, and the Ministry of the Interior on the immigration policies and mechanisms relating to migrants to Spain and the migrant worker selection process. In Spain, officials at the Senegalese consulate and migrant association leaders and members were interviewed in order to contextualize the implementation mechanisms of the migration scheme and investigate the extent to which migrants' rights are respected.

The main research challenge lay in having to overcome the suspicion of respondents, some of whom only agreed to be surveyed or interviewed in the presence of their husbands (due mainly to sociocultural norms). Some women wrongly assumed that the researchers were a mixed team of Senegalese and Spanish journalists, or that the Senegalese researchers were

9 In Spain, even irregular migrants can sign up with the padron municipal (the municipal registry), thus gaining access to social services (e.g. health care). This means that the country has relatively good estimates of the numbers of its irregular immigrant population. See the publications coming out of the MAFE project, which relied on data from the padron municipal for sampling purposes (<http://www.mafeproject.com/> (30 October 20I2). 
mere facilitators helping Spanish researchers to collect information from Senegalese migrants. This distrust can be explained by the fact that the survey was conducted only shortly after the broadcast, on a large scale, of Spanish TV documentaries chronicling the escape of Senegalese women sent to Huelva. Moreover, prior to the data collection period, a Spanish newspaper had published articles that drew links between prostitution and the presence of sub-Saharan migrants in Spain. Thus, building relationships of trust was a major challenge and a time-consuming activity. Using migrant associations and other gatekeepers and key informants as intermediaries was useful in this regard.

\subsection{Senegalese migration to the EU and Spain: A Brief History and Institutional Framework}

This section first gives a brief overview of the history of Senegalese migration to Spain, and then focuses on the institutional and legal framework governing Senegal-EU and Senegal-Spain migration and the Spanish labour market. Individual women migrants' decisions at the micro-level need to be placed in a broader perspective of the functioning of labour markets and states to understand the possibilities and constraints they encounter (Van Nieuwenhuyze 2009: I3).

While a detailed history of Senegalese migration to Europe is beyond the scope of this paper (see Van Nieuwenhuyze 2009: 67ff.; Kaplan Marcusán 2005), it is clear that the Structural Adjustment Programme conducted in Senegal during 1982-I992 resulted in a combination of economic growth with greater poverty, and a fifty per cent currency devaluation in 1994 increased the importance of remittances from abroad. More families invested in an international migrant, with the orientation shifting from France to other countries such as Italy and Spain, reaching three million out of eleven million Senegalese living abroad (Van Nieuwenhuyze 2009: 72-75).

Citing a 2002 survey of the labour market in Dakar of the Organisation for Economic Co-operation and Development (OECD 2005), Van Nieuwenhuyze (2009: 75) points out that underemployment (adding the unemployed to those working less than the official working hours and those working for less than the minimum wage) "hits nearly 72.5 per cent of the active population in Dakar". Apart from poverty and being pushed by family members, ambition and curiosity are also important factors in the migration decision. Indeed, Senegal is a country with a deeply rooted and long tradition of migration. The journey is assimilated in Senegalese society as something positive because it is supposed to build character and allow the one leaving to acquire material and/or intangible goods, even though it may entail difficult experiences. Migration thus represents for many young Senegalese the ability to access a first job that they would have little chance of finding in their own country (Bocquier 1992), while their elders see it as the only solution to improve a daily life marked by the "goorgoorlu" or "daily getting by" (Fall I998). Particularly now that education no longer represents social mobility in Senegal, (temporary) migration is seen by all segments of society as the only way to survive economically and, more importantly, to be someone (Van Nieuwenhuyze 2009: 76; see also Riccio 200I). As we will see below, in the face of Europe's closed doors, immigrants develop strategies to circumvent migration laws, as "legal and bureaucratic obstacles to migration and settlement are seen not as absolute barriers, but as factors to be taken into account in personal strategies, migration networks and community infrastructures" (Van Nieuwenhuyze 2009: 77, citing Castles 2002).

Though "the Senegalese migration to France has long been boosted by the special relations with the former colonial power, ease of movement and linguistic ties, French being the official language of Senegal" (Tall 2008: 42), the key turning points were the closure of French borders to labour migration in 1974 and the introduction in 1985 of visas for some African nationals, including Senegal, issued under certain conditions under the Schengen Agreement (Tall 2008). These processes affected the profiles of Senegalese migrants as well as their conditions of departure, arrival, settlement, and mobility. They also intensified the feminization of Senegalese migration to France as after 1974 family reunification became a major means of legal entry into France. Moreover, Senegalese migrants increasingly migrated to Spain and Italy, reflecting a change "in the spatial configuration of their mobility in Europe" (Coulibaly-Tandian 2008: 72).

Several factors explain this redeployment to Spain. In its early days, mainly "illegal" migrants were attracted by the relative permeability of the Spanish borders. Later, although Spain had begun to implement a migration policy in 1985 (see below), there were gaps. The Senegalese, like other migrants who arrived in the country, took advantage of legal loopholes to enter and settle there, especially because of the possibility of bringing their families to the country (Robin 
1996). The choice of Spain can also be explained by its economic dynamism in the labour-intensive small and medium enterprises and industries sector (especially in its vibrant underground economy) that required a massive and low-skilled workforce (Tall 2008).

To this diversification in terms of new destinations was added a diversification of origins, categories, and profiles of migrants. The profile of the migrant cannot be reduced to the classical picture of a rural and illiterate male. "The old figure of Senegalese migrants made up of rural and illiterate gives way - but without disappearing - to new players who have strong professional or human capital and are, generally, from the urban areas" (Tandian 2008: 366).

Here, women are gaining increasing importance among the migrating Senegalese. Most of them migrate within family reunification schemes, or to work or study. In doing so, some migrate legally and others illegally. Coming in the name of family reunification does not prevent these women from having an economic migratory project, however, even prior to their departure from Senegal. Today, Senegalese women migrants in Europe, generally speaking, have very varied characteristics and profiles both in regard to their geographical origins and socio-economic and education levels and motivations for migration. And whatever their migration conditions are, they almost all carry an individual and family economic migratory project (Coulibaly-Tandian 2008).

Indeed, the migration of Senegalese women to Spain has reached unprecedented numbers. According to the National Institute of Statistics, in 2009 there were 56,048 Senegalese in Spain, of whom 46,858 were men and 9,190 women (Instituto $\mathrm{Na}$ cional de Estadística 2009). ${ }^{10}$ These data are however to be put in perspective since many Senegalese living in Spain had not been identified at the time of the census. Most Senegalese women migrants are settled in Catalonia and Andalucía. This trend is reinforced as Spain is implementing quota policies resulting in employment contracts that favour women, as we will see below.

While the main focus of this chapter is on Senegalese women migrants who came to Spain as part of a temporary agricultural work scheme which they subsequently abandoned, mainly to work in the personal

10 Data for 2009 were obtained from the online database of "Municipal Register Population Figures" available at: $<$ http://www.ine.es/jaxi/menu.do?type $=$ pcaxis\&path $=\%$ 2Ft20\%2Fe245\&file=inebase\&L $>$ (I9 November 20I2). care sector, there is of course also the second, and arguably much larger, category of Senegalese women migrants who came to Spain independently of this or any other scheme (see García-Cano 2002). The latter generally work in the trade in exotic products, the catering and hotel sector, hairdressing, and personal care/domestic work. It should also be noted that it is not uncommon to find women who combine several activities. Although these women, often without professional training, have more chance of finding a job in Spain than in Senegal, they are concentrated in precarious, poorly paid, and low-status sectors. There are however also health workers and teachers for whom it is easier to obtain a visa to enter Spain as they fulfil the conditions (bank statement, professional identity card, etc.) and are considered by the Spanish consular authorities more likely to return to Senegal. These women often apply for a short-stay visa but then overstay their visas and acquire irregular immigration status.

We now turn to a short discussion of the changes in the Spanish economy and the labour market as well as the migration framework to provide the context for the research findings.

Since the economic downturn of the I970s, many European countries have experienced post-industrial economic restructuring, in which Fordist structures of mass production and rigid labour markets have been replaced by highly fluid and flexible production arrangements and labour markets, with an emphasis on new intermediate and support services, locational advantage, and changes in private consumption patterns. The 'casualization' of employment is reflected in downgraded and informal sectors staffed by migrant workers. Their lives and strategies are heavily influenced by the degree of protection in the labour market and the rules for redistributing welfare benefits by the state (Van Nieuwenhuyze 2009: 3I, 34).

Spain has only recently (in the last two decades) changed from being a labour exporter to becoming a country of net immigration. The low productivity sectors (intensive agriculture, tourism, construction, and small industries) have had to become dependent on immigrant workers from poor countries in order to stay competitive. These have also increasingly become part of the informal or underground economy which in 2000 represented twenty-two per cent of the total economy. Furthermore, temporary and part-time jobs represent more than thirty per cent of all jobs (Van Nieuwenhuyze 2009: 46-48; see also European Migration Network (EMN) 20IO).

Spain's recent status as a net immigration country ${ }^{11}$ and pressure from the EU explain the relatively 
rapid development of new laws imposing visas and work and residence permits, and establishing social and political rights. Most authors seem to agree that these represent an "ineffective attempt to organize legal entry, curtail illegal entry and regularize those already inside" (Van Nieuwenhuyze 2009: 37-38, citing Freeman 1995). This outcome reflects the tension between two opposite policy logics: compliance with strict border control polices as demanded by the EU (of which Spain has been a member since 1986) on the one hand, and the fulfilment of the need for unskilled workers in agriculture, industry, and services on the other (Van Nieuwenhuyze 2009: 49).

This tension explains the existence of legal restrictions that hardly allow other working possibilities for immigrants than the work in specific niches marked by precariousness and uncertainty and defined as "new employment mines" (Agrela Romero/Gil Araujo 2005: 5, cited in Dobner/Tappert 20I0: 7). As a consequence, three-quarters of the immigrants in Spain work in five labour market sectors: domestic work, agriculture, hotels and catering, construction, and the retail trade. These sectors represent less than forty per cent of the labour market (Dobner/Tappert 20IO: 7). ${ }^{12}$

The first Spanish law to regulate immigration was the 'Foreigners Act' in I985, widely regarded as controversial, restrictive, and discriminatory. It was replaced by a new 'Foreigners Act' in 2000 that hardened many conditions, including increasing the period of residence required for individual regularization from two to five years (Van Nieuwenhuyze 2009: 49). ${ }^{13}$ Regularization campaigns have been used on six occasions (I986, I99I, I996, 2000, 200I, and 2005) to try to address issues of exploitation and marginalization. As Van Nieuwenhuyze (2009: 50) states, "by legalizing all immigrants they give migrants living in Spain without a working permit or residence permit access to a legal and administrative status and facili-

11 Spain saw a more than fivefold increase in the number of immigrants between 2000 and 20I0, though annual growth has declined significantly since 2008 (EMN 20IO: I9-20). Despite the rapid increase, (legal) immigrants represent only two per cent of the country's population (Solé/Parella 2003: I2I-I22). In 2006, four per cent of the total immigrant population in Spain was from sub-Saharan Africa (see Lessault/Beauchemin 2009).

12 See also Corkill (200I) for a discussion of the Spanish labour market for migrants.

13 For more details on the 1985 Immigration Law and subsequent legal changes, see Solé/Parella (2003: I27ff.) and Mendoza (200I: I69ff.). tate their access to markets (labour, housing, banking, etc.) and public services (social security, education, health, personal social services, etc.)". The campaigns could however be criticized as providing strong incentives for further undocumented migration. Spain also adopted a quota system in 1993, but instead of attracting new workers, it functions more as a concealed regularization mechanism for migrants with irregular status already in Spain. A complicating factor is Spain's advanced degree of decentralization, which means that migration issues require the collaboration of both national and local levels (Van Nieuwenhuyze 2009: $46,50)$.

As a receiver of circular migration, Spain has considerable experience with non-European groups, particularly Moroccan workers. The first major Moroccan migration to Spain in search of work occurred in the I980s and was aimed at the agricultural areas of Catalonia's Maresme region, at a time when Moroccan citizens could travel to Spain without a visa. Both then and in the I990s (after the visa requirement was introduced in I99I but when irregular migration between Morocco and Spain was still in practice an easy option), many of the Moroccan migrants were actually practising circular migration, combining their work and period of residence in Spain for some months with farming activity and maintaining their family and home in Morocco. When irregular immigration became more difficult due to legal changes and increased monitoring of the Straits of Gibraltar (mainly since 2002), this kind of back-and-forth migration became impossible, especially for immigrants whose situation was still irregular and who did not wish to risk having to return to Morocco. From then on, circular migration was regulated through international agreements and was legally channelled via quotas. Romanians, Bulgarians, Moroccans, Ecuadorians, and Colombians made up the bulk of this contingent until the first two nationalities became able to migrate freely from January 2009. The total number of immigrants using this channel, mainly for seasonal agricultural labour migration, is very small compared to the total inflow, although, following the restrictions imposed on the arrival of new labour immigration as a result of the economic crisis, it has become one of the few means of legal immigration (González Enríquez 20II).

In terms of social policies, the Spanish welfare system pays lower benefits compared to other OECD countries, relying on family networks. As for migrants, "since the 2000 law, legal immigrants have the same civil and social rights as Spanish nationals, and 
undocumented immigrants have the right to basic social rights such as free access to public health care services, free compulsory education (three to sixteen years), and the very scarce public housing. This is based on the criterion of residence, explaining why even undocumented immigrants inscribe in the census" (Van Nieuwenhuyze 2009: 5I). However, specific policies are mostly reactive, and "many migrants rely on third-sector organisations and social services that help undocumented immigrants, often with support from state administrations", though these are very much locality-specific (Van Nieuwenhuyze 2009: 5I52, citing Domingo/Kaplan/Gómez Gil 2000).

In short, current migration policies, a segmented labour market, and a growing informal economy in Spain have led to an ethnicized and gendered labour market. Solé and Parella (2003: 124) define the Spanish labour market as 'ethno-stratified', in which immigrants are employed in the lowest positions, due to, among other reasons, the discriminatory practices of employers and the state, rather than a lack of qualifications.

Indeed, it has been argued that in Spain, the immigrants from the Third World, from different races and cultures, are facing racist oppression in addition to that related to their social class or gender. "This threepronged oppression puts the migrants in a position of extreme subordination regarding the power relations within the host society" (Solé I994: I5). In other words, Senegalese women of different culture and skin colour experience many difficulties in the Spanish labour market. This is especially the case in the domestic work sector, where, as Falquet, Hirata, Kergoat, Labari, Le Feuvre and Sow (20IO: IOI) observe, women are by definition 'invisible' to outsiders, "supporting children and the elderly and other hardly 'delocalizable' tasks, performed in families whose income allows the outsourcing of those activities in a specific social relationship, the one of domesticity. These women are most often without legal status [...] and have frequently left their own children and extended family in the country. Opinions differ on the consequences of their migration, because they are based on a sociocentric [and Western ethnocentric] conception of what is women's autonomy or the 'subject' and her 'desire', although of course, the individuality of these women cannot be reduced to the work they perform and that they have often not chosen to do."

These observations are linked to those made by feminist economists who have shown that deregulation and free market policies have created working conditions rather unfavourable for women. These pol- icies have increased the supply of certain jobs on the one hand but increased women's workload of paid and unpaid work on the other. This brings out the problem of reproduction and/or extensions of domestic work in the North, a question often concealed in conventional analysis (Sassen 2000). Irianto and Truong (this volume, chapter 2), analyzing the transformation of relations that organize domestic work, point out that such work "must be seen as contextual and nested in a mixture of care-related institutions within a broader policy framework concerning gender equality, the family, and women's economic participation in a nation state". We will return to some of these observations below with regard to the Spanish case.

\subsection{The Temporary Agricultural Work Scheme: Process and Outcomes}

This section discusses the temporary agricultural work scheme launched in 2007 that included more than 700 Senegalese women coming to Spain for three to six months, starting in January 2008 for the strawberry harvest in Huelva; many subsequently abandoned their workplaces to find other jobs, mainly in the personal care sector in Spain. The main dimensions of this case study are illustrative of other, similar schemes around the world ${ }^{14}$ and include weaknesses in the selection processes and hardships in the work itself linked to the nature of the work contracts, the relationship with the employer, living conditions, and finally, the nature of the work itself.

Before considering the case in more detail, it is useful to briefly review the main legal provisions for temporary migration to Spain. Indeed, the bulk of the temporary and circular migration entering Spain is coordinated through recruitment schemes for agriculture (EMN 20IO: I4). The general legal framework established by Organic Law 4/2000 introduced the possibility of residence and work permits for seasonal work under a special scheme while maintaining the association with the 'contingent' (Contingente de Trabajadores Extranjeros), the general programme for foreign seasonal workers who do not enjoy free circulation within the EU labour market. Newland, Agunias, Dovelyn and Terrazas (2008: 7) summarize the key features of the programme as follows.

14 For example, see Siregar (2010), Morgan and Nolan (20II) and Irianto and Truong (chap. 2 above) for similar issues with bilateral agreements on Indonesian migrants. 
It is annually adjusted by province and sector according to needs and establishes an easy procedure for hiring seasonal workers, for no more than nine months per year. The Contingente encourages circular migration with a combination of demands and incentives. First, it requires participating migrants to sign a binding commitment to return to their country of origin at the end of the work season. Migrants must register with a Spanish consulate in their origin country; the consulate then monitors compliance. A worker who returns home can participate in the program again without going through the selection process. After four years of following the rules, the migrant gains easier access to permanent work authorization.

The recruitment of seasonal workers in their countries of origin has thus come to be one of the main ways of managing migration flows and an important source of labour for seasonal work. Through this system, employers can offer temporary or seasonal jobs and contract work for a specific project. According to the provisions of article 39 of Organic Law 4/2000, vacancies can be generic or nominative (for hiring named individuals; EMN 20IO: 20-2I, 27; see also Kohnert 2007: I7).

Since 2000 , bilateral agreements have constituted an important mechanism for recruiting workers (both stable and seasonal) in their country of origin. Nonetheless, since 2004, the agreements have included a new dimension that now entails, in addition to worker recruitment procedures, flow control, the prevention of illegal immigration, readmission procedures, and development cooperation. These "second generation" framework agreements on migration aim to adapt the profile of workers to the structure of demand in the Spanish labour market while also fostering the development of countries of origin. At least in theory, they include actions to distribute information on channels of legal migration and the risks of their illegal alternatives, to promote training in the country of origin, and to set up offices for technical cooperation. To date, Spain has signed bilateral agreements with Colombia (200I), Ecuador (200I), Morocco (200I), the Dominican Republic (2002), Romania (2002), Bulgaria (2003), and Mauritania (2007). It has also signed cooperation agreements on immigration with The Gambia (2006), Guinea (2006), Guinea Bissau (2008), Cape Verde (2007), Mali (2007), Senegal (2007), and Niger (2008), all of which are second-generation agreements (EMN 20IO: 34).

In the case of Senegal, and with the assistance of the International Labour Organisation, a board of employment has been set up in Dakar to select candidates, manage the administrative processing of per- mits, and train workers for employment in Spain. In 2007, the agreements signed with Senegal led to the hiring of 700 female workers on farms in Andalucía and a further 2,000 (mainly male) on Spanish ships. ${ }^{15}$ Workers from Mauritania (2008) and Mali (2008 and 20I0) have also been recruited during agricultural seasons in recent years (EMN 20I0: 35; Burnett 2007).

The social protection conditions for workers who have been recruited collectively in their country of origin for fixed-term work and with a residence permit and who start work in Spain seem to be adequate, at least on paper. For example, they must register with the social security system at the start of their employment and may register as jobseekers with the public employment services if they lose their job before the end of the validity period of the permit or of the employment. They are however exempt from unemployment contributions but mandatory contributions are payable to cover the costs of occupational and nonoccupational accidents and illnesses. As mentioned earlier, they must agree to return to their country of origin at the end of the employment relationship. To verify that this return has indeed taken place, the worker must visit the diplomatic mission or consular office within one month of the end of his or her permit for work in Spain (EMN 20IO: 28-29, 3I).

On the part of the employer, Spanish legislation for seasonal workers requires them to guarantee decent accommodation with appropriate hygiene conditions and to organize the journey to Spain and back to the country of origin, bearing at least the cost of the first of these journeys and the expenses of transfer to and from the point of entry into Spain and the worker accommodation. Monitoring of compliance with accommodation conditions is carried out through the Work Departments and Provincial Labour Inspectorate. The legislation also requires diligence on the part of employers in ensuring that workers return to their countries of origin at the end of the employment relationship (EMN 20IO: 3I).

However, as will be shown below, experiences under the labour scheme as related by the migrant workers themselves contrast quite significantly with these provisions.

The political context in which the bilateral agreement that launched the scheme was signed on 9 November 2007 is important here. Senegal announced the scheme (the first of its kind) after it agreed to take back hundreds of illegal Senegalese migrants from

15 The findings presented here only discuss the experiences of the female workers in the agricultural sector. 
Spain in September 2007. A year earlier, in 2006, about 30,000 illegal immigrants had arrived in Spain, mainly on the Canary Islands, of whom at least half were Senegalese. Thus the scheme was seen by government leaders as a major way of combating illegal immigration. ${ }^{16}$ Perhaps Senegal also tried to use the threat of more illegal migration as a bargaining chip in achieving debt relief, more development aid, and eventually also more opportunities for legal employment-related migration. ${ }^{17}$ The fact that President Wade was preparing his re-election campaign at that time may also have played a role.

After the agreement was signed, Spanish job offers for 744 Senegalese women were received through the Spanish Embassy in Dakar, based on a quota determined by the Spanish farmers' union of employers. Under the terms of the contracts, the cost of travel from Senegal to Spain, around 600 euros or more, was to be covered by the employer. However, this amount was to be deducted from the salary paid to the worker. The agreement also stipulated that Senegal would deal with the selection. The key selection criteria were being female, competent in doing farming work, and originating from a rural area in Senegal. The Spanish government committed itself to taking care of the formalities for visa and travel arrangements in Spain through its appropriate structures.

The criterion for selecting female workers only was explained by the Senegalese Ambassador in Spain in an interview as follows: "For the choice of women, you know, the strawberry is very sensitive; it takes a lot of attention for the picking. Here you are! You know the women have hands that are very different from men's. They can pick strawberries without squashing them. I think that's why Spain wanted women to be recruited." However, a more convincing reason for selecting only female workers is probably that Spain anticipated problems with workers not re-

16 This reading was confirmed in an interview with the Senegalese Ambassador in Spain.

17 Earlier agreements between Senegal and Spain include the following but do not explicitly address issues of social protection: Framework Agreement on Cooperation for Development, signed on Io October 2006; Joint Statement on the management of migration flows of 5 December 2006; Agreement on the prevention, protection, repatriation, and reintegration of unaccompanied Senegalese migrant minors, signed in Dakar on 5 December 2006; Declaration of Intent signed in Dakar on I5 February 2007 between the Spanish Minister of Labour and Social Affairs and the Senegalese Minister of Youth and Youth Employment. turning to Senegal at the end of their contracts. Newland/Agunias/Dovelyn/Terrazas (2008: 8; see also González Enríquez 20II) report experience with an earlier seasonal worker programme which Spain had implemented progressively since 1999 and the European Union supported since 2005, and which opened legal channels for Moroccan women to work in the citrus and strawberry industries in and around Cartaya, Spain.
Although return of the workers was one of the pro- gram's objectives, only 5 percent of the 1,200 participat- ing workers in 2005 went home; in 2007 , therefore, only married women with children were selected for the pro- gram - and they were not permitted to bring the chil- dren with them. If they returned on schedule, they were guaranteed a job for the next season. After the 2007 sea- son, 85 percent of the 4,563 workers returned voluntar- ily.

In any case, the selection procedure was hampered by the lack of coordination and clear mandates of the various agencies involved, though according to some members of the National Commission for Management and Monitoring of Job Offers and members of various NGOs, the National Agency for Youth Employment (ANEJ) was the only institution that actually managed the selection of agricultural workers. According to the Executive Director of ANEJ,

the management of the departure and accompaniment of the selected workers was chaotic because of several changes in the staff in charge of the trip, linked to the governmental instability experienced by Senegal [...]. This has greatly affected the administrative structures of the various ministries involved in the management of Senegalese migration. ${ }^{18}$

Another level of dysfunction was found in the targeting or profiling of the candidates. During an interview, an official at the Ministry of Youth argued that "candidates had to submit a file including a medical certificate proving their good health, a certificate of training in agriculture and horticulture and the degree obtained". This contrasts with his later admission that "some girls expressed concerns about their abilities to do the job properly", and leads us to doubt the official view according to which Spanish employers were adequately represented in the recruitment commissions and had heard the candidates. This doubt seems justified in the light of complaints by Spanish employ-

18 Statement given during the launch ceremony of the research project on "Social protection and Senegalese migrants working in agricultural activities and personal care services in Spain", University Gaston Berger of Saint-Louis, Senegal, 26 June 2008. 
ers as well as women migrant workers about their difficulties of adapting to life and work in Spain and their declarations of illness. According to the Spanish recruiters, who went as far as insulting the Senegalese workers as 'lazy' or 'Naomi Campbell' and so on, some women became pregnant, in addition to many cases of unavailability due to illness. Moreover, even though a youth inspector said he did not see any cases of corruption in the recruitment procedure, he did mention having been the target of an attempted bribe by the parent of two girls who offered him two million CFA francs (3,000 Euros) in return for their selection.

Most importantly, the main stakeholders, namely the female agricultural workers selected, were not involved in drawing up the contracts, which led to their not being aware of their contents. During an interview in Seville, a Senegalese trade unionist observed:

I have heard that the girls did not know the terms of contracts, nor the conditions under which they were to work in Huelva. But again, I say this is the error of the Senegalese state, because it seems foolish to engage nationals without the support of a lawyer or a labour inspector. They signed without knowing what is stipulated in the contract, the salary procedures, the accommodation, etc.

The women interviewed in this study confirm this lack of detailed information concerning their tasks, remuneration, accommodation, working hours, etc. A woman selected at Diourbel and whom we met in Barcelona shares her experience:

As for the contract signed before coming, we did not even read it; we did not even know what it was about and the people who accompanied us told us nothing clearly on the contract. They only showed video images explaining the work in a strawberry field, not more. They also affirmed that we would be housed in apartments with all amenities required and that we would live in a good family atmosphere. Instead, we were thrown and enclosed in a kind of bush with no electricity or any type of basic convenience, with eight people sharing small rooms and not knowing the language. At Diourbel, after the interview they made to test our willingness and ability to work in fields, they had us sign some papers, but we do not even know what we have signed. Everything was in Spanish! Nothing was written in French! In Huelva, regarding the payslip, we have never had or seen one. Everything was confused with the story of labour contracts. I have no doubt that some women have the skills to work in fields. They are used to it. They did so for several years in Senegal, but next to them there are women who have paid to be selected. The women had promised to keep quiet but facing reality and the many difficulties, there was noise. Lots of noise. I preferred to go do something else and I do not regret it (Aissata ${ }^{19}$, who came to Spain for agricultural work, Barcelona).

These political and institutional failures, including lack of information about their work contract and salary, attempted or real bribery, and the dire living and working conditions arguably are part of the reason why migrant workers returned prematurely from Spain or 'escaped' to work in other sectors and lead us to question the viability and the transparency of the selection process. Admittedly, the negotiating capacity of these women was very limited during the recruitment process despite their regular status. They contented themselves with having been chosen among many in a Senegalese context where migration is highly valued and travel opportunities to Europe very limited.

As Van Nieuwenhuyze (2009: I06) points out, given the fierce global competition in the agriculture sector, it has some of the worst labour conditions in the informal sector, for both migrant and Spanish workers: workers need to be available (often staying at the farm), flexible in terms of overtime and able to accept that there may not be any work at all at times, and hard-working (accepting physically hard conditions). Salaries are low (about three euros an hour) and employment is never long-term or secure, as it depends on how weather conditions affect crops. Almost all work is therefore temporary. The trend towards casual work has increased with new laws imposing heavy fines on employers hiring clandestine workers, although labour inspections are relatively rare (Van Nieuwenhuyze 2009: I06-IO7, II6; Corkill 200I: 835). It is therefore no surprise that while agriculture is definitely a very common first employment sector for African (undocumented) migrants, most of them try to leave it as soon as possible for a more secure job in another sector (Hoggart/Mendoza I999, cited in Van Nieuwenhuyze 2009: I69).

Indeed, as mentioned earlier, the contracts stipulated that the Senegalese migrant workers were to return to their home country at the end of their activities. However, some preferred to stay in Spain by their own will or under the influence of their relatives. At Lavapies, a neighbourhood of Madrid, one of the Senegalese agricultural workers told us:

I had an employment contract for three months, but I worked for two months and fifteen days. [...] Fifteen days before the end of the contract I went to join my brothers. If I had not done it, my boss would have taken

19 All names of Senegalese women migrant workers have been anonymized. 
me back to Senegal. For me it was not an escape but a reasonable choice I made on the advice of my brothers, who have been living in Spain for several years (Aminata, who came to Spain for agricultural work, Madrid).

The first results of this temporary migration scheme suggest that migrants and their Spanish employers are disappointed by its method of operation, agreed at the highest level between the governments of Senegal and Spain. The strategy that was supposed to provide employment opportunities for migrants only increased the number of migrant Senegalese living clandestinely in Spain. The Spanish government authorities remain silent about future temporary migration schemes. The Spanish employers' refusal to renew contracts and to continue the programme is undoubtedly one more obstacle for the Senegalese migrants who have remained in Spain. According to EMN (20IO: 25-26), criticisms of this and similar programmes have also been aired over the last ten years by Spanish representatives of trade unions, NGOs, migrant associations, and the scientific community. On the selection of countries with which bilateral agreements have been signed (especially from 2000 to 2004), they argue that the criteria were motivated by reasons of diplomacy and strategic positioning and do not always coincide with the approach of the longterm migration policy or the true features of the flows of migrants they should be addressing. Secondly, there has been criticism that the procedures for the recruitment of foreign workers by employers do not include measures to guarantee that they are based on criteria of qualifications and experience, as opposed to cultural or racial preferences. However, it seems that for subsequent temporary work schemes, the selection procedures have been clarified, streamlined, and better coordinated (see EMN 20IO: 28 for details).

\subsection{Becoming a Migrant with Irregular Immigration Status: Senegalese Women in the Domestic Work Sector in Spain}

Some Senegalese women agricultural workers managed to 'escape' from their jobs in the agricultural sector through the complicity of their families who had been established in Spain for several years. ${ }^{20}$ From the survey, we learnt that some women abandoned the fields to join their husbands or family and friends in other cities in Spain (Barcelona, Seville, Madrid, Almeria, etc.) and Italy by car or train. Indeed, arriving in
Spain for the picking of strawberries seems to have been for many of them a mere pretext for easy access to Europe.

By abandoning their jobs and moving to urban centres, the women in fact became migrants with 'irregular' status, as the temporary residence permit with which they were able to travel to Spain obliged them to settle in the territories where they were recruited. In addition, the permits did not allow them to carry out any activity other than agricultural work. However, for some women, abandoning the fields clearly represented a better alternative to the harsh working conditions, even though they faced an uncertain future. Many ended up in the personal care/domestic work sector. Khady explains that after leaving the greenhouses in Huelva, she joined some friends settled in Barcelona. She lived for some time with them before leaving for Tarrasa:

After leaving the strawberry fields, I was trying to sur-
vive as I could. I joined some hairdresser friends and
that is what explains my initial presence in Barcelona. I
met with associations and I joined them thinking that
my living conditions would change, but as you can see
here, this is not luxury. It is a life of getting by day by
day! I have a membership card of the Association of
Senegalese in Catalonia, but I do not take part in their
activities. With my irregular situation, I preferred to
leave again and I moved to Tarrasa. I do odd jobs in
homes. I clean, I sweep, and I sometimes cook! It's bet-
ter than nothing, isn't it? (Khady, Barcelona, 37 years
old). Just like Khady who recently settled in Tarrasa to escape the harsh conditions of agricultural work, many Senegalese women left for other Spanish cities where they hoped to find new and less harsh job offers than those in Huelva. Very often they only found domestic work, as their new status does not facilitate their professional integration especially with the financial crisis affecting Spain (see below). Domestic work is the most accessible employment because many employers pay no attention to the legal status of their regular employees. Indeed, employees with irregular status are often preferred as their legal status prevents them

20 There are no exact figures available as to the extent of this phenomenon. According to comments gathered from several women who came to pick strawberries, more than half of the workforce defected to other Spanish cities or travelled to Italy. Tall and Tandian (20IO: II) mention the case of 70 women out of 540 who arrived in March 2008 and who did not report back when their contracts were discontinued or ended, i.e. about I3 per cent. 
from taking legal action in case of abuse. In the light of this precarious legal status, these migrants have very limited flexibility in their choice of employment, which explains their low bargaining power at the time of recruitment.

As indicated earlier, apart from the migrant workers who initially came to Spain on the agricultural work scheme, other Senegalese women working in domestic work came to Spain much earlier, as individuals or as part of family reunification. Those who came as part of family reunification usually have regular status and work with contracts through placement agencies while the others usually have irregular status and are self-employed, seeking their own clients and often working without a written contract, relying on an oral agreement. Their salary varies greatly because they can charge by the hour or by the day or specify fixed rates, depending on the assignment. Their working hours may be longer than those of contract workers but this seems to be perceived as a privilege because these workers can earn more, even though they are excluded from social protection. ${ }^{21}$

During a discussion, some migrants emphasized the ambiguity they live in: on the one hand, they are forced to keep their jobs even if they mean drudgery, harsh requirements by employers, and their own acceptance of the undesirable, while on the other hand, once they are determined, some migrants successfully manage to abandon domestic work if the work conditions become too difficult. This experience is illustrated by the following interview quotes:

At the home where I worked, there were eight rooms, five toilets, a tennis court, a bar, a large swimming pool. The house was so big that I cannot tell you the actual dimensions (...) and I was alone cleaning it, I was doing all the work. Can you imagine? (Fatima, 35, Valencia).

You know, if you are recruited for a job that you have never done in Senegal, it is normal that you suffer. And if you come across a demanding boss who does not value your work, as is often the case, things may be very complicated. I know Senegalese whose employers were very difficult. They also left their jobs after a few months. According to them, their work became pure exploitation. You know, sometimes women are forced to stay because they have no alternative but to endure what the employers demand. When you are in need, you

21 In Spain, three different subforms of domestic work are distinguished: internas (live-ins), externas (live-outs) and 'por horas' (hourly workers). Every sector presents different schemes for payment, duties, and hours of work (Dobner/Tappert 20I0: 2, footnote 3). can only resign yourself and bear all conditions (Yacine, 42, Valencia).

Facing these difficulties in domestic work, some women feel that street vending (of belts, glasses, etc.) is less restrictive although they recognize that with street trading, there are risks such as being chased by the police. Other women migrants feel that the benefits of street trading, as opposed to domestic work, are first, not to be regarded as a mere "slave" and secondly, to make money without having to endure an employer who demands the resumption of a task already done.

I think I was like a slave! I had no freedom. Not at all! I was only earning a small salary despite all the work I was doing. The salary did not match what I really deserved! I was not allowed out! My boss asked me to wake up at 7 a.m. and if I was not up she would come and wake me up before returning to bed. I was preparing breakfast before she woke up around 9 a.m., that is to say, two hours after me! I had to work hard for everything to be clean before they woke up. Once she was up I served them breakfast. And after all this, I cleaned the table and then walked the dog. It was slavery! It was really slave labour! (Fatim, 40, Madrid).

With domestic work, I was like a slave; this is how I could describe myself! You know why? It's because it is not possible to measure the heaviness of the work I performed! And then I had no freedom! Someone who works without freedom, what is she? What can she be called? Freedom is priceless and I had none at all! (Awa, 42, Madrid).

In addition to long working hours, some women suffer from isolation, a situation they have difficulty in accepting.

On some points, I can say I was treated well by my boss and her children. They gave me enough to eat and drink. But it is the isolation that bothered me. It hurt a lot! I was sidelined as if I had a disease and paradoxically it is me who was cooking for them! It was very painful to feel isolated! Yet it was me who was doing their bedrooms, I cleaned their toilets. In fact, I was like a slave in the house! The work I did reminded me of slavery! I started at 7 a.m. and went to bed at midnight. And it's a job I did for three years. I used to work flawlessly (Arame, 38, Madrid).

Moraleja! A bourgeois neighbourhood! When I was hired, I was alone! I had my own cup, my own table, my own spoon, my own fork, my own knife, etc. I was not eating with the others! No way! I had my own room, my own toilet. I did not share anything with others! Every morning I was obliged to get up early before the others. I put on my uniform and my crown. As seen on TV! That is how I dressed. At first it was difficult but I eventually got used to it. (...) This is what prompted me the most to emigrate and to accept this job, yet I was eight- 
een when I came to Spain. A humiliating job! Humbling because I was washing the dog! I did his daily toilet and when he got sick, it was me who would take him to the vet (Ndeye Marieme, 42, Madrid).

Given the clash of cultures inherent to the situation of migration, for many migrant domestic workers, washing dogs or walking them is considered demeaning and humiliating. According to the Muslim religion, which is the religion and sociocultural practice of reference for a majority of them, the dog is considered an unclean animal surrounded by many taboos. For example, Islam recommends washing clothes touched by a dog before praying.

Another issue is that some Senegalese migrant women experience a deterioration of their skills as they work in Spain in low-skilled activities, while in Senegal, some of them had considerable professional work experience. Thus, with migration, some Senegalese women experience a true professional downgrading, a situation that is very frustrating for them.

Despite the migrants' awareness of their demeaning working conditions, they prefer to stick to them to make money. This is due mainly to the pressure of relatives left in Senegal. As one migrant worker observed:

If the relatives remaining in Senegal were aware of the many deprivations which we endure to make money, they would spend every penny we send them with a twinge of regret (Soukeyna, 43, Malaga).

The expectation of the family residing in Senegal is not the sole reason for pushing migrants to continue to stay in personal care work. Sometimes, they stay because it is the only activity they can perform, given their precarious legal status.

In Senegal, it was my mother or my sister who were preparing food and were undertaking the cleaning work. (...) When I arrived in Spain and I began looking for work, I was informed that I could not do certain tasks because I had no documents. I was told that the only job I could do was to look after elderly ladies. When I asked my fellow countrywomen with whom I lived about this, I was told simply and clearly that I could only work in areas that the Spanish women did not want to be in. That's it! (Fanta, 4I, Seville).

Van Nieuwenhuyze (2009: I24-I28) confirms that giving up and returning home is not really an option if one has not been at least able to pay back the money the family has invested in the trip, and preferably one should return with much more money and a 'project'; often the moral pressure from the family pushes migrants to endure their hardships. Instead of giving up, many undocumented migrants move around between neighbourhoods, cities, and even countries to look for better opportunities. Search strategies usually rely on ethnic networks, i.e. fellow Senegalese, family members and friends, and word of mouth, which in turn leads them to be pushed into the same sectors. With a larger network and language skills come more options, though as no jobs for highly educated people exist in the informal economy, human capital and skills disappear. Most migrants are stuck in the shadow economy where they are vulnerable to abuse by the employer: for regularization purposes, they need a contract, no matter how abusive.

For one of our interviewees however, having a legal status or not was not her primary concern. Unlike other migrants, what mattered to her was to find work, earn money, and support her family back in Senegal:

I had no documents but I really needed to work and earn some money to send to Senegal, the documents were not a concern for me. I did not care about documents. What mattered to me was to work, earn money, and help the family (Khardiata, 42, Almeria).

The opinion of this migrant was different from most of the other women we interviewed. For them, their irregular status constitutes a real handicap. In the absence of a valid residence permit, migrants are in an economically precarious and legally vulnerable situation. By working informally, migrants sometimes find themselves exploited by their employers who dictate the terms of the arrangement:

Some Senegalese women work without being paid! Others face all kinds of difficulties before being paid. Such cases, we see them every day. I have seen here employers whose practices do not exist anywhere else. They will pay you only half the salary and ask you to wait until next month. It is abnormal! Everyone knows it is wrong but what can you do? Without the documents, it is hard to complain. In addition, the financial crisis does not help much. If you refuse a job, the next minute others will accept it and sometimes they may even offer to be paid less (Sara, 35, Granada).

As they are unable to fulfil the legal requirements for claiming labour rights, Senegalese migrants with irregular status are forced to contend themselves with having had the chance to find work:

Without documents! I'm in an irregular situation (...) I accept all kinds of work without complaining but once I have the resident card in my hand, I will claim all my rights. Without the documents, it is difficult to say no to the boss (Rokhaya, 35, Almeria).

Pregnant migrant domestic workers with irregular status are especially vulnerable to exploitation. This is 
the case with this migrant who was at an advanced stage of pregnancy but preferred to continue working:

When you are in need, you take risks! And afterwards, one wonders how can we take such risks? I happened to work in Dallus Milagros in a big house when I was in a very advanced state of pregnancy. But hey, I had no choice! I had just arrived and I had no documents. The work was very tough, given the advanced stage of my pregnancy. At one point I wanted to stop and resume work later but as I had no documents, I did not qualify for paid maternity leave. I was working informally. I had to hide my pregnancy as much as possible to avoid being dismissed by my boss. I was doing all sorts of activities. It was very tiring, especially given the pregnancy. Finally, I was forced to stop because I had enormous problems that jeopardized my pregnancy. I think it is because of some heavy tasks I was doing that I ended up giving birth by Caesarean section (Farmata, 35 , Sevilla).

These words reveal unambiguously the low flexibility and bargaining power of migrant workers caused by their irregular status, which deprives them of the rights to enjoy good working conditions. Employers are aware of and sometimes exploit this situation:

Some employers prefer to hire someone who does not have papers to pay him a pittance or nothing at all because they know that this person will not report them (Sara, 35, Granada).

Favouring the recruitment of women with irregular status to the detriment of others is a way for some Spanish employers to have a docile labour force at low cost. Indeed, "because migrants are forced to stay in the domestic service sector due to migration policies, quota politics and the ethno-stratified labour market Spanish employers believe that a long lasting work relationship is guaranteed" (Dobner/Tappert 20IO: I8).

Senegalese migrants are aware that their irregular status does not militate in their favour because it makes them 'invisible workers' with no legal legitimacy. According to Falquet, Hirata, Kergoat, Labari, Le Feuvre and Sow (2010: I02), with few exceptions, these migrant women are mostly invisible, like the work they do, and possess an involuntary feature which is often overlooked - they exert a downwards pressure on wages in the care sector. Despite their often very specific training as care professionals, these women accept working conditions and variable hours that Spanish women try to resist.

\subsection{Working Without Being Visible: A Denial of Existence}

The invisibility of some Senegalese migrant women in Spain is thus partly explained by the fact that they work without the required papers. ${ }^{22}$ In so doing they contribute to the growth of Spain's informal economy. This situation has been further accelerated by the financial crisis in Spain in recent years. The informal economy accounts for 19.2 per cent of the official Spanish GDP (Mallet/Dinmore 20II), while Spain had an unemployment rate of 2I.2 per cent in late 20II, a record among OECD countries (OECD 2OII). Not having the required documents exposes most Senegalese migrants to risky situations. Even if some of them are aware of the danger, they still prefer to follow this path to earn a living. During an interview, a migrant who has worked in domestic services in Madrid for several years argued, based on her own experience, that there is often a tacit agreement between the employer and the migrant worker on this issue:

I was working without proper documents, knowing that there are risks especially in case of accident! If this would happen, I would take care of myself by my own means. This was very clear in my mind! My boss was understanding. There was a tacit agreement between us on this point. But as I was doing my job well, she saw no reason to worry! I also worked for a lawyer and we never spoke about the documents. With some employers, you never talk about it unless they insist! (Mame Mariétou, 35, Madrid).

Particularly in Spanish households where both spouses are working, we found an increasing delegation of family responsibilities to their migrant domestic workers. These, in addition to preparing meals and cleaning the house, spend a lot of time with the children of their employers, and this in turn leads to greater closeness to them. This situation has become more visible on public transport (bus and metro) and in some school playgrounds in large cities where often women domestic workers are accompanied by

22 Van Nieuwenhuyze (2009: 98, 194) usefully points out that although we often distinguish between the formal and informal economy or jobs, this does not overlap completely with people being undocumented or not, as a migrant without papers (undocumented) can do formal work with someone else's papers, and documented migrants can do informal work. Moreover, the strict division between undocumented and regular migrant status is often blurred, partly because of the documentation strategies of migrants, partly because of informal toleration practices by the authorities. 
young Spanish children. This is part of the international transfer of social reproductive work related to the globalization of production that we observe around the world (Truong 1996).

Domestic workers come to Spain because they are able to fill this niche in the labour market. In that sense, Spanish society is also actively involved in the migration process. Thanks to the presence of migrant workers, Spanish women manage to balance household tasks and pursue leisure activities or paid employment, while the migrant workers are sometimes exposed to situations dangerous to their health, as we have seen with regard to pregnant migrant workers who prefer to hide their condition to avoid being fired. $^{23}$

Indeed, at the macro-level, Parella Rubio (2003: I87, cited in Dobner/Tappert 20I0: 2) identifies three different causes leading to an increased incorporation of migrants into domestic service in Spain: migrant networks, the migrant politics of the Spanish state, and changes in family structures and the gendered division of labour in Spain. The last includes the growth of the ageing population, falling birth rates, the integration of women into the labour market, and an increasing privatization of the social system since the I980s. Despite the growing participation of women in the Spanish labour market, traditional gender roles and the position of women as responsible carers in domestic work are maintained and reproduced in society and state policies. Domínguez-Folgueras and Castro-Martín (2008: 1518, cited in Dobner/Tappert 20IO: 3) define Spain as "still organized on the basis of a traditional model of gendered responsibilities within the family. The unpaid work of women as carers within the family remains an important pillar of social welfare, and public policies aimed at balancing family and work responsibilities remain underdeveloped." The outsourcing of domestic work is therefore usually resolved privately with the employment of migrant domestic workers, mostly women. There also is an increasing demand for domestic workers in the field of childcare due to low public financial support and limited public childcare services, with private childcare services only being affordable by a small sec-

23 Although probably only relevant for the case of regular migrants, in Spain employment tribunals (conseils de prud'hommes) continue to fight against the dismissal of pregnant domestic workers, enforcing workers' rights such as the law of work procedure, the law of reconciling personal and professional lives, and the law of effective gender equality, which all provide for the annulment of dismissals and the reinstatement of the worker. tion of society. Due to precarious employment conditions and low wages in the domestic service sector, domestic workers have thus become affordable for middle-class families who exhibit the highest demand for domestic workers in Spanish society. There is an ongoing demand for domestic workers in Spain, despite the economic crisis, and it is mostly met by female immigrants (Dobner/Tappert 20I0: 2-6).

Indeed, it is interesting to consider the impact of the financial and economic crisis. From the findings of a qualitative field study by Dobner and Tappert (20IO: IO-I3), it seems that working conditions are getting worse, especially in terms of working hours and wages. The crisis influences working conditions insofar as it leads to more dependency on the part of migrant domestic workers (with both regular and irregular status). Domestic workers who now want to change their labour sector see no chance of doing so and prefer to remain in the domestic sector. They are also more likely to accept poor and humiliating working conditions than before the crisis, for fear of not finding another job or one that is even worse than the current one. Migrant women who have not worked in the domestic work sector for a long time are being compelled to return to it. This is also the case for Spanish women, who are again increasingly seeking jobs as domestic workers. While the domestic work sector has not been hit as hard as other work sectors, the composition of the workforce is changing, as many women, female migrants as well as Spanish women, are seeking (secure) jobs, and some are returning to the domestic work sector. Labour competition thus increases, leading to a worsening of working conditions. There is a preference for migrant workers and therefore a positive discrimination towards them on the part of the employer, because of their greater dependency on the employer for work and a residence permit than is the case with Spanish domestic workers (Dobner/Tappert 20IO: I9-20; see also Solé/ Parella 2003: I24).

As indicated earlier, the demand for this kind of employment arrangement has to be set in the broader frame of an internationalized and globalized labour market, as well as taking into account international migration, in which the transnationalization and feminization of the workforce are linked processes. The demand for a flexible and cheap workforce in the labour market results in the production of identities shaped by gender, ethnicity, and class (FMP 2009: $7^{24}$, cited in Dobner/Tappert 20I0: 8).

To sum up this section: in terms of the individual migrant's life project, the process of 'becoming invisi- 
ble' and/or having irregular status could in many cases be seen as an expression of agency, with respect to how they navigate opportunities in the Spanish labour market, i.e. a rational decision though based on limited knowledge of the consequences. In fact, following Van Nieuwenhuyze (2009: 54), it is useful to think of an individual's migration project as comprising three stages in which he or she uses different strategies: 'survival strategies' apply mostly to migrants who arrive in Europe without the necessary documents or acquire irregular status, as in the group of women studied in this chapter; afterwards, many of them may try to regularize their stay, developing 'documentation strategies'; and finally, they may start to consider strategies for upward or geographical mobility. It is clear that the last strategy is increasingly being postponed due to the economic crisis, but it is worth - at least briefly - considering migrants' 'documentation strategies'.

\subsection{Seeking Access to Social Protection Rights}

Before turning to the issue of how Senegalese women migrants seek to access their rights, it is useful to briefly review the legal framework governing the domestic work sector in Spain. Since the 1980s, it has been declared a special work regime (Real Decreto $\mathrm{I} 424 / 85$ ) and does not form part of the common labour law. Rather it is defined as an "employment arrangement with exceptional characteristics". As a special work regime it contains many disadvantages concerning working conditions and social benefits, some of which have already been discussed. For example, work contracts are not obligatory; the wage is equal to the national minimum wage (624 $€$ a month), but working as a live-in can decrease the salary by up to forty-five per cent; maximum working hours are forty hours per week, but live-ins are often obliged to work more due to their continuous presence in the household. Most importantly, domestic workers do not have a right to unemployment benefits (Dobner/ Tappert 20IO: 3, footnote 7; see also Solé/Ribas/Bergalli/Parella 1998).

The work permit has to be applied for by the employer and can only be extended by him or her,

24 Federación mujeres progresistas (FMP), 2009: Tenemos la persona que necesita. Tres meses de garantía. See <http:// www.fmujeresprogresistas.org/images/contenidos/estudio\%2otrabajo\%2odomstico.pdf> (4 December 20I2). and this hinders the changing of employers and generates an extreme dependence on them, as domestic workers can lose their residence permit when changing employers or in periods of unemployment. The legal bundling of work and residence permit means that when they lose their job, or if for whatever reason they are not able to produce a job contract, the risk of not being able to extend the residence permit and therefore of being expelled is high. Live-ins in particular experience a high degree of vulnerability as they work and live in spaces that are invisible to the public, the private households of their employers, as we have seen in the examples cited above (Dobner/ Tappert 20IO: 7-8, I4).

Nevertheless, it is possible for undocumented migrants to register on the list of local residents at the municipality, provided they possess a valid passport and proof of housing/address, so that they can claim the right to health care and education for their children. However, the preconditions of registration exclude certain groups from access to health care (e.g. those who were never registered in Senegal), though a number of special health care centres focus on these groups (Van Nieuwenhuyze 2009: 133).

There is also the quite common practice of borrowing, renting, buying, or falsifying somebody else's documentation of residence and work permit to obtain a formal job using another name, though this can then jeopardize the regularization process (see Van Nieuwenhuyze 2009: I34 for examples). In any case, since, at least until recently, Spain preferred to control illegal immigration at the border rather than control undocumented migrants inside the country, undocumented migrants do not seem to have a high level of fear of repatriation. When a migrant is caught without a residence or labour permit, he or she can be administratively expelled but this is rarely translated into a physical expulsion (Van Nieuwenhuyze 2009: 138). However, even if the feeling of repression is not overwhelming, "the pending promise of 'papers' binds [migrants with irregular status] to jobs and employers, providing Spain with a vulnerable and therefore obedient labour force for the informal sector" (Van Nieuwenhuyze 2009: 156).

The 'invisibility' of Senegalese migrants in the domestic work sector is linked for some to the ignorance of their rights, the fear of losing their jobs, their unfamiliarity with the Spanish language, and their neglect of reading their work contract in the case of migrants with regular status. The latter sometimes show their employment contract to other people (spouse, friends, neighbours, etc.) to help them better under- 
stand the content. They usually prefer to use their social networks rather than private lawyers, work inspectors, social workers, etc.

Some migrant women turn to community associations when the terms of employment contracts are not respected, the tasks are not clearly defined, or the working hours are too long. This is often the case with women domestic workers with regular status who claim to be the victim of the strategies of some employers, who, citing the financial crisis, avoid giving the workers permanent contracts after nine months of work as required by law, preferring to terminate the temporary contract after a few months without any compensation. This contributes greatly to keeping Senegalese migrant women in a precarious situation. Thus Senegalese migrants are able to receive legal support or improve their living and working conditions, even if they sometimes question the effectiveness of such associations in the field of social protection. The lack of financial resources and trained personnel are a real handicap for Senegalese associations in Spain trying to meet their members' needs in terms of realizing their rights to social protection. We found that most Senegalese women migrants are aware of the social injustices which they suffer in the performance of domestic work, but their illegal status, their lack of mastery of the Spanish language, and their ignorance of the labour code prevent them from effectively addressing them.

At the national level, other authors (Danese 200I: 77; Solé/Parella 2003: I3I-I32) observe the weakened role of trade unions in representing all workers, including non-EU immigrants. While some have taken action to encourage non-discrimination and protect the rights of immigrant workers, and some have had a key role in the regularization processes, there are low levels of union membership in the domestic service, construction, and agriculture sectors, and the majority of (non-Latin American) immigrant workers have no experience of trade union practices in their country of origin. Dietz (2004: I092) shows how "the migrant populations recently appearing in Andalucía do not integrate into the local, urban or rural settings of the host-society neighbourhoods, but into the ethno-national networks which enable them to survive in the unstable continuum of legal and illegal economic activities".

\subsection{Conclusions}

By sending women to Spain for the picking of strawberries as part of a temporary migration scheme, the Spanish and Senegalese governments hoped to offer them a job in Europe as well as finding cheap labour for agricultural enterprises. Due to harsh working conditions and low wages which were misaligned to their profiles and expectations, some Senegalese women preferred to abandon the fields for other Spanish cities where they joined other Senegalese working in domestic service. Without regular residence permits, some of these women found themselves in precarious situations reducing their statutory and contractual rights. They encountered abuses such as overtime being rarely paid, extremely variable working hours, and sometimes even verbal, physical, and psychological violence. Domestic workers with legal status also face difficulties such as the downgrading of skills, isolation, and not being allowed to change employers or become pregnant for a certain number of years.

From the findings presented here, we can draw conclusions and policy implications for both temporary (agricultural) work schemes and for the situation of female migrant domestic workers in Spain, all of which revolve around labour market issues, questions of regulation, and unforeseen outcomes in terms of social (in)justice. In documenting the process of transition from one sector to another, we have also seen that while choices are limited as a result of the restrictive migration regimes and economic adverse conditions, agency remains important (Van Nieuwenhuyze 2009: 195).

The findings on the temporary agricultural work scheme show that policies which fail to understand the temporary migrant workers' lives - that many are well educated, that they are not merely pairs of harvesting hands, that they have networks in Spain, that allocation of places in temporary migration schemes will in Senegal inevitably be partly on the basis of patronage - can never obtain their objectives.

As for the findings on migrant domestic workers presented here, they illustrate very clearly the special characteristics found in the domestic work sector, namely "the intimate character of the social sphere where the work is performed; the social construction of this work as a female gendered area; the special relationship between employer and employee which is highly emotional, personalized and characterized by mutual dependency" (Lutz 2008: I, cited in Dobner/ Tappert 20I0: 8; see also Gutiérrez-Rodríguez 20IO). 
In terms of policy implications, legal immigration of the unskilled is arguably desirable, along with affordable social protection for these workers. Temporary migration schemes are seen as a good match between the needs of some labour markets, the pressure for migration, the fear of a brain drain, and the potential of return migration. Theoretically, if the system is transparent, predictable, and rights-based, it could be a realistic and cost-effective policy option (BaldwinEdwards 2004; Ghosh 2000; cited in Van Nieuwenhuyze 2009: 198). In practice, to address some of the shortcomings presented here it is necessary to build on the institutional capacities of the governments of countries of origin for the management of migration flows, increasing the number of diplomatic representations, consular offices, and jointly-run employment services, in order to streamline the processes of recruitment, selection, and return of foreign workers (EMN 20IO: 55; see also the lessons learnt from the management of seasonal Moroccan migration around Huelva as found in González Enríquez 20II). Other studies have also shown that the need for well-prepared workers includes training on contracts, knowledge of legal processes and resources in host country, including basic rights, some job skills training, cultural awareness, and adequate language abilities (Morgan/ Nolan 20II: I7).

However, if foreign workers do not wish to return home, the creation of a population of undocumented immigrants may be almost inevitable (Van Nieuwenhuyze 2009: 198).

This is particularly the case for Spain, which has not yet developed a legal framework to encourage the temporary or circular migration of documented foreign nationals living in Spain to and from their countries of origin. Although any foreign worker with a valid work and residence permit may enter and leave Spain, the requirement to fulfil the necessary residence and (uninterrupted) employment criteria for maintaining or renewing these permits restricts circular and temporary mobility from Spain to countries of origin. Only in the case of migrants with long-term residence permits (obtained after residence for a continuous five-year period) are there no practical restrictions on movement between Spain and countries of origin (EMN 20IO: 32).

It is therefore not surprising that Newland/Agunias/Dovelyn/Terrazas (2008: 22) conclude that "many of the conditions of migration programs for the less skilled, intended to 'enforce' circularity, seem to have the opposite effect of encouraging irregular migration: very short contract periods, non-renewable visas, visas tied to particular employers, and no flexibility to switch to other admission categories are all conditions that create incentives for migrants to leave the programs and move into irregular status". They therefore suggest that "incentives for circulation, like pension portability or an 'earned' right to remain permanently, may be more effective than enforcement measures" (2008: 23).

It seems that the Spanish government is making progress along these lines, as its Ministry of Labour and Immigration produced the Plan Estratégico de Ciudadanía e Integración (Strategic Plan for Citizenship and Integration) for 2007-20I0, which was approved by the Spanish Government in 2007. Among other measures, the Plan includes actions to foster the inclusion of seasonal workers and encourage their return with skills and resources enabling them to act as development agents in their places of origin. This is sought through active employment policies in countries of origin and voluntary return programmes. ${ }^{25}$ The Plan also seeks to encourage the signing of bilateral social security agreements with several countries (as of 20IO, not yet with Senegal) for the recognition of pension rights and other benefits, which could be a stimulus for temporary and circular mobility in the medium and long term (EMN 20IO: 22-23).

Since bilateral treaties still mostly do not take into account the views of the migrants themselves (Wabgou 2008: I48), such policy changes would help migrants to fulfil their life projects. As Riccio (200I: 590) observes, most Senegalese migrants in Europe would prefer to conduct truly transnational lives, living part of the year here and the other part there, and making the best of both worlds. However, "far from being in a post-national era [...], transnational organization still needs to negotiate with nation and local state regulatory and sometimes exclusionary practices as well as with the representations of immigrants held in the migration context" (Riccio 200I: 590, citing Grillo/Riccio/Salih 2000). ${ }^{26}$

25 See also the (limited) training activities organized by the ILO for Senegalese migrants, targeting among others the return and reinsertion of migrants (see <http://bitmigrant.wordpress.com/> (I9 November 2012). On return to Senegal within government-led initiatives and their misalignment with migrant perspectives, see Sinatti (20I2).

26 See also Sinatti (2011) for the argument that Senegalese migrants' self-perception of successful return is still largely associated with permanent return. 


\section{References}

Agrela Romero, Belén; Gil Araujo, Sandra, 2005: "Constructing Otherness. The management of migration and diversity in the Spanish context", in: Migration: A European Journal of International Migration and Ethnic Relations, 43-45: 9-33.

Apap, Joanna, 200I: "Extending Citizenship Rights to Third Country Nationals. The Correlation Between Migration and Integration: A Sample from South Europe", in: CEPS Policy Brief, I75 (October); at: <http:// www.ceps.eu/book/extending-citizenship-rights-thirdcountry-nationals-correlation-between-migration-andintegrat> (3 September 20I2).

Babou, Cheikh Anta, 2008: "Migration and Cultural Change: Money, 'Caste', Gender, and Social Status among Senegalese Female Hair Braiders in the United States", in: Africa Today, 55,2 (Winter): 3-22.

Baldwin-Edwards, Martin, 2004: "Immigrants and the Welfare State in Europe", in: Massey, Douglas S.; Taylor, J. Edward (Eds.): International Migration: Prospects and Policies in a Global Market (Oxford: Oxford University Press): 3I8-334.

Blanchard, Melissa (20I2): "Regard communautaire sur le parcours social et la sexualité des femmes sénégalaises 'solitaires' à Marseille", in: SociologieS (Dossiers, Amours Transi(t)s. Transactions sexuelles au prisme de la migration), published on-line on 27 January 20I2, at: <http://sociologies.revues.org/3863> (9 August 20I2).

Bocquier, Philippe, I992: "L'insertion et la mobilité professionnelles à Dakar” (PhD dissertation, Université René Descartes, Paris V).

Burnett, Victoria, 2007: "To Curb Illegal Migration, Spain Offers a Legal Route", in: The New York Times (II August 2007); at: <http://www.nytimes.com/2007/08/ II/world/europe/IIspain.html> (9 August 20I2).

Castles, Stephen, 2002: "Migration and Community Formation under Conditions of Globalization", in: International Migration Review, 36,4 (December): II43-II68.

Corkill, David, 200I: "Economic migrants and the labour market in Spain and Portugal", in: Ethnic and Racial Studies, 24,5: 828-844.

Coulibaly-Tandian, Oumoul Khaïy, 2008: "Socio-anthropologie des mobilités sénégalaises à Toulouse et Barcelone et leurs influences au Sénégal. Diversité des pratiques, Organisation en réseaux, Place des NTIC et Analyse de genre" (PhD dissertation, Université de Toulouse and Université Gaston Berger de Saint-Louis).

Danese, Gaia, 200I: "Participation beyond citizenship: migrants' associations in Italy and Spain", in: Patterns of Prejudice, 35,I: 69-89.

Dietz, Gunther, 2004: "Frontier Hybridization or Culture Clash? Trans-national migrant communities and subnational identity politics in Andalusia, Spain”, in: Journal of Ethnic and Migration Studies, 30,6: I087-III2.

Dobner, Marianne; Tappert, Simone, 20I0: "Female migrant domestic workers and their Spanish employers in times of crisis. A comparative analysis of consequences for women on both sides of the coin", Paper for the SGIR $7^{\text {th }}$ Pan-European International Relations Conference, Stockholm, Sweden, 9-II September.

Domínguez-Folgueras, Marta; Castro-Martín, Teresa, 2008: "Women's changing socioeconomic position and union formation in Spain and Portugal", in: Demographic Research, 19,4I (August): 15I3-I550.

Domingo, Andreu; Kaplan, Adriana; Gómez Gil, Carlos, 2000: Easy Scapegoats: Sans-Papiers Immigrants in Europe: Report on Spain (Barcelona: Centre d'Estudis Demogràfics).

EMN (European Migration Network), 20IO: Temporary and Circular Migration: Empirical Evidence, Current Policy Practice and Future Options in Spain (December); at: <http://extranjeros.empleo.gob.es/es/RedEuropeaMigraciones/Estudios_monograficos/EMN-ENCircular-Migration.pdf> (9 August 20I2).

Fall, Papa Demba, 1998: "Stratégies et implications fonctionnelles de la migration sénégalaise vers l'Italie”, in: Migrations Société, Io,60: 7-33.

Falquet, Jules; Hirata, Helena; Kergoat, Danièle; Labari, Brahim; Le Feuvre, Nicky; Sow, Fatou, 20Io: Le sexe de la mondialisation. Genre, classe, race et nouvelle division du travail (Paris: Presses de Sciences Po).

FMP (Federación mujeres progresistas); at: 2009: Tenemos la persona que necesita. Tres meses de garantía. <http:// www.fmujeresprogresistas.org/images/contenidos/ estudio\%20trabajo\%2odomstico.pdf> (4 December 20I2).

Freeman, Gary P., I995: "Modes of Immigration Politics in Liberal Democratic States", in: International Migration Review, 29,4 (Winter): 88I-902.

García-Cano, Ana Maria, 2002: "Limmigration non communautaire féminine vers l'Espagne" in: Migrance 2I, deuxième trimestre: II6-I3I; at: 〈http://www.generiques.org/ images/pdf/Migrance_2Ifra.pdf > (3 September 20I2).

Garreta Bochaca, Jordi, 200I: "Les immigrés africains sur le marché du travail espagnol", in: Migrations Société, I3,77: 7-I7.

Ghosh, Bimal, 2000: "New International Regime for Orderly Movements of People: What will it Look Like?", in: Ghosh, Bimal (Ed.): Managing Migration: Time for a New International Regime? (Oxford: Oxford University Press): 6-26.

González Enríquez, Carmen, 20II: "Temporary Migration between Morocco and Spain”, in: Real Instituto Elcano ARI, III/20II, 2I/07/20II; at: <http://www.realinstitutoelcano.org/wps/wcm/connect/7962228047aagcd88I2 6d9076e8e26e4/ARIIII-20II_Temporary_Migration_ Morocco_Spain.pdf?MOD=AJPERES\&CACHEID $=7962$ 228047aa9cd88I26d9076e8e26e4> (3 September 20I2).

González-Ferrer, Amparo; Graus Elisabeth, 20I2: "Migrantes senegaleses en Francia, Italia y España: primeros resultados de la encuesta MAFE-Senegal en Europa", in: Real Instituto Elcano ARI, 8/20I2, 02/O2/20I2; at: < http:// www.realinstitutoelcano.org/wps/wcm/connect/49ob5 e004a047dodaeo2bf39d72a98ae/ARI8-20I2_Gonzalez- 
Ferrer_Kraus_migrantes_senegal_Espana_Italia_Francia _MAFE.pdf?MOD=AJPERES\&CACHEID $=490$ b5eo०4 a047dodaeo2bf39d72a98ae> (3 September 20I2).

Grillo, Ralph D.; Riccio, Bruno; Salih, Ruba, 2000: "Here or There? Contrasting Experiences of Transnationalism: Moroccans and Senegalese in Italy", in: CDE Working Paper (Brighton: University of Sussex).

Gutiérrez-Rodríguez, Encarnación, 2010: Migration, Domestic Work and Affect: A Decolonial Approach on Value and the Feminization of Labor (New York Abingdon: Routledge).

Hoggart, Keith; Mendoza, Cristóbal, I999: "African Immigrant Workers in Spanish Agriculture”, in: Sociologia Ruralis, 39,4 (October): 538-562.

Kaplan Marcusán, Adriana, 2005: "From Senegambia to Spain: Migration process and social integration", in: Migration: A European Journal of International Migration and Ethnic Relations, 43-45: 52-65.

Kohnert, Dirk, 2007: "African Migration to Europe: Obscured Responsibilities and Common Misconceptions" in: GIGA Working Papers, 49 (May).

Lessault, David; Beauchemin, Cris, 2009: "Migration from sub-Saharan Africa to Europe: still a limited trend", in: Population \& Societies, 452 (January).

Lessault, David; Mezger, Cora, 20IO: "La migration internationale sénégalaise. Des discours public à la visibilité statistique”, in: MAFE Working Paper, 5 (April).

Lutz, Helma, 2008: "Introduction", in: Lutz, Helma (Ed.): Migration and Domestic Work: A European Perspective on a Global Theme (Aldershot: Ashgate): I-I2.

Lutz, Helma, 20II: The New Maids: Transnational Women and the Care Economy (London and New York: Zed Books).

Mallet, Victor; Dinmore, Guy, 20II: "Europe: Hidden economy", Financial Times (8 June 20II); at: < http:// www.ft.com/intl/cms/s/o/efc35Ioe-92I4-IIeo-geoo-ooI 44feab49a.html\#axzz2CgI7PMXu> (I9 November 20I2).

Mendoza, Cristóbal, 200I: "The role of the state in influencing African labour outcomes in Spain and Portugal”, in: Geoforum, 32: 167-180.

Morgan, Guy; Nolan, Chris, 20II: Step Up: Improving the Recruitment of Migrant Workers in Indonesia (BSRMigration Linkages); at: <http://www.bsr.org/reports/ Improving_Migrant_Worker_Recruitment_in_Indonesia. pdf> (9 August 20I2).

Newland, Kathleen; Agunias, Dovelyn Rannveig; Terrazas, Aaron, 2008: "Learning by Doing: Experiences of Circular Migration", in: Migration Policy Institute Insight (September).

OECD (Organisation for Economic Co-operation and Development), 2005: African Economic Outlook: Senegal (Paris: OECD).

OECD (Organisation for Economic Co-operation and Development), 20II: OECD Perspectives: Spain. Policies for a sustainable recovery, October; at: 〈http://www. oecd.org/spain/44686629.pdf> (I9 November 20I2).
Parella Rubio, Sònia, 2003: Mujer, inmigrante, trabajadora: la triple discriminación (Barcelona: Anthropos).

Riccio, Bruno, 200I: "From 'ethnic group' to 'transnational community'? Senegalese migrants' ambivalent experiences and multiple trajectories", in: Journal of Ethnic and Migration Studies, 27,4: 583-599.

Robin, Nelly, 1996: "La Multipolarisation de la Migration Sénégalaise”, in: Ma Mung, Emmanuel (Ed.): Mobilités et investissements des émigrés: Maroc, Tunisie, Turquie, Sénégal (Paris: L'Harmattan): 48-64.

Rosander, Eva Evers, 2005: "Cosmopolites et locales: femmes sénégalaises en voyage” in: Afrique \& histoire, 4,2: IO3-I22.

Sassen, Saskia, 2000: "Mais pourquoi émigrent-ils?", Le Monde Diplomatique (November); at: <http://www. monde-diplomatique.fr/2000/II/SASSEN/I4478> (3 September 20I2).

Sinatti, Giulia, 20II: “Mobile Transmigrants' or 'Unsettled Returnees'? Myth of Return and Permanent Resettlement among Senegalese Migrants" in: Population, Space and Place, I7: I53-166.

Sinatti, Giulia, 20I2: "Return Migration as a Win-Win-Win Scenario? Visions of Return among Senegalese Migrants, the State of Origin and Receiving Countries", Paper for the workshop Return migration and transnationalism: alternatives or complements?, Oslo, Norway, 4-5 September.

Siregar, Lukman Hakim, 20Iо: "Bilateral Agreements on Migrant Workers: Developing a Legal Instrument for Protecting Indonesian Citizens Abroad", in: Journal Diplomasi, 2/r: I69-186; at: <http://isjd.pdii.lipi.go.id/ admin/jurnal/2IIOI69I86_2085-6075.pdf> (I9 November 20I2).

Solé, Carlota, I994: La mujer inmigrante (Madrid: Ministerio de Asuntos Sociales, Instituto de la Mujer)

Solé, Carlota; Ribas, Natalia; Bergalli, Valeria; Parella, Sònia, I998: "Irregular employment amongst migrants in Spanish cities", in: Journal of Ethnic and Migration Studies, 24,2: 333-346

Solé, Carlota; Parella, Sònia, 2003: "The labour market and racial discrimination in Spain”, in: Journal of Ethnic and Migration Studies, 29,I: I2I-I4O.

Sow, Fatou, 2006: "Genre, droits humains et migrations en Afrique subsaharienne", Paper for the International Conference on Migration and Development, Rome, 8Io June; at: <http://www.cespi.it/CESPI-SID/Afrique_ subsaharienne.pdf> (3 September 2012).

Tall, Serigne Mansour, 2008: "La migration internationale sénégalaise: des recrutements de main-d'œuvre aux pirogues”, in: Diop, Momar-Coumba (Ed.): Le Sénégal des migrations. Mobilités, identités et societies (Dakar: CREPOS-KARTHALA-ONU HABITAT): 37-67.

Tall, Serigne Mansour; Tandian, Aly, 20IO: "Entre regroupement familial et migrations autonomes des femmes sénégalaises. Quelle analyse de genre des migrations sénégalaises?", in: CARIM Notes d'analyse et de synthèse, 2010/69; at: <http://cadmus.eui.eu/bitstream/ 
handle/I8I4/I5288/

CARIM_ASN_20IO_69.pdf?sequence=I $>$ (3 September 2OI2).

Tandian, Aly, 2008: "Des migrants sénégalais qualifiés en Italie: entre regrets et resignation" in: Diop, MomarCoumba (Ed.): Le Sénégal des migrations. Mobilités, identités et societies (Dakar: CREPOS-KARTHALAONU HABITAT): $365-388$.

Tandian, Aly; Coulibaly, Oumoul Khairy; Sow, Papa; Tall, Serigne Mansour; Wade, Cheikh Tidiane; Dioh, Adrien; Dime, Mamadou dit Ndongo; Ba, Amédoune; Badji, Mariama; Gueye, Cina; Mbaye, Thierno; Tandia, Aboubakr; Diallo, Sellou; Diagne, Moussa; Mbengue, Mamadou Abdoulay; Vasquez, José Luis; Seron, Gema; Kebe, Ndongo; Sane, Mamadou Bonaventure; Thiakh, Ababacar; Thioye, Alassane Ibrahima; Gueye, Cheikh; Niang, Ousseynou; and Ciss, Mareme (20II): "Protection sociale des migrantes Sénégalaises évoluant dans les activités agricoles et les services aux particuliers en Espagne: Rapport de recherche”, Le Groupe d'Etudes et de Recherches sur les Migrations (GERM) \& Faits de Sociétés, Université Gaston Berger de Saint-Louis, Senegal (Mimeo).
Truong, Than Dam, 1996: "Gender, International Migration and Social Reproduction: Implications for Theory, Policy, Research and Networking", in: Asian and Pacific Migration Journal, 5, I: 27-5I.

UNESCO (United Nations Educational, Scientific and Cultural Organization), 2008: People on the Move. Handbook on Selected Terms and Concepts. Version I.o; at: <http://unesdoc.unesco.org/images/oor6/oor636/ı6 362Ie. pdf> (3 September 2012).

Van Nieuwenhuyze, Inge, 2009: Getting by in Europe's Urban Labour Markets: Senegambian Migrants' Strategies for Survival, Documentation and Mobility (Amsterdam: IMISCOE Dissertations - Amsterdam University Press).

Wabgou, Maguemati, 2008: "Governance of migration in Senegal: The role of government in formulating migration policies", in: Adepoju, Aderanti; van Naerssen, Ton; Zoomers, Annelies (Eds.): International migration and national development in sub-Saharan Africa: Viewpoints and policy initiatives in the countries of origin (Leiden: Brill): I4I-I60.

Open Access. This chapter is distributed under the terms of the Creative Commons Attribution Non-commercial License, which permits any noncommercial use, distribution, and reproduction in any medium, provided the original author(s) and source are credited. 


\title{
$4 \quad$ Burmese Female Migrant Workers in Thailand: Managing Productive and Reproductive Responsibilities
}

\author{
Kyoko Kusakabe ${ }^{1}$ and Ruth Pearson ${ }^{2,3}$
}

\begin{abstract}
This case study argues that even in increasingly unstable circumstances women migrant workers have to continue to balance their reproductive responsibilities as mothers and daughters with their ongoing roles as wage workers and economic providers, often managing complex transborder care arrangements. The chapter extends the global care chain framework to investigate the ways in which Burmese migrant factory workers in Thailand organize reproduction and childcare in the place of destination and in the in-between places at the international borders between the two countries. The chapter provides new insights into ways migrant women factory workers adapt and strategize to achieve daily, generational, and biological reproduction needs and the links between these strategies and the pattern of capital accumulation in Thailand's border industrialization strategy. The elaboration of multiple forms of control and regulation from the state to the factory as well as community highlights the structures of constraint as well as the ways women negotiate around these constraints. The aim of the chapter is to delineate key issues of social injustice relating to their nationality and legal ambiguity of status (migrant or worker). Focusing on the individual agency of migrant workers, our research demonstrates that existing analyses of the women's experiences of work and of harassment in Thailand needs to be supplemented by an understanding of their ongoing but changing connections with home and family, in terms of resourcing care for children, the elderly, and other relatives in their home country, as well as their community and family obligations and responsibilities in their place of employment.
\end{abstract}

Keywords: Women, migrant workers, Thailand, Burma/Myanmar ${ }^{4}$, social reproduction ${ }^{5}$, border factories, global care chains, nationality, citizenship, graduated sovereignty

\subsection{Introduction}

Over the last two decades it has become clear that the current phase of globalization has been marked not just by transborder trade and investment but also by international mobility of labour. But it is only in recent decades that academic and policy analysis has focused on women who migrate to seek employment, rather than on those accompanying other migrant

1 Kyoko Kusakabe is an associate professor at Gender and Development Studies, School of Environment, Resources and Development, Asian Institute of Technology, Pathumthani, Thailand.

2 Ruth Pearson is Professor of Development Studies at the School of Politics and International Studies, Faculty of Education, Social Sciences and Law, the University of Leeds, Leeds, United Kingdom. workers, though of course many women straddle both categories. A central focus of such research con-

3 This chapter is based on the research findings of the IDRC-funded project "Gender, Cross-border Migrant Workers and Citizenship: A case study of the BurmeseThai Border", project number I0385I-OOI. It is an updated and expanded version of an article published in the International Migration Journal (See Kusakabe/ Pearson 20IO). It also draws on material discussed in Pearson/Kusakabe (20I2b). The research has been carried out with the support of Naw Htee Heh, Zin Mar Oo, Naw Eh Mwee, Cecil Khin. Also acknowledged are support from Kanokporn Jaroenrith, Lada Phadungkiati, San Sithilertprasit and Usamard Siampakdee. Support from MAP Foundation and its director Jackie Pollock, Yaung Chii Oo Workers' Association and Pattanarak Foundation were also indispensable for the completion of the research. 
cerns the links between the accumulation of capital and the processes and networks that provide for the reproduction of labour power-what feminists have termed social reproduction. This analysis focuses not just at the macro level on the structural causes and process of migration, but importantly on the micro level, which foregrounds the experiences, subjectivities, and agency of migrant women involved in globalizing production processes (see Silvey 2004).

This article explores how Burmese migrant women workers in Thailand negotiate conflicting responsibilities for the families they have left at home, for their new households formed in the Thai cities in which they now live, and for the paid work which is the purpose of their migration. It foregrounds women's agency and explores how migrant women workers negotiate with wider social and political structures (Parreñas 200I; Yeoh/Huang I998). This involves going beyond the analysis of the vulnerability to exploitation of migrant women workers, due to the lack of effective protection from either the sending or the receiving state, to analyzing the gendered implications of their responsibilities for reproduction (Thapan 2006: I3; Pearson/Kusakabe 20I2a). There is a continuous struggle between wage earners and the state to meet the resource and other costs of childcare and other reproductive responsibilities, which Pearson (1997) termed the 'reproductive bargain'. But when the state rolls back its responsibility for taking care of childcare, disabled and sick people, and increasingly, elderly people, it is most frequently women who have to extend their paid and unpaid work to ensure that any care deficit is covered. Very often this adjustment takes the form of unpaid work, which can restrict women's participation in the labour force, or the range of paid work which they can access, or both. Women's restricted participation can have negative ef-

4 Burma is the name of the country, used since British colonial rule. However, it was renamed by the ruling military junta as the Union of Myanmar in 1989 and in $20 I I$ the Republic of the Union of Myanmar. The name remains contested. The UN has endorsed the name 'Myanmar' although many governments still refer to the country as Burma. Media outlets have a mixed practice. Opposition groups, especially non-Burman ethnic groups refuse to recognise the new name because the term "Myanmar" has historically been deployed only by majority Burman ethnic group. Our practice is to retain the name 'Burma' which is universally used by migrant workers in Thailand in the English-speaking media and academia but we use Burma/Myanmar when referring to official treaties, documents or government actions where relevant fects on the economy, which in many cases has pressured the state to rethink its support for care, as is the case in contemporary Japan (Osawa 20II).

The situation for migrant workers in terms of support for childcare and other reproductive responsibilities is generally worse than for other workers. In most situations neither the state of origin nor the destination state takes any responsibility for the childcare needs of women migrant workers, who are usually excluded from any entitlements available to national citizens. Destination states consider migrant workers as only temporary residents in the country, so see no reason to invest in the reproduction of the next generation; and sending states, even those which sponsor the outmigration of women workers, are more interested in the repatriation of remittances from migrant earnings than in contributing to their childcare costs, particularly when the children are raised in another country. So most migrant workers are left to organize and finance the costs of bearing and raising their own children from their own resources without state or other support. In the face of this situation, which is coupled with low bargaining power as workers, and often indifference or even hostility from the receiving state, migrant workers actively mobilize their family and other networks in order to juggle their care responsibilities with the demands of their paid employment, in spite of the harsh environment they find themselves in.

This is the situation for Burmese migrant women in our study who are employed in the garment and textile factories in the border areas of northern Thailand, and are involved simultaneously in reproductive as well as productive work. The micro-level analysis of their experience enables an understanding of the ways in which migrant women's reproductive (domestic) labour is linked to the global economy. An important focus of recent research has been on 'global care chains', which describe the transborder commoditization of care work resulting from the migration of domestic and other care workers, mainly from low-wage developing economies of the global South to the industrialized economies of the North (Hochschild 200I; Yeates 2005; Sassen 2008). Our research extends this analysis by demonstrating how care work and global production are also linked by the reproductive work of women migrant factory workers who are employed in other sectors of the economy, but who still retain the responsibility to resource, organize, and often deliver care work for their own families, including their parents and siblings as well as their own children. ${ }^{5}$ 
This chapter analyses the experience of Burmese migrant women workers in Thailand, looking at the structure of constraints within which they have to exercise individual agency, particularly concerning the issue of social reproduction, that is, not just biological reproduction but also the reproduction of labour power as daily and generational processes (Mackintosh 1984; Folbre 1994). The existing literature on migrant workers in Thailand has provided a detailed, if grim, picture of the exploitative conditions where migrants work, mainly in the agricultural, construction, and manufacturing sectors. ${ }^{6}$ Attention has also been paid to the ways in which migrant workers' labour rights and human rights have been continually violated by immigration officials and the police and the military in Thailand. Our research takes this analysis further by demonstrating that the workers' experiences of work and of harassment in Thailand needs to be supplemented by an understanding of their connections with home and family, in terms of resourcing care for children, the elderly, and other relatives in their home country, as well as their community and family obligations and responsibilities in their place of employment. Their experiences are also shaped by the ways in which migrant workers have been regulated and controlled within Thailand historically, through a series of registration exercises seeking to "regulate irregular migration" (Traitongyoo 2008), which offer very temporary permission for 'illegal migrants' to remain in Thailand to work in specified jobs and economic sectors. Although the situation for migrant workers in Thailand has recently become more regulated with the introduction of temporary passports and work permits as the result of memoranda of un-

5 For a more theoretical treatment of this point see Pearson and Kusakabe (20I2a).

6 World Vision/Asian Research Center for Migration (2003); Institute of Asian Studies/Thailand Development Research Institute/Institute for Population and Social Research (2003); Thammasak (1998); Arnold (2004, 2006); FTUB (2004); FTUB Migrants Section/ Robertson Jr. (2006); Amnesty International (2005); Hveem/Than Doke (2004); Pearson/Punpuing/Jampaklay/Kittisuksathit/Prohmmo (2006); Chulalongkorn University (2003); Asian Human Rights Commission (2005); Asian Research Center for Migration/Institute for Population and Social Research/Thailand Development Research Institute (2004); Caouette (200I); Huguet/Punpuing (2005); Martin/Asian Research Center for Migration/Institute for Population and Social Research/Thailand Development Research Institute (2004); Myint/ Bhumiprabhas/ Kerdmongkol (2004); Pollock (2006); Punpuing 2006. derstanding (MOU) with neighbouring countries, migrant workers in Thailand remain in a precarious situation. Indeed in some respects their situation has deteriorated - for instance, workers registering under the previous system were covered by compulsory health insurance, ${ }^{7}$ but under the temporary passport and work permit system, migrants have to purchase private health insurance for themselves and employers no longer have any obligation to provide health insurance for them.

Migrants' opportunities and constraints are also affected by the national and bilateral citizenship and nationality regimes in both Burma (Myanmar) and Thailand, which have become more institutionalized with the introduction of the bilateral MOU in 2003, although this was not implemented until 2009-IO. At the same time, women face gendered constraints on mobility, enforced both by the gender regimes of their communities of origin and destination and by the factory owners and the police and immigration authorities in Thailand. And in spite of the fact that the majority of the migrant workers in this case study are of prime reproductive age, political discourses which construct Burmese migrants as polluting and problematic, as well as their economic constraints and lack of access to health care, education, and citizenship rights, all serve to further constrain these women's reproductive choices and practices. While it is widely acknowledged that global competition since the I970s has frequently been based on the search for cheap labour, the gendered ways in which transnational reproductive labour is performed reflect "the ways in which the globalization of the market economy has extended the politics of reproductive labour into an international arena" (Parreñas 200I: 62).

At the same time, as this chapter illustrates, the politics and policies of globalized production and labour markets reach down through regional and national policy arenas into the households and families of the migrant workers themselves. This chapter therefore seeks to explore these issues by tracing the connections between the experiences of transborder migration from Burma to Thailand of women factory workers in the context of the economic policies and strategies of the Thai government and a rapidly globalizing world. This chapter is organized as follows: the next section sets out the context of the case study research, and the details of the research methodology and data collected in the study. This is followed by a discussion of the regulation and control of Burmese

7 Bangkok Post, I3 May $20 \mathrm{I2}$. 
migrants working in the export factories of Mae Sot, in Tak Province, and the constraints on women workers' mobility. The subsequent sections set out the ways in which the costs of reproduction of labour, daily and generational as well as biological, are borne directly by woman workers who have to resource, and often deliver, the labour required to care for children and dependent elderly parents from a wage earned in precarious and often exploitative employment. Together these processes ensure that Thai factories have access to cheap migrant labour.

\subsection{Research Methodology and Context}

The location of this study was the border between Thailand and Burma: the town of Mae Sot, in the Thai province of Tak. Mae Sot has been designated for development by the government of Thailand, and was named in the context of the twin border cities included in the Bagan Declaration for mutual cooperation and development. ${ }^{8}$ The town has grown since the early I990s and is one of the areas in Thailand which has witnessed a rapid growth in migrant workers from different parts of Burma. Mae Sot is also the location of a large number of export garment and textile factories, many of which have relocated from other parts of Thailand, and which employ virtually roo per cent migrant Burmese workers. These factories range from large industrial enterprises with a workforce of up to two and a half thousand, to small "house factories" with a few dozen workers. Most of the factories are Thai-owned, and many are subcontractors for East Asian or Western supply chains producing for the international market.

This study draws on eighty in-depth interviews with migrant workers (sixty-eight women and twelve

8 The Bagan Declaration, adopted November 2003, states the intention of the four countries involved - Myanmar, Thailand, Laos, and Vietnam - to collaborate on a range of development projects over the following decade (in: Myanmar Times, I7-23 November 2003; at: <http:// www.mmtimes.com>) and was followed by a series of bilateral projects aimed at strengthening regional economic integration and border area development (Tsuneishi 2005). The stated aims of this bilateral cooperation are not only to facilitate flows of goods and investment, but also to reduce socio-economic disparities. Thailand pledged Ioo million baht (US\$ 2.5 million) for 2004 and 2005 , and was considering earmarking 10 million baht over a period of five years (ACMECS 2004). men) carried out by Burmese members of our research team in Mae Sot between June 2007 and December 20IO, as well as a semi-structured questionnaire survey of 302 migrant workers (women 2II, men 9I). Participatory workshops were also organized with male and female Burmese migrants as well as interviews with a number of migrant workers' organizations and individuals in Mae Sot between 2007 and 2009. The migrant worker interviews covered life histories, work histories, and working conditions and aspirations. This involved the researchers spending time in pagodas, libraries for migrant workers, and health clinics and hospitals, where they were able to get to know migrant workers and establish rapport with them and engage in informal discussions. The researchers conducted longer in-depth interviews with some of the workers who indicated that they were willing to talk at more length. By basing themselves for several weeks at a time in Mae Sot, the interviewers were able to build up relationships of trust with many of the interviewees, and make the acquaintance of more migrant workers through a snowballing methodology based on these workers' networks.

The semi-structured questionnaires were administered with the help of Yaung Chi Oo Workers Association (YCOWA) in Mae Sot. Rather than attempt to construct a representative structured sample, which was not possible because of the research context, which did not allow access to workplaces and lacked any reliable statistical data, the methodological approach taken was purposive sampling. Employees at specific garment factories were targeted based on the connections that YCOWA had within particular factories. The survey focused on married women and married men who had been working in Thailand for more than three years at the date of interview.

In addition, the research used secondary data, including academic studies and reports from both Thai and international NGOs and migrant organizations. It also drew on two workshops held in Mae Sot in July 2007 , one for representatives of organizations working with migrant workers, and one for factory workers themselves (Kusakabe/Pearson/Naw Eh Mwee/ Phadungkiati 2008).

The demographic profile of our respondents is detailed in table 4.I. It should be noted that the education level of migrant workers is not necessarily low, with most workers having completed primary school and many with secondary education or above. Many of our respondents were single when they initially came to Mae Sot, but had married since starting to work in the factories there. More than seventy per 
Table 4.1: Demographic profile of respondents in Mae Sot. Source: Authors' analysis of semistructured questionnaire.

\begin{tabular}{|c|c|c|}
\hline & Women & Men \\
\hline Average age & 29.77 & 29.81 \\
\hline $\begin{array}{l}\text { Average years of } \\
\text { schooling }\end{array}$ & 7.23 & 8.71 \\
\hline Marital status & $\begin{array}{r}\text { Married: } 89.6 \% \\
\text { Divorced: } 8.1 \% \\
\text { Remarried: } 1.4 \% \\
\text { Widow: } 0.9 \%\end{array}$ & $\begin{array}{l}\text { Married: } 94.5 \% \\
\text { Divorced: } 5.4 \%\end{array}$ \\
\hline $\begin{array}{l}\text { Number of } \\
\text { children }\end{array}$ & \multicolumn{2}{|c|}{$\begin{array}{l}\text { One child: } 75.2 \% \\
\text { ( } 227 \text { respondents) } \\
\text { Two children: } 21.9 \% \\
\text { ( } 66 \text { respondents) } \\
\text { Three children: } 2.3 \% \text {, } \\
\text { ( } 7 \text { respondents) } \\
\text { Four children: } 0.3 \% \\
\text { (1 respondent) } \\
\text { Five children: } 0.3 \% \\
\text { ( } 1 \text { respondent) }\end{array}$} \\
\hline Ethnicity & $\begin{array}{r}\text { Burman: } 78.2 \% \\
\text { Karen: } 11.4 \% \\
\text { Mon: } 8.5 \% \\
\text { Others: } 1.9 \%\end{array}$ & $\begin{array}{r}\text { Burman: } 90.6 \% \\
\text { Karen: } 1.2 \% \\
\text { Mon: } 3.5 \% \\
\text { Others: } 4.7 \%\end{array}$ \\
\hline
\end{tabular}

Based on questionnaire interview with 211 women and 91 men.

cent of the women migrant workers surveyed in Mae Sot gave birth to their first child after coming to Thailand.

The information gathered from these sources complements a range of previous studies which have documented the working conditions of Burmese migrant workers in Mae Sot's border factories (Arnold 2004, 2006; FTUB 2004; FTUB/Robertson Jr. 2006; Pollock 2006). The information derived from the workshops and interviews was triangulated with the views of key specialists within Thailand, particularly from NGOs and the Thai academic community. This allowed us to construct a more holistic understanding of the ways in which Burmese migrant women workers juggled their reproductive responsibilities with the demands and constraints arising from their working lives within the factories, and dealt with the gendered restrictions and constraints they faced in terms of the labour regimes within the factories, as well as the immigration regulations and restrictions on their mobility and entitlements within Thailand. These are discussed in the following section.

\subsection{Regulation and Control of Migrant Factory Workers in Thailand's Border Areas}

\subsubsection{Creating 'Cheap Labour' for Thailand's Export Industries}

Factories in Thailand have responded to growing global competition in export markets by seeking to reduce labour costs through the utilization of "cheap" migrant labour. As has been extensively noted by previous research on export sectors that involve manual operations, women have historically provided the most productive source of cheap labour, and their low unit costs of production are routinely attributed to their 'natural' attributes as unskilled, docile, and secondary (and therefore disposable) labour (Elson/Pearson I98I; Wright 2006). But they are also cheap in terms of the ways in which the capital that employs them, and the state in which they are situated, are able to avoid any contribution to the costs of reproduction of their daily labour power and the generational reproduction of the workforce. In Thailand as elsewhere, migrant workers are particularly vulnerable to exploitation in the form of below-standard wages and poor working conditions since they are generally not protected by labour regulation or citizenship rights. Moreover, they also subsidize capital and the state through the complex ways in which they manage their gendered reproductive responsibilities for securing housing, food, education, and health care and caring for children and elderly and disabled family members (Nagar/Lawson/McDowell/Hanson 2002). Burmese women migrant workers constitute an especially vulnerable and exploitable source of 'cheap labour' in manufacturing. Whilst in other contexts export factories have migrated to cheap labour platforms, for example from the United States to northern Mexico or the Asian Newly Industrialized Countries (NICs), in this instance Thai capital has remained in the country, whilst the cheap labour has migrated over the borders from Burma. Because of the economic and political repression in Burma (Fink 2009) and the limited rights of migrant workers within Thailand, Burmese women migrant factory workers are protected by neither their state of origin nor their state of destination, and, as has been extensively documented, are subjected to arbitrary and exploitative labour conditions including excessive hours of work, unhygienic living conditions, arbitrary deductions from their wages, and vulnerability to arbitrary dismissal, arrest, and deportation. 
Since the I990s, when the policy of employing migrant workers in Thailand's border industries took off, there has been a series of government measures aimed at exercising some control over the influx of transborder migrants into the country, a process frequently seen as "regulating the irregular" (Traitangyoo 2008). Regulation has sought to reconcile two competing concerns: the fear of migrants' bringing disease, criminality, and political unrest into the Thai polity, and the expressed desire of government and industrialists alike to access cheap labour in order to export to an increasingly competitive market where labour-intensive products such as garments and footwear face strong competition from emerging economies in the region, particularly China and Vietnam, who are able to undercut Thailand on the basis of lower labour costs. According to Chalamwong (2004), the Thai government's creation of a formal category of "registered irregular migrant workers", who are granted legal permission to work for a set and limited period of time, gives the utmost flexibility. Because they retain their illegal status, registration represents only a stay of execution of their expulsion and allows the government to deport them when their period of registration expires. This formula provides an opportunity for Thai industries to access cheap immigrant labour and offers government a source of revenue from migrant registration fees while at the same time enabling it to maintain a policy of controlling immigration and denying Thai citizenship to a range of foreign workers. The creation of this category of 'irregular' migrants reflects what Sparke, Sidaway, Bunnell, and Grundy-Warr (2004) have described as a "a clever remedy", whereby the state creates a regulatory framework which allows it ${ }^{9}$ to mete out different treatment to different segments of its population, allowing the market to benefit from such an arrangement.

As noted above, potential migrant workers are officially required to go through a verification of nationality in their country of origin and then apply for temporary passports and obtain a permit to work in Thailand. The permit is given for two years with the possibility of a single extension of two years. But this kind of official state-to-state agreement does not necessarily make the lives of migrants from Burma to Mae Sot any easier. On the contrary, many feared that

9 See MAP Foundation website on: "The regulation of migrant workers following the MOUs"; at: <http:// www.mapfoundationcm.org/Eng/MOUupdate/html> (accessed 3 April 2009). the nationality verification would make them more vulnerable because of the prevailing political situation in Burma. They were particularly afraid that their families back home would be harassed by the authorities, through higher tax collection and so on, if they gave Burmese officials information about their villages of origin. ${ }^{10}$ Even though the current moves towards greater democracy and political pluralism promise the legalization of trade unions and extension of workers' rights within Burma, such changes have not yet percolated through to the rural areas or the border states where ethnic minority groups are still fighting for autonomy. At the same time, although the MOU states that those who migrate under this process will enjoy a full guarantee of labour rights equal to those of Thai workers (FTUB/Roberston Jr. 2006), there is little confidence amongst the migrants that this is feasible or even possible. In fact the procedure is so complicated that workers are having to rely on so-called 'agents' to obtain temporary passports on their behalf, and this involves considerable expenditure, doubling the officially quoted fee for obtaining nationality verification of I,050 baht. ${ }^{11}$ Some migrant workers who opt to manage the process without the employer's help have hired agents to go through the process for them and have reported paying up to seven to ten times more than the official rate.

Meanwhile the flow of migrant workers to Thailand continues, though an increasing proportion remains outside any regulatory framework. There are no reliable estimates for the total number of migrant workers in Thailand. Martin (2007: 4), citing Rattanavut (2006) and Huguet (2007), estimated that in 2006, there were I.8 million foreign workers in Thailand, of which twenty-six per cent were registered. Other estimates have put the number much higher and figures of between 2 and 2.5 million are frequently cited (FTUB/Robertson Jr. 2006), with over sixty per cent from Burma. Of the registered Burmese migrants, 46.I per cent are women ${ }^{12}$. As of March 20II, there were 350,9I5 migrant workers who went through the nationality verification process (of which I59,662, or 45.5 per cent, were women), while a total

10 MAP Foundation website "The regulation of migrant workers following the MOUs"; at: <http://www.mapfoundationcm.org/Eng/MOUupdate/html> (accessed 3 April 2009).

11 Bangkok Post, I3 April 2012.

12 See MAP Foundation - No migrant worker is illegal website on: "Registration for migrant worker permit I996-2008",at: <http://www.mapfoundationcm.org/ news/registration_new.html> (accessed 3 April 2009). 
of 394,903 workers were still in the registration process (including 179,779 women). ${ }^{13}$ However, in Tak province, where Mae Sot is located, only 889 workers completed the nationality verification process (44I women), with a further 22,538 (I4,9I7 women) who were registered. ${ }^{14}$ There is less incentive for employers to go through the cumbersome nationality verification process in a border town like Mae Sot, where the employers think it is easy to get away with not following the verification process, despite inspections-the workers can cross the border and wait on the Burmese side whenever necessary. So after the temporary passport was introduced, in Mae Sot the number of workers who have legal status in Thailand decreased.

The increased employment of migrant workers in the textiles and garments sector reflects the declining fortunes of in the industry particularly since the 19978 financial crisis in Thailand. From being the largest export item for many decades, textiles' share of exports had fallen to fifth place by 2003 , and had disappeared from the top ten export items by 2006 (EXIM 2006). The decline in export importance since the crisis paralleled a fall in employment share, though textiles still accounted for twenty per cent of the 5.4 million industrial workers (Barimbun 2006). Up to eighty per cent of the sector's employees are women, a proportion that has remained remarkably stable in the face of changes in overall employment in this sector (Chalamwong/Amornthum 2002). And since the I997 crisis, production of garments and textiles has shifted significantly to the border areas in the north, north-west, and north-east of Thailand, which have seen both a fall in real wages and an increase in the employment of migrant workers. The growth in the number of factories and in total employment in this sector has been especially dramatic in Tak province, where Mae Sot is located. ${ }^{15}$

13 See MAP Foundation website at: 〈http://www.mapfoundationcm.org/pdf/eng/number_Mar2oII.pdf $>$ (accessed 28 July 20I2).

14 See MAP Foundation website at: <http://www.mapfoundationcm.org/pdf/eng/number_Mar2oII.pdf> (accessed 28 July 20I2).

15 According to an interview with the Labour Office of the Tak province, the 1997-8 economic crisis in Thailand provided particular opportunities for the province. Since it borders Burma, it has access to a large quantity of cheap labour making it attractive for labour-intensive industries to consider relocation, a view which is reinforced by the dramatic increase in the number of workers and number of factories after the recovery from the from the shock of the economic crisis of 1997 (see figure 4.2).
In recent years the Thai government has maintained that the objectives of Thai development initiatives were to close the economic gap between Thailand and its poorer neighbours and to stem the inflow of foreign workers into Thailand. But if this was the case, these measures have demonstrably failed, and nowhere more so than in the area around Mae Sot. Although a plan to establish a Special Economic Zone in Mae Sot ${ }^{16}$ has never materialized, the employment of migrant workers has expanded in the area. Of the total of 92I,482 registered migrant Burmese workers in Thailand in 2004, $\mathrm{I} 24,6 \mathrm{I} 8$ or $\mathrm{I} 3.5$ per cent were registered in Tak Province (FTUB/Robertson Jr. 2006), making it the largest concentration of registered Burmese migrants outside Bangkok, ${ }^{17}$ and various sources suggest that this figure should be multiplied by a factor of two to three to account for the large number of unregistered workers. Such a high number of migrant workers in a relatively small border province reflects the success of the Thai government's policy of concentrating migrant workers in border areas. The number of manufacturing establishments in the area has also grown rapidly. According to FTUB and Robertson Jr. (2006), there were I24 officially registered factories in 2004 in Mae Sot; approximately twothirds (eighty factories) were apparel factories, and these employed over I4,000 workers. ${ }^{18}$ If informal and unregistered factories were included, the total number was estimated to be greater than 200 , again reflecting the real situation in the town whereby the registered factories represent less than half the total number of establishments that rely on a cheap migrant workforce.

Together with new industrial development policies which emphasize advantages for Thailand from cooperation with neighbouring regimes in the Mekong subregion, Mae Sot offers a site for Thai industrialists to seek maximum benefit from access to cheap cross-border migrant labour from Burma with

16 Special Economic Zones were originally proposed for cities such as Mae Sai and Mae Sot, which are along the economic corridors.

17 According to the Ministry of Labour, the number of registered Burmese migrant workers in Tak province in 2007 was 26,9II, of which I8,II5 were women (Sciortino/Punpuing 2009: 64). They estimated that in 2007 , only twenty-seven per cent of migrants from Laos, Cambodia, and Burma were registered.

18 Ministry of Industry: "Accumulative number of the registered factories by province by type at the end of the year" data on 2006; at: <http://web.nso.go.th/en/survey/manuind/manufac.htm> (accessed 27 June 2007). 
few constraints on how that labour is recruited, deployed, respected, or remunerated. It is to these conditions of work and of life that we turn below.

\subsubsection{Restricting Women Migrant Workers' Mobility}

The high concentration of Burmese women workers in Mae Sot, and industry's need for cheap and 'disposable' labour, has led to practices which govern and restrict the movement of migrants in Mae Sot. The ways in which women migrant workers experience restrictions on their mobility comprise an aspect of the gendered nature of "graduated sovereignty" described by Ong (2000), whereby the state operates a system of differentiated regulation according to specific aspects - race, ethnicity, and nationality - of different sectors of the population. Many women interviewed for our research reported that they are, or perceived that they are, restricted to the factory compound and its immediate environs, unable to venture out into the town and beyond. The restrictions reflect different forms of constraint on workers' mobility. Firstly, many workers are expressly forbidden by the factory managers to leave the compound, except for specified occasions. One manager reported to us that the workers were like family and everything was provided for them; they had no need to leave the compound except for an afternoon once or twice a month.

Police spot checks and the regulation requiring work permits are further problems for workers moving about outside the factory. Registration documents indicate that a migrant is only permitted to remain within the province of registration; the authorities use this as a reason to check the papers of Burmese individuals, and this serves as a deterrent to workers' mobility. Even those who have registration papers are rarely able to keep the original; many of our interviewees reported that they were given only a photocopy of the document, which police usually rejected, and workers could be fined, imprisoned, or deported without the relevant papers. The restrictions apply to all workers, but they are experienced in a gendered manner. Figures from the Immigration Office in Mae Sot indicate that more men than women are deported back to Burma by the authorities, even though women comprise the vast majority of workers in the factories. In 2006, women comprised forty-two per cent of the 69,998 people deported from Mae Sot to Burma because of illegal entry. One male migrant worker reported that he had been arrested thirteen times by police in nine months. ${ }^{19}$ Our questionnaire survey indicates that male workers have had to pay off the police slightly more frequently than women (I.82 times per head, compared to women's rate of $\mathrm{I} .45$ ) and are also forced to pay a slightly higher amount than women (men pay I34.2 baht a time, while women pay I29.4 baht).

Explanations for this gender difference are that men tend to be out in the street at night and that they are viewed by the population at large, as well as the police, as a security threat. This leads to arrest and often violence not just from the police and immigration authorities, but also from groups of youths who are reported to roam the town harassing and threatening migrant workers. ${ }^{20}$ Women too are the objects of both physical and sexual harassment and violence from both police and local gangs. This makes women reluctant to take risks in the town. Indeed, we heard several reports of aggression from officials and local youths. Moreover, as is the case elsewhere, women, particularly recent migrants, tended to avoid risking such aggression and preferred to remain within the confines of the factory compound (see also Valentine 1989).

Many women and men get accustomed to being arrested and even deported, especially those who are involved in workers' organizations and can access training and advice from others. ${ }^{21}$ Moreover, some of the Burmese migrant workers, particularly those who had had several years' experience of living and working in Mae Sot, expressed some ambivalence about whether they felt they were worse off than they had been in their home country. Although they faced constraints on their mobility, those who had managed to negotiate some degree of freedom within the town valued the relative autonomy they had as workers in Thailand, in contrast to the strict nature of family and community vigilance and control which was particularly constraining for young women. However, this view was only expressed by those individuals who had

19 Interview, in: Mae Sot, 25 August 2007.

20 Ling (2007) noted such harassment by youth groups in Samut Sakorn, and our interviews in Mae Sot with migrant workers indicated that they are frequently targeted by groups of Thai youths.

21 This was reported by those participating in the NGO and Union workshop held in Mae Sot on 6 July 2007 (Kusakabe/Pearson/Naw Eh Mwee/Phadungkiati 2008). According to our informants from these organizations, this involved paying bribes to the police, alerting colleagues and employers to pay the authorities or produce appropriate documentation or both, and in some cases submitting to deportation and then re-crossing the border. 
gained confidence over a number of years, and who were involved in worker organizations or NGOs. ${ }^{22}$

\subsection{Gender and the Daily Reproduction of Labour Power}

Low wages and late payment of wages, long working hours, deduction of living costs from wages, restrictions on mobility, poor sanitary conditions in the workplace and in living quarters, and the confiscation of identity documents are all commonly cited as problems faced by workers. According to Punpuing (2006), migrant workers in Tak province earned only 50-80 baht ${ }^{23}$ per day, 38-69 per cent of the minimum wage in Tak province of 130 baht. The wage rate is much lower in Tak province compared with Bangkok where migrant wage rates are IOO-I20 baht a day, representing 55-66 per cent of the minimum wage of I80 baht. These figures reflect the higher proportion of migrant workers in the agricultural sector as well as the relative freedom of Tak factories to undercut minimum wages. Our questionnaire survey showed that the average daily wage for migrant workers in Mae Sot in 2008-9 was 97.8 baht compared with the official minimum wage of 157 baht during that period. ${ }^{24}$

Labour inspection officers said that it is difficult to detect the underpayment of wages, because on the books, workers are paid minimum wages, while the actual payment received by the workers is far lower, as we explore below. Many workers in Mae Sot work at piece rates, so that when orders are low this directly affects their level of earnings. Many workers reported that some factory owners gave workers twenty baht a day for food if there was no work, but the notion of any contractual obligation to pay workers was completely absent.

The calculation of migrant wages is invariably an overestimation. According to previous research, as well as our own interviews, the wages actually received by factory workers were well below the noti-

22 The women who talked about their relative autonomy were those who attended the workshop in July 2006 (see footnote 2I); interestingly, only a third of the delegates from these organizations who came to this event were women, reversing their representation in the Mae Sot factory labour force as a whole.

23 I baht $=$ US\$ 0.03 .

24 This does not include the earnings of workers who are paid at piece rate, who constitute around thirty per cent of the total respondents. There was a no significant gender difference in terms of earnings. fied rates. This is because deductions were routinely made to cover the cost of accommodation, food, and registration $^{25}$ (see also: Arnold 2004; FTUB/Robertson Jr. 2006). The cost of accommodation, which is frequently a mattress in a shared room of a dormitory in the factory compound, can range from 50 to 300 baht per month. Alternately, it can take the form of working in lieu of payment, which often means having to work without pay on the evening shift between 5 p.m. and 9 p.m. to cover the cost of accommodation.

The cost of obtaining a work permit is shouldered by the workers through deductions from their salary over several months. Those who are not eligible for a permit for whatever reason still have money deducted from their earnings for the 'immigration fee'. This can also cover a fund to bail (or bribe) the workers out when they are arrested, but many employers levy this charge simply to cover the fact that they (the employers) are taking a risk by employing illegal migrants, though there is little evidence that there are real risks of penalties in doing so. Some workers report that there is a further deduction of between two and three per cent of their earnings, and that they are not aware of the reasons for deduction, or that it is to cover something called a 'landing fee'. ${ }^{26}$

The working hours are very long in the border factories, which leaves the women hardly any time for themselves. A typical working day is 8 a.m. to 5 p.m. and then 6 p.m. to 9 p.m., with two thirty-minute breaks, although if there is a lot of work, shifts can extend late into the night. In theory, there is a six-day week, with a free day on Sunday, but many workers reported that they only get one or two days holiday per month. Usually these fall just after payday, and most of the time is spent arranging to send money and goods to their families back home.

Most women workers we spoke to organized their own shopping and cooking. During their breaks, they were able to buy vegetables from informal sellers in front of the factory, and then cook food using the rudimentary facilities in their dormitories. They had to

25 According to many of our informants, deductions were made for registration fees, whether or not the worker was officially registered and incurred costs for this.

26 This is a term used by a number of migrant workers we interviewed but does not appear to correspond to any recognised category. The workers said it was a fee that they had to pay to be allowed to work in the factories that was above the charges they paid to agents who arranged their transportation and introduction to the factories, though it is not clear to whom they paid this fee. 
fit in other tasks including cleaning, laundry, and bathing within their break periods. Women complained that their working day was too long, and married women and those with children ${ }^{27}$ especially complained of having extensive extra, gendered responsibilities in addition to their work in the factories, and of being unable to take sufficient rest, let alone have any free time for leisure activities.

It is clear that women experience stress from the pressure to ensure family survival with low wages and long working hours. According to a recent interviewee in Mae Sot:

Last week I could not sleep at night and I lost my memory. I could not remember where I put my things. I put money in front of me and I was searching for that money. Then, I told my problem to an Indian-Burmese woman who came to our compound and she gave me two tablets of medicines to sleep well. Oh, that it was very good for me and I slept very well for two nights and I became normal from that day. The woman said not to take these kinds of sleeping tablets every day (Interviewed on 23 April 2009).

The accounts by these women indicate that the responsibility for their well-being often rests solely on their own shoulders; but added to this is the burden of care and family support for family members. It would seem that their ability to reproduce their own labour power on a daily basis is compromised not just by the exploitative conditions of their employment, but also by the gendered restrictions on their mobility, as well as their responsibilities for their family's wellbeing.

\subsection{Gender and Generational Reproduction of Labour Power}

According to Mushakoji (2003: 152), "victims of exploitative migration have insecurity built into their biological reproduction as well as in provisioning for their caring needs". Although Mushakoji's research concerns migrant sex workers in Japan, the point applies well to migrant women in our study, who struggle with the demands of both biological and generational reproduction.

The factors that restrict both migrant women's and men's mobility conspire with employer practices

27 Among the semi-structured questionnaire survey respondents in Mae Sot (who were all ever married), $64 \%$ of them had some of their children living in Thailand while a similar number of respondents had some of their children living in Burma. to restrict migrant women's reproductive choices. The women migrant workers we had contact with reported that even though they are aware that Thai law allows a period of paid maternity leave among other rights for legally registered workers, this is rarely granted by the factory management. Some make limited adjustments for pregnant women by shifting them to a workplace with lighter work or allowing them to come five minutes later than other workers. But in practice there are real problems for women workers who become pregnant. Some women workers did talk about the possibility of maternity leave, but this usually meant only that they could return to work after the baby is delivered. Since they are paid daily wages, this means a loss of all income whilst they are absent. A number of women reported that their economic situation made it very difficult for them to take leave to have children.

Organizations working with migrant workers in Mae Sot also reported that many migrant women who became pregnant were forced into the difficult decision of seeking a termination, a situation that is supported by other research (Maung/Belton 2004). A significant proportion of women respondents in our study feared that pregnancy would make it more difficult to find or retain work in the factories, which they needed to earn remittances for family back home. ${ }^{28}$ But abortion among migrant women workers in Mae Sot is a dangerous undertaking. Dr Cynthia Maung reported that the rate of abortion amongst the Burmese women attending the Mae Tao Clinic ${ }^{29}$ had increased over the previous four to five years, and by 2007 some fifty-five per cent of maternal mortality was caused by post-abortion complications. ${ }^{30} \mathrm{~A}$ further deterrent to pregnancy is that many employers do not allow babies or children to stay in the workers' dormitory. Although some are able to find accommodation in the town, the demands of shift work and the lack of childcare facilities, as well as the other factors restricting women's mobility discussed above, all make it difficult for women to combine pregnancy and infant care with continuing employment in Mae Sot's factories.

28 Other reasons for abortion included abuse and abandonment by their partners, contraceptive failure, and pressure from relatives, friends, and husbands (Maung/ Belton 2004).

29 This clinic was founded and is directed by Dr Cynthia Maung, and provides free health care for refugees, migrant workers, and other individuals crossing the border from Burma to Thailand. See at: <http://www.maetaoclinic.org>. 
For those who continue with their pregnancy, another difficult decision concerns whether to have the child in Thailand or in Burma. According to Dr Cynthia Maung, compared to the previous five years, in 2007 more migrant women were delivering their babies in Mae Sot rather than choosing to return home to Burma for their confinement. ${ }^{31}$ This is not because they perceive any improvement in the relative attractions of staying in Thailand in the long term. It is rather because the insecurity of their employment and the irregularity of the wages from their factory employment mean that they can no longer commit the resources of time and money to returning home. This view was also supported by the testimonies of our interviewees who reported that the cost of delivering in the Mae Tao Clinic is cheaper even for non-registered migrant workers than returning to give birth in Burma, and others who said that the equipment in Thailand is better because of the general deterioration in the health services in Burma.

As we have indicated above, women migrant workers incur hardship with pregnancy and childbirth; these hardships in fact go well beyond immediate birth and infancy. Mothers are responsible for a child's welfare until the child is of working age or beyond, and older women frequently take responsibility for parents and other relatives who are beyond working age. For many Burmese migrant women workers in Thailand, the generational reproductive responsibility extends beyond bearing and rearing their own children. The very limited employment and income-generating opportunities faced by many households in Burma (Fink 2009) mean that the decision to migrate to Thailand is frequently a family strategy involving immediate and continual responsibility for the family back home. So the generational responsibilities of

30 This figure was provided by Dr Cynthia Maung during an interview on 9 July 2007. Maung/Belton (2004) reported that of the fourteen pregnant women who died in the Tak hospital in 200I/02, none were Thais and three of the deaths (twenty-two per cent) were due to unsafe abortions. Available statistics indicate that there is a much higher maternal and peri-maternal mortality rate for migrant workers than for the general Thai population. Thailand's maternal mortality rate was relatively low in international terms: 44 per 100,000 live births in 2000 (WHO 2006). Around five thousand pregnant Burmese women register at Mae Tao clinic each year. The cost of an illegal abortion is $1000-4000$ baht (Buschmann 20II).

31 Interview, 9 July 2007. women workers include the responsibility to remit money to their families in Burma.

Our research, together with other studies (see Kittisuksathit 2009), indicates that single women universally send money to their parental homes. Most women migrants report that the obligation to support birth families financially continues after marriage; in contrast, men are more likely to discontinue remittances after marriage. The single women respondents we interviewed for our research reported remitting quite large sums to their families in Burma, despite earning very low wages, which as we have seen are then further depleted by a range of deductions. One respondent who said she earned between 2000 and 4000 baht per month reported remitting between 2000 and 3000 baht per month, leaving almost nothing to cover her own living expenses in Mae Sot, a pattern common among women we spoke to. The semistructured questionnaire also shows that women do not always reduce remittances even when their income decreases or they become unemployed. Forty per cent of women respondents in Mae Sot said that they would reduce remittances when their income decreased, while more than forty-eight per cent of men respondents said the same. During the global economic crisis in 2008-9, both women and men decreased their remittances from the level of previous years (when they remitted nearly Io, ০0० baht per year), but women respondents still maintained their remittances at an average of 8,702 baht per year, while remittances from men dropped to 7,510 baht.

Another ongoing responsibility that women who have children have to deal with is decisions about how and where to care for these children. Whilst some women decided to withdraw from their jobs if keeping the child was not compatible with work, others reported changing their employment to a workplace where they were allowed to have their infant with them in the dormitory, if not in the factory. Some women are able to find older Burmese women in Mae Sot to care for their children in Thailand, but as the cost of paying caregivers to look after their children is expensive for low-waged women, this is normally the last resort or only a temporary arrangement. Many of our informants instead sent or took their children back home to Burma to be cared for by grandparents or other female relatives. Another common strategy is to support other relatives - usually parents or older siblings - to come to Mae Sot from Burma to care for infants. However, childcare by parents and other relatives coming to Thailand is an available option only for those who are relatively settled in Thailand, espe- 
cially those who are registered, or have access to better housing, or both. Table 4.2 summarizes the responses of our interviewees concerning arrangements made by Burmese migrant workers in Mae Sot to provide for the care of their children.

Table 4.2: Childcare patterns for children under six years old for respondents in Mae Sot who had had a child after coming to Thailand. Source: Questionnaire survey.

\begin{tabular}{|c|c|}
\hline & $\begin{array}{l}\text { Number of } \\
\text { respondents }\end{array}$ \\
\hline Childcare by oneself in Thailand & $19(9.2 \%)$ \\
\hline Childcare in Thailand with paid caretaker & $18(8.7 \%)$ \\
\hline $\begin{array}{l}\text { Childcare by oneself in Thailand then send } \\
\text { child to Burma }\end{array}$ & $78(37.7 \%)$ \\
\hline $\begin{array}{l}\text { Childcare by oneself in Thailand then invite } \\
\text { parents to come to Thailand }\end{array}$ & $96(46.4 \%)$ \\
\hline Childcare in Burma & $31(15.0 \%)$ \\
\hline Total number of respondents & $207(100 \%)$ \\
\hline
\end{tabular}

Note: This analysis is only for the 207 respondents who had their first child after they came to Thailand. It includes all the children of these migrant workers. Thirtyone of the respondents had two children and two had three children.

As table 4.2 indicates, arrangements for the care of migrant workers' infants and children reflect the relative economic security and family situation of the migrant workers, and are frequently amended in response to changing circumstances. Depending on their situation, which itself is subject to change, arrangements for childcare reflect the available resources. For example, one informant's parents came to Myawaddy (on the Burmese side of the border) when her child was two months old. But the informant found travelling across the border to visit them on her day off was expensive, and the parents also incurred the costs of obtaining residence permits since they were not residents of Myawaddy. After a few months she brought the child back to Mae Sot to be cared for by a neighbour, and when it was eight months old, she arranged for her parents to come to Mae Sot to provide ongoing care.

Another woman's account illustrates the complexities involved in making appropriate arrangements for infants:

I got pregnant while I was working there. ... I worked till eight months of pregnancy. When I cannot work they gave me leaves but no payment. ... When my baby got 4 months old, I went back to Burma with her to bring back my elder son, eight years old during his school holiday to look after my last baby. After three months, as my eldest son needed to attend the school, I sent him back to Burma, went with my little baby again and brought back my mother with me to look after my little baby. I moved the job to home factory, where I can stay with my baby. I kept my baby near me in the cradle while I was working. I can give breast feeding to her while I was working (Interviewed 22 March 2008).

Decisions about childcare are always complicated, and the costs fall on the shoulders of the women migrants themselves. Some women are lucky to have better-off parents or siblings back home, who will be able to give good care to their children, but in some cases this arrangement breaks down. One of the migrant workers interviewed reported that her mother was responsible for the care of five grandchildren including this worker's own daughter. She remitted 40,000 kyats $^{32}$ per month, which covers less than half of the minimum estimated cost of such a household, although other siblings probably made a contribution. But her ageing mother was unable to manage all five children, and this worker had to bring the child back to Mae Sot where she boarded her with a non-related Burmese women. Another migrant woman reported that she had to leave her baby with her mother, in spite of her mother's health problems. Another migrant woman who had left her baby in the care of her mother-in-law reported that when her mother-in-law passed away, she had to make an arrangement with a neighbouring woman in her home village to take care of her child.

A further aspect of generational reproduction is the education of children. Most of the women interviewed had high expectations for the education of their children. Even when infants are sent to Burma for care, many of them are brought back to Thailand once they reach school age. The Thai education system is, in theory, generous to migrant residents and a government decision in 2000 indicated that all children within the country regardless of nationality and status are permitted to attend Thai schools. However, in practice few do; attending school requires a household registration, which is rarely available to migrant children except when their parents have good connections to some Thai citizens.

In practice the majority of Burmese families in Mae Sot send their children to the numerous migrant schools in the town, which are supported by the overseas diasporic communities and by international

32 I USD= 950 kyat. 
organizations. ${ }^{33}$ Some Burmese parents consider the quality of the migrant schools in Thailand to be better than the alternatives; many schools recruit from nonmigrant families in the bordering provinces. They hope that the trilingual system of education - Burmese, English, and Thai - will be advantageous to their children's futures wherever that may be. One of the women migrant workers remarked:

I will keep my children in the school here until they get some level of education for their life to work here. At least if they can write and speak Thai and Burmese well, they can get good jobs here (Interviewed on 8 May 2008).

Where to raise the children is always a difficult decision and one that causes a great deal of anguish for women who are not just concerned about their children's access to education, but who also have the responsibility of maintaining their kin networks, even from across the border:

After giving birth, I left the children with my parents, but since my mother came to Mae Sot, I left my children with my parents-in-law. Now I am thinking of bringing my children to Mae Sot. My mother is already looking after three grandchildren [her sister's children]. I do not want to burden my mother. But I want to be with my children and give children good education. But my work is unstable, and I am afraid that if I do not have job, I cannot afford children's education in Mae Sot. Then, I have to send the children back to Burma, and that will affect their education. I also have to convince my mother-in-law who is now attached to the grandchildren (Interviewed on 23 March 2008).

But whatever decision is made, it is unlikely to be permanent, sustainable, or satisfactory. And as we discuss below, the situation is becoming more problematic for migrant workers and their children. Moreover, the opinions of Thai officials and the public are often hostile to facilitating the education of migrant children in Thai schools. In this excerpt from a newspa-

33 Except for the migrant schools and nurseries organized by NGOs and Buddhist monks, care of the children of migrant workers depends directly on the individual agency of the workers, especially of the women workers and their female relatives. In general the more collective actions undertaken by NGOs and trade unions are concerned with the migrant workers' working conditions and legal status. More recently there have been calls from Thai unions and human rights organizations for more attention to be given to the issue of the childcare of migrant children, but the limited resources and constrained situation of the migrant workers themselves make it difficult for these workers to organize collective childcare in Mae Sot. per report (Ekachai 2007), a police officer expresses an attitude that is widespread in the country:

Having migrant children studying in the town centre is also not appropriate, due to potential security problems. For safety, the migrant population should be in a restricted zone under state control. Also, if they want to study, their older peers should do the teaching, not our people.... I cannot see how educating these children can benefit our country in any way. We have to think about the burden society must shoulder if these children decide to stay on. ${ }^{34}$

A further aspect of women's responsibility for generational reproduction concerns access to health care for family members as well as themselves. Health services especially in the border areas are also in theory relatively generous to registered migrant workers, since they, like other low-paid workers in Thailand, can use the universal health care scheme to access health care ${ }^{35}$ although government officials fear the burden this places on Thai public services and finances (Archavanitkul 2002). However, the non-registered migrants or family dependents of registered migrant workers have difficulties accessing this service, which requires its own identity documents. In practice, migrant workers rarely attend public hospitals or health facilities; instead they tend to purchase medication directly, or attend NGO- or diaspora-funded clinics such as the Mae Tao clinic wherever available. Migrant workers are rarely aware of their entitlements to public health services in Thailand, and their restricted mobility and lack of knowledge of the Thai language further limits their possibility of using such services (Ling 2007). Many workers report returning to their home country if they or their family members have serious or chronic illnesses, and women's earnings are frequently central to the family's ability to access health care in Burma.

34 Recent research by this project indicated there was ideological resistance by teachers to accepting the children of migrant workers in their schools, as well as bureaucratic and financial obstacles, despite clear government policy for integration.

35 The scheme was launched in 200I, and was called a 30 Baht Universal Health-care Coverage Policy. Those who were not covered by any other health insurance scheme were given a card that would allow them to use health services with a payment of 30 baht per visit. In 2007 , it was changed to be free of charge. However, migrant workers were still required to pay the 30 baht. 


\subsection{Women Migrant Workers in Mae Sot's Export Factories: Negotiating Political, Economic, and Gendered Constraints}

As the economic situation in Thailand worsens as the result of the current global credit crunch and the fall in export demand for garments and textiles, the situation of migrant workers is uncertain, increasing the difficulties faced by women migrants seeking to secure the well-being of their children and other family members.

Changes in the registration of irregular migrant workers in Thailand referred to above indicate that the Thai state is unlikely to take on additional costs associated with the supply and employment of migrant workers. If for any reason the situation of a migrant worker were to change - for instance, if she were to lose her job or become unable to work due to health or other reasons, or if she became pregnant under the terms of this agreement the worker would be repatriated. Under the previous registration scheme as well as the current temporary passport and work permit scheme, documentation and entitlement applies only to individual "workers" with no provision for families or dependents, which would include both existing children and adult relatives. Strict enforcement of these terms would disallow the strategies currently employed by many migrant workers to meet their reproductive responsibilities by bringing in older relatives to provide childcare for children, or bringing elderly dependants to Thailand to support them there.

Ongoing economic difficulties in Thailand also raise the fear that hostility against migrants will be boosted for reasons of political expediency. A study by the Institute of Asian Studies (ISA), the Thailand Development Research Institute (TDRI) and Institute for Population and Social Research (IPSR) (2003) reported that hostility from the business community is well established. Opposition focused not only on the potential for migrants to displace Thai citizens in the economy, but also on the claim that migrants 'pollute' local society. Sizeable proportions of those interviewed considered that migrants were a threat to national security, life, and property, and that they carry transmittable diseases. As we have seen above, male migrants have long been seen as a security threat and blamed for social and political unrest. Women migrants are currently being constructed as the cause of a 'population explosion'. When the former Deputy Prime Minister Sonthi Boonyaratkalin visited a Burmese migrant community near Bangkok in November
2007, his response to the presence of pregnant migrant women and migrant children was that migrants should be prohibited from giving birth in Thailand. ${ }^{36}$

Such statements reflect the ongoing ambivalence of the Thai government towards the conflicting objectives of meeting demand for migrant labour, which may well increase during the current recession ${ }^{37}$, and addressing popular fears of migrants as threats to national employment and security. This ambivalence reflects the tensions resulting from the ongoing harassment of migrant workers and the policy of confining migrant workers to the border zone areas (FTUB/ Robertson Jr. 2006).

However, as we pointed out in the introduction, it is important to understand how migrants negotiate the structural constraints they face, not least in securing the care and well-being of their children whilst they continue to engage in waged work to support their families. Our research has indicated that there are many ways that migrant women navigate the controls and exploitative conditions imposed by the state and employers and mobilize resources to meet their reproductive obligations in a hostile and changing environment. In spite of the attractions of bearing and raising their children in their home country, which would in most cases make it more possible to obtain Burmese nationality for their children and to utilize family support and networks, as well as the difficulties discussed above in accessing health services and childcare in Mae Sot, women migrant workers are increasingly disinclined to send their children back to Burma.

Migrant women, especially mothers, juggle their care responsibilities across the border, and between different women (usually kin) in order to manage their childcare responsibilities. Their approach to the education of their children is equally pragmatic, weighing the pros and cons of the different locations and opportunities for education in the two countries. Constrained by their irregular status, their exploitative work experiences, and the institutional constraints on their mobility and entitlement, women are demonstrating remarkable resilience and making decisions that reflect their own aspirations for the future of

36 "Sonthi orders that foreign workers need to deliver children outside the country", in: Komchat Luk, I5 November 2007.

37 According to, for example, a report in The Economist on I9 March 2009: "Burmese migrant workers in Thailand - Myanmar's overflow”. 
themselves and their children. They acquire familiarity with the local area, and in time are less constrained by the restrictions of employers, authorities, or peer groups. They make difficult and complicated decisions about their own health issues and the care and well-being of their children and other family members. For these women, the border increasingly becomes less a division between absolutes - opportunities in Thailand and oppression in Burma - and more a porous contour across which they constantly strategize, moving themselves, their money, and their families to the location which would seem to offer the best short- or long-term advantages.

\subsection{Conclusion}

This case study has argued that even in increasingly unstable circumstances women migrant workers have to continue to balance their reproductive responsibilities as mothers and daughters with their ongoing role as wage workers and economic providers, often managing complex transborder care arrangements. Industrial strategy meanwhile is made on the basis of geopolitical interests or immediate economic crises with little or no concern about the process that delivers cheap and productive workers in the bodies of migrant workers crossing the river from Burma. As women continue to shoulder responsibilities for organizing the place and manner in which babies are born and cared for, for the economic and emotional support of families, and for the daily and future health and education of their children and other family members, women's agency and creativity will be tested. Whilst all women's agency is operated within constraints, in the case of Burmese migrant workers the constraints are more restrictive than in most other

\section{References}

ACMECS, 2004: "Ayeyawady-Chao Phraya-Mekong economic cooperation strategy", in: ACEMECS Ministerial Retreat, Krabi, Thailand, 2 November, at: <http:// www.acmecs.org/index.php>.

Amnesty International, 2005: "Thailand: the plight of Burmese migrant workers”, in: AI Index, June, (New York: Amnesty International).

Archavanitkul, Kritaya, 2002: Research Direction and Knowledge About Migrant [in Thai] (Bangkok: Institute for Population and Social Research, Mahidol University).

Arnold, Dennis, 2004: The situation of Burmese migrant workers in Mae Sot, Thailand. Working Papers Series, No. 7I (Hong Kong City: University of Hong Kong). contexts. But their situation illustrates the ways in which the globalization of the market is linked with the international division of productive as well as reproductive labour, which takes place across the borders between poor countries in the global South, as well as between countries of the richer North and the poorer global South. Importantly, as this case study illustrates, this international division of labour does not just concern women who migrate to take up jobs as domestic servants and other care workers; it also concerns the way in which women factory workers manage and support the reproduction of their own labour power and that of their families across the borders between often hostile and inhospitable states.

Women migrant workers, without support from the receiving state and even with the harsh treatment that they experience in childbirth and childcare, have tried to negotiate the spaces offered by the (limited) state's provision of health and maternity care as well as the lax border controls between Mae Sot and Myawaddy to manage their reproductive responsibilities whilst continuing to do their paid work in garment and textile factories. This often involves the continuous shifting of children and caretakers back and forth across the border to manage childcare. This might not be a positive reproductive bargain over division of responsibility with the state, but it does necessitate a certain level of negotiation with the state by circumventing the obstacles that they face in terms of their reproductive activities. And whilst the current international celebration of political changes within Burma might offer improvements in the rights and services available to Burmese workers, it is unlikely that the conditions and prospects of migrant workers in Thailand will be improved in the foreseeable future.

Arnold, Dennis, 2006: Capital Expansion and Migrant Workers: Flexible Labor in the Thai-Burma Border Economy (MA Dissertation, Salaya, Thailand: Mahidol University, Faculty of Graduate Studies).

Asian Human Rights Commission, 2005: "Update on urgent appeal" (Hong Kong: Asian Human Rights Commission, I6 September).

ARCM (Asian Research Center for Migration); IPSR (Institute for Population and Social Research); TDRI (Thailand Development Research Institute), 2004: "Thailand: improving the management of foreign workers: case studies on five industrial sectors", prepared for IOM (International Organization for Migration); ILO (International Labour Office); IOM, Mission with Regional Functions (Bangkok, Thailand). 
Barimbun, Anchana, 2006: "Future of Thai textile: crisis or opportunity", paper presented at the Situation of Textile Industry Two Years after Trade Liberalization, 20 December, at: <www.thaitextile.org/th/backup/PR/ $061220 / p p t>$.

Buschmann, Verena, 20II:"Thailand: backstreet abortions on rise at border among illegal migrant workers", European Pro-choice network, I9 July; at: <http://europeanprochoicenetwork.wordpress.com/page/II/> (2I May 20I2)

Caouette, Therese, M., 200I: Small Dreams Beyond Reach: The Lives of Migrant Children and Youth Along the Borders of China, Myanmar and Thailand, A Participatory Action Research project of Save the Children UK (London: Save the Children).

Chalamwong, Yongyuth, 2004: "Government policies on international migration: illegal workers in Thailand", in: Ananta, Aris; Arifin, Evi Nurvidya (Eds.): International Migration in Southeast Asia, (Singapore: Institute of Southeast Asian Studies), 352-373.

Chalamwong, Yongyuth; Amornthum, Somchai, 2002: Thailand: Improving Migration Policy Management with Special Focus on Irregular Labour Migration: Analysis of Thai Labour Market (Bangkok: Thailand Development Research Institute Foundation).

Chulalongkorn University, 2003: "Migrant workers from Burma and Thailand: policy review and protection mechanisms, commemorating Io years of policy governing migrant workers from Burma”, Proceedings of a seminar on Reviewing Policies and Creating Mechanisms to Protect Migrant Workers (Bangkok: Chulalongkorn University, 2I February).

Ekachai, Sanitsuda, 2007: "A place to learn”, in: Bangkok Post, 26 June.

Elson, Diane; Pearson, Ruth, I98r: "Nimble fingers make cheap workers", in: Feminist Review, 7 (Spring): 87I07.

EXIM (Export-Import Bank of Thailand): “Thailand's international trade”, at: EXIM website, Thailand, 24 August; at: 〈http://www.exim.go.th/eng/economic_information/ inter.asp $>$.

Fink, Christina, 2009: Living Silence in Burma: Surviving Under Military Rule, second edition (Chiang Mai: Silkworm Books; London - New York: Zed Books).

Folbre, Nancy, 1994: Who Pays for the Kids? Gender and the Structures of Constraint (New York - London: Routledge).

FTUB (Federation of Trade Unions Burma), 2004: Brief Report on Child Migrant Workers from Burma in Thailand, Case study - Mae Sot (Bangkok, Thailand: FTUB).

FTUB, Migrants Section; Robertson Jr., Phil S., 2006: The Mekong Challenge - Working Day and Night: The Plight of Migrant Child Workers in Mae Sot, Thailand. Mekong Sub-Regional Project to Combat Trafficking in Children and Women, International Programme on the Elimination of Child Labour (Bangkok: International Labour Organization).
Hochschild, Arlie, 200I: "Global care chains and emotional surplus value", in: Hutton, Will; Giddens, Anthony (Eds.): On the Edge: Living with Global Capitalism (London: Vintage).

Huguet, Jerrold W., 2007: "Thailand's policy approach to irregular migration”, mimeo, May, in: Martin, Paul (Ed.), 2007: The contribution of migrant workers to Thailand: Towards policy development (Bangkok: International Labour Office).

Huguet, Jerrold W.; Punpuing, Sureeporn, 2005: International Migration in Thailand (Bangkok: International Organization for Migration).

Hveem, Petter; Than Doke, 2004: "Hidden exploitation: Burmese migrants in Thai garment factories - hidden sub-contracting by Tommy Hilfiger Corporation and other brands, Mae Sot, Thailand”, third draft version, April (Bangkok: Norwegian Church Aid).

Institute of Asian Studies, Chulalongkorn University; TDRI (Thailand Development Research Institute); IPSR (The Institute for Population and Social Research); Mahidol University, 2003: Research project: demand of migrant worker in Thailand 2003-2005, submitted to the National Security Council, Prime Minister's Office, October.

Kittisuksathit, Sirinan, 2009: "Remittance-sending behaviour among migrants from Myanmar, the Lao PDR and Cambodia”. Paper presented at the International workshop on gender, migrant workers and citizenship in Greater Mekong Sub-region: Economic and political perspectives for a world in crisis, Asian Institute of Technology, Thailand, I-3 June.

Kusakabe, Kyoko; Pearson, Ruth, 20I0: "Transborder migration, social reproduction and economic development: A case study of Burmese women workers in Thailand", International Migration, 48:6, I3-43.

Kusakabe, Kyoko; Pearson, Ruth; Naw Eh Mwee; Phadungkiati, Lada, 2008: Analyzing Linkages Between Migrant Workers, Commodity Chains and Regional Development in Mae Sot and Migrant Workers' Workshop on Locating Ourselves in the Economy and Society (Bangkok - Pathumthani: Asian Institute of Technology).

Ling, Deborah, 2007: Burmese Migrant Workers' Access to Health Care Services in Thailand (M.Sc. thesis, Bangkok - Pathumthani: Asian Institute of Technology).

Martin, Philip, 2007: The contribution of migrant workers to Thailand: Towards policy development (Bangkok: International Labour Office).

Martin, Philip; Asian Research Center for Migration; Institute for Population and Social Research; Thailand Development Research Institute, 2004: Thailand: Improving the Management of Foreign Workers (Bangkok: International Labour Office; International Organization for Migration).

Mackintosh, Maureen, I984: "The sexual division of labour and the subordination of women", in: Young, Kate; Wolkowitz, Carol; McCullagh, Roslyn (Eds.): Of Mar- 
riage and the Market: Women's subordination in international perspective (London: Routledge - Kegan Paul).

Maung, Cynthia; Belton, Suzanne, 2004: Working Our Way Back Home: Fertility and Pregnancy Loss on the Thai Burma Border (Melbourne: Melbourne University; New York: Open Society Institute).

Mushakoji, Kinhide, 2003: "Social reproduction of exclusion: exploitative migration and human insecurity", in: Bakker, Isabelle; Gill, Stephen (Eds.): Power, Production and Social Reproduction: Human In/Security in the Global Political Economy (Basingstoke: Palgrave Macmillan).

Myint Wai, Bhumiprabhas; Subhatra;Kerdmongkol, Adisorn (Eds.), 2004: A Memoir of Burmese workers: From Slaves Labour to Illegal Migrant Workers (Bangkok: Thai Action Committee for Democracy in Burma [TACDB]).

Nagar, Richa; Lawson, Victoria; McDowell, Linda; Hanson, Susan, 2002: "Locating globalization: feminist (re) readings of the subjects and spaces of globalization", in: Economic Geography, 78,3: 257-284.

Ong, Aiwha, 2004: "Graduated sovereignty in South-east Asia”, in: Theory, Culture and Society, I7,4: 55-75.

Osawa, Mari, 20II: Social security in contemporary Japan: A comparative analysis, (London: Routledge).

Parreñas, Rachael, S., 200I: Servants of Globalization: Woman, Migration, and Domestic Work (Stanford Stanford University Press).

Pearson, Ruth, 1997: "Renegotiating the reproductive bargain: Gender analysis of economic transition in Cuba in the 1990s", in: Development and Change, 28,3: 671-705.

Pearson, Ruth; Kusakabe, Kyoko, 20I2a: "Who cares? Gender, reproduction and care chains of Burmese migrant factory workers in Thailand”, in: Feminist Economics, I8,2: I49-I75.

Pearson, Ruth; Kusakabe, Kyoko, 20I2b: Thailand's Hidden Workforce: Burmese Migrant Women Factory Workers (London: Zed Books).

Pearson, Elaine; Punpuing, Sureeporn; Jampaklay, Aree; Kittisuksathit, Sirinan; Prohmmo, Aree, 2006: Mekong Challenge - Underpaid, Overworked and Overlooked: The Realities of Young Migrant Workers in Thailand, Volume One, Mekong Sub-regional Project to Combat Trafficking in Children and Women, (Bangkok: International Labour Office).

Pollock, Jackie, 2006: "Cross-border migration: Burma-Thailand”. Paper presented at Asian Consultation on Gender, Migration and Citizenship, Asia Research Institute, National University of Singapore and International Development Research Centre, Singapore, 25-26 October.

Punpuing, Sureeporn, 2006; The Mekong Challenge: Underpaid, Overworked and Overlooked - The Realities of Young Migrant Workers in Thailand, Volume Two, Mekong sub-regional project to combat trafficking in children and women; International Programme on the Elimination of Child Labour (Bangkok: International Labour Organization).
Rattanarut, Nara, 2006: "Immigration management and administration in Thailand", in: Martin, P. (Ed.): The Contribution of Migrant Workers to Thailand: Towards Policy Development (Bangkok: International Labour Office).

Sassen, Saskia, 2008: “Two stops in today's new global geographies: shaping novel labor supplies and employment regimes", in: American Behavioural Scientist, 52,457: 457-496.

Sciortino, Rosalia; Punpuing, Sureeporn, 2009: International Migration in Thailand (Bangkok: International Organization for Migration).

Silvey, Rachel, 2004: "Power, difference and mobility: feminist advances in migration studies", in: Progress in Human Geography, 28,4: 490-506.

Sparke, Matthew; Sidaway, James D.; Bunnell, Tim; GrundyWarr, Carl, 2004: "Triangulating the borderless world: geographies of power in the Indonesia- Malaysia - Singapore growth triangle", in: Transactions of the Institute of British Geographers, NS29: 485-498.

Thammasak, Anchalee, I998: Workers' Situation and Needs for Remuneration: A Comparative Study Between Thai and Foreign Workers in Samutprakan Province (Master's dissertation, Bangkok: Mahidol University [in Thai]).

Thapan, Meenakshi, 2006: "Series introduction", in: Anuja Agrawal (Ed.): Migrant Women and Work, Women and migration in Asia, Volume 4 (New Delhi: Sage Publications): 7-I7.

The Economist, 2009: "Burmese migrant workers in Thailand - Myanmar's overflow”, I9 March.

Traitongyoo, Krongkwan, 2008: The Management of Irregular Migration of Irregular Migration in Thailand: Thainess, Identity and Citizenship ( $\mathrm{PhD}$ dissertation, Leeds: University of Leeds, School of Politics and International Studies).

Tsuneishi, Takao, 2005: The regional development policy of Thailand and its economic cooperation with neighboring countries. Discussion Paper, No. 32 (Chiba: Institute of Development Economies, Japan External Trade Organization).

Valentine, Gill, I989: “The geography of women's fear", Area, 2I: 385-390.

WHO (World Health Organisation), 2006: "Mortality country fact sheet" (Geneva: World Health Organisation)

World Vision; Asian Research Center for Migration, 2003: Research report on migration and deception of migrant workers in Thailand (Bangkok: Chulalongkorn University).

Wright, Melissa W., 2006: Disposable Women and Other Myths of Global Capitalism, (New York: Routledge).

Yeates, Nicola, 2005: Global Care Chains: A Critical Introduction (Geneva: Global Commission on International Migration).

Yeoh, Brenda S.A.; Huang, Shirlena, I998: "Negotiating public space: strategies and styles of migrant female domestic workers in Singapore", in: Urban Studies, 35,3: 583602.

Open Access. This chapter is distributed under the terms of the Creative Commons Attribution Non-commercial License, which permits any noncommercial use, distribution, and reproduction in any medium, provided the original author(s) and source are credited. 
 Transnational Marriage Migration and the East Asian Family-Based Welfare Model: Social Reproduction in Vietnam, Taiwan, and South Korea
}

\author{
Duong Bach Le', Thanh-Dam Truong ${ }^{2}$, and Thu Hong Khuat ${ }^{3}$
}

\begin{abstract}
Since the late I990s there has been a rising trend of Vietnamese women migrating to neighbouring countries (Taiwan, South Korea, Singapore, and China) for marriage. Previous studies of such cross-border marriages have emphasized either issues of choice and agency for women, or their poverty and victimhood. This chapter analyses this trend along the lines of the debate on the East Asian model of welfare and family policy, with case studies in Taiwan and South Korea. It views commercially arranged transnational marriages (CATM) as an institution that connects changing gendered regimes of social reproduction at the sending and receiving ends. Mediated by a combination of asymmetrical relations - gender, class, age, ethnicity, and national belongingthis institution operates in a transnational space through which material and symbolic resources are circulated. These in turn construct subjectivities and identities for participating actors. There is a dimension of trans-masculinity embodied in the practices of CATM and this requires further exploration regarding informed consent and the rights of its users. Beyond this, CATM should be further analysed in the context of changing family welfare and intergenerational care as gendered regimes, and such an analysis should also address how households adapt and devise new strategies to sustain and reproduce themselves economically, socially, and culturally. Such an understanding can help open the research agenda on social policy and rights and provide a regional perspective.
\end{abstract}

Keywords: Transnational marriages, East Asian family welfare model, gender, social reproduction, care, social policy, ethnicity, South Korea, Taiwan, Vietnam.

\subsection{Introduction ${ }^{4}$}

Economic and political transformation under the East Asian model of development and its South-East Asian followers has historically received much attention

1 Dr Duong Bach Le is Director of the Institute for Social Development Studies (ISDS) in Hanoi (Vietnam).

2 Dr Thanh-Dam Truong is Associate Professor in Women/Gender and Development Studies at the Institute of Social Studies in The Hague (The Netherlands).

3 Dr Thu Hong Khuat is Founder and Co-Director of the Institute for Social Development Studies (ISDS) in Hanoi (Vietnam).

4 This chapter is based on a project entitled "Transnational Migration of Vietnamese Women in Asia: Experiences, Rights and Citizenship", funded by the International Development Research Centre (IDRC) of Canada, project number: IO4093-OOI.
(Stiglitz/Yusuf 200I; Wade 2003). More recently, two emerging independent debates have opened a new line of enquiry on its reproductive side. One debate concerns the East Asian welfare model based on Confucian family ideology, which operates simultaneously as a welfare regime and a main source of hegemony and legitimacy in the model of the 'developmental state' (Jones I990; Goodman/Peng 1996). The other debate concerns the patterns of women moving from South-East Asian countries to East Asian countries for marriage. Enquiries into these marriages, formally labelled as 'international marriage', have so far followed two main tracks. One track emphasizes issues of cultural identity, desire for mobility, and women's agency in 'global hypergamy', notably where women marry to move up to a higher socio-economic location in the global hierarchy (Piper 2003; Constable 2005). The main issue here concerns the politics of inclusion/ex- 
clusion regarding their citizenship and their individual rights. The other track takes a socio-demographic perspective, arguing that changing gender relations in the household and labour market, as well as an imbalance in sex ratios that favours male births, are factors that have led to a 'marriage squeeze' for men among certain groups (Lee 2005). Suzuki (2003) refers to the vernacular expression 'bride famine', common in some rural areas in Japan, while Kojima (200I) uses the term 'patriarchy's coping strategy' to explain the involvement of local governments in finding eligible foreign women for marriage with their citizens-in an attempt to circumvent the effects of a structural problem of gender inequality. Political and ethnic factors behind the choice of the community of origin of the foreign brides have also been noted (Jones/Shen 2008; Lan 2008; Yang/Lu 20IO). The role of commercial agents in matching men's preferences with eligible women across borders has also been emphasized (Wang/Chang 2002). Recent research findings in the case of Vietnam by Bélanger and Tran (20II: 6I) suggest that that by 'marrying up', or simply marrying across borders, Vietnamese women may be creating a domino effect in the formation of a 'global marital and reproductive chain' that echoes the notion of a 'care chain' (Yeates 20I2).

This chapter examines the formation of commercially arranged transnational marriage (CATM) as a vehicle used among certain social groups in Taiwan, South Korea, and Vietnam in the context of the transition of the Confucian family within the East Asian welfare regime and its structural gendered features. After four decades as the backbone of welfare provision in support of the goals of the developmental state in countries classified as part of the East Asian Miracle (Japan, South Korea, Taiwan, Singapore), this welfare regime now shows signs of instability in terms of human reproduction and intergenerational care. The three countries of this study - Taiwan, South Korea, and Vietnam - share a common legacy of Confucian values, particularly visible in the domain of the family. Historically specific to this part of the world is the concept of the family as kinship ties, often conflated in practice with the household registration system as an administrative device for bio-control (births, deaths, marriages, divorces, migration, and social entitlements). ${ }^{5}$ The family and household are deeply interrelated but should be kept analytically distinct in order to discern: (a) how historically formed family practices of bio-control based on gender lines are articulated in relation to specific duties; and (b) how the household as a unit for resource allocation/manage- ment can be subject to change due to broader changes in the economy and state policy, which in turn can affect family relations.

While emerging practices of transnational marriage may signify a transition of the Confucian normative regimes of family and inter-generational care, their meanings may differ for the actors involved owing to very different development trajectories that generate a different understanding of gender equality and the family. To discern commonality and gendered difference in perceptions of transnational marriage, we adopted a multi-sited research methodology. An extensive review of the literature on marriage and the family in a transnational context was conducted in conjunction with an analysis of debates on gender regimes in migration in South-East Asia. In 2008, fieldwork was conducted in several rural communities in Vietnam known for sending women as brides to East Asia, where interviews with potential brides, returnees, and their parents were held. In 2009 we visited several cities in Taiwan and Korea where women who have used commercially arranged marriage as a vehicle to find husbands have found new homes. Snowball techniques were employed to identify and select respondents, which included local officials, the husbands, wives, and in-laws. ${ }^{6}$ The aim of in-depth interviews was to obtain information on the procedures of CATM as they have experienced it, and the adjustments required in a new country as a mother, wife, daughter-in-law, and member of the local community.

5 Hukou refers to a system of household registration dating back to China's ancient history. Originally, the system was designed to serve the purpose of administrative regulation of the population and representation of family authority under the male line of inheritance. Through direct and indirect influence, the system is also found in Vietnam (Ho khau), Korea (Hoju), Japan, and Taiwan (Koseki). In South Korea the system was abolished on I January 2005. In Japan and Taiwan the system still exists, but only as a tool for administration that has no impact on a resident's movement. In the People's Republic of China (PRC) and the Socialist Republic of Vietnam (SRVN) the system functions as a means to establish land use rights, the right of residence, and access to social entitlements.

6 In Vietnam, fieldwork covered 16 returnees as former wives through CATM from Taiwan (7) and South Korea (9); 2 mothers of the returnees and 3 officials from local authorities of the sending communes. In Taiwan, indepth interviews were held with I9 Vietnamese wives through CATM, 6 husbands, and 5 mothers-in-law. In South Korea, interviews were held with 25 Vietnamese wives through CATM, 4 husbands, and 4 mothers-inlaw. 
Section 5.2 clarifies the meaning of the terms 'transnational marriages', 'social reproduction' and 'the reproductive bargain'- the latter being considered a useful analytical tool to explore how interactions between institutions and people reproduce gender relations in the household and family and their structures. Section 5.3 discusses different manifestations of the crisis of social reproduction in Taiwan and South Korea, with a focus on: (I) a bio-crisis (human reproduction and inter-generational care) and a crisis of cultural reproduction vis-à-vis the Confucian familybased welfare system, and (2) a livelihood crisis vis-à-vis the position of the rural household after two decades of Vietnam's market reform. Section 5.4 discusses the emergence of the marriage business as a system of networks formed in both sending and receiving countries, as well as discursive constructs and practices of identity. Section 5.5 demonstrates the diversity in the social positioning of Vietnamese women as daughters-in-law and how within a transnational context the meanings of 'tradition' and 'modernity' can be made and remade. Some women are also able to negotiate their female gender-based duties and entitlements in their new homes while maintaining their distinctive identity as members of their birth families. The conclusion suggests the need for a more holistic analysis of transnational marriage as a formation through which a transfer of values and resources takes place and gender relations are reproduced in terms of trans-masculinity, with implications for social policy and rights.

\subsection{Viewing Commercially Arranged Transnational Marriages from the Perspective of Social Reproduction}

\subsubsection{Defining Transnational Marriages}

Marriage between people of different nationalities is commonly defined as international marriage, reflecting the nation state as the key actor in formalizing a union. The body of literature on marriage migration within and between different regions of the world has introduced two new key terms to indicate different conceptual emphases: cross-border and transnational marriage (Lu 2007; Constable 2005, 2009). The emphasis on borders distinguishes between those defined by the nation state (immigration and citizenship) and those operating at the inter-group level (race, ethnicity, class, gender). Both types of borders are often based on a binary construct of 'We' versus the 'Others', allowing for a selective and contextual understanding of the sense of belonging to a family, community, and nation state. Legal borders express the normative principles of marriage as an institution and embody the collective values of a nation state. Borders drawn up at inter-group level are more dynamic and fluid and express the collective memories of a social group.

In states ruled by strong nationalist sentiment, as in the case of East Asia, the foreign wives are commonly classified as cultural outsiders, particularly if they come from countries with a colonial legacy. They are called Ajia no hanayome (brides from Asia) in Japan; Chosnjok brides (brides from ethnic Korean communities living in China), later changed into the neutral term of damunwha or 'multicultural' marriages in South Korea; Waiji/dalu Xinniang (foreign/mainland brides) in Taiwan (Yang/Lu 20IO). Their status as foreign is specified in geo-political terms, with South Korea moving towards a more open position.

The concept of 'transnational marriage' borrows from Faist (2000: 199-200) the idea of a transnational social space, which refers to the combination of sustained social and symbolic ties and their contents and positions in networks and organizations that can be found in more than one nation state. Transnational marriages may be considered as unions formed within such a space, simultaneously sustaining it through bidirectional practices of financial, social, and cultural remittances (Suksomboon 2008). Linked to this concept is the notion of the "transnational family" defined as those "families that live some or most of the time separated from each other, yet hold together and create something that can be seen as a feeling of collective welfare and unity" (Bryceson/Vuorela, 2002: 3). Due to diverse kinship traditions and individual social histories brought into the marriage by the spouses, ${ }^{7}$ empirically the family in a transnational marriage may involve multi-layered flows of emotions, values, and resources between separate places. As perceptions about ties and positions may differ between spouses, families formed through transnational marriage should be considered in the context of more than one regime of family welfare and intergenera-

7 For example, in a patrifocal kinship relationships are centred around, or focused on, the father; in a matrifocal kinship they are centred around the mother, and in bilateral kinship both father and mother lines count. Bifocal practices allow a married woman to pay attention to the husband's household as well as her own birth household (Dube I997). 
tional care. Limiting the analysis of the family and of a gendered regime of care and welfare to a particular society, nation, or its culture is increasingly problematic in view of trans-border flows and conflicting perspectives on family duties.

\subsubsection{Social Reproduction and the Reproductive Bargain: A Perspective on Transnational Marriages}

Informed by, but critical of, the Marxist intellectual tradition which limits the concept of social reproduction to the renewal of social relations and material bases of the society and economy, feminist theorizations try to bridge the conceptual and theoretical separation between the production of things and the creation and maintenance of human lives (Katz 20II). Social reproduction in feminist terms encapsulates many layers of power relations that are historically shaped: sexuality and biological reproduction; reproduction of labour power inclusive of an intergenerational process of care provision; reproduction of social relations and institutions, of which the family and its relationship with the state is one of the most significant (Whitehead 2002). Social reproduction simultaneously is a material and a discursive system through which a society recreates itself biologically, emotionally, culturally, institutionally, and economically. As Kabeer (2004: IO) points out, this process involves an array of institutional structures and activities that embody gendered values and knowledge, therefore regimes of social reproduction are essentially gendered regimes, particularly as regards the significance attached to reproductive activities and the recognition given to those who carry them out.

It is here that the concept of 'reproductive bargain' introduced by Pearson (I997) is particularly valuable. The concept originally referred to the division of responsibility for different aspects of daily, generational, and social reproduction between the state, the household, and individuals in terms of resources that are collectively provided, and those that are accessed through wages and other money incomes. By studying the changing institutional arrangements in Cuba, which underwent a rapid transition in the 1990s, Pearson demonstrates how households adapt and devise new strategies to sustain and reproduce themselves, strategies that are patterned by an existing gender division of labour, and in some aspects, reinforced traditional gender roles.

Building on this insight, Gottfried (2009: 77) proposes a more general model to analyse an ensemble of institutions, ideologies, and identities around social provisioning and care for human beings. According to her the reproductive bargain:

[...] constitutes a hegemonic framework within which actors negotiate rules. Bargain implies a bounded agreement (structure) proscribing and prescribing conduct, but it also injects a dynamic notion of boundaries being made (agency). Actors negotiate from different structural positions of power with different resources (material, symbolic and organizational). As a social process, agents interpret rules and influence rule making that can call into question and alter the boundaries of the bargain.

The reproductive bargain as a concept is a useful tool for carrying out an inductive gender analysis of the contextually formed ensemble of institutions and the discursive practices that affect the family as a site of social reproduction (biological reproduction, intergenerational care). Within a given social structure that affords different resources (material, symbolic, organizational) to people, the boundaries of the bargain are redefined and altered as actors in different positions interpret, negotiate, and perform rules in a social process. Underlying the whole concept of the reproductive bargain is the primary question of how power relationships are negotiated and played out among actors, leading to specific outcomes regarding which aspects of reproduction are subject to commodification and market dynamics, and which are socialized (Clement/Prus 2004: 5).

Contextual discourses on gender, ethnicity, and identity also affect and interact with political and economic forces to structure a social environment in which the reproductive bargain takes place. In East and South-East Asia, there have been strong links between the institutionalization of marriage and ideologies of family in the process of nation-building (Toyota 2008). Biological reproduction in this context is also related to what Yuval-Davis (1997) refers to as the cultural reproduction of the nation, which involves the transfer of an essentialized notion of the "national culture' and its values, at times conditional on membership of the nation. Premised on a vision of the nation as a discrete self-contained entity, coterminous with the nation state and a national society, the notion of 'national culture' homogenizes diverse ethnic identities and bypasses trans-border cultural flows, coinfluencing beliefs, habits, and practices of gender. Ideal forms of masculinity and femininity are constructed in accordance with their relationship to the 'nation'. The reproductive bargain in this context concerns not only material resources but also subjectivities and practices of identity. 
Hearn (2010: 178 ) points out that, when analysing trans-border phenomena such as viewing the sex trade and its virtualization through information and communications technology (ICT) and media advertising, there is a clear construct of trans-masculinity that limits the possibility of moving towards gender equality where some social and legal foundations already exist. In this vein, commercially arranged transnational marriages that rely on a transnational space through virtualizations and inscription of masculine values may be considered as a manifestation of trans-masculinity that enables the cultural reproduction of a male-centred family. This process cannot be grasped by looking at a single site and at one period of time; it requires attention to signifiers of gender transformation over long periods.

\subsection{Different Places, Different Social Reproduction Crisis}

\subsubsection{The East Asian Family-Based Welfare Regime and Transnational Marriages: Deterioration of the Confucian Family?}

The debate on the East Asian family-based welfare regime (Japan, South Korea, Taiwan) is divided between those who endorse a cultural perspective and those who emphasize political and economic determinants. The cultural argument emphasizes as the key norms Confucian values such as filial piety, inter-generational reciprocity, and self-reliance of the family vis-à-vis the state. These values play a primary role in shaping the arrangement of welfare provisions around the family as a key institution enforced by strong social control. State assistance remains minimal and available only when other sources of support can no longer be found (Jones I990; Goodman/Peng 1996). The political economy argument points to different trajectories of East Asian welfare regimes that should be explained in terms of the corresponding development trajectories, political democratization, and the role of pressure groups in civil society (Aspalter 2006).

Notwithstanding variations in family and welfare policy among these four countries, there are some common socio-demographic changes after four decades of high economic growth. These include ageing population, declining or low fertility rate, delayed marriage, singlehood, and rising female labour participation (Chiu/Wong 2009). These features correspond to an increased number of registered international marriages, many of which involve a male national and a foreign woman. ${ }^{8}$ These may be signifiers of a social reproduction crisis vis-à-vis the Confucian family, and perhaps also the relative weakness of women's organizations in bargaining with the state for support in intergenerational care, currently defined as a female domain.

As the two countries which receive Vietnamese women as brides, South Korea and Taiwan have different welfare arrangements, largely influenced by the landscape of their industrialization. While large corporations have dominated South Korean industrialization and are governed by relatively patriarchal and authoritarian regimes, family-owned small companies have characterized Taiwan's path. These aspects have a bearing on the configurations of family welfare and care regimes and the forces behind democratization and policy reforms (Aspalter 2005: 9; 2006).

The post-war welfare regime in Korea was characterized as a family-based welfare regime built on a rigid gender division of labour. Corporations adopted the construct of the family wage paid to the male employee, who relies on the non-working wife to provide care for family members, while the state provided residual support (Aspalter 2006). As Truong (I999) has shown, the massive participation of women in the labour force-supporting the initial stage of rapid industrialization-was managed through the intervention of the state and firms into the cycle of their reproductive life: recruited for paid work at pre-marriage age and encouraged to leave employment to raise a family (most likely in a three-generation household) after marriage, women return to part-time employment after childbearing age.

In the post-Beijing period, policies to build a strong and competitive labour force have invested in women's education (Mark 2007), and recently social

8 Yang and $\mathrm{Lu}$ (20I0) note the following: in Japan the number of international marriages has grown from 0.43 per cent in 1965 to 0.93 per cent in 1980 , and then to 5.77 per cent in 2005, with Chinese and Filipina female spouses at the top of the list. In Taiwan, cross-border marriages involving brides from Indonesia, Vietnam, and the People's Republic of China gained numerical significance from the mid-I980s onwards, and by 2002 they comprised 27.4 per cent of all Taiwanese marriages in that year. In Hong Kong, the number of cross-border marriages between Hong Kong residents and mainland Chinese has increased tenfold from 1995 to 2005, accounting for more than one-third of registered marriages involving Hong Kong residents in 2005 . In South Korea, the number of international marriages multiplied 9.2 times between 1990 and 2005 , constituting 13.6 per cent of newly-weds in 2005 . 
policies designed to promote equal opportunity between men and women have emerged. ${ }^{9}$ The definition of gender equality is limited to equal opportunities in employment in order to fuel growth based on upgrading technology, allowing for a move into new areas of export (the knowledge economy and 'creative industries' such as media and communications technology) (Henry 2008; Marginson/Kaur/Sawir 20II). While women may have benefited from the opening of these new sectors, the structures of gender inequality that underpin the combination of the 'familialism' and 'developmentalism' model of economy remain unbroken (Peng 2008). As the society is facing a rapidly ageing population, and the fertility rate is below the replacement level (Rallu 2006), the state took an interventionist approach in 2004 , based on the family/work balance model that offers cash allowances, child care provision, after-school care, parental leave, and arrangements for care of the elderly. It recognizes the significant percentage of the elderly living with grown-up children. ${ }^{10}$ Yet inter-generational reciprocity in the Confucian family as an ethical principle remains strong while workplace practices remain familyunfriendly. Working women wanting to find a balance between work and family life must draw on the support of family members or in-laws living nearby, given that intergenerational care remains primarily the duty of women (Sung 2003).

Turning to Taiwan, though demographic changes are similar to South Korea, the family remains a significant force in enforcing obligations for intergenerational care. Women still provide a large proportion of unpaid care work, and both children and the elderly are still commonly taken care of by family members. ${ }^{11}$ This resilience of the traditional family is the main reason why Taiwan lags almost a decade behind Ko-

9 In South Korea, the Equal Employment Act was enacted with the purpose of increasing equality in the labour market between the sexes in 1985 . In the wake of the I995 Beijing Platform of Action, the Korean National Assembly passed the Women's Development Act, stipulating the duties of public bodies to eliminate discrimination, to promote the advancement of women in public life, and to enhance their welfare and living conditions within the family. The Ministry of Gender Equality was established in 200I and expanded in 2005 and renamed the Ministry of Gender Equality and Family (Won 2007).

10 This percentage has fallen from over 65 per cent in 1988 to 44 per cent in 2004 (Chiu/Wong 2009: I04).

11 In Taiwan the percentage of the elderly living with grown-up children had fallen from over 70 per cent in I986 to 63 per cent in 2002 (Chiu/Wong 2009: II5). rea in launching major family policy reforms, even though the pace of its democratization was not far behind that of Korea (Aspalter 2006).

According to Lan (2008), the Taiwanese government has deliberately praised and encouraged threegeneration households as a time-honoured solution to childcare and care of the elderly (Lan 2008). Lan (2008) also points out that for middle-class families, the solution to the shortage of care is to hire migrant domestic workers, whereas for working-class families who cannot afford this option, a foreign bride is the solution to the shortage of reproductive care labour through a marriage contract. The 'care deficit' can thus be seen as a narrative to rationalize the recruitment of cheap and disposable migrant labour for middle-class families, while the 'bride deficit' is a narrative used to justify working-class men's needs not only for brides but also for unpaid reproductive labour (Lan 2008; Wang 20IO). In 2008, Taiwan launched a Family Policy White Paper that includes cash allowances for child support, paid maternity leave (no paternity leave or childcare leave are mentioned), childcare provisions at the community level, and provisions for care of the elderly. The vision of the policy is far more modest than South Korea's (Chiu/Wong 2009: II7-II9).

In both countries, despite these reforms it would seem that traditional patterns are pervasive for a relatively large segment of society. Where gender norms in the family remain unchanged, and options within national borders are not available, searching for solutions overseas becomes inevitable. Because practices of care itself are culturally embedded, searching for partners with some cultural proximity appears necessary.

\subsubsection{Social Reproduction Crisis in Vietnam: A Focus on the Rural Sector}

While the Vietnamese culture is a part of the East Asian legal traditions influenced by Confucian ethics, its gender order remains an exception owing to the principle of gender equality in the Hong Duc Codes (fifteenth to eighteenth centuries). The Civil Codes preserved Confucian ethics by assigning the wife a lesser status than the husband in a patriarchal family, but forbade domestic violence and granted divorce on several grounds unknown to the Chinese Codes. ${ }^{12}$ The Codes not only retained a lasting influence up to the mid-twentieth century among the population, but also among the French colonial courts in Vietnam, particularly on the recognition of inheritance rights for women (Ta 1982). This can be seen in the 1959 Family Law of the Republic of Vietnam, which upheld 
equality of powers between husband and wife, as well as in two succeeding statutes, the 1964 Family Law and the 1972 Civil Code. The recognition of women's right to own land and their personal rights in marriage are considered by Vietnamese historians to be the formal recognition of women's active contribution to agricultural production, trades, and other economic activities over centuries, above and beyond their contributions to family well-being (Mai/Le 1978). Since the founding of the Democratic Republic of Vietnam in 1945, and in the now unified Socialist Republic of Vietnam, full legal capacity and equality has been granted to women in successive legislation.

Since the late I980s Vietnam has been undergoing a major process of reforms, known as Doi Moi or a gradual movement towards a market economy. Agricultural Decision No. Io in I988 aimed at liberalizing the agricultural sector in Vietnam and provided land use rights for ten to fifteen years of secure tenure. Output markets were privatized and investment decisions were decentralized and left to the household. This system, known as the household contract-based system (khoan ho), was supplemented by the Land Law of 1993 which gave households the right to inherit, transfer, exchange, lease, and mortgage their land use rights. Equal rights for men and women in land use rights are ensured. Land ownership remains entirely within state purview; land use rights can be withdrawn by the state for a specified purpose of national interest.

In practice, under the household contract-based system, the rural household became at once a unit of production and of social reproduction. The promotion of the household economy was also accompanied by the dismantling of local arrangements for social rights (childcare, care of the elderly, food entitlements when in need, primary health services, and education) that had been crafted into a network of cooperation between different local institutions (Truong 1997; 2006). Vijverberg and Haughton (2004) noted that as the household economy reached its first stage of saturation, surviving households became male-led. There was a tendency for men to 'take over' successful household enterprises and to play a more prominent role, despite women's having con-

12 For example, a husband who neglected his wife and, unless on a public mission, did not personally visit her for five months (one year if they had children), would be deprived of his rights over his wife; she might then report the fact to the authority and remarry. The Criminal Codes also acknowledged the personal rights of women (Ta 1982: 548). tributed many more hours of work. The rural household became a site of tension regarding the demands for both productive and reproductive labour that restrict women's ability to bargain for more time and resources for self-employment.

This withdrawal of the government from its role as the sole provider of employment and social services was a clear indicator of a major shift in the organization of social reproduction: from a state-led welfare regime to the East Asian Confucian family-based welfare regime, although in Vietnam there is no residual state support, except micro-credit in poverty alleviation programmes. Rural families now alter their strategy, placing considerable burdens on women. Both time and effort spent by women to meet daily and generational reproduction requirements in the family have significantly increased (Khuat/Bui/Le 2009). As market reforms deepened in rural areas, the need for women to engage in livelihood generation is also increasingly felt, particularly the need for a cash income to cover rising expenses in production and reproduction. Ironically, the more women engage in incomegenerating activities, the less they are able or willing to take on social reproductive roles as fully as expected by the revitalized gender norms in the family.

In particular, the pro-growth policies geared to turn Vietnam into a new 'tiger' economy have created many crises in the countryside, particularly around land use rights. One of the indications of this crisis is the increase of independent migration by women, both rural-to-urban and to neighbouring countries (Truong/Scott 2004; Nguyen/Truong/Resurreccion 2008). This trend may in part be a response to the risk of being landless, which is increasing as the state grants more favours to a few powerful actors, including foreign investors, state-owned companies, and state-backed private enterprises, and initiates the process of land reacquisition from farmers. One area where these land-related risks are high is the Mekong Delta; this is also where the migration of women to East Asian countries as brides is most common. Among the 635 households interviewed there in 2004 by Nguyen and Tran (2010: I65-I68), over eighty-one per cent of the parents hoped to escape poverty through their daughters' marriages overseas.

Rather than paying attention to the specific microforces that generate new forms of rural poverty and its gendered dimensions, the state is using a new rhetoric of the family as a domain 'naturally' fit for women, reflecting a return to idealized Confucian norms. Similarly, state policies use the social perception of feminine virtues that underlies women's chief 
role in child-rearing and care for elderly or sick members of the family to encourage women to be "good doers of both state and domestic works" (Khuat/Bui/ Le 20II). This emphasis on traditional gender roles by the government appears to be critically linked with the social and political stability of the nation (Gammeltoft 1998; Le 2004; Schuler/Anh/Ha/Minh/Mai/ Thien 2006).

The rural reproductive crisis in Vietnam after three decades of market reform appears to be linked to the short-lived success of the household economy, which has proved to be too weak to absorb emerging structural risks and vulnerabilities derived from land leased from the state and the penetration of industry into rural areas. Yet it is expected to function also as a family-based welfare system in line with other East Asian countries. The initial reproductive bargain between the state and rural households under the household-contract system has outlived its relevance, yet so far the law remains unchanged. The burden of reproducing the household falls heavily on middle-aged women and old people, as young men, single women, and married women out-migrate in search of an income to protect the land that had been leased to the family.

\subsection{Market Response: Arranging Marriages, Earning Profits, and Constructing 'Modernity'}

Transnational marriage migration in Vietnam on today's scale is unprecedented and rapidly increasing to the countries in the region-South Korea, Taiwan, and China (IOM 2008: I70). In 200I, some 60,000 Vietnamese women had married men from Taiwan, and by the end of 2008 the estimated number rose to over I00,000 (Tang/Belanger/Wang 20II). In South Korea, marriages between Korean men and Vietnamese women increased from an insignificant number (95 in 2000 ) to a total of IO,I3I in 2006 , or a 73 per cent increase in this period and representing 33.5 per cent of total cases for that year (Kim/Shin 2008). Private agencies involved in commercially arranged transnational marriages between Taiwan and Vietnam initially emerged in the late mid-I99os, and they are now also active in South Korea.

As our interviews with Vietnamese spouses and their husbands show, the agencies and sub-agencies through which their marriages were arranged form a complex web of activities interlinked across national borders. Given the poorly enforced regulation of matchmaking agencies in Taiwan and South Korea, and the virtual absence of regulation in Vietnam, both brides and grooms become vulnerable to the conduct of these agencies, which in many cases are deceptive and essentially exploitative.

To create a demand by Korean and Taiwanese men for cross-border marriage, matchmaking agencies in the two countries construct a favourable image of brides from less developed nations like Indonesia, the Philippines, and Vietnam. They are depicted as a traditional 'gift' that will meet the needs for traditional social provisioning and care not only for their husbands but also for their husbands' parents. Lowerclass men's access to matchmaking services is made easy, with attractive advertisements for 'purchasable traditional' spouses on television, in newspapers, and on street posters visible everywhere in these countries.

Typically, a Taiwanese or Korean man deciding to marry a Vietnamese woman would rely on a local agency or sub-agency in their own country, paying a fee for the service. The fee, which may be as high as US\$IO,০oo, includes service fees paid by the Taiwanese or Korean agencies to their Vietnamese counterparts; the cost of return travel to Vietnam and accommodation; viewing of potential brides; and the cost of organizing a wedding once a selection is made. Because Vietnam's revised Family Law in 2000 forbids international marriages for commercial purposes, Korean and Taiwanese agencies locate potential local brides through nationwide networks of Vietnamese agencies, sub-agencies, collaborators, and various informers, ranging from local authorities to people in the community, relatives, or family members. It is not uncommon to find recruiters living in the same community as the brides, as in most cases the brides are approached at home.

In Taiwan and Korea, agencies portray Vietnamese brides as 'traditional', 'virgins', and 'virtuous' (see also Wang 20IO), while in Vietnam recruiters construct Taiwanese and Korean men as being 'modern' and this makes them most desirable as marriage partners. They are frequently depicted as urban men with jobs or running their own business, apparently at least middle-class if not wealthy, decent-looking, and owing a home that is not shared with parents or other relatives. In Vietnam, the most common scenario involves the potential brides being taken from the Mekong Delta by the recruiters (or travelling by themselves) to Ho Chi Minh City. There, they stay for a period ranging from a few days to several months just to attend shows, often held by the agencies in small hotels, where they are introduced to men who seek a wife. 
The women are provided with food and accommodation and are rounded up whenever there are men who want to see them. According to the experience of one woman who had married a Taiwanese man:

\begin{abstract}
Almost every day I was taken to see foreign men from Taiwan, South Korea, Singapore, Malaysia. In three months.... many men, usually in groups of ten, but sometimes there were only one or two men.... The process is something like: the boss (recruiter) rents a room in a hotel; then men came in-five to six girls are shown for them to see; if they like someone, she can stay but she has to wait until they see all the girls, then they make the final decision. (A CATM wife from Can Tho, interviewed in Taoyuan, Taiwan.)
\end{abstract}

When the man has chosen a woman as a bride he has to pay for the costs of food and accommodation incurred prior to the selection; if the woman decides to leave, she will have to cover these costs. The woman from Can Tho quoted above said that in the beginning she often walked out of the room when she did not feel like being seen by potential grooms but she was then threatened by the 'boss' that if she continued to act in this way he would send her home, and she would have to pay the costs. She corrected her behaviour and finally found a Taiwanese husband after four months in Ho Chi Minh City.

Health checks, including blood tests (clearly with a fear of HIV), and mental health checks are always arranged in advance by the agencies with local health care centres or a hospital, public or private. These take place on the same day of the show, or the following day, to ensure that the chosen women are physically fit for marriage. A particularly degrading part of the health check is the so-called 'virginity check', though the brides are told it is a 'gynaecological check', for which most of the women are already psychologically prepared. ${ }^{13}$ These health checks are often conducted carelessly, and, at least in our research, no one had been disqualified, since the physicians are bribed by the agencies.

For blood test, we went to private doctors. For mental check, they took me to the hospital. But they know the doctors, they bribed them already so the test is very simple. The doctor just asked me a few questions and let me go, like they give me some questions on plus, minus, multiply... then let me go. (A CATM wife from Can Tho, interviewed in Taoyuan, Taiwan.)

13 A CATM wife revealed that her several friends have passed this 'moral' test with a fake hymen, subverting the required 'proof' of virtue that the prospective grooms demand.
After the health check comes the wedding. In most cases, the wedding is held before the official registration for marriage takes place at the office of the People's Committee of the commune or sub-district where the bride holds permanent household registration; official registration takes time, since most brides' communes are in the countryside. For the grooms, the wedding in Vietnam is just a small part of the 'business', an event to close the deal with the local agency, and to be introduced to the bride's family. For them, the actual wedding is organized in their home country, when their wives join them, though we found no instance of the bride's family being invited to attend the wedding celebrations in Taiwan or South Korea.

For the brides, the wedding is much more important than the marriage licence. It is a cultural seal marking a rite of passage in their life, from single to married status. Yet in a typical wedding commercially arranged by the agency, the conjugal rite is often downgraded from what in other circumstances would be a three-day celebration to a night at a hotel. While a feast is organized with the presence of the bride's family members, because the wedding cost is included in the package paid by the bridegrooms, the agencies always try to minimize expenses by limiting the numbers of guests to about ten people, including the bride and the groom, in order to maximize their profits.

They [the agency] arranged a table for ten people, including me and my husband. When my parents, sisters and brothers, nephews and nieces arrived at the hotel, it turned out that there are eleven people. So, one person could not sit at the table. They did not even ask the hotel manager to add an extra seat for her... (A CATM wife from Hau Giang, interviewed in Taichung, Taiwan.)

Some women reported that no wedding was held for them and a few others said that they were not allowed to invite any family members to the wedding, which was just a dinner with their husbands. For still others, the agencies organized one joint wedding event for several couples, all in one place and at the same time. For the brides, clearly these weddings are sad memories as they are culturally improper and personally devalued.

Mass media in Vietnam sometimes describe transnational marriage as a sort of daughter sale by parents. In this research, there is not a single case in which parents have a voice in the price of the bride. At the wedding, the brides are provided with jewellery by the agency, such as a wedding ring, a necklace, and earrings, befitting Vietnamese wedding customs. Their earrings, brought by the agencies, were always 
the cheapest possible. Several women said that the weight of all the jewellery combined was less than one 'Chi ${ }^{14}$ slightly above US\$IOO at the time of the interviews. The wedding is also the time for the grooms to give their parents-in-law some money, called bride price - which can be kept by the bride's family.

Interviews with the brides show the level of bride price ranges from US\$100 to US\$I,000. Often the agencies deduct a part of the bride price agreed to by the groom. In one extreme case, the agency did not give the bride's family any share of the amount (US\$I,200) agreed as the bride price. In another case, the agency only handed over US\$300 of the agreed US\$I,000. But none of the brides dared to ask for money back out of the fear that the agencies would make some troubles and cancel the marriage. They were led to understand that the deductions were to cover paperwork costs for the marriage licence or to obtain certification of marital status from the local authorities. The requirement for such paperwork also provides opportunities for the local authority to make money from the women's families by requesting material contributions. ${ }^{15}$ Hence, it can be seen that all actors through their practices have contributed to the commodification of transnational marriage.

Finally, ICT also contributes to the socialization of practices in transnational marriage, and to the production of new desires for 'modernity'. The increasing socialization among many Vietnamese women regarding the prospects of marrying a foreigner is both the cause and the outcome of the prevalence of transnational marriage. This is in direct contrast with the tradition in which marriage preference was for local partners, often from the same community. Particularly for women, the power holders in the state and the family used to see marriage with a foreigner as socially and politically undesirable.

As Vietnam becomes more integrated into the regional and global economy, a proliferation of transnational spaces for networking and exchange has emerged and marriage with foreigners is becoming increasingly accepted, even desirable, not only on economic grounds but also culturally. Young people cannot help but notice the proliferation of Korean and Taiwanese businesses, from large enterprises to small home-based businesses, and they have developed

14 One 'Chi' of gold is equivalent to 3.75 grams.

15 A father of one CATM wife in the study, for example, had to give up a plot of land to the commune's People's Committee, which was then used to build a communal cultural centre. widespread interests in products with Korean and Taiwanese brands, including Korean television movies and soap operas, fashion, cosmetics, and cuisine.

It should be stressed, however, that for the majority of the Vietnamese women interviewed, the economic considerations of a married life abroad is the major drive in their marriage decision. Beliefs in the prospect of a better economic situation, the possibility of supporting the family left behind, and of securing a better future for their possible children are all associated with such marriages. These beliefs are reflected in particular in one case in our study of a woman who herself borrowed from relatives 35 million Dong (about US $\$ 2,000$ ) to pay for the agency that introduced her to her present Taiwanese husband.

In some communities, transnational border marriage has become a central part of people's lives. The media have carried reports about the so-called 'Taiwanese island', i.e. a commune in the southern province of Can Tho where most of the single women married Taiwanese men, and researchers have confirmed this (Graeme/Nguyen 2007). A similar situation was found during our fieldwork in the northern province of Hai Phong, where young women deliberately 'save' themselves for foreign husbands, leaving local men out of the marriage question, and paying no interest to finding employment or doing business, expecting their economic future to be guaranteed by marriage to a Taiwanese or Korean husband. Clearly, this creates a marriage squeeze in these local communities, as well as having other social consequences. In many other communes across the country, the visible wealth of households having members working as migrant labourers, or marrying Taiwanese and Korean men, has shaped the way local people think of making a better life.

The role of social networks in facilitating cross-border marriage has increasingly become important, as the number of Vietnamese wives is growing quickly. Our findings suggest that currently some ten per cent of transnational marriages are conducted not through the service of the agencies but though introduction by other wives who live abroad, whether friends, relatives, or from the same communities. Reliance on social networks provides some confidence and trust that the wife can get a good husband and receive support from people who have entered transnational marriage earlier.

In sum, there is a mutual interplay between market forces and structural conditions that are driving transnational marriages between Vietnamese women and men from Taiwan and South Korea. Within this, the circulation of symbolic and material values through ICT and social networks also contribute to producing 
institutional practices that form an emergent system of trans-patriarchy in which Vietnamese women actively participate.

\subsection{Reproductive Bargaining in the Host Societies: Social Positioning, Self-Consciousness, and Dignity}

As a hegemonic framework, the Confucian familybased welfare system in the host countries proscribes and prescribes the conduct of the foreign wives. Within it, family members negotiate from different structural positions of power, each being endowed with different resources (material, symbolic, and organizational) and interpret rules in certain ways. Within the Confucian family welfare model, the role of a daughter-in-law is confined to biological reproduction (sustaining the in-law family lineage by having children, particularly sons) and care provisioning to enhance the welfare of the entire family. The Vietnamese CATM wife is expected by her husband and inlaws to fulfil these norms to show her 'quality' as a daughter-in-law, wife, and mother. As Wang (2007) has shown, this cultural hegemony has never been achieved fully but remains negotiated and contested. ${ }^{16}$

Though nominally a married woman in Vietnam is considered 'the daughter of the other family', in practice for many Vietnamese communities marriage does not change the status of a woman as a member of her birth family. As such, and within her own means, the married woman is expected to share some responsibilities with her siblings in providing care for her parents, however limited. In Taiwan and South Korea, a daughter-in-law is considered by a husband's family as its own and will object to her sending remittances to her birth family (Tang/Belanger/Wang 20II). In the process of bargaining over the long-term provision of reproductive services, successful wives draw on cultural commonalities to facilitate consensus and acceptance, easing adaptation and eventual mutual trust and tolerance.

Our research findings reveal different moments in which issues of contestation and compromise over

16 Wang shows that wives can use various strategies to resist or evade control by the family of their husbands. These may include the threat to return home and never come back, or frequenting public spaces such as Vietnamese restaurants, shops, and venues where they take Mandarin language courses to meet and share information. Some use a more expensive pre-paid card for their mobile phones to evade the surveillance of the family. the meanings of reproduction arise, particularly regarding which aspect of reproduction is being negotiated, whose family counts, and which ties should be prioritized. The reproductive bargaining process tends to be centred on the meanings of the family and the boundaries of interpretation of the sense of belonging, which has implications for defining the work of a woman and her control over her sexuality and mobility. Her failure or success in altering the boundaries of the bargain can be expressed in three moments: exit, loyalty, and voice. Exit becomes a reality when bargaining fails. Loyalty means full or partial compliance with the expected norms required for a wife, mother, and daughter-in-law in the host country before gaining the recognition of the rights of a person. This recognition in turn enables the wife to achieve some of her own objectives through voice and influence.

The initial social positioning appears favourable to the CATM wives, given the immense competition for waged employment in rural Vietnam. They imagined that transnational marriage would place them in an environment that would change their lives. Many turned away from their own families in crisis but remain loyal to some members, because of what they refer to as their 'moral debt'. All the women who participated in this study wanted to 'graduate' from a life of subsistence peasantry to become urban women with successful, non-agricultural jobs.

Some want to turn away from domestic violence and men they do not respect:

Many [Vietnamese] men now are using drugs, gambling, drinking, so I will not be happy to marry them. They look down on their wives, called them with bad words. (A CATM wife from Ho Chi Minh City, interviewed in Taipei, Taiwan.)

My father often got drunk. He never cared about us. My mother would not dare to do anything against his will, as he would beat her... So I thought I did not want to have my own family like that. Getting married with a foreign husband is ten times better. (A CATM wife from Can Tho, interviewed in Dangjin, South Korea.)

Others see marrying overseas as an opportunity to make a living in a better environment:

I know that it is not easy at all to have a happy marriage. Men in Vietnam and here [Taiwan] can be the same. But coming here I can make more money. At home we do not have enough to eat. (A CATM wife from Long An, interviewed in Taipei, Taiwan.)

I came here because I wanted to help my family. My parents are very poor, so the neighbours look down on us... Even our relatives do not want us to visit them because they are afraid that we will borrow money from them. 
(A CATM wife from Can Tho, interviewed in Taichung, Taiwan.)

Some express the desire for mobility

I got married with my husband not because I need his money. I want to get out of Vietnam to see the world. At home I had to do farming all the time. (A CATM wife from Ho Chi Minh City, interviewed in Hongseong, South Korea.)

In their image of 'modernity' a husband means someone with an urban background and a stable job, respecting his wife, loving his children, and affording the family a comfortable life. Because "South Korea is a 'modern' country, its people must be 'modern' too", opined one woman who decided to return home. In her words:

I returned home because my life with him brought no happiness, I had no future. I stayed at home all the time... having no one around, no friend. My husband only came home late at night, drinking. (A CATM wife returnee from South Korea, interviewed in Hai Phong, Thuy Nguyen district.)

In most cases, the image of the 'modern husband' comes into direct conflict with reality. This conflict is particularly acute when it relates to their desire to support their birth families by engaging in paid work. This, in the communities where their husbands belong, goes against the expected norms for a married woman.

We [the husband and his parents] want Thuy to stay home and take care of our family and our children... I make enough money for the family so there is no need for her to work.... Taking care of our children is more important. (A Taiwanese husband interviewed in Taichung, Taiwan.)

My parents are very old. My mother could not walk and needs help in moving. I am very busy at the factory and cannot return home early to take care of my parents. Sometimes I have to work until Io p.m. because my boss wants me to work late. (A Taiwanese husband interviewed in Taipei, Taiwan.)

All CATM wives in our study, whether in Taiwan or South Korea, are responsible for domestic work in their new families. For many wives, this situation can even be worse than what they themselves experienced or observed in Vietnam, particularly for those who came from the north, where society encourages daughters-in-law to work outside the home, and where husbands share some of the burden of domestic work.

Generally, of the ten [wives] come here seven of them stay at home, taking care of children, cooking. Very few of them work. ... In Vietnam, both husbands and wives work and care for parents-in-law like that. Here staying home to do domestic work is important to Korean people. (A CATM wife from Hau Giang, interviewed in Dangjin, South Korea.)

A clash of perspective about 'work' was also noted:

In Vietnam people will say a wife staying at home is lazy [emphasis added]. But here even if wives have college education or employment, they will stay home if they have children. Some [wives] work, but most stay home. (A CATM wife from Ho Chi Minh City, interviewed in Hongseong, South Korea.)

In a few cases, the wives were physically locked inside the home, or had their passport confiscated by their in-law family. As narratives from all sides indicated, this confinement stems mainly from fear on the part of the husbands' families of a loss of 'investment', since large amounts of money had been paid to obtain the wives. There was also a fear of 'losing face' with neighbours, when the wives would frequent their 'ethnic' networks, acquiring 'bad attitudes and conduct' from other CATM wives, or being suspected of having love affairs with other men, especially Vietnamese men who were migrant workers. Domestic violence was reported by women with alcoholic husbands, or husbands who lost employment. Domestic violence also arose through difficulties in communication due to insufficient knowledge of the local language, over-insistence on having their own income, or spending time with friends and compromising domestic duties and care provision. Expressing discontent with their triple role as wife, mother, and daughter-inlaw can lead to exit from the marriage through divorce or escape, and sometimes to a return forced by their husbands.

In the meantime, all the wives learn to prepare family meals as the members prefer them; they cannot follow their own dietary habits, except in isolation.

Here they do not use fish sauce in cooking. They said it is stinky. Instead they use soy sauce. (A CATM wife from Hai Phong, interviewed in Taoyuan, Taiwan.)

This dietary alienation enhances feelings of isolation and homesickness, further compounded by the inability to communicate in the local language, which in turn prevents them from finding paid work outside the home and thus sending remittances to their birth families.

No matter which country you are in, life gets complicated if you do not have a job. We must work. Without a job, people will look down on us, no matter how good the material conditions we are enjoying are. (A CATM wife from Bac Lieu, interviewed in Taichung, Taiwan.) 
This perspective can come into conflict with the expectations of in-laws.

The reason why many wives are having difficulties is mostly because they too often think of work to earn money and send to their families.... The parents-in-law think that their daughter-in-law should care for their family and their son, but she only cares about making money to send to her parents. (A CATM wife from Hau Giang, interviewed in Taipei.)

For all the wives the first year was the most difficult, as they became aware of their social positioning as foreign wives brought into the family through commercially arranged transnational marriage. Placed in a hierarchy of social relations defined by local cultural norms as well as their emotional, social, and physical isolation and linguistic constraints, their bargaining position depends on their awareness of the new context and ability to reposition themselves. Cases of successful bargaining show a common strategy that involves a step-by-step approach to 'winning the hearts and minds' of the husband and parents-in-law, particularly the mother-in-law.

A three-stage bargaining process was discerned. In the first stage, there is hardly any negotiation on tasks related to daily housework, sexual demands, and dietary habits. Differences in role expectations and interpretation of duties and obligation need to be overcome in order to demonstrate loyalty. In the second stage, usually after a few months of residence, the wives, having acquired sufficient experience, begin to understand their complex relationship in their in-law family, the rules and power relationships among members, and the expected roles that each family member should perform. All the women have tried to learn the language, with varying levels of success. While some still face difficulties, the wives' achievement in mastering language can be impressive:

At the beginning, I just knew how to say hello. I did not understand whatever my husband said. I cried a lot. Then I tried to learn the language myself. I have progressed fast. After six months, I understood everything people said. (A CATM wife from Vinh Long interviewed in Hongseong, South Korea.)

This process of learning the language and family rules helps them to adapt their behaviour to meet certain degrees of satisfaction from members of their in-law families. Once a sense of stability and confidence is established, the wives start to build up voice and status within their families. From here onwards, they could take certain stands, and began to argue about what was right or wrong regarding their conduct. In a number of extreme cases, quarrels with husbands and mothers-in-law did occur. Yet in most cases, the women try to avoid unnecessary conflict. Those who have learnt how to perform the expected triple roles of being wife, daughter-in-law, and mother to the satisfaction of in-laws can gain some respect and space for their agency.

I learnt how to cook good food the way my in-law mother likes. In Vietnam, I used fish sauce to cook. Now when I fry vegetables, I put soy sauce instead. I did what I observed from her. She likes it and complains less about many things I did when first coming here. (A CATM wife from Long Xuyen interviewed in Taoyuan, Taiwan.)

Adjusting to the dietary habits of in-laws appears to be a primary condition of gaining trust and stabilizing the domestic front, and a significant aspect of a bio-cultural aspect of reproduction. Gaining linguistic skills is necessary to influence the views of in-laws on the significance of paid work, as well as to establish positive social ties with neighbours and beyond. Gaining trust within the family also meant demonstrating that social networking with other foreign wives from the same ethnic groups could be positive in terms of providing mutual support mentally, socially, and economically. In several cases, paid work demonstrates to in-laws and neighbours their ability to use their own income to support their birth families, thus improving their status in the husband's family and in the neighbourhood.

They [the neighbours] asked 'how many times a year do you go home? How much money do you bring home each time?' I then replied 'this is my family's own business. It does not involve you.' (A CATM wife from Ho Chi Minh City, interviewed in Taichung, Taiwan.)

Knowledge of, and access to, legal services provided for foreigners, especially for foreign spouses, in South Korea and Taiwan helps the wives learn about immigration legislation and citizenship rights, as well as services available in the area of their residence (language and cultural education, shelters for victims of domestic violence, legal counselling). Although few actually used these services, knowledge of their availability enhances the confidence of the women in critical situations. Becoming a citizen in the husband's country is a shared aspiration for better protection of rights.

A few of the women interviewed have become successful businesswomen in the host society. The most impressive case that emerged in our research was a woman who started her life in Taiwan as an isolated CATM bride but became the owner of a large shop selling various merchandise and food to the local community in Taipei. She now runs an import business handling foods, clothes, and other items from $\mathrm{Vi}$ - 
etnam, catering for the Vietnamese community living nearby. Gains from this business enable her to make social and financial remittances to her siblings so that they can open businesses in Vietnam, as well as to ensure that her parents are well taken care of by a hired domestic worker.

Despite the contextual nature of the reproductive bargaining process at the household level, it can be observed that fair outcomes hinge on the ability of the CATM wives to recalibrate their imaginations in order to face the real structures of power into which they are placed and to find means and sources of local support to re-position themselves. A change in social positioning is central for them to find their own source of dignity as a person beyond and above the local cultural framing of 'womanhood'.

\subsection{Conclusion}

A unique feature of East Asian states is the inclination towards centralizing masculine power and idealizing society for the purpose of political and social stability. The rise of transnational marriages in conjunction with a demographic crisis has challenged such ideals, and reflects emerging contradictions in the transformation of social reproduction that raise new questions about gender and efficiency in this model of the economic miracle. From the perspective of Vietnam as a sending country, CATM reflects many changes in gender relations in production and reproduction, particularly in rural areas, which have spurred female outmigration in the last two decades, of which CATM is one form among many.

Transnational commercially arranged marriages between Taiwanese and South Korean men and Vietnamese women seem to manifest a triple complexity of masculinity embedded in the East Asian welfare regime, yet foiled by dominant discourses on the family and nation. At the first level, the prevalence of son preference and related practices manifest the historical dimension of masculine hegemonic power. The silent resistance by the new generations of more educated women, who no longer adhere fully to Confucian values, demonstrates the incompleteness of hegemonic power and how marriage and childbearing and -rearing remains an important arena of female resistance. At the second level, in the face of a near fertility collapse that threatens masculine hegemony as well as the model of East Asian capitalism, the state response in liberalizing choices in marriages boils down to the redefining of 'race' and 'ethnicity' and the embracing of cultural proximity as a pragmatic measure to help some families to preserve the threegeneration family structure and the Confucian gender order. While this may help address some dimensions of the reproductive crisis (human reproduction and intergenerational care), it postpones the question of the future viability of the family-based welfare model of East Asian capitalism. Responses from civil society to transnational marriages differ, depending on national political tendencies. South Korea is more inclined towards the model of multiculturalism as part of the nation-building effort (Lee 2008). There, transnational marriages involve partners from a wide range of countries beyond those sharing Confucian ethical features (Kim 20II). Taiwan adheres to the Confucian model but diversifies source countries to maintain its independence from China, linking transnational marriages with international relations.

At the third level, transnational masculinity through such marriages has to resolve the subtle difference between a patrifocal type of marriage under strict Confucian rules and a bifocal type prevalent in South-East Asian countries, including Vietnam. Maintaining family unity necessitates intra-family negotiation over rules and the conduct of wives towards the husband's family and their own. Yet the construction of their moral character at the inter-group level in the communities of the receiving countries as 'opportunist', and at the level of formal institutions in their native country as 'immoral' at worst and naive at best, displaces the real crisis of social reproduction. Transnational masculinity expressed through CATMs has many implications for social policy above and beyond the rights of women as wives, be they native or foreign. It calls for a renewal of feminist innovations in theorizing about social reproduction to capture its transnational implications. As transnational marriage migration concerns essentially the question of how sexuality and biological reproduction is valued and negotiated, and how the maintenance of daily life in one location is tied to the maintenance of relationships with members of the birth family left behind, analytical treatment of the relationship between structure and agency requires an approach capable of addressing the formation of multiple social borders (racial/ cultural, economic, and political) as structural constraints within which interaction based on subjective identities takes place. 


\section{References}

Aspalter, Christian, 2005: "The Welfare State in East Asia: An Ideal-Typical Welfare Regime", in: Journal of Societal and Social Policy, 4,I: I-20.

Aspalter, Christian, 2006: "The East Asian welfare model", in: International Journal of Social Welfare, I5: 290-30I.

Attane, Isabelle; Guilmoto, Christophe Z. (Eds.), 2007: Watering the neighbour's garden: The growing demographic female deficit in Asia (Paris: Committee for International Cooperation in National Research in Demography).

Bélanger, Daniele; Tran, Giang Linh, 20Iı: "The Impact of Transnational Migration on Gender and Marriage in Sending Communities of Vietnam", in: Current Sociology, 59,I: 59-77.

Bryceson, Deborah Fahy; Vuorela, Ulla, 2002: The Transnational Family: New European Frontiers and Global Networks (Oxford/New York: Berg).

Chiu, Stephen Wing-kai; Wong, Richard Ka-chung, 2009: A Literature Review on Family Policy in Four East Asian Countries (Hong Kong: The Chinese University of Hong Kong).

Clement, Wallace; Prus, Steven, 2004: "The Vocabulary of Gender and Work: Some Challenges and Insight from Comparative Research", unpublished paper presented at Gender and Work: Knowledge Production in Practice conference, October I-2, York University, Canada.

Constable, Nicole (Ed.), 2005: Cross-Border Marriages Gender and Mobility in Transnational Asia (Philadelphia, Penn.: University of Pennsylvania Press).

Constable, Nicole, 2009: "The Commodification of Intimacy: Marriage, Sex, and Reproductive Labor", in: Annual Review of Anthropology, 38: 49-64.

Dube, Leela, 1997: Women and kinship: comparative perspectives on gender in South and South-East Asia (Tokyo: United Nations University Press).

Faist, Thomas, 2000: The Volume and Dynamics of International Migration and Transnational Social Spaces (Oxford: Clarendon Press).

Gammeltoft, Tine, 1998: Women's Bodies, Women's Worries: Health and Family Planning in a Vietnamese Rural Commune (Surrey: Curzon).

Goodman, Roger; Peng, Ito, I996: "The East Asian Welfare State”, in: Esping-Andersen, Gøsta (Ed.) Welfare States in Transition (London: Sage).

Gottfried, Heidi, 2009: "Japan: The Reproductive Bargain and the Making of Precarious Employment," in: Vosko, Leah; Campbell, Iain; MacDonald, Martha (Eds.): Gender and the Contours of Precarious Employment (London: Routledge).

Graeme, Hugo; Nguyen, Thi Hong Xoan, 2007: "Marriage Migration between Vietnam and Taiwan: A View from Vietnam”, in: Attane, Isabelle; Guilmoto, Christophe Z. (Eds.): Watering the neighbour's garden: The growing demographic female deficit in Asia (Paris: Committee for International Cooperation in National Research in Demography).

Hearn, Jeff, 20IO: "Reflecting on men and social policy: Contemporary critical debates and implications for social policy”. Critical Social Policy, 30,2: 165-188.

Henry, Colette E., 2008: Entrepreneurship in the creative industries: an international perspective (Cheltenham: Edward Elgar).

Huang, Shirlena; Thang, Leng Leng; Toyota, Mika, 20I2: "Transnational Mobilities for Care: Rethinking the Dynamics of Care in Asia”, in: Global Networks, I2,2: I29-I34.

Hugo, Graeme, 2004: "International Migration in Southeast Asia since World War II", in: Ananta, Aris; Arifin, Evi Nurvidya (Eds.): International Migration in Southeast Asia (Singapore: Institute of Southeast Asian Studies).

IOM (International Organization for Migration), 2008: Situation Report on International Migration in East and South-East Asia (Bangkok: IOM).

Jones, Catherine, I990: "Hong Kong, Singapore, South Korea and Taiwan: Oikonomic welfare states”, in: Government and Opposition, 25,4: 446-462.

Jones, Gavin; Shen, Hsiu-Hua, 2008: "International marriage in East and Southeast Asia: trends and research emphases", in: Citizenship Studies, I2,I: 9-25.

Kabeer, Naila, 2004: Re-visioning "the social": towards a citizen-centred social policy for the poor in poor countries. Working Paper 19I (Brighton, Sussex: Institute of Development Studies).

Katz, Cindi, 20II: "Vagabond Capitalism and the Necessity of Social Reproduction", in: Antipode, 33,4:709-728.

Khuat, Hong T.; Bui, Huong T.; Le, Duong B., 2009: To be Good at Public and Domestic Work, I need Three Heads and Six Hands (Kyoto: International Research Center for Japanese Studies).

Kim, Young Jeong, 20II: "Daughters-in-law in Korea": Policies and Discourse on Migration in South Korea, Working paper No. 92 (Oxford: University of Oxford, Centre on Migration, Policy and Society).

Kim, Soon-yang; Shin, Yeong-gyun, 2008: "Immigrant brides in the Korean rural farming sector: social exclusion and policy response", in: Korea Observer, 39,I: I-35.

Kojima, Yu, 200I: "In the business of cultural reproduction: Theoretical implications of the mail-order bride phenomenon”, in: Women's Studies International Forum, 24,2: 199-210.

Lan, Pei-Chia, 2008: "Migrant Women's Bodies as Boundary Markers: Reproductive Crisis and Sexual Control in the Ethnic Frontiers of Taiwan", in: Signs-Journal of Women, Cultural and Society, 33,4: 833-86I.

Le, Thi, 2004: Gia dinh, Phu nu Viet Nam voi Dan so, Van hoa va su Phat trien ben vung (Hanoi: Social Sciences Publishing House).

Lee, Hye-Kyung, 2005: "Marriage Migration to South Korea: Issues, Problems and Responses, in: Korean Journal of Population Studies, 28,I:73-106. 
Lee, Hye-Kyung, 2008: "International Marriage and the State in South Korea: Focusing on Governmental Policy”, in: Citizenship Studies, I2,I: I07-I23.

Lee, Ming-Yu, 200I: What is the Impact of a Confucian Welfare Regime Upon the Lone Mothers in Taiwan? Unpublished PhD Thesis, University of Nottingham.

Lee, Yih-Jiunn; Ku, Yuen-wen, 2007: "East Asian Welfare Regimes: Testing the Hypothesis of the Developmental Welfare State", in: Social Policy and Administration, 4I,2: I97-2I2.

Lu, Melody Chia-Wen, 2007: "Transnational marriage in Asia”, International Institute of Asian Studies Newsletter, No. 45: 3 .

Mai, Thi Thu; Le, Thi Nham Tuyet, 1978: Women in Vietnam (Hanoi: Foreign Language Publishing House).

Marginson, Simon; Kaur, Sarjit; Sawir, Erlenawati (Eds.), 20II: Higher Education in the Asia-Pacific: Strategic Responses to Globalization (Berlin: Springer).

Mark, Grace C. L., 2007: "Women in East Asian Education and Society: Whose Gains in Whose Perspectives?" Springer International Handbooks of Education, 19,2: 343-358.

Nguyen, Thi Hai Yen; Truong, Thanh-Dam; Resurreccion, Babette, 2008: "Gender, Class and Nation in a Transnational Community: Practices of Identity among Undocumented Migrant Workers from Vietnam in Bangkok", in: Gender Technology and Development I2,3: 365-388,

Nguyen, Xoan; Tran Xuyen, 2009: "Vietnamese-Taiwanese Marriages", in: Yang, Wen-Shan; Lu, Melody Chia-Wen (Eds): Asian Cross-border Marriage Migration: Demographic Patterns and Social Issues (Amsterdam: Amsterdam University Press).

Pearson, Ruth, 1997: "Renegotiating the Reproductive Bargain: Gender Analysis of Economic Transition in Cuba in the I990s", in: Development and Change, 28,4: 67I705 .

Peng, Ito, 2008: Political and Social Economy of Care: South Korea, paper presented at Presented at the ISA RCi9 Conference, University of Stockholm, Sweden, 47 September 2008.

Piper, Nicola, 2003: "Wife or Worker? Marriage and Crossborder Migration in Contemporary Japan", in: International Journal of Population Geography, 9,6: 457-469.

Rallu, Jean Louis 2006: "Female deficit and the marriage market in Korea", in: Demographic Research, 15,3: 5I60.

Schuler, Sidney Ruth; Anh, Hoang Tu; Ha, Vu Song; Minh, Tran Hung; Mai, Bui Thi Thanh; Thien, Pham Vu, 2006: "Constructions of gender in Vietnam: In pursuit of the 'Three Criteria”, in: Culture, Health and Sexuality, 8,5, 383-394.

Stiglitz, Joseph E.; Yusuf, Shahid, 200I: Rethinking the East Asia miracle (Washington, D.C.: World Bank - New York: Oxford University Press).

Suksomboon, Panitee, 2008: "Remittances and 'Social Remittances': Their Impact on Livelihoods of Thai Women in the Netherlands and Non-migrants in Thai- land”, in: Gender, Technology and Development, I2,3: $46 \mathrm{I}-482$.

Sung, Sirin, 2003: "Women Reconciling Paid and Unpaid Work in A Confucian Welfare State: The Case of South Korea”, in: Social Policy \& Administration, 34,4: 342360.

Suzuki, Nobue (2003) “Transgressing 'victims': Reading Narratives of 'Filipina Brides' in Japan”, in: Critical Asian Studies, 35,3: 399-420.

Ta, van Tai, I982: "Vietnam's Code of the Lê Dynasty (I428 I788)", in: The American Journal of Comparative Law, 30,3: 523-554.

Tang, Wen-hui Anna; Belanger, Daniele; Wang, Hong-Zen, 20II: Politics of Negotiation Between Vietnamese Wives and Taiwanese Husbands, in: Tak-Wing Ngo (ed.), Politics of Difference in Taiwan, (London: Routledge).

Toyota, Mika, 2008: "Editorial introduction: international marriage, rights and the state in East and Southeast Asia”, in: Citizenship Studies, I2,I: I-7.

Truong, Thanh-Dam, 1997: "Uncertain Horizon: The Women's Question in Vietnam Revisited”, in: Beckman, Bjorn; Hansson, Eva; Roman, Lisa (Eds.): Vietnam Reform and Transformation (Stockholm: Stockholm University).

Truong, Thanh-Dam, 1999: "The Underbelly of the Tiger: Gender and the Demystification of the Asian Miracle", in: Review of International Political Economy, 6,2: 133I65.

Truong, Thanh-Dam, 2006: "From State Duty to Women's Virtue: Care under Liberalisation in Vietnam", in: Truong, Thanh-Dam; Wieringa, Saskia.E.; Chhachhi, Amrita (Eds.): Engendering Human Security: Feminist Perspectives (London: Zed Press - New Delhi: Women Unlimited - Basingstoke: Palgrave Macmillan).

Truong, Thi Kim Chuyen; Scott, Stephanie, 2004: "Behind the Numbers: Social Mobility, Regional Disparities, and the New Trajectories of Development in Rural Vietnam”, in: Taylor, Philip (Ed.), Social Inequality in Vietnam and the Challenges to Reform (Singapore: Institute of Southeast Asian Studies)

Vijverberg, Wim; Haughton, Jonathan, 2004: "Household Enterprises in Vietnam: Survival, Growth, and Living Standards", in: Dollar, David; Glewwe, Paul (Eds.), Economic Growth, Poverty and Household Welfare: Policy Lessons from Vietnam (Washington, DC: The World Bank).

Wade, Robert, 2003: Governing the Market: Economic Theory and the Role of Government in East Asian Industrialization (Princeton, NJ: Princeton University Press)

Wang, Hong-Zen, 200I: "Social Stratification, Vietnamese Partners Migration, and the Taiwanese Labor Market", in: Taiwan: A Radical Quarterly in Social Studies, 4I: 99-I27.

Wang, Hong-zen; Chang, Shu-ming, 2002: "The Commodification of International Marriages: Cross-border Mar- 
riage Business in Taiwan and Viet Nam”, in: International Migration, 40,6: 93-II6.

Wang, Hong-zen, 2007: "Hidden Spaces of Resistance of the Subordinated: Case Studies from Vietnamese Female Migrant Partners in Taiwan”, in: International Migration Review, 4I, 3:706-727.

Wang, Hong-zen, 2010: "Gendered transnationalism from below: Capital, woman and family in Taiwan-Vietnam's cross-border marriages", in: Heikkilä, Elli K.; Yeoh, Brenda S. A. (Eds.), International Marriages in the Time of Globalization, (Hauppauge NY: Nova Science Publishers).

Wang, Yi-Han, 20I0: “From 'Farming Daughters' to 'Virgin Brides' Representation of Vietnamese Immigrant Wives in Taiwan", in: Gender, Technology and Development, I4,2: 2I7-239.
Won, Soo-Yeon, 2007: "Institutionalised Powerlessness? The Reality of Women's Policy Units and their Gendered Dynamics in Korea”, in: Journal of Social Policy, 36: 26I-278.

Whitehead, Stephen M., 2002: Men and Masculinities: Key Themes and New Directions (Cambridge: Polity Press).

Yang, Wen-Shan; Lu, Melody Chia-Wen (Eds.), 20I0: Asian Cross-border Marriage Migration: Demographic Patterns and Social Issues (Amsterdam: Amsterdam University Press).

Yeates, Nicola, 20I2: "Global care chains: a state-of-the-art review and future directions in care transnationalization research”, in: Global Networks, I2,2: I35-I54.

Yuval-Davis, Nira, 1997: "Women and the biological reproduction of 'the nation", in: Women's Studies International Forum, I9,I-2: 17-24.

Open Access. This chapter is distributed under the terms of the Creative Commons Attribution Non-commercial License, which permits any noncommercial use, distribution, and reproduction in any medium, provided the original author(s) and source are credited. 


\title{
6 Masculinity at Work: Intersectionality and Identity Constructions of Migrant Domestic Workers in the Netherlands
}

\author{
Aster Georgo Haile ${ }^{1}$ and Karin Astrid Siegmann ${ }^{2}$
}

\begin{abstract}
$^{3}$
This chapter contributes to the emerging literature on men who do 'women's work'. It focuses on the 'feminine' occupation of domestic worker and on how male and female migrant workers balance their gender identities at the intersection of class, race, and immigration status. It addresses the related research gap in the Netherlands by focusing on the situation of migrant domestic workers from the Philippines with irregular status. From the perspective of hegemonic gender identities, male migrant domestic workers, too, are subjected to gender injustices. These injustices are rooted in the devaluation of everything coded as 'feminine', including their occupation. The resulting 'male femininities' are threatening male domestic workers' sense of self-worth and their societal recognition. This misrecognition adds to the exploitative economic circumstances that both female and male migrant domestic workers experience and has negative repercussions on male migrants' access to employment. Ironically, workers themselves contribute to reproducing these symbolic and material injustices and, hence, consolidate them. Redressing these injustices requires changes both in the economic structure and in society's ordering of status. When the demands for respect for domestic workers and for their labour rights are combined, this necessity is reflected in workers' national and international campaigns. They need to be complemented by national regulation that will protect all workers effectively, independent of the location of their work, their gender, their race, or their immigration status. Last but not least, given their crucial role in societal reproduction, domestic workers should be included in the categories of migrant workers who are welcome in European labour markets in redefined and relaxed transnational migration regimes.
\end{abstract}

Keywords: domestic work, gender hegemony, gender identity, gender justice, intersectionality, the Netherlands, the Philippines, migrants with irregular status.

\subsection{Introduction}

During the twentieth century, domestic work ${ }^{4}$ was seen as an anachronism in an industrial society. This occupation was assumed to vanish in the course of

1 Aster Georgo Haile, graduate student at the Africana Studies Department, University at Albany, State University of New York. She conducted the empirical research for this chapter in the context of her MA thesis at the International Institute of Social Studies (ISS) of Erasmus University Rotterdam, see Haile (20II).

2 Karin Astrid Siegmann, Senior Lecturer in Labour and Gender Economics, International Institute of Social Studies (ISS) of Erasmus University Rotterdam (corresponding author). modernization (King 2007: 48; Bartolomei, 20I0: 88). Yet even in the industrialized societies of Europe and North America, domestic work still has a significant role to play and is even increasing (ILO 20IO: 6). This

3 The authors are indebted to the women and men who shared their stories. Thoughtful comments and suggestions by two anonymous referees are gratefully acknowledged. They helped to significantly improve the chapter. All remaining errors are solely ours.

4 In spite of the heterogeneity of tasks performed by domestic workers - cleaning, looking after elderly people or children, guarding the house, driving children to school, gardening, cooking -, a feature common to all workers is that they work for a private household (Simonovsky/Luebker 20II: 2). 
growth in paid domestic labour has been debated as part of the commoditization and internationalization of social reproduction. The debate has raised questions regarding domestic workers' position in the labour market as well as the forms of injustice they face individually and collectively, particularly their effective access to social rights. The growth in paid domestic labour has also been shown to pose challenges to the gender identities of migrant domestic workers who are over-represented amongst those who fill the gap in reproductive work (e.g. Kilkey 20IO: I32-I33; Moya 2007; Sarti 2006: 23I). The literature on 'global care chains' has highlighted that, for many female migrant domestic workers, leaving behind their children undermines their ability to fulfil their idealized role as carers (Hochschild 2000; Lan 2003; Yeates 2004). This debate has ignored the situation of male migrants employed in domestic service (Kilkey 20IO: I28). An emerging strand of literature points out that men, too, struggle to combine their work in a feminized occupation with hegemonic masculinities (e.g. Bartolomei 20I0; Datta/McIlwaine/Herbert/Evans/ May/Wills 2009; Donaldson/Howson 2009; Herbert 2008). Yet the asymmetrical relationship of hegemonic masculinity and femininity has often dropped out of focus in studies on gender identity (Connell/ Messerschmidt 2005: 848), including those concentrating on domestic workers. By and large, they have focused either on female or - rarely - male gender identities. This relationship is crucial, though, for analysing the reproduction of gender inequalities as a process that intersects with other systems of discrimination.

This chapter explores the related experience of Filipino men and Filipina women ${ }^{5}$ with irregular immigration status ${ }^{6}$ who engage in domestic work in the Netherlands. Research on migrant domestic workers from the Philippines has focused on women (e.g. Asis/Huang/Yeoh 2004; Chang/Ling 2000; Hochschild 2000; Parreñas 2005). Far less work has been done on the experiences of their male colleagues, despite the fact that they form a significant group amongst migrant domestic workers in various European countries (e.g. Sarti 20I0: 29-30). While the situ-

5 In the following, the adjective 'Filipina' is employed to refer to women from the Philippines, while 'Filipino' denotes men from the same country of origin.

6 Following UNESCO (2008: 15), "persons with irregular immigration status" refers to persons "entering, travelling through or residing in a country without the necessary documents or permits". ation of migrant domestic workers in other European countries has been addressed in detailed studies (e.g. León 20IO; Lutz 2008; Sarti 20IO), little research has covered the situation in the Netherlands. The few existing studies largely take the perspective of employers (de Ruijter 2004; de Ruijter/van der Lippe 2009) or focus on the situation of female domestic workers (van Dijken 2002; Koo 20II; Marchetti 2005, 2010). ${ }^{7}$

The present chapter addresses two questions, namely: How do Filipino domestic workers in the Netherlands balance their sense of masculinity with doing work that is widely perceived as 'feminine'? And how do male and female migrant domestic workers with irregular status from the Philippines express their gender identity at the intersection of different relations of power, such as class, race, and immigration status? The chapter contrasts the construction of, and challenges for, male Filipino migrant domestic workers' gender identity with those of their female colleagues, while acknowledging the refraction of the resulting gender injustices through the prism of other social divisions. The chapter adopts Fraser's (2007) approach to gender justice that sees the gendered character of the political economy as inextricably interwoven with the cultural order. A full understanding of gender justice hence becomes available only if material reward and social recognition are considered simultaneously (Fraser 2007: 25).

Section 6.2 outlines the concept of hegemonic gender identities and their intersection with other social divisions. The specific contours of this hegemony for migrant workers from the Philippines are then sketched out. Section 6.3 reviews previous research that has applied the concept of gender as intersectionality to the study of domestic workers' identity constructions. Section 6.4 presents the sociopolitical context of the Netherlands that forms the stage for the present investigation, while section 6.5 describes its research methodology. Findings related to gender identity constructions of Filipina/o migrant domestic workers in the Netherlands and their intersections with class, race, and (irregular) immigration status are presented and discussed in sections 6.6 and 6.7. They are placed in the context of gender justice in the concluding section.

7 Botman (2OII) and van Walsum (2OII) are exceptions here. 


\subsection{Hegemonic Gender Identities - Concept and Context}

Femininity and masculinity are cultural ideal types of how women and men ought to be. Yet idealized features of masculinity and femininity as complementary and hierarchical gender identities also provide a rationale for social relations at all levels, from the self to global relations of domination. It is through social practice, including both behaviour and discourse, that this hierarchical relationship organizes the material relations of social life and (re-)produces gender inequalities (Schippers 2007: 9I-92, I00). Hegemonic masculinity is hierarchical and complementary in that it legitimates men's dominance over women as a group (Schippers 2007: 87). While not necessarily normal in a statistical sense, it is normative, embodying the most honoured way of being a man (Connell/Messerschmidt 2005: 832). The concept of hegemonic masculinity intersects with class and race in its conflation with middle-class status and whiteness, turning gender practices of subordinated classes and/or racialethnic ${ }^{8}$ men into 'male femininities' as "the characteristics and practices that are culturally ascribed to women" (Schippers 2007: 96). They threaten the hierarchical relationship between masculinity and femininity. As a result, "they are both feminising and stigmatising to the men who embody them" (Schippers 2007: 96). Yet their intersection with class also implies that features of hegemonic masculinities may be adjusted to economic necessities. Gutmann (I996, quoted in Schippers 2007: 97) demonstrates the intersection of gender identity with class for notions of fathering in Mexico. There, for lower-class families, economic changes have necessitated men's participation in childcare, leading to ideological changes in the meanings of fatherhood and its centrality for defining manliness. Rather than being self-reproducing, Connell and Messerschmidt (2005: 844) stress that hegemonic masculinity requires the policing of men as well as the exclusion or discrediting of women. Yet women's practices that comply with and hence reproduce patriarchy, enacting the qualities bundled in the concept of hegemonic femininity (Schippers 2007: 94), are central to many of the processes that construct masculinities, for instance as wives and as work-

8 Following Nakano Glenn (1992: 41), Duffy (2007: 333) employs this term to refer to "groups that have been socially constructed and constituted as racially as well as culturally distinct from European Americans”. ers in the gender division of labour (Connell/Messerschmidt 2005: 848).

In the contemporary Philippines, from which this study's respondents originate, hegemonic masculinity of urban middle-class men refers to a breadwinner father, while the ideal femininity relates to a caring, nurturing mother. Women can have jobs, but not careers, because of the constraint of domestic responsibilities (Medina 200I, quoted in Parreñas 2005: 33I). Gender identities are closely related to the ideal of the nuclear, heterosexual family as the social institution in the Philippines commanding the most loyalty, sacrifice, and affection (Asis/Huang/Yeoh 2004: 202). Explained as one of the consequences of Spanish and US colonization of the Philippines, these ideals form the background for the emergence of the 'woman family hero'. She is a construct that depicts the female migrant who makes sacrifices and dramatic choices in order to take responsibility for maintaining and improving her family's lifestyle as well as contributing to her country's economy (Marchetti 2005: 35).

\subsection{Domestic Work and the Production of Migrant Identities}

Historically, a high proportion of migrant workers has characterized domestic service (Moya 2007). During the last three decades, paid domestic work has emerged as an often unique employment opportunity for transnational migrant women in most industrialized countries (Marchetti 20IO: I22; Sarti 20IO: 25). The emergence of such 'global care chains' has been attributed, amongst other reasons, to the lack of attention paid to care policy in industrialized countries, which catalyses the demand for private solutions (ILO 20I0: 9). Sarti (20I0: 25) summarizes crucial demand factors when she writes that: "[ $t]$ hanks to immigrants, the supply of staff has become cheap and abundant".

Despite the economic significance of the occupation, domestic work has often not been recognized as real work and hence has been undervalued and poorly regulated (ILO 20IO; Luebker/Simonovsky/Oelz 20II; Oelz 20II). This lack of recognition and reward has been explained by reference to gender constructions of the occupation. It has frequently been perceived as an extension of unpaid female domestic responsibilities in the home (King 2007: 47; Ray 2000: 693). For Italy, Sarti (20I0: 24) shows that the popularity of women as servants par excellence during the first half of the twentieth century proceeded more or less in step with the emergence of the models of the house- 
wife and the breadwinner as idealized female and male gender identities. This gender-typing made it difficult for male domestic workers to live up to ideals of hegemonic masculinity, but also made it difficult for them to access employment. Similarly, male migrant domestic workers in the Netherlands interviewed by van Walsum (20II: 153) all experienced difficulties finding employment, unless they had been brought into the business as their wives' assistants. Acceptance of their job is facilitated by their lack of alternatives in the labour market. For male migrants in Australia, Donaldson and Howson (2009: 210) point out that the assumption that their new job is "for the betterment of their families" is one way to justify and accept the change in their lives. The choosing of indignities and difficulties for the sake of the family gives meaning to the paid work that men undertake: "There is honour in self-sacrifice for the family" (Donaldson/ Howson 2009: 2I2). This is also reflected in findings on male domestic workers in Calcutta (Ray 2000: 713). Besides relating their work to the masculine quality of breadwinning, other ideal constructions of masculinity that male domestic workers associate with their work include responsible fatherhood and physical strength. This enables them to reduce the tensions they experience in doing 'women's work' and that are caused by their work in the private sphere.

In addition to the gender connotations of the occupation itself, its location in the private sphere is gendered, too. Professional work and politics are ascribed to the public sphere and they become a male domain, while reproductive labour in the private sphere is classified as female (Lutz 2002: 96). Men involved in migrant domestic work challenge this gendered divide. It is also the location of their workplace in the private sphere that raises the issue of masculinity for domestic workers, rather than their work alone.

Race is another social division that has been shown to be an important aspect of the production of domestic workers' identity. Nakano Glenn (1992) demonstrates for several regions of the United States that, "despite the large-scale historical transformation of paid reproductive labour from a model of 'servitude' to one of 'service work', the relegation of the dirty work to racial-ethnic women has remained remarkably consistent" (Duffy 2007: 316). Bartolomei (2010: 99) describes the complex intersections between gender and race in the employer-employee relationship. A Burkinabé male domestic worker she interviewed found it very challenging to work for a female black employer as "to obey a woman can be re- ally degrading for a black man". This challenge is absent when working for white people from whom he is culturally distant. The advantages of the invisibility of one's identity, in that it helps to avoid humiliation, is expressed by a male domestic worker who comes from a very respected family: "I prefer to work for white people who know neither my past nor my family".

The push towards racialized occupational niches in the host country's labour market, such as domestic work, for many migrant workers, male as well as female, entails the experience of deskilling when they take up work below their professional qualification and previous experience. Notions of work and occupation are critically important in the construction of gender identities and, given men's dominant perception as breadwinners, especially of hegemonic masculinities (Datta/Mcllwaine/Herbert/Evans/May/Wills 2009: 865; Lupton 2000: S34). Donaldson/Howson (2009: 2II) point out that, as a result, performing work beneath their skill levels has a significant effect on migrants' sense of manhood. In addition, deskilling has negative material consequences, given the precarious and badly paid nature of the jobs open to migrants in rich countries. For these reasons, their ability to effectively perform their role as their families' breadwinner is often deeply compromised.

\subsection{Contextualising Migrant Domestic Workers' Experiences in the Netherlands}

Migrant domestic workers to the Netherlands enter a country with a long history of immigration (van den Bergh 2006: 5). The first-generation foreign population of the Netherlands totals about I.7 million, about a tenth of the Dutch population (Statistics Netherlands 20II). In 20IO, the total population of migrants from the Philippines was 19,658, of whom an estimated I,200 had irregular status (Commission on Filipino Overseas 20I0). In recent years, the country has transformed its migration regime from generous to more restrictive policies (van den Bergh 2006: 5). The question of migrants' integration into Dutch society had been for a long time easily dismissed, based on the belief that the Netherlands offered a successful model of 'multiculturalism' and 'tolerance', where racism and ethnic discrimination did not exist. Today, however, the tolerance that Dutch people considered a positive quality inherited from their past seems to stand on shaky ground (Marchetti 20IO: 55). Based on, amongst other reasons, European Union direc- 
tives (Merlino/Parkin 20II: 7), the 20I0-I2 Rutte cabinet intended to make irregular stay in the country a criminal offence, an initiative that has polarized the Dutch society.

Many people who participate in the paid labour market in the Netherlands employ domestic workers in their houses. The comparatively high labour market participation of Dutch women since the early I970s is an important determining factor here, even if it has been accompanied by a high ratio of part-time working (de Ruijter/van der Lippe 2009: IO-II). In 2004, this resulted in I.2 million ${ }^{9}$ Dutch households hiring domestic workers (Nes/van Gravesteijn-Ligthelm/van den Boom 2004: v). Especially in the larger Dutch cities, workers providing domestic services are almost all migrants, many of them with irregular immigration status (van Walsum 20II: I43). Despite the sizeable demand, domestic work has not provided a valid entry route to the Netherlands for international migrants (Botman 20II: 55; Lutz 2002: 93). For migrants with irregular status, the location of the occupation in the private sphere may offer a distinct advantage in terms of avoiding state surveillance (Kilkey 20IO: I33), a logic that has been supported for the Netherlands (van der Leun/Kloosterman 2006: 66-67; van Walsum 20II: 155 ). Yet the private location of their work does not only offer refuge, but also presents risks. Live-in migrants in the Netherlands - even when their status is regular - have been identified as the category of domestic workers most likely to be exploited (van Walsum 20II: 158).

For 2009, the number of migrants with irregular status residing in the Netherlands was estimated at a little less than I00,000 (van der Heijden/Cruyff/van Gils 20II: I6). They cannot contribute to the social security system because of their lack of a 'citizen service number' and their lack of a work permit. As a result, they are unable to legally access unemployment benefits, pensions, or health insurance (Abvakabo FNV 2008). Access to other basic necessities, such as decent housing and fair pay, are also affected. Moreover, trivial actions like boarding a tram or sending money home are associated with a high degree of anxiety giving that contact with the police or other controlling authorities can result in detention and deportation (van Walsum 20II: I54).

In this context of great vulnerability, this study investigates the question of how Filipina/o domestic

9 This figure excludes the demand for domestic services related to childcare. It represented another 683,000 households. workers with irregular immigration status in the Netherlands balance their gender identity with their occupation at the intersection of other, often marginalising, social divisions.

\subsection{Research Methodology}

In order to answer this question, empirical data were generated through semi-structured interviews and (participant) observation. The interviews focused on respondents' work experience, gender roles, and experiences as migrants with irregular status. All interviewees were domestic workers ${ }^{10}$ with irregular immigration status ${ }^{11}$ from the Philippines. Seven men and five women, aged between 38 and 58 years, were interviewed during the period of July to September 20 II. All respondents entered the Netherlands legally, i.e. equipped with valid work permits and/or tourist visas. Their employers included people of various nationalities who worked in different sectors of the Dutch economy, but mainly in government or diplomatic services. Snowball sampling was employed due to the respondents' irregular immigration status. It prevented them from easily disclosing their identity and from confidently trusting outsiders. Potential interviewees were therefore first approached through a gatekeeper. Another reason for snowballing was that there was no legal documentation which could serve as a sampling frame. Selecting respondents this way had as a drawback that the homogeneity of interviewees' backgrounds increased. As a result, interviewees were likely to be Catholic, married, recent migrants, from Manila, and relatively of the same age. Respondents' names were changed to ensure that they cannot be identified.

The following two sections are organized around the narratives of seven of the twelve informants who agreed for their interviews to be recorded. They included five men (Angelo, Marco, Micki, Rido, and Silvianos) and two women (Marie and Sifora). While not referred to directly, the five unrecorded interviews contributed significantly to our understanding.

10 Some respondents occasionally work in other types of jobs, such as construction, catering, or as an electrician. 11 One respondent, Rido, obtained a work permit shortly before the interview. 
Table 6.1: Profiles of selected respondents. Source: Compiled by the authors.

\begin{tabular}{|c|c|c|c|c|c|c|}
\hline Name $^{a)}$ & Age & Sex & Marital status & $\begin{array}{c}\text { Year of entry } \\
\text { to the NL }\end{array}$ & Type of visa & Previous occupation \\
\hline Angelo & 54 & male & married & 2006 & contract & business \\
\hline Marco & 43 & male & married & 2008 & tourist & security guard \\
\hline Marie & 39 & female & single & 2004 & tourist & unemployed \\
\hline Micki & 38 & male & married & 2004 & contract & electrician \\
\hline Rido & 46 & male & separated & 2008 & contract & cook \\
\hline Sifora & 46 & female & married & 2008 & tourist & business \\
\hline Silvianos & 46 & male & married & 2009 & tourist & college instructor \\
\hline
\end{tabular}

a) Names are changed in order to protect the respondents' identities.

\subsection{Balancing Migrant Domestic Work with Gender Identity}

This section focuses on how Filipino male domestic workers in the Netherlands reconcile their sense of masculinity with doing work that is widely perceived as feminine. It contrasts this balancing act with the experience of female colleagues.

Silvianos works six to twelve hours a day as a parttime domestic worker. He visits the households of his employers in The Hague, earning ten euros per hour, including five euros transport costs. His brother, who also works as a domestic worker, motivated him to come to the Netherlands. Silvianos explained that his brother's income as a domestic worker in the Netherlands was three times higher than his former salary as a college instructor in the Philippines. For him, this was a convincing reason to decide to overstay the duration of his tourist visa and to assume irregular immigration status after he had entered the Netherlands in November 2009. He thought that it was a good opportunity to earn more money so that he could invest in his family's future:

I could not save money with what I have been receiving in the Philippines, my brother bought a house [in the Philippines] in five years' time by doing domestic work here in the Netherlands (Silvianos).

According to him, in the community he had lived in and in Philippine society more generally, a man is responsible for generating income and covering the family's expenses, mirroring the features of hegemonic masculinity sketched above. The wife, in contrast, is responsible for the domestic chores and takes care of the children. The husband works outside, while the wife works in the private sphere. Silvianos saw the man as the one who steers the boat and takes the final decision in the family. The rigidity of these social expectations became clear when he noted that some unemployed men who stay back in the Philippines and take care of their own households while their wives work abroad were perceived "as isolated pieces" and as "something not good to people's opinion". He viewed the resulting financial incapability and unemployment as 'unmanly'. This mirrors findings from other studies of male migrants' gender identities (e.g. Donaldson/Howson 2009: 2II), in which incapability to fulfil the role of the provider in addition to doing a woman's work inside the household were considered aspects of failed masculinities.

Silvianos explained that he sends money to the Philippines every weekend in order to manage the family's budget and to live up to his family's expectations of him as a man. Fulfilling the role of the provider also legitimizes his role in taking relevant decisions. Information and communication technologies aid migrants like Silvianos to bridge the distance between them and their families in order to be involved in day-to-day family decisions. Taken together, being provider for and decision-maker in his family form crucial aspects of his masculine identity. However, it is his work in other people's households-something he earlier referred to as 'women's work' and as something that might diminish his manhood-that enables him to satisfy these expectations. Hence, paradoxically, he fulfils his masculine role of breadwinner by accepting jobs below the social status he used to have in his home country and that are associated with demeaning male femininities.

Angelo, a 54-year-old father of four children, came to the Netherlands with his wife to work as a butler. His sister-in-law who worked in a diplomat's residence recommended him. When their third employer treated them very unfairly, demanding long working 
hours for low pay, this affected the couple's physical and mental health. They decided to leave the employer's residence and assumed irregular immigration status. Asked whether he liked his job, Angelo responded:

I like it because I do not have choice. This is the only way I can have money to send to my children (Angelo).

For the same reason, he accepted unpaid overtime:

I do things for the sake of my children to keep my job, so, I do not mind or it does not matter how long I work (Angelo).

In the Philippines, he explained, even though he had a restaurant, he was not generating much income. Referring to that time, he noted:

You can buy food, dress. If you want to buy something else, it is hard. [...] If you have two sons in college, you cannot afford it, if I were in the Philippines (Angelo).

While his irregular immigration status limited his opportunities in the Dutch labour market to domestic work, this job enabled Angelo to send remittances and, in this way, play his manly role as a father.

In line with hegemonic femininities in the Philippines, the female domestic workers interviewed emphasized their roles as mothers and the related ideal of care-taking. They discursively reproduced this ideal by explaining that they are not happy about leaving at home their husbands, who are now responsible for taking care of their children. Forty-six-year-old Sifora was one of the women interviewed. Invited by a friend, she came to the Netherlands for the second time in 2008. After her one-month tourist visa expired, she became a resident with irregular immigration status and started to work in domestic service. She now works eight to ten hours a day with different employers. Sifora justified her decision to migrate as follows:

I came here for work and this does not mean I want to leave my family. It is because I need to help my unemployed husband. And at this time in the Philippines, we cannot handle life, everything is becoming expensive. So, I work here all days of the week except Sunday and I send my family money every month. Sunday is my day off and I spend the whole day talking with my children and the husband through Skype. My husband is a good person; he takes care of my children very well (Sifora).

As Angelo and Silvianos, Sifora migrated for economic reasons. As if to justify her husband's resulting involvement in housework, she made it explicit that, in their own household, they do not have a live-in domestic worker except someone who does the laundry and irons it. Sifora pays the bills, school fees, and all other expenses of her household in the Philippines. While, in actual terms, she is the family's provider, in the narration of her role, she carefully avoided defining herself as breadwinner. Her image of her role in the family that she narrated during the interview is merely supportive. It appears that this depiction as secondary income-earner and primary carer is congruent with hegemonic femininity in the Philippines. She expressed the responsibility for the care of her children by pointing out that she sacrifices her whole day off Skyping with her family as one way of bridging the spatial distance. In line with the feminine caring ideal, Sifora relates to her children as 'my' rather than 'our' children, even when talking about her husband's care for them. The societal belittling of housework reflected in Angelo's views is echoed in her way of describing her husband. Specifically, she relates to him as 'helpful', while he is actually running the household and taking care of their children. Her narration exemplifies women's co-responsibility in reproducing gender hierarchies amongst men (Connell/Messerschmidt 2005: 848), in a similar way to the Filipina migrants who mock their 'domesticated' husbands as 'houseband' or 'huswife' in Margold (I995, quoted in Lan 2003: 193). At the same time, Sifora seemed to protect her husband's image from being damaged by his (un)employment status. By acknowledging him as being 'helpful' and a 'good person', she defended his masculinity, countering prevailing social perceptions about 'domesticated' husbands. The fact that she points out the lack of a domestic worker in their home is probably intended to signal economic necessity. It implies a reference to intersections between gender and class, similar to the class-specific masculinity ideals described in Gutmann (I996, quoted in Schippers 2007: 97) that may reduce the damage housework does to her husband's conformity with hegemonic masculinity: because Sifora and her family's economic situation does not allow them to hire a domestic worker, her husband's involvement in housework and care is less degrading.

The way Sifora sees herself and her husband reflects ambiguity. On the one hand, the emphasis she puts on her husband's support in her household back in the Philippines helps to justify her own decision to migrate for work, hence leaving behind her responsibilities as homemaker and primary carer for him to take over. On the other hand, by praising his loyalty, she apparently attempts to compensate for the degrading effect of housework on her husband's masculinity. The stigma of the male femininity he has assumed may indirectly affect her social status due to 
the relational nature of hegemonic gender identities. Yet his work in their household makes him a 'good person', not a 'good man', possibly reflecting Sifora's internalization of masculine ideals and her implicit acknowledgement of the symbolic emasculation he experiences. These observations indicate that when lived experiences deviate from societal scripts, respondents seem uneasy to accept these incongruences. The discursive portrayal of her own, and her husband's, performance of gender is a way to bring a reality that deviates from accepted standards closer to societal ideals.

Another male respondent, Micki, a 38-year-old father of four, initially worked as a contract worker in a diplomat's residence. He lost his work permit when he left that employer because of the exploitative conditions he experienced in live-in domestic service. Micki explained that working as an electrician or cook, occupations that he refers to as 'good jobs' in contrast to domestic work, is what he likes to do. However, his irregular status prevented him from finding such work. He works nine to ten hours a day as a domestic worker. He found domestic service with a female employer a very difficult situation. When his boss was present he felt shy about cleaning the house:

You see, the woman is sitting there and I clean the house [laughs]. I was shy! How can a man clean? (Micki).

He added that, in that situation, he was hardly able to move, and, as a result, unable to clean during the given time. According to his own standards, by performing the feminine occupation of a domestic worker, he had ventured into what Schippers (2007: 96) denoted by male femininities, a stigmatising gender identity. The visibility of his work in the private sphere to his female employer augmented the humiliation as, paralleling the incident narrated in Bartolomei (20I0: 99), obeying a female employer turns conventional gender hierarchies upside down. Last but not least, the paralysis he experienced as a result also had financial implications as he could not finish his work on time. This possibly threatened the main justification for accepting the degrading occupation abroad, namely, to play his breadwinning role in a more financially successful manner. He expressed this justification, centring on his role as provider for his children, very clearly:

I do not want them to leave their country for work like me. I am sacrificing for them, I do not want my son or daughter to work in another family, I am doing it for them (Micki).
Similar to the experiences described by Ray (2000), he described his migration as a sacrifice for the sake of his family. Endurance of the difficulties associated with his situation as a migrant domestic worker with irregular status, such as the degrading entry into a feminized occupation, were depicted as part of that sacrifice and hence made acceptable. The heroism of this sacrifice probably enabled him to recover some of the masculinity threatened by the shift to a feminine occupation and the humiliation of serving a female employer.

In sum, this section has investigated how Filipina/ o migrants with irregular status in the Netherlands balance their gender identities with doing domestic work in an occupation widely perceived as 'feminine'. Based on earlier studies, it was assumed that this poses a challenge to male migrant workers' sense of masculinity in particular. The results reported and discussed above have shown that migrant domestic workers' constructions of their gender identity oscillate between their occupation threatening the expectations associated with their gender roles and contributing to fulfilling these expectations. Male and female respondents' respective ideals of masculinity and femininity are surprisingly homogeneous, enabling us to speak of hegemonic masculinities centring on heteronormative practices of breadwinning and fatherhood as provisioning and hegemonic femininities rooted in caring.

The associated normative expectations are challenging both for men and women. While women perceive their decision to leave their children as a possible betrayal of their role of care-taker, without seeing domestic work as a challenge to their feminine identity, men perceive the female-typed occupation as a threat to their sense of masculinity. Hence, for women it is their migratory status which is endangering the fulfilment of localized reproductive responsibilities. For men, in contrast, it is their employment in female-typed domestic work and, thus, the stigmatising male femininity that characterizes it that is experienced as a threat.

Filipina/o migrant domestic workers in the Netherlands have developed different strategies, actual and discursive, to balance these risks. Sending remittances to their families in the Philippines is the main actual strategy for successful performance of their gender roles. While materially identical, in an effort to discursively bridge the gap between their lived lives and ideal gender identities, the money transfer is presented as breadwinning by migrant men and constructed as mere support by women, enabling them to 
care for their children. Intensive communication with the children via modern technology is another way of bridging the space. This enables Filipina migrants to fulfil their motherly role, while their male colleagues underline their significance for their involvement in family decision-making. For female and male respondents, speaking about their livelihood as a sacrifice for their children's/family's sake is another way of compensating a threatened sense of gender identity. While studies on Filipinas' labour migration have underlined the offering aspect of their mobility as "martyr mothers, dutiful daughters or sacrificial sisters" (Asis/ Huang/Yeoh 2004: 200; see also Chang/Ling 2000: 39; Lan 2003: 196; Parreñas 2005: 332), Filipino migrant domestic workers' voices illustrate that "contrary to discourses of spousal/family abandonment, men often migrate in order to support their families, and particularly to afford their children more opportunities than they themselves had" (Datta/Mcllwaine/ Herbert/Evans/May/Wills 2009: 856). While also involving emotional attachment, fatherhood is largely understood in terms of material provisioning. This justifies men's migration and the sacrifice of entering a feminized occupation.

The narrations of Filipina/o domestic workers in the Netherlands highlight the ways in which gender hierarchies are reproduced in discourse. Rooted in their notions of valued gender identities, the lack of recognition of feminine-typed domestic work is exemplified and corroborated in their statements regarding what can be considered 'good' work (not domestic work, in Micki's opinion) and regarding who is a 'good' person (Sifora's husband's, despite his engagement in domestic work). Paradoxically, this way the respondents themselves contribute to reproduction of the symbolic and material injustices that migrant domestic workers suffer from.

\subsection{Domestic Work at the Intersection of Class, Race, and Gender}

While interactions between the construction of domestic workers' gender identities and other social divisions have been identified in passing in the previous section, this section focuses on them.

Respondents pointed out that, in the Philippines, domestic work is performed by the poor, who are often rural migrants (see also Lan 2003: 194). Silvianos, a former college instructor himself, specified that people with little or no formal education take up such low-status jobs. Therefore, the experience of deskilling that resulted from taking up domestic work as an occupation is a matter of shame for him:

I ask myself: Do I deserve this? (Silvianos).

As in Bartolomei (20I0: 99), making his background and, hence, the loss of social status invisible is a way of reducing the associated sense of humiliation:

Here, I am working domestic work around people who do not know my background, and this makes it a little easier. But, of course, in the Philippines, people know you well; you live and work around relatives and friends. And at this time I avoid telling my family, relatives and friends about my current work, as they could say something nasty comparing to my level of education, and my previous work as college instructor (Silvianos).

By moving to the Netherlands and taking up domestic work, Silvianos changed his class position from a salaried employee to an informal worker. The low social status of domestic work carries the connotation of poor levels of education. Silvianos' painful experience of deskilling contrasts with his simultaneous discovery that domestic work actually requires more skills than anticipated. He had thought domestic work was easy work, but realized its difficulty later:

... you need to know the techniques and master which place to start first in the household (Silvianos).

Rido moved from the skilled occupation of cook to domestic work. His comments further underline that this experience of declassing is difficult to accept. $\mathrm{He}$ told his family and friends that he is not a cook any more. Like Angelo, he justified this by explaining that, as a migrant with irregular status, he could not find any other job apart from domestic work:

They said it is okay, as long as you earn money [laughs] (Rido).

But he is disappointed with himself:

Yeah, I am angry at myself, I am domestic worker, I clean someone's house. Before, for twenty-five years, I have been a respected cook, cooking in big hotels and restaurants, I was a cook (Rido).

Besides the divergent skill and class connotations of his previous and current job, the location of his work has a role to play in how he perceived himself through the eyes of generalized others. The esteem associated with public places, such as hotels and restaurants, further contrasts with the invisibility and gender connotations of his current workplace in the private sphere. He occasionally works in the construction sector, taking on tasks like painting. This is work more in line with his notion of a masculine identity: 
I feel easy doing painting, because painting is men work. You see, I do it for the money in domestic work, I do not know how to do it (Rido).

More drastically, he stated:

... if I could be able to survive, I better choose to be unemployed than shifting from a cook to a domestic helper (Rido).

Keeping Silvianos' evaluation of unemployment as unmanly in mind, this statement is surprising. Possibly more than an actual preference, it was used as a rhetoric device emphasising - once again - the threat of male femininities that work in domestic service holds for Filipino men's sense of dignity. They are probably rooted in the perception that unemployment would preserve the higher class position - alongside the conformity with hegemonic masculinity - of his previous occupation.

Interestingly, Angelo and Micki mention that, in the Philippines, both women and men work as domestic workers, which contrasts with Micki's earlier exclamation: "How can a man clean?" Possibly, in Filipino society, their ranking above poor workers in domestic service explains this contradiction. Domestic work would be considered unmanly for middle-class males, but acceptable - or, at least, common - for working-class men. Such intersections between gender identity and class have also been identified in Sarti's (20IO) study on migrant domestic work in Italy. Despite the fact that the father of one of her respondents was a domestic worker back in the Philippines, the respondent thought that domestic work is "really a female's job" (Sarti 20IO: 30). She points out that: "By ignoring or denying the existence of male domestics, they reveal that they share the idea that male domestic workers are not really men and support a conception of masculinity which backfires on them" (Sarti 20IO: 3I).

In contrast to the men interviewed, female respondents did not complain about their occupation or emphasized the compulsion to do domestic work due to their immigration status. This is despite the fact that, for example, for Sifora, too, entry into domestic work involved a process of deskilling and a loss of the societal prestige associated with her earlier job as a businesswoman. This acceptance is probably rooted in the perception of domestic work as an extension of 'natural' female skills and associated with the female-typed sphere of the private home, something that both female and male respondents had internalized. It led to a perceived challenge to male respondents' gender identities, but is in line with female migrant domestic workers' gendered role expectations.

The discussion of the respondents' narrations above has indicated already that the workplace of migrant domestic workers in the private home plays a significant yet ambiguous role. In contrast to their female colleagues, the classification of the private sphere as feminine poses a challenge to male domestic workers' gender identity. Besides this, the exploitative circumstances of live-in arrangements, in particular, threaten all domestic workers' material and physical security - so much so that some of them preferred the vulnerability of irregular immigration status to it. Yet at the same time the invisibility of these private places of work appears to offer protection from state surveillance, especially for workers with irregular immigration status, and makes their misrecognized work less visible.

Marco's experience sheds more light on the dynamics operating between migrant domestic workers' gender and their immigration status, as well as on the role of employers in reproducing these dynamics. Marco is a 43-year-old married father of three. Entering on a tourist visa and invited by his sister, he has stayed in the Netherlands as a domestic worker with irregular immigration status since 2008 . For six days a week, he works a minimum of six hours a day, generating daily earnings of around seventy euros. This enables him to remit 400-500 euros per month to his family in the Philippines. Like all male respondents, Marco explained that domestic work is something that he learned in the Netherlands. He, too, underlined the compulsion that brought him to this occupation. He felt he was obliged to learn any kind of job in order to earn money. The association of domestic work with the female gender not only poses a challenge to his masculinity, it also leads to gender-based discrimination in access to jobs in domestic service. Once, a Filipina friend who is likewise a domestic worker recommended him to a potential employer. When calling him,

... the employer was a bit surprised and asked me whether I am documented or not and I lied that I am documented (Marco).

The employer told him that he had to discuss the issue with his wife and would respond later. After a couple of days, the employer told him that his wife was looking for a girl. Marco was disappointed. He noted that:

Some employers like to hire female domestic workers. Because, they take domestic work as a kind of work that 
belongs to female only. And they think women only can do much better than men (Marco).

Apparently, because of the gender connotations of domestic work, being a male domestic worker signalled irregular immigration status to this potential employer. Only the compulsion of scarce labour market opportunities typical for workers with irregular status would bring a male migrant to apply for employment in domestic service. Through this process of screening based on normative assumptions regarding the gender and immigration status interactions in domestic work, employers, as actors in a more powerful position in the arena of domestic work, play their part in reproducing these very assumptions (Ray 2000: 695) and entrenching the notion that valued masculinities are associated with whiteness and the middle class.

Marie is a 39-year-old domestic worker who works for ten families in The Hague. She placed employers' negative attitude vis-à-vis male domestic workers in the context of sexuality:

I have heard from one of my employers that her friends recommended her a male domestic worker and she refused to hire. She [employer] said that she wants her daughter to wear freely at home and she does not want her daughter feel an outsider's man attention in her own house (Marie).

Marie heard similar concerns from other employers, especially in families with teenage daughters. Highlighting the intersection of gender with sexuality in the social construction of domestic work, hiring male domestic workers is seen as a potential sexual threat to women in a family. Marie added that she knows many male domestic workers who work as the assistants of female domestic workers and who split the money between them as a strategic reaction to employers' gender preferences (see also van Walsum 20II: I53). Particularly when women workers have long working hours, they 'subcontract' work to male domestic workers. They describe this collaboration as giving assistance to their Filipino menfolk in increasing their employment opportunities. By emphasizing their own supportive role and their male colleagues' breadwinning role, this practice might be placed in the context of women affirming both their own and their male colleagues' congruence with hegemonic gender identities.

Other than assumed in the images of the 'tolerant' Netherlands, migrant domestic workers' racial background as well as racialized ascriptions also influence their position in the labour market and their life more generally. Angelo realized that Europe is not the champion of non-discrimination:

... they look at us as nobody and as if we are nothing (Angelo).

He did not feel respected by his white employers:

Especially in the [diplomatic] residence, I do not think they have respect, because you are there and you are helping them (Angelo).

While he saw domestic work as the only way to find work as a migrant with irregular status, he concedes that even with a regular work permit, racial discrimination in the labour market persists:

They may give us lower jobs. Even the professionals, I don't think they are professionals here (Angelo).

Rido preferred to work with English speakers rather than with Dutch employers, as it was hard for him to communicate in Dutch. At the same time, he did not want to work with employers from the Philippines, despite the common language. They pay low wages and:

... I am not comfortable if my employer is Filipino (Rido).

Similarly to Bartolomei's findings (2010: 99), his preference indicates that the same racial background may also represent a disadvantage. This has both material and symbolic dimensions. Normative expectations and benchmarks may be shared, too, implying that the invisibility of his degrading work is made impossible. Not unimportantly, Filipina/o employers are able to consider the lower living costs and wage levels in their home country in comparison with the Netherlands, explaining the poor pay. Emotionally, the discrimination and marginalization that respondents experience on the basis of their race is counterbalanced by positive ascriptions. Micki pointed out that Filipina/o domestic workers are well paid compared to other nationals (see also ILO 20IO: 7; van Walsum 20II: I52-I53). He relates the better pay to perceptions of diligence in and commitment to their work:

And one employer said I like Filipino, they are hard workers, I was happy and my heart was beating fast. Because Filipino work hard they do not focus on hours, they only care about their work. And Filipinos are good workers, and trusted by their employers, trust me (Micki).

Van Walsum (20II: I52) comes to the more sobering conclusion that Filipina/o domestic workers' comparatively higher payment is related to their reputation as "ideal providers of care and household services", 
actively promoted by the Filipino government and commercial brokers (see Rodriguez 20IO).

This section has shown how the (re-)construction of domestic workers' gender identities is intersected with class, race, and immigration status. Overall, for the respondents, domestic work has the connotation of working-class status. This is difficult to separate from gender features of the occupation, though. The fact that it is largely women who perform domestic work implies a social construction of low skill content resulting in the perception that this work does not deserve high wages. All three factors together generate the class connotation that the male respondents, in particular, refer to and which they experience as a painful loss of social status compared to with their earlier occupations. To deal with this experience of declassing and the stigma of male femininities, male migrant domestic workers point to the actual, demanding skill requirements of their occupation, something that resonates with other research findings (Datta/McIlwaine/Herbert/Evans/May/Wills 2009: 865-866).

Furthermore, their irregular status sets limitations to their agency, especially their "fear to be caught one day" (Angelo) and the limited opportunities for accessing the legal labour market. Male respondents in particular saw their inability to obtain a work permit as the main cause for taking up domestic work as one of the lowest threshold occupations in the Dutch labour market, characterized by a lack of employment, income, and social security. Yet the irregularity of their immigration status intersects with the location of their work in an ambiguous manner. While their work in the private sphere can be seen as protective against threatening surveillance by public authorities, this invisibility also increases employers' power over domestic workers and makes them vulnerable to economic and physical exploitation.

With regard to the intersection between race, gender, and domestic work, migrants' Filipina/o background channels them into a narrow set of labour market options, with domestic work being dominant amongst these. Within this racialized niche, their nationality is associated with a very good reputation. Van Walsum (20II: 153) highlights possible pitfalls of this branding as 'ideal domestic workers', as it could also work against them if they acquire legal status.

The emerging theme of domestic work as 'help' and 'assistance' can be considered a focal point of respondents' constructions of their work. Sifora defended her decision to migrate by her obligation to 'help' her unemployed husband, who again is 'helpful' by taking over the housework back in the Philippines. Rido referred to himself as a 'domestic helper', something that he experienced as a downgrading from salaried professional to wage worker. While Marie confirmed female and male gender identities by declaring the subcontracting of domestic work to male colleagues as 'assistance', Angelo described the position in the racial hierarchy in which migrant domestic workers in the Netherlands are placed as 'helpers'. The ways in which these notions were used with reference to domestic work imply subordinated agency (see Lan 2003: 205, footnote 6) as well as gender, class, and racial hierarchies in which migrant domestic workers are located at the lowest rank.

\subsection{Conclusion}

The bulk of scholarly work on migrant domestic work concentrates on women. Our research, in contrast, has taken the finding that a significant and growing number of migrant men are taking on domestic work as its point of departure. From the perspective of hegemonic gender identities, we have shown that male migrant domestic workers, too, are subjected to gender injustice. The injustices they experience are rooted in the devaluation of everything coded as 'feminine' (Fraser 2007: 26), including their occupation. The resulting male femininities are threatening male domestic workers' sense of self-worth and their societal recognition. This misrecognition adds to the exploitative economic circumstances that both female and male migrant domestic workers experience and has negative repercussions on male migrants' access to employment. Ironically, migrant domestic workers themselves contribute to reproducing these symbolic and material injustices and hence consolidate them. By adopting hegemonic gender identities as their normative point of reference, both female and male migrants implicitly support domestic work's low societal status through their belittling of their 'feminine' and declassing occupation.

Migrant domestic workers' individual struggles to deal with these experiences of injustice are embedded in contestations over the role of reproduction in wider Dutch society. Women's improved access to paid employment, which has gone unmatched by men's involvement in housework, has been achieved at the expense of respect and reward for migrant domestic workers. Their vital role for Dutch society, filling the reproductive gap that has opened as a result of greater gender justice in the paid labour market, con- 
trasts starkly with the invisibility of their work in private homes, as well as with their marginal social and economic status. The forms of injustices that female and male migrant domestic workers face in a variety of ways entrench the symbolic and material divides between migrants and employers, as well as between migrants' home and host societies. While this has been pointed out in earlier studies, we bring to the fore how migrant domestic workers' efforts to adhere to hegemonic gender identities not only reproduce patriarchal gender relations amongst themselves, but also corroborate white privileges in productive and reproductive work.

Given the 'two faces' of gender justice that Fraser (2007: 26) identifies, redressing these injustices requires changes both in the economic structure and in the status order of contemporary society. In combining the demands for respect and for labour rights for domestic workers, this necessity is reflected in domestic workers' national (see for example FNV Bondgenoten 20II) and international campaigns (see for example IRENE/IUF 2008; IDWN no date) that have culminated in the ratification of the International Convention Concerning Decent Work for Domestic Workers by the International Labour Conference (ILC 20II) as an intermediate success. These labour movements have taken on a new terrain of struggle. Beyond the traditional focus on the material aspects of labour conditions, the new approach has taken workers' social status into account and has also led to a campaign for greater respect. Its emergence is probably related to an increasing awareness of the rise of precarious employment relations amongst trade unions. Precariousness, in turn, is often related to the low social status of the respective work. ${ }^{12}$ Importantly, these struggles have included changes in domestic workers' own mindsets, from seeing themselves as 'helpers' to emphasizing their dignity as workers.

While national and transnational labour movements for greater social justice for migrant domestic workers have been effective, they are probably not the most powerful actors in this arena. In many cases, national labour regulation continues to neglect the private home as a workplace (ILO 20IO; Simonovsky/ Luebker/Oelz 20II) due to gendered association of work and breadwinning with the public sphere. This chapter's intersectional analysis has shown how these legal frameworks are underpinned by social constructions of migrant domestic workers' location of work,

12 We are grateful to Freek Schiphorst for pointing this out. their subordinate gender identities, race, and immigration status, and how these interact to mute demands for respect and adequate reward. In order to redress this situation and to achieve parity of participation in the labour market, national governments have to abandon the androcentric assumption that industrial workplaces are the benchmark for labour regulation. Rather, they should strive to effectively cover all workers, independent of the location of their work, their gender, their race, or their immigration status, with the protection they deserve.

The transnational nature of the social and economic relations that this chapter has investigated is a reminder that the nation state is no longer the sole territorial unit within which justice is applied (see Fraser 2009). As the social movement for respect and rights for domestic workers has become transnational, adequate regulation to prevent abuses and fraudulent practices in recruitment, placement, and employment of migrant workers should be based on bilateral, regional, or multilateral agreements (see Article $15 \mathrm{~d}$ in the International Convention Concerning Decent Work for Domestic Workers, ILC 20II).

Hence, policymakers at the level of the European Union and the World Trade Organization, for example, should reconsider whether they want to submit tasks that are as crucial to societal reproduction as domestic work to restrictive migration management based on the arbitrary definition that domestic work does not require skills. A redefinition and relaxation here is likely to lead to both greater societal recognition for domestic work and a subsequent improvement of their material conditions of work. This would be in line with Fraser's conclusion (2007: 34) that: "Only an approach that redresses the cultural devaluation of the 'feminine' precisely within the economy (and elsewhere) can deliver serious redistribution and genuine recognition."

\section{References}

Abvakabo FNV (Algemene Bond van Ambtenaren, Katholieke Bond van Overheidspersoneel Federatie Nederlandse Vakbeweging) (Public Sector Trade Union); since I982 known as Abvakabo FNV, 2008: Your Rights as a Domestic Worker in a Private Household (Zoetermeer: Abvakabo FNV); at: <http://www.abvakabofnv.nl/PDF/ downloads/folder-rechten-als-huishoudelijke-hulp/ I93055/.pdf> (23 July 20I2).

Asis, Maruja Milagros B.; Huang, Shirlena; Yeoh, Brenda S.A., 2004: "When the Light of the Home is Abroad: Unskilled Female Migration and the Filipino Family", in: Singapore Journal of Tropical Geography, 25,2: 198-215. 
Bartolomei, Maria Rita, 20Io: "Migrant Male Domestic Workers in Comparative Perspective: Four Case Studies from Italy, India, Ivory Coast, and Congo", in: Men and Masculinities, I3,I: 87-IIO.

Botman, Sjoukje Johanna, 20II: Gewoon Schoonmaken: De Troebele Arbeidsrelaties in Betaald Huishoudelijk Werk (Amsterdam: University of Amsterdam).

Chang, Kimberly A.; Ling, L.H.M., 2000: "Globalization and its Intimate Other: Filipina Domestic Workers in Hong Kong”, in: Marchand, Marianne H.; Runyan, Anne Sisson (Eds.): Gender and Global Restructuring: Sightings, Sites and Resistances (London: Routledge): 27-43.

Commission on Filipino Overseas, 20IO: "Responding to the Challenges of Migration and Development: Stock Estimation of Overseas Filipinos" (December 20IO); at: <http://www.cfo.gov.ph/index.php?option=com_content \&view=article\&id=I340:stock-estimate-of-overseas-filipinos\&catid $=\mathrm{I} 34>$ (23 July 20I2).

Connell, R.W.; Messerschmidt, James W., 2005: "Hegemonic Masculinity”, in: Gender \& Society, 19,6: 829-859.

Datta, Kavita; McIlwaine, Cathy; Herbert, Joanna; Evans, Yara; May, Jon; Wills, Jane, 2009: "Men on the Move: Narratives of Migration and Work among Low-Paid Migrant Men in London”, in: Social \& Cultural Geography, Io,8: 853-873.

De Ruijter, Esther, 2004: "Trends in the Outsourcing of Domestic Work and Childcare in the Netherlands", in: Acta Sociologica, 47,3: 219-234.

De Ruijter, Esther; van der Lippe, Tanja, 2009: "Getting Outside Help", in: Journal of Family Issues, 30,1: 3-27.

Donaldson, Mike; Howson, Richard, 2009: "Men, Migration and Hegemonic Masculinity", in: Howson, Richard; Pease, Bob; Hibbins, Raymond; Donaldson, Mike (Eds): Migrant Men: Critical Studies of Masculinities and the Migration Experience (New York: Routledge): 2IO-2I8.

Duffy, Mignon, 2007: "Doing the Dirty Work", in: Gender \& Society, 21,3: 313-336.

FNV (Federatie Nederlandse Vakbeweging) Bondgenoten, Last updated 20II: "Schoon Genoeg!" (Vakbond van Schoonmakers/FNV Bondgenoten website), at: <http:/ /www.schoongenoeg.nu/afdeling/domestic-workers/> (23 July 20I2).

Fraser, Nancy, 2007: "Feminist Politics in the Age of Recognition: A Two-Dimensional Approach to Gender Justice”, in: Studies in Social Justice, I,I: 23-35.

Fraser, Nancy, 2009: "Who Counts? Dilemmas of Justice in a Postwestphalian World", in: Antipode, 4I,SI: 28I-297.

Gutmann, Matthew C., 1996: The Meanings of Macho: Being a Man in Mexico City (Berkeley: University of California Press).

Haile, Aster Georgo, 20II: Masculinity, Work and Rights through the Lens of Citizenship: Filipino Male Domestic Workers in the Netherlands. ISS MA Research Paper (The Hague: International Institute of Social Studies of Erasmus University Rotterdam (ISS)).
Herbert, Joanna, 2008: "Masculinity and Migration: Life Stories of East African Asian Men”, in: Ryan, Louise; Webster, Wendy (Eds): Gendering Migration: Masculinity, Femininity and Ethnicity in Post-War Britain (Burlington etc.: Ashgate Aldershot): 189-203.

Hochschild, Arlie Russell, 2000: "Global Care Chains and Emotional Surplus Value”, in: Hutton, Will; Giddens, Anthony (Eds): On the Edge: Living with Global Capitalism (London: Jonathan Cape): I30-I46.

IDWN (International Domestic Workers' Network): "International Domestic Workers' NetWork” (IDWN webpage); at: <http://www.idwn.info/> (23 July 20II).

ILC (International Labour Conference), 20II: "Text of the Convention Concerning Decent Work for Domestic Workers", International Labour Conference $100^{\text {th }}$ Session (Geneva: ILO); at: <http://www.ilo.org/wcmsp5/ groups/public/--ed_norm/--relconf/documents/ meetingdocument/wcms_I57836.pdf> (3 August 20I2).

ILO (International Labour Office), 20I0: Decent Work for Domestic Workers: Report IV (I). International Labour Conference $99^{\text {th }}$ Session (Geneva: ILO); at: <http:// www.ilo.org/wcmsp5/groups/public/@ed_norm/@relconf/documents/meetingdocument/wcms_I04700.pdf> (3 August 20I2).

IRENE (International Restructuring Education Network Europe) and IUF (International Union of Food, Agricultural, Hotel, Restaurant, Catering, Tobacco and Allied Workers' Associations), 2008: Respect and Rights: Protection for Domestic/Household Workers! (Tilburg: IRENE/IUF); at: <http://www.irene-network.nl/download/ResRights.pdf > (23 July 20I2).

Kilkey, Majella, 20Iо: "Men and Domestic Labor: A Missing Link in the Global Care Chain”, in: Men and Masculinities, I3,I: I26-I49.

King, Alison Jill, 2007: Domestic Service in Post-Apartheid South Africa: Deference and Disdain (Aldershot: Ashgate).

Koo, Eunjung, 20II: Exploring Variations in Identity Dynamics Among Migrant Domestic Workers in the Netherlands. ISS MA Research Paper (The Hague: International Institute of Social Studies (ISS) of Erasmus University Rotterdam).

Lan, Pei-Chia, 2003: "Maid Or Madam? Filipina Migrant Workers and the Continuity of Domestic Labor", in: Gender \& Society, 17,2: 187-208.

León, Margarita, 20I0: "Migration and Care Work in Spain: The Domestic Sector Revisited", in: Social Policy and Society, 9,3: 409-4I8.

Luebker, Malte; Simonovsky, Yamila; Oelz, Martin, 20II: Coverage of Domestic Workers by Key Working Conditions Laws. Domestic Work Policy Brief 5 (Geneva: ILO); at: 〈http://www.ilo.org/wcmsp5/groups/public/ --ed_protect/-protrav/-travail/documents/publication/wcms_I57509.pdf> (23 July 20I2).

Lupton, Ben, 2000: "Maintaining Masculinity: Men Who do 'Women's Work', in: British Journal of Management, II (Special Issue): 33-48. 
Lutz, Helma (Ed.), 2008: Migration and Domestic Work: A European Perspective on a Global Theme (Aldershot: Ashgate).

Lutz, Helma, 2002: "At Your Service Madam! The Globalization of Domestic Service”, Feminist Review, 70: 89I04.

Marchetti, Sabrina, 2005: We had Different Fortunes: Relationships between Filipina Domestic Workers and their Employers in Rome and in Amsterdam (MA Thesis, Utrecht: University of Utrecht); at: <http://igiturarchive.library.uu.nl/student-theses/2006-0324-0832I3/ RMA\%20thesis\%20Marchetti.pdf> (23 July 20I2).

Marchetti, Sabrina, 20I0: Paid Domestic Labour and Postcoloniality: Narratives of Eritrean and Afro-Surinamese Migrant Women (PhD thesis, Utrecht: University of Utrecht), at: <http://igitur-archive.library.uu.nl/dissertations/20I0-05I7-20023I/marchetti.pdf > (23 July 20I2).

Margold, Jane A., I995: "Narratives of Masculinity and Transnational Migration: Filipino Workers in the Middle East”, in: Ong, Aihwa; Peletz, Michael G. (Eds): Bewitching Women, Pious Men: Gender and Body Politics in South East Asia (Berkeley: University of California Press): 274-298.

Medina, Belen Tan-Gatue, 200I: The Filipino Family (Quezon City: University of the Philippines Press).

Merlino, Massimo; Parkin, Joanna, 20II: Irregular Migration in Europe: EU Policies and the Fundamental Rights Gap (Brussels: Centre for European Policy Studies (CEPS)).

Moya, Jose C., 2007: "Domestic Service in a Global Perspective: Gender, Migration, and Ethnic Niches”, in: Journal of Ethnic and Migration Studies, 33,4: 559-579.

Nakano Glenn, Evelyn, 1992: "From Servitude to Service Work: Historical Continuities in the Racial Division of Paid Reproductive Labor”, in: Signs, I8,I: I-43.

Nes, Peter; van Gravesteijn-Ligthelm, José; van den Boom, Linda, 2004: De markt voor persoonlijke dienstverlening (Rotterdam: Stichting Economisch Onderzoek (SEOR), Faculty of Economics, Erasmus University Rotterdam Erasmus; at: <http://docs.szw.nl/pdf/I29/2004/ I29_2004_3_683I.pdf> (23 July 20I2).

Oelz, Martin, 20II: Remuneration in Domestic Work. Domestic Work Policy Brief I (Geneva: ILO); at: <http://www.ilo.org/wcmsp5/groups/public/ed_protect/--protrav/--travail/documents/publication/ wcms_I55654.pdf> (23 July 20I2).

Parreñas, Rhacel, 2005: "Long Distance Intimacy: Class, Gender and Intergenerational Relations between Mothers and Children in Filipino Transnational Families", in: Journal of Transnational Affairs, 5,4: 3I7-336.

Ray, Raka, 2000: "Masculinity, Femininity, and Servitude: Domestic Workers in Calcutta in the Late Twentieth Century”, in: Feminist Studies, 26,3: 69I-718.
Rodriguez, Robyn Magalit, 20I0: Migrants for Export: How the Philippine State Brokers Labor to the World (Minneapolis, MN: University of Minnesota Press).

Sarti, Raffaella, 2006: "Domestic Service: Past and Present in Southern and Northern Europe", in: Gender \& History, I8,2: 222-245.

Sarti, Raffaella, 20I0: "Fighting for Masculinity: Male Domestic Workers, Gender, and Migration in Italy from the Late Nineteenth Century to the Present”, in: Men and Masculinities, I3,I: I6-43.

Schippers, Mimi, 2007: "Recovering the Feminine Other: Masculinity, Femininity, and Gender Hegemony", in: Theory and Society, 36,r: 85-102.

Simonovsky, Yamila; Luebker, Malte, 20II: Global and Regional Estimates on Domestic Workers. Domestic Work Policy Brief 4 (Geneva: ILO); at: <http:// www. ilo.org/wcmsp5/groups/public/_ed_protect/-protrav/--travail/documents/publication/wcms_I5595I. pdf> (23 July 2OI2).

Statistics Netherlands, 20II: "Population; Key Figures" (The Hague: Statistics Netherlands); at: <http://statline.cbs.nl/StatWeb/publication/?VW=T\&DM=SLEN\& $\mathrm{PA}=37296 \mathrm{eng} \& \mathrm{DI}=\mathrm{a} \& \mathrm{D} 2=0, \mathrm{IO}, 20,30,40,58-59 \& \mathrm{HD}=0903$ O2- $\mathrm{IO} 45 \& \mathrm{LA}=\mathrm{EN} \& H D R=\mathrm{GI} \& S T B=\mathrm{T}>$ (23 July 20I2).

UNESCO (United Nations Educational, Scientific and Cultural Organization), 2008: People on the Move. Handbook on Selected Terms and Concepts. Version I.০, at: <http://unesdoc.unesco.org/images/oor6/ooı636/ı6 362Ie. pdf> (3 September 20I2).

Van den Bergh, Hiske, 2006: Causes of Different Reactions of EU Countries to Illegal Migration. Summary Research Report (Utrecht: Pharos).

Van der Heijden, Peter G.M.; Cruyff, Maarten; van Gils, Ger H.C., 20II: Schatting Illegaal in Nederland Verblijvende Vreemdelingen in 2009 (Utrecht: Universiteit Utrecht).

Van der Leun, Joanne; Kloosterman, Robert, 2006: "Going Underground: Immigration Policy Changes and Shifts in Modes of Provision of Undocumented Immigrants in the Netherlands", in: Tijdschrift voor Economische en Sociale Geografie, 97,I: 59-68.

Van Dijken, Wieke, 2002: Slaves Or Militants: A Study on Identity Formation Processes of Migrant Domestic Workers in the Netherlands (MA thesis, Amsterdam: Vrije Universiteit).

Van Walsum, Sarah, 20II: "Regulating Migrant Domestic Work in the Netherlands: Opportunities and Pitfalls", in: Canadian Journal of Women and the Law/Revue Femmes et Droit, 23,I: I4I-I65.

Yeates, Nicola, 2004: "Global Care Chains", in: International Feminist Journal of Politics, 6,3: 369-39I.

Open Access. This chapter is distributed under the terms of the Creative Commons Attribution Non-commercial License, which permits any noncommercial use, distribution, and reproduction in any medium, provided the original author(s) and source are credited. 
Part III The State and Female Internal Migration: Rights and Livelihood Security

Chapter 7 Traversing Myriad Trails: Tracking Gender and Labour Migration across India Indrani Mazumdar and Indu Agnihotri

Chapter 8 From 'Integration into Cities' to 'An Integrated Society': Women Migrants' Needs and Rights in Fujian Province, China

Yu Zhu and Liyue Lin

Chapter 9 Migration, Woodcarving, and Engendered Identities in San Martín Tilcajete, Oaxaca, Mexico

Serena Eréndira Serrano Oswald

Chapter 10 Strategic Invisibility as Everyday Politics for a Life with Dignity: Guatemalan Women Migrants' Experiences of Insecurity at Mexico's Southern Border

Martha Luz Rojas-Wiesner and Maria DeVargas 


\title{
$7 \quad$ Traversing Myriad Trails: Tracking Gender and Labour Migration across India
}

\author{
Indrani Mazumdar ${ }^{1}$ and Indu Agnihotri ${ }^{2}$
}

\begin{abstract}
$^{3}$
This chapter argues that the effacement of gender in macro-analyses of internal migration in India is based on the collective inability to delineate the contours of female labour migration from the official databases. While critiquing the monocausal approach to migration which overwhelmingly privileges social over economic reasons in female migration, the chapter essays a gendered macro-view of labour migration in India, for which new methods of approaching the data of the most recent macro-survey on migration in India (2007-08) are applied. The authors argue that the migration pattern is enhancing structural gender inequalities in the labour market. While the domination of services and industry in male migrant employment has contributed to a degree of diversification in the structure of the male workforce away from agriculture, the same is not the case for the female workforce.

Drawing on primary surveys conducted across 2009-20II, the chapter argues that a meso-level view shows a predominantly long- and medium-term migratory pattern among upper-caste women to have brought hitherto home-bound women into diversified employment in more white-collar services. On the other hand, short-term and circulatory migration involving hard manual labour with limited scope for social advancement predominates among women from traditionally disadvantaged castes/tribes. A distinctively gendered process of concentration among migrant women in paid domestic work, however, cuts across caste hierarchies. While women workers' involvement in family decisions to migrate and 'autonomous' migration by women is not insignificant, a broad tendency towards their concentration in a narrow range of occupations is identified. It is argued that the temporary nature of much of employment leads to a pullback to villages, despite agrarian crisis.

In foregrounding the intersections between caste, class, and gender inequalities, and arguing that such inequalities are being reconfigured through migration, the chapter draws on the perspective of the women's movement in India. It is argued that the absolute reduction in employment for women during the most distinctive phase of high GDP growth in India posits the need for more redistributive and equalizing growth as the path forward for social justice.
\end{abstract}

Keywords: India, labour migration, gender, typology of migration, circulatory migration, medium-term migration, occupational diversification, caste, tribe, women's movement.

\subsection{Introduction}

The most recent macro-survey of migration in India (National Sample Survey [NSS], 2007-08), estimated

1 Indrani Mazumdar is a Senior Fellow at the Centre for Women's Development Studies, New Delhi, India.

2 Indu Agnihotri is the Director of the Centre for Women's Development Studies, New Delhi, India.

3 This paper is based on the findings of an IDRC-funded project entitled "Gender and Migration: Negotiating Rights - A Women's Movement Perspective", project number I03978-00I. that some 327.7 million people in the country were internal migrants. Eighty per cent of them were female, and migrants accounted for nearly 29 per cent of the country's population. Defined as those who have changed their usual place of residence (UPR) any time in the past, migrants encompassed 48 per cent of the country's rural female population and 46 per cent of urban females. A decade and a half before, in 1993 , the rates of female migration were much less, at 40 per cent of the rural and 38 per cent of urban female populations. In contrast to such substantial increases in female migration rates in both rural and urban 
areas, migrants in the rural male population of India declined from six per cent to five per cent between 1993 and 2007-08, and increased by only two percentage points from 24 per cent to 26 per cent in urban India. $^{4}$

Despite such overwhelming numerical preponderance, the female migration data have hitherto been dismissed as irrelevant to development-oriented analysis of migration in India because the proportions of women identified as moving for employment-related reasons is exceedingly small. The majority of women are shown as migrating for marriage, unlike men, who are shown as moving predominantly for employmentrelated reasons. Several decades of data on migration have thus presented a largely unchanging picture of women migrating for mainly social reasons and men for economic reasons. The net result has been an established tendency among policymakers and analysts towards using male migration as the prime socioeconomic indicator for trends in migration in India, at the cost of gendered analysis and a complete statistical silence on the scale, dimensions, and patterns of female labour migration. This chapter attempts to break such a silence, to lay out some of the key gendered features of labour migration in India, and to examine their social trajectories from a women's movement perspective.

From the end of the I990s, in the midst of the unprecedented agrarian crisis that had unfolded within a decade of the structural shift in India's policy regime towards liberalization, mass-based women's organizations began reporting new forms of distress-driven migration by rural women in search of work -largely short-term, involving greater distances and different from traditional migration routes, sometimes without family members, and in conditions of heightened vulnerability (CWDS 2005; Ghosh 2005)..$^{5}$ By 2005, leaders and activists of the women's movement in India were chafing against the lack of official record of the "armies of women migrating in search of work" (Karat 2005). A few micro-studies from an earlier period had indeed drawn attention to the significant proportion of women in seasonal short-term labour migration, particularly in rural areas (Rao 1986; Banerjee/ Ray I99I; Karlekar 1995; Teerink 1995). Mostly regionor even community-specific, these studies had also

4 Government of India, National Sample Survey Office, Reports nos. 430 and 533.

5 See CWDS (2005): "Report of Seminar on Globalization and the Women's Movement in India”; at: 〈http:// www.cwds.ac.in/OCPaper/GlobalisationReport.pdf $>$. contributed to making available fairly detailed descriptions of some relatively long-standing migration patterns that could not be extracted from the macrodata. However, they rarely connected with the policy frameworks or the macro-context except in over-specific or over-general terms, and the impact of post-liberalization developments remained outside their frame. ${ }^{6}$ The countrywide breadth and scope of contemporary labour migration by women in both rural and urban areas thus remained invisible and eluded broader analysis. Consequently, there was a sharp disconnect between the experiences and conditions highlighted by the women's movement in India and the information and database on migration drawn on by policymakers or even concerned academics.

To meet the demand of the women's movement for better documentation of labour migration by women, the Centre for Women's Development Studies (CWDS) undertook a major research project on gender and migration in India, involving a critical engagement with the macro-data as well as extensive primary fieldwork, including a series of questionnairebased surveys in villages, towns, and cities across twenty of India's twenty-eight states between 2008 and $20 \mathrm{II}^{7}$ Drawing on the CWDS's research, this chapter essays a gendered macro-view of labour migration in contemporary India. It outlines some of the methodological issues and questions that emerged from probing the official data on migration, including additional information made available in the latest migration survey of the National Sample Survey (NSS). This is then juxtaposed with some of the insights and findings from the fieldwork and the surveys that have been consolidated as a meso-level approach to the types and modes of female labour migration in contemporary India. ${ }^{8}$

6 There were several excellent micro-studies on women's migration in the I980s, not all of which were published. Most of these studies have been referred to in: SchenkSandbergen (1995).

7 The CWDS research team for this project comprised the authors of this chapter and Dr N. Neetha, assisted by Shruti Chaudhry and Taneesha Mohan. The support of the International Development Research Centre of Canada (IDRC) which made this project possible is gratefully acknowledged.

8 Over a period of 24 months commencing January 2009, surveys with the pair of detailed and structured questionnaires were conducted across twenty states, covering 5,007 individual migrants and 5,558 households. These were drawn from village surveys as well as sectorbased surveys. 
As mentioned, the study approaches the subject of migration from a women's movement perspective. Many eyebrows may be raised at such an assertion, ranging from those who would question such declared partisanship to those who query the notion of a women's movement, given the diversity of ideologies and sectional interests that lay claim to the movement (or movements as they may say). A few words of clarification are therefore in order. From our point of view, what defines a movement perspective is its premise of the mobilization of women - in their independent but not necessarily individualistic capacities as a social movement. Such a perspective is thus distinguished from those of general development administration or even the many non-governmental institutions engaged in 'beneficiary'-oriented scheme delivery that inherently involves some form of patronclient relationships. That such a social movement would contain several strands of opinion is inevitable, but while a variety of opinion leaders and ideological emissaries have initiated processes of mass mobilization, the social movement that has been so generated in India since the late I970s has an aggregated force that is compellingly greater than its individual strands. There is an accumulating reservoir of experience of both plurality and commonality in the history of the women's movement in India, which is a major resource for the grounding of our perspective on gender and migration. ${ }^{9}$ Analytical assumptions of a division into autonomous vs. party-led women's organizations have underwritten much of the academic discourse on the contemporary women's movement in India. However, our understanding is in line with the argument that "in fact the history of the movement shows that no such clear dichotomy ever existed at the level of issue-based understanding...neither the 'autonomous' nor the mass organizations had a fully unified understanding, either amongst or between themselves" and on most issues "there was a criss-

9 There are of course several groups and organizations active in the women's movement in India, not all of whom organize on a mass scale. Yet alliances and unities on several common issues have become standard practice. The most prominent and sustained national level joint front, consisting of organizations with different political affiliations that evolved out of the movements of the early I980s, was initially called the seven sisters, although the number of components has varied across time. Many differences have cropped up in the course of the movement since then, and the organizational compositions of the various alliances have continuously been refashioned on an issue-to-issue basis. crossing between the two categories" (Agnihotri 200I). It is out of such an accumulating habit of practice of unities within differences and debates, combined with mass engagement, that the women's movement in India has continued to grow, not only in the public arena but also at the level of analysis.

That the programme of the women's movement is at one level multi-class and geared towards equality for women as women is axiomatic and does not perhaps require much elaboration. Less self-evident, but equally compelling, is the Indian movement's instinctive alignment with women as members of social classes who can broadly be termed peasants and workers, including a range of petty producers/sellers/ service providers in artisanal as well as modern technology-based industry and services. In a country mired and fissured by extreme levels of mass poverty and wealth, where women's confinement, purdah, and gross inequalities - jostling with the violences of superimposed capitalist modernity - define much of our social context and render constitutional mandates of equality and social justice as yet insubstantial, it is women from these social classes who have provided the anchor to the countrywide women's movement and a durable social base to the popular female-led surge on issues related to women's rights and conditions from the late I970s to the present. One can link the quite remarkable expansion of the contemporary women's movement in India to the inextricably entwined phenomena of a spreading tide of organic female ferment across classes and community categories on the one hand, and on the other, the more conscious and sustained attempts to extend the representative base of women's organizations. In the process, discrimination based on caste or social group and the differentiated/specific conditions of women as dalits and tribals ${ }^{10}$ and even as members of religious minorities have emerged as focal issues for the movement more than ever before. Not accidentally, but in fact driven by its expanding social base and perspective, the women's movement emerged in the forefront of the struggle against neo-liberal doctrine and its adverse effect on food security and the labouring

10 'Dalit' refers to historically disadvantaged caste communities stigmatized as 'untouchables". They are officially designated as 'Scheduled Castes' in the Indian Constitution. Similarly 'Tribes' refer to communities whose social organisation falls outside the mainstream caste based social order and whose livelihood and location was traditionally forest based. They are designated as 'Scheduled Tribes' in the Indian Constitution. Muslims constitute the largest religious minority in India. 
poor in India. It was the first to oppose the divisive practice and restrictive principle of narrow 'targeting' of subsidized food at only those officially declared below the poverty line (as distinct from the general poor). Its early arguments for adherence to the universal principle of food security were later taken up by various other rights-based groups. As such, as distinct from mere singularity of individual female identity, a contemporary women's movement perspective in India brings to the field of migration studies a perspective that is for women as women, as peasants and workers, as members of particularly oppressed communities, and as citizens, invoking general concepts of gender equality, redistributive justice, and freedom from poverty and subordination, but especially grounded in the cumulative experience of resurgent mass engagement. ${ }^{11}$

At the same time, in relation to both the debates and actualities of women's rights in India, it is well to remember that they have been shaped through multiple inequalities and through social and economic policies and developments on which the women's movement has had, as yet, only peripheral impact. To our minds, empirical research that draws its perspective from the women's movement must thus interweave into its enquiry questions based on the immediate issues and experiences of the movement while maintaining an overarching framework of strategic questions. For us, combining and referencing short-term issues with long-term strategic perspectives is supremely important. One reason is an awareness of the broad historical tendency in structurally unequal societies for every relative advance in women's status/conditions to simultaneously contain elements of relative regression, a point that has emerged sharply in the course of this study. Secondly, we believe that only through comparing our enquiry results against both short-term gains and longer-term strategic objectives can a more adequate and purposive understanding of gendered social processes in relation to migration be developed. The linking of the concrete or immediate issues to strategic objectives has enduring value as a guiding method and perspective for the women's movement and its researchers. Such an understanding informs and frames the issues and questions in relation to gender and migration in India that are discussed in this chapter.

11 The women's movement in India has a history stretching back to the pre-independence era. Nevertheless, its resurgent and clearly female-led mode from the late I970s marked the opening of a qualitatively new phase.
In the following sections, a perspective discussion on gender, migration, and development paradigms is initiated, along with a critical engagement with the gender-insensitive orientation of the official macrosurveys of migration in India. This is followed by a gendered macro-view of internal labour migration drawing from the 2007-08 migration survey by the National Sample Survey Office (NSSO). In approaching labour migration, a specific focus on paid workers has been maintained with the objective of highlighting the labour market outcomes of migration and embedded inequalities. The chapter then moves on to discussing some of the consolidated findings of the micro-surveys conducted by the CWDS. The scope of the CWDS surveys and methodology are first outlined. This is followed by description and analysis of various types of migration based on a typology developed by the study. Correlations are then drawn between types of migration, occupations, and caste hierarchies. The findings of the primary surveys cover occupational changes effected through migration and modes and manner of migration. The conclusion summarizes some of the key findings and questions laid out in the chapter.

\subsection{Gender, Migration, and Development Paradigms: Interrogating the Database}

Approaches to migration in development discourses and theories have been, in the main, preoccupied with transition from an agrarian to an industrial or even post-industrial capitalist social and economic order, a transition for which rural-to-urban migration is often seen as a rough proxy. A common underlying thread running through otherwise divergent economic policy paradigms in India, (i.e., the earlier state directed development policy [I953 to I985] and the later market supremacist approach [I99I to the present]) is the broad understanding that the migration process leads to some form of settlement at a particular destination (probably urban), usually accompanied by occupational/sectoral change (from the low productivity 'traditional' agricultural sector to the high productivity 'modern' industrial sector), enhanced incomes, and perhaps some degree of social mobility. In actuality, the experience has been of a relatively slow rate of urbanization (Kundu 1999), the continuance of agriculture as the majority employment, and the expansion of more circular forms of migration in, to, and around rural as well as urban ar- 
eas. ${ }^{12}$ Temporary and circular migration appear to have further gained ground in the face of the increasing rather than decreasing weight of unorganized/informal and intermittent forms of employment in rural and urban areas, and by the unsettling and shrinking of more durable organized sector employment (NCEUS 2007). As such, the assumptions and prognostications of early development theory's approaches to migration have long ceased to be really tenable in India.

Circular movements of labour were brought into the debates on migration not from analysis of the macro-data, but through a body of work drawing primarily on qualitatively inclined anthropological research and micro-surveys. This body of work drew attention to the significant proportions of women in short-term labour migration, particularly in rural areas (Banerjee/Ray I99I; Karlekar I995; Teerink I995). National data sets have, however, been slow to respond to research on circular, seasonal, and shortterm migration and have largely remained anchored in what has been called a 'permanent settlement paradigm'. The welcome recent addition of a separate category of short-term migrants in the 2007-08 migration survey by NSSO, as also the inclusion of an additional question on temporary migration for the UPR-defined migrants, is still dogged by definitional weaknesses that persist in excluding a large proportion of circular migrants, particularly those whose annual or perhaps more than annual migratory cycles exceed six months. It is also true that the official migration data based on change of residence relate primarily to population movements, in contradistinction to development or economic theories of migration which are primarily based on labour migration (Srivastava 2005), and there are genuine difficulties encountered in trying to distinguish between the two.

Nevertheless, the data on migration for employment (as the reason for migration) have long been thought to approximate the levels of economic/ labour migration. We believe that it is the monocausal approach (i.e., the attribution of a single reason for migration) followed by the national macro-surveys

12 The micro-studies on circular migration are too numerous to be cited here. It may be noted however, that in I99I, the National Commission on Rural Labour (NCRL) estimated the number of circular migrants in rural areas alone as around Io million including roughly 4.5 million inter-state migrants and 6 million intra-state migrants. Prominent in this research on circular migration or 'labour circulation' is the work of Jan Breman (I996), focused on the state of Gujarat and covering both rural and urban areas. that has been a major factor in camouflaging, under apparently non-economic social reasons, at least some economic/labour-based decisions in women's migration. For example, some implicit or actual labour migration by women may appear in the data as marriage migration or as other forms of associational movement by women simply because the two may coincide, but the social reason is presumed to be allimportant. Even where women of a migrant family enter the paid or income-earning workforce in their individual capacity at any given destination, it is still possible that marriage or family movement would be given as the reason for migration. An underestimation of female migrant workers thus appears to be inbuilt into the data.

A hidebound separation of economic reasons and social reasons for migration, implicit in the monocausal framework, is questionable on several counts. A preliminary question arises as to how such a separation could ever work in India, which is characterized by diverse levels of social organization; where petty production or 'self-employment' still accounts for the major part of the workforce, where several elements of socially reciprocal as well as production relations based on a feudal hierarchy and exchanges of a subeconomic nature persist, and where all the above are linked to the concentration of a large part of the female workforce in various forms of family production or family labour without any individual incomes or control over family income (unpaid labour). This question is relevant for all neo-classical development theory and its models, which tend to view a range of discrete social classes and categories only as labour in relation to capital, in either actual or potential terms (with gender at best as a subset of or associated with such labour). This blindness is notwithstanding a whole series of public policy devices in India that recognize and respond explicitly and implicitly to different social classes and categories such as peasants (or farmers to use the non-class term that has gained currency), landless and predominantly dalit labour in an agrarian social setting, artisans, forest dwellers/tribals, and nomadic communities, among all of whom only some have made a transition to a direct relationship with capital as labour. Even women have been brought in by policies and programmes, as a specific constituency for individual or group-based income generation activities. We would argue that multiple and variegated reasoning and decision-making are involved in the migration process, straddling both social and economic motivations or compulsions, regardless 
of whether migration is undertaken by individuals, families, households, or communities.

Further, circulation between sectors is widespread, since the wages of many of those employed in 'modern' (usually urban) industry or services do not cover the cost of social reproduction of the workers and their offspring/families, which then continues to be borne in part by rural peasant-based subsistence activities. In such cases, a difficulty exists in placing social categories and indeed even individuals as economic agents into an analytical frame based only on economic theories and categories that are derived from developed capitalism. These problems are not of India alone, but resonate through the developing world. Some of these difficulties have found expression in the evolution of the idea of an informal sector/economy, broadly characterized by a large number of selfemployed including family help, low income returns to labour, and the absence of formal social security and legally enforceable contracts. ${ }^{13}$ Despite several definitional disputes, the expanding size of the informal sector/economy rapidly acquired universal acceptance. It could no longer be conceived of as a 'residual category' in developing countries, as was initially argued by many economists. ${ }^{14}$ The delineation of informality was however dogged by questions as to whether the informal nature of the enterprise and self-employment should be taken as its defining feature or whether insecurity and lack of social protection in employment relations should be used for identifying an informal sector/labour. In India, such debate has moved towards decisive settlement by including both (NCEUS 2007). Nevertheless, to us, it appears that the complete jettisoning of the much criticized agriculture/industry/service sector-based frame of early development theories in favour of just a formal/informal divide poses additional problems rather than resolves them, and leads to an evasion of the agrarian question in India. Consequently, although the informal sector debates have indeed made a signal contribution to highlighting the poor conditions of work and the absence and need for social security provisions for the numerically extremely large, heterogeneous but essentially unorganized workforce, they have added little insight into the contemporary agrarian crisis, a crisis that activists in the women's

13 Three decades of debates and issues of conception related to the informal sector are discussed in Bangasser (2000).

14 See Kundu (1999) for a discussion on the difficulties of treating the informal sector as a residual category. movement instinctively perceive as central to understanding women's migration in India today.

Finally, there is the question of the presumption of individual units of labour in the wage economy. Anthropological research has long drawn attention to the circulation of family units or male/female pairs for wage labour in some industries/activities that are virtually completely reliant on migrants. For example, millions of migrant workers are recruited in pairs (jodis) or family units by contractors for brickmaking across the country and for harvesting sugar cane across large areas in western and southern India. ${ }^{15}$ Where direct piece rates are paid for the output of collective units of labour, whether of pairs, families, or ad hoc gangs, conceptual difficulties regarding the basis for the calculation of individual wages are inevitable, although disputes often remain hidden by social conventions. The point is that individual units of labour are not always clearly measured or as universal as is assumed by the employment and migration data and indeed even by the laws related to labour.

In sum, Indian government data and much associated work on migration in India reflect a permanent settlement paradigm, a monocausal approach to migration that tends to a rigid distinction between economic and social reasons for migration, a lack of focus on circular modes of labour migration, and a flattened-out conception/definition of work/employment that is purely based on the individual labour unit. Such a perspective makes the macro-data conceal many important features and trends in relation to labour, gender, and migration that operate in reality in India.

At the same time, many questions that the macrodata raises have not received due attention. We may begin by flagging the most striking feature of the data on enhanced female migration: the phenomenal increase in marriage migration rates in rural India. According to the NSS figures, the proportions of women migrating for marriage increased from 25 per cent of the rural female population in 1993 to 38 per cent in I999-2000 and then to 44 per cent in 2007-08. Increased rates of rural marriage migration is confirmed by census data for the I990s, foregrounding an immediate question as to what processes have led to a substantial rise in migration for marriage in rural areas. ${ }^{16}$

15 For such migration in Maharashtra, see Teerink (1995); and for Gujarat, Breman (1996) and Mosse, Gupta, Mehta, Shah, Rees (2002). For Tamilnadu and Karnataka, we have drawn on our own field observations. 
Running parallel to the remarkable increase in rural female marriage migration is an equally remarkable decline in rural female work participation rates from 33 per cent in 1993-94 to 29 per cent in 2007-08 and further to 26 per cent in 2009-IO. ${ }^{17}$ While rural employment for women is showing signs of acute constriction, urban female work participation rates too have declined from 15.5 per cent in $1993-94$ to 13.8 per cent in 2007-08 and remained the same in 2009-IO. Obviously the narrow base of urban female employment has not been offering much relief from constriction in rural areas. The most recent employment survey has revealed the shocking reality that not merely have the rates of women's work participation declined, but between 2004-05 and 2009-IO, some 2I million women were actually eliminated from the country's workforce. During this quinquennium, agriculture saw an absolute reduction by more than 20 million women workers, manufacturing by more than 3.5 million, and services by more than I.I million, with only construction showing some increases in employment for women (Mazumdar/Neetha 20II).

The experience in India has thus been conclusively contrary to the expectations of expanding employment opportunities and demand for women workers under a liberalized policy regime (the so-called femini-

16 A similar increase in urban marriage migration rates in the NSS surveys is not confirmed by the census of $200 \mathrm{I}$. Currently census data for $201 \mathrm{II}$ is still awaited. Till then we would have to go along with the census evidence for increased marriage migration in rural areas alone. Given the historical basis of settlement, community, and social and land relations in the villages of India, the camouflaging of labour migration under marriage seems less likely in rural areas in comparison to urban, although unsettled questions remain as to whether women who enter the casual wage economy in the village into which they marry or women who marry peasants who have settled in a new village should be considered labour migrants.

17 Work participation rates given here are all on the basis of usual status principal+subsidiary workers (UPSS), as defined in NSS Employment Unemployment Surveys. We may note that for female work participation, the NSS is better able to capture women's work than the census and so generally shows higher levels of female work participation. Generally, the large quinquennial rounds of the NSS, such as for 1993-94, 1999-2000, 2004-05, and 2009-IO, provide the more authoritative figures for employment in comparison to the thinner rounds in between. We have referred also to the medium large mid-quinquennial round of 2007-08, since it ran in tandem with the migration survey, which was not conducted in either 2004-05 or 2009-IO. zation of labour). Rather, it points to the unfolding of a major employment crisis, whose effects have been most sharply felt by rural women. Although a political response to the rural employment crisis indeed came in the form of the enactment of the National Rural Employment Guarantee Act, 2005, the social implications of its gendered features and multi-sector nature have yet to be adequately explored or incorporated in approaches to migration.

Given the focus on labour migration in this chapter, detailed discussion of increased marriage migration rates is not possible. Nevertheless, we should briefly touch upon findings that point to the need to recognize that developments in the sphere of women's work and employment crisis are indeed closely interlinked with social processes including enhanced marriage migration. An important issue through which the two become linked is dowry. Historical explorations of the spread of dowry indicate that the marginalization of women's traditional work in subsistence agriculture induced by colonial commercialization of agriculture had been a factor in the replacement of bride price by dowry in many communities in the lower echelons of the social order, where dowry was not earlier a traditional practice (Sheel 1997). Contemporary movement experiences and other studies of women's work indicate similar processes during the period of policy emphasis on marketdriven growth. Detailed micro-studies have shown that the shift from more female labour-intensive food and subsistence activities to more market-oriented and indeed more mechanized agriculture in the 1990s had been accompanied by a reduction of work availability for rural women (Rawal 2006). Women's movement documents point to a surge in the expansion of dowry into communities where bride price was more common, even some years ago (AIDWA 2003).

Further, a decline in the availability of common property resources for subsistence, particularly in mineral-rich areas of tribal concentration - where corporate-driven privatization has been particularly promoted - has had implications for many social arrangements, inducing a search for dowry-based accumulation through marriages outside local boundaries. ${ }^{18}$ Qualitative case studies of cross-regional marriages in various parts of the country show inability to raise dowry to be a prominent reason for parents to arrange or accept dowry-less marriages for their daughters outside traditional community/language/

18 See Menon and Vadivelu (2006) for the status of common property resources. 
culture/regional marriage boundaries, often in distant and culturally alien territory (Chaudhry/Mohan 20II). The expansion of dowry has generated criss-crossing responses all feeding into widening the search for marriage partners and increasing migration for marriage. In our view, the key issue propelling such interlinked processes is greater marginalization of women's work including marginalization of economic returns from their unpaid work for families, which has been further aggravated by the gendered nature of the employment crisis in India. It all, in a sense, foregrounds the centrality of the demand for independent paid work/employment and equality in the labour market as the way forward for women. It is such a perspective that underlies our approach to labour migration in contemporary India.

\subsection{Gendering the Macro-view on Labour Migration in India}

Deriving a macro-view on labour migration in India from statistics based on population movement inevitably requires a series of exercises that are tedious for both researchers and readers. For a gendered view, derivation is even more complicated because of the inclusion of unpaid labour in the workforce data, which in the case of women is particularly large. As mentioned earlier, a vast reservoir of women's work or economic activities, particularly in an unpaid form, is still largely contained within the family. Where and how such forms of work/labour fit into an understanding of what historians, development economists, and even anthropologists call labour migration is a question that necessarily troubles any gendered approach to labour migration. We have already argued that unpaid work by women (whether in the sphere of production or of social reproduction), needs recognition as a reason for migration. Nevertheless, a question remains as to whether the concept of labour migration per se could or should include such types of unpaid labour-based migration within its ambit.

From a women's movement perspective, a degree of ambiguity on this question is perhaps inevitable in the present social and economic context. At one level, as feminist economists pressing for rethinking 'the Economy' have argued, the unpaid 'care economy' in which people "produce services for their families, friends and neighbours on the basis of social obligation, altruism and reciprocity" (which encompasses a substantial part of women's work) also needs to be taken into account along with the 'commodity econ- omy'. And further, although unpaid care work may be outside the production boundary, its operation has implications both for human well-being and for what goes on inside the production boundary. It affects the quantity and quality of labour supplied to production and the quantity and quality of goods demanded from production (Elson 200I). There is thus a strong case for special attention to the role of unpaid labour in migration, particularly for public policy in relation to social reproduction activities. It has indeed found expression in the Indian women's movement's longstanding activism and demand for public provisioning of basic civic amenities - water, toilets, ration cards, access to health, shelter/housing conditions, etc. - for migrant worker families, particularly in urban areas; for such purposes, the distinction between unpaid work that falls within or outside the production boundary would actually be immaterial.

On the other hand, it cannot be forgotten that the patriarchal family context necessarily makes the unpaid labour of women both cause and consequence of their economic dependence, related unfreedom, and a constraint on employment/income and economic independence. The need for such independence, in turn, is recognized by the women's movement, as an important precondition for opening up greater possibilities for social independence and freedom for women. Yet the evidence of conditions in paid or 'commercial employment' themselves promoting gender inequality has also mounted. Whether in the form of unequal wages, concentration of a relatively larger proportion of the female workforce in particularly low income/productive informal/unorganized forms of employment, gendered hierarchies within production units, or outright discrimination against employing women, etc., gender-based inequalities in the labour market are standard. This is apart from the double burden of unpaid domestic work alongside work for income from outside. Further, and particularly for women struggling against poverty, paid employment has also extended the boundaries of their subordination, and vulnerability, from within the patriarchal family to their situation as workers. Rarely and only tangentially are such employer interests driven by the needs and demands of women workers/employees themselves for decent wages/incomes/hours of work and conditions of life. Income-earning mass self-employment (thought by some to be a form of 'being your own boss') does not appear to have provided any better alternative to such wage employment in a world of sinking incomes from petty production and the inexorable march of integrated markets. With larger 
markets in an unregulated environment inevitably favouring larger entities, the incomes from petty selfemployment, already compressed by a crowd of small producer/seller competitors, are known to often fall below subsistence level (Ghosh 2006).

Ambiguity towards paid/income-earning labour and employment outside the purely family setting and related migration is subjectively perceived by women workers themselves, particularly from among the large majority of the labouring poor, who often associate their need for paid work and related migration with family poverty and other distress conditions, rather than as an avenue of emancipation from patriarchy. Nevertheless, despite such ambiguities, for an approach to labour migration as feeding the development and characteristics of labour markets, there is a clear case for focusing on paid work. However, from a women's movement perspective, a particular focus has to be maintained on the conditions in which women are being drawn into such paid work and its links with the broader economic growth processes, and it is the terms of employment that must hold centre stage in an approach to labour migration, rather than just celebration of the fact of employment and related migration/mobility.

In constructing our macro-view of the gender dimensions of labour migration based on the National Sample Survey on Migration in India 2007-08, we have therefore focused on paid labour. Two preliminary methodological points must be made. First, as has been only recently pointed out, the workforce data in the published reports of NSS can be misleading in terms of the extent of women's paid or incomeearning employment because of the inclusion of unpaid workers (albeit within the production boundary). The gross workforce figures that subsume unpaid and paid work into a common category are therefore inadequate for the purposes of assessing actual employment among women (Mazumdar/Neetha 20II). Unitlevel data from NSS do provide for some subcategories by employment/activity status, thus allowing for the separation of unpaid helpers from other workers (at least from among the self-employed). Such a separation makes it possible to focus on paid/incomeearning workers alone by excluding unpaid helpers from the calculation of the employed. ${ }^{19}$ We do this and have counted only paid/income-earning workers in the category of labour migrants/migrant workers. Our emphasis on paid/income-earning workers is for eliciting the gender structure of the labour market that is absorbing migrants and not a negation of the importance of the unpaid labour of women.
The second point relates to our counting of all migrants who are workers from among migrants defined by change of usual place of residence (UPR) and who have given reasons other than marriage for migration as labour migrants. ${ }^{20}$ Our reasoning is as follows: firstly, the majority of women workers who give marriage as their reason for migrating are workers, only in their immobile and local capacity as wives and daughters-in-law of the village they have married into. As such, when such marriage migrants are counted as migrant workers, the industrial distribution of all female workers after migration appears as virtually the same as the overall industrial distribution of the female workforce in the country. By including marriage migrants, it is neither possible to understand the relative importance of the sectors/industries driving/absorbing labour migrants, nor is it possible to distinguish migrant workers from immobile local workers in the case of women. In order to overcome such problems, we have reluctantly accepted that the present nature of the NSS data offer us little option but to exclude female marriage migrants from the frame, as a preliminary step towards identifying patterns of female labour migration. Elimination of some degree of labour migration camouflaged by marriage is to our minds a lesser error when compared with the immensely inflated picture of female labour mobility if all marriage migrants who are workers were counted as labour migrants.

Secondly, while those who gave 'employment' as their reason for migration may, of course, $a b$ initio be identified as employment/labour migrants, to our minds a better estimation could be made if all usual status paid/income-earning workers from among migrants by UPR, giving 'family movement', 'education', and 'other reasons' for migration, were also counted as labour migrants, since the nature of their employment may be presumed to be premised on their having moved from some other area of origin. The category of short-term migrants should also eo ipso be counted as labour migrants, since they are defined as

19 Broad activity status categories followed by the NSS are I) self-employed, 2) regular salaried workers, 3) casual labour. Among the self-employed, there are three subcategories - namely, 'own account worker', 'employer', and 'unpaid helper'. In order to arrive at paid/incomeearning workers, we have excluded the 'unpaid helpers' from the count.

20 Attempts to locate work-based migration by women have hitherto concentrated on the evidence of higher work participation rates after migration in the gross UPR based migration data (Shanthi 2006). 
Table 7.1: Estimated numbers of labour migrants in sectors/industries (All India, 2007-08). Source: Calculated from NSS Report No. 533 (64/10.2/2).

\begin{tabular}{|c|c|c|c|c|c|c|c|}
\hline \multirow[t]{2}{*}{ Industry } & \multicolumn{2}{|c|}{$\begin{array}{l}\text { Paid/income-earning } \\
\text { migrant workers } \\
\text { excluding migrants for } \\
\text { marriage (UPR) [000s] }\end{array}$} & \multicolumn{2}{|c|}{$\begin{array}{c}\text { Short-term migrants } \\
{[000 \mathrm{~s}]}\end{array}$} & \multicolumn{2}{|c|}{$\begin{array}{c}\text { Total labour migrants } \\
{[000 \mathrm{~s}]}\end{array}$} & \multirow[t]{2}{*}{$\begin{array}{c}\text { Female } \\
\text { share of } \\
\text { total } \\
{[\%]}\end{array}$} \\
\hline & Male & Female & Male & Female & Male & Female & \\
\hline $\begin{array}{l}\text { Agriculture, hunting, } \\
\text { forestry, fishing }\end{array}$ & $\begin{array}{c}6,430 \\
(14.53)\end{array}$ & $\begin{array}{c}2,399 \\
(31.74)\end{array}$ & $\begin{array}{c}2,449 \\
(19.32)\end{array}$ & $\begin{array}{c}922 \\
(43.47)\end{array}$ & $\begin{array}{c}8,879 \\
(15.60)\end{array}$ & $\begin{array}{c}3,321 \\
(34.31)\end{array}$ & 27.22 \\
\hline Construction & $\begin{array}{l}4,257 \\
(9.62)\end{array}$ & $\begin{array}{c}402 \\
(5.32)\end{array}$ & $\begin{array}{c}5,289 \\
(41.73)\end{array}$ & $\begin{array}{c}700 \\
(33.00)\end{array}$ & $\begin{array}{c}9,546 \\
(16.77)\end{array}$ & $\begin{array}{c}1,102 \\
(11.39)\end{array}$ & 10.35 \\
\hline $\begin{array}{l}\text { Mining, manufacturing, } \\
\text { electricity }\end{array}$ & $\begin{array}{l}11,258 \\
(25.44)\end{array}$ & $\begin{array}{c}1,575 \\
(20.84)\end{array}$ & $\begin{array}{c}2,412 \\
(19.03)\end{array}$ & $\begin{array}{c}306 \\
(14.43)\end{array}$ & $\begin{array}{l}13,670 \\
(24.01)\end{array}$ & $\begin{array}{c}1,881 \\
(19.44)\end{array}$ & 12.09 \\
\hline Trade, hotels, restaurants & $\begin{array}{c}8,027 \\
(18.14)\end{array}$ & $\begin{array}{c}474 \\
(6.27)\end{array}$ & $\begin{array}{r}1,190 \\
(9.39)\end{array}$ & $\begin{array}{c}32 \\
(1.51)\end{array}$ & $\begin{array}{c}9,217 \\
(16.19)\end{array}$ & $\begin{array}{c}506 \\
(5.23)\end{array}$ & 5.20 \\
\hline $\begin{array}{l}\text { All services other than } \\
\text { trade, hotels, restaurants* }\end{array}$ & $\begin{array}{l}14,280 \\
(32.27)\end{array}$ & $\begin{array}{c}2,698 \\
(35.70)\end{array}$ & $\begin{array}{c}1,338 \\
(10.56)\end{array}$ & $\begin{array}{c}161 \\
(7.59)\end{array}$ & $\begin{array}{r}15,618 \\
(27.44)\end{array}$ & $\begin{array}{c}2,859 \\
(29.54)\end{array}$ & 15.47 \\
\hline Total & $\begin{array}{c}44,252 \\
(100.00)\end{array}$ & $\begin{array}{c}7,556 \\
(100.00)\end{array}$ & $\begin{array}{c}12,675 \\
(100.00)\end{array}$ & $\begin{array}{c}2,121 \\
(100.00)\end{array}$ & $\begin{array}{c}56,927 \\
(100.00)\end{array}$ & $\begin{array}{c}9,677 \\
(100.00)\end{array}$ & 14.53 \\
\hline
\end{tabular}

* All services other than trade, etc. covers community, social and personal services, finance, real estate, and business services, as well as transport, storage, and communication.

Table 7.2: Share of migrants in India's paid/income-earning workforce (2007-08). Source: Calculated from NSS Reports Nos. $533(64 / 10.2 / 2)$ and $531(64 / 10.2 / 1)$.

\begin{tabular}{|c|c|c|c|c|c|}
\hline & \multicolumn{2}{|c|}{$\begin{array}{c}\text { Paid/income-earning } \\
\text { workforce } \\
{[000 s]}\end{array}$} & \multirow{2}{*}{$\begin{array}{c}\text { Share of female } \\
\text { workers in paid/ } \\
\text { income- earning } \\
\text { workforce } \\
{[\%]}\end{array}$} & \multicolumn{2}{|c|}{$\begin{array}{c}\text { Share of migrant } \\
\text { workers in paid/income- } \\
\text { earning workforce } \\
\text { by sex [\%] }\end{array}$} \\
\hline & Male & Female & & Male & Female \\
\hline Agriculture, hunting, forestry, fishing & $\begin{array}{l}132,467 \\
(46.62)\end{array}$ & $\begin{array}{l}53,266 \\
(65.05)\end{array}$ & 28.68 & 6.70 & 6.23 \\
\hline Construction & $\begin{array}{c}26,529 \\
(9.34)\end{array}$ & $\begin{array}{l}3,145 \\
(3.84)\end{array}$ & 10.60 & 35.98 & 35.05 \\
\hline Mining, manufacturing, electricity & $\begin{array}{l}37,725 \\
(13.28)\end{array}$ & $\begin{array}{l}10,452 \\
(12.76)\end{array}$ & 21.69 & 36.24 & 18.00 \\
\hline Trade, hotels, restaurants & $\begin{array}{l}36,748 \\
(12.93)\end{array}$ & $\begin{array}{l}2,838 \\
(3.47)\end{array}$ & 7.17 & 25.08 & 17.83 \\
\hline All services other than trade, etc. & $\begin{array}{l}49,494 \\
(17.42)\end{array}$ & $\begin{array}{c}12,141 \\
(14.83)\end{array}$ & 19.70 & 31.56 & 23.55 \\
\hline Total & $\begin{array}{c}284,112 \\
(100.00)\end{array}$ & $\begin{array}{c}81,881 \\
(100.00)\end{array}$ & 22.37 & 20.04 & 11.82 \\
\hline
\end{tabular}

those who did not change their UPR but undertook short-term movements and stayed away from their village/town for a period of one month or more but less than six months for employment or in search of employment. Despite the fact that that some underestimation of labour migration by women would still occur (because of the exclusion of those giving marriage as their reason for migration), we believe that the picture of the structure of labour migration that has been so constructed would broadly reflect the actual pattern.

From the 2007-08 NSS survey, the estimated total numbers of so-identified labour migrants in India were 66.6 million, of whom fifteen per cent were female (9.6 million). A little over eighteen per cent of 
the paid/income-earning workforce in the country were migrants. Table 7.I presents our estimations of the numbers of migrant workers of both categories (UPR and short-term) by sector/industry while table 7.2 gives the percentage of migrants in each sector/ industry.

As is obvious from table 7.I, agriculture is the single largest employer of female migrants, despite the fact that table 7.2 makes it apparent that the country's agricultural workforce (both male and female) is overwhelmingly non-migrant or local. Nevertheless, the greater significance of agriculture in the composition of female migration marks out one of the major structural differences between the pattern of female and male labour migration, further reflected in the higher share of women in migrant agricultural labour (27 per cent) than in any other industry/sector.

At the same time, the broad sector composition of female migration gives the impression of a fairly even distribution between agriculture at 34.3 per cent, industry (manufacturing, mining, and construction) at 30.8 per cent, and services (trade, etc., and all other services) at 34.8 per cent. Among male migrants, services at 43.6 per cent and industry at 40.8 per cent are far more dominant, leaving agriculture accounting for only 15.6 per cent of the male migrant workforce. In other words, non-agricultural employment was the destination of some 84.4 per cent of male migration and 65.6 per cent of female migration, within which services also appear to have become very significant among both male and female migrants.

The remarkably even distribution of female migrants across sectors ought not, however, to deflect attention from what we would consider to be the most salient gendered feature of the migratory pattern, namely the strong and relatively greater malecentric bias of migrant employment in both services and industry. Ninety-five per cent of all migrant workers in trade and eight-five per cent of those in other services were male. Men commanded eight-eight per cent of migrant jobs in manufacturing/mining and ninety per cent of the jobs in construction. Further, only in agriculture and construction is the share of women in migrant jobs roughly the same as their share of general employment. In all other major categories of industries/services, women's share of migrant jobs is less than their share of general employment. It thus appears that the impact of diversification of female employment through migration is of a far more limited nature than is initially suggested by the even distribution of female migrant workers across the three broad sectors of agriculture, industry, and services. In fact, the gender biases in the migratory pattern appear to be aggravating the biases against women in non-agricultural employment. A corollary to such aggravated bias is that while migration does seem to be having some impact on the structure and composition of the male workforce in the country, more specifically in raising the share of employment in other sectors relative to agriculture, its impact on the structure of the female workforce is of a far more limited nature - one of the reasons why, despite a fall in the numbers of women in agriculture, it still accounts for over sixty-five per cent of the female workforce in India. Given that the pattern of gross domestic product (GDP) growth has been towards a reduction in the share of agriculture to a mere fourteen per cent and an increase in the share of services to fifty-eight per cent and of industry to twenty-eight per cent, an aggravation of gender inequality in employment incomes is indeed indicated.

Apart from the sectoral structure of migration, an important question that has come from a range of field observations concerns the temporary nature of much of the migratory movement of labour. The 2007-08 NSS data suggest that the movement of roughly one-third of all labour migration in India was definitely temporary. Short-term migrants constituted some 2I per cent of male labour migration and 22 per cent of female labour migration, and some io per cent of all UPR-based female migrants and 7 per cent of male migrants reported that their migration was temporary. Further, an acceleration in return migration is observable between 1993 and 2007-08 from I2.2 to I6.I per cent in the case of male migrants and from 4.4 to Io. 6 per cent in the case of female migrants. ${ }^{21}$ However, as evidenced in the CWDS field surveys, when a more worked-out typology of migration is applied, the actual proportions of temporary labour migrants among both men and women appear as far greater than the official macro-data suggest.

Although the NSS's 2007-08 migration survey has indeed proved somewhat amenable to providing a gendered picture of the sector composition of female labour migration, even apart from the persisting difficulty in arriving at more complete numbers of female labour migrants, there are several other issues and

21 The UPR figures here include not just labour migrantsthey include all workers and non-workers and paid and unpaid workers, but the somewhat common trend between men and women in temporary and return migration does indicate a link to the employment pattern. 
questions that have remained outside the pale of macro-surveys. Among them are the different types of migration, their characteristic features, the modes and manner of migration, the gender differentials, and the links between all of these and labour processes. The following sections of this chapter draw upon some of the findings of the CWDS primary surveys that focus on these questions, but first a few words of explanation of the method, rationale, and scope of the surveys.

\subsection{CWDS Gender and Migration Surveys: Constructing a Meso- level View}

The primary questions taken up by the CWDS surveys related to paid labour migration, and a key methodological issue that had to be addressed was whether the surveys should be directed at households or individuals. After an initial pilot round, it was decided to use two sets of questionnaires in tandem, one for collecting household characteristics, including some migration details of household members, and one for collecting more in-depth information on individual experiences of migration, including conditions of work.

A second question related to how the survey could be pitched at both the source and destination of migrants. Both were deemed necessary for a better understanding or comprehension of migration processes, including its compulsions, trajectories, and outcomes. As such, two categories of sites were taken for the questionnaire-based surveys: one comprising 'village sites', broadly representing source areas of migration (with room for including in-migrants to the village), and the second comprising a range of 'sector sites'. The latter targeted industries/occupations in primarily urban but also rural areas, where prior information indicated a concentration of women migrant workers. ${ }^{22}$

In the village sites, a village census preceded selection of a stratified sample of households, with social groups/caste categories as the primary axis, and perceived economic status as a secondary factor for sample selection. Since the focus was on migration, the

22 Two kinds of information guided the selection of sectors. The first was the employment patterns in urban areas based on NSS employment surveys, and the second was field-based information as to the sectors where women migrants were concentrated. selection process involved a major bias towards households with migrants (seventy per cent), and a minimum one-third quota for the specially marginalized castes/social groups, i.e., Scheduled Castes and Tribes. ${ }^{23}$ From these selected households, individual migrant workers were then selected, with a minimum quota of one-third of women.

In urban areas, broadly considered to be destination sites, only sector-based surveys were conducted based on a more flexible search for and purposive selection of only women migrants (opportunistic sampling). Thus, while several male migrants were covered by the questionnaire addressed to individual workers at village sites, in general they were excluded from the sector-based surveys.

The same questionnaires were used for village sites and sector sites, although differentiated methods of respondent selection were adopted. At the village sites, details of male and female members of all selected households were gathered, and individual migrants were drawn from the stratified household sample. However, where the entry was effected at the sector level, the household details followed from the selection of individual migrant worker respondents. Selection of both village and sector sites was done with an eye to dispersion among several states and an emphasis on prominent catchment areas of migrant labour recruitment or prominent destinations.

While such a method could not generate statistically validated macro-information, the utility of this meso-level view lies precisely in compensating for opacities or gaps in the available macro-statistics by adopting a more purposive site selection, as well as in upscaling micro-observations by introducing an intermediary level that incorporates greater spatial diversities and empirical breadth than do more localized micro-surveys.

Over a period of twenty-four months commencing in January 2009, surveys with the pair of common detailed and structured questionnaires were conducted across twenty of the country's twenty-eight states covering 5,007 individual migrants and 5,558 households. These were drawn from village surveys as well as sector-based surveys.

23 The quota for SC/ST was put in place because of our observation that women of these communities had a higher compulsion/propensity to be involved in labour migration. The minimum quota for individual women migrant workers could not however be filled everywhere, particularly in Uttar Pradesh and Bihar, which in a sense confirms the picture of male bias in labour migration observable in the macro-data. 
Figure 7.1: States where surveys were conducted named and coloured darker grey-rest of India lighter grey. Black dots indicate survey actual site locations. Source: The authors.

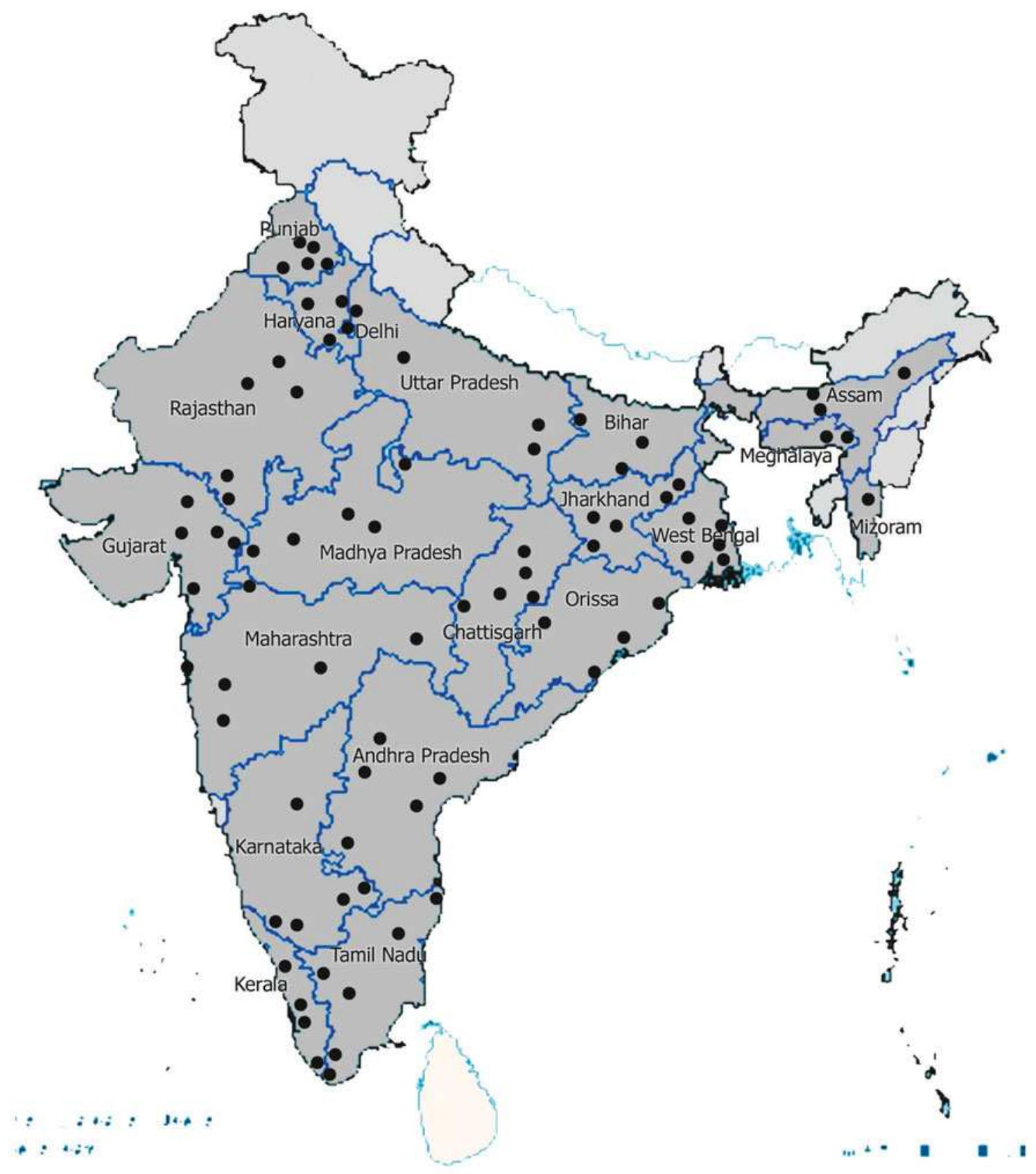

Comprehensive village surveys were conducted in thirty-five districts across seventeen states. Preliminary censuses covered I6, oro households in forty-three village sites, eliciting information on caste, relative economic status, and the number of economic migrants. These were followed by detailed questionnaires covering a total of 673 households without migrants and 2,564 individual migrants and their households. Of the individual migrants covered by the village surveys, I,903 were males and 66I were females.

Sector-based surveys directed at women migrant workers were conducted in twenty of the twenty-eight states, within which the urban areas covered consisted of seven large cities and ten medium-sized and smaller towns. Sector-based surveys covered 2,4I2 individual migrants and their households. 
In all, 3,073 female migrant workers and I,934 male migrant workers and their households were covered by the survey. Of the 3,073 women migrants, I,594 were surveyed in rural areas and I,479 in urban areas. In combination, the village- and sector-based migrant workers were accessed across more than seventy-five districts, apart from the seven large cities (including the three mega-cities of Mumbai, Delhi, and Kolkata). ${ }^{24}$

Whether regions/terrains should be classified into socio-cultural/historical, ecological, or agro-climatic zones for surveys on migration in India, a country with multiple scales of diversity, is still an open question for us. ${ }^{25}$ But for an idea of the mix that characterized the areas where this series of micro-surveys were located, we list the areas where the surveys were conducted and indicate them on the map.

They included

1. the agriculturally developed heartland of Malwa and Doaba regions of the state of Punjab; the developed but semi-arid western zone and eastern trans-Gangetic plains of Haryana; the upper Doab, Rohilkhand, and Purvanchal regions of the country's most populated state of Uttar Pradesh ${ }^{26}$ [all part of the landlocked north to north-west of the country];

2. the north-western, north-eastern as well as southern alluvial plains of the predominantly agricultural state of Bihar; the lateritic, red, and gravelly undulating region in the western part of West Bengal (eastern reaches of middle India's Chotanagpur plateau with a sizable tribal population), as well as the deltaic alluvial plains in the south of the state [north central and the coast of east India];

3. the ethnically highly diverse humid subtropical hills and valleys of the three states of Assam, Meghalaya, and Mizoram, [the north-east];

24 The other large cities were Bangalore, Chennai, Pune, and Ahmedabad.

25 The NSS divides each state into various regions, which are largely based on topographical/agro-climatic features.

26 Malwa in Punjab lies between the Sutlej and Yamuna rivers; its regional cultural history includes early mass conversion to Sikhism. Doaba is the tract of land between the confluence of the rivers Sutlej and Beas. In Uttar Pradesh, the Upper Doab refers to the western alluvial tracts between the rivers Ganga and Yamuna; Rohilkhand is on the upper plains of the Ganga; Purvanchal in eastern Uttar Pradesh is largely Bhojpuri-speaking.
4. the arid inland western parts as well as the coastal regions of Orissa state [east coast]; the newlyformed mineral rich states of Jharkhand and Chhattisgarh with large forest cover and tribal populations; the arid plains of Bundelkhand, the underdeveloped parts of the Malwa plateau area, and the agriculturally developed upper plains of the Narmada river basin in the country's second largest state of Madhya Pradesh [central highlands];

5. the semi-arid south-western reaches of the Aravalli Hills and sandy eastern plains in the physically largest state, Rajasthan [north-west India];

6. the significantly industrialized southern and the more backward north-eastern parts of the state of Gujarat; and in the otherwise most industrialized state of Maharashtra: Marathwada (west-central Deccan Plateau), Khandesh (north-western corner of the Deccan plateau with a significant tribal population) and the sugar cane belt in the southwest [western India];

7. the three cultural zones of the state of Andhra Pradesh - i.e., the semi-arid regions of Telengana and Rayalseema (eastern parts of the Deccan plateau) and the irrigated fertile coastal region of the state; the dry northern, torrid southern, and highly industrialized central parts of Tamilnadu; the Malabar coast in Kerala; and the fertile plains and slopes in the south as well as the northern arid regions of Karnataka [southern peninsula].

As it turned out, the survey sites were found to be located in thirteen of the fifteen agro-climatic zones in India, i.e., in the four zones of the Upper-Gangetic, Trans-Gangetic, Lower-Gangetic, and MiddleGangetic Plains, the four zones of the Eastern, Central, Western, and Southern Plateaus and Hills, the three zones of the East-Coast, West-Coast, and Gujarat Plains and Hills, the Western Dry Region, and the Eastern Himalayan Region. As such, the generalized findings are indeed of relevance in arriving at the big picture of gender and labour migration in India.

\subsection{Of Temporary and Permanent Migration: Developing a Typology}

The CWDS surveys applied a typology of migration that gave particular space to circularity, seasonality, contingency, and duration. Building on the range of observations garnered from earlier micro-studies and reports from the women's organizations, the typology 
evolved largely from pilot field observations. Based on such a typology, the household questionnaire generated data on types of migration for a total of 16,156 household members who were labour migrants, of whom 7,398 were female and 8,758 were male when the two categories of sites, sector-based and villagebased, were taken together. At a preliminary level, the most striking finding was the predominance of temporary migration among both men and women. Only forty-two per cent of women and thirty-six per cent of the men who were labour migrants in all the households covered by the surveys were long-term migrants, i.e., those who migrated for settlement at destination or who otherwise settled there. All others were various types of temporary migrants. The types of temporary migration became an area of special interest in this study. The large proportions of temporary migrants highlight the unsettled nature of the employment regime that is driving migration in contemporary India.

Circulatory migrants, i.e., those who migrate without any long-term workplace/residence at any particular destination and return to base for more than a month per year, appeared as the most significant type of temporary migration, comprising twenty per cent of the migrating women and twenty-three per cent of the male migrants in the households surveyed. These percentages include circulatory migrants of shorter duration (spells of less than four months) as well as of longer duration (more than four months). ${ }^{27}$ Around nine per cent of both male and female migrants were short-term seasonal migrants, i.e., those who migrate for work of a seasonal nature for a period ranging from a few days to around three months, and distinguished from circulatory in that they do not keep circulating back and forth, but spend most of the year at their base area. Two per cent of the female and three per cent of the male migrants were irregular short-term migrants, i.e., those migrating outside any established pattern or occupation, driven by abnormal contingencies/desperation rather than for any particular form or type of employment or seasonal demand for labour. Circulatory, short-term seasonal, and irregular short-term migration are all forms of short-term migration. The CWDS surveys suggest that

27 In the typology followed, a distinction was made between longer and shorter duration for circulatory migrants on the grounds that the experience of migration and related issues is somewhat different. From a broader perspective, however, both could be considered relatively short-term. the proportion of short-term migrants is roughly around one-third of male and female labour migration, significantly greater than the NSS estimates. It is the undercounting of short-term labour migration that, to our minds, is the key to the invisibilization of the 'armies of women' migrating for work.

Taking only the village sites, i.e., excluding the members of the households of women migrant workers in pre-selected sectors, the proportions of shortterm migrants actually increased, to 4I per cent among the women migrant workers and to 53 per cent among the male migrant workers. Circulatory migration increased to 24 per cent of labour migrants in the case of women and to 35 per cent in the case of men; short-term seasonal migrants increased to I4 per cent for women and I2 per cent for men; and irregular short-term movements rose to three per cent among women and five per cent among men. While this draws attention to the agrarian push as well as pullback involved in much short-term migration, several other processes are involved, including the absorption of semi-feudal patriarchal relations into the wage economy.

The second major type of temporary migration was medium-term, i.e., migration for employment/ work in any predetermined occupation/industry for a broadly fixed period of up to a few years. Among the women migrants of all households surveyed (village + sector), sixteen per cent were involved in mediumterm migration; among the men it was eighteen per cent. For the village sites alone, it is interesting that the proportions of medium-term migrants dropped sharply to nine per cent for women, but increased to twenty-one per cent for men. It appears that the points of origin among women migrant workers of medium term, particularly in urban areas, are more thinly dispersed across both rural and urban areas, and/or they are drawn/recruited from particular catchment pockets rather than by the more generalized kind of medium-term movement from village India that appears to be so significant in the pattern of male migration. Our sense was that the significance of medium-term migration is increasing, more so among male migrants, but also among female migrant workers in urban areas.

We turn next to the two other categories of migrants that are not normally included in labour migration, but were specially included in our typology thanks to discussions in the women's movement. One was long-distance commuters, i.e, those who commute across long distances (at least $50 \mathrm{~km}$ ) either daily or weekly, normally travelling to another district 
- from villages to towns/cities, from cities to rural areas, from one town to another town, etc. - all outside the perimeter of normal day-to-day movement for work within or around any village/town/city. The inclusion of commuting as a type of migration was based on early discussions within women's organizations about the phenomenon of the massing of women domestic workers in the trains coming from the rural interiors of districts in West Bengal to the city of Kolkata, leaving their homes as early as 3 or 4 a.m and returning late in the evening. Later, other reports also came in about women living in the towns of Maharashtra who undertake a reverse movement to rural areas for daily agricultural labour, although, compared to the Kolkata domestic workers, their commuting was for even less regular forms of employment (Sainath 2007). ${ }^{28}$ The same was observed during the pilot round in West Bengal, where women from the urbanized families of jute mill workers (an industry in endemic crisis) were seen commuting by trains till late at night for potato harvesting in rural areas more than $100 \mathrm{~km}$ from their residence, and that too for payment only in kind. Unable to afford the fare, many of the women commuters tend to travel without tickets, and are vulnerable to various types of harassment. Such commuting accounted for some six per cent of the women migrants when sector and village site households were combined, increasing by only one per cent from the universe of only village sites. Among men, it was significantly more from the village end at ten per cent, dropping to seven per cent in the combined universe. Of course, given the emphasis on households of only women migrant workers in the sector surveys, the male-female patterns are not strictly comparable when the sectors are included. Nevertheless, there is a suggestion that urban-to-rural commuting is perhaps of relatively greater proportions among women, a possibility that is supported by the evidence from NSS employment surveys of significantly higher proportions of urban women working in agriculture (Neetha/Mazumdar 2005).

The other specially included category was $m i$ grants for family care, i.e, those who migrate under the expectation (implicitly or explicitly) that they will perform various forms of unpaid care work for those who have migrated for employment. Separated from marriage migrants with unspecified purposes, migrants for family care accounted for four per cent of the women migrants when the households from sec-

28 The Hindu National Newspaper, 24 Jan 2007 - P. Sainath, 'It's been a hard day's night'. tors and village sites were combined, and five per cent in village sites alone. Given that the survey was primarily geared towards paid labour migration, the facets and patterns of migration for unpaid care work could not be elicited. There is need for further research in this area, which to our minds is significant for developing a greater understanding of how women's unpaid labour fits into circuits of migration. Some two per cent of the male migrants of the households in village sites also reported migrating for family care, perhaps because of responsibilities in relation to ageing parents, or even possibly wives and children. However, since the individual migrant questionnaires were not served on family care migrants, the surveys did not generate information on the question of the gendered features of such care and its implications.

\subsection{Types of Migration and Caste Hierarchies}

Types of migration are very closely correlated with particular sectors and occupations. Diversified service occupations, for example, are linked more with longterm and medium-term migration. Occupations based on hard manual labour, generally attached to degraded conditions of work, on the other hand, are more closely correlated with short-term and circular migration. At the same time, hierarchies of occupations in India also have a history of being correlated with caste hierarchies and other forms of marginalization of social groups such as adivasis (autochthonous tribal communities). At the time of adoption of the Indian constitution in 1950 , special provisions, including quota-based reservations in the legislatures, education, and government employment, were made for the members of castes that had for centuries been oppressed with the stigma of untouchability (dalits), recognized in the constitution as Scheduled Castes (SC), and similar provisions were made for marginalized tribal communities recognized as Scheduled Tribes (ST) ${ }^{29}$ Nevertheless, discrimination and marginalization based on their historical disadvantage has continued to resonate and even evolve to new levels.

29 Ninety per cent of the tribals live in tribal minority states spread over a broad girdle in middle India from Gujarat and Maharashtra in the west to West Bengal and Orissa in the east. The tribal majority states are all located in the north-east region of the country. Northeast tribals are, however, less than ten per cent of the total tribal population of India. 
Table 7.3: Distribution of types of migration of women workers within social groups/caste categories (\%). Source: The authors.

\begin{tabular}{|c|c|c|c|c|c|}
\hline Type of Migrant & $\begin{array}{c}\text { General }^{\mathrm{a}} \\
\text { (Upper } \\
\text { Castes) }\end{array}$ & OBC $^{\mathbf{a}}$ & $\mathrm{MBC}^{\mathbf{b}}$ & $\mathrm{SC}^{\mathrm{c}}$ & $S T^{d}$ \\
\hline Long-term migrant & 44.51 & 41.56 & 21.51 & 25.98 & 20.81 \\
\hline Medium-term migrant & 30.02 & 22.98 & 30.11 & 17.36 & 10.48 \\
\hline Short-term seasonal migrant & 3.93 & 11.91 & 10.75 & 14.54 & 25.16 \\
\hline Irregular short-term migrant & 6.42 & 1.13 & 1.08 & 1.08 & 1.45 \\
\hline Circulatory migrant of longer duration & 2.90 & 9.93 & 5.38 & 19.52 & 22.10 \\
\hline Circulatory migrant of shorter duration & 4.55 & 6.95 & 4.30 & 6.06 & 10.00 \\
\hline Daily/weekly commuters & 4.97 & 3.69 & 25.81 & 14.67 & 8.71 \\
\hline Migrant for family care & 2.69 & 1.84 & 1.08 & 0.81 & 1.29 \\
\hline All & 100 & 100 & 100 & 100 & 100 \\
\hline All Short-term including Circulatory & 17.81 & 29.93 & 21.51 & 41.18 & 58.71 \\
\hline \multicolumn{6}{|c|}{$\begin{array}{l}\text { a The legal category of General does not declare caste status and includes all castes/communities not listed under } \\
\text { other categories. It however is mainly comprised of upper castes in all communities/religions. It includes many Mus- } \\
\text { lims, for they are distributed only between the General category and other backward classes/castes (OBC). } \\
\text { b MBC refers to a sub-category of OBC called Most backward castes. MBC is a category used only in some states. } \\
\text { c In the Indian constitution, Scheduled Castes do not include Christian or Muslim castes/communities who by origin/ } \\
\text { status face similar historical disadvantage and stigma as their counterparts among the Hindus. } \\
\text { d Like all other non-general categories, Scheduled Tribes are also listed at state levels and some may be listed as ST in } \\
\text { some states and as SC or OBC in others. There are distinct social differences between the } 90 \text { per cent of STs located } \\
\text { in middle India and the close to } 10 \text { per cent whose tribal origins lie in the north-east, including the fact that the middle } \\
\text { India STs are low-status minorities in all the states where they are located, while the STs of the north-east include } \\
\text { some majority communities in their respective states with exclusive rights over the land. This table includes STs from } \\
\text { the north-east, although the majority were from the middle India belt. }\end{array}$} \\
\hline
\end{tabular}

Violent atrocities on dalits and tribals have been an important concern of the contemporary women's movement since the I970s. However, it was through engagement with the growing agrarian crisis that the movement came to focus on the complexities of caste, class-, and gender-based violence with a betterdefined understanding. At the same time, the manner in which politics around caste erupted on the Indian political scene in the context of implementation of recommendations for reservation (in government employment and education) for the intermediate category of other backward classes/castes (OBCs) ${ }^{30}$ and violent upper-caste resistance and opposition to it subsequently ensured a place for caste and identity on the political canvas as never before. It also ensured that movements for women's equality could not, henceforth, be immune to the entrenched basis of caste-

30 Interestingly, one of the factors taken into account for identifying OBCs by the Mandal Commission was "castes/classes where participation of females in work is at least 25 per cent above the state average". based inequalities. Discussions on women's rights could not therefore ignore the assertion of social identities. While this gave a critical edge to movements for equality, mass-based women's organizations moved on to absorb the issues emerging from identity-based experience and assertion into their overall perspective of interrogation of social inequalities. From such a reconceptualized perspective, examination of the distribution of the relative shares of the various types of migration among female migrant workers of the various social group/caste categories brings interesting insights. Table 7.3 above presents such a distribution as it emerged from the CWDS survey of individual migrants. The table follows the official and legal categorization and listings of castes and communities.

A feature evident from the table is that among upper-caste women migrant workers the share of longterm and medium-term migration was predominant, with close to 75 per cent of them concentrated in long- and medium-term migration. In contrast, shortterm and circulatory migration accounted for around 
59 per cent of migrant women workers from scheduled tribes and 4I per cent of scheduled caste women migrants. The concentration of scheduled castes and tribes in this mass of general labour that circulates at the lower end of the productive economy, in which casual labour in agriculture, construction, and brickmaking figure prominently, draws attention to the present limitations of current migration, as conditioned by the prevailing economic and social system, in effecting the transformation of degrading feudal hierarchies.

When examining the more detailed occupational profiles of individual migrant workers, we found that sixty-six per cent of upper-caste female migrant workers were in the fairly diversified service sectors, as professional, technical, and related workers, call centre employees, sales workers in the more developed parts of the retail industry, nurses, office workers, and in other white-collar services. Further down the caste hierarchy there was progressively more concentration in hard manual-labour-based bhattas (brick kilns), seasonal agriculture, and paid domestic work. Migrant women workers from other backward castes/classes (OBC) were also relatively more concentrated in paid domestic and agricultural seasonal work although well over a third of them were distributed across various other services. Scheduled Caste (SC) women appeared to be more concentrated in brickmaking, while Scheduled Tribe (ST) migrant women were more concentrated in construction. ${ }^{31}$ The corollary of such concentrations of SC and ST women in manual occupations of a casual nature based on hard labour was their low proportion in white-collar services. White-collar services accounted for just nineteen per cent of SC and eighteen per cent of ST women migrant workers.

In contrast to these extremes separating workers across caste categories, paid domestic work occupied a significant place in the occupational profiles of women migrants of all caste categories, while textilebased manufacturing employment was fairly evenly present in all the categories, other than the ST category. As such, the indications are that concentration in migrant manual labour in agriculture, construction, and brickmaking at one end and access to diversified, relatively more settled, and white-collar forms of employment for migrants at the other are more determined by initial location in caste hierarchies. On the

31 More than 22 per cent of SC women migrants were in brickmaking while 28 per cent of ST women migrants were construction workers. other hand, gender, rather than caste lines, is obviously the primary axis that determines migration for paid domestic work.

\subsection{Patterns of Change in Women's Occupations through Migration: Diversification or Concentration?}

Four occupations dominated the profile of the women migrant workers who responded to the individual questionnaire-agriculture (I7.5 per cent), paid domestic work (I5.9 per cent), brickmaking (II.8 per cent), and construction (I4.3 per cent). The remaining forty per cent included vendors or petty traders, textile (spinning/tailoring/stitching) and other factory workers, home workers, sales workers in large malls as well as other shops, nurses in hospitals and other medical establishments, security guards and sanitation workers, beauticians, teachers in formal and informal educational institutions, call centre employees, a range of office workers, and professionals such as lawyers, doctors, journalists, and engineers. To get an idea of the pattern of occupational shifts and changes effected through migration, figures 7.2 and 7.3 present the occupations before and after their last or present round of migration for migrants with rural destinations, and figures 7.4 and 7.5 do the same for urban destinations.

In rural areas, the big story is the shift from a number of occupations (including in agriculture) to brickmaking. The share of brick kiln workers more than doubled from around nine per cent in the premigration profile of the workers to over twenty-one per cent post-migration. ${ }^{32}$ Such a concentration has several negative implications, particularly in relation to gender. Brickmaking in India is one of the most arduous manual occupations - involving softening of the soil/mud with water, digging out of the softened mud with a spade (generally done by males), packing the clay into moulds with hands, emptying them on the ground in rows (done by men and women), then stacking them for further drying in the sun (done by women and children). These workers (patheras) who

32 Estimates of the number of brick kilns in India vary from 50,000 to I00,000. According to World Bank sources, in 2010 brick production was estimated to be I40 billion per year, with production increasing 5-IO per cent a year. Estimates of the number of workers vary widely from 5-IO million to 25 million, of whom roughly 45 per cent are women. 
Figure 7.2: Occupations of women workers before migratiom. Rural destinations. Source: CWDS survey, Individual migrant questionnaire (village sites and sector sites combined).

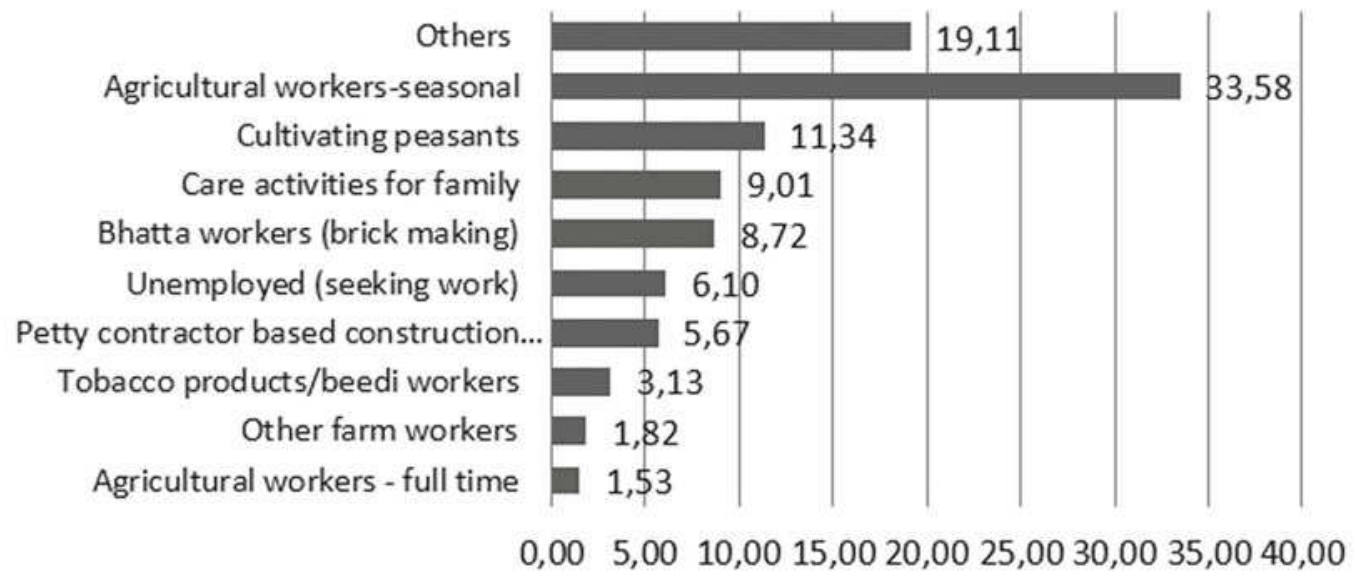

Figure 7.3: Occupations of women workers after migratiom. Rural destinations. Source: CWDS survey, Individual migrant questionnaire (village sites and sector sites combined)

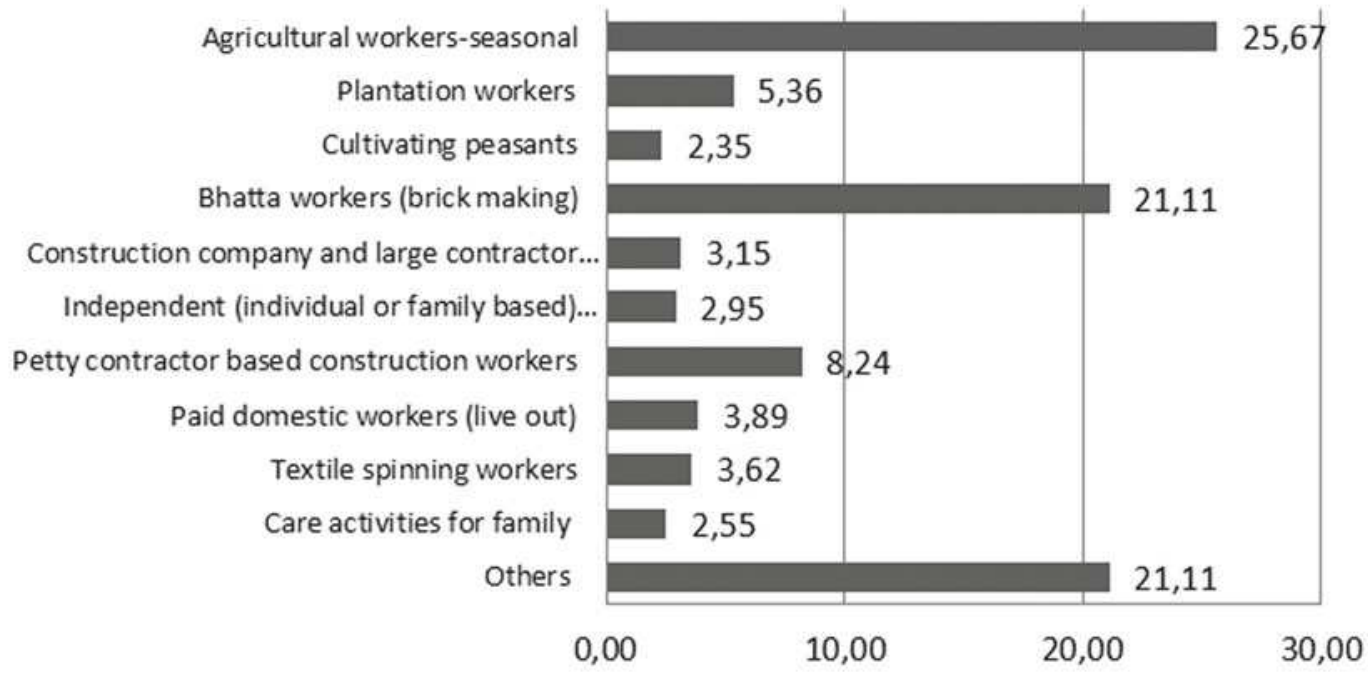

mould the raw bricks are recruited in male/female pairs (jodis). Specialized firers of the kilns, on the other hand, are always male and generally different from all other categories of brick workers in community and areas of origin. Other categories of workers include (with some permutations and combinations) those who manually carry and arrange the green bricks at the kiln (beldars) and those who manually carry the fully baked and cooled bricks to storage points (nikasis) - mostly women, recruited in male/ female groups, but not necessarily in pairs. All functions involve hard toil out in the open all day. Payment rates are fixed per I,000 bricks for all categories except the firers who have time-rated wages. The workers stay on site, at some distance from any village or other residential settlement, in rough temporary shacks, although some of the more long-standing and larger kilns have built single-room tenement lines.

Significant catchment areas for migrants in brickmaking are the drought-prone inland western parts of Orissa with high tribal concentrations, from where workers migrate to the southern states of Andhra Pradesh, Karnataka, and even Tamilnadu, though several districts in Tamilnadu are themselves recruiting grounds for Karnataka kilns. Kilns in West Bengal and Bihar draw workers from Jharkhand even as workers from Bihar travel eastwards and westwards to kilns in other states. From Rajasthan, Chhattisgarh, and now Uttar Pradesh, workers are taken to the kilns of Gujarat. Often it is assumed that the catchment areas are 
only economically backward and arid areas. Yet the green revolution belt of western Uttar Pradesh is perhaps one of the biggest suppliers of workers to the kilns across Punjab, Haryana, and other parts of Uttar Pradesh. Along with uneven regional development, it is inequities and iniquities within village India, the loss of artisanal occupations and the absence of other employment opportunities that has condemned large proportions particularly of dalits to conditions of dire poverty, even in developed regions, which in turn makes them amenable to migrating year after year to the brick kilns. The brickmaking season across the country generally falls within September/October to June, and with few exceptions it has become a completely migrant occupation. The predominant mode of recruitment is by labour contractors through the payment of advances to workers at the villages of origin, often well before the season begins. At the beginning and close of the season, railway stations close to the catchment areas in Orissa and districts on the Madhya Pradesh/Gujarat border can be seen packed with workers carrying their pots and pans and other daily necessities. If at the time of transportation to the kilns contractors' agents may be seen dealing with the police and facilitating passage, the worst situations arise during return journeys, when workers are abandoned to their own resources. Jam-packed into the trains as they are, there have even been cases of deaths through suffocation.

The hard labour involved in the circular migratory occupation of brickmaking, the fact that it virtually condemns women and men to a lifetime of six to eight months away from their homes every year, the fact that their children's education suffers, and the fact that it offers little potential for autonomy because the unit of labour is a family and wage payment is piece-rated - all indicate that although some survival may be ensured from this form of labour migration, it offers virtually no opportunity for social advancement or economic independence for women. Since brickmaking is included under manufacturing in the $\mathrm{Na}$ tional Industrial Classification (NIC), the shift from agriculture to brickmaking would appear in the macro-data as a shift to manufacturing and may be seen as diversification. The reality, is, however that labour migration to brick kilns and fields presages social immobility even as it involves permanent migratory circulation (Agnihotri/Mazumdar 2009). ${ }^{33}$

Agriculture including for plantations remains the largest occupational destination for rural women migrants and accounted for 33.4 per cent of rural female migrant workers in the CWDS surveys. However given its higher share in the pre-migration profile of the workers (48 per cent) it appears that although agriculture remains the most significant destination and in fact the share of women migrants in agriculture may be increasing (Venkateswarlu 2007), there is also a significant move away from agriculture in the rural migratory pattern. ${ }^{34}$ Agricultural migration is generally directed at pockets or regions of more developed or irrigated agriculture, but the streams of migration by women are more driven by other social factors. For example, women have not been a significant proportion of the large-scale migration streams from Bihar for agricultural labour in Punjab. On the other hand, prominent routes for women are from the rain-fed tribal pockets in the eastern parts of Jharkhand and southeast Bengal to the irrigated agriculturally developed paddy and potato areas of West Bengal, and from the upland Rajasthan/Gujarat/Madhya Pradesh border, which again has concentrations of tribal communities, to the cotton and groundnut fields in various parts of Gujarat. Young adolescent girls are particularly in demand for hybridized cottonseed farms (Bacillus thuringiensis, BT) that are linked through contracts to the major multinational corporation seed monopolies. $^{35}$

Perhaps the most concentrated form of migration by women in agriculture is for sugar cane harvesting in western and southern India, for a much longer period than is commonly seen in seasonal agricultural work. Unlike in the other areas mentioned above, farmers themselves are not so involved in recruitment of migrants. ${ }^{36}$ It is the sugar mills (cooperatives as well as other private mills), rather than the farmers of Maharashtra, south Gujarat, and Karnataka, that use labour contractors to recruit workers for harvesting on the farms from which sugar cane is supplied. For these sugar cane cutters, the pattern of migratory life and work is of a longer duration than is otherwise seen in agricultural migration. It involves a significant

33 A striking instance of the scale of immobility observed in the field was the case of a young woman from Jharkhand in an advanced stage of pregnancy whom we met in a kiln located in north-east Bihar, and who had herself been born in a kiln where her mother had been working.

34 In figure 7.2 workers in agriculture before migration include seasonal agricultural labour, cultivating peasants, full-time agricultural workers, and other farm workers.

35 Gujarat has become a major centre for such cottonseed farms, although they are also found in Andhra Pradesh and Karnataka (Venkataswarlu). 
part of the year (generally October to May), and as in the case of brick kiln workers, there is little scope for social mobility, despite the use of modern factory production and accumulation systems. ${ }^{37}$ However, unlike brick workers, who generally work around one kiln in a season, cane cutters move from site to site within a single season, as a form of nomad labour. They are recruited in gangs, but again composed of male/female pairs, and wages are piece-rated (per tonne). The male/female pairs are referred to as koytas, which also refers to the sickle-like implement used for cutting the cane, and while the men cut the cane, the women bundle and carry it on their backs to whatever mode of transport is used by the mills. Without any fixed place to stay, these workers and their families are protected from the elements only by small tents that are pitched near wherever they may be working. They have even greater difficulties in accessing water and sanitation facilities than brick workers.

High-density routes that have been established for this male/female pair-based migration for sugar cane harvesting are I) from districts in Marathwada and $\mathrm{Vi-}$ darbha, Maharashtra to the southern districts in the same state that are home to the largest concentration of sugar mills in the country, 2) from the contiguous tribal belt along the borders of Maharashtra, Gujarat, and Madhya Pradesh to the sugar mills of Gujarat, and 3) from the north-eastern parts of Karnataka to the state's Belgaon Dharwad corridor adjacent to the sugar belt of Maharashtra, as well as to the agriculturally developed southern parts of the state (Mysore area) and even into Tamilnadu. ${ }^{38}$ Major communities involved in such migration include large concentrations of dalits, adivasis, and other backward castes, including some denotified tribes (DNT). ${ }^{39}$ In Maharash-

36 Second only to Brazil in cane sugar production, India is also the world's largest consumer of sugar. A total area of I. 8 million hectares is under cane sugar in Maharashtra, Karnataka, Gujarat, and Tamilanadu. Of the 566 sugar mills, 56 per cent are in the cooperative sector, 34 per cent in private hands, and the remainder in public ownership. Sugar cane is the third major crop after paddy and wheat and the second largest agro-processing industry after cotton and textiles.

37 Estimates of the number of such sugar cane cutters based on output and required labour inputs place the number of workers at one million in Maharashtra alone, of whom 70 per cent work in Maharashtra and 30 per cent in Gujarat.

38 In the north Indian state of Uttar Pradesh, the state that otherwise produces the largest share of the country's sugar cane, women are not, however, a part of migration for sugar cane harvesting. tra, even as their low wages for this backbreaking labour have become a regular source of agitation, sugar cane cutters recently waged a strike struggle against attempts to introduce the mechanical harvesters that would displace them from even such degraded conditions of employment. ${ }^{40}$

Two occupations that were absent in the pre-migration profile of any of these rural female migrants are noticeable. They are paid domestic work and textile spinning workers. The presence of migrants among rural domestic workers is a new phenomenon, and it is possible that they initially migrated for other occupations or in association with other migrant workers. The spinning mill workers, on the other hand, are recruited migrants, generally young and unmarried girls; for example in Tamilnadu girls have been recruited from the southern districts of the state for production work in spinning mills in the state's north central districts of Erode, Dindigul, Tirupur, and Coimbatore. For some years such labour recruitment operated under the guise of an apprenticeshipcum-marriage-assistance scheme, known as the 'Sumangali Marriage Scheme', whereby girls worked on a two-to-three-year contract with a spinning mill, at the end of which a lump sum was given to them purportedly for use in their marriage (read dowry). Since the girls were confined to residential camps run by the mill managements, it became known as a 'camp coolie system' and following a court order in 2007, decreeing it as 'bonded labour' and therefore illegal, the scheme as such has gone underground, although the pattern of migration it initiated does not appear to have changed. At the same time government district rural development agencies (DRDAs) seem to have become recruiters of young girls from districts such as Anantapur and Vizianagram in Andhra Pradesh and Ganjam, Orissa for spinning mills in ru-

39 Many of India's nomadic communities were notified as 'criminal tribes' by the British colonial regime through the infamous Criminal Tribes Act, I87I. After independence, they were denotified and are still referred to as Denotified Tribes (DNT), although they may be otherwise differentially classified as scheduled caste/tribe (SC/ST) or other backward class/caste (OBC) in various states of the country. See Government of India, National Advisory Council, Working Group on Denotified and Nomadic Tribes.

40 In 2008 , demanding higher wages, the union of cane cutters stopped the lorries coming to pick up workers at the beginning of the cane cutting season from entering Beed district. At the same time, a statewide agitation against the introduction of imported mechanized harvesters had been able to stop their use in most areas. 
ral parts of southern India. Some of these mills are state of the art in terms of technology, but located in rural isolation.

In urban areas, the patterns of employment are visibly more diversified. Rural-to-urban movement accounted for eighty per cent of the surveyed urban migrants. The pre-migration profile of the urban migrants indicated that around thirty per cent of the workers had been unemployed or engaged in only cooking, cleaning, and care activities for their families, and around one-third had been in agriculture, construction, and domestic work taken together. Thirtyseven per cent were in various diversified occupations even prior to their latest round of migration including some manufacturing workers, but mostly in a range of services. ${ }^{41}$ What is, however, the most striking feature of the transformation of occupations in rural-to-urban migration is the visible process of concentration in paid domestic work. The pre-migration profile of the urban women migrants shows that only around ten per cent were domestic workers. This share practically trebled to twenty-seven per cent in the post-migration profile. Arguably, the intensity of the process of concentration is part of an ongoing structuring of gender and class-based social hierarchies in urban India, in which the concentration of women workers in paid domestic work is emerging as a key element, a process that is to some extent being driven by migration from rural areas.

Domestic workers who 'live out', i.e., not with their employers, constitute the majority of such migrant domestic workers who generally migrate along with some family members. Among 'live in' domestic workers, who generally migrate singly, patterns of migration are being driven by contractor/agents (placement agencies) who have targeted tribal girls from Jharkhand and even plantation areas of West Bengal and Assam as their prime recruiting grounds. The average monthly wage for the live-out domestic workers was around three-quarters of the national floor for rural wages that has been established by the Mahatma Gandhi National Rural Employment Guarantee Scheme (MGNREGS) (the national floor being Rs 100 , equivalent to slightly less than two dollars per day), while the live-in workers earned just about equivalent to the floor.

41 In the figures, the category of 'others', includes all occupations that were less than I.5 per cent of the sample, but actually covered a range of services in both rural and urban areas.
Three of the service occupations of these urban migrants were singularly absent in the pre-migration profiles of the workers, namely sales workers in retail outlets, beauticians/hairdressers, and call centre workers. Further, the share of manufacturing/production more than doubled from 5 per cent pre-migration to I2 per cent post-migration. The share of vendors/ petty traders also doubled from 2.6 per cent pre-migration to 6 per cent post-migration, and the share of nurses rose from 2.6 to 4.24 per cent. Apart from the above, the urban sample had some 36 per cent in more diverse services (including sales workers, beauticians, call centre workers, and professional/technicalrelated workers), whereas the pre-migration profile showed less than 27 per cent in diversified services.

Interestingly, among urban women migrants in construction, it appears that independent and petty-contractor-based construction (both in roughly equal measures) and large-scale companies are all involved in drawing women into urban construction activity. From around ten per cent before migration, the numbers in the post-migration urban sample had risen to fifteen per cent. The greater presence of independent construction workers indicates that the migration of these workers to urban areas was perhaps less contractor-driven in comparison to rural areas and more based on independent expectations of finding employment.

But the most significant change effected by migration to urban areas that needs to be highlighted is that thirty-one per cent of the surveyed women workers who were unemployed or involved in only familybased domestic duties (in a sense housewives) before migration were able to effect entry into paid employment in urban areas. At the same time, it is noticeable that only around fourteen per cent of the urban workers had actually made a transition from agricultural to non-agricultural employment. This reinforces the point that emerged from the NSS data that female labour migration is not leading to a large-scale structural shift of the female workforce out of agriculture. However, the reasons for the fact that only a small proportion of urban migrant women workers are being drawn from the agricultural workforce, and a much larger proportion are being drawn from unemployed or hitherto housebound women, perhaps need to be located in the different attitudes that control or direct women's involvement in relation to paid employment according to feudal caste and status hierarchies. It is well known that upper-caste women were traditionally restricted from working outside the home, and certainly less involved in the manual la- 
Figure 7.4: Occupation pattern of female migrant workers before migratiom (Urban) [\%]. Source: CWDS survey, individual migrant questionnaire (village sites and sector sites combined).

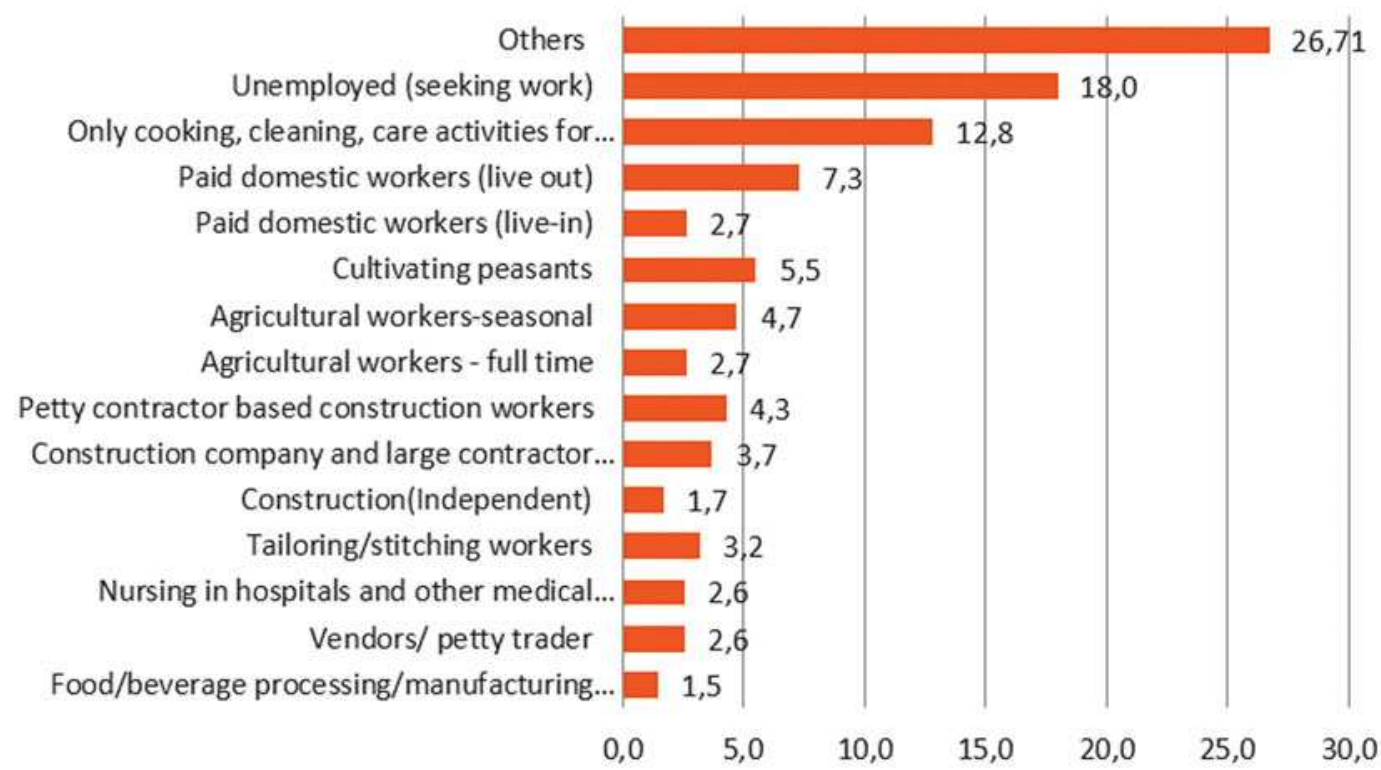

Figure 7.5: Occupation pattern of female migrant workers after migratiom (Urban) [\%]. Source: CWDS survey, individual migrant questionnaire (village sites and sector sites combined).

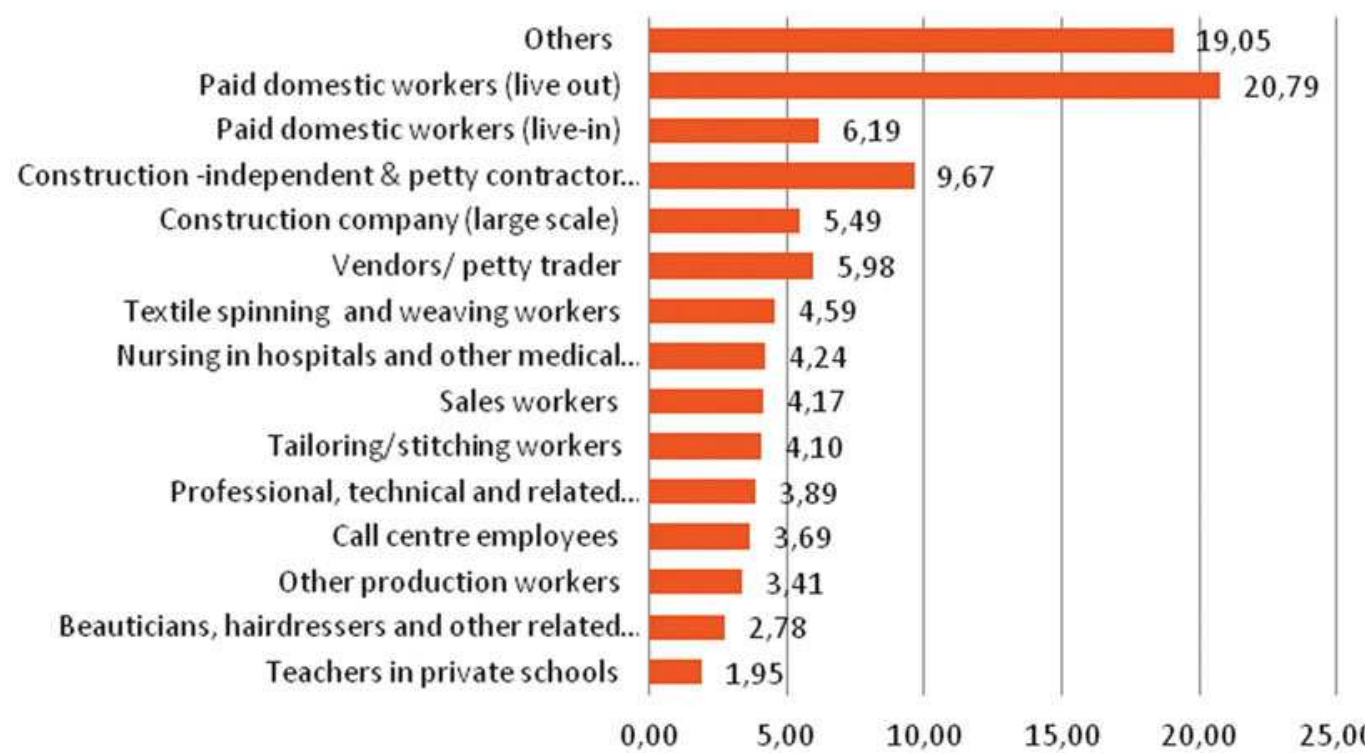

bour associated with agriculture. Conversely, lower social and caste status compels greater involvement of women in paid work in agriculture. The more diversified and less stigmatized service occupations that have developed in urban areas have clearly opened up more opportunities for hitherto more restricted upper-caste women than for traditional female workers in agriculture, who are more drawn more from SC, ST, and even OBC backgrounds.

\subsection{Of Contractors and Independence: Modes and Manner of Migration.}

Interestingly, information gathered on the mode of migration, given in figure 7.6 indicates the prevalence of strong independent motivation in labour migration by women in both rural and urban migration streams. Such independence is substantially greater among ur- 
ban women migrant workers (80.7 per cent). Of course, this independent mode of migration also includes decisions taken by couples/nuclear families and not necessarily in a purely individual capacity. This becomes clear from the manner of their migration given in figure figure 7.7 which shows that the largest category is of women who migrated with only family members (43.2 per cent) in contrast to men among whom the largest category is of those who have migrated alone (42.7 per cent). ${ }^{42}$

Nevertheless, it is significant that a great majority of the female migrant workers in both rural and urban areas felt a degree of involvement in decisions related to their migration. The CWDS field surveys indicate that the overwhelming majority of the women workers migrated with clear intentions of finding employment, including perhaps even some of those who otherwise moved for associational reasons. Further, the fact that almost a quarter (close to twenty-three per cent) of female migrant workers reported that they have migrated alone indicates that 'autonomous' migration by women is on the rise. With another seven per cent of female migrants indicating that they migrated in all-female groups, autonomous migration by women for employment, particularly in urban areas, is a phenomenon that can no longer be ignored.

At the same time, employer or contractor mobilization of workers is significant in rural female labour migration. ${ }^{43}$ Some twenty-five per cent of rural women migrant workers were mobilized by contractors (figure 7.6). Here some separation has been made between local and outside contractors, although given the prevalence of tiers among contractors, it is probable that at least some of the local contractors were themselves mobilized by outside agents.

Within mobilization by contractors, the dominance of the outside contractor/agent/employer is clear, particularly in migration for brick kilns (bhattas) and agriculture and in some cases for construction. Among urban women migrant workers, however, only

42 Among women migrant workers, even among the over 24 per cent who migrated in mixed male and female groups, there were many who had migrated with husbands.

43 The lineages of the contractor regime for recruiting/ mobilizing/controlling workers for manual labour in India go back to forced labour in colonial times-its continuing exploitative nature long recognized by labour law in the country, which is why the abolition of contract labour (defined in Indian law as employment through a contractor) has been a long-standing demand of the labour movement. a little over six per cent were mobilized by contractor, but even here the outside contractor is slightly more of a factor than the local. Among such workers mobilized by contractors were women who had migrated alone or in all-female groups, raising questions as to how appropriate it would be to assume that they are all autonomous migrants. The greater role of non-local contractors in the mobilization of women workers also runs counter to the common assumption that the relationship between women and contractors is based on kin or local/social associations. It remains true that the nature of contractor-driven migration, which is often based on advances given well before actual migration, often leads to forms of debt bondage

The Inter-state Migrant Workmen's Act, 1979 (the only labour law that specifically addresses migrant workers) was designed to provide for some worker entitlements in precisely such contractor-driven modes of migration (although only for those who cross state boundaries). It has remained the most ineffectual of all the labour laws, as has repeatedly been pointed out (2nd Labour Commission 2002; NCEUS 2007). It stipulates that transportation and related costs have to be borne by contractors, and that wages should be paid for even the journey time. It also has provisions for a displacement allowance, apart from other provisions for ensuring decent conditions of work. But this law is known more for its violation than its implementation and does not even apply to intra-state migration. In practice the advance from employers for movement costs is treated as a loan, so that workers have to pay it off through their labour; our fieldwork showed that indeed the amount advanced to them was generally deducted from their wages at the end of the migration round.

\subsection{Concluding Remarks}

This chapter has attempted to highlight some of the most neglected and hitherto poorly delineated dimensions of internal labour migration in India from a perspective drawn from the experiences of the contemporary women's movement in the country. The CWDS research project on which it is based has been distinctive in trying to cover not just one or a few corners of India; it attempted to reflect as far as possible the entire current picture. As such, the chapter's main arguments and findings - summarized below - concern tens of millions of diverse women moving within a billion-plus country of sub-continental proportions. 
Figure 7.6: Mode of last migration by women migrant workers (\% distribution). Source: CWDS survey, individual migrant questionnaire (village sites and sector sites combined).

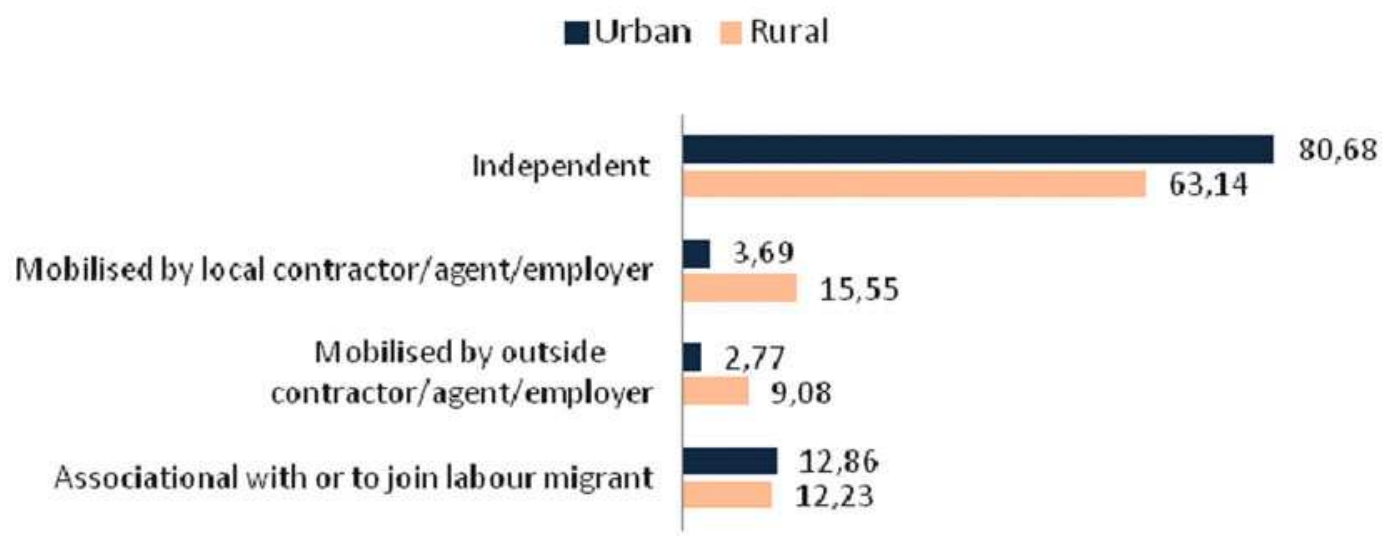

Figure 7.7: Manner of last migration (\% distribution). Source: CWDS survey, individual migrant questionnaire (village sites and sector sites combined).

Female $\square$ Male

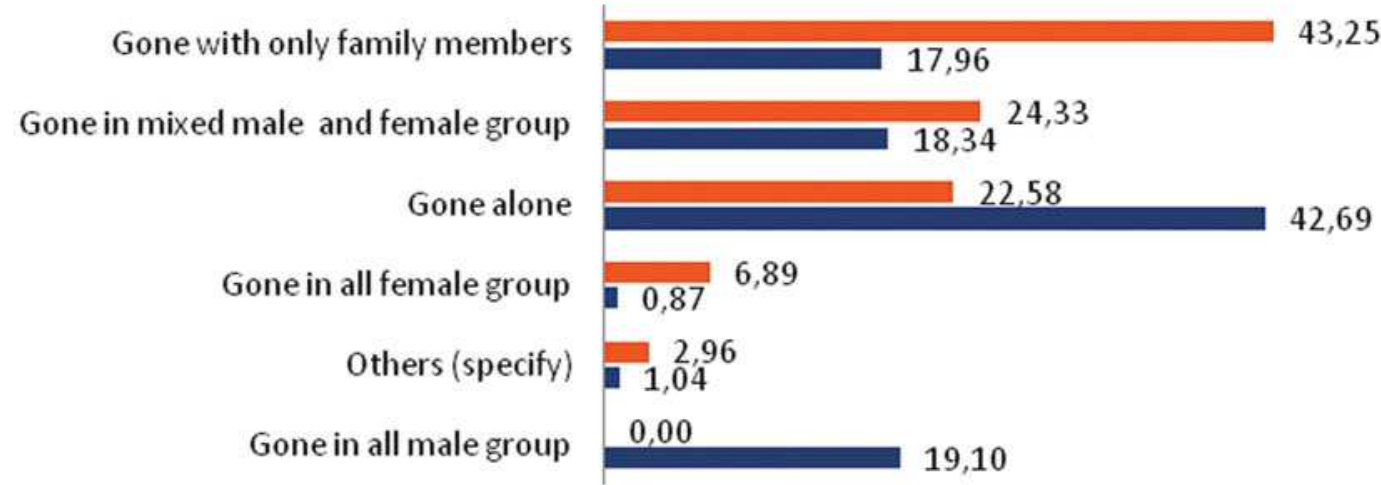

At a general level, the findings of primary surveys conducted by the CWDS from 2009 to $201 \mathrm{II}$ using a socially grounded typology of migration provide a meso-level view of the predominance of the temporary in contemporary labour migration, including medium-term and circular labour migration. Temporary migration is shown to be a more significant phenomenon than is indicated in the available macro-data for both men and women. As such, the primary research findings posit the need for reorientation away from the present conceptual dominance of a permanent settlement paradigm in the official macrosurveys, and greater recognition of different types of temporary migration in the concepts and definitions adopted. We argue that the macro-level underestimation of short-term and circular labour migration is a most significant factor in invisibilizing much of women's labour migration in India.
Regarding the social direction of the patterns of women's labour migration in India, the meso-level view from this research project provides the following major findings.

- There is strong evidence that migration has led to only limited diversification of women's employment, in precisely the period when the country's higher levels of particularly service-driven growth had become the most celebrated topic of Indian development discourse.

- The empirical evidence indicates occupational shifts through migration leading to greater concentration of women in a relatively narrow band of occupations, often with limited scope for social advancement, generally differentiated however along the fault lines of entrenched social hierarchies based on caste and community. 
- It shows more medium-term and long-term migration among women workers from upper-caste communities accompanying relatively greater levels of diversification of their employment into various types of services in urban areas.

- At the other extreme is the concentration of migrant women workers from the historically disadvantaged and stigmatized communities of scheduled castes and tribes in short-term and particularly circular migration for hard manual labour with little scope for social advancement.

- At the same time, while a distinctive movement towards concentration of women in paid domestic work, particularly through rural-to-urban migration, cuts across all castes/tribes/communities, textile-based factory production also appears relatively less characterized by caste features, having drawn migrant women from all communities other than scheduled tribes.

- Further, in some circular migration-based employment regimes with high levels of female density, such as brickmaking across the country and sugar cane cutting in western and southern India, women's wage work in the capital-accumulationoriented modern sector is itself subsumed in labouring units comprised of male/female pairs or family units. When such subsumption is combined with piece rates, not only is there no scope for independent work/activity and income, but indeed legal quantification of the value of individual women's work becomes an insurmountable problem. This is compounded by a cycle of advances and debt-based tying of such labouring units that means that while survival may be ensured by such modes of migration, the possibilities of social advancement are severely limited.

The macro- and meso-level findings as laid out in this chapter challenge some assumptions that have become commonplace in approaches to women's work and work-based migration.

- On the one hand, the low shares of women in labour migration for industry and diversified services run counter to the assumption that liberalization and globalization leads to feminization of labour and to related migration. In fact, the escalated devaluation of women's traditional work appears to be confronted with employment constriction and a narrow range of options, rather than compensation for loss of earlier employment through adequate expansion and diversification in paid employment opportunities for women.
- Overall, female labour migration has had less of an impact on the structure of the female workforce in comparison to men, reflected in the continuing and relatively greater concentration of women in agriculture and in low employment rates among urban women, evident in the macro-statistics.

- It appears that such a continuing weight of agriculture in the structure of the female workforce is also partly maintained because relatively smaller proportions of women migrant workers in urban areas have been drawn from the agricultural workforce; instead more of them (particularly from the higher castes) have made a transition from nonemployment to employment.

- Both the macro-data and the village sites component in the CWDS meso-level study indicate an extreme degree of male bias in migration-based employment in industry and services (less so in agriculture) at levels even greater than in non-migrant employment. It is argued that the pattern of migration in India is actually enhancing structural gender inequalities in the labour market, and needs to be correlated to the massive reduction in the absolute numbers and employment share of the female workforce, evident in the official workforce statistics for 2007-08 and 2009-IO.

The fact that the above findings are for a period of high growth in India raises several additional questions. Obviously such growth, characterized by a rapidly declining share of agriculture in the country's GDP and accelerated growth primarily in services and to a lesser extent also in industry, has not generated commensurate demand in terms of employment, for which women have paid the main price of reduced employment. Despite the push towards migration from distress induced by the agrarian crisis, a pullback also appears to be operating, linked to the predominantly temporary nature of the developing employment regime, and the widespread inability of the migrant workforce (male and female) circulating at the lower ends of the economy to sustain social reproduction without periodic retreat to the village economy, even as the village economy is not providing sufficient employment. As such, the overall analysis implicitly draws attention to the need to bring into the debate questions related to structural limitations to the migration enterprise under the current growth path: limitations in effecting a) durable or structural occupational shifts away from agriculture for women workers, b) escape from or transformation of degrading semi-feudal social relations based on caste hierarchies and patriarchy, and c) escape from the massive employment crisis 
that women are now facing in India.

Nevertheless, the urge to change the conditions of their life and work is evident in the high proportion of women migrant workers declaring that they themselves decided to migrate, whether in families or independently. This, combined with a significant presence of autonomous migration by women, does indeed indicate a wave of social assertion and aspirational motivation, so important for the advance of the women's movement. Yet the overall findings of the CWDS study show that structural constraints shaped by macro-processes under neo-liberal-driven economic growth have narrowed the field of opportunity for women's work-based migration and indeed sometimes reinforced entrenched patriarchies.
While focusing on the empirical features of female labour migration in India, the chapter's emphasis on a gendering of the issues and questions from a women's movement perspective has foregrounded the intersections between gender, caste, and class differentials and inequalities that are reflected in migration patterns in contemporary India. The social outcome of much of female labour migration does not appear to be moving towards the lessening of such differentials; and even demand-driven migration patterns appear to be reconfiguring and providing new foundations for inequalities. Our study thus highlights the need for a redistributive and equalizing growth agenda for the country, a demand for which the women's movement in India has been among the most active advocates.

\section{Annex}

Table 7.4: Location of CWDS survey sites. Source: The authors.

\begin{tabular}{|c|c|c|}
\hline $\begin{array}{l}\text { Geographic region in } \\
\text { India }\end{array}$ & States - subregions & Districts/ metropolitan cities \\
\hline \multirow[t]{2}{*}{ North to north-west } & $\begin{array}{l}\text { Punjab - Malwa lies between the Sutlej and Yamuna } \\
\text { rivers; its regional cultural history includes early mass } \\
\text { conversion to Sikhism, and Doaba, the tract of land } \\
\text { between the confluence of the rivers Sutlej and Beas }\end{array}$ & $\begin{array}{l}\text { Districts: Bathinda, Sangrur, Patiala, } \\
\text { Jalandhar, Ludhiana }\end{array}$ \\
\hline & $\begin{array}{l}\text { Haryana - semi-arid western zone and eastern trans- } \\
\text { Gangetic plains }\end{array}$ & Districts: Hisar, Rewari, Panipat \\
\hline \multirow[t]{4}{*}{$\begin{array}{l}\text { North-central to east } \\
\text { coast }\end{array}$} & $\begin{array}{l}\text { Uttar Pradesh - Upper Doab, western alluvial tracts } \\
\text { between the rivers Ganga and Yamuna, Rohilkhand, } \\
\text { on the upper plains of the Ganga so named because } \\
\text { of the rule of Rohilla Pathans established in Mughal } \\
\text { times. Purvanchal, eastern Uttar Pradesh, largely Bhoj- } \\
\text { puri-speaking }\end{array}$ & $\begin{array}{l}\text { Districts: Baghpat, Badayun, Varanasi, } \\
\text { Azamgarh }\end{array}$ \\
\hline & $\begin{array}{l}\text { Bihar - north-western and southern alluvial plains of } \\
\text { this predominantly agricultural state }\end{array}$ & Districts: Siwan, Begusarai, Nawada \\
\hline & $\begin{array}{l}\text { West Bengal - the lateritic, red, and gravelly undulating } \\
\text { region in the west (eastern reaches of middle India's } \\
\text { Chotanagpur plateau with a sizeable tribal population) } \\
\text { and deltaic alluvial plains in the south of the state }\end{array}$ & $\begin{array}{l}\text { Districts: West Medinipur, North } 24 \\
\text { Parganas, South } 24 \text { Parganas, Bardha- } \\
\text { man }\end{array}$ \\
\hline & $\begin{array}{l}\text { Orissa - the arid inland western parts as well as the } \\
\text { coastal regions }\end{array}$ & $\begin{array}{l}\text { Districts: Balangir, Khorda, Bhadrak, } \\
\text { Ganjam }\end{array}$ \\
\hline \multirow[t]{2}{*}{ North-east } & $\begin{array}{l}\text { Assam - warm, humid, lower and upper Brahmaputra } \\
\text { valleys }\end{array}$ & Districts: Kamrup, Nalbari, Dibrugarh \\
\hline & Meghalaya and Mizoram-humid subtropical hills & $\begin{array}{l}\text { Districts: East Khasi Hills, Jaintia Hills, } \\
\text { Aizawl }\end{array}$ \\
\hline
\end{tabular}




\begin{tabular}{|c|c|c|}
\hline $\begin{array}{l}\text { Geographic region in } \\
\text { India }\end{array}$ & States - subregions & Districts/ metropolitan cities \\
\hline \multirow[t]{4}{*}{$\begin{array}{l}\text { Central Highlands to } \\
\text { north-west }\end{array}$} & $\begin{array}{l}\text { Jharkhand - Chotanagpur plateau south of the Indo- } \\
\text { Gangetic plan with a large tribal population. Dry, sub- } \\
\text { tropical climate }\end{array}$ & $\begin{array}{l}\text { Districts: Ranchi, Lohardagga, Gumla, } \\
\text { Dumka, Jamtara }\end{array}$ \\
\hline & $\begin{array}{l}\text { Chhattisgarh - Plains region between the 'Northern } \\
\text { hilly region' in the north and the 'Bastar plateau' in the } \\
\text { south of the state }\end{array}$ & $\begin{array}{l}\text { Districts: Korba, Janjgir-Champa, Rajn- } \\
\text { andgaon, Raipur, Mahasamund }\end{array}$ \\
\hline & $\begin{array}{l}\text { Madhya Pradesh - arid plains of Bundelkhand (Uttar } \\
\text { Pradesh border), the Malwa plateau area, and agricul- } \\
\text { turally developed upper plains of the Narmada river } \\
\text { basin }\end{array}$ & $\begin{array}{l}\text { Districts: Tikamgarh, Jhabua, Indore, } \\
\text { Bhopal, Raisen }\end{array}$ \\
\hline & $\begin{array}{l}\text { Rajasthan - semi-arid southwestern reaches of the } \\
\text { Aravalli Hills and sandy eastern plains }\end{array}$ & $\begin{array}{l}\text { Districts: Udaipur, Dungarpur, Nagaur, } \\
\text { Sikar, Jaipur }\end{array}$ \\
\hline \multirow[t]{2}{*}{ Western Region } & $\begin{array}{l}\text { Gujarat - the significantly industrialized southern and } \\
\text { the more backward north eastern parts }\end{array}$ & $\begin{array}{l}\text { Districts: Surat, Ahmedabad, Gand- } \\
\text { hinagar, Mehsana, Dahod, Panchmahal }\end{array}$ \\
\hline & $\begin{array}{l}\text { Maharashtra - rain shadow region of Marathwada, the } \\
\text { coal belt of Vidarbha, Khandesh (south of the Satpura } \\
\text { range with a significant tribal population), and the } \\
\text { concentrated sugar cane belt in the south-west of the } \\
\text { state }\end{array}$ & $\begin{array}{l}\text { Districts: Parbhani, Chandrapur, } \\
\text { Nandurbar, Satara, }\end{array}$ \\
\hline \multirow[t]{4}{*}{ Southern Peninsula } & $\begin{array}{l}\text { Karnataka - the fertile plains and slopes in the south } \\
\text { as well as the northern arid regions }\end{array}$ & $\begin{array}{l}\text { Districts: Mysore, Kodagu, Kolar, } \\
\text { Koppal }\end{array}$ \\
\hline & $\begin{array}{l}\text { Andhra Pradesh - semi-arid regions of Telengana and } \\
\text { Rayalseema (southern plateau) and the irrigated fertile } \\
\text { coastal region that constitute three cultural zones of } \\
\text { the state }\end{array}$ & $\begin{array}{l}\text { Mehboobnagar, Anantapur, Guntur, } \\
\text { Prakasam }\end{array}$ \\
\hline & $\begin{array}{l}\text { Tamilnadu - the dry northern, torrid southern, and } \\
\text { highly industrialized central parts }\end{array}$ & $\begin{array}{l}\text { Districts: Villupuram, Dindigul, Tirunel- } \\
\text { veli, Kanya Kumari, Tirupur }\end{array}$ \\
\hline & $\begin{array}{l}\text { Kerala - the Malabar coast in the north of the state as } \\
\text { well as southern and central parts of the erstwhile } \\
\text { state of Travancore-Cochin }\end{array}$ & $\begin{array}{l}\text { Districts: Mallapuram, Ernakulam, Kot- } \\
\text { tayam, Trivandrum }\end{array}$ \\
\hline Metropolitan cities & $\begin{array}{l}\text { NCT of Delhi (city state), Maharashtra, West Bengal, } \\
\text { Karnataka, Tamilnadu }\end{array}$ & $\begin{array}{l}\text { Cities: Delhi, Mumbai, Kolkata, Banga- } \\
\text { lore, Chennai, Hyderabad, Pune, }\end{array}$ \\
\hline
\end{tabular}

\section{References}

Agnihotri, Indu, 200I: "Re-reading histories", Seminar, 505, at: <http://www.india-seminar.com/cd8899/cd_frame 8899.html>.

Agnihotri, Indu; Mazumdar, Indrani, 2009: "Dusty Trails and Unsettled Lives: Women's Labour Migration in Rural India”, in: Indian Journal of Gender Studies, I6 (September/December): 375-399.

AIDWA (All India Democratic Women's Association), 2003: Expanding Dimensions of Dowry (New Delhi: Publisher).

Banerjee, Narayan; Ray, Lokenath, I99I: "Seasonal Migration: A Case Study from West Bengal”, New Delhi: Centre for Women's Development Studies (Mimeo).

Bangasser, Paul E., 2000: The ILO and the informal sector: an institutional history, ILO Employment Paper, 2000/ 9 (Geneva: ILO).
Breman, Jan, 1996: Footloose Labour: Working in India's Informal Sector (Cambridge: Cambridge University Press).

Centre for Women's Development Studies, 2005: "Globalization and the Women's Movement in India, Seminar report”, 2005, at: <http://www.cwds.org/occasional papers.htm> and <http://www.cwds.ac.in/OCPaper/ GlobalisationReport.pdf $>$.

Chaudhry, S; Devi Mohan, T.; Devi, T.; 20II. "Of Marriage and Migration: Bengali and Bihari brides in a UP Village”, in: Indian Journal of Gender Studies, I8,3 (October): $3 \mathrm{II}-340$.

Elson, Diane, 200I: "For an Emancipatory Socioeconomics" (Geneva: UNRISD), at: <http://www.unrisd.org/ $80256 \mathrm{~B}_{3} \mathrm{Coo}_{5} \mathrm{BCCF} 9 /$ (httpPublications)/o3BA6AogBE 6 E42D8Ci256BC900453D9B?OpenDocument>.

Ghosh, Jayati, 2005: Trade Liberalization in Agriculture: An Examination of Impact and Policy Strategies with Spe- 
cial Reference to India (New York: UNDP, Human Development Report Office, Occasional Paper I2).

Ghosh, Jayati, 2006: "Being your own boss", in: Frontline, 23,23 (Nov. I8-Dec. OI).

Hugo, Graeme, 2003: "Circular Migration: Keeping Development Rolling?”, at: <http://www.migrationinformation.org/feature/display.cfm?ID=I29>.

Karat, Brinda, 2005: "Neo-liberal Agendas and Rural Women's Concerns", in: Globalization and the Women's Movement in India (New Delhi: Centre for Women's Development Studies): 2I-26.

Karlekar, Malavika, 1995: "Gender Dimensions in Labour Migration - An Overview”, in: Schenk-Sandbergen, Loes (Ed.): Women and Seasonal Labour Migration (New Delhi: Sage).

Kundu, Amitabh, 1999: Urban Informal Sector in India: Macro Trends and Policy Perspectives. Issues in Development, Discussion Paper 25 (Geneva: ILO).

Mazumdar, Indrani; Neetha, N., 20II: "Gender dimensions: Employment trends in India, I993-94 to 2009-IO”, in: Economic and Political Weekly, XLVI,43.

Menon, A.; Vadivelu, G. A., 2006: "Common Property Resources in Different Agro-Climatic Landscapes in India”, in: Conservation \& Society, 4: I32-I54.

Mosse, David; Gupta, Sanjeev; Mehta, Mona; Shah, Vidya; Rees, Julia [KRIBP Project Team, 2002: "Brokered Livelihoods: Debt, Labour Migration and Development in Tribal Western India”, in: Journal of Development Studies, 38,5: 59-88.

NCEUS (National Commission for Enterprises in the Unorganised Sector), 2007: Report on the Conditions of Work and Promotion of Livelihoods in the Unorganised Sector (New Delhi: Government of India, NCEUS).

Neetha, N.; Mazumdar, Indrani, 2005: "New developments in labour hiring and employment in urban India" (Mimeo) (New Delhi. Centre for Women's Development Studies).

NSS (National Sample Survey) Office, 20Io: Employment and Unemployment Situation in India 2007-2008. NSS Report 53I, NSS 64 ${ }^{\text {th }}$ Round (64/Io.2/I) (New Delhi: Government of India, Ministry of Statistics \& Programme Implementation).
NSS (National Sample Survey) Office, 20I0: Migration in India: 2007-2008, NSS Report 533, NSS $64^{\text {th }}$ Round (64/Io.2/2) (New Delhi: Government of India, Ministry of Statistics \& Programme Implementation).

NSS (National Sample Survey) Office, Migration in India, I993, I999-2000, 2007-2008; Employment and Unemployment Survey Reports, I993-I994, I999-2000, 2004-2005, 2007-2008, and 2009-2010. Various Rounds (New Delhi: Government of India, Ministry of Statistics \& Programme Implementation).

Rao, M.S.A. (Ed), I986: Studies in Migration (Delhi: Manohar).

Rawal, Vikas, 2006: “The Labour Process in Rural Haryana (India): A Field-Report from Two Villages”, in: Journal of Agrarian Change, 6,4 (October): 538-583.

Sainath, P., 2007: “It's been hard day's night", in: The Hindu National Newspaper, 24 January 2007; at: <http://www. hindu.com/2007/oI/24/stories/20070I2404621300. htm>.

Schenk-Sandbergen, Loes (Ed.) I995: Women and Seasonal Labour Migration (New Delhi: Sage).

Second National Commission on Labour, Report, 2002, (New Delhi: Govt. of India, Ministry of Labour).

Shanthi, K., 2006: Female Labour Migration in India: Insights from NSSO Data, WP-o4. (city: Madras School of Economics),

Sheel, Ranjana, 1997: The Political Economy of Dowry (New Delhi: Manohar).

Srivastava, Ravi, 2005: "Internal Migration Links with Poverty and Development, Country", Regional Conference on Migration and Development in Asia, Lanzhou, China (Mimeo). (London: DFID).

Teerink, Rensje, I995: "Migration and Its Impact on Khandeshi Women in the Sugar Cane Harvest", in: Schenk-Sandbergen, Loes (Ed.): Women and seasonal labour migration (New Delhi: Sage).

Venkateswarlu, Davuluri, 2007: "Recent Trends in Employment of Child Labour in Hybrid Cottonseed Production in India” (Mimeo) (Hyderabad: Glocal Research and Consultancy Services).

Open Access. This chapter is distributed under the terms of the Creative Commons Attribution Non-commercial License, which permits any noncommercial use, distribution, and reproduction in any medium, provided the original author(s) and source are credited. 


\title{
8 From 'Integration into Cities' to 'An Integrated Society': Women Migrants' Needs and Rights in Fujian Province, China
}

\author{
Yu Zhu and Liyue Lin $^{1}$
}

\begin{abstract}
$^{2}$
This chapter addresses the rights issues of women migrants in China in the context of their complex, lengthy, unstable, and diverse migration processes, and from a gender perspective. It first documents recent efforts by governments and relevant institutions in China to address the rights issues of women migrants. It then presents results from two recent surveys of rural-urban migrants and from subsequent in-depth interviews in Fujian Province, a major destination of rural-urban migrants in China. Although great efforts have been made and significant progress has been achieved, major rights issues still exist for women migrants. The chapter suggests that the common conceptualization of rural-urban migration as a one-way transition is oversimplified. It proposes a non-urban-centred and non-residence-based approach to migrants' rights. Migrants require inclusion in a system of rights that extends wider than the municipality or locality level, probably to a nationally integrated system, to be adequate to their real, complex patterns of movement, instead of integration into a locality-specific system of social rights only. In addition, the chapter illustrates other policy implications that flow from a more gendersensitive analysis of key issues affecting the achievement of women migrants' rights and social entitlements, including education and access to work after the age of forty.
\end{abstract}

Keywords: China, Fujian Province, women migrants, needs, rights, social integration, urban integration, urbanand residence-based approach.

\subsection{Introduction: Studying Migrants' Differentiated Needs}

China has perhaps the largest internal migrant population in the world, and nearly half of this flow is com-

1 Professor Yu Zhu is Professor in the School of Geography and Director of the Centre for Population and Development Research, Fujian Normal University, Fuzhou, China. Dr. Liyue Lin is a Lecturer at the School of Geography, Fujian Normal University, Fuzhou, China.

2 This chapter is based on the results of the research project on 'The differentiation of women migrants in the migration process and their rights issues: Case studies from Fujian Province of China', funded by the International Development Research Centre (IDRC) of Canada (IDRC Grant number: I05447-00I). It has also benefited from the authors' research supported by the Social Protection in Asia (SPA) policy research and network-building programme funded by the Ford Foundation and IDRC. The authors would like to thank the Fujian Provincial Population and Family Planning Commission for facilitating this research, and Des Gasper, Thanh-Dam Truong, and two anonymous referees for their invaluable help in the preparation and revision of this chapter. posed of women. Women migrants both benefit from and make important contributions to society through migration, as do their male counterparts. A large body of literature has emerged both in China and internationally on the social rights of migrants, some of which has shown that women are still placed in a disadvantaged position, especially in society and in the communities of destination (e.g., Chan 1996; Solinger I999; Cai 2000; Yang and Chen 2000; Yang 200I; Fan 2003; Xu 2006). Addressing women migrants' rights is of great significance not only to migration research, but also to relevant social policy-making.

While some of the academic work is more refined, policy debates on and practices to promote the rights of internal migrants in China are by and large premised on an urban-centred and/or residence-based approach, and on the principle of the bukou. ${ }^{3}$ The urban-centred approach is linked to the debate on 'urban citizenship', and seeks to establish migrants' full rights in the destination cities by granting them an urban status (e.g., Chan 1996; Solinger 1999; Wang/ Zhang 2006). The popular tendency is to treat migrants as a homogeneous group, without paying atten- 
tion to the complexity of 'difference', in terms of gender, age, and ethnicity. In cases where particular attention has been paid to women migrants and their specific rights issues, a gender perspective is often lacking.

This chapter contributes to the policy debates on women migrants' rights issues in China by moving beyond the debate surrounding only the hukou to bring into focus issues of rights arising from, and embedded in, the migration process itself. The chapter shows how the migrants' unsettled position may be related to other factors besides the hukou system, such as their household strategies and the intrinsic demand of the destination cities for temporary migrant labour. Diversification in the migration process in terms of the final destinations has been noted, such that cities where migrants work and live cannot be necessarily assumed to be the location where they will finally settle down (Zhu 2003, 2007; Zhu/Chen 20I0). While paying special attention to women migrants, the chapter also includes men migrants in the analysis, and makes explicit gender comparisons, which show both differences and similarities between women and men in terms of the migration process and rights issues.

Using data from a survey in Fujian Province, a related survey of the five districts of its capital city Fuzhou, and subsequent in-depth interviews, the chapter highlights the complexity and diversity in migration processes and outcomes and argues for treating women migrants as a socially differentiated category which spans different patterns of migration flows and corresponding needs for rights protection. Located in the coastal area of south-east China, Fujian Province is one of the major destination areas for internal migration, along with other coastal provinces ${ }^{4}$ (Zhu 2007; $\mathrm{Zhu} /$ Chen 20IO), and so we expect that the research findings in Fujian may have a wider reference value.

3 China's hukou system dates back to the Northern and Southern Dynasties some I,500 years ago. Its recent form was shaped through the promulgation of the 'regulation on household registration' in 1958. This stipulates that all citizens must register with the relevant authorities at the places of their permanent residence, with the household as the basic registration unit; all births, deaths, and migrations are required to be registered by the same authorities; the transfer of one's household registration from a rural to an urban place needs to be approved; and all people are assigned a registration status as either 'agricultural' or 'non-agricultural' in the registration system (Zhu 2004). However, since the reform era, there have been various reforms in the hukou system, causing various changes to this regulation in different places.
Bringing the understanding of mobility patterns of migrants closer to rapidly changing realities and emerging needs will have implications for policy-making for China as a whole.

In the following section (8.2) we highlight recent efforts by governments and relevant institutions to protect the rights and interests of both women and men migrants. This provides the context against which our findings are discussed. As many rights issues of women migrants in China have been examined in the literature without distinguishing between men and women, as is also the case when governments and relevant institutions address these issues, we will assess such efforts without singling out women migrants. The later sections, specifically on Fujian, will advance these discussions by focusing on women migrants and making explicit gender distinctions and comparisons. In section 8.3 we will document women migrants' rights issues as reflected in their socio-economic characteristics and working and living conditions. Section 8.4 examines the current dominant approach in addressing these issues in relation to women migrants' complex and diversified migration flows. Section 8.5 puts forward some policy recommendations for improving rights protection for women migrants.

\subsection{Progress in Migrants' Rights Protection in China within the Current Urban-Centred and Residence-Based Approach}

The needs of migrants and their families for rights protection manifest themselves in many aspects of their work and life, especially unequal access to and insecurity of employment (Wang/Zhang 2006; Cook 2008; Du et al. 2008), low income level (Zhu 2007), low social insurance coverage (NBS 2006; Zhu 2007),

4 According to the latest 2010 census, the total population of the Province was $36,894,216$, and the size of the Province's 'floating population', namely those who had left their town (township, sub-district) administrative boundaries for more than half a year at the time of 2010 census (excluding those moving between the sub-districts of the same municipality) amounted to I0,244,08I persons, with 4,313,602 of them from outside Fujian Province. The population of Fuzhou city, the five districts directly under the administration of Fuzhou Municipality, was 2,92I,700 at the 2010 census, and the city is one of the major migrant destinations in Fujian Province. 
exclusion from housing security (Wu 2002; Lin/Zhu 2008), and unequal access to educational opportunities for children (Liang/Chen 2007), as well as the great difficulties that migrants' children face in migrants' places of origin (Xiang 2007; Duan/Yang 2008). In recent years, the need for rights protection for migrants and their families has been increasingly recognized in China, and various efforts in the form of policies, insurance programmes, and other practices have been made to meet such needs, especially since 2000 . So far, extending the coverage of the conventional urban-hukou-based and residence-based social welfare system or its post-reform variations to include migrants has been the dominant approach (Zhu et al. 2009). In a way, migrants are regarded as newly added members of urban society, and various efforts have been made to integrate them so that they can enjoy the same rights and benefits as local urban residents. We refer to this as the urban- and residencebased approach.

The most significant progress has been achieved in addressing the rights issues of migrants in terms of their employment and income (Zhu et al. 2009; Zhu/ Lin 20II). Once seriously compromised by policies restricting and controlling rural-urban migration and migrant employment in the cities, migrants' access to employment opportunities in many destination cities has been significantly improved through a number of new policies (Ministry of Labour I994). Government at various levels has released and implemented various documents to reduce the institutional basis for the discriminatory treatment of migrants in urban employment (General Office of the State Council 2003; The State Council 2006; Song/Hou 2007). ${ }^{5}$ In short, all the regulations treating migrants differently in terms of employment, even those regarding employment in government departments and public institutions, have now been abolished. ${ }^{6}$ As a result, both

5 The promulgation of the minimum wage standards, and the promulgation at the beginning of 2008 of the Law of the People's Republic of China on Employment Contracts, provide further protection for migrants in terms of minimum wages, overtime work, working contracts, etc. (Liu 2007; Standing Committee of the People Congress of PRC 2007). Governments at various levels have taken measures to abolish unreasonable fees imposed on migrants and to solve the problems of delayed wage payment and payment in arrears; in some cases they have even directly intervened (General Office of the State Council, 2003; National Development and Reform Commission et al. 2004; Liu/Zhou 2007). women and men migrants are now increasingly enjoying improved conditions of employment and income.

A second area of progress concerns measures to ensure equal access to education and equal treatment in the destination cities for migrants' children, a major concern for women migrants who are mothers or future mothers (The State Council 2006; Duan et al. 2008). China's educational resources are allocated according to the size of the schooling population with local hukou status. As most migrant children do not have such hukou status, this used to be one of the biggest obstacles to migrant children's attending school. Public schools that accommodate migrant children often charged an extra fee called 'jiedufei' (guest student fees), thus limiting their access. In recent years, the Ministry of Education and the Ministry of Public Security have released various documents with new policies and measures aimed at ensuring migrant children's equal access to educational opportunities. These policies and measures are collectively reflected in "Opinions of the State Council about solving the problems of rural-urban migrant workers", which stipulates that, in principle, children of rural-urban migrant workers should have equal access to compulsory education, and governments of the destination areas should take the main responsibility for this (The State Council 2006). ${ }^{7}$

Following the above guidelines, governments at local level have made many efforts to meet the needs of migrant children for education, and to give them equal treatment in schools. At the turn of the new century the enrolment rate of school-age migrant children, including those able to attend public schools, has increased significantly compared with the I990s (Duan et al. 2008), though much remains to be improved, both in public schools in the destination cities and for the children of migrants who are left behind (Duan/Yang 2008).

A third policy area is the extension of the coverage of existing urban social insurance to migrants, so that they can be directly included in the system (Peng/ Qiao 2005). Social insurance programmes of this kind

6 Our interviews with officials from the Fujian Province Department of Labour and Department of Social Insurance suggest that while there may still be some discrimination against migrants at the local level, there is now no institutional and legal basis for such discrimination (Interview record of the Fujian project, May 2009).

7 The State Council of the People's Republic of China, that is, the Central People's Government, is the highest executive organ of state power, as well as the highest organ of state administration. 
mainly cover old-age insurance, insurance against work-related injuries, medical insurance, and unemployment insurance, with the priority placed on the first two areas and on insurance against major diseases. The system of migrants' old-age insurance is made up of two components, the overall pooling of social funds (Shehui Tongchou) and individual accounts (Geren Zhanghu), and both migrants and their employers contribute to the system. Because the issue of the portability of rights has not been taken up, these programmes have not been effective in reaching the migrant population. For example, as has been pointed out (Gao 2006; Li/Yang 2007), when migrants withdrew from such programmes, they could only take away their own contribution to the insurance funds. Their employers' contributions would remain in the funds of the cities where they used to work. At the time of the Fujian survey at the end of 2009, migrants still could not take insurance benefits with them when they moved from one place to another, making the insurance invalid in their later life. This problem had significant negative effects on migrants' participation in various social insurance programmes. In fact, many migrants who joined the programmes subsequently withdrew from them, and it is widely reported that the non-portable nature of social insurance programmes was the main reason (Song 2007). In recent years, the first steps in dealing with the portability issue have been taken but many practical issues remain to be resolved ( $\mathrm{Zhu} / \mathrm{Lin} 20 \mathrm{IO}){ }^{8}{ }^{8}$ In general, the proportion of migrants joining various urban-based social insurance programmes is still very low.

A fourth policy area which has started to attract attention is migrants' housing needs. In 2005 , migrant housing was listed as a key priority by the Ministry of Construction. This was the first time that the issue of migrant housing had become part of the agenda of the Ministry (Liang 2005). In the same year, in a document issued by the Ministry of Construction, the Ministry of Finance, and the People's Bank of China,

8 At the beginning of 20I0, the "Provisional measures for the transfer and continuation of the basic old-age insurance for the employees of urban enterprises", enacted jointly by the Ministry of Human Resources and Social Security and the Ministry of Finance, began to be implemented. The "Provisional measures for the transfer and continuation of the basic medical insurance for mobile employees", enacted jointly by the Ministry of Human Resources and Social Security, the Ministry of Health, and the Ministry of Finance, were promulgated and took effect from I July 20 Io. it was stipulated that rural-urban migrant workers could join the public reserve fund for housing if certain conditions were met (Ministry of Construction et al. 2005). In the important "Opinions of the State Council about solving the problems of the rural-urban migrant worker" released in 2006, the State Council gave the instruction "to improve the housing conditions of the floating population" (The State Council 2006). The State Council asked relevant government departments to enhance monitoring and administration to ensure that the living places of migrants met basic sanitation and safety standards. At the end of 2007, the Ministry of Construction and four other ministries jointly issued a document entitled "Guiding opinions on improving migrant workers' housing conditions", in which, for the first time, it is stipulated that work units or enterprises are the main institutions responsible for improving the housing conditions of rural-urban migrant workers, and that governments at various levels should incorporate the issue of rural-urban migrant workers who will live and work in the cities on a long-term basis into housing planning (Ministry of Construction et al. 2007).

These recent documents at national level have laid down the principles for the measures to be taken by governments at local level to meet the housing needs of rural-urban migrants. Attempts have been made in some migrant destination cities, including Fuzhou and Xiamen in Fujian Province, to include some migrants who meet certain strict conditions into the existing urban housing security system, so that they can enjoy various housing benefits provided to local residents, such as low-rent housing, affordable owner-occupier housing, and the public reserve fund for housing (e.g. Lai 2007). In the major migrant destination cities of Fujian Province, local governments have also adopted the practice of developing low-rent or free housing in the industrial parks for rural-urban migrants, in cooperation with migrants' employers, with funds allocated for such projects (Du 2008). However, these efforts are sporadic and only cover a very limited group of migrants; in general, housing is still a little-addressed rights issue for migrants in China, including in Fujian Province.

Summing up, despite major efforts to address the rights of internal migrant workers in China in recent years, limitations must be recorded in areas such as the low coverage of migrants by various social insurance and housing benefits, and barriers to migrants' children in public schools. 


\subsection{Women Migrants' Rights and Aspects of Gender Differences}

The following section discusses the findings of the Fujian and Fuzhou surveys on the socio-economic characteristics of women respondents and the working and living conditions they face, in order to shed light on the existing rights issues of women migrants and their gender differences.

\subsubsection{Fujian and Fuzhou Surveys and Subsequent In-depth Interviews: Research Design}

The survey in Fujian Province ${ }^{9}$ was supported by IDRC and jointly conducted by the Centre for Population and Development Research at Fujian Normal University and the Fujian Provincial Population and Family Planning Commission in December 2009, when China was recovering from the financial crisis of the late 2000s. As the emphasis of the research was on women migrants, the sample sizes of women and men migrants were determined as 2,000 and I,000 respectively, with the latter serving as the comparison group for gender analysis. We then used a four-stage probability proportional to size (PPS) ${ }^{10}$ sampling procedure to randomly select the county-level, townshiplevel, and village-level administrative units, and then to randomly select ten women migrants and five men migrants in each selected village. ${ }^{11}$ Using the above procedure and after data cleaning, we obtained a data set with 2,977 valid responses, I,963 from women migrants and I,OI4 from men migrants. ${ }^{12}$

The survey in Fuzhou city was conducted in February 2009 during the height of the late 2000 s financial

9 The database for all members of the floating population, which was established and managed by Fujian Provincial Population and Family Planning Commission and considered to be the most complete migrant data base in the Province, was used as the sampling frame, and the potential respondents were both women and men migrants in the database who were 15 to 64 years old, employed as labourers or in business, who had migrated out of the boundaries of their original countylevel administrative units, and had lived in their current places of destination for more than one month.

10 Probability proportional to size (PPS) is a sampling technique in which the probability of selecting a sampling unit (e.g. village, township, county) is proportional to the size of its population.

11 In some villages more than ten women migrants and more than five men migrants were selected. crisis, and covered 600 migrants who met the same criteria as those of the Fujian survey, ${ }^{13}$ half of whom worked in industrial, trade, and service enterprises in Fuzhou's major industrial zones and commercial areas, and half of whom were engaged in informal employment as street vendors, motorbike-taxi drivers, porters, day labourers, and informal employees in small enterprises. The quota-sampling method was used in the Fuzhou survey to select respondents for both formal and informal employment, and a sampling framework with stratification across major occupational categories was developed. We obtained 194 responses from women migrants and 406 responses from men migrants. ${ }^{14}$

The in-depth interviews were conducted during the above two surveys, and covered six government officials in relevant government departments, including the Departments for Labour and Social Insurance of Fujian Province, the Department of Education of Fuzhou Municipality, the Department of Construction and Housing of Fujian Province, three employers of migrants, and thirty-eight migrants in both formal and informal employment. The analyses in the following sections are mainly based on the above two surveys and subsequent in-depth interviews.

12 As the proportions of women and men migrants in the total migrant population were both close to 50 per cent in the sample frame, we randomly selected half of the responses $(\mathrm{I}, \mathrm{OI} 6)$ of women respondents and combined them with those of the I,OI7 men respondents to form another data set, excluded 22 invalid responses from it, and obtained a data set with 2,OII valid responses, including 997 responses from women migrants and I,OI4 responses from men migrants. Analyses of this data set demonstrate some basic features of migrants in Fujian: the average age of the respondents was 3I.3 years, and 66.06 per cent of them had educational attainment at or higher than junior high school. Some 68.52 per cent of them were married, and 85.93 per cent of the married respondents lived together with their spouse.

13 See footnote 8 . This survey was conducted as part of the Social Protection in Asia (SPA) policy research and network-building programme funded by the Ford Foundation and the International Development Research Centre (IDRC).

14 The average age of these respondents was 30.59 years, and 76.67 per cent of them had educational attainment at or higher than junior high school. Some 49.67 per cent of them were married, and 80.87 per cent of the married respondents lived together with their spouse. 


\subsubsection{Low Educational Attainment and Unequal Access to Educational Opportunities}

The results of the Fujian survey demonstrate two major issues related to the educational attainment of women migrants. First, compared to the local residents in their destination cities, women migrants' educational attainment is lower. This is an important factor affecting their competitiveness in the labour market, and delays their upward socio-economic mobility in both their destination cities and their places of origin if they return home. The typical educational attainment of most women migrants in the Fujian survey was junior high school or below, and the proportion of women migrants who had completed senior high school stood at only 17.7 per cent. This is much lower than the proportion of employees in the secondary and tertiary industries of Fujian Province who had completed senior high school, which stood at 5I.5 per cent according to the second national economic census of 3I December 2008. ${ }^{15}$

Second, compared to their male counterparts, women migrants are further disadvantaged. This is reflected in several aspects of our survey results: the average length of women respondents' education was 7.53 years, I.03 years shorter than that of men respondents; the proportion of women respondents who had received no education beyond the level of junior high school was 82.3 per cent, 7.2 percentage points higher than that of their male counterparts; the proportion of female respondents who had received education at or above the level of junior high school was 59.4 per cent, 15 percentage points lower; and 26.I per cent of women respondents had dropped out of school, 8.5 per centage points higher.

\subsubsection{Vulnerability in Employment and Income}

The results of the Fujian survey show that in terms of income and employment, corresponding to the increasingly equal treatment of female and male migrants in their employment in the destination areas mentioned above in section 8.2, more than seventy per cent of both women and men respondents in the Fujian survey did not feel discrimination against their migrant and gender status in their employment. In the

15 Migrant workers were included in the above-mentioned employees. If they were excluded, the educational attainment of local employees would be even higher.
Fuzhou survey, the proportion of respondents who thought that their non-local hukou status did not affect their employment opportunities was 8I.2 per cent. This shows that discrimination against migrants in terms of employment is no longer a major issue. ${ }^{16}$ Furthermore, 87.3 per cent of male respondents and 90.2 per cent of female respondents in the Fujian survey reported that their wages were paid in full and on time, suggesting that significant progress has been made in solving the issues of delayed payment and payment in arrears to migrant workers, once a serious problem in China. However, despite these significant achievements, female migrants are still vulnerable to employment instability and other problems related to their social inclusion or exclusion at the destination.

\subsubsection{Insecurity and Instability in Employment}

The results of the Fujian survey show that some 59.I per cent of women respondents had the experience of changing their jobs, and 29.0 per cent of them had changed their jobs twice or more since they entered the migration process. On average, female respondents in our sample had been engaged in 2.II jobs before the survey. ${ }^{17}$ The job instability of female respondents is also reflected in the status of their working contract: only 40.8 per cent had signed employment contracts; this proportion was slightly lower than that of their male counterparts (44.0 per cent). Furthermore, among those women migrant workers who had signed a contract, only a very small proportion of them (around one per cent) had a long-term contract, indicating the temporary nature of their jobs (see also table 8.I). The unstable and temporary nature of women migrants' employment often puts them at a disadvantage in the labour market; with no employment contract, their ability to protect their rights in labour disputes would be compromised.

\subsubsection{Segmented Nature of Employment, Little Upward Occupational Mobility, and Age Discrimination}

The Fujian survey results show that women migrants were concentrated in the manufacturing and service

16 The Fujian survey results show that the average monthly income of women respondents was I,534.3Yuan (US\$243.9) at the end of 2009, much higher than the overall average level of below I,000 Yuan (US\$159.0) only five years ago (Zhu/Chen 20IO), although a significant gender gap still exists.

17 The average migration duration of female respondents was seven years. 
Table 8.1: Distribution of lengths of respondents' working contracts (\%). Source: The authors, based on the 2009 Fujian survey prepared for the IDRC project.

\begin{tabular}{|c|c|c|c|}
\hline $\begin{array}{l}\text { Length of } \\
\text { working con- } \\
\text { tracts }\end{array}$ & $\begin{array}{l}\text { Female } \\
\text { respondents } \\
(\mathrm{N}=\mathbf{8 0 8})\end{array}$ & $\begin{array}{c}\text { Male } \\
\text { respondents } \\
(\mathrm{N}=446)\end{array}$ & $\begin{array}{l}\text { All respond- } \\
\text { ents } \\
(N=1254)\end{array}$ \\
\hline $\begin{array}{l}\text { Less than } 3 \\
\text { months }\end{array}$ & 0.7 & 0.4 & 0.6 \\
\hline 3-6 months & 1.4 & 0.4 & 1.0 \\
\hline 6-12 months & 43.8 & 38.1 & 41.8 \\
\hline $1-3$ years & 46.3 & 49.1 & 47.3 \\
\hline 3-5 years & 3.8 & 4.3 & 4.0 \\
\hline $\begin{array}{l}\text { More than } \\
5 \text { years }\end{array}$ & 1.1 & 1.6 & 1.3 \\
\hline $\begin{array}{l}\text { Casual } \\
\text { contracts }\end{array}$ & 2.8 & 6.1 & 4.0 \\
\hline Total & 100 & 100 & 100 \\
\hline
\end{tabular}

industries. As table 8.2 shows, production workers, sales and service workers, and workers in individual businesses were the most common occupations of the female respondents, with 80.2 per cent of them engaged in these three types of occupation. This is a much higher proportion than that in the general female population employed in the urban areas of Fujian Province, which stood at 62.7 per cent in 2009. ${ }^{18}$ In contrast, professional and technical workers, administrative and managerial workers, and clerical workers only accounted for II.6 per cent of women respondents, and this proportion was much lower than that of men respondents, which stood at 20.4 per cent.

Furthermore, figure 8.I shows that the occupational structure of the female respondents' most current jobs was remarkably similar to that of their first jobs since migration, suggesting little upward occupational mobility. The only noticeable occupational mobility identifiable from figure 8.I was the shift from being production and transport workers to running individual businesses, and this does not represent a fundamental change of employment structure, since the majority of individual businesses require low skills and are labour-intensive and small-scale. Nor could any significant upward mobility be identified in our in-

18 Calculated based on the data provided by the Statistical Bureau of Fujian Province in: Fujian Statistical Year Book (20IO); available at: 〈http://www.stats-fj.gov.cn/ tongjinianjian/dzIo/index-cn.htm> (tables 3-I5 and 3-I7).
Table 8.2: Occupational structure of female respondents (\%). Source: The authors, based on the 2009 Fujian survey prepared for the IDRC project.

\begin{tabular}{|c|c|c|c|}
\hline Occupation & $\begin{array}{l}\text { Proportion } \\
\text { of women } \\
\text { respond- } \\
\text { ents }\end{array}$ & Occupation & $\begin{array}{c}\text { Proportion } \\
\text { of women } \\
\text { respond- } \\
\text { ents }\end{array}$ \\
\hline $\begin{array}{l}\text { Administra- } \\
\text { tive workers }\end{array}$ & 4.2 & $\begin{array}{l}\text { Transport } \\
\text { workers }\end{array}$ & 0.5 \\
\hline $\begin{array}{l}\text { Clerical } \\
\text { workers }\end{array}$ & 4.5 & $\begin{array}{l}\text { Individual busi- } \\
\text { ness owners }\end{array}$ & 16.6 \\
\hline $\begin{array}{l}\text { Technical } \\
\text { workers }\end{array}$ & 2.9 & Petty traders & 2.1 \\
\hline $\begin{array}{l}\text { Sales and ser- } \\
\text { vice workers }\end{array}$ & 16.6 & Casual workers & 1.8 \\
\hline $\begin{array}{l}\text { Production } \\
\text { workers }\end{array}$ & 47.2 & Others & 1.2 \\
\hline $\begin{array}{l}\text { Construc- } \\
\text { tion workers }\end{array}$ & 2.4 & Total & 100 \\
\hline
\end{tabular}

depth interviews, although more evidence is required for more conclusive findings.

Furthermore, age discrimination is a major issue for women migrants, as only young women migrants are regarded as skilful and deft and welcomed in the labour market. 48.0 per cent of the female respondents reported that there was an age limit in their employment; the average upper age limit reported for female migrant employment was 4I.I years, compared to 54.9 years for male migrants. This is a dramatic difference. So while women are preferred over men as young factory workers, they are not wanted when they are over forty.

\subsubsection{Insignificant Roles of Governments and Intermediaries in Providing Employment Information and Training}

The Fujian survey results show that, as with their male counterparts, most women respondents found their jobs on their own (30.2 per cent), through their family members, relatives, townsmen, colleagues, friends, and classmates $(56.2$ per cent), or through advertisements in newspapers and on TV and the Internet (8.8 per cent), and only 4.8 per cent of them through employers' recruitment, introduction by intermediaries, job asignments or recommendation upon graduation, or government-organized labour export programmes. This suggests that the role of governments and intermediaries in providing employment information for migrants is rather weak. Furthermore, most women migrants have not received training for their employ- 
Figure 8.1: The first and current occupations of women respondents. Source: The 2009 Fujian survey in the IDRC project.

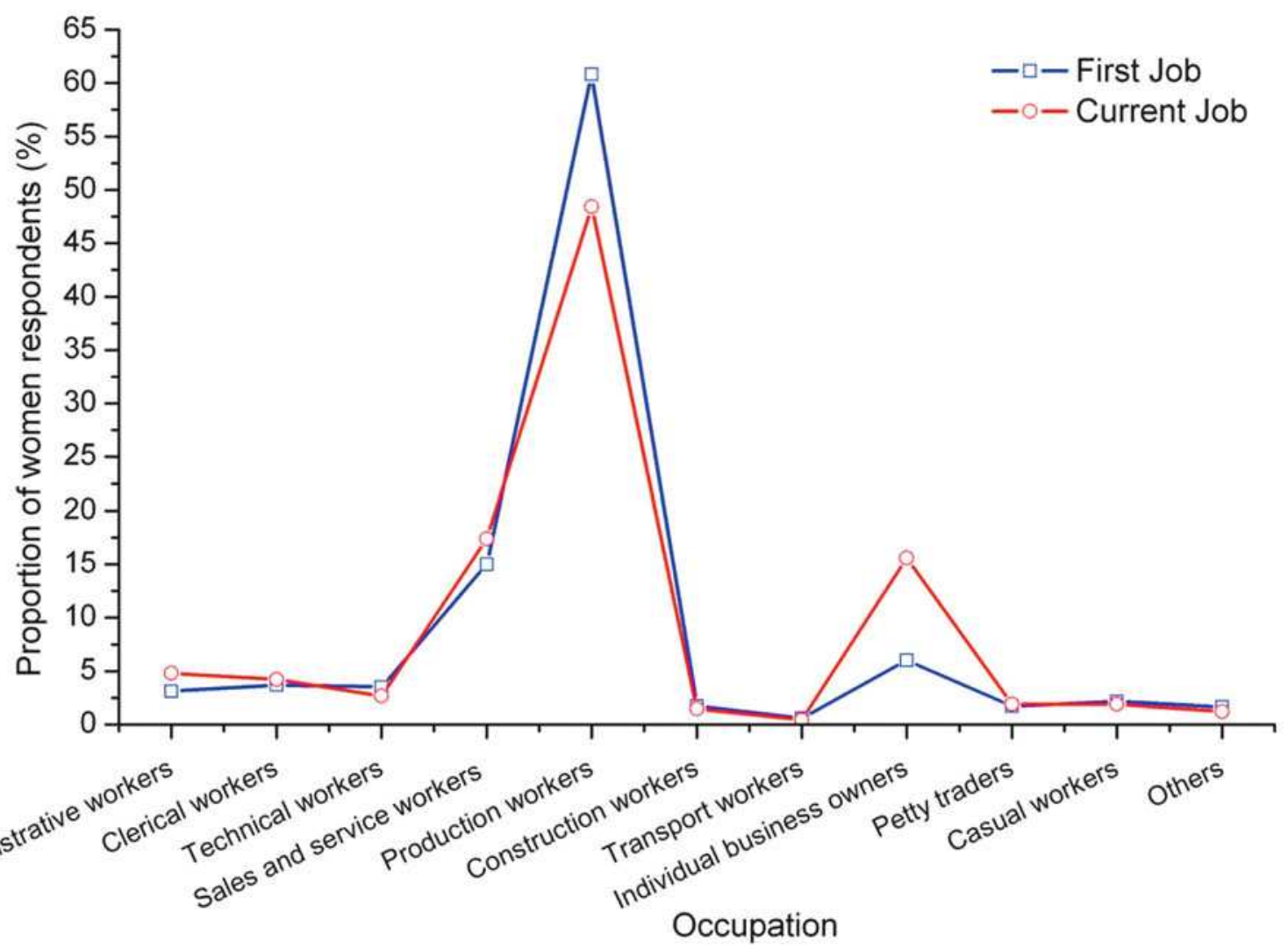

ment, and the relevant government departments have played an insignificant role in this regard. Only 8.7 per cent of female respondents had received training before their migration, and the government accounted for only 4.7 per cent of such training. In the process of their migration, the proportion of female respondents who had received training increased to 32.7 per cent, thanks to on-the-job training; however, the role of relevant government departments decreased, accounting for only 2.9 per cent of on-the-job training reported by the female respondents. Our in-depth interviews with officials of relevant government departments in Fujian Province in early 2009 revealed that employment training programmes were usually only provided to local residents and migrants from within the province, and therefore migrants from outside Fujian Province were excluded (interview conducted in May 2009 during the IDRC project).

\subsubsection{Employers' Domination in Determining the Migrant Pay and Gender Gap in Income}

According to the Fujian survey, 60.2 per cent of women respondents and 52.4 per cent of men reported that their pay was determined unilaterally by their employers, and only I8.4 per cent of women and 23.3 per cent of men reported that it was determined through negotiation with employers, trade unions, and relevant government departments. Besides this, collective bargaining played an insignificant role, and women migrants were clearly more disadvantaged than their male counterparts, one possible factor behind the gender gap in income. We mentioned earlier that the average monthly income of women respondents was I,534.3 Yuan (US\$243.9); while this represents a significant increase in the income level of female migrants, it was much lower than that of their male counterparts, which was 2,0I2.7 Yuan (US\$320.0). Even in the same job category of production workers, in which the largest proportion of both female and male respondents were engaged, the average monthly income of female respondents was 
I,456.3 Yuan (US\$23I.5), still much lower than that of their male counterparts, which stood at I,87I.I Yuan (US\$297.5). Such gender gaps in income reflect the fact that there is still gender discrimination against female migrants in the labour market; but they also partly result from the gap in human capital between migrating women and men.

\subsubsection{Excessive Overtime}

The Fujian survey results suggest that the average length of working time for female respondents was I0.03 hours per day, similar to that of male respondents (9.97 hours), and female respondents took only 2.22 days off in a month, even less than their male counterparts (2.32 days). Furthermore, 29.5 per cent of women respondents reported that they were not compensated for overtime work, and for those who were, the compensation (on average 6.03 Yuan or US\$0.96 for women respondents and 7.25 Yuan or US\$I.I5 for men) was below even the wage standard stipulated for normal working hours.

\subsubsection{Low Social Insurance Coverage and Unequal Access to Urban Public Services}

Another major concern identified in the Fujian survey is the very low social insurance coverage of both female and male migrants, and their unequal access to urban public services. This is consistent with our earlier assessment that national efforts to address these issues have not been satisfactory so far.

\subsubsection{Very Low Proportion of Female Migrants Covered by Various Social Insurance Programmes}

Data from the Fujian survey show that the proportions of women respondents covered by old-age insurance for urban employees, medical insurance for urban employees, unemployment insurance, and insurance against work-related injuries were only 13.3 per cent, I6.5 per cent, I0.2 per cent, and 17.7 per cent respectively, and that the situation for migrant men was similar. This suggests that despite the great efforts devoted in recent years to extending urban-based social insurance system to migrants, only limited progress has been achieved, and the majority of both female and male migrants have not benefited. Interestingly, rural-based social insurance programmes have played an unexpectedly important role in recent years, as evidenced by the Fujian survey result that 43.50 per cent of female respondents joined the New Rural Cooperative Medical Scheme before or during migration. It can be expected that with the implementation of the New Rural Social Pension Scheme in the future, more female and male migrants will also join this kind of rural-based old-age social insurance programme.

\subsubsection{Migrants' Unequal Access to Urban Public Services: Housing and Children's Education}

Migrants' unequal access to urban public services is particularly evident in the status of their housing security in their destination cities. According to the results of the Fujian survey, 54.8 per cent of women respondents lived in rental housing, followed by 35.9 per cent in dormitories provided by their employers. This is in strong contrast to the housing situation of the local residents in Fujian Province, 64 per cent of whom owned their housing (Lin/Zhu 2008). Furthermore, only 6.I per cent of female respondents received housing benefits from their employers, and an even smaller proportion (I.8 per cent) from the government. The disadvantaged housing situation of migrants is also reflected in the size of their dwellings. In the Fujian survey, the per capita usable area of women respondents' housing was 9.8 square metres, less than one-third of the per capita usable area of Fuzhou local residents' housing, which stood at 34.2 square metres in 2005 (Fujian Statistical Bureau 2006).

Besides this, children's education remains a major concern for female migrants. Data from the Fujian survey show that while 53.3 per cent of female respondents brought some of their children to their places of destination to receive education, only 64.9 per cent of these children were admitted to the public schools, and respectively 30.6 per cent and 4.5 per cent of them had to go to private schools or schools for children of migrants operated by NGOs and/or the migrant population themselves. At the same time, 52.I per cent of female respondents had left children behind to be cared for by grandparents or other relatives and to receive education in the places of origin. Children of migrants face problems of educational neglect in different ways. Those who accompany their parents, or are born in the destination cities, often go to schools privately set up for them by NGOs or the parents themselves, despite the formal commitment of the government to their education. High tuition fees, the poor conditions of the schools, and lack of supervision mean that the teaching quality of these schools cannot be guaranteed. Those children who do not move with their parents are deprived of parental 
supervision in their daily lives, and this negatively affects both their school performance and psychological development, and even causes much deviant behaviour (Research team on issues of left-behind children 2004).

\subsubsection{Lack of Awareness and Channels for Rights Protection}

In the Fujian survey, more than half (54.0 per cent) of female respondents and 48.7 per cent of male respondents said that they were not aware of relevant information concerning their own rights and interests, such as wage standards, social insurance policies, policies concerning their children's education, and employment contract policies, at their working and living places. Only 9.3 per cent and I.5 per cent respectively of female respondents joined local trade unions and local women's federations, the two most relevant organizations for the protection of their rights and interests; the proportion of male respondents who joined local trade unions was II.2 per cent. In addition, their high mobility marginalizes them in the political life of both their places of origin and destination, reflected in the facts that only 24.9 per cent of female respondents and 29.2 per cent of male respondents had ever participated in the village committee election of their home areas, and that only I.I per cent of female respondents and I.2 per cent of male respondents had done so in the election of urban neighbourhood committees in their places of destination. These survey results indicate the lack of well-organized channels for both female and male migrants, particularly for women to obtain information concerning the protection of their rights, to express their interests, and to seek support to protect their rights.

Data from the Fujian survey show further that when their rights and interests were violated, the most common reaction of female respondents was to turn to family members, relatives, and friends to seek help (30.9 per cent), followed by arguing directly with their employers (2I.3 per cent). The corresponding figures for male respondents were 24.39 per cent and I9.I2 per cent. Only I3.I per cent of female respondents and I9.08 per cent of male respondents would turn to relevant government departments for help; those who would take legal action only accounted for 7.4 per cent of female and 8.98 per cent of male respondents; and those who would seek the help of trade unions and women's federations only accounted for 2.I per cent of female and I.6 per cent of male respondents. These figures suggest that there is much room for official channels such as relevant government depart- ments, legal institutions, trade unions, and women's federations to play a bigger role in the protection of rights and interests for both female and male migrants, especially the former.

\subsection{Female Migrants' Complex and Diverse Migration Flows: Limits of the Urban-Centred and Residence-Based Approach}

Above we showed that although great efforts have been made to protect the rights and interests of female and male migrants, they have not been universally effective. While such a situation can be attributed to many reasons, including the neglect of the changing nature of female migrants' rights issues, the inadequate roles of the governments and relevant institutions, and the barriers caused by the hukou system, all of which will be addressed below, one particularly important factor is the current urban- and residencebased approach, which is inadequate as a way of understanding the rights issues of women migrants and of underpinning relevant policy-making. We examine next this inadequacy in the context of the mobility patterns of female migrants, hoping that more sophisticated and diverse approaches can be developed.

\subsubsection{The Mobility Patterns of Women Migrants: Beyond the Conceptualization of a Rural-Urban One-Way Transition}

The underlying rationale of the current urban-centred and residence-based approach on the protection of rights for migrants seems to match a common understanding that conceptualizes rural-urban migration as ultimately a one-way transition (Zhu/Chen 20IO). Although there has long been recognition in China of the circular nature of much contemporary rural-urban migration, this circular nature is often attributed to the barriers caused by the hukou system, which has made it difficult for migrants to settle permanently in cities and to enjoy the same rights as local residents (see e.g. Chan/Zhang 1999; Solinger I999; Liang 200I). It is assumed that without the hurdles caused by the hukou system, most migrants would settle permanently in cities, and that granting migrants the $h u$ kou status of their destination cities and thus integrating them into the destination urban society would be the best way to protect their rights and interests (Zhu/Lin 20II). 
Figure 8.2: The settlement intentions of the respondents from the Fujian survey (\%): Source: Prepared by the authors.

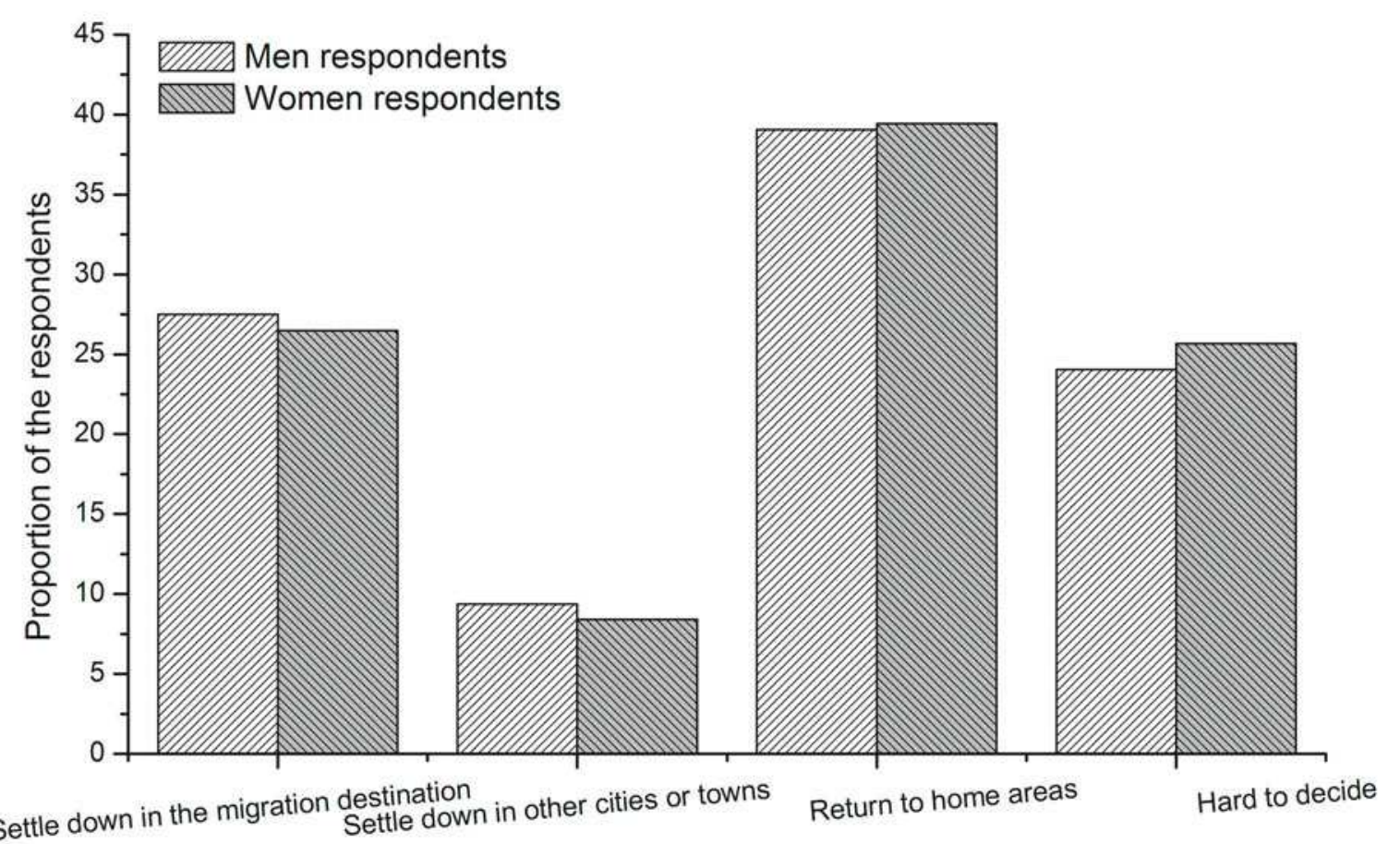

The settlement intention

However, the Fujian survey indicates that such a simplistic conceptualization of rural-urban migration is not valid, and that the mobility patterns of migrants are much more complicated. First, as can be seen from figure 8.2, the diversity of migration flows was an important feature among both female and male migrants. Answers to the question 'If you had a free choice, what would be your long-term plan?' indicate the diversity of the respondents' choices of the final direction of their migration movements, and it is noticeable that instead of settling down in the current or future destination cities, going back to their home areas remained their most common choice. It is also noticeable that a large proportion of respondents, both women and men, had not made up their mind, as this is no easy decision to make. Thus, there was a threeway division (settling down in cities, returning to home areas, and keeping in circulation) in their migration patterns, with little gender difference.

It is uncertain whether the above low intention of the respondents to settle permanently in their current or future destination cities is caused by the hukou system or by related institutional constraints. Based on the Fujian survey, figure 8.3 documents the responses to the question 'If you were qualified (allowed) to transfer the bukou of your family to the destination, what would be your choice?': those who chose to transfer the bukou of the whole family to the destination city, those who chose to keep the hukou at the place of origin, and those who could not make a decision each accounted for around 30 per cent, so only a few chose to transfer the bukou solely to the destination city. Again no significant gender differences exist. Since hukou is widely regarded as the biggest hurdle for rural-urban migrants to settle down in their destination cities, the reluctance of our respondents to transfer their registration from rural places of origin to urban places of destination suggests that the their decision to remain mobile or return to home areas reflects their own priorities and conditions. In fact, it is understandable that the majority of the respondents were reluctant to transfer their bukou and move permanently to the cities, since transferring $b u$ kou from places of origin to places of destination, especially when this is conditional on giving up land at the places of origin, implies a complete abandonment (often irreversibly) of the bi-local status that has enabled them to benefit from both the rural and the urban worlds (Zhu/Chen 20IO). In the Fuzhou survey the respondents' answers were similar and again without important gender difference (Zhu/Lin 20II), except that higher proportions of both women and men migrants wanted to go back to their home areas and keep their bukou at the places of origin, because the 
Figure 8.3: The choices on hukou transfer of the respondents from the Fujian survey (\%). Source: The authors.

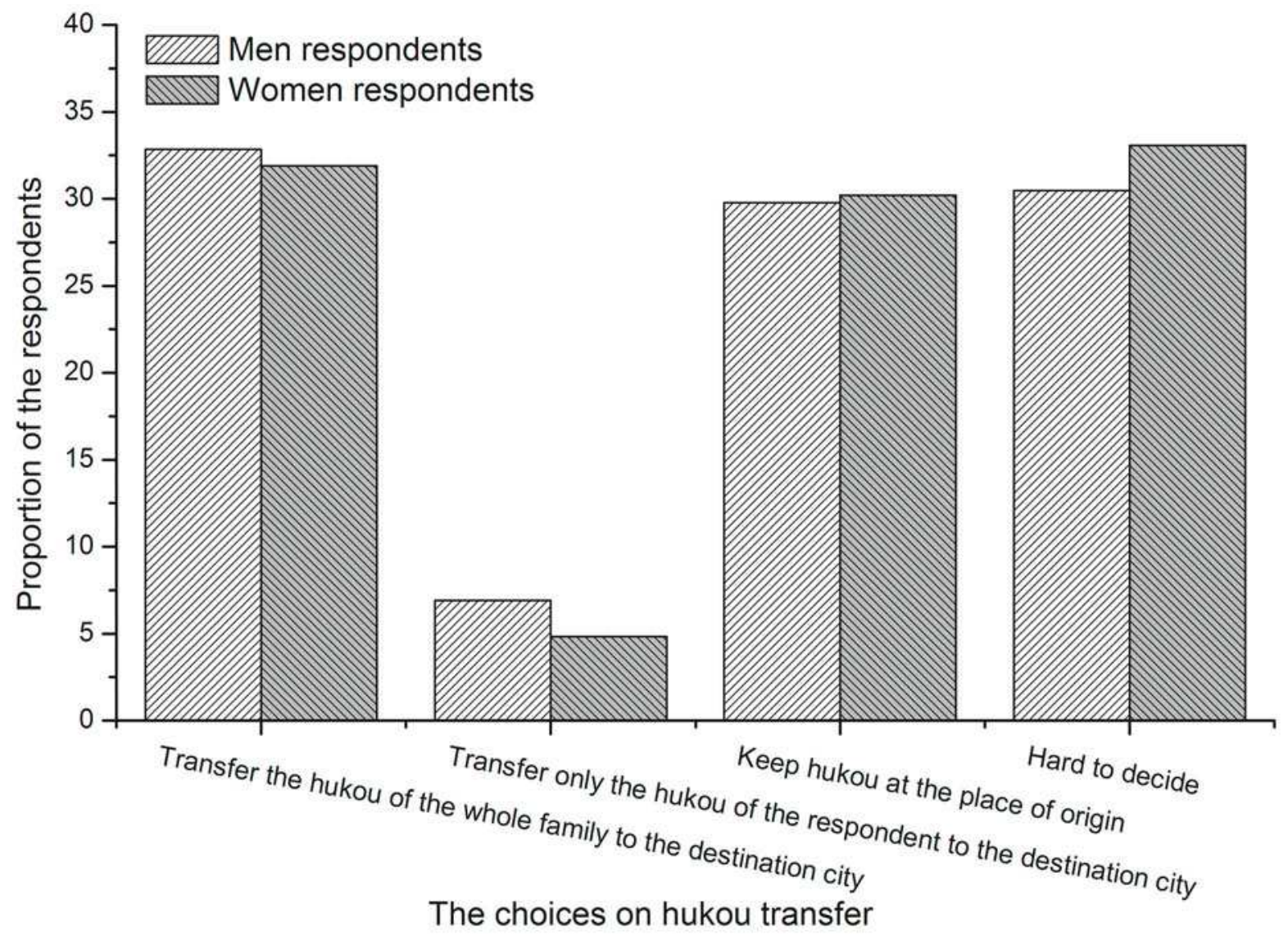

Fuzhou survey was conducted during the financial crisis (Zhu/Lin 20II).

Job instability is another important factor affecting mobility patterns. Among the respondents, 59.I per cent had experienced changing jobs, and 28.9 per cent had changed jobs more than twice. This job instability is also reflected in the status of their working contracts, as discussed above. Furthermore, among those who had signed a contract, particularly among women, only a very small proportion had a long-term contract, indicating the temporary nature of their jobs (table 8.I). As argued elsewhere (Zhu 2007), although the fact that most migrants do not have local hukou status in their destination cities may contribute to the unstable and temporary nature of their employment, the instability of the labour market per se is the major factor, and this cannot be changed easily. Such job and income instability makes it necessary for migrants to move frequently, and this makes it even more difficult for them to get settled in their destination cities.

The evidence from the Fujian and Fuzhou surveys and in-depth interviews demonstrates that the mobility patterns of both female and male migrants in
China are more complicated than commonly perceived, and that their multi-local status combining both rural and urban areas, the different patterns of their migration flows, and job instability feature strongly in their migration process. The current urban-centred and residence-based approach in the protection of rights for both female and male migrants is based on the conceptualization of ruralurban migration as a preferred fairly rapid and complete transfer of residence to urban areas, but this is incompatible with the actual mobility patterns, and needs to be reassessed.

\subsubsection{Reassessing the Needs of Female Migrants for Rights Protection: Current Inadequacies}

The first limitation of the current urban-centred and residence-based approach to the rights issues of female and male migrants is that it is incompatible with the highly mobile and prolonged migration process. This is particularly evident in the status of the social insurance of female migrants. As we have seen above, 
according to the Fujian survey only a few women were covered by social insurance programmes at their urban destination. This may be attributed to many factors (Zhu/Lin 20II), but a key factor is that these programmes cannot be transferred. These social insurance programmes should have the same level of mobility as the women migrants themselves, and the urban-centred and residence-based approach cannot meet this requirement. Fortunately China has moved in the right direction by beginning to address the issues of transfer and continuation of old-age and medical insurance programmes, though much more remains to be done.

The second limitation of the urban-centred and residence-based approach to the rights issues of female migrants is the neglect of the distinctive needs of migrants due to their mobile nature; these needs are different from those of local or urban residents. This is particularly evident in the case of the needs of migrants for housing security. China's current urbanbased housing security system basically consists of the provision of affordable owner-occupier housing, lowrent housing, and the public reserve fund for housing, ${ }^{19}$ which are made available to local urban residents who meet certain socio-economic criteria (Wu 2002). In the Fujian Province survey, the housing security system was entirely inaccessible to 98.2 per cent of female respondents, in Fuzhou city to 9I.2 per cent. This suggests a clearly disadvantaged situation for female migrants in destination cities. Therefore, to extend the existing urban housing security system to female migrants is no answer. The answers of female respondents (table 8.3) to the question 'What are the most important measures that the governments and/ or your employers can take to protect the housing security of rural-urban migrants?' in the Fuzhou survey ${ }^{20}$ referred to a) the provision of rental subsidy, b) the provision of low rent housing, and c) the provision of free accommodation by employers. This suggests that among the three main components of the conven-

19 The public reserve fund for housing is a way of providing housing benefits and security in China, whereby employees are required to contribute a certain proportion of their salaries to the fund, matched by a certain contribution from their work units. All contributions become the property of employees and can only be used for housing-related purposes.

20 Unfortunately, no questions were asked regarding the needs of migrants for housing security in the Fujian Province survey, and therefore we have to rely on the results of the Fuzhou city survey in this regard. This is also the case in our following analysis on the needs of migrants for social insurance and so on. tional urban-based housing security system, only lowrent housing is what most women migrants are interested in, and they have their own priorities regarding housing security, different from those of local residents. Some differences between women and men appeared, but the general patterns of their selections were similar.

As we have demonstrated elsewhere ( $\mathrm{Lin} / \mathrm{Zhu}$ 2008), the housing needs of migrants differ from those of the local urban residents. Most migrants, because of their unsettled nature and multi-local status, view reducing the costs of housing as the top priority. Unlike local urban residents, most have little incentive to invest in stable, high quality housing in the destination cities.

The third limitation of the current urban-centred and residence-based approach to the rights issues of female migrants is its neglect of the various needs of migrants caused by their different final destinations. Table 8.4 shows the social insurance programmes preferred by women in the Fuzhou survey. Contrary to expectation, when asked 'What is the best type of social insurance programmes you would like to choose so that your future life will be secure?', only 34.5 per cent chose the existing urban social insurance programmes. Instead, 24.2 per cent chose social insurance programmes designed according to the characteristics of migrants, and 30.4 per cent chose social insurance programmes designed for rural residents at their home areas. Female migrants seemed slightly more likely to choose an urban-based social insurance programme than men migrants, but the important fact is that there was a near-equal three-way split for the selection of social insurance programmes by women and men, where urban-based insurance programmes were only one alternative.

The diverse choices of female migrants on social insurance programmes are closely related to their different preferences with regard to their final settlement. In the Fuzhou survey (table 8.5), those women who wanted to settle in the cities were clearly more inclined to choose the existing urban social insurance programmes. However, those who wanted to return to their home areas were more likely to prefer the social insurance programmes designed for rural residents; and those who wanted to circulate between their places of origin and destination were divided between these two groups. Thus, rather than assuming rural-urban migration to be a one-way transition and concentrating all efforts in migrant destination cities, efforts should also be made to develop non-urbanbased and non-residence-based social insurance pro- 
Table 8.3: Stated needs of women and men respondents for housing security (\%). Source: The authors, based on the 2009 Fuzhou survey.

\begin{tabular}{|c|c|c|c|}
\hline Measure for migrant housing security & $\begin{array}{l}\text { Women } \\
\text { respondents } \\
(\mathrm{N}=194)\end{array}$ & $\begin{array}{c}\text { Men } \\
\text { respondents } \\
(\mathrm{N}=406)\end{array}$ & $\begin{array}{c}\text { All } \\
\text { respondents } \\
(\mathrm{N}=600)\end{array}$ \\
\hline Provision of free accommodation by employers & 15.0 & 14.0 & 14.3 \\
\hline Provision of housing for migrant couples by employers & 5.0 & 6.3 & 5.9 \\
\hline Provision of low rent housing & 16.0 & 17.3 & 16.9 \\
\hline Provision of rental subsidy & 31.7 & 27.6 & 28.9 \\
\hline Entitlement to 'affordable owner-occupier housing' & 8.2 & 9.7 & 9.1 \\
\hline Entitlement to the public reserve fund for housing & 10.0 & 7.3 & 8.2 \\
\hline Provision of loans and preferential treatment in taxation & 8.1 & 10.7 & 9.9 \\
\hline Setting up of housing standards for migrant dormitories & 6.0 & 7.2 & 6.8 \\
\hline Total & 100 & 100 & 100 \\
\hline
\end{tabular}

Note: Each respondent could choose three answers and rank them first, second, and third. Each figure in the table is the weighted average of these responses, with respective weights of $0.5,0.3$, and 0.2 .

Table 8.4: Selection of the types of social insurance programmes (\%). Source: The authors, based on the 2009 Fuzhou migrant survey.

\section{Type of social insurance programmes}

Joining the existing urban social insurance programmes

Joining the social insurance programmes designed according to the characteristics of migrants

Joining the social insurance programmes designed for rural residents in their home areas

Going back to home areas if having great difficulties at the places of destination

Total

grammes, and places of origin are therefore crucial. In fact, this is already reflected in the significant role of Rural Cooperative Medical Schemes in their medical insurance, as shown by the Fujian survey, and it can be expected that the newly announced plan to gradually develop a nationwide New Rural Pension Scheme will also play an important role in old-age support for migrant women.

The importance of migrants' places of origin in their rights protection is also reflected in the educational needs of their children. As our Fujian survey results show, while 53.4 per cent of the women had children migrating with them to the destination city, an

\begin{tabular}{c|c|c|}
$\begin{array}{c}\text { Women } \\
\text { respondents } \\
(\mathbf{N = 1 9 4 )}\end{array}$ & $\begin{array}{c}\text { Men } \\
\text { respondents } \\
(\mathbf{N}=\mathbf{4 0 6})\end{array}$ & $\begin{array}{c}\text { All } \\
\text { respondents } \\
(\mathbf{N = 6 0 0 )}\end{array}$ \\
\hline 34.5 & 32.5 & 33.2 \\
\hline 24.2 & 25.1 & 24.8 \\
\hline 30.4 & 36.2 & 34.3 \\
\hline 10.8 & 6.2 & 7.7 \\
\hline 100 & 100 & 100 \\
\hline
\end{tabular}

almost equal proportion (52.I per cent) had children left behind. It is important to note that the Fuzhou survey asked why the respondents left children in their home areas, and the three most important reasons were 'unable to afford the high tuition fees at the destination city' (40.68 per cent), 'no economic capability to afford the high living costs in the city' $(36.44$ per cent), and 'job instability' (29.66 per cent). ${ }^{21}$ While the first reason can be attributed to the lack of educational resources and the migrants' unequal access to education in the destination cities, the other

21 This question was not asked in the Fujian survey. 
Table 8.5: Selection of the types of social insurance programmes by female migrants and their preferred settlement (\%). Source: The authors, based on the 2009 Fuzhou migrant survey.

\begin{tabular}{|c|c|c|c|c|}
\hline Types of social insurance programmes & $\begin{array}{l}\text { Settle down } \\
\text { in the cities } \\
\qquad N=55\end{array}$ & $\begin{array}{l}\text { Circulate between } \\
\text { places of origin } \\
\text { and destination } \\
\qquad \mathrm{N}=66\end{array}$ & $\begin{array}{c}\text { Return to } \\
\text { home areas } \\
\quad \mathrm{N}=73\end{array}$ & $\begin{array}{l}\text { All women } \\
\text { respondents } \\
\mathrm{N}=194\end{array}$ \\
\hline $\begin{array}{l}\text { Joining the existing urban social insurance } \\
\text { programmes }\end{array}$ & 60.0 & 22.7 & 26.0 & 34.5 \\
\hline $\begin{array}{l}\text { Joining the social insurance programmes designed } \\
\text { according to the characteristics of migrants }\end{array}$ & 25.5 & 28.8 & 19.2 & 24.2 \\
\hline $\begin{array}{l}\text { Joining the social insurance programmes designed for } \\
\text { rural residents at their home areas }\end{array}$ & 12.7 & 33.3 & 41.1 & 30.4 \\
\hline $\begin{array}{l}\text { Going back to home areas if having great difficulties at } \\
\text { their places of destination }\end{array}$ & 1.8 & 15.2 & 13.7 & 10.8 \\
\hline Total & 100 & 100 & 100 & 100 \\
\hline
\end{tabular}

two reasons are mainly related to their socio-economic characteristics, which make it necessary for them to rely on their resources in their home areas, and they consider it desirable to leave some family members at the places of origin. This need is in turn reflected in the fact that nearly all female respondents in the Fujian survey (95.3 per cent) felt that it was necessary for them to keep their land in their home areas, although they have been away for a long time. Therefore, keeping some family members and resources at their places of origin is a rational choice for many migrants (including women) in China, and new homearea-based approaches to rights protection should be developed to meet these needs.

\subsection{Policy Suggestions: Seeking New Approaches for the Protection of the Rights of Female Migrants}

\subsubsection{From 'Urban Integration' to 'Societal Integration': Extending Temporal and Spatial Coverage of the Protection of the Rights of Female Migrants and Respecting their Diverse Needs}

In recent years, great efforts have been made to ensure that the rights of migrants in their destination cities will not be compromised by their non-local status. Great progress has indeed been made in this regard. However, some important rights of migrants have still not been effectively addressed. Major reasons for this unsatisfactory situation are the over-simplified conceptualization of rural-urban migration as-in essence-a one-way transition, and the corresponding urban-centred and residence-based approach that focuses only on the rights issues of migrants in their destination cities and on the role of the bukou system in hindering the integration of migrants and their rights (e.g. Solinger I999; Zheng/Huang Li 2007). This approach neglects the complex, lengthy, unstable, and diversified nature of the mobility processes of migrants; it fails to take into full consideration their needs to have their rights protected in the long transition process and at different locations (including their places of origin) before their final (re)settlement, and it is therefore incomplete in both spatial and temporal coverage. We therefore recommend that a non-urbancentred and non-residence-based approach should be adopted to extend the coverage of the rights of migrants to all stages and locations in their migration process. Under such an approach, the protection of the rights of migrants should not rely on 'urban citizenship', and the whole society (rather than the destination cities) should bear the responsibility for protecting the rights of all citizens, including female and male migrants, no matter where they live. Thus, instead of advocating the 'urban integration' of migrants, policies should be formulated to promote their 'social or societal integration', and to ensure that migrants' rights and interests are not compromised anywhere or at any time. Such an approach will inevitably require the gradual equalization of the rights and interests of urban and rural residents; it will benefit not only permanent migrants, on whom the conventional urban-centred and residence-based approach is focused, but also circular and temporary migrants, and is therefore socially more inclusive.

A related recommendation is to respect the different needs of female migrants to protect their rights. 
The conventional urban-centred and residence-based approach may capture the situation of the limited group of migrants who intend to settle and are capable of settling in the cities; it is not suitable for those migrants who need and/or prefer to circulate between rural places of origin and urban places of destination, and for those who will eventually return to their home areas. Migrants in the latter two groups have to change their migration flows and choose urban places as their destination if they want to take full advantage of efforts to protect their rights under the conventional approach; however, this is not necessarily in their best interests. Great efforts must also be made to link the policies and measures targeting different groups with different migration flows, so that their protection will not lapse if they transfer from one migration flow to another.

\subsubsection{Upgrading the Efforts in Addressing the Rights of Migrants: Shifting From a 'Survival-Oriented' to a 'Development- Oriented' Approach}

During the first few years of this century when migrants' rights issues started to attract public attention in China, most academic and policy discussion was focused on their rights of a 'survival nature', i.e. those related to their restricted access to urban employment opportunities, very low and often delayed wage payment and payment in arrears, and the low admission rate of their school-age children. Although issues of this kind still exist and need to be further addressed, their priority has gradually lessened, and other legal issues, not necessarily new but relatively neglected, now stand in need of attention. Among them are those relating to their educational attainment and employment training, the segmented nature of their employment and occupational mobility, their employment, social and housing security, their access to social insurance and public services, and their awareness of and channels for legal protection that are more of a 'developmental nature'. They reflect the fact that with China's rapid socio-economic development, rights issues pertaining to migrants should now be addressed with a view to raising standards.

We suggest that while continued attention must be paid to improving migrants' basic working and living conditions, more comprehensive and sophisticated efforts should be made to facilitate migrants' access to public facilities and services and to promote their upward mobility. Particular attention needs to be paid to promoting and ensuring migrants' rights to receive de- cent education before and employment training during the migration process, to enjoy working conditions that meet the standards stipulated in relevant laws and regulations (including those concerning their working days and hours) and more upward occupational mobility, to enjoy more social security without it being compromised by their migration process, to have equal access to public services, particularly those relating to housing and children's education, and to access more channels for their rights protection. Again, measures to address the above issues should not be urban-centred; in fact, some of the issues cannot be fully addressed without going into their root causes in migrants' places of origin in rural areas (such as migrants' education), or being linked to their rural components (such as migrants' social insurance and the education of their children). Policies of this kind will not only improve migrants' situation in terms of equality and social inclusion, but will also enhance their human and social capital and their position in society, and eventually promote economic growth and the social cohesion of all of society.

\subsubsection{Developing a Clear Legal and Institutional Framework that Defines the Rights of Migrants and Obligations of Governments: Towards a Rights Approach for Citizens}

Achieving the two policy objectives discussed above requires a legal and institutional framework that defines the rights of migrants and the obligations of governments and relevant institutions. China's conventional legal and institutional framework does not suit this purpose well because it is hukou- and residencebased, and is ambiguous when it comes to what migrants' rights are and whose responsibility it is to protect such rights, as migrants are away from their places of origin where they have their hukou registration. Significant progress has been made towards solving this problem; though progress so far has not been solid and complete. Policies and measures for the protection of the rights of migrants are often described by the authorities at the national level as 'opinions' or 'guidelines'. They are often presented in general terms, are not legally enforceable, and can easily be compromised at the local level. We suggest that policies concerning the rights of migrants in the form of 'opinions' or 'guidelines' should be carefully examined and transformed into laws or regulations if possible. At the same time, a legal and institutional framework should gradually be developed to implement the 
notion that protecting the rights of migrants is a duty of the whole of society rather than that of certain places where migrants are affiliated, and changes in relevant legislation should also be made to base this protection not only on the labour rights of migrants, but also (perhaps more importantly) on their citizen's rights. Currently, local governments at the destination cities of migrants and their employers are primarily responsible for providing migrants with social benefits and security and ensuring their rights. Such an institutional arrangement can no longer suit the situation of migrants and should be changed, with the central government and governments at higher levels gradually playing a bigger role.

\subsubsection{Strengthening the Roles of Relevant Government Departments and Other Societal Institutions in Protecting the Rights of Migrants}

A crucial issue is the establishment of a new financing mechanism so that the rights of migrants can be effectively protected. Both the extension of temporal and spatial coverage and upgrading the protection of the rights of migrants can no longer rely on the conventional state financial sources and financing mechanisms. New ways of financing mechanisms that take into consideration the highly mobile and multi-local nature of migrants need to be explored. As migration is a cross-region phenomenon, the central government, and the governments at higher levels, should gradually bear more responsibility in this regard, and financing mechanisms based on fiscal revenue should gradually play bigger roles; otherwise, the non-local nature of migrants can easily put them at a disadvantage if the local budget is insufficient. To solve this problem, a new financing system and more financial allocation from the central or higher governments are needed. Such a new financing mechanism should be designed along with a redefinition of the rights and obligations of the various parties involved, and should be well informed by knowledge of migrants and their needs. In addition to the government role in the new financial mechanism, there are many other aspects where the roles of the government and relevant institutions can be strengthened. Particular efforts should be made to enhance the roles of the government and of relevant institutions in providing migrants with employment information and training and housing security; in supplying information about rights protection and creating formal channels to implement this; and in determining migrants' wages. Women's federations and trade unions, the two institutions most concerned with the rights and interests of migrants, can increase efforts in these areas.

\subsubsection{Increasing Attention to the Protection of the Rights of Female Migrants}

Our recommendations so far largely apply to both female and male migrants. This suggests that the migrating patterns very much determine the characteristics of the rights issues of female migrants and their specific needs for protection of their rights. Female and male migrants have very much in common here. However, our survey results also show that rights issues related to migrants do have gender dimensions, and we therefore recommend that particular attention should be paid to the following aspects where female migrants are more disadvantaged. First, the relevant government departments both at places of origin and of destination (especially the former) should make more efforts to ensure that relevant laws on schooling are enforced, so that female migrants will receive the nine years of legally compulsory education before joining the migration process. This will significantly contribute to their labour market performance, their longer-term employability, and their position in the power relations of both their family and society.

Second, efforts should also be made to advocate the equal position of men and women in the family, so that female migrants would not make sacrifices by dropping out of school and withdrawing involuntarily from the migration process when the family is in difficulties.

Third, more efforts need to be devoted to promote employment security, social security, and housing security for female migrants, who are in a more disadvantaged position. In particular, we noted that female migrants are often not considered employable beyond the age of forty. In addition, measures should be taken to address family concerns regarding the migration process, such as the care of elderly family members and children. Female migrants are more affected by these issues, which contribute to the interruption of their migration process and the insecurity of their employment.

Fourth, more efforts should be made to promote their equal access to employment without age- and gender-related discrimination, and to promote equal pay. Our results show that women migrants continue to be more disadvantaged in the above aspects of their work and life in their migration process, and require more and special efforts to address their rights issues. 


\section{References}

Cai, Fang, 2000: "An analysis of the political economy on Chinese cities restricting migrant worker's access to employment" (in Chinese), in: Zhongguo Renkou Kexue [Chinese Journal of Population Science], 4: I-Io.

Chan, Kam Wing, 1996: "Post-Mao China: A two-class urban society in the making", in: International Journal of Urban and Regional Research, 20,I: I34-50.

Cook, Sarah, 2008: "The challenge of informality: Perspectives on China's changing labor market", in: IDS Bulletin, 39,2: 48-56.

Drafting Group of the Final Report on Rural-Urban Migrant Workers, 2006: "Report on the problems related to rural-urban migrant workers in China", in: Project Team of the Research Office of the State Council (Eds): Zhongguo Nongmingong Diaoyan Baogao [Research Report on Rural-Urban Migrant Workers in China] (Beijing: Zhongguo Yanshi Chubanshe): I-6I.

Du, Jing, 2008: "Implementation of the 'zero-rent' housing: Fujian vigorously promotes housing security for ruralurban migrant workers" (in Chinese); at: <http:// www.66163.com/house/newsinfo.php?id=688\&lanmu=snxw $>$ (Io September 2008).

Duan, Chengrong; Yang, Ge, 2008: "The left-behind children of migrants in rural China" (in Chinese), in: Renkou Yanjiu [Population Research], 32,3: 15-25.

Duan, Chengrong; Yang, Ge, 2008: "A study on the latest situation of the floating population's children in China" (in Chinese), in: Renkou Xuekan [Population Journal], No. 6: 23-3I.

Fan, C. Cindy, 2003: "Rural-urban migration and gender division of labor in transitional China", in: International Journal of Urban and Regional Research, 27,1: 24-47.

Fujian Statistical Bureau, 2006: Fujian Economic and Social Statistics, Population Volume (in Chinese) (Fuzhou: Fujian People's Press).

Gao, Shusheng, 2006a: Shehuibaozhang Gaige: Hequ Hecong? [Social Security Reform: What Course to Follow?] (Beijing: Renmin University of China Press).

General Office of the State Council, 2003: "Circular on effectively accomplishing the work in the administration of and service for farmers employed in the cities" (in Chinese); at: <http://www.5Ilabour.com/lawcenter/ lawshow-2II70.html> (20 July 2008).

Lei, Liwei, 2007: "Laborers of Fuzhou and Xiamen have been covered by the housing security system" (in Chinese); at: <http://www.zj.chinanews.com/detail/777026. shtml> (I7 October 2007).

Li, Xiaoyun; Yang, Longbo, 2007: “Thoughts about the problems of social security for rural-urban migrant workers" (in Chinese), in: Shichang yu Renkoufenxi [Market and Demographic Analysis], 13,3: 49-55.

Liang, Qi, 2005: "Ministry of Construction listed the housing issue of rural-urban migrant workers as a key of this year's work" (in Chinese), in: <http://house.focus.cn/ news/ 2005-OI-08/87762.html > (II January 2005).
Liang, Zai, 200I: "The age of migration in China", in: Population and Development Review, 27,3: 499-524.

Liang, Zai; Chen, Yiupor, 2007: "The educational consequences of migration for children in China”, in: Social Science Research, 36,I: 28-47.

Lin, Liyue; Zhu, Yu, 2008: "Housing conditions of the floating population under the double residential status and the factors affecting them: A case study in Fujian Province" (in Chinese), in: Renkou Yanjiu [Population Research], 32,3: 48-56.

Liu, Yangyang, 2007: "Two measures of the ministry of labor and social security on resolving the issue of low payment for rural-urban migrant workers" (in Chinese); at: 〈www.gov.cn/jrzg/2007-oI/26/content_509855.htm> (26 January 2007).

Liu, Zheng; Zhou, Tingyu, 2007: "Sun Baoshu (vice-minister of ministry of labor and social security): Government of China helps rural-urban migrant workers recover more than 433 billion Yuan in overdue wages" (in Chinese); at: <http://news.xinhuanet.com/ newscenter/2007-I2/ 26/content_73I8733.htm> (20 August 2008).

Ministry of Labor, I994: "Interim provisions on interprovincial migration and employment of rural labors" (in Chinese); at: <http://www.5Ilabour.com/lawcenter/lawshow-I8987. html> (I8 July 2008).

Ministry of Construction; Ministry of Finance and People's Bank of China, 2005: "Guiding opinions of Ministry of Construction, Ministry of Finance and People's Bank of China on the issues concerning the public reserve fund management" (in Chinese); at: <http://www.5rlabour. com/lawcenter/lawshow-39434.html> (20 July 2008).

Ministry of Construction; National Development and Reform Commission; Ministry of Finance; Ministry of Labor and Social Security and Ministry of Land and Resources, 2007: "Guiding opinions on improving ruralurban migrant workers' housing conditions" (in Chinese); at: <http://www.5Ilabour.com/lawcenter/lawshow-750I9.html> (20 July 2008).

National Bureau of Statistics, Population and Employment Statistics Division \& Ministry of Labor and Social Security, Planning and Finance Division, 2006: China Labor Statistical Yearbook 2005 (in Chinese) (Beijing: China Statistics Press).

National Development and Reform Commission; Ministry of Finance; Ministry of Public Security; Ministry of Labor and Social Security; Ministry of Agriculture; Ministry of Health; Ministry of Education; the State Council's Office for Correcting Industrial Illegitimate Practice; and the State Population and Family Planning Commission, 2004: "Circular on further reviewing and abolishing the discriminatory provisions and irrational fees on farmers for their inter-regional employment and employment in the cities" (in Chinese); at: <www.5Ilabour. com/lawcenter/lawshow-35684.html> (20 July 2008).

National Bureau of Statistics (NBS), 2006: "Survey reports on the living quality of rural-urban migrant workers in the cities (I): Employment and social security" (in Chi- 
nese); at: <www.stats.gov.cn/_oldweb/tjfx/fxbg/ t2006IOII_402358407.htm> (I9 July 2008).

Peng, Zhaiwen; Qiao, Libin, 2005: "Dilemma and outlet of migrant workers' social security: A perspective of social policy" (in Chinese), in: Gansu Shehui Kexue [Gansu Social Science], 6: 173-77.

Research team on the issues in the development of leftbehind children, 2004: "A research report on the issues of rural left-behind children" (in Chinese), in: Jiaoyu Yanjiu [Educational Research], IO: I5-18, 53.

Song, Jian; Hou, Jiawei, 2007: "Management of the floating population in Beijing: Seen from the perspective of policies and regulations" (in Chinese), in: Shichang yu Renkou fenxi [Market and Demographic Analysis], I3,3: I4-23.

Solinger, Dorothy J, I999: Contesting Citizenship in Urban China: Peasant Migrants, the State, and the Logic of the Market (Berkeley: University of California Press).

Standing Committee of the People's Congress of PRC, 2007: "Law of the People's Republic of China on Employment Contracts" (in Chinese); at: <http://law. 5Ilabour.com/lawshow-8I688.html> (20 August 2008).

The State Council, 2006: "A Few Opinions on Resolving the Issues of Rural-Urban Migrant Workers" (in Chinese); at: <http://www.5Ilabour.com/lawcenter/lawshow-44300. html> (20 July 2008).

Wang, Guixin; Zhang, Dezhi, 2006: "A Research on the Living Conditions and Social Inclusion of Rural-Urban Migrant Workers in Shanghai Municipality" (in Chinese), in: Shichang yu Renkoufenxi [Market and Demographic Analysis], I2,5: I-I2.

Wu, Weiping, 2002: "Migrant housing in urban China: Choices and Constraints", in: Urban Affairs Review, 38,I: 90-II9.

Xiang Bin, 2007: "How far are the left-behind left behind? A preliminary study in rural China", in: Population, Space and Place, I3,6: I79-I9I.

$\mathrm{Xu}$ Wei, 2006: "Segmented local labor markets in postreform China: Gender earnings inequality in the case of two towns in Zhejiang province", in: Environment and Planning A, 38: 85-109.

Yang, Yunyan; Chen, Jinyong, 2000: "Segmentation and competition of the transitional labor market" (in Chinese), in: Zhongguo Shehui kexue [Social Science of China], 5: 28-38.

Zheng, Gongcheng; Huang Li, Ruolian, 2007: Zhongguo Nomingong Wenti yu Shehui Baohu [Rural-Urban Migrant Workers in China: Issues and Social Protection] (Beijing: People's Press).

Zhu, Yu, 2003: "The floating population's household strategy and the migration's role in China's regional development and integration", in: International Journal of Population Geography, 9,6: 485-502.

Zhu, Yu, 2004: "Changing urbanization processes and in situ rural-urban transformation: Reflections on China's settlement definitions", in: Champion, Anthony, Gerard; Hugo, Graeme J (Eds.): New Forms of UrbanizationBeyond the Urban-Rural Dichotomy (Aldershot: Ashgate): 207-228.

Zhu, Yu, 2007: "China's floating population and their settlement intention in the cities: Beyond the hukou reform", in: Habitat International, 3I,I: 65-76.

Zhu, Yu; Chen, Wenzhe, 20I0: "The settlement intention of China's floating population in the cities: Recent changes and multi-faceted individual-level determinants", in: Population, Space and Place, 16,4: 253-267.

Zhu, Yu; Lin, Liyue, 20II: "The mobility patterns of ruralurban migrants and their social protection: Beyond the extension of urban-based approaches", CSP Research Report oI, Institute of Development Studies, University of Sussex, UK.

Zhu, Yu; Lin, Liyue; Wang, Bin, 2009: "Social protection for rural-urban migrants in an era of increasing population mobility and socioeconomic transformation: China's experience since the late I970s”, SPA working paper 2009 issue 03; at: <www.socialprotectionasia.org/pdf/ CPDR-SPA-WPo3.pdf> (29 January 2009).

Open Access. This chapter is distributed under the terms of the Creative Commons Attribution Non-commercial License, which permits any noncommercial use, distribution, and reproduction in any medium, provided the original author(s) and source are credited. 


\title{
9 Migration, Woodcarving, and Engendered Identities in San Martín Tilcajete, Oaxaca, Mexico
}

\author{
Serena Eréndira Serrano Oswald ${ }^{1}$
}

Are you willing to spend some time to look deeply into my eyes and ask me who I really am? [Lamberto Roque]

\begin{abstract}
This chapter offers a perspective on gender relations in a predominantly male migrant-sending community in Mexico. The aim is to bring to the fore the impacts of migration as lived in the sender community and their implications for social justice and human security. The case of the indigenous rural municipality of San Martín Ticlajete in the state of Oaxaca, Mexico, a male migrant-sending community, is examined, drawing on methods of critical feminist ethnography and social representations theory to illustrate the changes for the women who stay behind. Parallel to migration, the community has also experienced important transformations due to the development of a woodcrafts trade and increasing tourist activity. Very gradual changes in gender representations and empowerment have taken place, with women becoming de facto household heads, as well as craft makers and retailers, educators, administrators, agricultural producers, social figures, and civil servants. Nevertheless, detailed narrations of women's experiences show that their new roles and responsibilities do not necessarily translate into greater social, political, and economic autonomy, or recognition of the invisible material and emotional costs linked to migration.
\end{abstract}

Keywords: Social justice, migration, social representations theory, critical feminist ethnography, Mexico.

\subsection{Introduction}

The present case study crosses disciplinary boundaries to look at the impacts of migration in an indigenous area in Mexico, with special reference to women's lives. The chapter addresses the consequences of migration for the community of origin, not abroad. Most work on Mexican migration has been preoccupied by quantitative analyses of migration flows and remittances or by study of the networks that facilitate these flows. Too little attention,

1 Serena Eréndira Serrano Oswald is a postdoctoral fellow at the Centre of Regional Multidisciplinary Research, National Autonomous University of Mexico (CRIM-UNAM). The author is grateful for the research grant received from UNAM's Postdoctoral Programme. Especially, she wishes to acknowledge the support and guidance from the editors of this volume and the feedback from anonymous peer reviewers. Email: <sesohi@ hotmail.com>. relatively speaking, has gone to studying the lives of the stay-behinds, viewed in the round, including what happens in their hearts and minds, their identities and relationships, and their communities and culture.

In the traditionally indigenous locality that I examine (the municipality of San Martín Tilcajete in Oaxaca state), which is devoted to subsistence agriculture, processes of modernization and urbanization have led to mass migration, but these forces have come to the region accompanied by an increasing presence of tourism and the development of woodcarving production as an important economic alternative making seasonal international migration a viable choice. As we shall see, these processes are not gender-neutral. In a community setting such as San Martín Tilcajete, a cradle of mass migration, why do women not even have the right to migrate and yet must always assume the consequences and costs of others' migration? Furthermore, in a de jure male-led community, where men leave for abroad for work and leave women in charge 
de facto, when will changes at the political, economic, social, and cultural levels reflect this empowerment and aim at greater social justice for all? Following Nancy Fraser's approach to understanding social justice, in which recognition and representation as well as redistribution are all important and connected aspects, I look at the consequences of migration in this locality, with special reference to the nature of and any evolution of ideas, identities, norms, and conflicts about gender.

The chapter is organized in six sections. After this Introduction (9.I), which provides the general outline of the chapter, comes a discussion of Human Security and Social Justice (9.2), the guiding themes of the book and this chapter. Later, the specific research position I have used is presented, linking Social Representations Theory (SRT) with Critical Feminist Ethnography (CFE; 9.3). The municipality of San Martin Tilcajete then takes centre stage. Section 9.4 includes an introduction to the area of study (9.4.I), and a more detailed account of migration in the municipality (9.4.2), male migration (9.4.3), and woodcarving (9.4.4) as an economic alternative to migration and a major interacting factor. Section 9.5, the heart of the study, is devoted to Women and Migration in San Martin Tilcajete and considers female migration in Tilcajete (9.5.I) and case study examples of the women who stay behind (9.5.2). It closes with a summarized list of the findings of the study regarding the costs and implications of migration (9.5.3). Finally, some Concluding Remarks (9.6) are presented.

\subsection{Human Security and Social Justice}

For a world where we can be socially equal, humanly different and totally free. [Rosa Luxemburg]

Social justice is one of the most important challenges regarding migratory processes (emigration, transmigration, immigration, forced migration, etc.) in the world today. Historically, the nation state has sought to monopolize control of movement of people across its borders in order to protect its territorial sovereignty, for its own security. However, the nature of threats and the security referents have changed under global capitalism. Both as a scientific and as a political concept, security has been reconceptualized in the post-Cold-War era (see Brauch/Oswald/Mesjasz/ Grin/Dunay/Behera/Chadha/Chourou/Kameri-Mbote/ Liotta 2008). Narrow conceptions of security focusing on military and political dimensions have been wid- ened to include economic, sociocultural and environmental dimensions, and have been sectorialized into specific domains - such as health, energy, water, food, livelihood - with distinct periodicity (short-, mid-, and long-term). They have also been deepened in terms of scale in order to include not only the state as referent (national security) but also the individual (human security), interacting at inter-personal, community, national, international, regional, and global levels. Finally, they have been enriched by attention to the subjective and emotional aspects of security, including the content and evolution of identities. It is important that discussions of social justice in migration be anchored in a complex, dynamic, and ample perspective of human security that looks beyond the state, without neglecting it. In this chapter I consider the stresses, threats and opportunities in many dimensions of local people's lives, especially in women's lives, in a small community in Mexico that has become heavily engaged in migration, especially international migration.

For the purposes of considering social justice and migration from a human security perspective, this study employs Nancy Fraser's work. As Novak points out "the trouble with 'social justice' begins with the very meaning of the term... books and treatises have been written about social justice without ever offering a definition of it. It is allowed to float in the air as if everyone will recognize an instance of it when it appears" (2000: I). One general definition of the goal of social justice is "the full participation and inclusion of all people in society, together with the promotion and protection of their legal, civil and human rights. The aim of social justice - to achieve a just and equitable society where all share in the prosperity of that society - is pursued by individuals and groups through collaborative social action" (IRP 2008: 53). Nevertheless, some of the tensions surrounding its conception already become apparent; they have to do with the difficulty of balancing its individual (personal), group collective (social), and mass collective (societal) dimensions and its level of analysis and implementation (micro-, meso- and macro-). As Habermas points out (2005: I), "if the core of the liberal constitution is the guarantee of equal individual liberties for everyone", both classic and modern conceptions and edifices have been challenged by the dynamism and complexity of contemporary social relations, where globalization undermines the State and its structures, and global relations in the transnational era remain marked by profound structural and symbolic inequalities. 
From a critical feminist standpoint, Nancy Fraser advocates a theory of social justice for the knowledge society era of post-Social politics. Her approach seeks to transcend 'either/or' dichotomies and account for the interrelationships of the local, national, regional, and global beyond the Westphalian frame that has focused on national security rather than on justice. She discusses a tripartite model of social justice aiming at 'participatory parity', with reference to the economic dimension of redistribution, the cultural dimension of recognition, and the political dimension of representation (Fraser 200I, 2005, 2008). Unlike other approaches, in her view and in order to be effective in terms of social justice, all three dimensions must have equal weight:

Insofar as the stress on recognition is displacing redistribution, it may actually promote economic inequality. Insofar as the cultural turn is reifying collective identities, it risks sanctioning violations of human rights and freezing the very antagonisms it purports to mediate. Insofar, finally, as struggles of any type are misframing transnational processes, they risk truncating the scope of justice and excluding relevant social actors (Fraser 200I: I3).

In order to tackle the displacement of egalitarianism under hegemonic neoliberalism, Fraser proposes a conception of justice which encompasses recognition and distribution; to counter reification, she provides an account of the politics of recognition that does not lead to identity politics; and against misframing she offers a multi-tiered conception of sovereignty that decentres the national frame (Fraser 200I: I3). The economic dimension of egalitarian redistribution implies overcoming class exploitation, restructuring the political economy, and altering social burdens and social benefits. Recognition implies "a process of consideration and judgment, in which the identity or attributes of an object, person or relationship are first noticed, and then acknowledged and affirmed" (Connolly/ Leach/Walsh 2007: I). Thus, the politics of recognition takes into account minorities, women, vulnerable groups, devalued identities, and deconstructive tendencies, rejecting essentialisms; and linked to representation it implies autonomy, i.e., the political means to assert oneself and one's group's civil liberties and political rights. Fraser's integrative approach, ${ }^{2}$ if linked to the deepened conception of security mentioned earlier, can contribute to greater social justice in the transnational era.

\subsection{Research Position: Social Representations Theory and Feminist Critical Ethnography}

The quotidian speaks quietly with the eternal. [R.M. Rilke]

The Theory of Social Representations ${ }^{3}$ (TSR) is useful in order to ethnographically research economic, cultural, and political processes where distribution, recognition, and representation are all intertwined and are important for human security (broadly understood) and social justice. ${ }^{4}$ It is important to go beyond an individual-societal dialectic and explore the interrelation between social dynamics at the heart of identity processes at all levels and the social representations that sustain these processes. The community and domestic units (blood-related or legal and ritual family units in this case) are the social institutions that mediate the causes and consequences of migration at the material and symbolic level. From a social psychological perspective, much mainstream research linked to justice in Mexico, Latin America, and North America (e.g. research into difference, discrimination, racism, violence, personality, identity, gender, inter-group relations, cooperation, and competition) has been undertaken from an individual and group perspective, leaving behind or in second place anthropological, societal, and sociological considerations. ${ }^{5}$ This has to do with the influence and weight of the behaviourist perspective, which can be traced back to figures such as G.W. Allport. ${ }^{6}$ Without diminishing the relevance

2 The debate surrounding the interrelation of universalism, minorities, and individualism has been at the core of liberalism (Beck 2008). According to Habermas (2005: I), "the idea of equal individual liberties for all satisfies the moral standard of egalitarian universalism, which demands equal respect for and consideration of everyone" on the one hand, while "it meets the ethical standard of individualism, according to which each person must have the right to conduct her life according to her own preferences and convictions" on the other.

3 At this point it is important to distinguish between [I] representation as part of the politics of justice (political means to assert oneself and one's groups, civil liberties, and political rights) and [2] 'social representations' (the category rooting Social Representations Theory, SRT), which are how people are defined and depicted within a society. SRT is a theoretical and methodological perspective for addressing social justice, as will be explained in detail in the following section.

4 For a feminist discussion of the broad security perspective, its challenges for women, and the usefulness of Social Representations Theory, see Serrano (in press). 
of such research when considering issues of social justice and human security, the historical, societal, and cultural dimensions that root and reproduce injustice must be considered.

\subsubsection{Social Representations Theory}

Social Representations Theory (SRT) is multidisciplinary in its origins; it draws directly from psychology, sociology, and anthropology. It originated as part of the critique of individualizing and reductionist perspectives, as well as those that advocate the collective as the pinnacle of human achievement. Congruent with Fraser's social justice approach, TRS accounts both for social structure and the processes whereby the social subject constantly generates, interprets, and transforms knowledge inter-subjectively. Unlike the Marxist conception of ideology as false consciousness, or the Durkheimian conception of passive social subjects paralyzed in the face of 'social facts' and social control, Moscovici explored the ways through which social groups are structured and act according to different yet shared social representations, enabling them to perceive, give sense to, and transform them, appropriating and gestating knowledge, communicating, and becoming active minorities created by but not only determined by power structures (the social change conception). In this view, conflict and tension in the social sphere are addressed positively as motors of change and not necessarily of crises, a process of innovation that is normalized as well as questioned

5 For example, the Framework for Enabling Empowerment (FrEE), which has been developed since 1985 by the Mexican Institute of Family and Population Research (Pick/Sirkin 20II), is based on individual needs, capabilities, and behaviours, developing resources in the face of poverty. Under the slogan "I want to, I can”, workshops provide information guiding decisions and communication skills in order to promote autonomy and control over rights (<www.imifap. $\operatorname{org} . \mathrm{mx}>$ ). Without denying the importance and usefulness of such an approach that is said to have benefited nineteen million people, this chapter in contrast applies Social Representations Theory as it implies the potential of addressing justice, rights, identities, change, and culture in a much deeper sociological psychological way than would be possible under an individualistic-empowerment and behaviourist frame (for a discussion regarding each socio-psychological tradition see Farr 1996).

6 Migration studies have also been heavily influenced by behaviourism (see Truong/Gasper 20II, especially chapter I). where representational activity occurs (Arruda 2002; Arruda 20IO).

A social representation is constructed in culture and is not an individual psychological or cognitive construct. Social representations are social products derived from interaction and their nature is relational. Social subjects re-present reality, which is to say that they do not merely reproduce it mechanically as a mirror; they interpret and transform it and at the same time are transformed by it. This has direct implications for social scientific and feminist gender studies of migratory contexts, given that representation processes are linked to the processes of conformation, maintenance, and transformation of social and collective identities. The multi-level identity approach considers relations within individuals and between ingroups and out-groups, as well as historical, societal, and ideological processes, including deeply embedded representations of gender such as world outlooks and other constructs that are more flexible and less resistant to change.

\subsubsection{SRT and Critical Feminist Ethnography}

As Madison (2005: 4) points out, consistent with Fraser's arguments "political representation has consequences: how people are represented is how they are treated". Critical ethnography research emphasizes giving local people, women, and invisibilized groups the right to express and represent themselves, establishing a dialogue and collaboration with them and being critical of its own standpoint; engaging in serious longitudinal studies that enable one to acquire an honest meta-reflexive position and deep insights with regard to and in relation to the research context and people, while considering silences, omissions, and processes of invisibility; and enabling researchers to be an active part of the social process, collaborating in the transformation of society, for example through participative-action research (Delgado 20IO). It "begins with an ethical responsibility to address processes of unfairness or injustice within a particular lived domain", and this 'ethical responsibility' means "a compelling sense of duty and commitment based on moral principles of human freedom and well-being" (Madison 2005: 5).

Gender is a "system of social regulation that orients a specific cognitive structure, built following a biological referent that makes notions of the masculine and the feminine normative" (Flores 200I: 7). Such a system, that has gender representations at base, constitutes the cultural framework from which identities 
are elaborated, others are identified, and relations and world views are established. Researching from a critical gender perspective implies elements of participatory and critical research, a democratic exercise in which the researcher together with research subjects participate in order to reclaim spaces to value their voices and actions in areas where hegemonies of everyday life have silenced and devalued them. Researching together with women as social subjects implies working together for a space of memory and re-presentation, a space where they can talk, think about themselves, remember their lives and experiences, and share them with laughter and often with tears, reflecting about themselves, their identities, relations, and life experiences.

\subsection{Migration, Gender, and Woodcarving in San Martín Tilcajete}

This is a trip toward the unknown; toward the deep corners of loneliness, and the insides of the intestines of a monster that feeds itself by devouring others. [Lamberto Roque]

The work presented in this chapter was all undertaken in the municipality of San Martín Tilcajete, in the state of Oaxaca. It draws from different and interconnected research projects in the same community at different times, with various individuals (both male and female), families, and groups (school groups with children and adolescents, groups of women and men, artisan groups, people at the health clinic and those involved in the government's 'Oportunidades' programme, official community committees, etc.), starting in the year 2003; it is still ongoing. Altogether, it has involved nine years of critical feminist ethnography, with different research periods while living in the research area (the longest lasted for two continuous years) and recurrent visits and communications during the rest of the time. It has also included a variety of research techniques, of which the most relevant for the purposes of the present chapter have been applying an exploratory free association questionnaire to explore the community's social representations $(n=I 50)$, two local censuses (2004-2005 and 20082009), and a series of longitudinal in-depth interviews with a sample of eleven women which were transcribed in nearly five hundred pages and later analysed. ${ }^{7}$ Currently, in-depth interviews with men are being undertaken, transcribed, and analysed, although they will not be drawn on here.

\subsubsection{Setting the scene: San Martín Tilcajete}

The state of Oaxaca in the south of Mexico, with almost four million inhabitants (INEGI 20IO), is one of the two poorest states in the country; those states also have the most indigenous presence. ${ }^{8}$ Administratively, the state is divided into seven regions. In the region of the Central Valleys, we find the City of Oaxaca, capital of the state and a tourist hub hosting over a million national (eighty-four per cent) and foreign (sixteen per cent) tourists per annum (Boletín Estadístico 2004). ${ }^{9}$

The municipality ${ }^{10}$ of San Martín Tilcajete is located approximately 32 kilometres south-east of the capital city. Allegedly, the locality was founded two centuries BCE, but the present-day community is of Zapotec origin and dates back to the year I600 (Reyes 2003: 4). Although census data vary, a realistic estimation of the population based on fieldwork data and the medical centre census is a total of two thousand community members, of whom fifty-five per cent are female and forty-five per cent male (Fernández/Serrano 2004). The community covers $27 \mathrm{~km}^{2}$ and contains private, communal, and ejido lands. In I98I it was recognized as an autonomous community within the district of Ocotlan. It is governed by a political system of 'traditional uses and customs' rooted in a hierarchical system of communal duties and obligations, organized through male-headed family units. The male heads or 'contributors' must pay fixed annual and temporary quotas to the local administration committees and provide unremunerated community service in yearly periods, with a rotating active and passive term in office every twelve months, till citizens are sixty years old or they reach the highest possible rank.

In a community where 95.3 per cent of the population is Catholic and the Zapotec language has been

7 For the full results, access to transcript sections, coding frames, and the direct voices of tileño women presented at greater length, see Serrano (20IO).

8 Twenty-eight out of the sixty-eight ethnolinguistic indigenous groups of Mexico converge in Oaxaca (Barabas/ Bartolomé/Maldonado 2003).

9 Valid data for 2004 are used, because of important variations in estimations following the APPO crisis in 2006. The crisis involved a confrontation between the state of Oaxaca, which eventually deployed federal forces, and the Popular Assembly of the Peoples of Oaxaca (APPO).

10 Almost every town or community in Oaxaca is a municipality, most governed by a traditional sociopolitical system. 
lost three generations ago, the social and cultural organization responds to a very active calendar of public and private feasts. The public festivity calendar begins with the celebration of the Day of the Dead in the last days of October and extends until the Mother's Day festival on Io May. During these six months, there are at least two grand celebrations per month - each of which lasts several days and has an 'octava' or minor scale replay celebrated a week after the original party. The community is well known for the frequency and sumptuous nature of its festivities. Private feasts include baptisms, confirmations, 'quinceañera' or fifteen-year celebrations, weddings or fandangos, burials, and birthdays. Most members of the community are related in some way and everybody knows all the members of the community at least by name and reputation. Gossip and the constant vigilance of fellow community members ensure compliance with social canons. Breaches of the law or misconduct are handled by the municipal authorities; fines are usually paid for with cement bulks used for building public infrastructure. There is a community room designated as a prison for handling minor offences, although domestic problems and violence are treated as private and are thus seldom denounced or castigated; when they are, cement bulks for public use might help restore social ties but they hardly compensate for or alter intra-family relational dynamics where women are the most common victims.

Traditionally, San Martín was reliant upon subsistence agriculture for domestic consumption (Perez I99I). Nowadays, following the fall in international agricultural prices, land erosion and global environmental change, the end of agricultural subsidies in Mexico, and facing competition from larger-scale technologically-equipped national and international farms, the community has turned to woodcraft production and migration as the two main means of subsistence; economic transformation in the past four decades has been tremendous, as will be discussed. The practice of agriculture remains common, given the importance that food sovereignty, growing one's own food, and contact with nature still have in local culture, especially amongst the older generations. A risky activity because of changing weather and rainfall patterns in a semi-dry area, agriculture and farming are still felt as important even though in most cases they entail lost investments and are significantly subsidized by entire families working the land or hiring external labour. Resources to subsidize agriculture come from either migration or woodcraft production, and agriculture is an 'officially' male-dominated process, though women, children, and elders also partake in it. ${ }^{11}$ The families that only engage in agriculture are the poorest families in the community, including a few female-headed households made up of women, children, and elders, or women and elders, who live way below the poverty line.

\subsubsection{Migration in San Martín Tilcajete}

The history of international migration from Oaxaca to the USA dates from the beginning of the last century. The Bracero Programme in the forties had the "greatest influence to promote international migration in Oaxaca, given that not even the devastating effects of the Mexican Revolution in many towns or the construction of the railroads in the USA at the beginning of the century had such impact" (Reyes/Gijón/ Yúnez/Hinojosa 2004: 20I). At national level, during the twenty-two years that the Bracero Scheme lasted, it "mobilized an average of 350 thousand workers between 1954 and 1960, hiring 4.5 million workers in total" (Durand/Arias 2005: 20). San Martín Tilcajete became part of the programme following the construction of the Pan-American Highway in the forties, when the community was directly linked with the outer world. From that time, the itinerant circuit that is very common nowadays, from the community to the capital city Oaxaca, was established for work, education, recreation, medical care, banking, administrative and government services, etc.

When the Bracero Programme ended and the USA closed its borders, migration in the state of Oaxaca remained intra-national, from rural zones to urban areas, towards the regional economic centres. Given the proximity and the routes of communication between San Martín and the capital city, intra-state migration was not significant. Instead, the flows towards the centre of the country (the Metropolitan Area of the Valley of Mexico) were significant, as well as those towards the plantations in the north of the country for agricultural work and to the south-east for tourist developments. These migrations were both temporary and permanent, and the number of

11 The political system of male authority in the community, which had been ideologically reinforced by the Catholic religion, was substantially backed by the agricultural land distribution following the Revolution (I9IO onwards) and the National Project of President Lázaro Cárdenas (I934-I940). Twenty-five million hectares were granted under collective ownership (ejido and collective lands), organized in male-headed agricultural productive units. 
tileños $^{12}$ that have family in Mexico City today or once lived there is considerable. Nevertheless, following the fall in international oil prices and agricultural prices in the eighties, the weakening role of the state, the crisis of the welfare state and the rise of neo-liberalism, extreme wealth disparities, increasing poverty, and demographic pressure, international migration towards the USA gained an unprecedented force (see Ruíz I992).

According to a study undertaken by College of Economic Professionals of the state of Oaxaca, remittances as proportion of State GDP have increased rapidly, from seven per cent in 2003 to ten per cent in 2007. In 2008 the total remittances were estimated at I2.5 per cent of the State's GDP. Remittances sent by Oaxacan migrants living in the USA are the third biggest source of revenue for the state of Oaxaca after federal funds and tourism (Pacheco 2009). According to data from the Central Bank, the state of Oaxaca received US\$I,457 million dollar in remittances in 2008.

\subsubsection{Male Migration in San Martín Tilcajete}

In the community of San Martin Tilcajete, migration has been male-dominated. The history matches that for Oaxaca as a whole. The first significant period of international migration dates back to the Bracero Programme (I944-I964), when the USA sought cheap Mexican labour through 'contracts', usually for short and specified periods of time. Migrants usually returned to their communities after fulfilling their contracts. When the programme gained increasing appeal, the USA closed its borders and terminated it, although some of the scheme's pioneers settled in the USA permanently.

The second period of migration, from the I960s to the I980s, was characterized by intra-national migrant flows, as communications and transport improved, or followed emerging job opportunities in Mexico City or in the agricultural producing states in the north of the country and in the south-east in tourist developments in the Caribbean. Where opportunities were good, migrants settled permanently in those locations.

In the third and current phase, international migration from San Martin recommenced in the I970s, though it substantially decreased during the woodcraft boom (I986-I994). It soared following the 1994 crisis and has remained constant till today, with an in-

12 The term tileño denotes a person from San Martin Tilcajete; its plural form is tileños. crease after the APPO crisis in 2006 and sustained growth despite the international crisis in 2008. The community has established itself as a cohesive group in Santa Cruz, California, where the extraterritorial community of San Martin Tilcajete is located, following decades of migration, with some tileños and/or their children already holding US citizenship. Most illegal immigrants find support from other tileños who are currently there or have been there before - sometimes several times - and have established important networks of support, services, work contacts, and so on. Migration has also spread to Los Angeles, San Francisco, San Jose, Oakland, Chicago, Oregon, and New York. Job prospects for tileños in the USA as illegal and semi-skilled workers remain concentrated in agriculture, work in hotels, cleaning, car washes, personal and care services, and construction and building.

Although some families of early migrants have moved permanently to the USA and settled there, migration is very largely cyclical-pendular. Typically it is male-led and represented by a specific age range, although women and members of all age groups also participate. ${ }^{13}$ Despite the perils of migration or perhaps exactly because of the importance of facing and overcoming them, it has typically become an almost inescapable rite of passage to adulthood for young male adults following the end of high school and before considering marriage. Once they have faced their first migrant period, men return to marry and after settling with their wives in their paternal parental home or having their wives pregnant, men resort to migration in order to save and build their own room

13 Estimating migration for San Martín Tilcajete has been very difficult, as migrants come and go and data variability throughout the year and across years makes it very hard to estimate. In addition, the illegal nature of international migration from San Martín Tilcajete means that family members left behind in the community of origin are very reluctant to respond to surveys regarding migration. For example, according to the National Census by INEGI, San Martín Tilcajete has had twenty-eight international migrants in total since the year 2000; this figure is absurd. If we take the share of migration amongst the economic activities in the community (thirty per cent in 2004) in relation to the number of families, we would find that a very conservative estimate of migrants would be I5O people (I30 men and twenty women). Considering the national proportion of migrants relative to families involved in the migratory phenomenon (I.7), the estimate would then give us a total of 294 migrants. This fits better with discussions held in the community. 
or small house back in the community. For men between sixteen and fifty, international migration remains a preferred economic alternative, although it alternates with periods of residence back in San Martín, working as carvers and in agriculture. The interaction between migration, woodcarving, and agriculture is important as it provides economic alternatives for tileño families. As woodcarving has become increasingly successful as a source of income and prestige since the mid-eighties, it has become an important interrelated factor that has transformed the community of origin and also migration, although not all families combine migration with carving. Most frequently, migration is combined with agriculture in order to produce home-grown foods and preserve land tenure, although agriculture always involves an expense and does not always yield favourable returns, given the mounting prices of materials and poor land conditions in a semi-arid region with water shortages, land erosion, and climate variability.

Once they have some capital and as they grow older, migrant men return to the community to settle back with their original family; if they have children (particularly, though not exclusively, males), they tend at some point of their migrant trajectories to take them abroad to live with them and work. Migrating and overcoming the perils associated with migration from adolescence onwards holds important social value for men; it confirms their masculinity in the community of origin and abroad amongst peers. Most domestic chores that men learn and perform whilst in the USA for work and for their everyday survival are always undertaken by women back in San Martín; this applies also to families where both spouses and children have emigrated. As will be discussed below, this often also applies to authority to run the household and its economy, agricultural lands, the woodcarving business, and political positions in the local hierarchy. This shows the importance of analysing gendered social representations, and the meanings and practices associated with them in the community of origin.

\subsubsection{Woodcarving in San Martín Tilcajete}

Since woodcarving has been such an important interacting phenomenon in San Martín Tilcajete, sometimes providing resources for emigrating and sometimes as part of a valued return or stay-home strategy, it deserves special attention. Ethnic-cultural tourism is important in the Central Valleys region, following the designation of Monte Albán and the City of Oaxaca as a World Heritage Site by UNESCO in $1987 ;{ }^{14}$ it has been a catalyst for the development of an important arts and crafts industry. San Martin Tilcajete is one of the three main alebrije ${ }^{15}$ woodcraft-producing communities in Mexico. From the mid-eighties the woodcarving boom meant that most household members residing in the community, as well as migrants during periods spent in San Martín, turned to woodcraft production; this included women, children, and elders. There are two main types of woodcraft production: i) high-quality, unique, time- and labour-intensive specialized pieces, and ii) average-quality, pattern-repetitive, quickly-made, small inexpensive pieces (for a detailed account, see Chibnik 2003; Cant 20I2). From the resources derived from migration and those generated since the carving boom, the community has been radically transformed. Private and public infrastructure and tourist services have substantially improved.

Despite intensive female labour, artisan households are male-led. Local men are in control of most of the craft's productive process (sometimes deciding even from abroad how, when, and where pieces are made, and the labour distribution). However, sales and commercialization of woodcarvings are under the control of exogenous male regional, national, and international retailers and intermediaries who sell woodcarvings for much higher prices. In the actual socio-economic 'glocal' setting, with interdependent multi-level networks of exchange, individuals have autonomy and choices, but these are limited and bound to specific contexts. As with migration, men head the processes of wood production, retailing, and commerce inside and outside of the community, and this brings our attention to the topic of economic distribution and social justice, with a specific gender analysis.

Although resources have increased from both migration and woodcarving, and the quality of life is of an overall higher standard, competition linked to woodcarving and envy due to migration have weakened social cohesion, hampering any attempts to organize in large collective commercial associations or productive projects. ${ }^{16}$ It is only extended families and smaller-scale groups that have organized in productive

14 This is complemented by the recent declaration of the Prehistoric Caves of Yagul and Mitla as a UNESCO World Heritage Site in August 2010 in the same region of the Central Valleys of Oaxaca.

15 Alebrijes are woodcrafted figures made out of copal wood, with exotic colours, lively patterns, and creative designs. The consolidation of this activity has placed the community in global production and distribution chains, taking tileño art and artists to national and international exhibitions. 
processes, in overt competition to other groups in the community. Envy, lack of cooperation, exploitation, competition, piracy, and public offence have characterized woodcarving. ${ }^{17}$ Nevertheless, the social nature of interpersonal relations that makes friends part of the extended family through lifelong ties and practices of mutual obligation, reinforced at private feasts and public celebrations, has led to the formation of bigger workshops with a specialized division of labour and cooperation. Paradoxically, higher incomes have meant that reciprocal exchanges are more selective but more defining; educational standards are higher and alternatives open, allowing for stronger intra- and inter-group cohesion despite intra-community atomization following carving and migration. These two facets permeate the community, providing its members with esteem and a common identity bridge over a deepening abyss that hinders the definition and articulation of collective goals.

Lastly, woodcarving has been possible through unpaid family labour, especially by women and to a lesser extent by children and elders. Typically, men carve wood and women prepare and paint the pieces, although most men also paint and some women carve. Direct and regional sales are led by women, unless the commercial relations involve core clients, in which case men handle business transactions. Most pieces are signed by the male household leader, who forges an individual reputation and is always in control of sales revenues, even if he temporarily migrates to the USA. In the production chain, time invested in carving and painting pieces is on average the same for women and men; however, alongside woodcrafts women must fulfil their care, domestic, and social obligations. In a study conducted in San Martin in I99I, women were found to work on average at least fourteen hours more per week than men (Pérez I99I: 30I). With the demise of agriculture, the extra responsibilities imposed on women by migration - for example, caring for children throughout the day and painting at night - mean that today women work on average twenty to twenty-five hours more per week

16 Examples of this are two important yet competing groups that organize parallel alebrije festivals and events for tourists and the inability of the entire community to agree on a single collective trademark, especially as other communities and regions of the country (and even internationally) have started to copy and produce alebrijes with the innovations developed in San Martín Tilcajete that make the pieces unique.

17 It also has led to many factions that seek to control municipal authority. than their male counterparts. In a community where economic, social, political, and cultural power and esteem have traditionally been monopolized by men, domestic chores, parenting work, and other care work undertaken by women have been historically invisible. This has not changed with modernization, and in addition women's labour in the woodcraft trade tends to be devalued. Nevertheless, two of the best known paintresses of alebrijes are women: María del Carmen Mendoza Mendez, leader of the Ángeles workshop together with her husband, and María Jiménez, famous for her angels.

\subsection{Women and Migration in San Martín Tilcajete}

At last I wonder how many marriages and families have not gone through what I am going through? Cristina $[$ ㅇ, 30-35]

\subsubsection{Female Migration in Tilcajete}

Female migration has very distinct features when compared to male migration. Dominant gender social representations lead to different ways of organization, whereby women are often discriminated against. Following Fraser's social justice axes, let us now look at migration in the concrete case study, bearing in mind the political, sociocultural, and economic dimensions. The societal weight given to care associated to femininity and imposed upon women at the sociocultural level is tremendous. Care has been ideologically naturalized and politically justified, linked with the privatedomestic vs. public realm dichotomy in the polity. Nevertheless, in a traditionally male-led community where migration has meant an important exodus of adult men who are supposed to be in charge of political, economic, and administrative activities, the consequences have been tremendous de facto changes in gender roles, even though female leadership and work often remains unrecognized and migrant men remain the de jure authority or seek to exercise it de facto through relatives, even through their mothers. Besides, if women migrate, it is mostly linked with the fulfilment of these conventional care ethics.

During the second wave of migration, in the I960s-I980s, women migrated alone, especially within Mexico at a young age and as maids, returning to San Martin after a few years to marry or take care of the sick and elderly, or staying away and sending remittances to family members when single. Since the I990s, female migration has also taken place interna- 
tionally to the USA, normally as companions to their husbands or fathers who have previously established themselves in networks there. Children are a deciding factor, as some families have sought to have children in the USA in order to obtain US citizenship, though women tend to return to the community in Oaxaca to raise them, unless a close female relative in San Martín stays in charge of care duties throughout infancy. There is a strong bond with the community of origin, which is reinforced by endogenous marriage patterns, investments and retirement there, close family ties, and the possibility of coming and going to the USA, even though tightening security controls have made crossing the border more difficult and expensive. Both parents typically emphasize the importance of raising their children in San Martín, even if that means leaving them in the hands of relatives. However, the preferred choice tends to be mothers returning and raising their children whilst living with their husband's parents and siblings, with the male migrant spouse periodically returning. This pattern is congruent with national migration estimates of communities of 2,500 people or fewer, where 86.8 per cent of international migrants are male, and only $\mathrm{I} 3.2$ per cent female (INEGI 20II; see also INEGI 20I0, 2005).

Campaigns promoting human rights for citizens in developing countries in the context of migration often now voice the demand 'the right not to migrate' or to migrate in acceptable conditions. In contrast to the first phase of campaigns that aimed at improving relations and realities in migrant destinations - addressing the stresses, humiliations, and abuse endured by migrants - the more recent phase advocates a radical transformation in the settings in which migration is generated. Returning to Fraser's discussion we need though to ask: Why do women in a community setting such as San Martin Tilcajete, cradle to mass migration, not even have the 'right to migrate? ?18 Women who are affected in their everyday lives by mi-

18 Balancing recognition, representation, and redistribution in the migratory process, as will be seen, here refers to 'choice'; it is not presented as a legal interdiction per se given that the Federal Constitution is more important than indigenous traditional rights or municipal or local state laws. Nevertheless, it is relevant to distinguish between de jure rights guaranteed to all Mexicans, men and women, by the Federal Constitution and the de facto reality in the local setting. Let us remember that San Martín Tilcajete is a community governed by traditional law which is based on traditional practices of everyday life that have restricted free movement of women for centuries and still do so as a social practice. gration and must invisibly assume its costs directly and indirectly (see section 9.5.3) do not even have the option to migrate because of the prevailing social and cultural canons, and when they do, it must be by accompanying husbands, parents, or other family members, in order to be controlled by them, otherwise community and family members will impose sanctions on a woman for migrating. Women may migrate within the country, usually as housemaids, since their work is closely supervised and their earnings benefit others. However, if migration is a step towards women's autonomy, education, self-affirmation, or liberty, sanctions can be as subtle as segregation and denial or escalate to overt expulsion from a marriage, family, or community. In such a rigid social system, women who do not conform to socially sanctioned rules must leave their families and the community for good, losing every right to struggle for redistribution, recognition, and representation in the local area.

Although studies of female migration in Mexico have been common since the late I990s, studies of the costs assumed by women in the community of origin and their social, political, and economic implications are scarce and remain a challenge; much less emphasis has been given to recognition, representation, and redistribution. Some noteworthy studies are a general two-volume compilation of the effects of remittances and migration on peasant and indigenous women in various areas of the country (Suárez/Zapata 2004); a discussion on gender, migration, and social control in Veracruz (García/Ruiz/Ruiz 20II); a comparative article on indigenous migrant women from Oaxaca (Sánchez/Barceló 2007); a study regarding the impact of migration on marriage in a Mixtec community (Martínez 2003); a study regarding women and men in the development and organization of a productive cooperative in a migrant-sending context in Ayoquezco, Oaxaca (Figueroa 20II); and various studies regarding the implications of migration for public health in the community of origin, covering chronic and psychosomatic diseases up to the spread of HIVAIDS (for one example linking this with social representations see Flores/Serrano 20I2).

As stated, the findings given here follow more than nine years of critical feminist research looking at everyday life in Tilcajete, triangulating feminist ethnographic fieldwork with the free association questionnaires, two local censuses, and eleven longitudinal indepth interviews. ${ }^{19}$ The next section will present two detailed illustrative examples or testimonies in order to give voice to women and contextualize the discussion. It will be followed by a list of core findings in 
terms of implications and costs of migration for women in the migrant-sending community.

\subsubsection{Case Study Examples: The Women Who Stay Behind}

\subsubsection{Case of Adriana [DAD, $9,18-25]$ and Erika [DAE, $\$, 40-45]$}

The relationship of Adriana ${ }^{20}$ with migration is the story of coming of age in Tilcajete as the daughter of Erika, an unusually self-determined and empowered mother (whose testimony and words will also be presented), an alcoholic stepfather, and a biological father who has lived away in the USA and has been absent during all her life but whose symbolic presence and family have been defining in her upbringing, given the community setting. She does not know him at all except for the contradictory stories that she has heard from her mother, her biological father's family, and from others.

Rodolfo (his name) left for the USA when Erika became pregnant. Erika and Rodolfo were not married and for many years Erika thought he did not want to settle and establish a family with her; that is what she had heard from Rodolfo's parents: "He left. He did not want to have anything with you. He is not sure your daughter is his", "You have loose morals" they would say. Erika did not decide his departure, but she did not mind. According to her, unlike most other women she was looking for a family, which meant a child and not necessarily a husband and much less a conflictive relationship with his parents trying to control her; she had enough personal, family, and economic resources to be a single mother and she cut all ties with them. She had planned to become pregnant by one of the best-looking men in town because she wanted a "beautiful daughter" and she was prepared to raise her daughter on her own despite the social implications of her decision: gossip and pressure from the community. Besides, she had her own home and after her father's death she had seen her mother's example of strength and work.

Socially, being a fatherless single mother in a maleled and male-organized community was quite unusual

19 For the full results, access to transcript sections, coding frames, and the direct voices of tileño women at greater length, see Serrano (20I0).

20 Note: names and some details have been changed to protect the identity of informants. Quotations have been translated, while trying to respect their original meaning and style as closely as possible. at the time. Erika [DAE, $\$, 40-45]$ said her pride helped her: "I struggled... I had nothing to be ashamed of", although she was constantly singled out. It proved difficult and after a few years Erika found another partner named Luis. He was willing to accept her daughter Adriana although he also wanted "a family of his own blood". Unlike other women, Erika did not want to get married despite significant pressures: "They will always speak about others [but] no, we are fine like that. Otherwise it is harder to separate. It would be more difficult. It's better just like that so if we choose to go in different directions, each can just leave as we entered [the relationship], just like that". Surprisingly, given commonplace patrilineal endogamous marriage in Tilcajete, they settled together in her house where they bore a son to consolidate their union. ${ }^{21}$ Nevertheless, politically and de jure he is the household head. Despite an irregular and precarious income (US\$5-8 per day on average), Erika is and has been the economic pillar of the family. According to Adriana, Luis used to work in construction and be responsible, that is, fulfil his role as provider, 'but he has turned into an alcoholic for many years now': "He would finish working and would not come back home, we would have to go get him lying lost on the ground... I think it was the pressure of the other builders because he lived with us.... I worry because of my brother, he suffers most... My mom is fed up, I told her to leave him, and once she did, but then the next day his mother came to speak for him and he is back since" [DAD, ㅇ, I8-25].

The economic empowerment and decision-making of Erika as de facto household head in Tilcajete are noteworthy. She decided to establish her own household, to work independently of Luis's income, to raise her daughter on her own without relating with Rodolfo's family, to have a second partner and son and not get married. Even if the central cultural and identity premise was still that of making a family and complying with motherhood as defining femininity, and her initial choices were reactive following Rodolfo's departure, they certainly break with traditional ways. Perhaps later Luis was a useful compromise in the light of societal pressure, and although without

21 The practice of bearing children to consolidate unions is commonplace, although following migration it has become a most important practice, almost like a ritual. It is a private and public confirmation that the union is still solid, and many male migrants will seek to get their partners pregnant during each visit to the community of origin. This has led to many women secretly resorting to contraception. 
recognized representation or recognition she was and is the de facto household head. Erika's story is also notable as it was one of the first cases of the kind at the time. Single mothers are now more common in the community although they tend to remain under the protection and vigilance of their families, especially bound to the authority of male figures such as fathers or brothers.

Another striking feature of this case is the later struggle of Erika with Rodolfo's family for Adriana and Adriana's upbringing. Initially, she grew up believing Luis, and not Rodolfo, was her father. Those were her "happy years". Nonetheless, throughout her childhood, the family of Rodolfo and the community would let her know and constantly remind her of her origins and of the desirability of leaving her mother's side and 'terrible example' in order to follow her biological father abroad, regardless that he had abandoned her. A woman who is the economic pillar of the family and makes choices, seeking recognition and representation whilst reorganizing her life and thus defying social canons, was unacceptable, even in the face of a partner's and a father's abandonment. Adriana states that often Rodolfo's parents, especially his mother, would try to persuade her to go shopping to the capital city Oaxaca or to go and meet her father, with the hope of kidnapping her; for years she was afraid they would. She still has not figured out if that was to send her to the USA with her father, to take her to live at their household, or just to distance her from Erika and her more autonomous example.

An adolescent student now, Adriana struggles throughout the interview to put her life and identity into a different perspective, although she is aware of her current resources. She speaks of a life story of confusion and pain as a child, which centres in her emotional and not her economic needs; the questions of the interview even serve as a means of unveiling a past full of mixed messages that she has tried to forget. Here is an extract:

I never met him [my biological father]. There is the story my mom told me... then the man I thought to be my father, [but] besides all those women would tell me stories and ask me about my life, they would sow so much gossip around my life that I would run home crying. I was a little girl. Mom would tell me 'Don't listen to them, when you become adult and have use of reason I will tell you the truth. I am your mother, trust only me'. Still, every time they would tell me things like 'Your dad is a rich man in the USA, he can buy you the things you need; you should look for him and live better', 'That ugly man is not your dad'. Back then I was very lonely. I would cry a lot. Now I only want to work and study so my mom does not have to work all the time... Sometimes my friends ask me if I don't feel curious about my dad. Well, I don't know, maybe [nervous laughter]. I never met him and with time I have learned not to have any feelings for him, nothing [DAD, $9,18-25]$.

Although she is now a young adult, Adriana's words enable us to see the impact of migration on children in the community of origin, which is a topic that has been little discussed in the Mexican literature. Of course the details of her case are unusual because Rodolfo never returned whereas most migrant fathers in Tilcajete come and go, although the confusion and feeling of loneliness, abandonment, and neglect, the pain, the fear, and the desire for a united family are common amongst children of migrants. The same is the case with the vigilance of the community and the extended family of the migrant. The peculiarity of this case is that after Rodolfo left, Erika resisted keeping in contact with him, residing in the house of her inlaws, or giving up her daughter to them. Usually, in a hegemonic culture, the migrant's extended family keep economic control and political power over the migrant's spouse, his children, and remittances. Even women who do not have much public authority in the community are highly empowered within the household with regard to the wife and children of their migrant sons.

The trans-generational power dynamics are so weighty that in the story of Erika and Adriana it was the family of Rodolfo that forced him abroad. Apparently, following the news of Erika's pregnancy - and since she was publicly represented as an autonomous and liberal woman - they involved Rodolfo in a family offence to his uncle that led him to flee the community or risk going to jail; and so he never returned. Back then, he had to leave immediately, in the middle of the night. The reasons for his migration were not necessarily economic or lack of commitment to establishing a family. Apparently in the following years he was still interested in his daughter and partner. Nevertheless, according to social canons, his family was the communication vehicle with Erika and Adriana, and neither of them received any direct communication or economic support from his side. Later, through another common contact, Rodolfo found out that his family had used the remittances he had sent for Erika and Adriana for many years in order to build a threestorey concrete house and for their own sustenance. He ceased sending money, and perhaps letters, ${ }^{22}$ although he could still not legally return to the community and establish a direct link with them. 


\subsubsection{Case of Cristina [all citations are from DTC, 9, 30-35]}

The case of Cristina highlights other relevant features of the impact of migration on women in the migrantsending community in relation to the economic, cultural, and political dimensions identified by Fraser. Her story has two main features. The first is commonplace for most women, spouses of migrants, who parent and raise children on their own. Despite the remittances and advice she receives from her husband by telephone, Cristina is fully in charge of three children on an everyday basis. She is also responsible for the household and domestic chores and her husband's public obligations in the community, and she produces and retails alebrijes. The second feature has to do with the tremendous dilemma posed by learning of her husband's parallel family in the USA. Although extramarital affairs abroad are very frequent, and some develop into lasting partnerships whilst migrants are abroad, implicit social and cultural rules always favour the spouse and children back in the community of origin as the legitimate family. However, the presence of children abroad disrupts this fragile equilibrium. In the process, the dilemma of ending the relationship or accepting the spouse back is not only a private affair involving the family or couple. Knowledge of behaviour, relationships, and children abroad is transmitted by the extra-territorial community and it becomes known and mediated by all. So, as will be seen in the case of Cristina, whichever decision she makes will still mark her socially and place her and her children in a vulnerable position.

Cristina married her husband José at the age of seventeen. She finished high school but could not study further due to lack of resources, so she started working. According to her, had she been able to study, perhaps she would have married later. Nevertheless, she had an urgent need to leave her family of origin due to a very bad relationship with her mother who was "very harsh and uncaring". She married, very much in love with her husband whom she considered "the example of perfection". They lived at his parents' house and worked producing woodcrafts. The decision to migrate was his, although the plan was to save money and build a house of their own; she accepted and as expected stayed in San Martin in charge of their son. His migration was pendular, and they had

22 Although currently there are many private phone lines in tileño households today, they date from less than a decade ago. At the time, even public phone lines were very scarce. more children in the periods he spent back at the community of origin.

At first, when José left, Cristina lived with her inlaws. Even though she had no problems with her inlaws regarding the resources sent by José for their children, they had authority over everything. She describes the difficulties of being mother and father at once, without having any familial, social, or political authority over her children: "They were very spoiled because we lived with their grandparents and I could not shout at them or show them limits... So I complained to my husband, because they would use my low status. Logically my status was below theirs because they are the elder parents". Also, her children would get very confused in terms of their parental figures, calling their grandparents and uncles 'fathers': "[they] started calling both grandfathers father, saying 'Dad Max' and 'Dad Josh'... and one day asked me 'Mom, why do I have so many fathers?'... so I had to act". At the first opportunity Cristina moved to the small house they were building. Her relationship with her in-laws remains good, "because they can't complain about anything, they see that I am impeccable with my husband and children".

Cristina explains in detail the burdens and challenges of being responsible for her children on her own during José's migration. "I have to take care of school, homework, domestic work, the house, the woodcrafts, of paying for special courses for them, everything." This reflects the multiple workloads of women who nevertheless lack recognition, redistribution, or representation. "For me it is very hard to be mom and dad, it is really very difficult, because I have the responsibility for everything, absolutely everything... if they are healthy and if they fall ill... If there is a problem with the house or if the children turn out to be a problem." The fear of underperforming and not being "good enough" is also a recurrent source of stress for these mothers, who increasingly experience anxiety-related symptoms and psychosomatic illnesses for which some are medicated (according to files at the local health clinic). They have to be accountable to their spouses, their in-laws, and the community as a whole in every realm: "Here at home they [the children] understand, but outside they act differently. ... I cry at the parents' meeting [at school]... I feel so bad because I think I am not doing things right. What am I not doing? He sees me [José], he knows. I sit and cry when I can't cope anymore... I wonder, what am I doing wrong, where is the mistake? Do they want an evil mother who does not feed them, who does not wash their clothes, who hits them with a belt all the time, 
or what is it they want? I always speak to them but I don't know why it has been so hard."

Besides, in the eyes of her children she also takes all the blame for José's stay abroad, which she lives as an "injustice": "They started to complain, blaming me time and time again. They started crying and I asked them 'Why do you blame me? Why only me? If it's about putting on blame, then it should be fair and include mom and dad, but why only me? Why don't you have a go at your father?' 'Because he is not here and the only one here is you' they say. Well, if the only one here is me, then you should understand me because all the responsibility of dad is mine. I have the full responsibility, and if I work, I don't work for me, it's for you and I am so very tired... Why are you so unfair with me? Complain when I don't fulfil my duties, then complain". Linked to this, in the absence of the head of the household, children frequently assume parental responsibilities. Boys take on roles of authority (especially older boys) and girls assume caring duties regardless of their age.

José exercises his fatherhood through the phone. He calls three times per week, sometimes every day. Cristina says that unlike many other migrants in Tilcajete José is an exemplary father. "He has always looked after his children. He sends them so many things and gifts, I even tell him to stop spoiling them ... I have no complaints with him as a father". Technology has been fundamental in enabling closer relations between migrants and their families in the community of origin, though unfortunately not all households have access to a telephone as there are only a limited number of phone lines available and these date only from the year 2005. Mobile phones are more common although they are much more expensive and have very bad reception in the valley. Since 2008 computers have become an increasingly valued asset and investment, linked with migrants and with the importance of education. Nevertheless, internet access is also limited and of very poor quality. There is also a generational gap in terms of technology use. Youngsters are much better prepared to use technology. Thus, phones (in homes, with relatives, or at local phone booths) remain the preferred option. Videos and photographs are also crucial. When children do not know their fathers, they become acquainted with them through photographs, videos, and phone calls.

Money is a central topic in families with migrants and it is usually one of the main reasons causing emigration, although it is not the only one. Many newlyweds resort to migration in order to seek economic independence and build a home. Living alone - for a family, not for women - means access to representation and recognition. Some men who migrated as youngsters prefer to work in the USA; they can build savings there and rise socially. However, money and the goods it can buy have become an emotional currency in inter- and intra-family relations. Sometimes money creates expectations that lead to further migration in a vicious circle. For example, to some of the children, goods and toys become a replacement for the absent father. The television, mobile phones, toys, clothes, videogames have an increasing role in the education of tileño children. At school and in relationships between children, the display of imported goods figures prominently. This leads to some rifts between the children of those who go and those who stay, between endogenous traditional values and modern exogenous ones. It makes it harder for the women who stay behind to set limits: "I often wonder if we are not spoiling our children. Where should we set the limits if we give them so much?" However, migration is not an economic panacea. It is highly irregular since it depends on the job market in the USA, and it involves costs that are often displaced on to women since they stay behind and face the maintenance of the household on a daily basis and they face the relationships with creditors (for example for the money for the crossing). Most migrant wives also work and engage in economic activities besides the household and care of children, although they invest their earnings in the family; it is usually the men or in-laws who decide in what.

With migration, the role of institutional education has been transformed. Previously, when the community was devoted to agriculture, going to school was contingent upon what help was needed in the fields, and it targeted literacy. Now, education is a top priority for most families as it improves prospects for working as professionals, to administer the household and woodcarving unit, to deal with increasing tourism, or even to have better skills as migrants. In the words of Cristina: "You have to study, to prepare and have a career... I don't want a child that is linked to vandals running around insulting people or causing harm." Perhaps because of the conflict between traditional and modern values, with elders having the authority of experience, education currently represents a highly socially esteemed asset for the younger generations: "I told them [the other parents] 'I will no longer be called Cristina if my son is not a professional and I will prove it to you. Even if you laugh at me now. And when my son is an important professional I will laugh 
at you and it will not be an evil laughter but one of satisfaction, you will see' I said." This also reflects the parents' own desire to study, for they invest important resources in their children's education including private schools, extra-curricular activities, materials, private tuition, etc. Although levels of education have increased for all the younger generations, including men and women, not all parents will accept their daughters' going to study outside the community once they finish high school, and long-distance learning is not yet an alternative for them.

The most striking feature of Cristina's case is José's infidelity and parallel family in the USA. Although the sexual politics of migration and their consequences deserve a study in their own right, this case can provide a window. The first stage involved finding out, knowing that others know, and locking herself in at home with anxiety crises. The support of other women was noteworthy:

I started to lock myself in at home. I would just not go out. Here, here was my world and whenever I went out I would just walk the streets without greeting anybody... Of course they found out because here everyone knows everything. I did not say anything but they heard it from the people there [in the USA]... My close friend came to talk to me: 'Comadre what is wrong? You did not fail, you are in your same position and we are all with you... Be brave, you are worth a lot as woman, don't feel bad, it's not your fault.' At the time I did not sleep, I was very affected. I was always in a bad mood, shouting, I did not want to hear any noise. I was desperate, with my heart beating fast. I would tell my children to go away, to stop bothering me, I felt so miserable. But later I said to myself 'What am I doing to my children? I don't want to be like that.'

In the second stage, realizing his marriage and family were at risk, José came back to Tilcajete in order to sort out the situation with Cristina. In such a situation where Cristina and the children were vulnerable vis-àvis a stranger, his family stood on her side: "My fatherin law scolded him. 'It is not possible that you did this to your wife. She has respected you and behaved well. She is master of her house and from now on I don't want to see you disrespecting her again." The same with his mother: "I have no other daughter-in-law but her and even if you think this is painful I will not accept any other grandchildren but hers, the ones that lived in my house... No other woman will enter my house but her with her children", she said.

The subsequent negotiation between the couple highlights the unequal power relations in such a context. Cristina had to choose whether to forgive him and take him back or not, but the consequences of her choice for her children and herself are brutal in either case. If she forgives him because she puts her family first, Cristina has to cope with sharing resources with the other woman and their son, and in the community and in front of her children she has to act as if nothing has happened; to put herself last. If she does not forgive him, she has to leave and be responsible for the break-up of the family (even if then she might take the children with her back to her parents' home), and finally, if she seeks revenge she loses everything. She concludes in relation to her unfaithful husband:

You know I will not be fighting you because of your responsibility [the other son]. He has needs and it is not his fault. At the end of the day you will have to make a double effort to support him. Look, I am your wife, and even more than your wife I am your friend. As spouse I am very hurt, but I have to support you because we are a couple. Of course if I had been unfaithful I know you would have kicked me out on the streets and kept my children. Why? Because you are a man and you think that 'Oh yeah, I am a man but she is a woman and she is not allowed to be unfaithful'... I know you would not have accepted me. But put yourself in my position, what would you have done if you come back and you find me with a son of another man, what would you have done?... Listen, I am not going to do it just for revenge, because I am a woman who does not only think about herself. I think about my children and about the example that I give them. Maybe you think there will be no problem with you because you did it far away and when you come back there will be no problem, your children will not see you doing wrong. The difference is that if I do it my children will disrespect me, they will lose all the respect they have for me, I will lose my house, my marriage, everything, all that I have struggled for a lifetime in order to build.

Although not all the features of Cristina's testimony are typical, it highlights how in the social and cultural construction of motherhood and female identity the economic, cultural, and political dimensions lead to a fragile equilibrium in which women are socially vulnerable. All suffering and sacrifices are justified. If mothers have to be for others in the first place, in a migrant-sending community where 'a mother is the only hope of her child' the boundaries of motherhood and maternal responsibilities never end: "All that I care about are my children and the tranquillity of my family. That is all I care about. Whatever else people say or do I am not interested... You would not imagine the suffering a mother is willing to endure for her children." Surely greater resilience in terms of redistribution, recognition, and representation in the local area would lead to greater intra-gender social jus- 
tice. Unfortunately, the process is very gradual and invisible, as it is women-led.

\subsubsection{Summarized Findings of the Study: List of Implications and Costs}

Given the pattern of male-led migration in San Martin Tilcajete, with most women staying at home, women directly assume migration costs. These costs apply also in similar settings and are insufficiently recognized and discussed in migration studies. Some of the most relevant of these implications and costs are:

I. Assuming the consequences of a spouse's or family member's decision to migrate even if the woman disagrees or was not asked for her opinion (as in the cases of Erika and Adriana, Cristina);

II. Initial economic and psychological support of migrants: payment of part of or the full cost of the trip to the USA (Cristina);

III. Sustenance of the household until remittances are received and/or when they cease (Erika, Cristina);

IV. Intermittent or permanent economic and psychological support for migrants whilst abroad (Cristina);

V. Provision for the migrant's family or close relations $^{23}$ (Cristina);

VI. Financing migrants upon their return (Cristina);

VII. Assuming a migrant's social and political obligations without any modification to women's status: women must assume all social responsibilities for community service and obligations for migrants without gaining any official visibility in terms of recognition or representation; and following this women's work and after women have climbed the social hierarchy for men, men return to fulfil important political posts in the local hierarchy and get social recognition for them (Cristina);

VIII. Having their body, sexuality, and reproductive and mothering capacities at the service of a complex transnational migratory process, in the community of origin, abroad, and throughout the migratory process (Cristina);

23 In the 'stepfamily'-'stepdaughter' relation, the wife of the migrant often becomes the maid of the extended family and in-laws, with all her chores, relations, and earnings being controlled. Sometimes children - especially girls - also suffer part of this abuse, not having their father as male figure present to give protection.
IX. Taking full responsibility for parenting often without full parental decision-making control which is instead exercised by telephone and enforced through the husband's family (Cristina, Erika);

X. Taking responsibility for the woodcarving business often without formal visibility, decision-making control, or access to profits and recognition as artists (Cristina);

$\mathrm{XI}$. Coping with transformed relations in the community and increased vigilance regarding women, without a mainstream male support figure (whether it is a father, [great-] grandfather, uncle, brother, a husband, relative-in-law, a son, godfather, or any other close relation of a male migrant), including neglect, harassment, abuse, and other forms of external control exerted by all members of the community (Adriana and Erika; Cristina) ${ }^{24}$.

XII. Regarding illnesses and migration, it is important to note the appearance of HIV-AIDS in the community as a migrant-related disease. There are four cases of HIV-AIDS reported in the community, so far affecting men but endangering women. Three are of recent appearance in the past five years and one of a male migrant who is already dead. The stigma of the disease has meant keeping the disease secret and a total lack of social programmes of health prevention. Unsafe unprotected sexual practices are rooted in prevailing social representations of virility and masculinity, reinforced through the heterosexual control of the female spouse's body and reproduction. The demand of symbolically consolidating the marital union during the temporary male migrant's visit, usually resulting in pregnancy, has

24 Traditionally, women in San Martín belonged to their households and to private spaces destined for their work as carers. Most people confirm that even as late as the I980s, women were not allowed to walk around alone in the community or to go alone to the regional market of Ocotlán or to Oaxaca City. Following migration and perhaps also the introduction of the health clinic and secondary school in 1994, women have increasingly gained visibility in public spaces; but few of them drive even nowadays, and their movement is constantly monitored by all community members, including other women. If they do not act impeccably according to social canons that often go against their interest, they are seen as responsible for eliciting physical or verbal violence from others. The phrase ella se lo buscó (she asked for it) is frequently given as justification for acts of violence or discrimination against women. 
been commonplace. Thus, most women secretly resort to contraception but they are not in a position to demand or negotiate condom use.

Overall, the women in the community of origin must cope with the bodily, economic, physical, relational, emotional, and social burdens of migration, including isolation or de facto abandonment, without this automatically leading to greater recognition, representation, or redistribution. Nevertheless and ironically, migration also offers a relief from dysfunctional relations, and although unilaterally, migration is also implemented as an intra- and inter-family conflict-mediating strategy or as a mechanism of empowerment. All these aspects need to be studied in greater qualitative depth in migrant communities and circuits.

\subsection{Concluding Remarks}

Here is my body. Here are my arms to embrace unwanted jobs. Here are my legs to carry me away, to take me to a safe place if something menaces my integrity. Here is my entire being for anything by any necessary means. Here is my declamatory voice to remind you that I am here. [Lamberto Roque]

Migration is a movement of human beings, a flow of identities and relationships, not just changes in the location and mobility of an uprooted working force. People involved in migration processes, women and men, adults, children, and elders, migrants and nonmigrants in migrant-expelling settings, educated, lowskilled, and indigenous groups from rural and urban settings, are constantly engaging in a dialogue with their families, groups, communities, with time and humanity, with themselves and their liminal identities, in a process of self-actualization and reflexivity (Giddens I99I). This dialogue is multivocal by definition and modernity does not automatically replace tradition in it. As has been seen, gender remains strongly defining.

San Martín Tilcajete presents an interesting case study in order to research migration from a feminist critical ethnographic standpoint, seen from the community of origin. It is a setting where a povertystricken subsistence agricultural locality has undergone rapid economic transformation following migration, woodcarving, and tourism in the face of a hegemonic patriarchal, risk-prone, unsafe, and precarious mode of capitalism. Modernization and globalization coexist with the Zapotec world outlook, with some of its core values still defining everyday life within the community and also abroad in the transnational migratory chain.
While a changing context implies novel knowledge and practices, these do not automatically challenge old and profoundly rooted social representations. $\mathrm{Ob}$ serving everyday life provides a door into complex, hidden, obscured, and invisibilized facets of exclusion and injustice relating to migration. It is important to develop research into concomitant factors that are associated with economic imperatives but not solely based on them. For example, migration seen as a rite of passage; as a conflict-mediating strategy within marriages, and within and between families, generations, and groups; as a micro-empowerment strategy; for the advancement of education or service-related opportunities; for seeking children born in the USA who will have double nationality; in the face of collective pressure, illness, etc. The relationships between migration, security, gender, and social justice that we have seen call for the 'participatory parity' envisaged by Fraser, consisting of economic equality, diversity in the group, and collective identities that receive recognition and are valued as different, and a wide scope of justice in which excluded social agents find ways to represent themselves and to affirm their rights and value.

In a world marked by power differences, amongst the most vulnerable groups one finds indigenous women, who must not be taken for granted or invisibilized, as has frequently occurred with migration studies that do not account for identity and for relational and meta-level interconnections. In the present case study, migration was explored as an everyday-life phenomenon seen from the perspective of the migrant-sending community, that is, emphasis was not given to migrants or migration trajectories as such (as in, for example, Hondagneu-Sotelo's study of Mexican Experiences of Immigration, 1994; Ariza's study regarding the transformation of women during the migrant process, 2000; or Oehmichen's analysis of social control given cultural change and indigenous women's identities in the transnational community, 200I), but to migration's repercussions and the gender social representations linked to it in the place of origin. As in the study of Mexican Women and the Other Side of Immigration, looking at the way in which women are transformed by the impact of migration in San Ignacio, Jalisco (Gordillo 20IO), the doctoral thesis on marriage and transnational conjugal practices in San Miguel Acuexcomac, Puebla by D’Aubeterre (I998), or in Martínez's study of the incorporation of new values such as individual choice and romantic love coexisting with the authority of traditional marriage patterns in San Juan Mixtepec, Oax- 
aca (Martínez 2003), our interest lies in the symbolic, representational, and discursive regimes that lead to specific gender identities and relations. Attention to identity and subjectivity enables us to deepen our analysis of migratory contexts, identifying the representational elements of the sentimental and social order which are implicated in unequal and unjust relations (Besserer 2004). Arredondo (2008) has spoken of mujeridades, to refer to the experiences of women on-the-move and their relation to and defiance of social expectations. As partner to that, the present case study has presented the everyday life experiences of womanhood in a changing community setting, that is, of mujeridades in the home area.

From the case study of San Martín Tilcajete, it is clear that both the migrants and the people living in migrant-sending communities are agents of transition, forging and acting within discursive social contexts and adjusting representations. In a context of deepening globalization, we see that migration in its interaction with woodcarving has become an alternative way of social, political, and economic integration, though with identity articulations culturally rooted in the lo-

\section{References}

Ariza, Marina, 2000: Ya no soy la que dejé atrás (Mexico: Plaza y Valdes - IIS-UNAM).

Arredondo, Gabriela, 2008: Mexican Chicago: Race, Identity and Nation, I916-39, (Urbana: University of Illinois Press).

Arruda, Ángela (Org.), [II998] 2002: Representando a Alteridade (Rio de Janeiro: Editora Vozes).

Arruda, Ángela, 20Io: “Teoría de Representaciones Sociales y teorías de género”, in: Blazquez Graf, Norma; Flores Palacios, Fátima; Ríos Everardo, Maribel (Coords.): Investigación Feminista: Epistemología, metodología y representaciones sociales, (Mexico: CEIICH - CRIM Facultad de Psicología - UNAM): 317- 338.

Barabas, Alicia Mabel; Bartolomé, Miguel Alberto; Maldonado, Benjamín (Eds.), 2003: Los Pueblos Indígenas de Oacaca: Atlas Etnográfico (Mexico: INAH - FCE - SAIOaxaca).

Beck, Mansvelt, 2008: "Liberalism, Minorities and the Politics of Societal Differentiation", $2^{\text {nd }}$ Pavia Graduate Conference in Political Philosophy; at: <http://cfs. unipv. t/ seminari/beck.pdf>.

Besserer, Federico, 2004: Topografías Transnacionales (Mexico: Universidad Autónoma Metropolitana-Iztapalapa - Plaza y Valdés).

Boletín Estadístico: Indicadores Básicos de la Actividad Turística del Estado de Oaxaca, 2004 (Oaxaca: Gobierno del Estado); at: 〈http://www.aoaxaca.com〉.

Brauch, Hans Günter; Oswald Spring, Úrsula; Mesjasz, Czeslaw; Grin, John; Dunay, Pal; Behera, Navnita cal community, not abroad. This said, migration has high human costs and is not gender-neutral.

Yet although women do not have the same right to decide about migration as men, migration does imply changes in the community of origin, in the family, in organization, in distribution, in power, identities, and the emergence of mujeridades, etc. In San Martín, woodcarving and tourism have been dynamic concomitant factors interacting with migration. Together, while they have given men the chance to come and go, they have enabled women to empower themselves de facto, even though economic, political, social, and legal changes are only slowly catching up. Instead of only resorting to migration as a survival strategy because of the lack of opportunities locally, the specific system of coming and going in San Martín Tilcajete means tileños having a chance to enter into dialogue with the globalizing world; and the challenge is to make these dialogues not only multilocal but multivocal for both women and men in such a way that women may effectively claim their rights to redistribution, representation, and recognition.

Chadha; Chourou, Béchir; Kameri-Mbote, Patricia; Liotta, P.H. (Eds.), 2008: Globalization and Environmental Challenges: Reconceptualizing Security in the $2 \mathrm{I}^{\text {st }}$ Century. Hexagon Series on Human and Environmental Security and Peace, vol. 3 (Berlin: Springer)

Cant, Alanna, 20I2: "Practising Aesthetics: Artisanal production and politics in a woodcarving village in Oaxaca, Mexico" (Ph.D. dissertation, London School of Economics and Political Science, Department of Anthropology).

Chibnik, Michael, 2003: Crafting Tradition: The Making and Marketing of Oaxacan Woodcarvings (Austin: University of Texas Press).

Connolly, Julie; Leach, Michael; Walsh, Lucas (Eds.), 2007: Recognition in Politics: Theory, Policy and Practice (Newcastle: Cambridge Scholars Publishing, Newcastle).

D’ Aubeterre Buznego, Maria Eugenia, I998: “Matrimonio, Vida Conyugal y Prácticas Transnacionales en San Miguel Acuexcomac, Puebla" (Ph.D. dissertation, National School of History and Anthropology, ENAH).

Delgado Ballesteros, Gabriela, 20I0: "Conocerte en la acción y el intercambio. La investigación: acción participativa”, in: Blazquez Graf, Norma; Flores Palacios, Fátima; Ríos Everardo, Maribel (Coords.): Investigación Feminista: Epistemología, metodología y representaciones sociales (Mexico: CEIICH - CRIM - Facultad de Psicología- UNAM): 197- 216.

Durand, Jorge (with Patricia Arias), 2005: La Vida en el Norte: Historia e iconografía de la migración México- 
Estados Unidos (Guadalajara: El Colegio de San Luis/ UDG).

Farr, Robert M., 1996: The Roots of Modern Social Psychology (Oxford: Blackwell).

Fernández Jarquín, Nelly; Serrano Oswald, Serena Eréndira, 2004: Diagnóstico de Salud: San Martín Tilcajete (Oaxaca: Jurisdicción Sanitaria No. I: Valles Centrales).

Figueroa Díaz, María Elena, 20II: "Representación social de la migración en Ayoquezco, Oaxaca”, in: Cultura y Representaciones Sociales, 6, II (September): I33- I58; at: <www.culturayrs.org.mx>.

Flores Palacios, Fátima, 200I: Psicología social y género (Mexico: McGraw Hill - dgapa-UNAM).

Flores Palacios, Fátima; Serrano Oswald, Serena Eréndira, 2OI2: "Process analysis of the impact of HIV/AIDS and its representations in seropositive people in Mexico", in: Journal of Research in Peace, Gender and Development, 2, I3 (December): 304- 3IO; at: <http://www.interesjournals.org/JRPGD>.

Fraser, Nancy, 2008: "Social Justice in the Age of Identity Politics: Redistribution, recognition and participation", in: Henderson, George L.; Waterstone, Marvin (Eds.): Geographic Thought: A Praxis Perspective (Oxon: Taylor \& Francis): 72- 89.

Fraser, Nancy, 2005: "Reframing Justice in a Globalizing World”, in: New Left Review, 36 (Nov- Dec): I- I9.

Fraser, Nancy, "Social Justice in the Knowledge Society: Redistribution, Recognition and Participation”, Gut zu Wissen conference paper, Heinrich Böll Stiftung, 5, 200I: I-I3; at: 〈www.wissensgesellschaft.rg>.

García Oramas, María José; Ruiz Pimentel, Susana; Ruiz Vallejo, Sara, 20II: "Las que se quedan: Género, Migración y Control Social”, in: Amérique Latine Histoire et Mémoire. Les Cahiers ALHIM, 2I; at: <http://alhim.revues.org/index3803.html>.

Giddens, Anthony, 1991: Modernity and Self-Identity: Self and Society in the Late Modern Age (London: Polity Press).

Gordillo, Luz María, 20I0: Mexican Women and the Other Side of Immigration: Engendering Transnational Ties (Austin: University of Texas Press).

Habermas, Jürgen, 2005: "Equal Treatment of Cultures and the Limits of Postmodern Liberalism”, in: The Journal of Political Philosophy, I3, I: I- 28.

Hondagneu-Sotelo, Pierrette, I994: Gendered Transitions: Mexican Experiences of Immigration (London: University of California Press).

INEGI (National Institute for Geography and Statistics), 20II: Mujeres y Hombres en México 20II (Mexico: INEGI).

INEGI (National Institute for Geography and Statistics), 20Io: Censo General de Vivienda y Población (Mexico: INEGI).

INEGI (National Institute for Geography and Statistics), 2005: Censo Nacional de Hombres y Mujeres 2005 (Mexico: INEGI).
IRP (Integrated Resource Package), 2008: "I2 Social Justice”, in: Integrated Resource Package (Province of British Columbia: Ministry of Education), I- 54; at: <http:// www.bced.gov.bc.ca/irp/pdfs/social_studies/2008socialjusticeI2.pdf>.

Madison, D. Soyini, 2005: Critical Ethnography: Methods, Ethics, and Performance (London: Sage Publications).

Martínez Medrano, Elvia Rosa, 2003: "Efectos de la Migración en las Uniones Conyugales de San Juan Mixtepec, Oaxaca" (MSc. disseration, National School of History and Anthropology, ENAH).

Moscovici, Serge (Ed. by Gerard Duveen), 2000: Social representations. Explorations in social psychology (London: Polity Press).

Moscovici, Serge, 1976: La Psychanalyse: Son image et son public (Paris: Presses Universitaires de France).

Novak, Michael, 2000: "Defining Social Justice", on: First Things, December; at: <http://www.firstthings.com/ article/2007/OI/defining-social-justice-29>.

Oehmichen Bazán, María Cristina del Pilar, 200I: "Mujeres Indígenas Migrantes en el Proceso de Cambio Cultural. Análisis de las Normas de Control Social y Relaciones de Género en la Comunidad Extraterritorial” (Ph.D. dissertation National Autonomous University of Mexico, Institute for Anthropological Research).

Pérez Vargas, Isabel, I99I: "Etnografía de San Martín Tilcajete" (BA dissertation, Autonomous Metropolitan University, Iztapalapa).

Pick de Weiss, Susan; Sirkin, Jenna, 20II: Pobreza: Cómo romper el ciclo a partir del desarrollo humano (Mexico: Limusa).

Reyes López, Sinhue Emmanuel, 2003: Diagnóstico de Salud: San Martín Tilcajete (Oaxaca: Jurisdicción Sanitaria No. I: Valles Centrales).

Reyes Morales, Rafael G.; Gijón Cruz, Alicia Sylvia; Yúnez Naude, Antonio; Hinojosa Ojeda, Raúl, 2004: "Características de la migración internacional en Oaxaca y sus impactos en el desarrollo regional”, in: Delgado Wise, Raúl; Favela, Margarita (Coords.), Nuevas tendencias y desafíos de la migración internacional México- Estados Unidos (Cámara de Diputados LIX Legistalura - UAZ CEIICH-UNAM - Miguel Ángel Porrúa): 195- 223.

Roque Hernández, Lamberto, 2009: Here I Am (Oaxaca: Proveedora Gráfica de Oaxaca).

Roque Hernández, Lamberto, 2002: Cartas a Crispina (Oaxaca: Editores Carteles).

Ruíz Martínez, Alfredo, I992: "Las causas de la migración internacional campesina en los Valles Centrales de Oaxaca”, in: Corbett, Jack; Musalem Merhy, Murad A.; Ríos Vázquez, Othón; Vázquez Hernández, Héctor A. (Eds.): Migración y Etnicidad en Oaxaca (Tennessee: Vanderbilt University): I47- I65.

Sánchez Gómez, Martha Judith; Barceló Quintal, Raquel, 2007: "Mujeres indígenas migrantes: cambios y redefiniciones genéricas y étnicas en diferentes contextos de migración”, in: Amérique Latine Historie et Mémoire. 
Les Cahiers ALHIM, I4; at: <http://alhim.revues.org/ index2292.html>.

Serrano Oswald, Serena Eréndira, i.p: "Debates teóricos en torno a la seguridad de género: reflexiones para una paz sustentable en el siglo XXI", in: Abrego, Guadalupe; Serrano Oswald, Serena Eréndira (Eds.), Memorias del Congreso Latinoamericano de Investigación para la PAZ- CLAIP (Puebla: BUAP/Benguna Bée).

Serrano Oswald, Serena Eréndira, 20I0: "La Construcción Social y Cultural de la Maternidad en Sam Martín Tilcajete, Oaxaca" (Ph.D. dissertation, National Autonomous University of Mexico, Institute for Anthropological Rerearch).

Serrano Oswald, Serena Eréndira, 2009: "Engendering Security and the impossibility of securitizing gender", in:
Brauch, Hans Günter; Oswald Spring, Úrsula; Grin, John; Mesjasz, Czeslaw; Kameri-Mbote, Patricia; Behera, Navnita Chadha; Chourou, Béchir; Krummenacher, Heinz (Eds.): Facing Global Environmental Change: Environmental, Human, Energy, Food, Health and Water Security Concepts. Hexagon Series on Human and Environmental Security and Peace, vol. 4 (Berlin: Springer): II43- II56.

Suárez, Blanca; Zapata Martelo, Emma (Coords.), 2004: Remesas: Milagros y mucho más realizan las mujeres indígenas y campesinas. Vol. I and II (Mexico: GIMTRAP).

Truong, Thanh-Dam; Gasper, Des (Eds.), 20II: Transnational Migration and Human Security: The MigrationDevelopment-Security Nexus (Berlin: Springer).

Open Access. This chapter is distributed under the terms of the Creative Commons Attribution Non-commercial License, which permits any noncommercial use, distribution, and reproduction in any medium, provided the original author(s) and source are credited. 


\title{
Strategic Invisibility as Everyday Politics for a Life with Dignity: Guatemalan Women Migrants' Experiences of Insecurity at Mexico's Southern Border
}

\author{
Martha Luz Rojas-Wiesner ${ }^{1}$ and Maria DeVargas ${ }^{2}$
}

\begin{abstract}
$^{3}$
The re-scaling of border control and the conflation of migration, crime, and national security in Mexico in the last decade have generated new practices of 'flow management' at the southern border with a differentiated impact on migrants. This chapter draws on research findings on Guatemalan im/migrant ${ }^{4}$ women (some of whom have been living in Mexico for generations) to examine the kinds of insecurity they face in daily life as migrants of Mayan origin. ${ }^{5}$ By engaging with the contextual and specific meanings of in/securities generated by the processes of 'othering' experienced by these migrants, especially those with an irregular status, the chapter focuses on the significance of the politics of everyday life and how in/visibility becomes a strategic field of struggle for them, both to ensure daily well-being and to avoid the risks of being detected and the punitive responses that follow. The chapter proposes that where the concepts of citizenship and rights are unlikely to be satisfied for those who need them most, the analytical lens must shift from a normative understanding of rights to the interface between the practices of border control and migrants' strategies. Understanding in/visibility is introduced as a strategy to help discern the power dynamics that affect their social conditions and the consequences for policy advocacy.
\end{abstract}

Keywords: Re-scaling border control, Mexico's southern border, Guatemalan women's migration, in/visibility, everyday politics.

\subsection{Introduction}

There is a consensus among migration scholars and human rights advocates that the recent strengthening

1 Martha Luz Rojas-Wiesner has been a senior researcher in the Department of Society, Culture, and Health of El Colegio de la Frontera Sur (ECOSUR) since 1998. She works specifically on female migration along the southern border of Mexico at her office in Tapachula, Chiapas.

2 Maria DeVargas is a research assistant and project officer for the project promoting this book at the International Institute of Social Studies (ISS), Erasmus University Rotterdam. She is a psychologist with a Master's in Development Studies from ISS.

3 This chapter is based on the findings of an IDRC-funded project 'Advancing the Rights of Migrant Women in Latin America and the Caribbean', project number I04785003. The authors are grateful to Thanh-Dam Truong for her key role orienting and contributing to the writing of this chapter. They also want to thank Rosalba Icaza for her recommendations and inspired debates. of the measures of containment and control of migratory flows in specific parts of the world has created new types of risks and vulnerabilities for migrants, thought the experiences of discrimination they may face takes particular contextual forms and expressions (Anguiano/López 20IO; FitzGerald 20II). Scholars have generally acknowledged that women migrants ${ }^{6}$ encounter situations of exclusion and discrimination

4 The word 'im/migrants' covers the following persons from Guatemala in Mexico. I) Those who entered Mexico during the civil war in Guatemala in the I980s, were granted refugee status, and became naturalized Mexican citizens, as well as women who arrived for other reasons and have permission to stay and work. 2) Those who entered in the I990s primarily in search of economic opportunity and personal security but do not have the same protection, and may be classed as migrants with irregular status (or persons who have entered Mexico or remain in the country without authorization). 3) Those who are seasonal or frontier workers with or without regular status. 
in distinctively different ways from men (Jolly/Reeves 2005; Bastia 2009; Gregorio 20I2; Petrozziello 20I2). The multiple and overlapping forms of identity-based vulnerabilities found in local situations of marginalization have yet to be addressed adequately in their own terms, and in relation to specific public policies. These forms are contingent on the specific character of a given local sphere of migration, producing layers of discrimination and insecurities that cannot be reduced to gender as a single cause.

The complexity of migration is clearly expressed in border areas where migratory processes are bearers of particular features of social exchange ${ }^{7}$ and political histories, and where new flows have become 'global' preoccupations (Sassen 2003; Castles 20I0; Papademetriou 20II). Concerns over law and order are allowing states to choose specific border crossingpoints and their vicinity, identified as vulnerable to illegal trade and migration and to organized crime, where Hobbesian measures of border policing are adopted. These are legitimized by the need to protect national sovereignty and control crime (Bigo/Tsoukala 2008). In the name of national security, such practices of border control tend to go hand in with processes of 'othering' (Pécoud/Guchteneire 2006) that underpin the fixing of territorial boundaries based on identities and belonging, ${ }^{8}$ field of access, and the scale of transgressions (Van Houtum/Van Naerssen 200I).

The southern border of Mexico is one example of such a border area. Known historically ${ }^{9}$ as a 'convergence area', it is generally considered to be a unified zone socially, culturally, and economically (Fábregas I997; Castillo 2002). This border had been

5 The term 'Mayan origin' here refers to persons who are descendants of Mayans. Today many of them are mixed with other races but they still have some common physical features. Many of them still follow some traditions, customs and speak a variety of indigenous languages. Also, those who do not follow Mayan traditions are still considered as indigenous and are mistreated on the basis of their identity as socially constructed by other racial groups.

6 As shown by Hania Zlotnik, during the last forty years of the twentieth century the number of female migrants was almost equal to that of male migrants: 47 per cent in 1960 and 49 per cent in 2000 (Zlotnick 2003). In more developed countries, $5 \mathrm{I}$ per cent of all immigrants are women (United Nations 2009).

7 Even with gaps in information, it is estimated that nearly the half of migration processes are between SouthSouth countries, and around 80 per cent of them "take place between countries with contiguous borders" (Ratha/Shaw 2007: 3). fluid and open to a variety of movements (trade, agricultural workers, displaced people, families), though variations have depended on the intensity of exchanges and causes of displacements (Castillo 2003). Since the I980s, these movements have become a 'problem' for the Mexican regional governments as a result of a combination of migratory flows - refugees from Central America fleeing direct violence caused by civil wars, followed by economic migrants driven by persistent socio-economic hardships in the postwar years in the I990s. The porosity of this border also gradually made it accessible to long-distance migrants (also referred to as 'transmigrants') who pass through this border on their journey northward to the United States or Canada (Angeles 20IO; Castillo 20IO; Verduzco/de Lozano 20II). Since Mexico joined the North American Free Trade Agreement (NAFTA) in I994, attempts to curb all forms of unauthorized migration that may affect the whole NAFTA territory have generated new types of global-local interactions and scales of border control. For many migrants, these interactions and scales of control have produced intersecting life-worlds and social fields of action for survival.

This chapter deals with Guatemalan im/migrant women, mainly in Chiapas and primarily with those without appropriate migratory documents. ${ }^{10}$ Some of them have been living in the state for over twenty-five years. It explores their manners of coping with the new control measures and how emerging forms of in/ securities have affected their daily lives and social re-

8 From this perspective we will use also 'othering' to refer to discrimination, because it involves broad forms and practices of discrimination, abuse, and exclusion which are closely interconnected with ethnic and cultural factors. Within our framework, this concept involves Bourdieu's concept of 'habitus' related to the practices and ways of discriminating against 'others' which are normalized within societies.

9 The region is part of the area sometimes called Mesoamerica, a "convergence area, in which the story is shared with Central American and Caribbean peoples" (Fábregas 1997: 349)

10 By women without appropriate migratory documents, we mean those women who do not have any immigration papers, as well as women who entered the country with an immigration document and are working even if they do not have authorization to work. The latter is the case for those women who entered with a Migratory Form for Local Visitors (FMVL) and are engaged in economic activity, such as traders, vendors, and domestic workers. It also includes women whose documents have expired. 
lations. Conscious invisibility may be seen as a multipurpose strategy: I) to protect themselves against detection by the authorities or denouncement by persons in the communities in which they work or live; 2) to prevent their being potential victims of 'othering' due to their country of origin. In this sense 'invisibility' may be seen as a form of everyday politics to ensure daily well-being, as well as to avoid the risks of being found out and the punitive responses that may follow. Yet, paradoxically, this form of everyday politics also denies them access to basic social services and to some of the protection which they are entitled to, especially the long-term immigrants. By shifting the analytical lens from a normative framework of migrants' rights to the interface between the practices of border control and migrants' strategies for achieving well-being in everyday life, the chapter offers some reflections on the implications of migrants' strategic invisibility for future debates and actions.

Section I0.2 highlights the key aspects of migration at the Mexican southern border, emphasizing those aspects that are central to the understanding of the situation of the women who are the subjects of this study. The concept of re-territorialization proposed by Brenner (I999), defined as the re-scaling of forms of territorial organization such as cities and states, is adjusted to refer to the re-configuration and re-scaling of organizational forms of boundary control that has been taking place in Mexico during the last decade and its implications for migrants in subordinate positions. Section I0.3 presents the stories of Guatemalan women im/migrants in Mexico, moving from a general profile to the individual motivational stories of a group of fifty-five women, and introducing some of the effects of the new practices of 'flow management' on their lives. Section I0.4, based on multi-sited research, illustrates through the women's narratives what such insecurities mean for them and the reasons for their conscious invisibility. In section I0.5 we examine the paradox of in/visibility in the politics of everyday life, with reference to similar cases discussed by other authors. The chapter concludes by linking the three layers of power affecting the women: the introduction of new concepts of 'border', the new concept of order in migration management, and the multiple processes of 'othering' the migrant population with respect to their identities. Migrants' rights advocates in Mexico need to work to deepen understanding of how strategic invisibility can be an effect of the contextual workings of multiple and interlinked forms of power so as to be able to translate their concerns into actions that can help the migrants achieve an existence with security in daily live as a basic condition for achieving dignity ${ }^{11}$ and rights. Moreover, it is necessary to find more appropriate mechanisms to support them while at the same time respecting their autonomy. In this regard, the adequate distribution of information becomes relevant to establishing enabling conditions towards individual processes of informed decisions (Baehr 20I2). In other words, it is important to promote knowledge among the im/migrants so that social boundaries and individual fears do not become restrictions in the process of accessing legal identities and rights.

\subsection{Contextualizing Migration at Mexico's Southern Border}

Inter-regional migratory dynamics in Latin America and the Caribbean are historically multi-layered. In recent decades these have become more complex for a variety of reasons. The most significant is the increase in the magnitude of movements from this region into the United States, and this has led to a re-scaling of forms of border control within the territory of the United States itself as well as areas it considers to be within its broader security perimeters, such as the Mexican southern border, with the state of Chiapas being the focal point of concern.

According to Villafuerte/García (2006), intense internal migration in Chiapas began in the second half of the twentieth century, stimulated by colonization of the Lacandona Jungle, the demand for labour for coffee plantations, and hydroelectric construction. This was followed by migration to the oilfields of Tabasco and to the tourist area of Cancun in the I980s. Since the I990s, as a result of economic crises, migratory flows from this region have extended to the north of Mexico, the United States, and Canada. The exacerbation of poverty levels and the neglect of certain sectors of the population by the government led to the formation of the Zapatista movement in I994, and consequently to an increased presence of military forces in the region. In parallel, from the I980s to the mid-I990s Chiapas became host to many Guatemalan refugees fleeing civil war in their own country, adding

11 Following Habermas, we use the concept of 'dignity' or 'a life with dignity' as the essential minimum required to live, which should constantly be considered as having an entrenched relationship with personal expectations of well-being (Habermas 20IO). It is therefore a space where legal struggles for human rights and quality of life may be pursued. 
Figure 10.1: Mexico's southern border. Source: Laboratorio de Análisis de Información Geográfica y Estadística de El Colegio de la Frontera Sur (ECOSUR). Permission was granted on 15 January 2013 by ECOSUR.

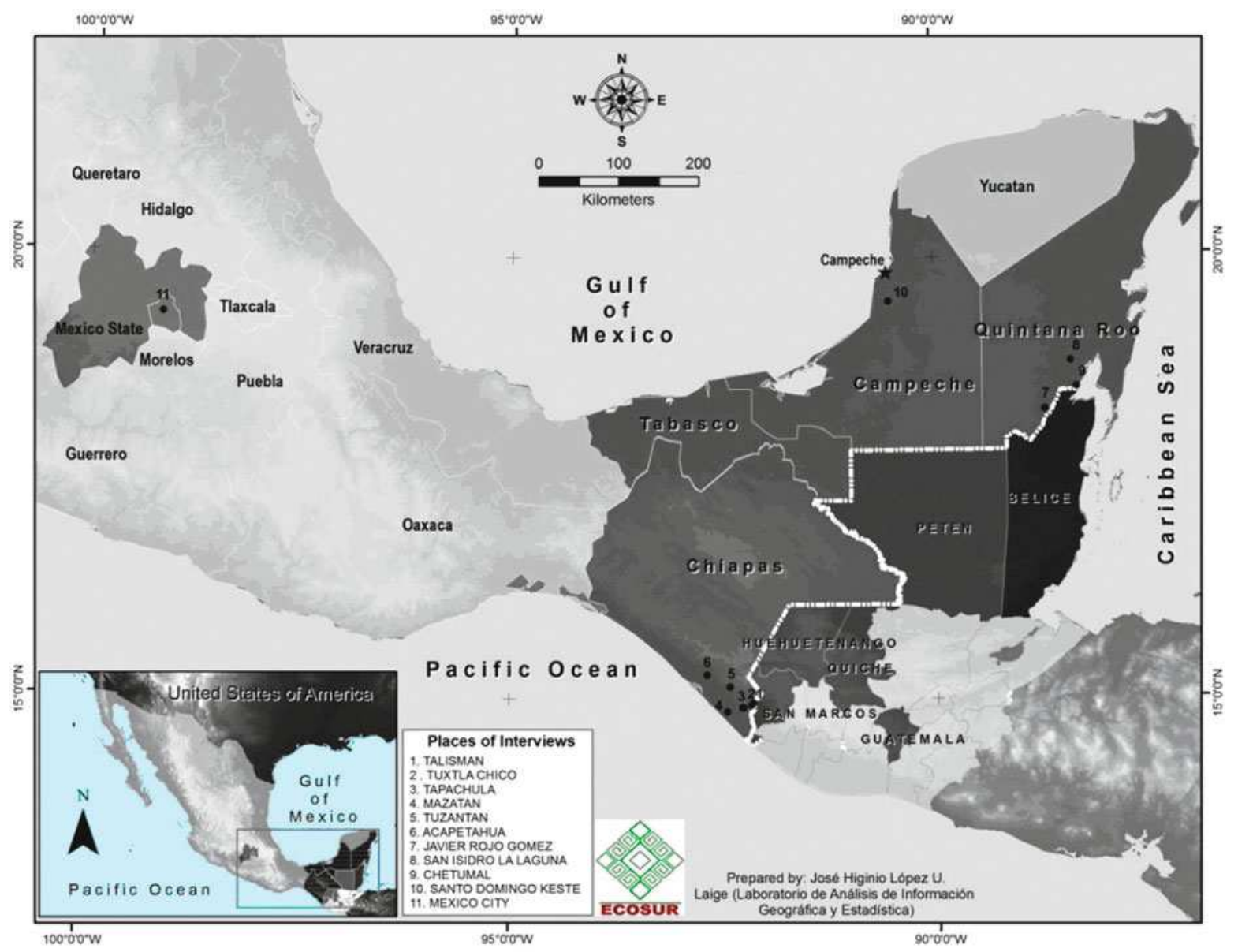

to the historical migration of Guatemalan seasonal agricultural workers and daily movements of residents along the Mexico-Guatemala border (Kauffer 2005; Rojas 20II). Due to the geographical characteristics of the area and the lack of institutional attention to the borderline, there are many unclear demarcations. The internal migratory dynamics in this area are such that many established immigrants move from one location to another without being aware of the border (Angeles/Rojas 2000; Castillo 200I).

In the last two decades, this border has seen more restrictive immigration measures due to a confluence of migratory flows. Following persistent post-war socio-economic decline and poverty, the flow of economic migrants from Guatemala into Mexico has intensified (Alba/Castillo 20I2). In addition, Mexico's proximity to the United States has become a decisive factor in shaping the flows of migrants from different parts of the world through its southern border, mainly from 2000 when a statistical increase became appar- ent (Morales/Lopez 1999; Angeles/Rojas 2000; Alba 200I; Rodríguez/Berumen/Ramos 20II). This reality was made visible in international forums, especially around the time of the preparation of the United $\mathrm{Na}$ tions Convention on Transnational Crime (UNCTC) and its Protocols on Human Trafficking and Human Smuggling. In these forums emphasis was placed on the significance of the migratory flows through this border destined for the United States. Much less attention has been given to the transformations of the local sphere of migration around the southern border itself, and their impacts on migrants caused by the inappropriate construction of them as a homogeneous group.

As a member of the North American Free Trade Agreement (NAFTA), ${ }^{12}$ and subsequent to the 11 September 20II terrorist attacks in New York, Mexico followed the United States discourses on national security and immigration control and revamped measures implemented since the r980s, often conflating 
the term 'security' with 'migration control' (Adamson 2006). Mexico's commitment to NAFTA implies an intensification of control measures to contain migrants entering the United States via Mexico, legitimized by Mexico's national security. These measures are along the lines of those adopted by the United States in its 'war on terror'. The Mexican territory was defined as part of the inner circles of the United States' homeland security perimeters, i.e. Mexico and its borders with Guatemala and Belize are now considered as the most southern external perimeters of the NAFTA trade zone (Castillo 1997, 2003; Cortés 2003; Alba/Leite 2004; Hernández 2008; Verduzco/de Lozano 20II). The links made between terrorism and the growing waves of organized crime in Mexico, especially the measures adopted to combat the drug trade and to dismantle organized crime, have also fuelled the violence surrounding these controls (Hernandez 2008). As there is a confluence of migrants of different types ${ }^{13}$ the governments are confronted with different kinds of societal insecurity (drug trade, violent crime gangs, and so on) as interlinked phenomena with migration flows. This has enlarged and strengthened what immigration authorities call 'the administration or management of migration flows' in Mexico. The primary aim was the control and containment of crime of various types linked to networks in the United States, as well as irregular migrations (human trafficking and human smuggling) towards the United States. ${ }^{14}$

In Mexico, measures to contain and control transmigrants bound for the United States have had different impacts for several categories of migrants: I) immigrants (persons already living in Mexico for a long period); 2) temporary workers (persons who enter only to work on a temporary (seasonal) basis; 3 ) commuters (those who live in Guatemala and enter Mexican territory for work on a daily basis, who may or may not have an identity document in conformity

12 NAFTA was signed by Mexico, the United States of America, and Canada, and entered into force on 1 January 1994. This agreement offers the United States the most favourable position with regard to power and trade.

13 There is a confluence of international migrants - from Central America and from Chiapas to the United States; transitory and temporal migrants; internal migrants between rural and urban localities of the same state; and regional and internal displacements caused by religious, social, or political conflicts. In addition, natural disasters and the construction of dams have also caused the displacement of many people into and through this area (Castillo 2003; Villafuerte/Garcia 2006). with legal requirements). Immigrants with regular status must strictly comply with the procedures and requirements to renew their residence permit. Those who do not have regular status must apply for a residence permit as an immigrant. Temporary workers and commuting workers are permitted to enter as frontier workers or local visitors and regularize their presence through registration, the Migratory Form for Frontier Workers (FMTF), and the Migratory Form for Local Visitors (FMVL) respectively. ${ }^{15}$

Although immigrants with irregular status (without an identity document, or one which is not valid), some of whom have been living for more than twenty years in the country, have always faced the risk of deportation when found out, since 2008 immigration officials have become stricter in requiring immigration documents at border check-points. However, there is a tendency among immigration authorities to apply measures to contain migration indiscriminately, i.e. by targeting all those persons without a proper identity document (im/migrants with irregular status), irrespective of their histories of migration. Thus transmigrants with irregular status as a category can be

14 Since the late I990s, the following migration control programmes or actions can be cited: the "Sealing the Southern Border" plan (I998); the "Southern Plan" (June 200I); the pilot plan between Mexico and Guatemala for "safe and orderly repatriation" (June 200I); the "Agreement for Swift, Safe and Orderly Repatriation of Salvadorian Migrants by Land" (May 2005); and the "Agreement for the Safe and Orderly Repatriation of Central American Migrants on the Mexican-Guatemalan Border" (June 2005). Furthermore, there have been various adjustments to the Manuals and Procedures for granting visas and migration permits in Mexico during the last decade. Other actions have explicitly responded to national security strategies that had contained migration flows, such as the "Sentinel Director Plan" (2003), the "National Security Act" (2005), and the "Merida Initiative" (2007). Furthermore, Mexico has signed some plans and agreements with neighbouring countries that have also affected migratory flows: the "Panama Puebla Plan" (2000, today called the "Mesoamerica Project"), and the high-level border security agreements between Mexico and Belize (2005) and between Mexico and Guatemala (2002, 2008).

15 During the mid-2000s, the requirements for applicants for different types of visas ('immigration forms'), either to enter, remain, or naturalize in Mexico, became more stringent. Lawyers (or 'brokers') who assist with immigration procedures, tourists, and immigrants informally interviewed in recent years have indicated that it was more difficult to obtain a visa to enter Mexico than the United States. 
treated in the same way as long-time immigrants also with irregular status. Given the perception that transmigrants are a threat, possible criminals, or terrorists, long-time immigrants are also afraid of being affiliated with crime and terror, given the consequences. Therefore, immigrants with irregular status have no option but to limit their movements for fear of being caught by the authorities, or identified as being affiliated with criminal gangs. The limitation of their movement has also led to their social exclusion at a greater level of significance than before. In some contexts these people have to make themselves 'invisible', or to conduct their lives at such a level of discretion that they can pass unnoticed by the public (Castillo 2003).

The institutionalization of the perceived links between migration, crime, and terror, or migration and the threat to national security, became visible in 2005 when the Mexican government integrated the National Migration Institute (INM) into the National Security Council (Coria 20II). ${ }^{16}$ This had already been justified in the I990s when the South Beta Group of Migrant Protection was affiliated with the National Institute of Migration's Regional Delegation in Chiapas. This addressed gang violence against migrants in the border zone with Guatemala, specifically between Hidalgo city and the cities of Tapachula and Huixtla, and along the train route along the coast of Chiapas a route frequently used for migrants' movement. This problem worsened in the late I990s during a time of increasing flows of Central American migrants to the United States and increasing Mexican migratory controls (Ruiz 200I, 2004). This has caused many migrants to seek alternative routes where they face greater risks of being assaulted, in other words greater danger and greater risks of violation of their human rights. Despite the various complaints that have been made, the concern is that official actions to combat criminals who attack, abduct, and murder migrants passing through Mexico have been rare and scarce (Amnesty International 20I0). This shows that less emphasis is placed on the protection of migrants than on the protection of national security.

16 During this year 2005, many factors influenced this event: the great increase in the number of migrants, the emphasis on national security discourses linked to migration, and the increase of the phenomenon whereby transitory migrants have not only been exposed to, but increasingly been victims of, more extreme and inhumane forms of violence in Mexico carried out by organized criminal groups (Amnesty International Report 20IO).
At the societal level, the perception of migration as a 'threat' to national security also generates anti-migrant sentiments among the local populations. For example, according to the National Survey on Discrimination in Mexico conducted in 20I0, which involved a nationally representative sample of 1375 I households, 25 per cent of respondents consider that the Mexican government should control migration; 76 per cent believe that immigration causes divisions in Mexican society; 27 per cent would not allow an immigrant to live in their house; 38 per cent said that "Mexicans can build a great nation only if we have a similar culture and values" (CONAPRED 20II: 84). The same source indicates that there is a general belief among the population surveyed that the migrants' presence has led to problems of insecurity because migrants often attract various types of criminals who attempt to kidnap or assault them. Long-time immigrants without a regular identity are affected by these attitudes in the communities where they work and live. There is a fear of denouncement that applies not only to their neighbours, but also to their employers, who want to evade responsibilities towards them. They also fear the mafias and criminals who can attack them, in addition to the fear of the consequences of being detected by the authorities as workers with irregular status. Despite the fact that Mexico has a significant proportion of citizens who are in favour of having foreigners in the country, testimonies from migrants who are Guatemalan, economically disadvantaged, indigenous, and/or migrants working in the agricultural and service sectors (as domestic workers and sex workers), have shown that they are often victims of 'othering' and exploitation (CONAPRED 20II). This type of abuse also goes unreported due to fear of losing one's job or fear of being handed over to the immigration authorities. In conclusion, the survey emphasized that the discrimination and intolerance towards migrants revealed by the survey "directly confronts the discourse and imaginaries of a society that calls itself multicultural, hospitable, and generous to those coming from abroad" (CONAPRED 20II: 7).

Access to services and rightful treatment at work has become increasingly problematic for im/migrants in such a context. Although Mexico's Migration Law of 25 May 20II states that immigrants have access to various services and rights regardless of their immigration status, these rights continue to be denied at the local level (Articles 6, 8, 9, II, I2, and I4). ${ }^{17}$ Several provisions of the new law on verification and migration control are already being implemented by the im- 
migration authorities, while, as of July 20I2, the relevant regulations that grant migrants rights without their having to prove their legal status still have not been published. In the current milieu of xenophobia and 'othering' among different groups in the Mexican population, the gap between the law and its implementation have forced migrants (including immigrant women) into self-chosen invisibility, not only towards immigration authorities but also towards people in their close environment. Additionally, within Mexican society, discriminatory attitudes towards the indigenous population persists, affecting the majority of the Guatemalan immigrant population in Mexico, many of whom have indigenous facial features and still wear traditional clothes and use their own languages.

\subsection{Stories of Guatemalan Women Migrating to Mexico}

According to the latest Mexican national census, the Guatemalan immigrant population represents a small part of the immigrant population in Mexico (INEGI 20IO). Although their numbers have increased from 23967 to 35322 between 2000 and 20I0, Guatemalan immigrants only accounted for 4.9 per cent of all recorded immigrants in 2000 and 3.7 per cent in 2010. This population has become important in Mexico's southern border region (Chiapas, Campeche, Tabasco, and Quintana Roo), where many people from Guatemala live. Small-scale studies have indicated a similar picture with a significant number of women immigrants and migrants (irrespective of their migration histories) exposed to a series of risks and who face 'othering', exclusion, and marginalization (Rojas 2002; Rojas/Ángeles 2008). This ill-treatment can be based on their migrant status (regular or irregular), class membership, gender, ethnicity, and even their geographical location and the length of their stay in the place of arrival, or on a combination of some or all of these factors. As López Sala (2005) notes, distinguishing between groups of im/migrants is necessary because strategies of invisibility may differ according to migrants' identity background and migratory history. Using the formal criteria of classification, Guatemalan women $\mathrm{im} /$ migrants in Mexico are distinguished as: I) immigrants, 2) temporary migrants, and 3) commuters or residents on the frontier with Guatemala.

17 See this law at: <http://dof.gob.mx/nota_detalle.php? codigo $=5190774 \&$ fecha $=25 / 05 / 20 I>$ (I5 October 20I2).
The national census cited above indicates that in Mexico's southern border region, 43 per cent of immigrants are of Guatemalan origin, 56 per cent are women, and most of them ( 83 per cent) live in Chiapas. An estimate of temporary migration can be made from the data collected through the Southern Border Migratory Survey ${ }^{18}$ - an ongoing survey that applies to some of the migratory flows on the border between Guatemala and Chiapas. In 2009, information was gathered on 324519 border crossings by temporary workers; 23.5 per cent had no immigration papers and I7.6 per cent of the total flow were women. As for commuters, the same EMIF-Sur survey gathered information from 190904 border crossings by residents in border regions: 55.0 per cent had no immigration papers; 83.3 per cent were working, but with papers that did not authorize them to work; and 42.6 per cent of the total flow were women (INM/CONAPO/ COLEF/SRE/STyPS 2OI2).

To supplement this information, in our research ${ }^{19}$ we collected data through semi-structured personal interviews with Guatemalan women and with some key institutional informants. Various strategies were employed to contact the women from whom information was collected and the connections were established by key informants. Subsequently, to identify additional respondents a snowball technique was used with women already interviewed, local organizations, and ECOSUR networks. Initially, many women were reluctant to participate in the interviews through fear of deportation, but gradually as they came to know the researchers better they were more willing to share their experiences.

Given the proximity and historical interaction between Chiapas and Guatemala, the largest number of women interviewed for this project was from Chiapas and to a lesser extent from states where the census recorded Guatemalans (Campeche, Quintana Roo, and Mexico City). The majority of these women were im-

18 In Spanish, EMIF-Sur is used for Encuesta sobre Migración en la Frontera Sur.

19 This chapter will present findings of the research conducted in Mexico by Martha Luz Rojas Wiesner and Hugo Ángeles, together with Cristina Robledo and José Bernal (Research Assistants), which is part of the "Advancing the Rights of Female Migrants in Latin America and the Caribbean" project, coordinated by Tanya Basok and Nicola Piper, and financed by the International Development Research Center (IDRC). The larger project was independently carried out in five countries: Costa Rica, Chile, Argentina, Mexico, and the Dominican Republic. 
Table 10.1: Profile of Guatemalan women interviewed. Source: Interviews with Guatemalan women in Mexico, 20092010, based on data from the IDRC Project.

Total women interviewed

Average age of women at time of interview

Age range of women at time of interview

Average age at time of first migration to Mexico

Age range of women at time of first migration to Mexico

13 to 64 years

17.5 years

Location of interview

\begin{tabular}{|c|c|}
\hline Chiapas & 33 \\
\hline Campeche & 9 \\
\hline Quintana Roo & 8 \\
\hline Ciudad de México & 5 \\
\hline \multicolumn{2}{|l|}{ Number of women according to migration status } \\
\hline Immigrant or established women in Mexico & 41 \\
\hline Temporary or seasonal migrant women & 8 \\
\hline Border-resident women & 6 \\
\hline \multicolumn{2}{|l|}{ Number of women by migratory legal status } \\
\hline Women with appropriate immigration papers & 16 \\
\hline Naturalized women & 12 \\
\hline Women with irregular status & 27 \\
\hline \multicolumn{2}{|l|}{ Number of women by region of origin in Guatemala } \\
\hline San Marcos & 22 \\
\hline Huehuetenango & 9 \\
\hline Guatemala & 6 \\
\hline El Petén & 3 \\
\hline Quiché & 3 \\
\hline Escuintla & 3 \\
\hline Otros & 9 \\
\hline \multicolumn{2}{|l|}{ Number of women by status of activity } \\
\hline Women engaged in trade-related activities & 16 \\
\hline Live-in domestic service workers & 11 \\
\hline Women engaged in artisan/craft or support work & 7 \\
\hline Women engaged in agricultural work & 4 \\
\hline Women engaged in personal service industry (restaurants, cleaning services, etc.) & 5 \\
\hline Professional, employed in administrative or office setting & 5 \\
\hline Women engaged in unpaid household/domestic work & 7 \\
\hline \multicolumn{2}{|l|}{ Principal motives for migrating to Mexico } \\
\hline Economic motives & 29 \\
\hline Fleeing political violence & 13 \\
\hline Fleeing a situation of domestic violence & 4 \\
\hline Family reunification or to raise a family & 9 \\
\hline
\end{tabular}

migrants, followed by migrants with the status of temporary workers and commuters predominantly from the Guatemalan border states of San Marcos, Hue- huetenango, El Petén, and Quiche. ${ }^{20}$ In Chiapas, the largest group of women came from San Marcos, while in Campeche and Quintana Roo, the women mainly 
came from El Petén, Huehuetenango, and Quiche (see figure IO.I). As a group, the women immigrants came to Mexico for the first time between 1965 and 2008 , and were between six and thirty-eight years old when they migrated (median age 17.5 years). On average, these women have been living or working in Mexico for almost twenty years - some reported that they have lived for over thirty years in some places ${ }^{21}$ in Mexico, and of these, some were still without immigration papers.

Guatemala is one of the most unequal countries in the world and its poverty level is among the highest in the region (Menjivar 2008; World Bank 2004). The three provinces from which the majority of women interviewed are from have poverty levels of above 50 per cent. In Mexico, the municipalities at the border are also extremely poor, as can be seen in the following index of general and extreme poverty: Tacaná ( 84.5 per cent and 32.2 per cent), Tajumulco (93.3 per cent and 48.9 per cent), El Quetzal (79.5 per cent and 26 per cent), and Malacatán (7I.4 per cent and I8.7 per cent) (SEGEPLAN 2006). This mestizo population of indigenous ethnic origin and with a high percentage of illiteracy depends on informal work in agricultural and commercial activities. The combination of these factors contributes to their social exclusion. In this context it is not surprising that the main motivation for migrating to Mexico is economic. In Mexico, they were engaged in trade-related activities, as independent traders, trade employees, or peddlers. A smaller number was engaged in domestic work, in crafts or artisan work (personally or as assistants), while some were engaged in agricultural work, and others as personal assistants in professional, clerical, or administrative positions. We also interviewed a few women who had no gainful employment.

Regarding their immigration status, nearly half of the women interviewed have regular migratory status in Mexico, either because they have a certificate of naturalization or immigration papers. Those who had naturalization papers were mainly women who had sought refuge in Mexico during the early 1980s and

20 Guatemala is divided into eight regions, and each region is made up of one or more states that have a similar geography, culture, and economy; each state is divided into departments and municipalities. Currently Guatemala has twenty-two departments and 331 municipalities (Congress of the Republic of Guatemala, 2011: Administrative division of the Republic of Guatemala at: <http://www.congreso.gob.gt> (I3 May 20II)).

21 The dots in figure IO.I indicate the localities where the women were interviewed. did not return to Guatemala after the peace agreements were signed in 1996. Not all women refugees were naturalized and some do not have identity or migratory documents. Women who continued to live in Mexico and who did not return to Guatemala were given government support to settle in Mexico and granted a small plot of land and naturalization, while those who returned to Guatemala after the conflict and later re-entered Mexico as economic migrants were without support. The rest of the women interviewed did not have identity documents or had insufficient papers to show their legal presence. The latter situation could refer to immigration papers expiring and migrants not yet renewing them, or to situations where immigration papers had been issued but do not authorize the migrant to carry out remunerated activities.

Fleeing poverty is the principal motivation for the majority of the women who migrated to Mexico. Olga, ${ }^{22}$ an immigrant without an identity document after eight years living in Mexico, is currently earning her living by washing other people's clothes.

I came to work because we have no money over there. Then I quit school because my father died and my mother stayed alone and so I came to work here [2001] when I was thirteen years old (Olga, 2I years old).

Besides economic reasons, escaping political or domestic violence is of significance. The majority of Guatemalan women have been exposed to a pattern of continuous violence, and this is a key factor in their choice to remain invisible. Maria Luisa came to Mexico fleeing gender-based violence in 199I. She has no identity document and is a widow and mother of five children. She left the three older children in Guatemala, and her two small children, five and eleven years old, who were now with her in Mexico, were not registered and were not attending school at the time she was interviewed.

This Tuesday my father called me to enrol my children because he was coming to collect them. I said 'No'. 'How come?' (he said)... I said to my boy, if you want to stay with my father, I leave this up to you, but my father is not going to take my girl from me.' Because my dad raped me, I don't want this to happen to my daughter... Then the next day, it was like Tuesday night, on Wednesday around 5.30 a.m. I threw two mudadas [clothes for two days] for the girl into a bag, two for me and two for the boy. With that I came here [to Tapachula]. I had nothing... Ah! and my ID card... I left

22 The names presented in this section in the transcript narratives are pseudonyms used to protect the identity of the women interviewed. 
around ten in the morning from Guatemala. I came here around five in the afternoon, and it was when I came here with her [her mother was already living in Tapachula] (Maria Luisa, 36 years old).

Although patterns of violence were often linked to the several years of civil war, brutal violence against women was also widespread, particularly during the I980s. Sexual abuse and murder of women during the civil war was common. The high levels of impunity for those crimes have contributed to the normalization of violence against women in Guatemala (Menjivar 2008; Carey/Torres 20I0). Some women mentioned that during the war events in the 1980s, they were forced to live for long periods hidden in the forest of Guatemala, near the border with Mexico, to avoid the physical abuse perpetrated by Guatemalan military forces. Miriam, a naturalized immigrant, arrived in Mexico in 1985 fleeing the Guatemalan conflict. Currently she is married, but her husband is a migrant worker currently in the United States. They have four children.

They took refuge in the mountains. Then, we got to the same place and they were there, meaning we stayed with them because since they also were in the same place. And the same day in the afternoon the army arrived, and they attacked us and it was when fourteen people died, fourteen of my relatives (...) not my brothers, but cousins, uncles, in that place, killed by the army. And my two nephews, two nieces that I had, who were sixteen, fifteen years old ... were two cousins, my two cousins whose breasts had been cut off..., had been split in two, they had been treated like that (...) at that time as I say, I was very young still had ... I was not even thirteen (...) And we got out secretly, we fled [for Chiapas] (Miriam, 43 years old).

Many women indicated how the demand for immigration documents at the border controls has increased since 2008 , while a small number said that they originally entered Mexico without being asked for any documents. It is important to note that according to these women the tightening of immigration controls in the state of Chiapas in 2012 has resulted in a series of 'operations', in which immigration officials have visited businesses, farms, and even a local news agency to search for, arrest, and deport workers with irregular status - actions that had not been previously recorded in the region. Juana is a migrant without papers, married and with two children. She arrived in Mexico in 1985 at the age of thirteen, fleeing an attempted rape by her father-in-law. She travelled with her brother, who helped her to search for a job.

Well, it was already many years ago but they didn't ask me for papers. They asked only him [the husband]. And right now, you see that there are seals of migration, the soldiers and that ... and because of it I have not gone [to Guatemala] (Juana, 40 years old).

Since 2000, Mexican immigration authorities have carried out legalization programmes ${ }^{23}$ for migrants, one of which ended in May 20II. These programmes aimed to support migrants with immigration procedures, principally by facilitation of the requirements needed to legalize or formalize their migratory status. Despite being written into the Migration Law, these programmes were limited in their scope and many migrants with irregular status in particular were unaware of them (Guevara 20II). Many of the migrant women interviewed still have irregular migratory status because they lack adequate information about the law for formalizing their stay, or because they lack financial resources, or support from social networks to do so, or simply because they continue to fear deportation if they attempt to solicit information from the authorities about the process. Because the campaigns of information do not reach the places where these women live - remote localities or marginal areas -, they can be easily deceived, threatened, and manipulated (by husbands, employers, neighbours etc.). Not being informed is one reason, but also their fear of deportation if they turn up to begin the procedures of regularization with the immigration authorities. Only few women know that there are some civil organizations that can guide or defend them.

On the whole, migrant women without regular status have many difficulties in maintaining a life with basic rights and dignity because of interlinked difficulties as a result being a migrant with irregular status, of 'indigenous' background, and of Guatemalan origin. This affects the type of work they can do and also their place of residence. Their place of residence in turn affects their access to adequate information. These factors cannot be sharply separated but are usually expressed jointly. They interact and change over time and within the context (Anthias 2008). As for the perception of 'othering', there is a difference between women who came as refugees in the 1980 s and are now naturalized, and those who are more recent immigrants. The first group has closer ties to Guatemalan networks already settled in Mexico, while the second group is more exposed to Mexican society. The harsh side of 'othering' faced by Guatemalan women migrants who came to Mexico as economic migrants affects those who lack the minimum requirements for a life with dignity, i.e. economic and social

23 Programas de Regularización Migratoria. 
rights such as access to health care and education for themselves and for their children. They also mentioned abuses of favour and difficulties linked to violence, housing, and the preservation of their cultural identity.

Women with regularized migrant status and who are professionals were able to interact with people in the mainstream of the Mexican society despite their feelings of discrimination. Rocio, interviewed in Tapachula in 2009, was married without children. She works as a professional. Rocio has lived in Mexico for three years because of her Guatemalan husband's job.

(...) I believe that there is much discrimination for those coming from Guatemala. But I also understand as a Guatemalan, meaning that it definitely bothers me. Therefore I try to understand it, because there is always a reason. There has always been a rivalry between Mexicans and Guatemalans. I do not know why, I do not know if it comes mixed from the story, due to all that has happened, right? But yes, even if you try to understand it gives you courage... and you get angry and you vent your spleen, then. To some extent you try to understand why that happens, and try to talk to the person, but (...) (Rocio, 27 years old).

\subsection{Understanding Strategic In/ visibility}

Reacting to situations of 'othering' and exclusion, many migrants prefer to face their problems alone or with little assistance. Although male migrants also face a similar situation, migrant women face a greater degree of risk and hence greater vulnerabilities due to their gender identity. ${ }^{24}$ Depending on their resilience and their individual resources or those made available to them by others, migrants used various forms of agency to neutralize or resist the temporary or permanent particular situations of abuse and 'othering'. Here, we will concentrate on the narratives about invisibility or passing unnoticed, a strategy used by a large percentage of the women interviewed.

Some women are living in situations of invisibility because it is the best strategy for living or working in

24 Some theoretical agreements indicated that vulnerability is linked with undesired outcomes, due to being exposed to dangers that caused some damage. But vulnerability is also related to responsiveness as a resistance or resilience. In this last sense, the levels of responsiveness depend on the assets available to a person or to a family or group to face the risks and to overcome the critical situations and their consequences (Busso 200I; Naudé/Santos-Paulino/McGillivray 2009). their current situation. Other women keep silent or try to move in an way that means they are unnoticed as a protection strategy when facing risks such as losing their jobs or housing, being deported, being involved in trouble, or being separated from their children by forced circumstances. Some women indicated their intention to avoid the establishment of friendly relations with other people in order to avoid any kind of problems. But this also denies them the possibility of having supportive networks or persons around, and locates them in an isolated and solitary living position. Yolanda, who was interviewed in Quintana Roo in 2009 , was working as a domestic worker. She was divorced and with one son born in Mexico. She arrived in Mexico in 200I because of her marriage to a young Mexican who was descended from a Guatemalan family. Yolanda had already started her process of regularization; however, she could not pay the fee required for the process. After the interview we were informed that she had been denounced to the migratory authorities by neighbours, and after that she disappeared.

I am a girl who wants to avoid problems. I don't get involved with people because I am afraid that they are going to accuse me of something. I have the fear that the police would come (...) Many people from here, the ones who live around here, say to me 'you neighbour, you just pass by always enclosed'. But like I said to you, it is to avoid problems, I like to avoid problems (Yolanda, 25 years old).

Some women are compelled to keep silent or hide their anger due to their fear of the same risks, which in many occasions are reinforced by external threats from people in their daily network. Further, some women consider visibility a pointless action, which lacks positive outcomes for them and can affect their sources of income. Lupita is a temporary farm worker and migrant with irregular status who was interviewed in 2009. She arrived in Mexico for the first time in 2003 to work on a farm with her parents. Lupita has a child two years old who was born on the farm where she works, but the midwife did not give her a birth record, so she registered her child in Guatemala. She was abandoned by her partner, and currently lives with her sisters on the farm, where they have seasonal work. At the time of the interview, she had no immigration papers and she indicated that she had never needed them.

He [the manager of the farm] has treated me badly, nothing more, I say. I think that's why he hasn't given me vacations; because, he says that he is the boss and that he decides who will get them [vacations]. There are 
those for whom it has been slow to get their vacations, but I have never got them. I have had problems with him and he has already mistreated me twice. Once he gave me a shove. I had my baby in my arms and then he told me 'I'll send you to jail'. So I was scared, and I he took my job away... Then, since I didn't want to leave this place and because I don't have any work over there, I went back to ask him for work. At first he didn't want to hire me, but at the end he gave me a job. But only with him I have had problems. I'm ashamed [to speak] and afraid if he listens to me, he can hurt me all of a sudden, or something (Lupita, 20 years old).

Other women choose to go unnoticed leaving behind the traditions that identified them as indigenous. They do not wear their traditional dress and do not speak their original Mayan language. Some women also try to blend into their surroundings to circumvent the fact of being a focus of attention. Margarita is a self-employed woman who arrived in Mexico for the first time in I98I when she was fleeing the Guatemalan violence. She is separated and has one son. At the time of the interview she had lived in Mexico for twenty years, of which eighteen had been spent in Campeche.

At first I used to say that I am from Chiapas. 'No, you are not from Chiapas, you are from Guatemala' (they said)... and like that until one day that I said 'No, even if I say as much that I am from Chiapas, I am not from there because it is noticeable in my way of speaking, of behaving, better no'. Honestly, 'Where are you from?', 'I am from Guatemala', I said, but when I said it, I said it with shame, or something like it. And I don't know, until now I ask 'Why did the father of my son leave me?' $\mathrm{Ah}$, maybe this is the reason. As now he sought another (woman), I said 'No doubt perhaps because I am Guatemalan'. So, so, so in my mind I had this idea (Margarita, 40 years old).

Others prefer to keep quiet and to remain in secret situations of humiliation by others, or not to report incidents of abuse and violence due to their ethnic origins, because they are afraid of further damage. This is particular relevant in situations of domestic violence. Matilde, an immigrant who has lived in Mexico for twenty-six years, had no document certifying her status as an immigrant and the length of her residence. When she was interviewed, she was given advice about how to formalize her stay in Mexico. She was married and has three children. Since she was young, and after having been orphaned, she has had different problems with abuse. In order to have some extra income, Matilde works selling food she prepares herself, but she does so in secret as her husband refuses to allow her to work.
He gives everything for me, for his children, but when he is drunk he changes; he becomes another person, eh? ... At the beginning, before he would hit me he would say: 'pinche cachuca, ${ }^{25}$ this is my homeland, here nobody will defend you' and thump, he would give me a slap... oh the bruises in the face. He would say that 'you are a...', 'you're the...... he calls me 'india', ${ }^{26}$ he humiliates me horribly... My mother-in-law said: 'Look, I don't want problems (...) don't you go denouncing Manuel, don't mess with my son, because look, we like you, you're a great woman'. Then my sister-in-law said: 'Look girl, if you call the police, you can be sure that you will lose us... you will lose the case because we are Mexicans and you are a foreigner' (Matilde, 35 years old).

Some women try to pass unnoticed by not using particular services or not claiming rights such as education or health. In the case of education, many women prefer their children not to go to school rather than handle the procedures and the documentation process required for school enrolment. Maria Luisa, cited above, said:

My mother filled me with fear, she said that they will take my kids, because she doesn't want us to be here. So, I did not want to go to do it, because I don't want that they take my children from me. But, now the woman owner of the house said I have to put them in the school, I agreed and said to her that I am scared, so she went to speak with Lorena and she already said that they will help me (Maria Luisa, 36 years old),

In the case of health, the women prefer to go to Guatemala because they will not be discriminated against because of their origin. Also, women often choose to receive medical attention by professionals in a chain of low-cost pharmacies, where their migratory status is not relevant to whether they are treated. When they travel for medical attention, it is important to point out how increased border control is affecting this possibility, particularly at the crossing-points where it is necessary to use the bridges connecting Mexico and Guatemala, and therefore to go through formal migratory procedures within official offices.

The truth, the truth is, I had not worried about asking if there is a health centre. Because, like when one goes, or something like that, they ask one for papers, and I don't have the documents for my children, so I don't go. I'd rather go to the 'Similares' ${ }^{27}$ too (Lupita).

25 Cachuca is a degrading term used to refer to someone of Guatemalan origin.

26 The expression India is also used in a derogatory manner and has a strong discriminatory connotation. 
Summing up, strategic invisibility as a practice appears to be very common among many Guatemalan im/migrant women. This strategy is sometimes chosen as a protection strategy, but in some cases it is a forced choice or due to fear of further consequences. Also, some women do not see any sense in making themselves or their situations more visible, because they will not receive positive or supportive responses from their social or institutional network.

\subsection{Reflection on In/visibility as a Form of Everyday Politics}

The study of women's migration has revealed that migrant women encounter situations of 'othering' in distinctive ways, whether their migration is within a country or between countries, or whether it is regular or irregular in character. As has been pointed out by a number of authors, civil society organizations, and international agencies, situations of discrimination have increased the major risks to and vulnerabilities of migrant women as a result of the strengthening of containment measures and migratory controls in specific parts of the world in recent years (Anguiano/López 20IO; Dobrowolsky/Tastsoglou 2006; FitzGerald 20II). Paradoxically, while researchers and advocates work to make women migrants more visible, there are women migrants who do not want to be visible. From the perspective of rights advocates, visibility is the main condition for seeking recognition of the fundamental settings for life and liberties, while for the im/ migrants invisibility is consciously chosen as a strategy to protect themselves against the authorities, or against people in their neighbourhoods or the communities in which they work, especially if they foresee any type of risk or threat on account of being a foreign or migrant person. In other words, invisibility for some women $\mathrm{im} /$ migrants can be a mechanism for avoiding contact that may be 'othering' or abusive to them, and also a way to avoid control and surveillance by others.

As a chosen option, this in/visibility can be a form of everyday life action with political and transformative significance, as captured by Kerkvliet (2005) with the term Everyday Politics (EDP), which he defines as the subtle or low-profile practices that influence the

27 This refers to the 'Similares' brand of pharmacies, which sell generic drugs at affordable prices and also offer medical attention for a cost approximately equivalent to US\$2.50. Many migrants use their services. control, allocation, and use of tangible and intangible resources. $^{28}$ As noted by Kerkvliet (2009), even if the practice of invisibility is not associated with being 'political', it is a mechanism for resisting and challenging the normative regulations within one's environment. From this perspective, the subtle nature of the practice of invisibility becomes relevant within the context of the agency of the women $\mathrm{im} /$ migrants, because it is a way of resisting control by the authorities and contest the surveillance of others. As such, invisibility is a form of EDP that belongs to the typology ${ }^{29}$ of resistance or defiance, as well as evasion (Kerkvliet 2009; Hobson/Seabrooke 2007). Understanding invisibility from this perspective allows the recognition of agency in the Guatemalan migrant women, returning to them a role in the realm of politics, with some possibilities for bottom-up adjustment. However, it is important to note that the chosen strategy of invisibility can also limit their opportunities for advocacy purposes (Kihato 2007). And in many cases, invisibility is not necessarily a protective measure against domestic violence, nor a challenge to increasingly restrictive immigration policies, but just a form of protection against daily life 'othering' and exclusion inside their communities. Some women revert to this type of strategy in particular situations, while for some women it is a form that becomes more permanent.

This dilemma between being visible and being invisible is related to what Andrea Brighenti (2007) has called the "field of visibility". This refers to a more complex phenomenon than just a single visual dimension. According to Brighenti, this field of in/visibility is the intersection of two domains - "the perception of relations" and "relations of power", which are usually asymmetrical, and therefore the visibility relationships are also unequal (Brighenti 2007). In this sense, according to the power locations the reciprocity of vision or inter-visibility can be imperfect and limited, because for example one domain can just choose not to

28 A more extensive definition is proposed by Hobson and Seabrooke (2007), who identified Everyday Politics as the "acts by those who are subordinated within a broader power relationship but, whether through negotiation, resistance or non-resistance, either incrementally or suddenly, shape, constitute and transform the political and economic environment around and beyond them" (Hobson/Seabrooke 2007: I5-16).

29 Besides 'resistance', other forms of everyday politics are: 'support, modification and evasion', and 'compliance' (Kerkvliet 2009). This classification was re-delineated by Hobson/Seabrooke (2007) as 'defiance, mimetic challenge', and 'axiorationality'. 
see the 'other'. However, visibility can be a doubleedged sword, which on one side can lead to empowerment $^{30}$ when it is closely related to recognition by others or to access to restricted resources or services. But on the other, it can also facilitate control, exclusion, and discrimination by others, creating an ambivalent situation for migrants. This is the case for migrant women in irregular situations, and women victim-survivors of sexual and gender-based violence. Recognition is a form of social visibility with implications for minorities and for those who are socially excluded.

Often perceptions of visibility are distorted due to the entrenched social representations of marginal subjects, and so visibility and recognition are not related in a linear way: there may be different ways of seeing and being seen, and the social impact of this visibility will depend on who is more visible and in which social location they are placed (Brighenti 2007). Total 'visibility' may lead to total control, as explained in Foucault's discussion of the panopticon - a symbol of total surveillance (Gordon 2002). In addition, visibility can lead to regulation, selectivity, or stratification. So the relationship between seeking recognition or visibility and being controlled is a close one. This tension between achieving recognition and suffering control or discrimination generates complexity in the relationship between in/visibility and power, and therefore between migrants and their context. In these terms, visibility does not necessarily lead to relief nor does it imply better life while invisibility cannot only be seen or considered as a lack of power (Brighenti 2007).

Invisibility as a strategy for power is reflected in the cases of silence and secrecy. Secrecy is not only centred within power, but secrecy by others also creates the possibility to escape or oppose power (Brighenti 2007; Amster 2008). Silence and secrecy can be key survival strategies, can offer protection, and in some cases can create spaces to renegotiate harmful gender relations and practices. In this respect, it is important to discuss the role of in/visibility in empowerment processes. If we are to consider the active participation of migrants in processes that will allow them access to better conditions of life, and what that might imply in the current context of border controls heightened by international requirements, we need to first question in what manner in/visibility could con-

30 Empowerment refers to the process by which those who have been denied the possibility of taking strategic decisions in life acquire such capacity (Kabeer 1999). tribute to these achievements. Ghorashi (20IO) has raised similar questions, noting that unless the assumptions of the dominant discourse are also challenged, visibility does not help much in the process of accessing rights. In many cases visibility can even reinforce 'the boundaries' in relation to migrants, as presented in her study of Islamic women in The Netherlands, where the migrants are constructed as the 'other' - as not belonging to the nation, but living within it (Ghorashi 20IO). This construction of otherness implies that migrants are those who 'do not belong', but this occurs not only for the first generation of migrants but also for their descendants. Floya Anthias has documented this type of 'othering' using ethnic distinctions in the United Kingdom with secondand third-generation Greek Cypriots. According to the author, the Greek Cypriot young people occupy a very ambivalent and contradictory position within society; on the one hand, they are invisible in terms of discourses about ethnicity and racialization in the United Kingdom, and on the other, they are visible as a cultural group that is geographically concentrated in specific urban spaces that are considered 'multicultural' (Anthias 2002).

However, there are many critiques of the notion of everyday life as political actions. For the case of the migrants' in/visibility it is also worthwhile questioning the sense of agency of this strategy. It is important to examine in more depth through additional research the ambiguity of direct claims, the conscientious decision of these acts as political, and the limited possibilities for effective advocacy and social change (Escobar 2008; Gardiner 2004; Kerkvliet 2009). Here, the time factor matters because this bottom-up process requires a long time to attain changes and the life of each migrant person should be worthy enough to consider possibilities of collective action that could ensure faster outcomes with long-term settings. In other words, in/visibility may be effective as a strategy of survival, but it may not be enough to achieve stable settings for a better quality of life. Having a voice does not necessarily mean that assistance or a positive response will come in return. Also, having a 'voice' in other situations can be a positive way to fight back to negotiate rights. On the other hand, invisibility enables daily mobility with fewer risks and less surveillance by others. Besides the fact of feeling safe, from this hidden position women can achieve short-term minimum conditions for survival. Hence, the exercise of agency through silence and invisibility entrenches a complex paradox, because it allows short-term achievements as conditions for survival. But as a long- 
term strategy it could be untenable, because the minimal gains achieved on a daily basis do not necessarily become established conditions for the life of the migrants and it might entrench superior circumstances of exploitation and abuse.

Women's responses to situations of 'othering', such as their invisibility, cannot be considered in opposite terms as positive or negative strategies. They should be analysed in reference to their social location and the structural conditions that generate complex processes of migration, which turn into incentives for the women's decision to exercise their own agency by becoming invisible (Parpart 2009). Therefore, invisibility and/or silence are specific strategies for survival just as much as visibility. The former is useful for protection and for achieving daily needs, while recognition, and therefore visibility, can offer the possibilities of accessing better life conditions and also rights in the long term (Parpart 2009). There are links between the conscious decision to become invisible or to pass unnoticed, and the ability to exercise agency and seek formal recognition of rights. The question of making women visible is challenged by the conditions under which they live and their strategies of fighting for it. Making women visible does not mean an end to their problems. Thus we cannot just propose the necessity of making them visible precisely because for many women invisibility has been a question of survival.

The in/visibility paradox has especial relevance to the terrain of accessing rights and formal protection, because to raise awareness of rights it is necessary that certain sectors speak out about their lack of substantive rights. In the context of human security, social justice should entail the philosophical perspective of the 'right to have rights' proposed by Hannah Arendt, which means guaranties for the safety conditions of vulnerable individuals regardless of their legal migratory status (Oman 20IO). Women migrants' conditions of life need to go beyond 'gender' as a dichotomous variable and to examine its situational and relational character, revealing the social meanings of access to rights from the perspectives of the women migrants themselves. Given the increasingly restrictive conditions limiting their mobility, the claim to rights cannot yield positive results unless supported by other actors (social networks, civil organizations) which initiate processes that would make their experiences visible, and guarantee that their voices are heard by the state and other actors responsible for gender justice initiatives and processes (Molyneux 2008).
In the field of rights, much progress has been made in Latin America from research and advocacy. However, there are still many restrictions and biases involved in accessing these rights and achieving social justice in practice. During the last three decades of the twentieth century many initiatives were undertaken in Latin America to advance the rights of women, and these are also linked to those for the advancement of international migrants. In this respect, Molyneux (2008) pointed to three classes of crucial initiatives in the campaign for the rights of women in the region. Firstly, movements were launched for 'the right to have rights' in situations where people sought to restore democracy following authoritarian regimes. Thus, the language of rights has become a way of demanding justice and recognition. Second, ideas of citizenship that linked the state to passive subjects, that is, citizens as receivers, were re-examined. These ideas were replaced with ideas of 'active citizenship' that highlighted participation and agency, and favoured a more substantive form of citizenship - one that was more participative and socially responsible. Third, as a result of the first two initiatives, feminist movements began to see citizenship as a way of overcoming social exclusion. During the nineties, these three initiatives were reinforced and supported by an international development agenda that emphasized rights, women's empowerment, ${ }^{31}$ and participation (Dagnino 1998; Kabeer 2007; Molyneux 2008).

Considering that the achievement of social justice implies the access to rights, it is important to review how from reflecting on invisibility as a form of women's agency it is possible to identify alternative forms of support for migrants that respect their autonomy. If in/visibility is a question of survival, it is important to offer migrants the conditions required to make it as an informed decision. Many women argued that invisibility allows them to attain what they aspire to, namely a job, housing, children; "leaving their party in peace" ${ }^{32}$ However, their range of expectations could be limited by the lack of information, which delineates a minimal spectrum of possibilities for them. Perhaps, if they have access to more information on what they are entitled to get in terms of rights, services, and protection, many of these women will amplify their perspectives and possibilities so that

31 Women's empowerment is understood as a woman's ability to act and create change in the world.

32 'Viviendo su fiesta en paz' is a common expression used in this region of Mexico, which means to do things without generating trouble. 
they can realize longer-term conditions for a life with dignity. In other words, if women do not know what they are entitled to, they will not expect it. But if they are informed about their rights as well as the procedures for accessing them, perhaps their exercise of invisibility will be more strategic in its nature.

\subsection{Conclusions}

This chapter has shown how the re-scaling of border control in Mexico has affected Guatemalan im/migrants along Mexico's southern frontier. The meaning of borders, usually confined to territorial limits, can be extended to the construction of the 'othering' of social boundaries (Van Houtum/Van Naerssen 200I). Discourses on migration processes based on the 'fear' and 'threat' of crime and national security affect the horizontal relationship between migrants and people in their social networks, generating additional dimensions of vulnerability for the migrants by stressing the differences. The emphasis on the threat of crime linked to migration and border control policies has triggered social processes of 'othering' that have severely impacted everyday life and the survival experiences of Guatemalan im/migrant women, mainly those migrants who have irregular status. Migrants, particularly women, become more vulnerable to abuse, violence, and insecurity in a variety of daily relationships: employer-employee; neighbour-to-neighbour; inter-group relations; husband-wife. The re-scaling of forms of border control aims to create orderly management of migrations, as Mexico's new Law of Migration guarantees the socio-economic and civil rights of immigrants even for those with irregular status. But local social dynamics of power linked with gender, ethnicity, and economic features are such that the new law remains unreachable for many Guatemalan im/migrants.

Many women im/migrants who have faced multiple forms of insecurity tend to select a strategy of invisibility to conserve their daily survival in subtle ways, which include a commitment to protecting their children and families by safeguarding dignified conditions that many of them have not achieved themselves - i.e. without physical, mental, or verbal abuse. In this sense, invisibility becomes a relevant form of empow- erment, an everyday exercise of politics of resistance to enable access to the minimum conditions of life. Also, the practice of invisibility is the result of their own search for personal locations where they can feel safe and autonomous. Ironically, this strategy of invisibility can be counterproductive for them, because in a context of lack of information, it prevents them from access to the benefits of the new migration law that could ensure more long-term conditions for a better quality of life. Dignity for migrants has a public dimension derived initially from their legal existence in Mexican society, but many migrants remain ignorant of and out of reach of civil organizations advocating their rights. So far, given the discourses and local spheres of power, Guatemalan women migrants, mostly with irregular status, must face multiple dimensions of insecurity derived from recent discourses and practices that focus on the link between 'irregularity' and national insecurity. As a result, there is an impediment to their achieving dignity and rights, especially for those living in remote rural areas and in marginal urban zones where information and formal procedures are not accessible.

In such instances, it is important to pay attention to the interface between the normative framework of $\mathrm{im} /$ migrants' rights and the dynamics of the local sphere of migration that obstruct the enabling conditions for women im/migrants to achieve a legal existence on their own account and which respects their autonomy. In this sense, information is an important instrument for creating the conditions needed to break down the dominant relationships of subordination, where women can adopt in/visible strategies through processes of informed decision. Enabling conditions should be built through the dissemination of more information about their rights as guaranteed by the new Migration Law, which can help migrant women to construct better long-term conditions for their future and that of their children. The construction of these enabling conditions remains a big challenge for society, a challenge which should be addressed by the joint efforts of social institutions and civil organizations, the media, and even the academic world, as well as by strengthening the practices of public officials, policymakers, and those involved in the migrants' networks. 


\section{References}

Adamson, Fiona B., 2006: "Crossing Borders: International Migration and National Security", in: International Security, 3I,I (Summer): I65-I99.

Alba, Francisco, 200I: Las Migraciones Internacionales (Mexico: Consejo Nacional para la Cultura y las Artes).

Alba, Francisco; Leite, Paula, 2004: "Políticas Migratorias Después del II de septiembre: Los Casos del TLCAN y la UE”, in: Migración y Desarrollo (April): 4-20.

Alba, Francisco; Castillo, Manuel Ángel, 20I2: New Approaches to Migration Management in Mexico and Central America (Washington, CD: Migration Police Institute)

Amnistía Internacional, 20Iо: Víctimas Invisibles. Migrantes en Movimiento en México (Madrid: Amnistía Internacional).

Amster, Matthew H., 2008: "The Social Optics of Space: Visibility and Invisibility in the Borderlands of Borneo", in: Space and Culture, II,2: I76-I95.

Ángeles Cruz, Hugo, 20I0: "Las Migraciones Internaciones en la Frontera Sur de México”, in: Alba, Francisco; Castillo, Manuel Ángel; Verduzco, Gustavo (Eds.): Los Grandes Problemas de México: Migraciones Internacionales, III (Mexico: El Colegio de México): 437-479.

Ángeles Cruz, Hugo; Rojas Wiesner, Martha Luz, 2000: "Migración Femenina Internacional en la Frontera Sur de México", in: Papeles de Población, 23 (JanuaryMarch): I27-I5I.

Anguiano, María Eugenia; López Sala, Ana María (Eds.), 20IO: Migraciones y Fronteras. Nuevos Contornos para la Movilidad Internacional (Barcelona: CIDOB/Icaria).

Anthias, Floya, 2002: "Where do I belong?: Narrating collective identity and translocational positionality", in: Ethnicities, 2, 4: 49I-5I4.

Anthias, Floya, 2008: “Thinking Through the Lens of Translocational Positionality: An Intersectionality Frame for Understanding Identity and Belonging", in: Translocations: Migration and Social Change, 4,I (Winter): 5-20.

Baehr, Amy R., 20I2: "Liberal Feminism”, in: Zalta, Edward N. (Ed.): The Stanford Encyclopedia of Philosophy (Fall); at: <http://plato.stanford.edu/archives/fall20I2/ entries/feminism-liberal/>, (3 November 20I2).

Bastia, Tanja, 2009: "La Feminización de la Migración Transnacional y su Potencial Emancipatorio", in Papeles, I04: 67-77.

Brenner, Neil, I999: "Globalisation as Reterritorialisation: The Re-scaling of Urban Governance in the European Union", in: Urban Studies, 36,3: 43I-45I.

Bigo, Didier; Tsoukala, Anastasia, 2008: "Understanding (In)security”, in: Bigo, Didier; Tsoukala, Anastasia (Eds.): Terror, Insecurity and Liberty. Illiberal practices of Liberal Regimes After 9/II (London - New York: Routledge): I-9.

Brighenti, Andrea, 2007: "Visibility: A Category for the Social Sciences”, in: Current Sociology, 55,3: 323-342.
Busso, Gustavo, 200I: "Vulnerabilidad Social: Nociones e Implicancias de Políticas para Latinoamérica a Inicios del siglo XXI", Documento para el Seminario Internacional: "Las Diferentes Expresiones de la Vulnerabilidad Social en América Latina y el Caribe" (Santiago de Chile: CEPAL).

Carey, David Jr.; Torres, M Gabriela, 20Io: "Precursors to Feminicide. Guatemalan Women in a Vortex of Violence", in: Latin American Research Review, 45,3: I42I64.

Castillo, Manuel Ángel, I997: "Las Políticas Migratorias de México y Guatemala en el Contexto de la Integración Regional”, in: Bovin, Philippe (Ed.): Las Fronteras del Istmo. Fronteras y Sociedades Entre el Sur de México y América Central (Mexico: Centro de Investigaciones y Estudios Superiores en Antropología Social; Centro Francés de Estudios Mexicanos y Centroamericanos): 203-2I2.

Castillo, Manuel Ángel, 200I: "Los Flujos Migratorios en la Frontera Sur de México”, in: Les Cahier Amérique Latine: Histoire \& Memoire (ALHIM), 2; at: <http:// alhim.revues.org/index603.html> (3 May 20I2).

Castillo, Manuel Ángel, 2002: "Región y Frontera: La Frontera Sur de México. Elementos Conceptuales para la Definición de Región Fronteriza”, in: Kauffer, Edith (Ed.): Identidades, Migraciones y Género en la Frontera Sur de México (San Cristóbal de las Casas, Chiapas: El Colegio de la Frontera Sur): 19-47.

Castillo, Manuel Ángel, 2003: "Mexico-Guatemala Border: New Controls Transborder Migrations in View Recent Integration Schemes?", in: Frontera Norte, I5,29 (January-June): 35-65.

Castillo, Manuel Ángel, 20ıo: "Las Políticas y la Legislación en Materia de Inmigración y Trasmigración”, in: Alba, Francisco; Castillo, Manuel Ángel; Verduzco, Gustavo (Coords.): Los Grandes Problemas de Mexico: Migraciones Internacionales, III (Mexico: El Colegio de Mexico): $547-578$.

Castles, Stephen, 20I0: "Understanding Global Migration: A Social Transformation Perspective", in: Journal of Ethnic and Migration Studies, 36, I0 (December): 1565I586.

Consejo Nacional para Prevenir la Discriminación (CONAPRED), 20II: Encuesta Nacional Sobre Discriminación en México 20Io. Resultados Sobre Personas Migrantes (Mexico: CONAPRED).

Coria Márquez, Elba Y., 20II: "Estudio Migratorio de México”, in: Palma, Silvia Irene; Bonnici, Gisele L.; Coria, Elba Y. (Eds.): Estudio Comparativo de la Legislación y Políticas Migratorias en Centroamérica, México y República Dominicana (Mexico: Instituto Centroamericano de Estudios Sociales y Desarrollo; Sin Fronteras IAP): $380-438$.

Cortés Larrinaga, Mario, 2003: "Política Inmigratoria de México y Estados Unidos y algunas de sus Consecuencias", in Región y Sociedad, 15,27: 3-33. 
Dagnino, Evelina, 1998: "Culture, Citizenship, and Democracy: Changing Discourses and Practices of the Latin American Left", in: Álvarez, Sonia; Dagnino, Evelina; Escobar, Arturo (Eds.): Cultures of Politics, Politics of Cultures: Re-visioning Latin American Social Movements (Boulder: Westview Press): 33-63.

Dobrowolsky, Alexandra; Tastsoglou, Evangelia, 2006: "Crossing Boundaries and Making Connections", in: Tastsoglou, Evangelia; Dobrowolsky, Alexandra (Eds.): Women Migration and Citizenship: Making Local, National and Transnational Connections (Hampshire: Ashgate Publishing): I-36.

Escobar, Arturo, 2008: Territories of Difference: Place, Movements, Life, Redes (New Ecologies for the Twenty First Century) (Durham: Duke University Press).

Fábregas Puig, Andrés, 1997: "Vivir la Frontera Sur de México", in: Bovin; Philippe (Ed.): Las Fronteras del Istmo. Fronteras y Sociedades Entre el Sur de México y América Central (Mexico: Centro de Investigaciones y Estudios Superiores en Antropología Social; Centro Francés de Estudios Mexicanos y Centroamericanos): 343-349.

FitzGerald, Sharron A. (Ed.), 20II: Regulating the International Movement of Women. From Protection to Control (New York: Routledge).

Gardiner, Michael, 2004: "Everyday Utopianism", in: Cultural Studies, I8,2-3 (March-May): 228-254.

Ghorashi, Halleh, 20I0: "From Absolute Invisibility to Extreme Visibility: Emancipation Trajectory of Migrant Women in the Netherlands", in: Feminist Review, 94: $75-92$.

Gordon, Neve, 2002: "On Visibility and Power: An Arendtian Corrective of Foucault", in: Human Studies, 25: I25-I45.

Gregorio Gil, Carmen, 20I2: “Tensiones Conceptuales en la Relación entre Género y Migraciones. Reflexiones desde la Etnografía y la Crítica Feminista”, in: Papers, 97,3: 569-590.

Guevara Bermúdez, José Antonio, 20Iı: "La Nueva Ley de Migración: Una Oportunidad Perdida para Garantizar Derechos", in: Defensor: Revistas de Derechos Humanos, 6 (June): 27-33.

Habermas, Jürgen, 20I0: "El concepto de dignidad humana y la utopía realista de los derechos humanos", in: Revista Diánoia, LV,64, (May): 3-25; at: <http://dianoia.filosoficas.unam.mx/info/20Io/DIA64_Habermas.pdf $>\quad$ (3 November 20I2).

Hernández Joseph, Daniel, 2008: "Política Migratoria y de Control Fronterizo de Estados Unidos hacia México y Centroamérica”, in: Revista Enfoques, 6,008: 193-2I4.

Hobson, John M.; Seabrooke, Leonard, 2007: "Introduction - Everyday IPE: Revealing every day forms of change in the world economy", in: Hobson, John M.; Seabrooke, Leonard (Eds.): Everyday Politics of the World Economy (Cambridge, UK: Cambridge University Press): I-23.
Houtum, H. van; Naerssen, T. van, 2002: "Bordering, Ordering and Othering", in: Tijdschrift voor Economische en Sociale Geografie (TESG), 93,2: I25-I36.

INEGI (Instituto Nacional de Estadística y Geografía), 20I0: "Conociendo... nos todos", in: Informativo Oportuno (Censo de Población y Vivienda), I,2.

INM (Instituto Nacional de Migración); CONAPO (Consejo Nacional de Población); COLEF (El Colegio de la Frontera Norte); SRE (Secretaría de Relaciones Exteriores); STyPS (Secretaría de Trabajo y Previsión Social), 20I2: Encuesta Sobre Migración en la Frontera Sur de México, 2009. Serie Histórica 2004-2009 (México: INM, CONAPO, COLEF, SER, STyPS).

Jolly, Susie; Reeves, Hazel, 2005: Género y Migración. Informe General (Brighton, Sussex: Institute of Development Studies).

Kabeer, Naila, I999: "Resources, Agency, Achievements. Reflections on the Measurement of Women's Empowerment", in: Development and Change, 30: 435-454.

Kabeer, Naila, 2007: "En Busca de una Ciudadanía Incluyente: Sus Significados y Expresiones en un Mundo Interconectado”, in: Kabeer, Naila (Ed.): Ciudadanía Incluyente: Significados y Expresiones (Mexico: Programa Universitario de Estudios de Género, UNAM): 7-33.

Kauffer Michel, Edith F., 2005: "De la Frontera Política a las Fronteras Étnicas: Refugiados Guatemaltecos en México", in: Frontera Norte, I7,34 (July-December): 7-36.

Kerkvliet, Benedict J. Tria, 2005: The Power of Everyday Politics: How Vietnamese Peasants Transformed National Policy (Ithaca, N.Y.: Cornell University Press).

Kerkvliet, Benedict J. Tria, 2009: "Everyday Politics in Peasant Societies (and Ours)" in Journal of Peasant Studies, 36,I (January): 227-243.

Kihato, Caroline Wanjiku, 2007: "Invisible Lives, Inaudible Voices? The Social Conditions of Migrant Women in Johannesburg", in: African Identities, 5,I: 89-IIO.

López Sala, Ana María, 2005: Inmigrantes y Estados: La Respuesta Política Ante la Cuestión Migratoria (Barcelona: Anthropos).

Menjívar, Cecilia, 2008: "Violence and Women's Lives in Eastern Guatemala: A Conceptual Framework", in: Latin American Research Review, 43,3: Io9-I36.

Molyneux, Maxine, 2008: "Reconfigurando la Ciudadanía. Perspectivas de la Investigación Sobre Justicia de Género en la Región de América Latina el Caribe”, in: Mukhopadhyay, Maitrayee; Singh, Navsharan (Eds.): Justicia de Género, Ciudadanía y Desarrollo (Bogota: International Development Research Centre/Mayol Ediciones SA): 47-89.

Morales Meléndez, Víctor Hugo; López Figueroa, Luis Ricardo, I999: "La Política de Inmigración de México. Interés Nacional e Imagen Internacional”, in: Foro Internacional, 39,I (January-March): 65-92.

Naudé, Wim; Santos-Paulino, Amelia U.; McGillivray, Mark, 2009: "Measuring Vulnerability: An Overview and Introduction", in: Oxford Development Studies, 37,3 (September): I83-I9I. 
Oman, Natalie, 20I0: "Hannah Arendt's 'Right to have Rights': A Phiolosophical Context for Human Security”, in: Journal of Human Rights 9:3 (London: Routledge) 279-302

Papademetriou, Demetrios G., 20II: "International Migration: Global Trends and Issues", in: Smith, Rogers M. (Ed.): Citizenship, Borders, and Human Needs (Philadelphia: University of Pennsylvania Press): 13-36.

Parpart, Jane L., 2009: "Choosing Silence: Rethinking Voice, Agency and Women's Empowerment”, in: RyanFlood, Róisín; Gill, Rosalind (Eds.): Secrecy and Silence in the Researcher Process: Feminist Reflections (London: Routledge): I5-29.

Pécoud, Antoine; De Guchteneire, Paul, 2006: "International Migration Border Controls and Human Rights: Accessing the Relevance of a Right to Mobility”, in: Journal of Borderlands Studies, 2I,I (Spring): 69-86.

Petrozziello, Allison J., 2012: Género en Marcha. Trabajando el Nexo Migración-Desarrollo desde una Perspectiva de Género. Guías de Aprendizaje (Santo Domingo: ONU-MUJERES).

Ratha, Dilip; Shaw, William, 2007: South-South Migration and Remittances (Washington: World Bank).

Rodríguez Chávez, Ernesto; Berumen Sandoval, Salvador; Ramos Martínez, Luis Felipe, 20II: "Migración centroamericana de tránsito irregular por México. Estimaciones y características generales”, in Apuntes sobre migración (México: Centro de Estudios Migratorios, INM): I (July).

Rojas Wiesner, Martha Luz, 2002: "Mujeres Migrantes en la Frontera Sur de México", in: Migración: México Entre Sus Dos Fronteras, 2000-200I (Mexico: Foro Migraciones): 93-I03.

Rojas Wiesner, Martha Luz, 20II: "Haciendo Distinciones en la Dinámica Migratoria”, in: Ecofronteras, 4I (January-April): I2-I5.

Rojas Wiesner, Martha Luz; Ángeles Cruz, Hugo, 2008: "Gendered Migrations in the Americas. Mexico as Country of Origin, Destination, and Transit”, in: Piper,
Nicola (Ed.): New Perspectives on Gender and Migration. Livelihood, Rights and Entitlements (New York London: Routledge - UNRISD): I89-245.

Ruiz Marrujo, Olivia, 200I: "Riesgo, Migración y Fronteras: Una Reflexión”, in: Estudios Demográficos y Urbanos, 47 (May-June): 257-284.

Ruiz Marrujo, Olivia, 2004: "La Migración Centroamericana en la Frontera Sur: Un Perfil del Riesgo en la Migración Indocumentada Internacional, Center for U.S.-Mexican Studies"; at: 〈http://repositories.cdlib.org/ usmex/ruiz> (3 November 2004).

Sassen, Saskia, 2003: Contrageografías de la Globalización. Género y Ciudadanía en los Circuitos Transfronterizos (Madrid: Traficante de Sueños).

SEGEPLAN (Secretaría de Planificación y Programación), 2006: Mapas de Pobreza en Guatemala al 2002 (Guatemala: SEGEPLAN).

United Nations (UN), 2009: Trends in International Migrant Stock: The 2008 Revision, CD Rom Documentation (New York: United Nations, Department of Economic and Social Affairs); at: <http://www.un.org/ esa/population/migration/UN_MigStock_2008.pdf> (5 May 20I2).

Verduzco, Gustavo; de Lozano, Maria Isabel, 20II: "Migration from Mexico and Central America to the United States: Human Insecurities and Paths for Changes", in: Truong, Thanh-Dam; Gasper, Des (Eds): Transnational Migration and Human Security. The Migration-Development-Security Nexus (Berlin: Springer): 39-56.

Villafuerte Solis, Daniel; García Aguilar, María del Carmen, 2006: "Crisis Rural y Migraciones en Chiapas", in: Migración y Desarrollo (Primer semestre): IO3-I3O.

World Bank, 2004: Poverty in Guatemala (Washington, DC: The International Bank for Reconstruction and Development/The World Bank)

Zlotnick, Hania, 2003: "The Global Dimensions of Female Migration”, Paper for the Migration Policy Institute, I March 2003; at: <www.migrationinformation.org> (5 October 2004).

Open Access. This chapter is distributed under the terms of the Creative Commons Attribution Non-commercial License, which permits any noncommercial use, distribution, and reproduction in any medium, provided the original author(s) and source are credited. 


\section{Part IV Complexity of Gender:}

Embodiment and Intersectionality

Chapter 11 Masculinities and Intersectionality in Migration: Transnational Wolof Migrants Negotiating Manhood and Gendered Family Roles

Giulia Sinatti

Chapter 12 Intersectionality, Structural Vulnerability, and Access to Sexual and Reproductive Health Services: Filipina Domestic Workers in Hong Kong, Singapore, and Qatar

Thanh-Dam Truong, Maria Lourdes S. Marin, and Amara Quesada-Bondad

Chapter 13 Sub-Saharan Migrants' Masculinities: An Intersectional Analysis of Media Representations during the Libyan War 2011

Maria DeVargas and Stefania Donzelli

Chapter 14 Complexity of Gender and Age in Precarious Lives: Malian Men, Women, and Girls in Communities of Blind Beggars in Senegal

Codou Bop and Thanh-Dam Truong 
 Wolof Migrants Negotiating Manhood and Gendered Family Roles
}

\author{
Giulia Sinatti ${ }^{1}$
}

\begin{abstract}
Men are seldom a topic of concern in migration research as gendered subjects who experience the implications of social justice, for instance in aspects relating to lives in their families such as fairness of representation, consequences of material redistribution, and management of emotions. Economic migrants in particular, who are seen as matching the role of breadwinners and confirming the status of dominant patriarchal men, are a particularly underrated case. Using the experiences of Wolof men who emigrate from Senegal to become the main providers for their families, this chapter questions this assumption by drawing insights from a theorization on 'transnational families', 'intersectionality' and 'masculinity' as developed within migration and gender studies. The chapter discusses how male gender roles become interlocked with other categories, as asymmetries (be they real or perceived) intervene between the migrant and the stay-behind, and as geographic distance forces them to revisit the propriety of arrangements that enable them to enact their gendered responsibility within families. Caught between pressures deriving from their economic and moral obligations towards family and kin on the one hand, and personal aspirations of fitting the part of successful men on the other, the ethnographic research presented in this chapter shows that migrants engage in an emotional journey that may challenge, rather than confirm, their expectations of 'hegemonic' masculinity.
\end{abstract}

Keywords: family relations, gender relations, hegemonic masculinity, intersectionality, manhood, men, Senegal, transnational migration, Wolof.

\subsection{Introduction}

The study of transnational families has become an established area within the field of migration studies. This literature has increasingly brought to the fore a concern for the gendered nature of migration and transnational relations and the implications for equality and social justice, for instance raising questions about the effects of migration on the empowerment or marginalization of migrant or stay-behind women. Transnational families are an important socializing institution where gender roles are constructed and hierarchies of authority and power defined. Yet research on transnational families suffers from two major shortcomings: it focuses predominantly on the experiences of women, and it overemphasizes the role of

1 Dr. Giulia Sinatti is a Research Fellow at the International Institute of Social Studies, Erasmus University of Rotterdam, The Netherlands. culture, identity and emotional factors to the detriment of more structural factors that shape intra-family inequalities in a transnational sphere. Transnational families are made up of individuals who succeed in maintaining a sense of unity by upholding kinship relations across geographic distances. As well as being a source of identity, transnational families also provide welfare and mutual support to their members (Bryceson/Vuorela 2002; Chamberlain/Leydesdorff 2004). As socially ascribed gender roles are bound to be redefined in transnational families, migration introduces new inequalities between family members, and these are often interwoven with gender lines and require both women and men to adjust to them in the transnational family space. This chapter investigates how gender and other sources of social inequality in families that result from the asymmetries generated by migration mutually shape each other and the power dynamics that they entail. It applies the construct of 'intersectionality'. This refers to how social inequali- 
ties are shaped by gender differences as well as by the interaction between gender differences and other socially and culturally constructed categories such as race, class, ability, and age. The focus is on men and masculinities as largely under-researched issues in existing work on transnationalism and gender. Specifically, this chapter attempts to answer the question of how male migrants engaging in transnational migration negotiate their aspirations to fit the patriarchal norms expected from men, and how this is reflected in daily practices with family members. An intersectional approach can be beneficial to the study of transnational families. It allows the fluid and plural nature of masculinities to be grasped, masculinities that are questioned and redefined at the intersection of unequal power relations in multiple spheres.

There are various reasons why Senegalese migration is an exemplary case study for the analysis of the issues outlined. Firstly, transnational migratory practices and the establishment of transnational families are common among the Senegalese. Emigration from Senegal involves approximately one-tenth of the country's population, ${ }^{2}$ and most families have at least one member who is living abroad. Leaving the family behind is, in fact, often a deliberate choice: a circumstance that is at once a reason for and cause of the strong transnational character of Senegalese migration. Migrants from Senegal remain deeply attached to their country of origin, where they can uphold family and other social ties and make regular visits in the hope of returning permanently one day. Secondly, the emigration of largely unskilled labourers seeking their fortune overseas most often results in unequal access to resources between and within families. This is particularly striking in the case of intercontinental migration, as Senegalese migrants to France, Italy, Spain, or the United States are able to remit significant resources across borders that make a difference in the livelihoods of receivers back home. Thirdly, despite feminization trends being on the rise, emigration remains a predominantly male affair in Senegal. Typically, Senegalese emigrants are young and unmarried Wolof men who migrate alone and later use their trips back home to choose a wife (sometimes more than

2 A policy document issued by the Government's Ministry for Senegalese of the Exterior in 2006 indicated an unofficial estimate of the Senegalese diaspora of over one million people worldwide. For the same year, projections based on the latest population census estimated the total national population at II,343,328 people (see: $<$ http://www.ansd.sn/publications/annuelles/SES_2006. pdf>, accessed I8/05/20I2). one) and create families of their own. Successful migration will allow them to establish with time a separate household independent from their birth household.

This chapter is based on research conducted between 2004 and 2010 with a broader concern for the mobility patterns and aspirations of Senegalese migrants between their home country and Italy. A body of data gathered from participant observations conducted in the homes of Senegalese immigrants in Italy, in addition to direct visits to their families in urban and rural areas of Senegal, ${ }^{3}$ provides new qualitative insights that are reflected upon separately here. Above and beyond the initial research design, the transformation of men's gender identities through migration and the implications for understanding masculinity as a social construct emerged throughout fieldwork as a significant issue. Gender roles and identities are more easily observed through everyday practices than openly and profusely spoken about, and extensive multi-sited observations provided the most valuable insight into migrant men's experiences of masculinity. Observations and informal talk with respondents about the meanings of masculinity facilitated the building of trust and confidence ahead of supplementary in-depth qualitative interviews conducted with selected Senegalese migrants. ${ }^{4}$ The experiences of these migrating men add to, as well as challenge, the existing body of knowledge that emphasizes aspects of rational calculation in the male breadwinner role, devoid of other aspects such as emotional gains and losses. Criteria of reasoned choice ensured that the sample covers various male profiles in terms of their social positionings in Senegal. ${ }^{5}$ Rather than assessing the frequencies of given phenomena in a representative way, such a sampling strategy allows trends common to all cases within the sample despite its di-

3 Research focused on two regions of northern Italy (Lombardy and Veneto) where Senegalese immigrants are highly concentrated. In Senegal, the families of $3 \mathrm{I}$ migrants were the object of multiple visits in the Dakar region, as well as in smaller cities and rural villages in the regions of Diourbel, Kaolack, Louga, Saint Louis, and Thiès.

4 Interviews were conducted with 79 migrant men. In addition to this data, another I2 interviews with women migrants ensured comparison on gender-sensitive issues and further interviews with nine key informants were used to validate preliminary findings during the progress of research. It should be noted that the data was collected with a deliberate exclusive focus on heterosexual masculinities, and on transnational families in a hetero-normative context. 
versity to be identified, as well as focusing on how specific structural factors of inequality may interact with gender differences in outlier cases.

In order to capture the experience of masculinity among male migrants, this chapter uses a theoretical framework for the understanding of transnational families that does not take gender roles as a fixed reality, but maintains openness to the transformation of gendered relations of power and hierarchy and how they affect men as gendered social beings. This framework, outlined in the following section, is constructed by combining insight from theorization on transnational family relations with theories of intersectionality and masculinity. The two subsequent sections present an analysis of the research through this theoretical lens. The importance of inequalities in access to material resources and the resulting power disparities between migrant breadwinners and their families emerges in a strikingly uniform way across the research sample as a source of confirmation for their roles as hegemonic and patriarchal men (II.3). This evidence is contrasted with an illustration of other factors that challenge such visions of masculinity and manhood (II.4) and gives an insight into some of the individual responses to this challenge adopted by migrants. Concluding remarks are offered in the final section (II.5).

\subsection{Framing Migrant Men: Transnational Families, Intersectionality, and Hegemonic Masculinity}

Kinship and its related social institutions are often at the centre of studies of transnational migration. Scholars inspired by the New Economics of Labour Migration theory, for instance, identify households as important sites of production in which migration decisions are taken as a collective strategy that allows the sharing of economic risks between members. The debate about migrant transnationalism, moreover, has been interested in families as sites more for cultural reproduction than for material production (Levitt/

5 On the basis of social class and occupation prior to migration, social caste, affiliation to the main Senegalese Islamic brotherhoods (Muridiyya, Tijaniyya, Layenne, Qadiriyya), as well as other dimensions that could influence respondents' status as males (such as rural/ urban origin, young/mature age, with/without independent family, brief/long migration experience).
Glick-Schiller 2004). A substantial corpus of work currently exists that investigates the reproduction of cultures and identities in families through the transnationalization of rituals (Al-Ali 2002; Gardner/Grillo 2002) and emotions (Chamberlain/Leydesdorff 2004; König/de Regt 20IO; Svasek/Skrbis 2007; Svasek 2008; Yeoh/Huang/Lam 2005).

Literature on transnational families has been particularly sensitive to calls inviting the incorporation of a gender dimension to analysis (Fouron/Glick-Schiller 200I; Mahler/Pessar 200I, 2003, 2006; Truong/ Gasper 2008). Suggestions for research were made on how "gender as it is lived across the borders of nationstates" may "sustain gender divisions, hierarchies and inequalities" or "help build more equitable relations between men and women" (Fouron/Glick-Schiller 200I: 540). Similarly 'gendered geographies of power' (Mahler/Pessar 200I) have been advocated in order to grasp how, in transnational spaces, the reconfiguration of gender categories can challenge or fortify related hierarchies. Much of the resulting research investigating changes in gender relations within transnational families suffers, however, from a major limitation. It overwhelmingly concentrates on the effects of migration on the marginalization or empowerment of women, with research variously addressing: the effects of female migration on power dynamics within gender relations (Dannecker 2005; Marques/Santos/ Araujo 200I; Purwani/Williams 2005); transnational care chains and the strains of transnational motherhood on migrating women (Aranda 2003; Hondagneu-Sotelo/Avila 1997; Parreñas 200I \& 2005; Ryan/ Sales/Tilki/Siara 2009); the influence of gender on remittance behaviour and development outcomes in the homeland (Dannecker 2009; Nyberg Sørensen 2005; Wong 2006); and the effects of transnational migration on women who stay behind (Buggenhagen 200I; de Haas/van Rooij 20I0; Lo 2008; Lukasiewicz 20II).

The limitation outlined above may be overcome by focusing on alternative male experiences and calling for a deeper enquiry into the relations between migration, transnational families, and changing masculinities. This emerging area of research may benefit from the adoption of theories of 'intersectionality' and 'hegemonic masculinity' that can help explain how manhood is constructed and masculinity negotiated within transnational families and provide an analysis that is sensitive to interactions between different sources of social inequality.

Originally coined by legal scholar Kimberlé Crenshaw (I99I), the concept of 'intersectionality' has gained widespread success within feminist studies, 
where it is used as a conceptual tool for the analysis of gender as a multi-dimensional phenomenon where multiple axes of identity (gender, race, class, ability, age) interact on multiple and often simultaneous levels, creating a system of oppression that reflects the 'intersection' of multiple forms of discrimination. Though intersectionality has a long historical heritage in the struggle against slavery and classism, the concept was renovated by feminist scholars (more precisely black feminist scholars in the United States) to investigate mechanisms of discrimination against women of colour and indigenous women as groups that are disadvantaged, excluded, or oppressed. Given that in a situation of social inequality men are often implicitly assumed to be the ones holding privilege and power, research applying intersectionality to men is relatively rare (Hearn 2009; Hurtado/Sinha 2008). Intersectionality might nonetheless be useful to study relationships of dominance and oppression that affect men and women at intra- and inter-group levels.

Connell's (1995) work on hegemonic masculinity appears a useful tool for exploring male gender identity as being intersectional. Hegemonic masculinity is defined as "the currently most honoured way of being a man, it require[s] all other men to position themselves in relation to it, and it ideologically legitimate[s] the global subordination of women to men" (Connell/Messerschmidt 2005: 832). Connell conceptualizes masculinity in plural terms, as a multiple construct where different notions of manhood are defined in relation to hegemonic masculinity. Hegemonic masculinity is therefore an essentialist normative ideal and socially legitimated dominant patriarchal model, in relation to which counter-hegemonic masculinities-including subordinate, complicit, and marginalized masculinities-are defined. Connell recognizes that hegemony is "a historically mobile relation" (1995: 77); nonetheless, in reality not only the relation between hegemonic and other masculinities but also dominant models of masculinity are best conceptualized in fluid terms. This allows it to be recognized that alternative and even conflicting notions of manhood may be variously combined within hegemonic masculinity itself.

'Intersectionality' and 'hegemonic masculinity' are both based on the assumption that gender relations and hierarchies are constantly negotiated and subject to change. Moreover, both concepts share an interest in understanding how such change is embedded in hierarchies of power arising from specific contexts and situations. Applied to the study of transnational migration, both concepts can advance current debates.
Intersectionality is a means of overcoming a culturalist bias that has placed greater emphasis on "the identity orientations and the cultural traits of migrants, and on social interaction within transnational social spaces" and has neglected the economic basis of transnationalism, so that "social inequality and fragmented social spaces have not received the analytical attention they deserve" (Bürkner 20I2: I9O). Intersectionality can help bring into being an analysis that incorporates Mahler and Pessar's 'gendered geographies of power' in the study of transnational family relations, and help the understanding of "how the social constructs of masculinities and femininities shape migration decisions and experiences" and how "the social construction of migrants' identities [...] connects a variety of domains in social lives - sexuality, gender, work, home maintenance and child care, institutional life, domination and resistance" (Truong/Gasper 2008: 290). Reference to hegemonic masculinity, moreover, allows the repercussions of transnationalism on gender relations to be studied from a male perspective, given that work analysing the relation between masculinity and transnational migration is still relatively rare (Broughton 2008; Datta/McIlwaine/ Herbert/Evans/May/Wills 2009; Elmhirst 2007; Malkin 2004; Monsutti 2007; Osella/Osella 2000; Pribilski 20I2). Transnationalism does nonetheless "offer the potential for processes of extension of some men's transnational intersectional power" (Hearn 20II: 99), processes which deserve to be studied and which "may take the form of non-responsibility, of surveillance and destruction, of loss of expected security/privilege" (Hearn 20II: 99). This requires the investigation of how masculinities are negotiated as people move across borders while maintaining ties with their families of origin in a transnational space, and how essentialist understandings of hegemony and patriarchy may be challenged, confirmed, and transformed.

\section{3 'Breadwinning' and Other Markers of Manhood for Senegalese Migrants within their Transnational Families}

Families constitute a central pillar of Senegalese society and their importance is not wavering in the face of the increased geographic dispersal imposed by intercontinental migration. Family values, in fact, are found to hold strong even among the Senegalese diaspora (Riccio 2008). Patriarchal and matrilinear in 
structure, families in Senegal include not only parents and siblings or spouses and children, but stretch to include other members of the extended kin such as grandparents, aunts, uncles, cousins, and nieces and nephews. It is common for a family living in the same compound to be made up of various nuclear households. Following the principle of patrilocality, for instance, upon marriage the wife traditionally moves into her husband's home, which involves living with in-laws. The line that separates kin from strangers, moreover, is largely a matter of self-perception: as an enactment of the Wolof saying dëkkaale bu yàgg, mbokk la (tr.: living together for a long time turns neighbours into relatives), the extended family may also include significant others who are not related through blood and kinship. As synthesized by Bass and Sow, marriage, consanguinity, kinship ties, and being associated with a shared surname are at the basis of family affiliation; nonetheless, "extensive shared social experience may also be sufficient to provide both kin and household membership" to outsiders (2006: 9I).

This model of family operates as an economic system of welfare and exchange: it is along the lines of extended family bonds that distribution and redistribution of wealth is organized. The Wolof word mbokk, indicating those related through ties of blood and kinship derives from bokk, which means 'to share' or 'to have in common'. Although Islamic brotherhoods have also played a crucial role in the establishment of Senegalese migration in Italy and elsewhere, families are always indicated by respondents as being at the core of male providers' decisions to emigrate as a household strategy, and as being the fulcrum of transnational connections and practices upheld throughout migration (Sinatti 20II). ${ }^{6}$ Migration is followed by striking asymmetries between migrants

6 A copious literature exists on the links between Senegalese transnational migration and membership in Islamic brotherhoods. The Muridiyya in particular undoubtedly played a major role in the initial phases of Senegalese migration to Italy, where early migrants relied on the brotherhood's tight networks and were inspired to work hard as a means of achieving heavenly blessing. With the progressive affirmation of Italy as an established migrant destination, however, the centrality of Murid affiliation has been diminishing: the presence of other brotherhoods has gained importance, and the arrival of young urbanites joining the ranks of earlier Murid migrants has contributed to a secularization of Senegalese immigration in this country and to the emergence of different ways of being transnational (Riccio 200I; Sinatti 2008). and the stay-behind in terms of access to mobility, capital, and other resources (Bryceson/Vuorela 2002; Carling 2008). As has been suggested by Levitt and Glick-Schiller, "many migrants gain more social power, in terms of leverage over people, property, and locality, with respect to their homeland than they did before migrating. It is this complex intersection between personal losses and gains that any analysis of power within transnational social fields must grapple with" (2004: IOI3-IOI4). This imbalance is at the basis of an economics of exchanges that take place between family members, in which migrant men are invested with important responsibilities towards their relatives in Senegal. Remittances cover the everyday basic needs of many Senegalese households (Diagne/Rakotonarivo 2010) and migrants interviewed for this research all confirmed that they regularly send money home: ${ }^{7}$

"When you have a family you're no longer alone. You can't only think of yourself and your own needs, but you have to think also of them. [...] The way I see it, when you have a family you no longer live for yourself. A part of you remains yours, but another part of you is no longer yours" (Bathily).

"It is a question of kóllëre ${ }^{8}$, there are certain people that I cannot forget" (Makhtar).

In addition to their economic and instrumental function, remittances to family members also have an affective function, as shown in research also among other West African transnational migrants (Åkesson 20II; Carling 2008). Evidence from other regions of the world, moreover, shows that for male migrant breadwinners gendered aspects are also relevant, and that there is a relationship between economic support or gift-giving and constructions of manhood (Johnson/Stoll 2008; Malkin 2004; Osella/Osella 2000; Pribilsky 20I2). Work and money play an important part in the practice of migrants' male masculinity: fulfilling the breadwinner role allows respect and status to be gained from the migrant experience. Interviewees in this research often mentioned the hardships of migration, but they also unanimously indicated the need to work and support their families as the drive allowing them to overcome such daily difficulties:

7 All interviewees quoted or mentioned in this chapter have been given fictitious names in order to preserve their anonymity.

8 Kóllëre is a Wolof word indicating loyalty in relationships. It refers to bonds that may even extend beyond kin, for instance between families that have been close for various generations. 
"In Italy we live and work in hard conditions, but we have to goorgoorlu. It is for the sake of our families that we do this" (Adama).

The term goorgoorlu indicates how close the link is between masculinity and work: as a verb it means 'to get by', as a noun it refers to people in the informal sector surviving on occasional jobs. Yet goor means 'man' and by extension goorgoorlu also means 'behaving like a man'.

Alongside other key ritual moments in a man's life (circumcision, pilgrimage to Mecca, etc.), taking responsibility firstly for one's family of origin and then for one's independent household are seen as central steps in transition to manhood and in later progression towards more mature visions of masculinity. There is a diachronic side to the construction of masculinity over time that also shapes economic responsibilities towards the family in different ways throughout migration. Upon reaching adulthood, sons are expected to contribute to the well-being of their families of origin (Antoine/Sow 2000). Fathers are seen as having to be repaid for having brought their sons up with solid moral values and religious principles. ${ }^{9}$ Obligation is particularly strong towards mothers, especially in polygamous households where the father's responsibilities over numerous wives and children often require women to integrate family revenues. Migrants therefore feel compelled to provide for the well-being of their parents and siblings:

"I am responsible for the whole of my family. In Senegal, if I have a mag bu jigéen [elder sister], I am responsible for her because I am a man and she is a woman, even if she is older than me. I am responsible for her, my brother, my wives and children, my mother ... everybody, the whole family" (Makhtar).

With a first wife living with his elderly parents in his village of origin and a second wife and children settled in Dakar, Makhtar brings evidence of how, although all migrants have financial responsibilities towards the family, the nature and extent of provisions depend on a migrant's specific positioning in one or more households. While Makhtar has sole responsibility for the well-being of the urban household, he also feels obliged to contribute to the rural one where his parents and first wife live.

Dispensing monetary and material support to family members through migration is not only a response to economic and moral obligations held by all mi-

9 Respondents often spoke of fulla ak fayda, which indicate firmness of character and determination, as a core inheritance that is passed from father to son. grants, but is also a marker of manhood. Remittances are a source of virtue and prestige, a means for the migrant to assert himself as a benevolent, honourable, and respected man in his sending community. Unequal transnational distribution of resources between migrants and the stay-behind leads to relations that are frequently fraught with tensions (Carling 2008; Riccio 2008) and, regardless of the situation of need of the family back home, cases were frequently observed in which migrants were put under considerable pressure by constant demands for support beyond the monthly dépense ${ }^{10}$ owed to the households over which they have direct responsibility. The rewards associated with remittances and other transfers in terms of avowing hegemonic visions of the patriarchal man nonetheless lead most migrants to speak of their efforts as leading to personal gratification and fulfilment.

Migration, moreover, has become a means for Senegalese men to access adulthood and that can shape their further opportunities to progress along the socially legitimized steps leading to the apex of mature manhood. This requires a man first to access marriage (Carling and Carretero 2008), then claim independent status for his own household while still under his father's roof (beru), relocate the new household to a separate roof (sanc kërëm), and eventually become the established head of an extended family (boroom kër). Similar findings from research in Kerala indicate that " $[\mathrm{m}]$ igration may accelerate an individual's progress along a culturally idealized trajectory towards mature manhood" (Osella/Osella 2000: II8). The case of Yoro and Talla is an example of how migration can offer a shortcut in this progression. They left Senegal when still under eighteen by forging their dates of birth in order to be eligible adults for the tourist visas that they later overstayed. Despite being de facto still minors, in their home families they were already praised as responsible young males, whereas some of their elder brothers struggling to make ends meet while they pursued university education in Senegal were frowned upon.

In a similar way to how Yoro and Talla succeeded in overcoming signifiers of manhood with relation to age, migration can become a means to break through

10 The dépense is the fixed amount constituting the core of remittances transferred by a migrant, to which extra transfers and gifts may be added with greater flexibility and variation. The dépense is calculated in advance on the basis of the average costs of running the household for which the migrant may be fully responsible or simply contributing to. 
social categories such as caste and class. Migrant grooms belonging to the lower social castes of Wolof society have higher chances of marrying upward, outside their own caste. ${ }^{11}$ Birame, instead, was able to marry cutting across categories of social class. A simple and illiterate man of rural origin who used to work in Senegal as a boroom sarret (horse and cart driver), he would not have stood a single chance of meeting a woman of urban middle-class background willing to be his bride. Against these odds and after having succeeded in building a house in a prominent neighbourhood of Dakar thanks to many years of lowskilled factory work as a transnational migrant, a charming and educated young lady became his second wife. The lure of achieving higher standing in terms of social class was evident as Birame declaimed the attributes of his new spouse. His migrant peers, however, heavily criticized his choice and foresaw troubled relations lurking ahead with this new wife, whose middle-class expectations they believed he would be ill-equipped to anticipate and manage.

In a country offering grim opportunities for employment at home, migration is seen as a valuable avenue that can allow caring for parents and siblings, moving forward in an ideal progression of manhood, and more broadly advancing one's social standing. Over the last decades Senegal has experienced a growing erosion of patriarchal control over household dependants in particular in rural areas, where neo-liberal economic reforms introduced in the mid-r980s made it more difficult for rural livelihoods to rely solely on cash-crop income and pushed women into petty trade, thus undermining male provider status (Perry 2005). Migration has therefore become established as a means for men to restore their role as economic providers and principal breadwinners, and thus reaffirm their masculinity in this sphere. Migration is nowadays central to people's images of the 'good life' and migrants are celebrated in popular culture as veritable national heroes. However, as argued next, transnational living may also challenge masculinity in other spheres.

11 Senegalese society among the Wolof (and other ethnic groups such as the Sereer and Toucouleur) is organized into a hierarchical caste system on the basis of the division of labour within society (Diop 1985). The géér represent the nobles, the ñeeño are people of caste, and the jaam are slaves and their descendants. Surnames are an indicator of people's belonging to one or the other group and such traditional societal divisions remain influential.

\subsection{Challenges to Manhood and Emerging Masculinities in the Transnational Family Sphere}

The imaginations of people back home contrast sharply with migrants' own experiences of day-to-day existence in countries of destination, where Senegalese men join the ranks of immigrant minorities and occupy the bottom ranks of the labour market as workers in low-skilled and precarious jobs. In Italy, they mainly engage in blue-collar employment in the industrial sector, in odd jobs in the services sector, and in agricultural labour, often with temporary or seasonal contracts. While most Senegalese immigrants in Italy were engaged in humble jobs before leaving Senegal, their social advancement at home thanks to migration makes them ill-equipped to accept that their social condition will remain low in the country of immigration. This feeling is even stronger in the exceptional cases of individuals who experience significant downward social mobility upon arriving in Italy, after having given up socially valued clerical or teaching jobs in exchange for the lures of migration. Exclusion and oppression along the lines of class and ethnicity in the new country of residence are experienced by all migrant men as a challenge to their masculinity. Against such challenges, economic accomplishments in Senegal become surrogates allowing migrants to restore in the public eye their roles as hegemonic men, at least at home. This is evident, for instance, in the symbolic meanings associated with real-estate investments in housing (Sinatti 2009), which are the first investment priority for any migrant who is not yet a home-owner and which are seen as symbolizing economic success as well as migrants' accomplishments as respected husbands and fathers:

"In Senegal [...] we are all keen on inviting each other in our own homes. It's a form of competition, because we all want to show our friends how we live in our families, how we behave with our families, our family environment, in what ways we have invested in our houses. We want to show our investments and what we have managed to do" (Diadié).

Through the celebration of money and economic accomplishments Senegalese migrating men defend patriarchal roles and demonstrate a hyper-masculinity that portrays them as victors over adversity and abundant providers (Datta/McIlwaine/Herbert/Evans/ May/Wills 2009: 856). In their countries of immigration, however, additional factors combine to threaten hegemonic roles. In the living quarters that they most often share with other co-nationals they are forced to 
perform a number of tasks and chores that are traditionally reserved to women: taking care of the cooking, laundry, and housework is demeaning. These aspects are not publicly vented at home, but may constitute a cause for complicity with wives or mothers:

"My wife gives me cooking tips on the quiet. When I am in Senegal, though, I wouldn't be seen dead inside the kitchen by other people" (Gallaye).

In the flat shared by Gallaye with other urbanite immigrants like himself, it is not uncommon to observe appreciation from other men of his cooking skills, usually followed by sniggers about the contents of his weekly phone conversations with his wife. Intimate relations are in fact a matter that is not overtly spoken about, as this is seen as unmanly. Among migrant men of all backgrounds this taboo rarely falters, as was evident from the reactions triggered by a middle-aged rural migrant with an established household of his own in Senegal who was observed publicly declaiming the virtues of a potato peeler that he had bought as a gift for his wife. Ngouda later confided that migration made him a better husband, as he had become more understanding of the difficulties and needs that his wife faces as a woman. This gift to her testified his love and understanding of the strains of a woman's daily chores.

Challenges to established gendered roles may lead to greater intimacy and mutual appreciation; however, handing over to others the family roles conventionally performed by the head of household can also force migrating men to redefine their masculinity in new ways. Transnational living particularly places under stress those legitimized roles of patriarchal men that hinge on daily social interactions with others within the family. In Senegal, the boroom kër is consulted regarding the regulation of family affairs, ranging from the education of children, the choice of spouses, the resolution of family disputes, to the organization of family ceremonies (Diop 1985: 178). Although the advice dispensed is not necessarily binding for the enquirer, nonetheless respect for the virtues attributed to this hegemonic patriarchal figure at the apex of his 'career' ensures that he be consulted. Respect and obedience are due to the boroom kër in the name of a legitimized moral authority based on gender, age, experience, and wisdom. Among migrants, however, non-presence challenges such processes and requires manhood to be constantly renegotiated in ways that can compensate for lack of daily face-to-face interaction. How new ways of expressing loyalty, intimacy, and love restructure such processes in a transnational space has emerged as an area of inquiry of considerable significance for migration studies with an interest for how "conventional relationships between husband and wife, parent and child or amongst siblings can be subjected to substantial revision" (Bryceson/Vuorela 2002: I6). Lack of day-to-day interaction means that migrants are no longer immersed in the intricate daily dealings of their extended families. Instead, they depend on others to brief them in the hope of obtaining sufficient information for them to formulate such advice. This often turns the tables, resulting in others advising the migrant on the advice he should be giving and ultimately forcing the migrant to entrust others with the fulfilment of his obligations. Migrants build trust relationships with relatives as they share or fully delegate decision-making with fathers, mothers, wives, siblings, or children, depending on the family structure. Although this may lead to greater complicity and equity in such interpersonal relations, it nonetheless also results in the migrant's own male authority being diminished. In particular, those with a short migration history who are still young and unmarried (and as a result more easily exposed to economic pressures from relatives back home) struggle to find ways of affirming their own position as men in their families beyond the breadwinning role. A young migrant with a relatively affluent family in Dakar spoke of his own situation as being not so different from that of most other migrants with less fortunate backgrounds than himself:

\footnotetext{
"Everybody considers us a reservoir of wealth. Economic support is the first thing they delegate to you. [...] The biggest frustration of the Senegalese immigrant is this role given to him by the family back home. We are like milk-cows. Immigration has cancelled any other role or place for us, it has wiped out our participation and has reduced it to a mere economic role. I hand out the dough and beyond this, I don't exist" (Moussa).
}

Many, like Moussa, feel exposed to exploitation. The practice of mbaraan (tr.: taking advantage of someone) used to the detriment of migrants has in fact become so well-known that the word has come to indicate also the person who is victim (Nyamnjoh 2005: 302).

In some spheres, migrating men feel that their absence simply cannot be replaced. For more mature migrants who have already formed a family of their own, decisions regarding children and distant parenting, for instance, are often a matter of great concern. Migrant fathers take strongly to heart the education of younger generations: 
"My children back home are growing up. I need to go home and supervise them" (Selle).

"As an emigrant in Italy it is too difficult to give our sons a basic education. We are losing ground. Without my presence, my wives are too soft" (Bara).

Among those who are closely affiliated to Islamic brotherhoods and value the importance of religious upbringing, this is considered the children's essential heritage and in absence of the head of household it is feared to be inadequate, particularly for boys:

"When the father is away, an important thing is missing. Children are brought up badly if their father is not present, because the first thing in a child's education is religion" (Laye).

These interviews confirm that migrating men feel that authoritative fatherhood is threatened when they are far away, and that the issue of children staying behind raises feelings of anxiety and emotional unrest in the migrating parent (Orellana/Thorne/Chee/Lam 200I). Against the recognized risk of losing time-honoured moral virtues and values, some transnational fathers take pride in the fact that as migrants they can offer their children better opportunities, for instance through access to formal education and schooling. In addition, migrants explore new ways of exercising fatherhood that can respond to new challenges deriving from the fact that "[i]ntergenerational lifestyle conflicts common to families everywhere may be more marked in transnational families" (Bryceson/Vuorela 2002: I3).

As a transnational father, Aliou offers a striking example of some of the creative ways adopted by a migrating parent in response to the broadening intergenerational gap between himself and his children. Having migrated to Dakar with his family from a small village in inner Senegal, and being convinced that moving to the city would offer his family a life of higher standing, Aliou later migrated to Italy, where he had spent twelve years in precarious employment in factory work as a welder. In between his intermittent presences at home, his children grew up as part of an urbanite generation in the city. When the author visited his home in Senegal, his teenage elder son was carrying a PlayStation in his hands that he presented with pride. This touching and amusing image brought to mind the other side of the story as told by Aliou in Italy, who had received a specific request for this toy that had to fit the make and model en vogue. It had taken Aliou a big effort to acquaint himself with the market so as not to disappoint his son's expectations and he had taken on such attentiveness to detail wholeheartedly as a new way of expressing his fa- therly care. This scenario clashed strongly with the austerity and integrity associated with the discipline and control that characterize visions of hegemonic masculinity that Aliou and those of his generation most likely experienced during their childhood with respect to their own fathers.

In a context in which neo-liberal economic reform and decline of rural livelihoods are reducing men's economic hold over their households, traditional visions of hegemonic masculinity have long been subject to erosion in Senegal. Migration and its economic returns have become viewed by men as a means of reconquering their dominant position. As migrants' multi-local lives straddle different localities in the countries of origin and of residence, however, they are presented with varying power over different facets of masculinity. Whereas their role as main breadwinners and providers for their families is affirmed, migration makes them lose ground on other important sources of respect and authority associated with hegemonic masculinity, and forces them to invent new, alternative masculinities in different spheres. Masculinity, in fact, not only changes in progressive steps during a man's lifetime, but transnational migrant men are also called to perform different masculinities with different audiences (their families, other migrants, their local communities) that may differ significantly from the hegemonic ideal that originally encouraged them to migrate.

\subsection{Conclusion}

This chapter has challenged the notion of men as a unitary category of social power. By extending the concept of intersectionality to study the experience of Senegalese men migrants as breadwinners, transnational families were analysed as sites where social interactions can reproduce hegemonic and dominant masculinities, whilst also challenging and questioning them. An intersectional understanding of family relations is beneficial to migration studies, as it allows researchers to grasp how masculinities may be redefined as people move across cultural, social, and national borders, and as they encounter and cope with different regimes of power at the intersection of other social categories. The stories illustrated here show how migration is clearly shaped by understandings of specific male and female roles and how, in turn, migration is a vehicle for the transformation of hegemonic ideas about masculinity. Just as authoritative masculinity can be threatened when relating to 
wives, children, and other relatives at a distance, so caring about loved ones staying behind can cause anxiety and unrest among migrating men. After all, for these men, migration was a strategic choice to improve the well-being, at present and in the future, of the family. While they may be fulfilling this role economically, they remain vulnerable emotionally to the implications of fully exercising their gendered roles at a distance, and thus to the possibility of losing part of their socially learned authority.

Transnational family formations have the potential to deeply challenge aspirations among migrating men of fitting the ideal of hegemonic masculinity. An intersectional perspective on masculinity reveals how gender identities are fluid and multifaceted, as breadwinning transnational migrants experience and renegotiate their role as men within their families. Work, money, remittances, and gifts are important elements in the distant construction of hegemonic masculine identities, whilst other everyday practices among migrants show that transnational migration forces Wolof society to rethink social and cultural beliefs about males and females and the differences between them. Understanding these processes requires a plural and fluid notion of masculinity that is in line with Lindsay and Miescher's (2003) analysis of modern sub-Saharan African masculinities. These authors suggest that there may be conflicting visions of what should be masculine behaviour and that essentialized ideals of hegemonic masculinity may not apply indiscriminately in all spheres. The findings of this chapter confirm this observation. Rather than fitting a unitary construct of masculinity, migrants develop multiple masculinities across (and within) time and space. As was shown above, the renegotiation of masculinities is a constantly ongoing process that becomes even more complex in transnational spheres. These, in fact, call for the redefinition of family relations and male and female roles in work, care, and authority that intersect with gender, age, ethnicity, and class. The requirements imposed by transnational family living demand that, out of these complex intersections, men negotiate their status within the family and elaborate alter- native masculinities, incorporating them into dominant patriarchal and hegemonic visions.

The findings of this chapter confirm the usefulness of intersectionality as a key concept applied to the study of male experiences in migration that allows more fine-grained differences to be revealed than widespread interpretations of migrant men as 'modern-day heroes' who save their families and nations from poverty and debt. Combined reference to intersectionality and hegemonic masculinity provides conceptual tools that result in a more nuanced and varied account of migrant masculinities, attentive to gendered hierarchies and power differentials. A broader application of intersectionality is therefore proposed here beyond the field of women's studies, in which it is predominantly used to study men also, and more broadly to study how gender relations are affected and transformed in transnational spheres. It was shown above that migrating men and masculinities may be better understood through an intersectional lens and it was suggested that future research agendas should look comparatively at how the same intersectionalities may shape different outcomes that are specific to women and men. Feminization trends of migration, for instance, may be accompanied by new transformations in gendered divisions of labour, responsibility, and authority that could be further investigated: while there already is research evidence of the ways in which such transformations may be empowering for women, much less is known about the kinds of demands and adaptations that they may require on the part of men. In addition, it would be useful to investigate how and when innovative features of masculinity adopted by transnational migrant men are received by non-migrant men in the country of origin. This would not only allow the exploration of how different masculinities may relate to each other, but also the investigation of the implications of migration in relation to broader social transformations beyond the family sphere, such as the establishment of new gender norms and relations in the sending country at large. 


\section{References}

Åkesson, Lisa, 20II: "Remittances and Relationships: Exchange in Cape Verdean Transnational Families", in: Ethnos: Journal of Anthropology, 76, 3: 326-347.

Al-Ali, Nadje, 2002: "Gender Relations, Transnational Ties and Rituals among Bosnian Refugees", in: Global Networks, 2, 3: 249-262.

Antoine, Philippe; Sow, Oumar, 2000: "Rapport de Genre et Dynamiques Migratoires”; in: Bozon, Michel; Locoh, Thérèse (Eds.): Rapports de genre et question de population (Paris: Ined): II2-I23.

Aranda, Elizabeth M., 2003: "Global Care Work and Gendered Constraints. The Case of Puerto Rican Transmigrants", in: Gender and Society, I7, 4: 609-626.

Bass, Loretta E.; Sow, Fatou, 2006: "Senegalese Families: The Confluence of Ethnicity, History, and Social Change”, in: Oheneba-Sakyi, Yaw; Takyi, Baffour K. (Eds.): African Families at the Turn of the Twenty-First Century (Westport: Praeger): 83-IO2.

Broughton, Chad, 2008: "Migration as Engendered Practice. Mexican Men, Masculinity, and Northward Migration”, in: Gender and Society, 22, 5: 568-589.

Bryceson, Deborah Fahy; Vuorela, Ulla (Eds.), 2002: The Transnational Family: New European Frontiers and Global Networks (Oxford: Berg).

Bürkner, Hans Joachim, 20II: "Intersectionality: How Gender Studies Might Inspire the Analysis of Social Inequality among Migrants”, in: Population, Space and Place, I8, 2: I8I-I95.

Buggenhagen, Beth Anne, 200I: "Prophets and Profits: Gendered and Generational Visions of Wealth and Value in Senegalese Murid Households", in: Journal of Religion in Africa, 3I, 4: 373-40I.

Carling, Jørgen, 2008: "The Human Dynamics of Migrant Transnationalism", in: Ethnic and Racial Studies, 3I, 8: I-26.

Carling, Jørgen; Hernandez Carretero, Maria, 2008: "Kamikaze Migrants? Understanding and Tackling High-Risk Migration from Africa", paper presented at the conference Narratives of Migration Management and Cooperation with Countries of Origin and Transit, I8-I9 September (Brighton: Sussex Centre for Migration Research, University of Sussex).

Chamberlain, Mary; Leydesdorff, Selma, 2004: "Transnational Families: Memories and Narratives”, in: Global Networks, 4, 3: 227-24I.

Connell, Raewyn W., I995: Masculinities (London: Polity Press).

Connell, Raewyn W.; Messerschmidt, James W., 2005: "Hegemonic Masculinity: Rethinking the Concept", in: Gender and Society, I9, 6: 829-859.

Crenshaw, Kimberlé, 1991: "Mapping the Margins: Intersectionality, Identity Politics, and Violence against Women of Color", in: Stanford Law Review, 43, 6: I24I-I299.

Dannecker, Petra, 2005: "Transnational Migration and the Transformation of Gender Relations: The Case of Bang- ladeshi Labour Migrants", in: Current Sociology, 53, 4: 655-674.

Dannecker, Petra, 2009: "Migrant Visions of Development: A Gendered Approach”, in: Population Space and Place, I5, 2: II9-I32.

Datta, Kavita; Mcllwaine, Cathy; Herbert, Joanna; Evans, Yara; May, Jon; Wills, Jane, 2009: "Men on the Move: Narratives of Migration and Work among Low-Paid Migrant Men in London”, in: Social and Cultural Geography, Io, 8: 853-873.

de Haas, Hein; van Rooij, Aleida, 20I0: "Migration as Emancipation? The Impact of Internal and International Migration on the Position of Women Left Behind in Rural Morocco", in: Oxford Development Studies, 38, I: 43-62.

Diagne, Alioune; Rakotonarivo, Andonirina, 20I0: Les Transferts des Migrants Sénégalais vers la Région de Dakar: Ampleur et Déterminants, MAFE Working paper No. 9 (Paris: Ined).

Diop, Abdoulaye Bara, 1985: La Famille Wolof (Paris: Karthala).

Elmhirst, Rebecca, 2007: "Tigers and Gangsters: Masculinities and Feminised Migration in Indonesia”, in: Population, Space and Place, I3, 3: 225-238.

Fouron, Georges; Glick-Schiller, Nina, 200I: "All in the Family: Gender, Transnational Migration, and the Nation State”, in: Identities, 7, 4: 539-582.

Gardner, Katy; Grillo, Ralph, 2002: "Transnational Households and Ritual: an Overview", in: Global Networks, 2, 3: I79-190.

Hearn, Jeff, 2009: "Patriarchies, Transpatriarchies and Intersectionalities", in: Olesky, Elzbieta H. (Ed.): Gender and Intimate Citizenships: Politics, Sexualities and Subjectivity (London: Routledge): I77-I92.

Hearn, Jeff, 20II: "Neglected Intersectionalities in Studying Men: Age(ing), Virtuality, Transnationality”, in: Lutz, Helma; Herrera Vivar, Maria Teresa; Supik, Linda, (Eds.): Framing Intersectionality: Debates on a Multifaceted Concept in Gender Studies (London: Ashgate): 89-IO4.

Hondagneu-Sotelo, Pierrette; Avila, Ernestine, I997: “'I'm Here but I'm There?': The Meanings of Latina Transnational Motherhood", in: Gender and Society, II, 5: 54857I.

Hurtado, Aída; Sinha, Mrinal, 2008: "More than Men: Latino Feminist Masculinities and Intersectionality", in: Sex Roles, 59, 5-6: 337-349.

Johnson, Phyllis J.; Stoll, Kathrin, 2008: "Remittance Patterns of Southern Sudanese Refugee Men: Enacting the Global Breadwinner Role”, in: Family Relations, 57, 4: 43I-443.

König, Reinhilde; de Regt, Marina, 20Io: "Family Dynamics in Transnational African Migration to Europe: An Introduction”, in: African and Black Diaspora, 3, I: I-I3.

Levitt, Peggy; Glick-Schiller, Nina, 2004: "Conceptualizing Simultaneity: A Transnational Social Field Perspective on Society", in: International Migration Review, 38, 3: IOO2-IO39. 
Lindsay, Lisa A.; Miescher, Spehan F. (Eds.), 2003: Men and Masculinities in Modern Africa (Portsmouth, New Hampshire: Heinemann).

Lo, Marième S., 2008: "Beyond Instrumentalism: Interrogating the Micro-dynamic and Gendered and Social Impacts of Remittances in Senegal", in: Gender Technology and Development, I2, 3: 413-437.

Lukasiewicz, Adam, 20II: "Migration and Gender Identity in the Rural Philippines. Households with Farming Wives and Migrant Husbands", in: Critical Asian Studies, 43, 4: 577-593.

Mahler, Sarah J.; Pessar, Patricia R., 200I: "Gendered Geographies of Power: Analyzing Gender Across Transnational Spaces", in: Identities, 7, 4: 44I-459.

Mahler, Sarah J.; Pessar, Patricia R., 2003: "Transnational Migration: Bringing Gender In", in: International Migration Review, 37, 3: 8I2-846.

Mahler, Sarah J.; Pessar, Patricia R., 2006: “Gender Matters: Ethnographers Bring Gender from the Periphery toward the Core of Migration Studies”, in: International Migration Review, 40, I: 27-63.

Malkin, Victoria, 2004: “We Go to Get Ahead'. Gender and Status in Two Mexican Migrant Communities", in: Latin American Perspectives, 3I, 5: 75-99.

Marques, Margarida; Santos, Rui; Araújo, Fernanda, 200I: "Ariadne's Thread: Cape Verdean Women in Transnational Webs", in: Global Networks, I, 3: 283-306.

Monsutti, Alessandro, 2007: "Migration as a Rite of Passage: Young Afghans Building Masculinity and Adulthood in Iran”, in: Afghan Refugees, 40, 2: 167-185.

Nyamnjoh, Francis B., 2005: "Fishing in Troubled Waters: Disquettes and Thiofs in Dakar", in: Africa, 75, 3: 295324.

Nyberg Sørensen, Ninna, 2005: “Transnational Family Life across the Atlantic: The Experience of Colombian and Dominican Migrants in Europe", paper presented at the International Conference Migration and Domestic Work in a Global Perspective 26-29 May (Wassenaar, NIAS).

Orellana, Marjorie Faulstich; Thorne, Barrie; Chee, Anna; Lam, Wan Shun Eva, 200I: "Transnational Childhoods: The Participation of Children in Processes of Family Migration”, in: Social Problems, 48, 4: 572-59I.

Osella, Filippo; Osella, Caroline, 2000: "Migration, Money and Masculinity in Kerala", in: Journal of the Royal Anthropological Institute, 6, I: II7-I33.

Parreñas, Rhacel Salazar, 200I: "Mothering from a Distance: Emotions, Gender, and Intergenerational Relations in Filipino Transnational Families", in: Feminist Studies, 27, 2: 36I-390

Parreñas, Rhacel Salazar, 2005: "Long Distance Intimacy: Class, Gender and Intergenerational Relations between
Mothers and Children in Filipino Transnational Families", in: Global Networks, 5, 4: 317-336.

Perry, Donna L., 2005: "Wolof Women, Economic Liberalization, and the Crisis of Masculinity in Rural Senegal", in: Ethnology, 44, 3: 207-226.

Pribilsky, Jason, 20I2: "Consumption Dilemmas: Tracking Masculinity, Money and Transnational Fatherhood Between the Ecuadorian Andes and New York City", in: Journal of Ethnic and Migration Studies, 38, 2: 323-343.

Purwani Williams, Catharina, 2005: “'Knowing one’s Place': Gender, Mobility and Shifting Subjectivity in Eastern Indonesia”, in: Global Networks, 5, 4: 40I-4I7.

Riccio, Bruno, 200I: “From 'Ethnic Group' to 'Transnational Community'? Senegalese Migrants' Ambivalent Experiences and Multiple Trajectories", Journal of Ethnic and Migration Studies, 27, 4: 583-599.

Riccio, Bruno, 2008: "West African Transnationalisms Compared: Ghanaians and Senegalese in Italy", in: Journal of Ethnic and Migration Studies, 34, 2: 217-234.

Ryan, Louise; Sales, Rosemary; Tilki, Mary; Siara, Bernadetta, 2009: "Family Strategies and Transnational Migration: Recent Polish Migrants in London”, in: Journal of Ethnic and Migration Studies, 35, I: 6I-77.

Sinatti, Giulia, 2008: "Diasporic Cosmopolitanism and Conservative Translocalism: Narratives of Nation among Senegalese Migrants in Italy", in: Studies in Ethnicity and Nationalism, 6, 3: 30-50.

Sinatti, Giulia, 2009: "Home is Where the Heart Abides. Migration, Return and Housing Investment in Dakar, Senegal", in: Open House International, 33, 4: 49-56.

Sinatti, Giulia, 20II: “'Mobile Transmigrants' or 'Unsettled Returnees'? Myth of Return and Permanent Resettlement among Senegalese Migrants", in: Population Space and Place, 17, 2: 153-166.

Svašek, Maruška, 2008: "Who Cares? Families and Feelings in Movement", in: Journal of Intercultural Studies, 29, 3: 2I3-230.

Svašek, Maruška; Skrbiš, Zlatko, 2007: "Passions and Powers: Emotions and Globalisation”, in: Identities, I4, 4: $367-383$.

Truong, Thanh-Dam; Gasper, Des, 2008: "Trans-local Livelihoods and Connections: Embedding a Gender Perspective into Migration Studies", in: Gender Technology and Development, 12, 3: 285-302.

Wong, Madeleine, 2006: "The Gendered Politics of Remittances in Ghanaian Transnational Families", in: Economic Geography, 82, 4: 355-382.

Yeoh, Brenda S. A.; Huang, Shirlena; Lam, Theodora, 2005: “Transnationalizing the 'Asian' Family: Imaginaries, Intimacies and Strategic Intents", in: Global Networks, 5, 4: 307-3I5.

Open Access. This chapter is distributed under the terms of the Creative Commons Attribution Non-commercial License, which permits any noncommercial use, distribution, and reproduction in any medium, provided the original author(s) and source are credited. 


\title{
Intersectionality, Structural Vulnerability, and Access to Sexual and Reproductive Health Services: Filipina Domestic Workers in Hong Kong, Singapore, and Qatar
}

\author{
Thanh-Dam Truong, ${ }^{1}$ Maria Lourdes S. Marin, ${ }^{2}$ and Amara Quesada-Bondad ${ }^{3}$
}

\begin{abstract}
In this chapter the experiences of Filipina domestic workers in Hong Kong, Singapore, and Qatar are examined in the framework of their structural vulnerability to health problems. The chapter shows how their poor state of Sexual and Reproductive Health (SRH) can be the outcome of a combination of forms of institutional discrimination that are interconnected and should be investigated in respect of: (a) the worth of their 'identity' (migrant, female, the work they do); (b) the distinct aspects of discourse on sexuality and normativity which specifically relate to their presence in the destination countries; and (c) ideational and material realities constraining their own agency in finding adequate care. The chapter shows how variations in the potential for access may be explained by the types and degree of their structural vulnerability regarding labour rights, their relationship with employers and migrants' associations, and their personal SRH awareness-together with what emerges from cooperation between those government officials and civil society organizations who work with migrant domestic workers. Attentiveness to the particular combination of forms of institutional discrimination in a given cultural and institutional context, especially the ways in which the Sexual and Reproductive Health of Filipina domestic workers are linked to the ways in which labour migration are organized, should be helpful for effective SRH advocacy.
\end{abstract}

Keywords: Filipina Domestic Workers, Hong Kong, Singapore, Qatar, Sexual and Reproductive Health, Advocacy, Structural Vulnerability, institutional Discrimination, Sexuality.

\subsection{Introduction}

Health control in international migration has historically been driven by the concern of receiving states to screen newcomers for disease in the interest of protecting their citizens from health risks. This has led to the tendency for migrants to be portrayed by some ac-

1 Dr Thanh-Dam Truong is Associate Professor in Women/Gender and Development Studies at the International Institute of Social Studies, Erasmus University Rotterdam (The Netherlands).

2 Ms Maria Lourdes S. Marin is the Executive Director of Action for Health Initiatives (ACHIEVE), Inc., a Philippines-based organization working on migration, gender, and health issues.

3 Ms Amara Quesada-Bondad has been the Programme Officer of ACHIEVE in Quezon City in The Philippines since $200 I$. tors involved as a risk to public health. In recent years the global campaign for the right to health as a fundamental human right has opened the way for civil society organizations and scholars to develop and establish an approach to the health needs of labour migrants which enables their voices to be heard and properly addressed (WHO 20IO). The plight of labour migrants who occupy the range of occupations in the global economy defined as low-skilled or unskilled (often with temporary contractual arrangements, or in sectors not covered by labour protection laws in either the sending or destination countries, or both) has become a major concern from the standpoint of social justice in health (Dwyer 2004). The fragmented understanding of sexuality in health matters calls for more creative cooperation between health research and migration research to steer policy agendas towards providing more appropriate responses to the SRH needs of labour migrants. 
Uncovering the complex relationship between migration and health (particularly how the operation of certain migration systems these days can have a serious impact on the occupational and personal health of transnational labour migrants) requires a revision of the ways of understanding labour migration. Most policy and research concerning migration presents a prototype of the labour migrant as a unit in the macroeconomic theory of exchange, and focuses on financial gains and losses rather than on the realities as lived by migrants. More attentiveness and openness to how life actually is for people on the move across borders, and to the patterns of their inclusion in and exclusion from societies, is crucial for an effective approach to their right to health in line with international human rights law. ${ }^{4}$

Sexual and Reproductive Health (SRH) is a relatively new field of inquiry in migration research. Here, we take a holistic approach and explore how a combination of forms of institutional discrimination that are interconnected can affect how SRH problems are solved for migrant domestic workers. First, the concept of SRH is set out as a normative framework, and this is followed by a discussion on the concept of structural vulnerability to ill health that has been introduced in medical anthropology and applied to the situations of marginal labour migrants. This concept is then adjusted for the analysis of SRH situations faced by domestic workers from the Philippines in Hong Kong, Singapore, and Qatar. Data compiled on the experiences of migrant women domestic workers during their years of employment in these destination countries are presented, and the variations discussed. ${ }^{5}$ The conclusion proposes new avenues for SRH advocates to take on board the needs of mobile populations in a globalized world and to cooperate with mi-

4 The International Covenant on Economic, Social and Cultural Rights, art. I2; the 1965 International Convention on the Elimination of All Forms of Racial Discrimination, art. 5(e)(iv); the 1966 International Covenant on Economic, Social and Cultural Rights, art. I2; the 1979 Convention on the Elimination of All Forms of Discrimination against Women: arts. II(I)(f), I2, and I4(2)(b); The 1989 Convention on the Rights of the Child, art. 24; the 1990 International Convention on the Protection of the Rights of All Migrant Workers and Members of Their Families: arts. 28, 43(e) and 45(c); the 2006 Convention on the Rights of Persons with Disabilities, art. 25. See at: <http://www.ohchr.org/Documents/Publications/Factsheet31.pdf $>$ (accessed I9 July ○০০০). gration researchers, so that they can promote appropriate responses to migrant workers' health needs.

\subsection{Understanding SRH from the Perspective of Intersectionality and Structural Vulnerability}

The Report of the 1994 Cairo International Conference on Population and Development (ICPD) includes a definition of Reproductive Health as:

[T]he state of complete physical, mental and social wellbeing and not merely the absence of disease or infirmity, in all matters relating to the reproductive system and to its functions and processes. Reproductive health therefore implies that people are able to have a satisfying and safe sex life and that they have the capability to reproduce and the freedom to decide if, when and how often to do so. 6

Three other concepts associated with this definition are: (I) reproductive health care as the constellation of methods, techniques, and services contributing to (2) reproductive health and well-being (through prevention and remedy to reproductive health problems); (3) sexual health as enhancement of life and personal relations (beyond and above an understanding limited to counselling and care related to reproduction and sexually transmitted diseases).

Glasier, Gülmezoglu, Schmid, Moreno, and Look (2006) point out that SRH encompasses the totality of a person's sexual and gendered existence, and involves multiple and overlapping domains: the body, social identity, beliefs, attitudes, expressions, behaviour, and the social relationships through which desires are expressed and health is ensured. Although the majority of sexual and reproductive health issues affect women, men are also subject to such health risks, and are party to many of the related methods, techniques, and services that ensure healthy lives. It should be emphasized that sexual and reproductive health is not only about illness and disease but also

5 The data presented in this chapter were collected between 2008 and 2010 in the framework of a research project funded by IDRC, project number: I05637-00I, and entitled: "The Health of Our Heroes: A Qualitative Study on Access to Sexual and Reproductive Health Services and Information of Women Migrant Domestic Workers". Field research conducted by ACHIEVE, Inc. has been supplemented by desk research.

6 UN Report of the International Conference on Population and Development, Cairo, 5-I3 September 1994, United Nations, New York (1995). Sales No. 95.XIII.I8. 
about "a collection of related health and human rights issues and many people are still confused about what it [SRH] consists of" [italics added] (Glasier/Gülmezoglu/Schmid/Moreno/Look 2006: I604). This ambiguity has significant implications for SRH advocates (in respect of migrant populations) as well as for migrants themselves. In particular, SRH advocacy is very limited for workers on temporary contracts in countries where their work is not included in the labour law provisions, and where there is limited social consciousness of the significance of SRH generally and within a person's emotional life specifically.

As they are mostly of reproductive age, women migrant workers do not become sexually inactive once they cross a national border. Though loneliness and homesickness are common for newly arrived and firsttime migrant workers, for those who have had to leave their families and partners for work many times, periodical yearnings for intimacy and for the feeling of 'being home' socially and sexually continue to occur (Marin 20I2). Having to manage an existence which stretches between different localities with multiple identities-citizen, migrant, worker, wife, husband, intimate partner, son, daughter-these migrant workers also must renegotiate meanings of love, loyalty, and affection at a distance, while simultaneously establishing a new set of social bonds in their new place. Emotional expression in such a context requires the careful consideration of the specific social boundaries defined by the time-bound nature of their stay, the intersubjective and cultural meanings of intimacy, and the consequences they must face when transgressing the norms of propriety related to SRH at the place of their employment (Marin 20I2). Knowledge about the SRH of migrant domestic workers as a social group cannot be gained from a specific position declared as 'universal'. It requires the unravelling of many layers of power in different places that shape migrants' overlapping social identities and sense of belonging, layers which define the right to reveal their SRH needs and entitlement to care services.

The World Health Organization's report on the health of migrants (2008) notes that migrants travel with their epidemiological profiles, their level of exposure to infectious agents, their susceptibility to certain conditions, and their genetic and lifestyle-related risk factors, along with their culture-based health beliefs. They also travel with their sexual histories and SRH notions and practices. Access to health and medical services not only has a direct impact on their health outcomes but also on a range of other indirect benefits at the societal level: a healthier society with fewer burdens on public services caused by the progressive complications of health problems (Gushulak 20IO).

A useful source of ideas about public health activism in the field of SRH for migrant domestic workers may be found in Farmer's pioneering work (2004) on the pathological workings of power relations in the health sector. Using the concept of structural violence, borrowed from Galtung (1990), Farmer shows how denial of access to health treatment is systemically embedded in social structures, and how poor health outcomes among certain population groups can be the result of numerous processes of marginalization by governments, health sector officials, and industry, combined with microdynamics intersecting class, gender, age, ethnicity, and other criteria of belonging.

Criticism of Farmer's overemphasis on macrostructures calls for more nuanced understanding of access to health, shaped by more subtle processes of differentiation in the social distribution of well-being and illness. Quesada, Hart, and Bourgois (20I2: 34I) identify the following: I) the formation of social hierarchies buttressed by a hierarchy of symbolic meanings of worthiness (Bourdieu 2000); and 2) historically distinctive discourses of normativity and sexual ethics (Foucault 1979). In this way, they redefine the concept of 'structural violence' as 'structural vulnerability' in respect of ill health. In the light of Bourdieu's concept of positionality, structural vulnerability to ill health may be seen as produced by an individual's location in a given hierarchical social order that either enables or constrains the ability to act, negotiate, and change those contextually specific power relations affecting personal health. Quesada, Hart, and Bourgois (20I2) suggest that positionality-defined as the interplay between subjective and objective-can help bridge the binary distinction between structure and agency in order to give more visibility to the socially learned dispositions, skills, and ways of acting that are often taken for granted, but which are acquired primarily through the activities and accumulated experiences of everyday life.

Research into health among particular groups of immigrants, undocumented migrants, and transient migrant workers has shown a heterogeneity in the degree to which transnational migrant workers are vulnerable to ill health (Derose/Escarce/Lurie 2007; Lorant/Van Oyen/Thomas 2007). The key question is whether this heterogeneity reflects the functioning of health care systems per se, or whether there are, indeed, barriers to health services which may well be the outcome of the ways labour migration pro- 
grammes are organized - and thus shape workers' agency and health-seeking behaviour as well as access to services. This brings up the relevance of the concept of intersectionality as (I) a combination of forms of institutional discrimination (gender, age, migrant status, and ethnicity) that are interconnected and cannot be examined separately, and (2) the link between a labour migration system and a health care system.

As they are on temporary contracts, migrant workers often circulate between different places of employment and their home countries. Health insurance systems in their countries of origin may not cover expenses abroad and insurance in the host countries may not be easily affordable, particularly for lowskilled workers. Low-cost health insurance applicable across borders does not exist in many countries, and where it does there are major limitations. ${ }^{7}$

Even when their health status is cleared before departure, once on the move the employment situation of migrant workers in their destination countries becomes what basically underlies their overall state of well-being. It defines the boundaries of their new environment and its social connectivity, which in turn can directly and indirectly affect many aspects of their health physically and psycho-emotionally. Those who are undocumented, or have an 'irregular' status, are particularly disadvantaged and deprived because of their social invisibility. Lacking social and legal protection from frequent violence and abuse at the workplace, they run the risk of arrest and deportation when accessing public health systems. Seeking private health service providers with steeper costs, turning to self-medication, or experimenting with indigenous or alternative practices are basically the only options they have when encountering health problems (Marin 20I2).

There is a real and pressing need to understand structural vulnerability as produced by a combination of interconnected forms of institutional discrimination and by the link between migration systems and health systems. The right to health as built into international human rights law has no meaning until migrants can exercise them. Advocacy approaches to SRH justice for migrant domestic workers would ben-

7 For example, the Sekuye plan health insurance covers medical care in both the USA and Mexico, and the option to have treatment in Mexico. This will probably only be attractive to frequent migrants or those living near the border. The plan does not cover emergency medical costs. See at: <http://healthcare-economist.com/2008/02/28/cross-border-health-insurance/> (accessed Io May 20I2). efit from a full understanding of exclusion/inclusion processes which occur through finely-differentiated modes of power embedded in different contexts and workplaces.

\subsection{Power, Transience, and the Structural Vulnerability of Domestic Workers to SRH Problems}

The structural vulnerability of domestic workers to $\mathrm{SRH}$ problems may be conceptualized as an outcome of a process which hinges upon the following: I) the normative discourse about the body and sexuality which frames SRH and its application to the situation of domestic workers as a group; 2) cultural, social, and legal definitions of a domestic worker in the host country that define their social location and the corresponding consciousness and sense of accountability for their right to health care; and 3) the ways in which individual SRH problems are connected with practices at the workplace, which in turn, define their inclusion or exclusion from available and affordable health programmes and services.

Advocating for the SRH rights of migrant domestic workers faces major challenges. Given the wide definition of SRH, few countries can afford a comprehensive strategy. SRH services are mainly organized through a piecemeal approach, with the exception of education. Much depends on socio-demographic factors and the actual SRH problems which surface, and on budgetary constraints and the level of cooperation between health departments and civil society organizations. Attentiveness to social groups whose identities are invisible within the public realm does help influence the provision of services.

As a labour-sending country the Philippines has one of most rigorous policies and programmes in the world for protecting the rights of its citizens who work overseas. It has recently identified domestic workers as one of the main groups to be protected from violation of rights, along with entertainers and seafarers. ${ }^{8}$ Action in the SRH domain has been hampered by the position of the Catholic Church, which has conflated fertility management and use of contraception with abortion, leading to its vigorous opposition to the passage of the Reproductive Health Bill in the Congress of the Philippines. The church hierarchy, represented by the Catholic Bishops' Conference of the Philippines (CBCP), has consistently put pressure on the state regarding matters of sexuality and re- 
productive health. So therefore, despite formal commitments made by the government to implement international standards on $\mathrm{SRH},{ }^{9}$ programmes have mainly been supported by international development organizations. ${ }^{10}$ The resulting absence of a national policy on SRH hampers the implementation of comprehensive and concerted programmes within the country, and undermines the commitment to the sexual and reproductive well-being of overseas workers.

Efforts from civil society organizations and some local government units have been made to provide services that cover all the ten elements of reproductive health recognized by the Philippine government. But these remain far from the international normative framework of SRH rights. Family planning services are available in most public health facilities but with

8 The Republic Act No. 8042 puts together the national policies on overseas employment and establishes a higher standard of protection and promotion of the welfare of migrant workers, their families, and overseas Filipinos in distress. Together with the amendatory law RA I0022 of 2009 it defines in more concrete terms the diplomatic and consular duties of the Department of Foreign Affairs (DFA) and its embassies abroad. In 2009 the total number of contracts processed for Overseas Filipino Workers (OFWs), reported by the Philippine Overseas Employment Administration (POEA) for both rehires and new hires reached I,479,070. Of these, $7 \mathrm{I}$ per cent were land-based $(\mathrm{I}, 043,555)$ and 29 per cent $(435,515)$ were sea-based. 35 per cent $(362,878)$ of the land-based OFWs were new hires. Domestic workers comprised about 20 per cent $(7 \mathrm{I}, 557)$ of total new hires for 2009 , of which 97 per cent $(69,669)$ were women (Sobritchea/Subingsubing/Quesada 20IO: Io).

9 The Philippine government recognizes ten elements of reproductive health as follows: I) family planning information and services; 2) maternal, infant, and child health and nutrition; 3 ) prevention of abortion and management of abortion complications; 4) prevention and treatment of RTIs/STIs/ HIV/AIDS; 5) education and counselling on sexuality and sexual and reproductive health; 6) treatment of breast and reproductive tract cancers and other gynaecological conditions; 7) male involvement and participation in reproductive health; 8) adolescent and youth reproductive health; 9) elimination of violence against women and children; Io) prevention and treatment of infertility and sexual dysfunction. This chapter deals specifically with I, 3, 4, and 5 .

10 These include training, advocacy, and service programmes on the prevention of HIV and AIDS, the reduction of maternal deaths, and the promotion of education in adolescent sexuality. Sex education is now integrated into the curricula of secondary and public tertiary schools. varying degrees of effectiveness, because of the strong influence of faith-based organizations who only accept natural family planning methods. There has been erratic and uneven dissemination of SRH information across the country. Moreover, access to quality health services is constrained by high costs, inefficiencies in health care management, and socio-cultural norms. There is limited availability of contraceptives and poor dissemination of information on how to prevent early unwanted pregnancy, or the risk of pregnancy. The power of the church means that contesting the normative understanding on the relationship between sexuality and health and attempts to meet some of the critical SHR health needs of the population can only be negotiated between civil society organizations and local government institutions. For overseas workers, restrictions imposed by the host countries on the practice of non-national health professionals limit the ability of embassies and consulates to provide actual and direct medical services. They can only refer overseas workers to service providers in the host countries, or facilitate repatriation.

The scope for the government of the Philippines to take responsibility for ensuring migrant women domestic workers have access to SRH services does remain limited. The existing body of knowledge on SRH of migrant workers is too small and does not contain the hard data often required by policy-makers and programme implementers to institute the necessary services. Furthermore, there is an overwhelming concern among civil society organizations about labour issues, which is putting SRH rather in the shade on the government agenda. In destination countries faith-based organizations have been in the lead in raising SRH consciousness through programmes conducted with migrant workers and local authorities. Since they are at the bottom of the hierarchy of social worthiness, migrant domestic workers must rely on either their employers or faith-based organizations to recognize their right as persons to health and well-being.

\subsubsection{Regulating Domestic Work in Hong Kong, Singapore, and Qatar: Implications for Workers' SRH}

Hong Kong (Special Administrative Region of China), Singapore, and Qatar share the characteristic of being small in area yet having a large stock of international migrants as a percentage of the total population (Hong Kong 39 per cent; Singapore 4I per cent; Qa$\operatorname{tar} 87$ per cent), ${ }^{11}$ with a large proportion of them be- 
ing domestic workers. These workers are mainly from South Asia and South-East Asia. The three places enjoy the status of being among the richest in the world with excellent health care systems. That the presence of these migrant workers fills the labour gaps in lowskilled and low-paid sectors where work is too onerous by national standards has become common knowledge; less widespread is knowledge about the relationship between the presence of domestic workers and sending countries' labour export policies (Oishi 2005) and how the right to health is or is not ensured under such policies. Concerns are emerging about socio-demographic transition, family structures, and the ageing factor in these societies, especially in Hong Kong and Singapore (Huang/Yeoh 2005). Unless family policy can effectively address intergenerational care (Chiu/Wong 2009) the presence of domestic workers should be treated as a bilateral issue between sending and receiving countries rather than only from the perspective of individual choice and agency.

The migration system for domestic workers is based on a two-year period, with allowance for renewal for a period of the same duration. Of the three countries, Hong Kong is legally the most advanced in terms of ensuring labour standards for migrant domestic workers. They are protected by Chapter 57 of the Laws of Hong Kong, covering a comprehensive range of employment protection and benefits for employees $^{12}$ and by the Occupational Health and Safety Ordinance which ensures the protection of employees in the workplace regardless of citizenship or documentation status. ${ }^{13}$ The Race Discrimination Bill prohibiting discrimination, harassment, and vilification on the grounds of race introduced recently has had a limited effect on domestic workers, given the exception clause applicable in any work situation where fewer than five persons are employed. ${ }^{14}$ A related policy, the Sex Discrimination Ordinance, prohibits employers from doing the following: refusing to hire a

11 Figures are from IOM's (2010) World Migration Report, and fact sheets. See at: <http://www.iom.int/jahia/Jahia/ about-migration/facts-and-figures/lang/en> (accessed 7 May 2OI2).

12 Labour Legislation, Employment Ordinance, Chapter 57. See at: 〈http://www.labour.gov.hk/eng/legislat/content2. htm> (accessed Io November 2009).

13 Labour Legislation, Employment Ordinance, Chapter 57. See at: <http://www.labour.gov.hk/eng/legislat/ content2. htm> (accessed Io November 2009).

14 See at: <http://www.hg.org/article.asp?id=5324> (accessed 22 April 20I2). woman because of pregnancy; limiting a worker's transfer or training options because she is pregnant; firing or forcing a worker to leave because she is pregnant or on return from maternity leave; taking away credit for service because of maternity leave.

In Singapore foreign workers are classified by level of education and income, according to which the government grants permission for terms of residence. Employment passes are granted to foreign professionals whose monthly earnings reach a certain threshold set by the government; they are widely known as 'foreign talents'. At the lower end of the income/profession spectrum, employers are granted permits to take 'unskilled or semi-skilled' workers, whom Singaporeans refer to as 'foreign workers'. Foreign domestic workers are called "Foreigners in Our Homes" (Teo/ Piper 2009). The work permits are issued on the condition that the women do not marry Singaporeans nor become pregnant. Standard employment contracts in Singapore now state that registered employers must ensure medical care and treatment is covered for the duration of the employment. Foreign workers without valid work permits are unable to access the government health system to the same degree as those with permits, and they do not have access to a government health subsidy. In March 2012 the Manpower Ministry granted foreign domestic workers a weekly rest day. ${ }^{15}$

By contrast, Qatar has a very poor record in the treatment of foreign workers. They are excluded from Law I4 of 2004 that governs labour in the private sector, which limits working hours and sets requirements on paid annual leave, health and safety, and prompt payment of wages each month. Neither this law nor supporting legislation sets a minimum wage. The Law allows only Qatari workers to form unions, and permits strikes only with prior government approval. Qatar has I50 labour inspectors to monitor compliance with the labour law, though inspections do not include worker interviews. ${ }^{16}$

Excluded from the labour law as they are, foreign workers do not benefit from these provisions. Together with construction workers, domestic workers come under a 1963 'Sponsorship Law', known as the kafala system, which regulates their entry and employment. Under this system migrant workers cannot

15 See at: <http://www.hrw.org/news/20I2/03/05/singapore-domestic-workers-get-weekly-day-rest $>$ (accessed 20 July 20I2).

16 See at: 〈http://www.hrw.org/world-report-20I2/worldreport-2OI2-qatar> (accessed 22 April 2OI2). 
change jobs without their sponsoring employer's consent, other than in exceptional cases with permission from the Interior Ministry. A Qatari company, which can be run by a private citizen or a foreign national, acts as the sponsor who procures a visa for a worker. The sponsor has effective control over the movements of their worker in Qatar for the duration of the contract. They frequently confiscate workers' passports, although this is in violation of the Sponsorship Law. The worker cannot leave the country, buy a car, or rent a home without the sponsor's permission. Although sponsors are required to give workers an endof-year bonus, a return airline ticket, and medical insurance, failure to do so is often not penalized. Nonobservance of requirements for minimum wage, overtime wage, and timely payment is common. Non-compliance which results in the disadvantaged employees leaving the job situation can be a basis for the employer to report the worker as 'having absconded', which leads to a threat of detention and deportation. ${ }^{17}$

Despite these variations in the legal treatment of migrant domestic workers in the three countries, socially these workers share a common condition of being confined to individual households as their place of work as well as residence. In Hong Kong and Singapore, where they are allowed to have a day off, their regular use of public spaces around the cities - to socialize and enjoy a brief moment of privacy away from their employers - has led to the formation of 'ephemeral enclaves' which have become an issue for local citizens who perceive this as a form of nuisance, inconvenience, or even threat. Markers of cultural and ethnic identities have emerged as a 'cordon' around the public spaces used; these are then avoided by local citizens (Koh 2009; Tillu 20II). Such is the powerful effect of cultural inscriptions on physical space. In Qatar some employers have allowed their domestic workers a day off every Friday, in principle to study Islam. This was the only way the domestic workers could spend time outside the house of their employers. ${ }^{18}$

17 Field findings of this research indicate that there are employers who allow domestic workers to use their cell phones and the Internet to communicate with their families and friends, to have some days off from work, and have a rest period during the day. Some of have been allowed to visit their families even before the end of their two-year contract. This latter experience may be attributed to having expatriate employers who were mostly Westerners, or for having served their employers for a long period of time.
It can be said that the social standing of migrant domestic workers within the hierarchy of foreign labour is defined by specific processes of inclusion and exclusion. The interplay between different identitieslegal, economic, political, and sociocultural-is accentuated in conjunction with gender, sexuality, ethnicity, and nationality (Yeoh/Huang 2000, 2010). One common concern is sexuality, where the condition of nonentry and expulsion includes medical 'unfitness', covering 'being pregnant' and having Sexually Transmitted Diseases (STDs), Acquired Immune Deficiency Syndrome (AIDS), or Human Immunodeficiency Virus (HIV). Once placed in their jobs, domestic workers must go through periodic mandatory health checks for specific SRH (Guild/Mantu 20II: 80-IO3). Birth prevention during migration, with all the legal and medical risks involved, is left to a migrant's discretion.

In response to incidents of abuse of migrant domestic workers that have been made public, faithbased institutions in Hong Kong and Singapore have played a critical role in providing immediate assistance to those who have escaped from their workplaces and agents, and in setting up other services for those who remain employed. The Catholic Church has pioneered the giving of assistance to Filipino migrant workers. The increased diversification of ethnicity and nationalities among the population of migrant workers has led to mosques and Buddhist temples also providing programmes for them which include religious education and recreational activities. There has also been a rise in the number of Non-Governmental Organizations (NGOs) active in lending support and assistance to migrant workers. ${ }^{19}$ It is also important to note that the general consciousness of SRH in Hong Kong promoted under the Family Planning Programme $e^{20}$ is resulting in some direct benefits for migrant domestic workers, as will be shown in the next section.

18 Our field research has noted a number of cases of domestic workers ostensibly converting to Islam to benefit from this allowance.

19 Some major organizations are: I) HOME, a recognized institution that responds to the needs and concerns of migrant workers in the country; 2) the Transient Workers Count Too (TWC2), which works to improve the lives of domestic workers in Singapore through research, advocacy, and the provision of direct services; 3) Aidha, a charitable non-governmental organization focusing on organizing part-time financial and businessrelated courses for domestic workers. 
The SRH experience of migrant domestic workers can be seen as contingent on the nature of domestic work and its formal and informal regulations, the cultural framing of sexuality, and social understanding of their bodies. Identity construction processes selectively emphasize 'gender' in heterosexual terms that are intersected by the workers' ethnic, religious, and class identities, making the subject of control so intricate that interpretation of SRH norms must take serious note of the contextual articulations of power relations.

\subsection{Individual SRH Problems and Intersecting Power Relations}

The data discussed in this section were gathered from seven in-depth interviews in a broader research involving I47 Filipina domestic workers and twenty-nine interviews with key informants in Hong Kong, Qatar and Singapore. Three participants in focus group discussions (FGDs) experienced reproductive health ailments and were interviewed at length as case studies. Local research partners further identified four other domestic workers who had experienced sexual and reproductive health problems as case study informants. In-depth interviews generated important information on how the women dealt with their health problems, given their knowledge of and attitudes towards health and conditions of work. A key point that has emerged is the intersection of individual SRH problems with various facets of institutional exclusion.

SRH services are generally available in all three study sites, but financial and social barriers to access are the major problem. Policies on certain sexual and reproductive health issues differ between the three study sites. Abortion is legal in Hong Kong and Singapore within specific parameters: it has to be performed by a doctor; the woman has to undergo counselling and a medical going-over performed by at least two physicians who approve the procedure. In Qatar abortion is illegal. Though all three countries have policies on health insurance applicable to migrant domestic workers for the duration of their employment

20 This consciousness has helped ensure quality reproductive health care for citizens, as reflected in the low rate of maternal mortality. In Singapore the rate is 9 per I00,०००. While there is no separate figure for Hong Kong, the equivalent statistic for China is 38, for Qatar 8, and for the Philippines 94. See at: <http://data. worldbank.org/indicator/SH.STA.MMRT> (accessed 9 May 20I2). contract, information gathered from fieldwork suggests it is mainly only workers in Hong Kong who enjoy this privilege. In Singapore there were participants who had insurance and there were those who said they didn't. There were also participants who did not know they were supposed to have health insurance. This was common among the participants in Qatar; those who could access medical services emphasized the instigating role of the employers.

Nearly all the interviewed domestic workers belonged to the reproductive age group. Sixty per cent of the total number of research participants belonged to the 20-39 age group; thirty-eight per cent were between 40 and 59. One domestic worker was under twenty; one other was over sixty. There were slightly more in the older age bracket in Singapore and Hong Kong compared with those in Qatar. Forty-five per cent were unmarried, forty-two percent married, eight per cent had separated, and the rest were widows. The relatively younger average age of domestic workers in Qatar could be explained by the fact that recruiters specifically target young women from rural areas in the southern part of the Philippines. The rapid processing of documents allowing them to leave within a month's time and the fact that the agents do not collect placement fees were cited as the main reasons.

More than half the research participants had children, ranging in number from one to nine. One in three of the mothers had only one child; forty-one per cent had two to three, and twenty-six per cent four or more. The higher percentage of women who had fewer than four children can be explained by the relatively young age of the majority. The data on the number of years of work abroad indicate that more than half of the research participants had been out of the country for less than five years; forty-four per cent had been abroad and separated from their families for six to twenty years. Female domestic workers continued to bear children throughout the cycle of their overseas employment. This finding reveals their dire need for regular access to reproductive health information and services.

Many FGD participants mentioned suffering repeated physical battery and verbal abuse not only from their employers but also from the latter's 'spoiled' children. Heavy workloads and close monitoring emerged as being of greatest concern.

The family took me on 'vacation' to Jordan to visit siblings. I had to clean three houses because my employer's siblings didn't have a maid. (Case study participant, Qatar). 
Although Hong Kong mandates a 24-hour day off for domestic workers, some employers expected the worker to be continuously active during working days. One reported being followed around by her employer's mother-in-law with a monitoring camera, and never allowed to sit down between tasks. In her words:

You go to the toilet not because you have to urinate but so you can have a little rest. You sit down and lean back and close your eyes, and in that way you get rid of some of your drowsiness. (An FGD participant, Hong Kong).

One worker who benefited from health leave told the following story:

Yes, I got seven day's leave after my surgery, but I still had to do some sweeping. (An FGD participant, Hong Kong).

Even when they were maltreated, very few went to the authorities to complain. They were afraid that their contract would be terminated as a consequence. In the words of one interviewee, a member of a supporting organization:

Especially when they're new, they're thinking about the debts they've incurred, they're thinking about their families who are waiting for their remittances. So even when they get sick, they just continue working. ... This is something that I wish our government would do something about.

Many put up with the maltreatment because they feared losing their jobs. The participants spoke of domestic workers who were fired for becoming ill or pregnant. As this kind of termination is illegal in Hong Kong, some employers there have waited until the worker has gone through surgery or come back from a hospital confinement, and then found some other reason for dismissing them. One of the key informants in the study, an expatriate employer in Hong Kong who serves as a volunteer for the organization 'Helpers for Domestic Helpers', said that she has known of women whose employment contracts were terminated in just that way. In her words:

[The employers] do this for their own convenience. ... They don't want someone who is slowed down, or tired or whatever, because they're pregnant. Or they don't want someone who's not doing their job as efficiently because they're unwell.

One FDG participant revealed that while on vacation in the Philippines she got married and returned to work pregnant. She asked permission to return home. Her employer told her to go to a doctor and ask for a particular medicine. The worker did not know it was an abortifacient. She got angry with her employer be- cause she had wanted to keep the baby. The president of the Asia Pacific Mission for Migrants shared the following:

Some employers tell their maids 'Don't get pregnant'. Should they even have a say in that area of your life?... It's your right, as a woman, as a married person, to have a child if you want to. But because you are a domestic helper, and your employer doesn't want you to get pregnant, you follow their order. But they are stepping on your right to form a family.

Exclusion from SRH education emerged as a key point of issue affecting health-seeking behaviour. The level of SRH awareness among interviewees varied but was generally very low and included a number of misconceptions with consequences for their health. Traditional gender norms, which dictate that women should remain ignorant about matters pertaining to sex and sexuality, reinforce their exclusion from SRH education. A sense of discomfort surged among some of the FGD participants when these matters came up for discussion as they were considered shameful. Even when they experience SRH problems they find it uncomfortable to talk to their friends, and even more so to a male doctor who is not even a Filipino. Going for a medical examination that would involve showing a doctor their private parts is even more unthinkable. As a result, a simple infection of the reproductive tract can become serious because only when their condition has worsened do they find the courage to make mention. Those who talked with more comfort about the matters related to sex and SRH were older and had worked in the study sites longer. They did not mind sharing intimate experiences such as masturbation and showing the younger women in the group that they should learn to be more comfortable about issues of sexuality, reject taboos, and accept these issues as a normal part of life.

Some FGD participants admitted to engaging in sexual relationships while in their country of employment, divulging also that they used condoms. They did not always seek medical attention or health services when they felt sick. They kept their conditions to themselves and endured pain and discomfort in silence for fear that their contracts would be terminated if their employers were to find out and they would be sent home.

The case of a 44-year-old unmarried domestic worker in Qatar shows the detrimental consequences of inadequate SRH education.

I met him through a friend. After a year of casual friendship we had a sexual relationship. We both wanted it to happen but we didn't think about using protection 
because it never occurred to us that I would get pregnant. Besides, my menstruation still came every month. I didn't notice that my abdomen was getting bigger because I have always been fat. One time I noticed it was hard to the touch. I told my employer about it, but she dismissed it as merely gas pains. I also ignored it. Then one evening after going out with my employer's family I felt an excruciating pain in my abdomen. I thought it was a very bad stomach ache. My employer took me to the doctor, who injected me with medicine and gave me some tablets to take. After that we went home. That night I couldn't sleep. The pain was persistent. I slept in the bedroom of my employer's children and they noticed I was crying in pain. They told their mother so my employers took me back to the hospital. Doctors took my x-ray and tested my urine. That's how they found out that I was pregnant and that I was already in my ninth month, which was a big surprise to me because I never missed my period. I did not experience any morning sickness otherwise my employer would have noticed and would have taken me to the hospital sooner. (Case study participant, Qatar).

Birth prevention through self-medication is widespread. A health official in Hong Kong revealed the prevalent use of Cytotec (misoprostol or synthetic prostaglandin E1 $)^{21}$ for the purpose of termination of pregnancies. In Hong Kong and Singapore any method of inducing abortion that does not follow the regulated protocols of medical abortion is considered illegal. To keep the knowledge of their pregnancy to themselves, domestic workers use Cytotec because it can induce abdominal contractions, which may result in labour. One domestic worker was jailed in Hong Kong for trying to abort a foetus that was more than twenty-four weeks old by taking Cytotec.

Cyctotec has a low rate of success as an abortifacient, simply because users do not have accurate information about dosage and proper administration. The FGD participants were aware that "if it only causes you to bleed and you don't abort completely it may result in more complications". One case study informant, who had terminated a pregnancy using Cytotec, believed this was why she developed myoma (fibroids). "Not all the blood came out and that is what grew into a tumour." Myoma became a topic of discussion.

It's what we talk about when my friends and I get together. It's our number one question: why do so many

21 WHO currently includes misoprostol (Cytotec) in its evidence-based guidelines and Model List of Essential Medicines for early pregnancy termination together with mifepristone, medical management of miscarriage, and labour induction. See at: 〈http://whqlibdoc.who. int/hq/20IO/WHO_RHR_IO.II_eng.pdf> (accessed 9 May 20I2). of us have myoma? Is it from being on our feet the whole day? (Case study participant, Hong Kong).

There have been many instances when an employer will say, after the domestic worker has gone to the doctor two or three times:

Okay, I think that it's better that you return to the Philippines and rest. (FGD participant, Hong Kong).

The fear of being sent home for having SHR problems can be reinforced by financial limitations. ${ }^{22}$ In most cases FGD participants gave priority to saving for remittances over spending their salaries to care for their own health. They rely on self-medication-bringing medicines with them from the Philippines; medicines they are familiar with that can be bought over the counter; medicines for pain, fever, colds, coughs, and diarrhoea. If they run out of these medicines they rely on non-prescription medicines without first consulting a doctor.

Though exposure to education programmes organized during pre-departure orientation seminars as well as in the country of destination does make a difference in the level of SRH consciousness (as also does sharing experiences with their peers), their access to SRH services in destination countries depends largely on their employers. The existence of policies enabling workers to access health services in general or SRH services in particular can facilitate such access but does not guarantee it. In Hong Kong, for example, employers of migrant domestic workers are required by law to ensure that their workers have a valid Hong Kong Identification Card (ID) allowing them access to government hospitals and medical services at a very affordable rate. However, a domestic worker, though in possession of this ID card, may not be able to readily reach any health facility if her employer does not allow her to leave the house at any time except on Sundays.

Having a good relationship with their employers can greatly facilitate workers' access to health services. It makes it easier for a worker to inform her em-

22 The Philippine government requires employment agencies to prescribe a minimum monthly salary of US\$400 for departing domestic workers but the findings show widespread violation of this regulation. Except for those in Hong Kong and for some in Singapore, there are many deployed domestic workers who are not getting the prescribed minimum salary. Some departing domestic workers are made to sign an employment contract before they leave that conforms to this policy and then made to sign another employment contract specifying a much lower monthly salary once they are abroad. 
ployer if she gets sick and asks permission to go to the hospital, or even to go on leave after a serious illness. Responses from the employers do vary though. Some participants in FGDs stated that their employers took care of them when they got sick; others said that despite a good relationship with their employers they still had to work right after getting home from time in hospital. Employers depended on them to keep the house in order and make sure the children were taken care of.

One study participant was diagnosed with breast cancer, requiring treatment by chemotherapy, for which reason her employer fired her. In Hong Kong the worker could have filed a case against her employer for terminating her contract due to an illness, but most of the time the domestic workers do not pursue such cases. They would actually rather go back to the Philippines.

I am worried because the doctor said that the chemotherapy is not totally free of charge and I will have to pay a portion of the cost. I know I won't be able to afford this because my employers terminated my contract. I don't blame them. They have been very good to me and call me to ask how I am. But they do not have a lot of money so they cannot afford to support me. If I were to stay with them, I would n't be able to fulfil my duties, yet they would be required to pay me. How will they manage? This is why they had to let me go. ... I need to have my visa extended so I can continue having my treatment in Hong Kong. The Immigration Department has already extended my visa for three months. ... Immigration officers told me that I could demand support from my employer. They said I could file a case against them with the Labour Department because in Hong Kong, an employer cannot terminate a domestic worker if she is undergoing treatment. I know this but I don't want to file charges against my employer. I love this family. (Case study in Hong Kong.)

Apart from the kind of relationship they have with their employers, the influence of family and friends also counts. In many instances the family in the Philippines, as well as friends, can serve as facilitating factors for migrant domestic workers to access SRH services. They can positively influence health-seeking behaviour by giving information on where to get help, and can also provide emotional and moral support. When they share positive experiences with health care facilities in the host countries, family and friends can effectively encourage them to continue to seek these services. If they share negative or traumatic experiences, family and friends may discourage or even scare them off from pursing their case. In the words of a rape victim in Qatar:

My employer has actually offered to pay me five thousand riyals and buy me a ticket back to the Philippines to have me shut up. But he can't just pay me off for what he's done to me. I really want to pursue this because he took my virginity. I find this very hard to accept. And I am waiting for my next period. What if he has gotten me pregnant? Then it would be even more difficult for me to accept. My mother in the Philippines now knows what has happened to me. She wants me to go home but I told her that I want to pursue and win this case, though the people here at the Embassy have told me these criminal cases take time, maybe two years. (A case study in Qatar.)

In Hong Kong and Singapore there are NGOs and migrant organizations who serve as support groups for migrant women domestic workers. These institutions can be sources of SRH information and services. They can also reinforce positive health-seeking behaviour through awareness-raising activities. FDG participants generally experienced positive treatment by the medical and health care personnel when in a hospital or clinic in the destination country, though some felt that the doctors did not spend enough time on them to find out what their ailments really were. They felt they were rushed through the consultation and were simply given pills without any explanation of what the pills contain or what they were supposed to be curing.

Communication barriers are another issue when being dealt with by health care personnel. Participants in Hong Kong and Singapore confided that, because of colloquial usage, they couldn't understand what their doctors were saying even though they were speaking in English. Hong Kong's Racial Discrimination Ordinance provides for meeting a patient's request to have an interpreter when accessing services in a hospital. The problem was that the migrant workers were not aware of this policy and so remained frustrated by the difficulties in communicating with medical and health care personnel. In Qatar, there were domestic workers who noticed that the doctors treated them better when their employers were with them during a visit to the hospital. They felt that they were not treated as well when on their own and believed that they were discriminated against because they were domestic workers. A number of the study participants also said that the nurses looked down on them because they were just migrant domestic workers.

The diverse experiences of Filipina domestic workers with $\mathrm{SRH}$ problems concerning access to services, and the limited scope of this research, do not permit taking any firm position on the causal relationship between migration and SRH, especially regarding the intersection of individual medical problems with social inclusion/exclusion. What has become clear is that migrants do not leave their sexual 
lives behind them when they cross borders for work and also that the institutional context of labour regulations matters a great deal in their SRH health-seeking behaviour. Yet the rigorous pregnancy control of domestic workers seems to manifest a social consciousness about female efficiency, but efficiency that must be delivered by a body that is supposed to remain infertile. This has implications for the emerging research field of migration and SRH, both theoretically and practically.

\subsection{Conclusion}

As an emerging issue in global migration, SRH research in the Philippines still has a long way to go to come up with policy messages useful for setting up services to groups of migrants whose health has been affected by the ways their migration is organized. Findings on overseas domestic workers from the Philippines in this study show how power relations can be articulated in ways that shape their structural vulnerability to SRH problems. The articulation depends greatly on context and place irrespective of the fact that the three countries share the common denominator of an excellent health system. Most significantly, the link between the SRH problems experienced by a migrant domestic worker as an individual and the mechanisms of exclusion from, or inclusion in, SRH services operates simultaneously at ideational and material levels. Ensuring affordable services is not enough; gaining awareness and knowledge about the right to exercise the right to SHR health seems crucial, particularly among migrant domestic workers whose health-seeking behaviour is constrained by conventional norms of sexuality and a range of choices that are far from risk-free.

International migration connects countries of origin, transit, and destination, and it is important for governments to recognize the complex intersection between migration systems and health systems. A purely national approach to migration and health is too limited to respond to the health needs of migrant workers. Bilateral, multi-country, and multi-sectoral dialogues would help foster collaboration and partnership to harmonize the responses to these needs. Various regional and subregional forums addressing transnational health challenges such as HIV and AIDS, SARS, avian influenza, and the $\mathrm{H} 1 \mathrm{~N} 1$ virus are already in place. Efforts to address migrants' health, and in particular SRH, must take note of the specific structural vulnerability they are subject to and recog- nize the intricate workings of power over the female human body. Such power intersects with a wide range of institutional practices and has consequences for their health.

Over the next few decades international migration is likely to be transformed in scale, reach, and complexity due to growing demographic disparities, the effects of environmental change, new global political and economic dynamics, technological revolutions, and evolving social networks (IOM 20IO). The sheer magnitude of the movement and flow of persons in a given region and throughout the world necessitates critical discussion on the health aspects of migration. Depending on the situation and location, the health of migrants may have important implications for the populations from which they originate, through which they travel, and where they live and work. At the same time aspects of migrants' health are influenced and affected by how they travel and to what destination, and where they temporarily reside or permanently settle (Gushulak 20I0).

Addressing migrants' health involves integrating key human rights concepts into sound public health approaches. The key is to eliminate disparities in access to health services, facilities, and goods between migrants and host populations, bearing in mind the financing implications for existing health systems. It implies the creation of an environment that enables migrants to enjoy their full rights, which must include those of sexual and reproductive health. This will need to be done along with proactive strategies that address the totality of migrants' human rights. In the area of migrants' SRH it is important to continue generating more evidence. This should include further investigation and analysis of trends and patterns in the SRH status of migrant workers, the mapping of existing SRH services, policies, and information, and identification of good practices in addressing migrant workers' SRH needs. Qualitative evidence of needs articulated through the voices of migrants is crucial to improving existing SRH programmes and services. As Marin (2OI2) emphasizes, the gathering, dissemination, and utilization of information must take into account issues of human security such as security of identity, since disclosure of sensitive data or information about migrants could put them in a precarious situation. This is especially true in the case of irregularly documented migrants, for whom a more nuanced approach will be required. 


\section{References}

Bourdieu, Pierre, 2000: Distinction: A Social Critique of the Judgement of Taste (Cambridge, Mass.: Harvard University Press).

Chiu, Stephen Wing-kai; Wong, Richard Ka-chung, 2009: A Literature Review on Family Policy in Four East Asian Countries (Hong Kong: The Chinese University of Hong Kong).

Derose, Kathryn Pitkin; Escarce, José J. Lurie, Nicole, 2007. "Immigrants And Health Care: Sources Of Vulnerability", in: Health Affairs, 26,5: 1258 -I268.

Dwyer, James, 2004: "Illegal Immigrants, Health Care, and Social Responsibility", in: Hastings Center Report, 34,I: 34-4I.

Farmer, Paul, 2004: Pathologies of Power: Health, Human rights, and the New War on the Poor (Berkeley: University of California Press).

Foucault, Michel, 1979: The History of Sexuality Volume I: An Introduction. Translated by Robert Hurley (London: Allen Lane).

Galtung, Johan, 1990: "Cultural violence", in: Journal of Peace Research, 27,3: 29I-305.

Glasier, Anna; Gülmezoglu, A. Metin; Schmid, George P.; Moreno, Claudia Garcia; Van Look, Paul F.A., 2006: "Sexual and Reproductive Health: a Matter of Life and Death" in: Lancet, 367. 1595-1607.

Guild, Elspeth; Mantu, Sandra, 20II. Constructing and Imagining Labour Migration: Perspectives of Control from Five Continents (Burlington, VT: Ashgate).

Gushulak, Brian, 20I0: "Monitoring Migrants' Health". Paper presented at the WHO-IOM Global Consultation on Migrant Health. Madrid, Spain. March 2010.

Huang, Shirlena; Yeoh, Brenda, 2003: "The Difference Gender Makes: State Policy and Contract Migrant Workers in Singapore", in: Asia and Pacific Migration Journal, I2,I- 2: $75-98$.

IOM (International Organization for Migration), 20I0: World Migration Report 2010 (Geneva: IOM).

Koh, Cha-Ly, 2009: The Use of Public Space by Foreign Female Domestic Workers in Hong Kong, Singapore and Kuala Lumpur (Cambridge, Mass.: Massachusetts Institute of Technology).
Lorant, Vincent; Van Oyen, Herman; Thomas, Isabelle, 2008: "Contextual factors and immigrants' Health Status: Double Jeopardy", in: Health \& Place, I4,4: 678692.

Marin, Maria Lourdes S., 20I2: "Navigating Borders, Negotiating Bodies: Sexual and Reproductive Health and Rights of Women Migrant Workers". Paper presented at "Beyond ICPD and MDGs: NGOs Strategizing for Sexual and Reproductive Health and rights in Asia-Pacific. Kuala Lumpur, Malaysia, 3-5 May $20 I 2$.

Oishi, Nana, 2005: Women in motion : globalization, state policies, and labor migration in Asia (Stanford, Calif.: Stanford Univ. Press).

Quesada, James; Hart, Laurie Kain; Bourgois, Philippe, 20II: "Structural Vulnerability and Health: Latino Migrant Laborers in the United States", in: Medical Anthropology, 30,4: 339-362.

Sobritchea, Carolyn I.; Subingsubing, Dino Alberto; Quesada, Amara T., 20Io: Health of our Heroes Access to Sexual and Reproductive Health Services and Information of Women Migrant Domestic Workers (Quezon City: Action for Health Initiatives [ACHIEVE] Inc.)

Teo, Youyenn; Piper, Nicola, 2009: "Foreigners in Our Homes: Linking Migration and Family Policies in Singapore", in: Population, Space and Place, 15,2: I47-159.

Tillu, Jasmine S., 20II: Spatial Empowerment: The Appropriation of Public Spaces by Filipina Domestic Workers in Hong Kong (Cambridge, Mass.: Massachusetts Institute of Technology).

World Health Organisation, 20Io: Health of Migrants: the Way Forward - Report of a Global Consultation, Madrid, Spain, 3-5 March 2010 (Geneva: WHO).

World Health Organization, 2008: Secretariat Report. Health of Migrants, $6 I^{s t}$ World Health Assembly (Geneva: WHO).

Yeoh, Brenda S. A.; Huang, Shirlena, S. L., 2000: “Home’ and 'away': Foreign Domestic Workers and Negotiations of Diasporic Identity in Singapore", in: Women's Studies International Forum, 23,4: 413-429.

Yeoh, Brenda S. A.; Huang, Shirlena, S. L., 20I0: "Sexualised Politics of Proximities among Female Migrants in Singapore”, in: Population, Space and Place, 16,1: 37-49.

Open Access. This chapter is distributed under the terms of the Creative Commons Attribution Non-commercial License, which permits any noncommercial use, distribution, and reproduction in any medium, provided the original author(s) and source are credited. 


\title{
13 Sub-Saharan Migrants' Masculinities: An Intersectional Analysis of Media Representations during the Libyan War 2011
}

\author{
Maria DeVargas and Stefania Donzelli ${ }^{1}$
}

\begin{abstract}
Studies of the role of the media in conflict situations have brought to the fore the significance of representations as an important part of the process of knowledge production about wars and the actors involved. The media can influence interpretations and framing of conflicts, moulding specific understandings of their causes and modalities of intervention. The Libyan war in $20 \mathrm{II}$ is an interesting case to reflect on the United Nations (UN) principle of Responsibility to Protect (RtoP), and how conflict affects those populations who occupy a subordinate position in multiple stratification systems (gender, race, and class), whether they are locked in conflict zones or are trying to join the flow of people fleeing across borders. In the context of humanitarian intervention, specific understandings of the migrants as social subjects become strongly correlated with corresponding support mechanisms. This chapter conducts an intersectional analysis to provide a perspective on the politics of the media representation of 'migrants' in Libya, discerning the key links between the constructions of their masculinities and the practices of protection for 'people on the move'. We show how, being situated at the bottom of the social hierarchy in Libya, sub-Saharan black Africans were inappropriately presented in media coverage during the initial phase of the conflict as subjects of adequate protection. Their invisibilization and subordination by the media have been largely framed within international political and economic interests, which have also reinforced the idea of the international community as the legitimate protector of civilians. We argue that these representations reproduce migrants' vulnerability and, by placing them in a situation of triple jeopardy (structural, political, and representational), undermine the possibility of conceiving and understanding security beyond their 'naturalized' victimization and subordination.
\end{abstract}

Keywords: Masculinities, intersectionality, media representations, sub-Saharan migrants, Libya, human security.

\subsection{Introduction}

Following the United Nations' report Human Security Now (Commission on Human Security/UNOPS 2003), the Responsibility to Protect (RtoP) has now become the main normative framework for approach-

1 Authors' names are indicated in alphabetical order as their contributions to the paper are considered equally valuable. Maria DeVargas works as Researcher Assistant and Project Officer for the project promoting this book at the International Institute of Social Studies (ISS), Erasmus University Rotterdam. She is a psychologist with a Master's in Development Studies at ISS. Stefania Donzelli is a Ph.D. researcher at the International Institute of Social Studies (ISS), Erasmus University Rotterdam. Her main research project focuses on migration, feminism, and social movements. ing human vulnerabilities and international community interventions (Fukuda-Parr/Messineo 20I2). While human security thinking is mainly concerned with the multidimensional impacts of threats to peoples, communities, and individuals, and is complementary to thinking on state security, the RtoP relates specifically to how the international community - employing a variety of means, including military ones can prevent and stop genocides, war crimes, ethnic cleansing and crimes against humanity occurring in internal conflicts (Hoogensen/Stuvoy 2006; Saxer 2008). These normative frames when associated to migration, "treat security as a value or condition" to be achieved by people on the move. In doing so, they move beyond the traditional understanding of state security, recognizing that "political concerns regarding security and mi- 
gration have shifted beyond the state to the transnational and global level" (Huysman/Squire 2009: 5).

Among the factors influencing access to security, social relations of power delineated by gender play a fundamental role. A consistent body of literature, emerging in the last decade, has focused on the relationships between women, gender, and the international security agenda, particularly UN Security Council Resolution 1325 introduced in 200I (Carey 200I; McKey 2004; Hudson 20I0; Heathcote 20II). Some authors have entered the debate focusing on the variety of forms of insecurity faced by women in conflict situations and while on the move, and showing women as actors who can help to create a more positive environment for social well-being (Hill/Aboitiz/ Poehlman-Doumbouya 2003; Pezzotti 2005). Others have broadened the meaning of security to cover many complex global problems beyond its conventional understanding, including environmental issues, HIV/AIDS, and economic crises (Scheffran/Brzoska/ Brauch/Link/Schilling 20I2; Gasper 20IO; Truong 2009; Kristoffersson 2000). In general, most scholars using the concept of gender have focused on women, and have failed to develop more comprehensive approaches to men and masculinities. Yet, as shown by Das (2008), empirical research has highlighted that attention to gendered differences in terms of constructions of masculinities and femininities can illuminate the complexity of situations of vulnerability. Such broader understandings of gender analyses, as Hoogensen and Stuvoy (2006) argue, have the potential to expand the definition of security from bottom-up perspectives by drawing attention to subjective experiences and allowing more complex comprehensions of the determinants of human insecurities. However, in order to open spaces for people-centred meanings of security, we claim the importance of deconstructing the dominant understanding of those considered subjects of protection as conveyed in public discourses. In fact, by showing problematic aspects of dominant discourses, we aim to highlight the importance of bottom-up voices to promote a debate on how identity constitutes a key element in articulating relationships of security and protection, and also on how subjects of protection as political actors in their own right can construct more inclusive forms of protection.

This chapter seeks to contribute to this literature by examining the links between migration, media construction of masculinities, and human security, focusing on the war in Libya in 20II, which triggered a critical migration emergency in the region. Our core concern relates to the role and influence of media representations in socially constructing sub-Saharan black Africans' identities. We argue that by reinforcing their status of multiple subordinations, these media representations contributed to reducing their access to protection while fleeing the Libyan conflict or sheltering from violent situations. For our purposes, we do not focus on evaluating the limits and merits of relief programmes developed in the context of Human Security and RtoP, but we seek to reflect on the media's function in implicitly communicating proposals about who should get access to these programmes and how and why they should get it, as well as in legitimating the underlying normative frames.

In order to enter the debate on who gets access to security, this study comprehends the meaning of 'border' as not limited to sovereignty and territoriality, but also as the demarcation of legal and social boundaries that allow different identities and groups to be defined as subjects of protection. In these terms, the meaning of border as the legal boundary of being a 'refugee', 'migrant worker', or 'expatriate staff' needs to be exposed so that definitions of accountability and norms as used by humanitarian organizations to administer evacuation and provide protection can be grasped. Similarly, the understanding of borders as cultural, ethnic, and racial frontiers arising from intergroup dynamics allows us to discern the different pathways through which people become 'locked into' a conflict zone, or are made socially visible as human subjects in need of protection. Exposing such legal and social meanings of boundaries and the particular value systems on which they are based, this chapter reflects on a constitutive element of the 'politics of representation' ${ }^{2}$ relevant to achieving more egalitarian justice, namely constructions of differential locations and forms through which diverse groups access protection, while others grant it (Fraser 2009). In this sense, the analysis of boundaries among collective identities presented in media information becomes relevant to issues of 'protection' in so far as the common representational strategies used by the media designate particular groups as 'subjects' to be protected or as responsible for protecting others. In other words, the representation of actors involved in conflict through such strategies as naturalization, normalizing, categorization, or framing entails the construction of the accountability of subjects, politics,

2 For readers unfamiliar with the concept, this 'politics of representation' or media representations means the forms in which media present identities and realities of different subjects and events. 
and actions in the field of human security (Hall I997; Leudar/Marsland/Nekvapil 2004; Zarkov 20II).

In Libya, the group of black people and sub-Saharan black Africans is a heterogeneous population, internally stratified by race/ethnicity, age, religion, class, sense of loyalty, nationality, and history of migration into the country. They also constitute a highly gendered group of migrants, in the sense that a considerable majority are male as men are more easily integrated into the construction, agriculture, and oil sectors offered by the Libyan labour market. Their treatment and subordination have been largely determined $^{3}$ by intersectional and dynamic patterns of violence related to the unfolding of the conflict. However, in addressing how the media construct subSaharan black Africans' masculinities in connection with the Libyan conflict, it is important to observe how, despite their diverse social locations, they tend to be homogenized by race/ethnicity along the lines of a 'threat' to different actors, and how this undermines their entitlements to security and protection as human subjects under international norms.

Studies of media and conflict have pointed out the significant role and risky implications of media categorization and other representational strategies regarding the selective exposure and characterization of certain actors and their particular conditions, which provide moral accounts and justification for particular actions (Hall I997; Zarkov 20II; Tucker/Triantafyllos 2008; Fudge 20IO). Media, located within the broader frameworks of contemporary processes of globalization and relying on discourses and forms of representation embedded in global societal power relations, propose specific understandings of international involvement, and may support non-intervention or call for action (Hall I997; Didero 20II; Fraser 2009). In vi-

3 This group of population includes Libyan citizens and foreigners in transit, with temporary or permanent status. In addition to their nationality and migratory status, the class elements are relevant to defining their position in the Libyan social hierarchy according to their education and type of job. It is also important to contemplate the diversity of race because not all come under the labels of black race or sub-Saharan ethnic groups. However, political and conflict dynamics define a large part of their treatment. For example: a black African who has Libyan nationality and is loyal to Gaddafi is in a very different position to a sub-Saharan black African migrant worker, or one who is in transit to Europe, or one detained by Gaddafi under his agreement with Italy on extra-territorial control. However, during the conflict the pattern of actions taken against black 'mercenaries' affected all the black population. olent conflicts, media construct perpetrators and victims in dichotomous ways, and often the information presented is unable to capture the cultural and structural dynamics behind processes producing intersectional identities, multi-layered belonging and affiliated vulnerability within conflict zones and during the process of fleeing. This makes the application of norms of protection by the 'protectors' a dubious area that must be subject to scrutiny towards the assembly of more egalitarian perspectives on justice.

To develop this argument, the chapter firstly discusses the theoretical posture on intersectionality elaborated by Crenshaw and its relevance to reflecting on the representation of sub-Saharan masculinities during the conflict. It then presents the preconditions for migrants' vulnerability in Libya, showing how systematic discrimination against them, emerging also from the historical development of migration policies in Libya, affected sub-Saharan migrants during the 20II Libyan conflict. Further, it discusses Bourdieu's concept of symbolic violence in relation to media representations of sub-Saharan and others' masculinities during the war in Libya. Finally, the study analyses the findings on sub-Saharan migrant masculinities as represented in three mainstream online news media: $A l$ Jazeera, The New York Times, and The Guardian. These media were selected because they address an international audience and have been influential actors in conveying specific understandings of the events during the war (Leudar/Marsland/Nekvapil 2004). To conclude, we present some reflections on the relevance of intersectionality to analysing media characterization of various vulnerable groups, discussing the importance of uncovering media's symbolic forms of violence within the claim for more comprehensive, egalitarian, and bottom-up understandings of human security. Some reflections on the practice of journalism and migration policies are also presented. In particular, the Libyan case raises important concerns in terms of the regulation of human mobility and the guidance and practice of Responsibility to Protect.

\subsection{Understanding Masculinities Through the Lens of Intersectionality}

The concept of intersectionality, since its emergence within black and third world feminist movements in the I970s and its academic re-elaboration from the late $\mathrm{I} 980$ s into the present, has inspired a comprehen- 
sive body of literature that focuses on multiple and cross-cutting forms and practices of exclusion, discrimination, and oppression (Bürkner 20I2). A main contribution in this field was made by Crenshaw in 1989, who coined the term intersectionality to address black women's experiences of domestic violence at the intersection of race and gender at different levels, a neglected juncture between different systems of oppression. Her approach allows an important distinction between the inequalities constituted by structural variables, e.g. to be poor, black, and male, and by political factors, e.g. cultural variables and social relations according to political agendas (Walby/Amstrong/Strid 20I2). The lens of intersectionality reveals how subjects are positioned and constituted by mutual shaping and constitution of intertwined context-specific structural conditions, discourses, and social practices (Yuval-Davis 2006; Walby/Amstrong/ Strid 20I2). These social practices are understood as context-based arrangements articulating overlays of oppressions linked to the distribution of locations and resources in society around different categories such as gender, ethnicity, and class, and at different levels such as structures, representations, or identity construction (Bürkner 20I2). Within this framework, the understanding of contextual elements avoids essentialism and generalizations that do not reflect the intersectionality of various categories.

Crenshaw (I99I) delineates three levels of intersectionality: structural, political, and representational. Structural intersectionality refers to the production of disempowered locations generated by intersecting structural patterns of subordination. In the case of black women addressed by the author, the junction of race and gender make their experience different from that of white women or black men. Political intersectionality speaks of clashes in the political agendas of different groups performing advocacy around particular features of marginal sectors and the imperatives that the marginal subjects are facing. For instance, the situation of black women is often ignored by the political agendas of both anti-racist and feminist groups, who have marginalized the specific circumstances of subordination of women of colour. Finally, representational intersectionality is linked to the construction of subjects' identities in popular culture. One example would be constructions of black men as agents of sexual violence against white communities, which become their fixed potential victim (Crenshaw I99I).

Crenshaw's frame contributes to debates on the potential of the concept of intersectionality for analysing the conditions of different social groups, by grasp- ing the complexity of factors involved in producing vulnerability and differentiated experiences of access to a life with dignity and safety. This angle on intersectionality can enable a more integral examination of the normative frame of human security, both in terms of deconstructing dominant notions and advancing a people-centred perspective. It is consistent with feminist approaches to human security that have highlighted the importance of acknowledging the differences masked by the term 'human' when addressing the politics of multiple overlapping social relations of power when engaged in the construction of the subjects (Hudson 2005). In this sense, the concept of intersectionality from Crenshaw's perspective contributes to enriching the paradigm of human security, because it facilitates the identification of multidimensional aspects and cross-cutting factors that condition a person's life. In the migrants' case, it is also applicable to an analysis of access to safe spaces and life with dignity, in terms of both an absence of direct threats as well as the conditions required for a better quality of life within a peaceful environment.

The case of sub-Saharan migrants during the Libyan conflict reflects an experience of the notion of 'triple jeopardy' used by feminist movements, meaning the oppression generated by simultaneous and interconnected patterns of oppression proceeding from the systems of racism, imperial capitalism, and sexism (Aguilar 20I2). The location of sub-Saharan migrants at the bottom of Libyan society as well as their vulnerability during the war appear linked to racialized, classed, and gendered constructions of their identity. These constructions are not fixed and their dynamics are to a large extent defined by contextual factors. They shift in the Libyan political system, moving from an understanding of black migrant workers as a necessary recruited labour force to economic burdens to deport. These changes in the construction of migrants' identity make their lives precarious, reinforcing their subordination, in a continuum along the structural and representational levels proposed by Crenshaw (199I). For this study, we focus on the representational level, where media play an important role in reinforcing or transforming the contents of those social constructions. An intersectional analysis of media representation will therefore result in a valuable tool for deconstructing how certain subjects are included in the ideas of security advanced by media. In this sense, the 'triple jeopardy' location of sub-Saharan migrants as well as their representations in media become highly influential factors in the achievement of their human security as media participate in 
establishing the frame of the debate on mechanism of protection.

Since, in the Libyan conflict, skin colour was a factor relevant to migrants' vulnerability, we are interested in race. Race is here understood as a constructed differentiation of people who are grouped around 'exclusionary/inclusionary boundaries' according to phenotypic features (Yuval-Davis 2006: 20I). Racial differences have been also used to construct and justify ideas of superiority, discrimination, and exploitation, which become normalized within society (Gopalkrishnan/Babacan 2007). Racial social hierarchies have deep historical roots, and they have not always been rationally constructed nor consciously identified. However, in conflict situations it is common to find that the link between race and ethnicity is an important habitual strategy of representation used by media to construct the 'good' and 'bad' actors. Further, media's selective reference to actors and events in racial terms raises or lowers the visibility of victims and perpetrators (Zarkov 20II). Inside this process, the role of media in perpetuating 'stereotypical images' could undermine the security of vulnerable groups because these 'symbolic tools' can influence practices dealing with the protection of civilians (Carpenter 2005).

In the case of Libya, a 'rentier' state with a small population extremely dependent on a foreign workforce, sub-Saharan migrants have usually been placed at the bottom of social hierarchies, becoming scapegoats for societal issues while performing jobs that are unwanted by the local population under exploitative conditions. Therefore, to understand migrants' vulnerability it is relevant to reflect on the topic of class, because class is a form of social boundary "grounded in relation to the economic processes of production and consumption" (Yuval-Davis 2006: 20I). In addition, class variables generate different forms of inequality and therefore are relevant to understanding marginalized groups and masculinities. In conflict situations class is a key aspect linked to risk because class determines the possibility of access to livelihood resources, and is therefore a crucial element in guaranteeing access to security. At the representational level, class divisions are usually normalized and migrants have become naturalized as part of the lower classes, so that selective access to protection is justified.

As mentioned earlier, gender is also a main aspect of interest for this study because its analysis allows the recognition of power relations established between and within groups of men and women, in the frame of societal structures that broaden or limit their op- portunities in differentiated forms. Gender is here understood as a "mode of discourse that relates to groups of subjects whose social roles are defined according to constructed [sexual] differences" (YuvalDavis 2006: 20I). This analysis helps us in conflict situations to appreciate the dissimilarities in terms of gendered participation in and, the differentiated impact of violence on women and men (Lorentzen/ Turpin 1998). Further, gender analysis uncovers additional understandings of media representations of how male/female migrants deal with and should access protection and security. For example, representations of civilian men in wars usually entail forced participation in violence or involuntary-compulsory exile from their community. This aspect of analysis is particularly relevant to the Libyan case, where most migrants are male. ${ }^{4}$ Moreover, centring the analysis on men makes it possible to identify how masculine characteristics and values of physical force, bravery, and honour are associated with the role of different actors and their particular gendered involvement in conflicts. This is not to say that manhood and masculinity are homogeneous categories: they intersect and interact within various social relations of power embedded in media representations. By adopting the intersection of race, class, and masculinities within the conditions of being sub-Saharan migrant workers as the main focus of analysis, we aim to understand how different masculinities are set in hierarchies, defining both priorities and positions from which to access protection and security. To understand these hierarchies, it is useful to begin with Connell (2005), who defines representations of masculinities as "symbolic processes of configuring practices" that transform gender relations over time. Within these processes, different types of masculinities can be identified: hegemonic, complicit, and subordinated (Connell 2005: 72).

Hegemonic masculinity comprises a set of values associated with the socially idealized model of manhood, implies dominance over other forms of masculinity, and shapes the organization of social and symbolic processes because of its links with institutional power (Connell 2005). It tends in international media representations - which often identify global values and norms with mainstream Western ones - to be associated with a secular, independent, and well-educated Western white bourgeois man, who is able to

4 Surveys of returnees during the Libyan war suggest the vast majority (over 95 per cent) are male and young (20 to 40 years) sub-Saharan migrants as well as Egyptians, Tunisians, and Bangladeshis (IOM 20I2). 
properly participate in wars to protect the nation and its ideals (Das 2008; Foster 2007; Carrigan/Connell/ Lee I985; Mohanty I99I; Connell 2005). Currently, hegemonic masculinity tends to be considered as not marked by aggressiveness (which in a conflict context is linked with modern warfare as the 'civilized' exercise of violence through the "mediation of law and technology" (Das 2008: 286)), but as rule-bound and rational among the relevant 'heroic' virtues.

Complicit masculinities refers to a type of manhood that, even if lacking some of the qualities and standards of hegemonic masculinity, still benefits from it and sustains the same hegemonic project (Connell 2005). From this logic complicit masculinities gain recognition in the masculine arena and achieve better power status for negotiation and broader opportunities for their interests. Within a warfare situation, this is the case for men who maybe do not fulfil all characteristics (such as race, class, knowledge, technology, or rationality) associated with the West, but who embody "the image of idealized masculinity through which they imagine themselves as participating in a universal worldwide military culture" (Das 2008: 288).

Finally, subordinated masculinities are the constructed sets "symbolically expelled from hegemonic masculinity" (Connell 2005: 78), which therefore lack legitimacy and whose characteristics tend to be blurred with feminine ones. This category is usually assembled as fragile, fearful, disgraceful, poorly educated, and therefore disempowered to act in negotiation or to control affairs. Within conflict, subordinated masculinities are usually presented as lacking any heroic virtue such as courage or capacity for selfsacrifice. Furthermore they are effeminate through references of fear, fragility, and dependence, and sometimes exposed within shameful situations to confinement, torture, or even sexual violence (Das 2008; Zarkov 20II).

In addition to these three types of masculinity, Connell (2005) introduced the category of marginalized masculinities, related to a more complex set of masculine hierarchies in which social differentiations based on gender intersect with other features directly associated with race, class, and so on. Marginalized masculinities embody different symbolic roles which are not just excluded from but antithetical to hegemonic masculinities. Within conflicts, for example, marginalized masculinities would include behaviour seen as savage and under the control of visceral passions. Their irrational characters lead them to inherently nihilistic forms of violence. Moreover, they are often represented as feminized in order to produce a humiliation of their manhood (Das 2008).

\subsection{The Production of Vulnerabilities and Instrumentalization of Migrants in Libyan Regulatory Migration Regimes}

In Libya's territory, migrants are a significant presence: they account for between eleven and twenty-five per cent of the population according to different figures, representing around 2.5 million foreign nationals in the country before 2OII (IOM 20I2). This figure includes from I to I.5 million sub-Saharan Africans, mainly from Niger, Chad, Mali, Nigeria, and Ghana (CARIM 20II; IOM 20I2). During the uprising and the conflict in Libya in 2OII, these groups suffered repeated experiences of violence, which strongly evidenced the conditions of vulnerability and life-threatening conditions lived by sub-Saharans staying in or transiting through Libya.

The International Organization for Migration (IOM) claims that this conflict has caused the worst migration emergency in the region since the first Gulf War. About 790000 migrants and their families crossed borders and concurrently a consistently high but indefinite number of migrants were caught in a situation of involuntary immobility, exposed to the violence of the war, stranded in overcrowded transit areas and camps, and obliged to use unsafe escape routes. Sub-Saharan Africans constituted a large part of this group, which was not in a position to be evacuated from the country (IOM 20I2; IMI 2OII; CARIM 2OII).

A number of historical preconditions gave rise to sub-Saharan Africans' vulnerability during the Libyan war in 20II, including most importantly the historical regulatory regime of migratory movements. In fact, changing and sometimes contradictory migration policies have made migrants' conditions in Libya precarious. This particularly affected sub-Saharan Africans, who have come to inhabit the most vulnerable positions in Libyan society, from which access to legal protection and economic resources is limited. Shifts in migration policies have been employed to cope with internal economic and political needs and used to satisfy the requirements of the international alliances established at each time. In particular, Libya's profile as a 'rentier' state meant that it both needed to attract an immigrant workforce and was exposed to the volatility of oil prices. The latter in particular led to periods 
of unemployment during which the presence of migrants was seen as a burden. Furthermore, in its shifting political alliances with Arab, African, and European countries, the Libyan state saw advantages in instrumentalizing the presence of migrants as political leverage in international diplomacy, prioritizing its raison d'état over the security of migrants.

Historically, transnational mass migration to Libya started in the early I960s with the discovery of energy resources in 1959 and the consequent establishment of large modernization programmes, which stimulated a high demand for a low-skilled labour force. Given that the Libyan population was small, large numbers of workers from neighbouring countries were recruited and Libya begun to rely heavily on immigrants for its economic development (Brachet 20II; De Haas 2008; IOM 20I2). This trend continued until the r 980 s, when the collapse of oil prices and the pressure of international embargoes ${ }^{5}$ made the country enter a period of recession. In an attempt to curb unemployment, Libya reduced, through mass deportations, the numbers of migrant workers in the country (Altunisik 1996). Given their presence in Libya at that time, these deportations disproportionately affected sub-Saharans, ${ }^{6}$ with a consequent reinforcement of their status as the most marginal migrants in the country. At the beginning of the 2000s, Libya faced an economic downturn and again used migrants as a scapegoat for societal problems (Huliaras 200I; Paoletti 20II; IMI 20II). Particularly emblematic of this second trend were the deportations following the clashes between Libyan and sub-Saharan workers in 2000 that had led to the killing of hundreds of migrants (Johnson 2000). In this case, state authorities did not pro-

5 During the I970s and I980s Gaddafi pursued an antiWestern imperialist policy, financially supporting insurgencies and radical governments in different parts of the world, including sub-Saharan Africa. During those years, Libya was accused by the West of supporting international terrorism. In response to the country's conduct in international affairs, the United States set up an oil blockade in 1982, the European Union established arms restrictions in 1986, and the UN imposed an air and arms embargo in 1992 (Ronzitti 2009).

6 Migrants from the sub-Saharan region represented nine per cent of the total migrant population in Libya in 1984 (Paoletti 20II). However, when oil revenues decreased in 1985, Tripoli expelled or laid off more than I00000 workers from Mali, Mauritania, and Niger in response to an economic crisis (Huliaras 200I). In the same year, 80000 Tunisians and Egyptians were deported in a general context where Libya accused Tunisia and Egypt of being pro-US (De Haas 2008). tect the sub-Saharans. On the contrary, responding to the hardening of anti-immigrant sentiments, more restrictive immigration policies were introduced and mass expulsions organized. This, together with arbitrary police treatment reserved for sub-Saharan migrants, increased the vulnerability of the wider black population (De Haas 2008).

Since coming to power in 1969, Gaddafi took a very pragmatic approach in his external policy, modifying Libya's alliances in response to transformations in the political and economic international environment (Paoletti 20II). A common trend until the end of the I990s was a strong anti-Western stance. At the beginning of the Gaddafi regime, Libya embraced Nasser's pan-Arabism (Huliaras 200I). As part of this agenda, preferential treatment for Arab migrants was given by, for example, facilitating access to Libyan citizenship and to other rights (Global Detention Project 2009; CARIM 20II). This established an unfavourable context for sub-Saharan Africans in terms of legal protection, with most able to access only the lowest-paid and least-protected jobs, making them easily exploitable and relatively more exposed to arbitrary police treatment (De Haas 2008). Beginning in the 1990s, Libya had to face the lack of support from Arab countries in the face of a UN embargo, and started to pursue a pan-African policy. Among the leverages employed by Libya to strengthen this new alliance, instrumental management of migrants took a substantial role. Thus a policy of threatening and carrying out deportations was later reversed into an open-door policy towards sub-Saharan nationals, to show Libya's commitment to reinforce ties with African countries. More precisely, the I990s saw the adoption of legal regulations to end visa requirements for sub-Saharan Africans: Libya thus became a major destination for migrants from West Africa and the Horn of Africa (CARIM 2OII).

Another major change in Gaddafi's international agenda came with his alignment with Europe at the beginning of the 2000s. This shift came about in relation to Libya's intention to regain international respectability, lift the embargo, and attract direct foreign investment. European interests in externalizing 'border control' to neighbouring countries also explain this $\operatorname{shift}^{7}$ (Paoletti 20II). As a result, Libya positioned itself as an EU partner in the governing of migratory movements by firstly reviving Italian-Libyan colonial ties and later by cooperating with the European Union. Among the main agreements it is worth remembering the 2003 operational pact, allowing Italy to sponsor the construction of detention camps 
for undocumented migrants in Libya; Italian financing of Libyan police training for border surveillance, border control equipment, and deportations of migrants from Libya to their countries of origin since 2004; and the 2008 Friendship, Partnership and Cooperation Treaty that sanctioned intense cooperation in different sectors and introduced new and contested measures such as pushing back practices in violation of the 'principle of non-refoulement' ${ }^{8}$ (Ronzitti 2009; Kumar 20II). This collaboration securitized migration, following the EU tendency to conflate crime, terrorism, and migratory movement. This reduced access to legal protection and the absence of any pressure on Libya to ensure the protection of refugees made the condition of its migrant workers and asylum seekers from sub-Saharan Africa even more precarious (Global Detention Project 2009; Kumar 20II). Thus both economic and geopolitical peculiarities of Libyan history led to the instrumentalization of migrants as political leverage.

The result of the cooperation between the EU and Libya is a good example of how instrumental regulation of migratory movements affected the security of migrants in Libya. In fact, this new international policy on sub-Saharan migrants resulted not only in tighter border controls and an expanded detention infrastructure but also promoted two further reforms reducing migrant security. In 2004, harsher penalties, heavy fines, and up to twenty years' imprisonment for crossing borders without the required travel documents were established (Global Detention Project 2009). In 2007, open-door policies were ended and visas for both Arabs and Africans became obligatory. At

7 At the end of the I990s and beginning of the 2000 s the EU increasingly framed Libya as a strategic territory for the movements of people through the Saharan and Mediterranean regions, despite the fact that the transSaharan space has been traditionally crossed by people in movement (Blanchet 20II). On the one hand, economic downturns and regional conflicts increased migration flows in the trans-Saharan space and tight controls on other parts of the Mediterranean coast, in particular the Straits of Gibraltar, resulted in a partial reorientation of migratory movements with migrants trying to reach Europe from Libya. On the other, Libya remained mainly a destination country, but its description as a transit area has been used as political leverage for Gaddafi to negotiate with European governments (De Haas 2008; Branchet 20II; Paoletti 20II).

8 The principle of non-refoulement refers to "the obligation of states not to forcibly return people to countries where they face persecution or serious harm" (UNHCR 2OII). the same time, changes concerning residence and labour permits suddenly turned an unknown number of immigrants into irregulars (CARIM 2OII). In this context, racist insults ${ }^{9}$ and attacks, inequitable police treatment, thefts, and failure to be paid after completing work were increasingly reported by sub-Saharan Africans (Hamood 2008). These trends highlight how the processes of migration management engender conditions of vulnerability and open spaces for diffused legitimate violence against the migrant population.

In sum, marginalization of migrants in Libyan society, differential treatment for racially differentiated groups of migrants, contradictory political agendas, economic interests, and the processes of EU externalization of migration controls all laid the basis for the reproduction and escalation of violence against subSaharans during the 2OII conflict. This trend was evident even at the beginning of the protests: in February 20II, rumours and statements regarding Gaddafi's hiring of mercenaries from sub-Saharan Africa resulted in rebel forces attacking black people, both migrants from sub-Saharan Africa and black Libyans. At the same time, sub-Saharans and blacks feared both rebel attacks and being drafted into Gaddafi's army (Del Grande 20IIc). Their situation did not reach the attention of the international community, while stories of black mercenaries did. The international community did however uphold the principles of Responsibility to Protect and human security as its underlying framework with the declared intent of avoiding mass violence and guaranteeing the safety of civilians (ICRtoP 20I2). In March 20II, UN resolutions 1970 and 1973 first imposed an arms embargo and a travel ban on the Gaddafi family and members of government, froze the assets of the Gaddafi family, and referred the situation to the International Criminal Court for investigation, and later sanctioned a no-fly zone to protect Libyan civilians, and authorized Member States, in cooperation with the Security Council, to take "all necessary measures [...] to protect civilians and civilian populated areas under threat" (UN 20II). ${ }^{10}$

This lack of attention to the position of sub-Saharans was evident again in the process of evacuation organized by the international community. While Libyans and groups of migrants fled the country in large

9 It is common in Libya to refer to a black person with the derogatory and depreciatory term of ' $a b d$ ', in English 'slave' (Hamood 2008: 40).

10 See Press Release from United Nations, Security Council 10200-6498 $8^{\text {th }}$ Meeting; at: <http://www.un.org/ News/Press/docs/20II/scIO200.doc.htm>. 
numbers, in most cases sub-Saharan migrants did not find a safe escape route and were involuntarily immobilized in Libya without the basic conditions for a life with dignity (IMI 20II; UNCHR 20IIa). Sub-Saharan migrants who reached the Tunisian, Egyptian, and sometimes the Chadian borders requested refugee status but remained stuck in transit camps (UNCHR 20IIa). Even in the absence of precise data, ${ }^{11}$ it is possible to state that great numbers of civilians who escaped by sea died in the attempt (Forte 20IIa). Those who did manage to reach the coasts of Italy and Malta found themselves in the detention-deportation system of the European Union regime of migration control (Del Grande 20IIa). In particular, the measures provided by the Italian state under the framework of an emergency Reception National Plan ${ }^{12}$ have been criticized for holding asylum seekers under inhumane conditions, examining asylum applications with extreme slowness, and denying refugee status to most non-Libyan nationals on the basis that they are in a position to return to their home country (Garelli/ Tazzioli 20II; Vassallo Paleologo 20II). Concurrently, internal displacement persisted, and violence against blacks did not cease (Koser 20II; UNCHR 20IIa/ b). ${ }^{13}$ Furthermore, the war in Libya has had negative consequences for all migrants in terms of employment and income, increasing their vulnerability by reducing their access to food and health care. This material vulnerability is reflected in migrants' returning to their home countries, where they face a lack of economic resources and their families are confronted by the absence of remittances (IMI 20II; IMO 20I2).

A set of contradictory interests have crossed the discourses and practices of the international community during this conflict, prioritizing migration control over concerns about the security of migrants remain-

11 According to UNHCR, "More than I500 drown or go missing trying to cross the Mediterranean in 20II" (UNHCR 20I2); at <http://www.unhcr.org/4F2803949. html>.

12 To consult the plan see at: <http://www.protezionecivile. gov.it/resources/cms/documents/Piano_migranti.pdf>.

13 In a press release of 22 August 20II, Antonio Gutterres, High Commissioner for Refugees, is quoted as follows: "We have seen at earlier stages in this crisis that such people, Africans especially, can be particularly vulnerable to hostility or acts of vengeance" (UNCHR 20IIa). Addtionally, at the time of writing [August 20I2], three sub-Saharan asylum seekers were killed by the Libyan military during a protest in a detention centre for refugee applicants to the east of Tripoli. See at: <http:// habeshia.blogspot.it/20I2/o8/a-massacre-of-asylum-seekers-in.html> (30 August 20I2). ing in Libya. In fact, even where external intervention was planned to guarantee civilian safety, NATO forces did not act consistently to protect sub-Saharan migrants and refugees within and outside Libya. Minimal evacuations and actions were organized to address the particular dimensions of risks and threats to the sub-Saharan population. On the contrary, European countries saw any movements towards their territories as an 'incoming invasion' ${ }^{14}$ and failed to act in favour of migrants' security, something particularly needed for this group. Emblematic of this attitude has been the Atlantic Alliance's refusal to help migrants' drifting boats at the end of March and at the beginning of August, which caused dozens of deaths (Del Grande 2OI2b). Even as substantial resources were allocated for humanitarian aid and some emergency evacuations were organized by UN agencies later in the war, the protection of sub-Saharans' lives was not a clear priority. Instead, precedence seemed to be given to the control of migratory movements. Indicative of this is a proposition by the Italian government in June 2OII that solicited NATO to block migrants' ships and return them to the southern shore of the Mediterranean, which clashed with Italian and European discourses and practices concerning humanitarian aid and support (Migreurop 20II). In short, the EU understanding of sub-Saharans as a potential threat increased migrant vulnerability to violence and life-threatening circumstances.

\subsection{Symbolic Violence and Media Representations of the Libyan Conflict}

To confront the violence lived by sub-Saharan migrants in Libya and the limited political will as well as the action displayed by the international community to guarantee their security, it is relevant to show how the identities of sub-Saharan migrants have been constructed within the media. As the principal source of

14 De Haas (2012) has noted that both European politicians and media have repeatedly referred to an incoming invasion. For example the Italian Minister of Foreign Affairs, Franco Frattini, has talked about "an invasion of two to three hundred thousands of migrants", while the Italian Interior Minister has referred to a "human tsunami”. See at: <http://www.corriere.it/esteri/11_feb braio_22/evacuazione-italiani-libia_I3FI56FC-3E78-IIe0-a0 25-F4888ad76c86.shtml>; <http://ricerca.repubblica.it/ repubblica/archivio/repubblica/20II/O4/2I/la-polemica. html> (20 June 20I2). 
information on which global public opinion relies, media representations produce meanings and relations that make sense of the violence they narrate and, consequently, suggest appropriate behaviour and conduct (Titscher 2000). Representations of different actors in war contexts, through specific narratives, framings, and categories, are key elements through which media implicitly or explicitly advocate, construct, or justify modes of action (Leudar/Marsland/ Nekvapil 2004). It follows that how sub-Saharan migrants have been approached will be strongly connected to media representations of the Libyan conflict as well as of its causes, responsibilities and contributing factors, and the possible solutions to the migration crises that it entailed.

As mentioned earlier, intersectional analysis can illuminate how the positioning and constitution of subjects and groups in society are constructed at different levels and through different and interrelated social discourses and practices. Since social discourse is at a macro-level filtered through and by media, our focus on media aims to address the level of symbolic representations circulating in societies. Such representations have been defined by Bürkner (20I2), following Crenshaw (I99I), as part of the meso-dimension of intersectionality, revealing interdependencies among different societal structures (macro-dimension) and processes of identity construction (micro-dimension). However, for our purposes, only the interconnections between symbolic representations and structures need to be addressed. Thus here intersectional analysis is employed to enable us to comprehend how media representations of sub-Saharan migrants during the 20II Libyan war suggested why and how migrant security should be addressed and who should address it, and placed this within a context of transnational migration management. In addition, this analysis specifically focuses on how the intersections of the categories of masculinities, race, and class enable a deeper comprehension of media representations and their role in conflict, as well as how this affects other actors.

Finally, the analysis reveals suggestions conveyed by such representations about how to address migrants' access to security in conflict, expressed in many cases through categorization ${ }^{15}$ strategies. For example, when sub-Saharans are defined as 'mercenaries' - in journalists' reports 'according to rumours' ${ }^{16}$ -

15 'Mercenaries', 'poor desperate', 'helpless', and 'trapped' are some of the most frequent terms found in the news media in reference to the sub-Saharan population in Libya. some media implicitly argue for the need to control and securitize 'these dangerous' subjects, instead of arguing for their protection. This type of categorization also supports the rebels' call for an external intervention by the international community in order to pacify the situation. ${ }^{17}$ In addition, when migrants are described as 'poor' and 'desperately hoping' to reach Europe, the implicit message argues for the importance of limiting arrivals of sub-Saharans on European coasts, as they might constitute a danger for the local population because of their condition of despair. ${ }^{18}$

Media representations of sub-Saharans during the coverage of the Libyan war as well as their implications for migrants' security have been debated both in academia and other circles. The international media's silence about the lynchings of both sub-Saharan migrants and black Libyans in the first stage ${ }^{19}$ of the conflict has been criticized as diminishing the dignity and worthiness of these lives (Chatora 20II; Marshall 20II; Forte 20IIa/b). Further, media emphasis on the rebels' claims about sub-Saharan mercenaries may, it has being argued, have fuelled these events, firstly by corroborating unconfirmed information and secondly by making violence against the black population in Libya acceptable by framing sub-Saharan migrants as dangerous subjects. These media representations have been seen as reinforcing the urgent claims for external support to the rebellion, later concretized with the NATO humanitarian intervention. Overall, media also have been thought to support the narrative of a united Arab Libyan people committed to fighting against an isolated Gaddafi, supporting calls for an international intervention (Forte 20IIa/b; Marshall 20II). International media have also been criticized for constructing the fear of an invasion of Europe by overemphasizing sub-Saharans' movements from Libya to Europe across the Mediterranean, without questioning the dimension of the real numbers ${ }^{20}$ or the lack of protection experienced by migrants (De Haas 20I2).

16 See Forte, 20II "The top ten myths in the war against Libya"; at: <http://pambazuka.org/en/category/features/77439>.

17 See for example article (I) analyzed from the New York Times.

18 See for example article (2) analyzed from the New York Times and articles (3) and (4) from Al Jazeera.

19 We consider the first stage to have lasted from February to July 2011, when violence against sub-Saharan Africans was invisibilized. It was not until August, with the publication of human rights and other international studies, that media started to mention in a more visible way the lychings of sub-Saharan Africans. 
However, research exploring sub-Saharan racialization has failed to intersect such understanding with gendered social practices. Thus this study, conducted on the media representation of sub-Saharan migrant masculinities during the Libyan conflict, may be one of the first. It shows that the construction of their identity in the news has strongly relied on ideas about maleness: as presented by different studies, migration, conflict, and state ${ }^{21}$ are highly gendered processes and institutions whose meanings media contribute to constructing. For example, sub-Saharan men were often framed as potentially active actors in the conflict, whether as mercenaries or as objects of forced enlistment: ${ }^{22}$ their participation or exclusion from the war as well as their sense of loyalty were part of the construction of their maleness. The same could be said about the media representation of 'migrants' in Libya as an exclusively male category. These elements influenced their positioning at the bottom of different hierarchies of masculinities, at the same time that it had important repercussions for the framing of their vulnerability and the possible understanding of their human security. This shows the relevance of considering masculinities of migrants in the 20II Libyan conflict. Additionally, as some studies in racist violence suggested, masculinity is relevant "since the perpetrators of most racial attacks are young men attacking other young men" (Anthias 2007: I4).

Thus, media representations constitute and position subjects, suggesting, justifying, or promoting particular behaviours and actions (Leudar/Marsland/ Nekvapil 2004). In so doing, such representations may exercise forms of symbolic violence by legitimizing as valid certain models and norms. As Bourdieu suggests, symbolic violence is a "hidden [...] gentle, invisible form of violence, which is never recognized as such" (Bourdieu 1977: 192). It assigns characteristics to social groups that make acceptable and even natural their subordinated or privileged location, while questioning these positions is made harder precisely because such normalization is not openly exposed (Bourdieu 1977). Additionally, as socio-psychological studies have shown, the symbolic violence intrinsic to stereotypes and prejudices is difficult to convert with-

20 It is estimated that just 24465 persons ( 3.9 per cent) of the overall 790000 migrants and their families fleeing Libya arrived in Italy and Malta (IMO 20I2).

21 Charlotte Hopper (2008) is one of the few authors who elaborate on the links between masculinities and state, particularly in the book Manly States: Masculinities, International Relations and Gender Politics.

22 See Al Jazeera (2), (3), (6), and (9). out detailed and deep analytical reading, because much of the content and subtle assumptions of such stereotypes and prejudices can be beyond rational awareness (APS 1997). Therefore it is important to reflect on dominant discourses, observing the elements and actors included, the ways in which they are represented, and the consequences of these representational strategies for debates about security. Representation may thus justify subordination, discrimination, exclusion, and marginalization of subjects who do not meet established norms. In Fraser's terms, "representation [is] the defining issue of the political", establishing who is subject to what security (Fraser 2009: I8).

\subsection{Visibilizing the Role of Media in the Creation of Human Insecurity: Information on the Libyan War 2011}

As the Libyan conflict became an international issue with the involvement of the so-called international community, this chapter uses three international mainstream media that aimed to address a global public. All three have online editions, generally free and more accessible, and in this chapter we consider a selected number of news and opinion articles covering the period of the conflict from the beginning of the protests in February 20II to the death of Gaddafi in October 20II. The media selected are The New York Times (NYT), The Guardian (TG), and Al Jazeera English (AJ). The first is a US national daily newspaper and its online edition is one of the most viewed in the world, despite the fact that since $20 \mathrm{II}$ free online access to its archive has been limited. Its political line is considered centrist, and it is owned and financially controlled by a corporation. The Guardian is a British national daily newspaper, also with an international online multimedia presence. Its editorial line tends towards centre-left liberalism and its position on migration issues tends to be considered quite progressive. Its contents and archives are freely available online. Funded by a charitable foundation, The Guardian claims to be characterized by political independence. Al Jazeera English is a news channel broadcasting from Doha and London. It aims to provide a liberal perspective from the Global South on global issues, specifically conveying a Middle Eastern point of view. It has been criticized for adopting both a pro- and an anti-Western bias, and also for reporting in a crude style described as a 'negative trend'. ${ }^{23}$ Financially, $A l$ 
Jazeera depends mostly on Qatari government subsidies.

In addition to their wide audience, the criteria applied for selecting these media have been their recognition at the international level and the different perspectives they are believed to offer in terms of political and geographical standpoints. For the selection of articles, at first we conducted a research exercise into archives to identify news dedicated to the Libyan conflict and focusing on sub-Saharan Africans. Second, from this base sample we chose specific articles to analyse - news and opinion texts - connected to relevant events ${ }^{24}$ during the conflict which saw the involvement of sub-Saharan migrants; in doing so, we attempted to balance the selection of articles to cover the period mentioned. After a detailed examination of thirty selected articles, ${ }^{25}$ the analysis demonstrated homogeneous patterns in terms of the representation of masculinities among all selected articles - notwithstanding the different sensibilities and ideological inclinations of both media and journalists. In this way, we arrived at thematic/data saturation as the purpose of our sample was "not to count opinions [...] but to explore the range of [...] different representations" of subjects (O’Reilly/Parker 2OI2: 3).

The analysis procedure first focused on identifying the main narratives presented in the material analysed, specifically the assumptions and values produced in the text in the way characters, actions, and events relate to each other (Titscher 2000). These were searched for clues to understand how media suggest addressing the security of sub-Saharan migrants in the conflict. This analysis was further enriched by reasoning about the framing of the articles analysed, especially the aspects of reality made more salient or excluded so as to convey a particular understanding of the events narrated (Zarkov 20II). Finally, categorization analysis allowed for an understanding of how

23 Adjective used in a letter attributed to Mike Maples, director of the US Defense Intelligence Agency, in a wikileaks, at: <http://www.cablegatesearch.net/cable. php?id=06DOHA37I $>$ (May 20I2).

24 The relevant events considered have been: evacuations and spreading of rumours about sub-Saharan mercenaries at the beginning of the conflict (February and March 20II), sub-Saharans' boat voyages in the Mediterranean (April-August 20II), relevant battles in Misrata (May 20II) and Tripoli (August 20II), media acknowledgement of massacres of sub-Saharans (August and September 2011), death of Gaddafi (October 20II).

25 A complete list of the selected articles and their internet links is presented in table 13.3 below.
sub-Saharan migrants and their masculinities have been represented, and how these representations justify certain type of actions towards them (Leudar/ Marsland/Nekvapil 2004).

Within the articles considered, three main narratives related to the 20 II Libyan conflict have been identified through a reading of the text aimed at identifying 'topoi' or argumentations explaining the situation in which sub-Saharans found themselves in Libya (Reisigl/Wodak 200I). These refer to the revolution, migration crisis, and humanitarian intervention, with racism as a cross-cutting theme. They were not developed at the same time in all the articles analysed, but these implicitly supported each other and offered a general framework of interpretation for the events that the media provide an account for. Along this line, all three media offered common readings and perspectives and only a few differences or major tendencies can be noticed. Al Jazeera tended to provide more information regarding the context of Libya and the sequencing of events, acknowledging the complexity of its society. For instance it recognized differences in terms of ethnic/racial groups living in the country, acknowledging diversity in the Libyan population in terms of phenotypes. ${ }^{26}$ The Guardian was more inclined to present migrants as victims and claim the moral importance of addressing issues related to their security, consequently celebrating its role as an ethical agent. ${ }^{27}$ Finally, The New York Times distinguished itself by insistently essentializing

26 This is the case in the Al Jazeera article (2) where under the subtitle of dangerous racism, it is stated: "In the past, Gaddafi has oppressed both black Libyans and ethnic Arab Berbers in the western Nafusa Mountains. Last year, the regime lashed out against the Tabu tribe, darker-skinned Libyans who live in and around the towns of Sabha and Kufra near the Chad border." This information confirms once more that the black population belongs to diverse groups of black Libyans, instead of just sub-Saharan Africans.

27 In all pieces analysed from The Guardian, concern for sub-Saharan migrants is expressed, with a tendency to portray them as victims. In articles (3), (7), and (IO), the role of media as actors denouncing injustice and thus contributing to attracting attention to problems to be resolved is openly celebrated. No discussion of the frame which media adopts to foster their denunciations is offered. On the contrary, when it is recognised that journalists may have participated in falsely labelling subSaharans in Libya as mercenaries, article (IO) minimizes these errors, arguing that media have showed to be able to correct themselves, proving the reliability of their reports and interpretations. 
spaces of Africa, Libya, and Europe, thereby reducing the complexity of the processes described. ${ }^{28}$

At the outset of the analysis it is important to point out that the revolution ${ }^{29}$ is represented as a stage in a positive and necessary developmental process moving toward Western liberal democracy as a sort of end of history. That is, in the heart of the struggle for power between anti-government protesters and Gaddafi's loyalists, the former are represented as champions of democracy and human rights moving closer to the accomplishment of these values (AJ 2-96; NYT 2-5-9; TG 7-IO). Notwithstanding the military imbalance between the two groups, since the beginning of the protests the rebels' possibilities of success are exalted, while Gaddafi is constantly described as on the brink of defeat (AJ 5-6; NYT 1; TG I-9). A highly teleological vision is deployed, according to which Libya is seen as chasing the West and its ideals with the whole country's population united in supporting this effort (AJ 6-9; NYT I-5; TG 7-IO). A Western liberal democracy, a market-oriented economy, and modern social organization are represented as the best and more likely future, guaranteeing justice, freedom, and prosperity to 'all' those living in Libya. However, the rebels' approach to democracy is seen as incomplete because - despite their rhetoric of secularism, transparency, and rule of law - the opposition's commitment to Western values remains to be proven in the post-revolutionary period. This is presented in contrast with the long history of Western democratic experiences, which emerge as superior (AJ 2; NYT 2-3-5; TG 7).

Episodes of non-legitimate violence committed by the rebels were denoted as indicative of the limits of Libya's revolution: "Libya's spectacular revolution has been disgraced by racism" as titled by the Guardian at the end of August (TG, Io). ${ }^{30}$ However, in the media, the origin of such violence was identified as the weight of Gaddafi's inheritance, diminishing the opposition's responsibility (AJ 2-3-9; NYT 5; TG 2-3-4-6IO). The racist attacks against sub-Saharans in Libya

28 This tendency is particularly evident in articles (I), (2), and (3) from the NYT. In these cases Libya tends to be represented as a dangerous place, Europe is a stable and prosperous area, while sub-Saharan countries are characterised by poverty, corrupt governments, and stagnant economies.

29 It is important to notice that the understanding of revolution as a necessary step is one of the main narratives found in media, and it also became a justification for the conflict and its consequences.

30 See also articles (5), (9), and (Io) from NYT, and AJ (2). are emblematic of this story line: the root cause of this violence was identified as a long history of exploitation and discrimination against sub-Saharan migrants throughout Gaddafi's regime, in some way normalizing the spread of racism $^{31}$ in society. The weakness of the revolution was seen as proceeding from years of repression which have caused the absence of organized movements able to move beyond racist understandings of nationalism and construct an inclusive sense of belonging (TG Io). The violence of the repression ordered by Gaddafi was then presented as a multiplier of the racist tendencies of Libyan society: the brutal attacks of government loyalists obscured the protesters' capacity of judgement (AJ I; NYT 4; TG 3). This subtle message is particularly reinforced through the image of sub-Saharan Africans as mercenaries, which also explains the violence suffered by them (AJ I-6-7; NYT I-9-IO; TG I). Further, it was the war that - by impeding the implementation of a justice system - enabled a situation of diffused violence. The opposition was presented as having good intentions and Western sympathies, while the savage and cruel forces of Gaddafi worked to undermine the revolution as a hope for democracy (AJ 5-6; NYT i; TG 4-7-IO).

The migration crisis was represented by media as fully the responsibility of Gaddafi (AJ I; NYT 5; TG 3). This is exemplified by another title: "Helping Libya's refugees is the better way to beat Gaddafi" (TG 7). Opposing and resisting a necessary change, the Colonel was generally seen as the principal subject to blame for the disastrous effects of the war. In particular, complex migratory movements and increased vulnerabilities that resulted from the conflict and affected all migrants in Libya (sub-Saharan or not) was understood as taking place due to Gaddafi's choices. He was seen as committed to 'creating' refugees by spreading violence within Libya and impeding rescue efforts; he was also presented as attempting to force sub-Saharan Africans in Libya to fight on his side or leave the country (AJ 2-3; NYT 3-4-5; TG 2-4-5--IO). Finally, he was portrayed as 'exploiting boat people' by facilitating their journey across the Mediterranean in order to frighten Europe with the possibility of massive arrivals of migrants (AJ 2; NYT 2-5; TG 4-7). To support such a reading of the crises, as noted earlier, media tended to diminish the responsibility of the rebel anti-Gaddafi forces with regard to migrants' security (AJ 2-3-7; NYT 4-5-9; TG 2-4-5-IO). In short, the media story was that as a result of a conflict desired by Gaddafi, migrants were obliged to expose them-

31 See AJ (2) and (6), and NYT (9). 
selves to very risky situations: internal displacements or perilous travels across the Mediterranean, carrying additional dangers and insecurities for sub-Saharan migrants previously living and working in Libya.

Movements of people were seen by media as carrying negative consequences not only for the migrants themselves, but for other actors too. For example, European states were represented as legitimately perceiving their coasts as 'invaded' and facing resentment towards migrants by their populations, widely supportive of anti-immigration stances (AJ 4; NYT 23; TG 5-8). The rightness of such positions was then justified by the idea that migrants, especially sub-Saharans, are untrustworthy and dangerous subjects for Europe (AJ 3; NYT 2-3). The media suggestion was that most, by entering Libya illegally, had proven themselves to be disrespectful of rules. Further, their desperate condition was seen as a factor that might cause further problems to European countries, as desperation leads to desperate and irrational behaviours (NYT 2-3). In addition, Tunisia and Egypt were other actors presented in some of the articles analysed as facing the problems of migratory movements. Notwithstanding their proven goodwill in helping migrants, the two North African states had to face exasperation from their own citizens for the problems caused by sub-Saharans in refugee camps who 'stupidly protested' about their situation without appreciating the efforts made by those countries (TG 6). As a consequence, the needs for border control, refugee camps, and organized management of migratory movements were implicitly presented as necessary and appropriate solutions for avoiding additional problems in destination countries and for migrants themselves (AJ 3-4; NYT 3-7; TG 6).

From these understandings of the conflict and migration crises, the humanitarian intervention was established by media as a necessity in order to save lives from the irrational violence of Gaddafi's forces. The international community was the actor charged with the responsibility of preventing fighting from escalating and alleviating suffering (AJ I-2-5-6-7-8; NYT I-2-34-7; TG I-3-5-7). However, even if the term 'international community' conventionally refers to the community of world states and UN organizations as supposedly super partes actors, in media it more often indicates just Western states and certain international agencies as high moral subjects committed to protect Others, beyond the principle of sovereignty (AJ I- 8 ; NYT I-2; TG I-2). Such selective use of the term establishes a hierarchy in which states like Egypt or Tunisia, though actively engaged in the organization of human- itarian support, are represented as less organized and proactive in the effort to save human lives (TG I-6). This contrasts with visions of Western states and UN agencies as endowed with the means and resources for assessing the situation and best planning any intervention. In this vision, they are courageous and generous agents ready to self-sacrifice, have great care for human lives, and have the capacity to act (AJ I-3; TG I-2).

When the international community fails to comply with these standards publicly, its accountability is established through different techniques. First, other responsibilities are identified and often these are not elements within the control of the so-called international community: for example, the weather or the bureaucratic system is seen as hampering rescue efforts in the Mediterranean (TG 2-4). Also, the irrationality of other actors can be used to explain the international community's failures: sub-Saharans in desperate situations would be inclined to not exercise clear judgement and to put their lives at risk, as when, trying to capture the attention of a rescue boat, they move to one side of their ship, causing it to capsize (TG 2). Moreover, NATO and EU states are pictured as self-reflexive and prone to take actions that will improve their tactics and strategies of intervention, for instance improving coordination efforts for evacuations and lifesaving missions at sea (NYT 5-7; TG 78:). Finally, media and other actors take the role of powerful watchdog, engaged to show the international community unforeseen problems and to envision possible solutions, as in the case of unanticipated migratory movements towards Europe or racist attacks on black Libyans and migrants in Libya (AJ 2-35-6; NYT 5; TG 5-7-IO). In this case, in addition to migrants' testimonies employed to confirm the information presented, many references to Western values of liberal democracy serve as guidelines for actions, completely legitimizing the actual organization of the world order and failing to address existing inequalities and imbalances (AJ 2-6-9; NYT 5; TG 7).

In a nutshell, media represented the Libyan conflict as a step in the country's process towards Western ideals and modernity; they show its migration crises as the result of irrational, cruel, and short-sighted policies by Gaddafi, and this implies that support for the management of migratory movements by Western interventions was necessary to achieve security, freedom, and the democratic principles of the international order. Direct and subtle associations in the articles analysed indicate strongly that media conveyed suggestions that reinforced mainstream international models while play-acting mobilizations for migrants' 
Table 13.1: Media narratives related to the 2011 Libyan conflict. Source: The authors.

\begin{tabular}{|c|c|}
\hline \multirow[t]{4}{*}{ Revolution } & $\begin{array}{l}\text { Stage in a developmental process directed towards a model of society based on liberal } \\
\text { democracy, free market, and other values presented as Western. }\end{array}$ \\
\hline & $\begin{array}{l}\text { Result of long years of Gaddafi's regime, which spread hate and enabled episodes of ille- } \\
\text { gitimate violence to take place (e.g. repression, racism, and violence against different eth- } \\
\text { nic groups). }\end{array}$ \\
\hline & $\begin{array}{l}\text { Contributes to demonstrating the backwardness of some countries and the superiority of } \\
\text { the West that does not need conflicts to provide freedom, stability, and prosperity. }\end{array}$ \\
\hline & $\begin{array}{l}\text { Event to support the process of democratization in other parts of the world through } \\
\text { Western institutions and organizations. }\end{array}$ \\
\hline \multirow[t]{3}{*}{ Migration crises } & $\begin{array}{l}\text { Result of Gaddafi's behaviour: he did not care about putting the life of migrants at risk in } \\
\text { Libya as his way of resisting a necessary change. }\end{array}$ \\
\hline & $\begin{array}{l}\text { Situation of danger for migrants themselves, but also for Europe and Libya's neighbour } \\
\text { countries. }\end{array}$ \\
\hline & $\begin{array}{l}\text { Situation to support an efficient and organized management of migratory movements as } \\
\text { a necessity for achieving security }\end{array}$ \\
\hline \multirow[t]{3}{*}{ Humanitarian intervention } & $\begin{array}{l}\text { Situation for the West to use its generosity, skills, and abundant resources to save the lives } \\
\text { of thousands of civilians. }\end{array}$ \\
\hline & $\begin{array}{l}\text { Event to support Libya's path towards liberal democracy, free markets, human rights prin- } \\
\text { ciples, etc. }\end{array}$ \\
\hline & Action through which the West establishes its accountability. \\
\hline
\end{tabular}

security. This reading of the events and processes described is reinforced through different strategies, including media's silences over certain elements. For example, the lack of mention of the civilians killed by the NATO intervention allowed a dichotomous vision of the conflict in which good and evil faced each other, making invisible those suffering and whose experience could not function to support such readings of the conflict. The superiority of Western democracies, in relation not only to the Gaddafi government but also to the incoming opposition, was made possible by excluding memories of past European colonization and the present reality of a legitimized racism against black Africans. The absence of any reflection on how EU migration control policies played a role in limiting sub-Saharan migrants' possibilities for safe evacuation contributed to a polarized comprehension of the situation, which is revealed in the silence surrounding the expulsions of asylum seekers from Europe. The lack of acknowledgement of Western geopolitical and economic interests also contributed to legitimizing and celebrating the NATO intervention. More examples could follow, but for the purposes of this study, our attention is now turned to the media categorization of sub-Saharan migrants.

Within media representations, different sets of masculine values can be distinguished, organized in hierarchies and associated with different social groups. The hegemonic model of masculinity is here linked to constructs of the international community as a neutral actor not directly involved in the conflict, but whose efforts aim at saving lives. In doing so, the international community displays skills related to rationality, expertise, moral strength, and determination, while being guided by heroic virtues related to courage, generosity, and capacity for self-sacrifice (AJ I-3-4-7; NYT IO; TG I-2-7-9). Further, the availability of means and resources not only represents the international community's capacity to feasibly respond to crises and conflicts, it also makes it possible to relate actors to different ideas of success (AJ 8; NYT I-2; TG I). As emerged from the narrative analysis, the term 'international community' often refers to only Western states and selected international agencies. From here it is easy to infer that the success associated with hegemonic masculinity in this case refers not only to the economic area, but is a manifestation of Western achievements in different fields, mainly connected to the model of the white race, professional education, aid workers, policymakers, entrepreneurs, or corporate managers. Media representation of hegemonic masculinity thus becomes involved in legitimizing a specific array of values and reproducing dominant social relations (Carrigan/Connell/LeeReviewed I985; Connell r998).

The complicit category of masculinity in the context of the Libyan war could be identified in the rebels, the opposition to Gaddafi. Anti-government 
forces, "former regime notables, businessmen and professionals as well as exiles" (TG IO), were in fact associated with certain values of hegemonic masculinity: proactivity and determination, advanced education, democracy, and the principles of the free market. However, the rebels distanced themselves from the international community's hegemonic model of masculinity by fighting a war using violence and by their lack of military technology and strategy (AJ 5-6; NYT 9). Because Gaddafi's opposition sought to engage in conflict rather than just employing its resources in the service of others - as Western masculinity is represented to do - they are seen as developmentally a step behind the international community (NYT 2-3-5; TG 7). Nonetheless, this behaviour is identified as a necessary act of courage. From this perspective, the rebels are allowed to receive support from the international community because they fulfil the majority of qualities of the hegemonic model of masculinity, including their concern for assisting and supporting those in need (NYT 4; TG 9). As a result, the values in media representations associated with the rebels' complicit masculinity work again to support hegemonic masculinity's values and the dominance of the rational, polite, and educated man moving within the frame of capitalist interests. An illustrative example is the start of one Al-Jazeera article: "Sporting a crisp well-tailored grey suit and pink tie, Harris Mohamed Zuwei looks more like an aspiring banker than a Libyan pro-democracy fighter who took a bullet for the cause" (AJ 6).

The subordinate model of masculinity is here embodied by Gaddafi, the 'mad dog' of the Middle East, as President Reagan defined him in the I980s. ${ }^{32} \mathrm{Me}$ dia portrayed the Colonel as a non-modern and irrational figure, whose cruel and unreasonable decisions had very serious and negative consequences for already marginalized subjects. ${ }^{33}$ Demonstrating a deficiency of clear judgement by choosing to oppose what is presented as an upcoming and inevitable change, Gaddafi and his loyalists put at risk the lives of the vulnerable and thus came to symbolize cowardice and the lack of any heroic virtue, "gangster[s] who hold foreigners at knifepoint in the Libyan streets" (NYT

32 See BBC News: "Profile: Muammar Gaddafi", 27 June 20II; at: <http://www.bbc.co.uk/news/world-africaI2488278>.

33 "Sins of the father, sins of the son" is a title of a news article in Al-Jazeera on 27 February 20II, where Gaddafi is accused of "exploitation of the plight of the African people” (AJ 9).
2). Egotistically attached to power, their behaviour is explained by media with reference to hysteria, associating this subordinate manhood with feminine features (TG 3 ). This type of masculinity is then banished from the hegemonic model, and lacks legitimacy in relation to the norms supported by the latter. However, this expulsion does not constitute a negation, as in fact Gaddafi is still represented as a subject endowed with agency: he does not simply react; on the contrary he is an extremely proactive agent. From this sense of initiative, his moral and ethical condemnations emerge and find justification (TG 7). Consequently, according to the logic of contraries, the hegemonic masculinity embodied by the Western international community is again reinforced by the media through the insistent message of its necessary action to control Gaddafi's 'erratic' performance (AJ 9).

Mainstream international media fixed images of sub-Saharan migrants through categories associated with ideas of passivity or dangerousness. The representations of sub-Saharan black Africans entrenched a dispossession of hegemonic masculinity's qualities and resources, making them useless, helpless, ${ }^{34}$ or irrationally violent actors. They are 'poor', 'desperate', 'afraid', 'trapped', or 'brutal mercenaries', 'on the front line'. In this way sub-Saharan migrants are subordinated when represented as marginalized masculinities: in fact, not only gender, but also class and race play an integral part in the construction of manhood. As it is stated by Connell (2005), "Race relations may become an integral part of the dynamic between masculinities. In a white-supremacist context [as the media discourse turned out to be from this analysis], black masculinities play symbolic roles for white gender construction” (Connell, 2005: 80). Following this line, it is possible to explain the functionality of this construction of sub-Saharan migrants for Gaddafi's international negotiations, for the rebels' claim on the need for international intervention, and for the validation of the role of the international community - including media and journalists. ${ }^{35}$ Additionally, explanations of migrants' insecurity and vulnerability to violence are rooted in the negation of Western ideals by actors involved in the conflict. Also, the normalization of victimhood and danger impedes the development of alternative accounts more centred on the migrants' voices, because - within this hierarchy

34 See for example AJ (I), (2), (4), (7), and NYT (7).

35 The modern profession of journalism finds its origins in the Enlightenment period and so is usually associated with Western values and forms. 
of masculinities - experiences and needs expressed by migrants themselves as well as their role as political actors are undermined. On the contrary, migrants' voices appear in media merely to support facts or opinions presented by journalists: the existence of sub-Saharan migrants is not seen independently from the Western presence; it is through media that sub-Saharans prove their existence and living conditions. Both ways of classifying $^{36}$ sub-Saharans, as well as the logic presented, become functional for justifying international intervention in the conflict and the contemporary regime of migration control as the main instruments for guaranteeing human security. The hegemonic model of masculinity is then the one reproduced and legitimized in media representations through the silencing of subSaharan voices or by contrasting them with (or by the celebration of) Western values, with their ideals of democracy and economic wealth.

Concluding the analysis, we note that media representations of different forms of masculinities - within the narratives presented - worked to construct an idea of security linked to dominant modern Western values, including liberal democracy, market-based economies, rationality, and expertise. Norms and behaviours associated to masculinity reinforced these propositions. Following Bourdieu's understanding of symbolic violence, we see that it is the normalization of vulnerability as well as hostility towards sub-Saharan work as a form of symbolic violence that makes reflections on and questions about the current dominant conception of security and the actions undertaken from this perspective difficult. In fact, the media legitimization of RtoP as normative frame shifts the attention beyond the state as a protector, to include for example international agencies and NGOs. However, it undermines the role of sub-Saharan migrants as political actors, in so far as the media limited the understanding of bottom-up initiatives to security initiatives (Huysman/Squire 2009). In short, media discourse during the Libyan conflict supported the implementation of RtoP and limited the possibilities for its critical discussion. ${ }^{37}$

Further, we have highlighted that responses to situations of diffused insecurity have been seen as proceeding almost entirely from Western capacity and values, as well as the Western paternalistic and heroic predisposition to help others. However, in repeated situations these urgent humanitarian actions ignored the needs and circumstances of sub-Saharan migrants'

36 As mercenaries or as vulnerable population.

37 See for example Forte (20IIa). insecurity, generating questionable gaps in the effectiveness of those actions as adequate protection. This is the case for the Western management of the migration crisis, which we argue has not stopped migrants' insecurity or mobility, but led to the death of many sub-Saharans due to the prioritization of control and borders over the rights of asylum, protection, ${ }^{38}$ free mobility, and so on. We raise serious doubts about the possibility of fostering migrants' security through these types of actions and discourses, including the representations that they entail in terms of migrants' identities and needs. Moreover, categorizations are usually coupled with justifications of past or future actions (Leudar/Marsland/Nekvapil 2004). Finally, we conclude that mainstream media representations played a central role in the construction of gendered, racial, and class-based categorizations that undermined the possibilities for debating social justice beyond the dominant frames of security and migrants' stereotypes.

\subsection{Conclusion}

Investigating the links between migration, the media representation of masculinities, and human security, this chapter aimed to show the relevance of intersectional analysis in illuminating the complexity of the conditions of insecurity faced by vulnerable groups in conflict situations. The concept of intersectionality elaborated by Crenshaw has proved to be a useful tool for studying how power relations at political, representational, and cultural levels affect not just women's conditions, but also those of other social groups in marginal positions. Moreover, the understanding of different levels of intersectionality as a continuum, where different knowledge and spheres interact, ${ }^{39}$ allowed an examination of the symbolic representations as elements influencing structural and institutional levels and vice versa. The triple jeopardy situation is reflected for example in how the role of migrants is conceived by job market forces and institutions, influencing the ways in which the presence of migrants in Libya is understood by policymakers pushing for the endorsement of different kinds of state migration pol-

38 This is the case with asylum seekers who were returned to their country of origin, the lack of assistance for boats at risk, and the prioritizing of detention centres over adequate living conditions in a life-threatening context.

39 Leudar, Marsland and Nekvapil (2004) make reference to the concept of 'dialogical network' to refer to the links that exist between various media events and that are created by different actors around the world. 
Table 13.2: Media representations of masculinities during the 2011 Libyan conflict. Source: the authors.

\begin{tabular}{|c|c|c|}
\hline Models of masculinity & Associated to & Characterized by \\
\hline Hegemonic masculinity & $\begin{array}{l}\text { Associated to western actors and embodied } \\
\text { by the figures of aid workers, professionals } \\
\text { of the international community, entrepre- } \\
\text { neurs and corporate managers. }\end{array}$ & $\begin{array}{l}\text { Rationality, expertise, wealth, moral } \\
\text { strength, courage, generosity, capacity for } \\
\text { self-sacrifice. }\end{array}$ \\
\hline Complicit masculinity & $\begin{array}{l}\text { Associated to the Rebels, and embodied by } \\
\text { Gaddafi's opposition, stakeholders of the } \\
\text { new regime, notables, businessmen, profes- } \\
\text { sionals, exiles. }\end{array}$ & $\begin{array}{l}\text { Proactivity, determination, courage, care for } \\
\text { others, advanced education, need to be sup- } \\
\text { ported. The 'lack' of knowledge and strate- } \\
\text { gies for violent actions. }\end{array}$ \\
\hline Subordinated masculinity & $\begin{array}{l}\text { Associated to Gaddafi's loyal forces and } \\
\text { embodied by Gaddafi himself. }\end{array}$ & Irrationality, cruelty, cowardice, proactivity. \\
\hline Marginalized masculinity & $\begin{array}{l}\text { Associated to sub-Saharans in Libya and } \\
\text { embodied by the poor black migrants. }\end{array}$ & $\begin{array}{l}\text { Poverty, desperation, victimhood, irrationa- } \\
\text { lity, aggressiveness. They are politically under- } \\
\text { mined and have a lack of agency capacity. }\end{array}$ \\
\hline
\end{tabular}

icies in the country and elsewhere; this would in turn affect foreign workers' quality of life and media information regarding actors involved in migration flows. In the Libyan case, the structural conditions of vulnerability of sub-Saharans have been understood by media as motives to represent migrants as either passive victims or dangerous subjects, and this became an impediment to identifying solutions that addressed the need for the dignified protection of migrants within particular life-threatening circumstances.

Further, the possibility to observe this type of dynamics offered by intersectional analysis has also enabled us to put the spotlight on the symbolic violence embedded in media discourses about who should be protected and by whom, which strongly require questioning, deconstruction, and reflection. In fact, looking critically at media's construction of identities, we observed that the proposed set of categorizations served to discriminate groups of civilians and normalize an understanding of selective protection which, for instance, favoured expatriate staff from the international community' over migrant workers and refugees. The timeline of organized evacuations for migrants at the beginning of the conflict is one example of this trend. Thus, acknowledging that civilians are not a homogeneous group but are divided along sociocultural and legal boundaries, we argue that media discourses rhetorically approached the problems of those structurally disadvantaged and legitimized selective protection of the better-off. In sum, media have been an actor and an instrument contributing to insecurity.

In terms of media responsibility it is difficult to make conclusive proposals. The debate about the possibilities of changing journalists' practices has been long-lasting and the prioritization of different elements - regulatory practices, material resources, knowledge, sources of information, political agendas, and ethics involved, among others - has led to a multiplicity of positions. One of the authors argues from a socio-constructivist perspective for the importance and urgency of promoting normative regulations concerning the use of specific categories that reinforce symbolic violence and cultural stereotypes of contempt for the black race or marginal groups, particularly within a context of conflict. Her reasoning, in line with APS (1997) recommendations, also implies processes of cultural awareness within which one's media should "take responsibility for representing ethnic groups, ethnic differences and conflict between ethnic groups, in ways which highlight the diversity within groups and similarities across groups, thereby discouraging stereotyping" (APS, I997: 42). The other author shares the importance of undermining the circulation of racializing and racist discourses, but is sceptical about the capacity of regulatory practices to change the editorial choices of mainstream media and their shareholders, and considers that any regulation would instead run the risk of increasing the legitimation of mainstream media practices. She instead makes a claim for supporting independent and self-organized media that make explicit the standpoint from which they speak. In line with Harding's (I993) ideas of strong objectivity, she suggests moving beyond ideas of neutrality in journalism, which often translate objectivity as being a white, bourgeois, and male standpoint, and favours editorial projects ${ }^{40}$ which ac-

40 Examples of independent and self-organized media might be the Spanish Diagonal; at: <http://www.diagonalperiodico.net/-Quienes-somos-.html $>$ or the PanAfrican Pambazuka; at: 〈http://www.pambazuka.org/ en/about.php>. 
knowledge biases and openly discuss their approach to social justice (Durham, I998).

To discuss the issues of migrants' security, the Libyan context provides a meaningful case of analysis to illuminate the consequences of migration policies in conflict situations. In fact, this country has been one of the first involved in the process of the externalization of EU border control. Further, regulations producing the illegality of migrants and the restriction of mobility have not only worked to relegate migrants to situations of precariousness and marginality in peaceful times. These regulations also impeded migrants' safe escapes during conflicts and suspended people's lives for the indeterminate period of being held in refugee camps. As the deaths in the Mediterranean showed, the EU regime of migration control does not foresee the possibility of accessing airports for sub-Saharan workers in Libya (Kumar 20II). Nor does it allow the mobilization of resources, knowledge, and relations outside the rules of humanitarian emergencies.

Reflecting on the guarantees offered by the normative frame of RtoP is important because, as an ex- isting mechanism to protect civilians, it failed in the Libyan case to provide safeguards for sub-Saharan migrants. Instead of suggesting concrete alternative understandings of security, we emphasize the importance of promoting further research to identify mechanisms and practices of protection from a bottom-up perspective. Intersectional analysis can prove to be a useful tool for empirical studies that move beyond universalistic standpoints and instead search for migrants' own understanding of security. We would encourage the Arendtian approach of 'right to have rights' as the right of those in insecure situations to choose what security might signify for them and how it would be possible to improve their conditions (Oman 20I0). Doing so may also imply generating discourses and practical alternatives to the unilinear mainstream media's narratives on how things 'should be'. From this perspective, we argue for a future with open possibilities to practise alternatives to Western liberal democracy market-based economies, and the related understanding of security, that makes possible a human life with dignity.

Table 13.3: Articles analysed

\section{Al Jazeera articles}

1. "Libya migrants' plight 'desperate': British minister demands 'unfettered access' to help thousands of migrants fleeing violence amid anti-Gaddafi uprising"; at: <http://www.aljazeera.com/news/africa/2011/03/201135165632260669. html>.

2. "Migrants suffer in Tripoli camps: Black Libyans and migrants are stuck in Tripoli in squalid conditions and threats of violence"; at: <http://www.aljazeera.com/news/africa/2011/09/201191102134823327.html>.

3. "Migrants forced to fight for Gaddafi: 'They said we must stay to fight when the Americans come', a Ghanaian worker tells Al Jazeera from a refugee camp"; at: <http://www.aljazeera.com/indepth/features/2011/04/2011481 8291705627.html>.

4. "Migrants 'fleeing Libya' drown off coast: Bodies of some 70 Eritrean asylum seekers fleeing the conflict are reported to have been found off the coast", at: <http://www.aljazeera.com/news/europe/2011/04/ 201143201853574844.html>.

5. "The day the Katiba fell: Libya's turning point may have come when protesters overwhelmed a barracks in Benghazi", at: <http://www.aljazeera.com/indepth/spotlight/libya/2011/03/20113175840189620.html>.

6. "Tales from the front: A Libyan rebel speaks: Who are Libya's fighters? And can they defeat Gaddafi? An injured rebel says yes, but military analysts aren't so sure"; at: <http://www.aljazeera.com/indepth/features/2011/04/ 20114922636100124.html>.

7. "African migrants targeted in Libya: Rights groups fear dozens killed in violent backlash against supposed Gaddafihired mercenaries from sub-Saharan Africa". With video (2:10min); at: <http://www.aljazeera.com/news/africa/ 2011/02/201122865814378541.html>.

8. “Libya no-fly zone supporters push for UN vote: Washington says the Security Council may need to take measures that go beyond a no-fly zone in Libya"; at: <http://www.aljazeera.com/news/africa/2011/03/201131715122293202. html>.

9. "Sins of the father, sins of the son: While Gaddafi has relied on empty revolutionary slogans to maintain power, his son looks to oil money for his"; at: <http://www.aljazeera.com/indepth/opinion/2011/02/201122271939751816. html>.

10. "Scores killed in Libya tribal clashes: Fighting in southern town of Sabha has killed more than 70 people as African tribe says it is facing a 'massacre'"; at: <http://www.aljazeera.com/news/africa/2012/03/201232901547564337. html>. 


\section{The Guardian articles}

1. "Libya: Britain sends planes to help with mass airlift of refugees"; at: <http://www.guardian.co.uk/world/2011/mar/ 02/libya-britain-sends-planes-refugees?INTCMP=SRCH>.

2. "300 migrants feared dead after boat capsizes off Sicily"; at: <http://www.guardian.co.uk/world/2011/apr/06/300migrants-feared-dead-sicily? INTCMP=SRCH>.

3. "Gaddafi targets relief ship as it evacuates Misrata wounded in Libya"; at: <http://www.guardian.co.uk/world/2011/ may/04/gaddafi-targets-relief-ship-misrata-libya?INTCMP=SRCH>.

4. "Aircraft carrier left us to die, say migrants"; at: <http://www.guardian.co.uk/world/2011/may/08/nato-ship-libyanmigrants>.

5. "Libyan regime accused of exploiting boat people"; at: <http://www.guardian.co.uk/world/2011/may/11/libyaaccused-of-exploiting-humanitarian-crisis? INTCMP=SRCH>.

6. "Refugees from Libya attacked in Tunisian desert"; at: <http://www.guardian.co.uk/world/2011/may/25/libya-refugees-gaddafi-regime-attacked>.

7. "Helping Libya's refugees is the better way to beat Gaddafi"; at: <http://www.guardian.co.uk/commentisfree/2011/ may/11/libya-refugees-gaddafi-african-migrants? INTCMP $=S R C H>$.

8. "Italy demands to know if Libya blockade warship ignored refugees"; at: <http://www.guardian.co.uk/world/2011/ aug/05/nato-ship-ignored-libyan-refugees-claim?INTCMP=SRCH>.

9. "Tripoli facing three-sided advance by the Libyan rebels"; at: <http://www.guardian.co.uk/world/2011/aug/19/ tripoli-facing-advance-libya-rebels>.

10. "Libya's spectacular revolution has been disgraced by racism"; at: <http://www.guardian.co.uk/commentisfree/ 2011/aug/30/libya-spectacular-revolution-disgraced-racism?INTCMP=SRCH>.

\section{New York Times articles}

1. "Refugee Agency Reports 'Humanitarian Emergency' as Multitudes Flee Libya"; at: <http.//www.nytimes.com/ 2011/03/01/world/europe/01 refugee.html?_r=1\&ref=libya>.

2. "Many Refugees From Libya Don't Want to Go Home"; at: <http://www.nytimes.com/2011/03/10/world/africa/ 10migrants.html>.

3. "250 Migrants Missing After Boat Sinks Off Italy"; at: <http://www.nytimes.com/2011/04/07/world/europe/ 07migrants.html>.

4. "On Ship of Evacuees From Libya, Harrowing Tales"; at: <http://www.nytimes.com/2011/04/19/world/africa/ 19 evacuees.html>.

5. "The Killing Seas"; at: <http://www.nytimes.com/2011/05/19/opinion/19lucht.html>.

6. "The Lives at the End of the Rockets' Arc"; at: <http://www.nytimes.com/2011/05/06/world/africa/ 06misurata.html>.

7. "NATO Crew Failed to Aid Migrant Ship, Survivors Say"; at: <http://www.nytimes.com/2011/08/06/world/africa/ 06refugees.html>.

8. "New Fighting Outside Tripoli as Foreigners Seek an Exit"; at: <http://www.nytimes.com/2011/08/20/world/africa/ 20libya.html>.

9. "Libyans Turn Wrath on Dark-Skinned Migrants"; at: <http://www.nytimes.com/2011/09/05/world/africa/ 05migrants.html?_r=1>.

10. "Accused of Fighting for Qaddafi, a Libyan Town's Residents Face Reprisals"; at: <http://www.nytimes.com/2011/ 09/24/world/africa/accused-of-fighting-for-qaddafi-tawerga-residents-face-reprisals.html>.

\section{References}

Aguilar, Delia, 20I2: "Tracing the Roots of Intersectionality", in: MRzine a project of the Monthly Review Foundation; at: <http://mrzine.monthlyreview.org/20I2/ aguilarI204I2.html> (2I May 20I2).

Altunisik, Meliha, I996: "A rentier state's response to oil crisis: economic reform policies in Libya", in: Arab Studies Quarterly, I8,4.
Anthias, Floya, 2007: "Boundaries of 'Race' and Ethnicity and Questions about Cultural Belongings", in: Gopalkrishnan, Narayan; Babacan, Hurriyet (Eds.): Racism in the New World Order: Realities of Cultures, Colours and Identity (New Castle: Cambridge Scholars Publishing): I2-20.

APS (Australian Psychological Society), I997: "Racism and Prejudice: Psychological Perspectives”, Position Paper; at: <http://www.psychology.org.au/Assets/Files/racism _position_paper.pdf>, 25 April $20 \mathrm{I2}$. 
Bourdieu, Pierre, 1977: Outline of a theory of practice (Cambridge: Cambridge University Press).

Branchet, Julien, 20II: "The Blind Spot of Repression: Migration Policies and Human Survival in the Central Sahara", in: Truong, Thanh-Dam; Gasper, Des (Eds.): Transnational Migration and Human Security: The Migration-Development-Security Nexus (Berlin - Heidelberg: Springer): 57-66.

Bürkner, Hans-Joachim, 20I2: "Intersectionality: How Gender Studies Might Inspire the Analysis of Social Inequality among Migrants", in: Population, Space and Place, I8,2: I8I-I95.

Carey, Henry, F., 200I: "Women and Peace and Security: the Politics of Implementing Gender Sensitivity Norms in Peacekeeping", in: International Peacekeeping, 8,2: 49-68.

CARIM (Consortium for Applied Research on International Migration) [written by Anna Di Bartolomeo, Thibauot Jaulin and Delphine Perrin], 20II: Migration Profile: Libya (Florence: European University Institute, Robert Schuman Centre for Advanced Studies)

Carpenter, R., Charli, 2005: "Women, Children and Other Vulnerable Groups: Gender Strategic Frames and the Protection of Civilians as a Transnational Issue”, in: International Studies Quarterly, 49,2: 295-334.

Carrigan, Tim; Connell, Bob; LeeReviewed, John, I985: "Toward a New Sociology of Masculinity", in: Theory and Society, I4,5: 5I-604.

Chatora, Arthur, 20II: "Mainstream Media Coverage of Libya Disturbing", at: <http://www.iss.co.za/iss_today. php? ID $=$ I37O $>$ (29 April 20I2).

CHS (Commission on Human Security); UNOPS (United Nations Office for Project Services), 2003: Human Security Now (New York: UNOPS Communications Development in Washington, DC)

Connell, Robert, I998: "Masculinities and Globalization", in: Men and Masculinities, I,3: 3-23.

Connell, Robert, 22005: Masculinities (Cambridge: Polity Press).

Crenshaw, Kimberlé, W., I99I: "Mapping the Margins: Intersectionality, Identity Politics, and Violence against Women of Color", in: Stanford Law Review, 43,6: I24II299.

Das, Veena, 2008: "Violence, Gender, and Subjectivity", in: Annual Review of Anthropology, 37: 283-299.

Del Grande, Gabriele, 20IIa: "Generazione revolution: da Benghazi a Lampedusa”, at: <http://fortresseurope. blogspot.com/20II/o3/generazione-revolution-da-benghazi.html> (29 March 20I2).

Del Grande, Gabriele, 20Irb: "Un'altra strage: morti 65 eritrei, i superstiti accusano la Nato"; at: <http://fortresseurope.blogspot.com/20II/04/i-sette-superstiti.html> (29 March 20I2).

Del Grande, Gabriele, 20IIc: "Tra due fuochi. Gli stranieri in Libia al tempo della rivoluzione"; at: <http://fortresseurope.blogspot.com/20II/04/tra-due-fuochi-glistranieri-in-libia.html> (29 March 20I2).
De Haas, Hein, 2008: "The myth of invasion: the inconvenient realities of African migration to Europe”, in: Third World Quarterly, 29,7: I305-I322.

De Haas, Hein, 20I2: "The Arab Spring and Migration"; at: <http://heindehaas.blogspot.com/20I2/03/arab-springand-migration.html> (I4 April 20I2).

Didero, Maike, 20II: "Media images and everyday realities: German-Moroccan perspectives on translocational positionalities", Paper presented at the international RC2I conference The struggle to belong: Dealing with diversity in $2 \mathrm{I}^{\text {st }}$ century urban settings, Amsterdam, 7-9 July 2OII

Durham, Meenakshi, Gigi, I998: "On the Relevance of Standpoint Epistemology to the Practice of Journalism: The Case for Strong Objectivity", in: Communication Theory, 8,2: II7-I40.

Forte, Maximilian, 20IIa: "The top ten myths in the war against Libya”, in: News, 27 October 20II; at: <http:// pambazuka.org/en/category/features/77439> (20 January 20I2).

Forte, Maximilian, 20Irb: "The War in Libya: Race, 'Humanitarianism', and the Media”, in: News, 20 April 2OII; at: <http://mrzine.monthlyreview.org/20II/forte 2004II.html> (20 January 20I2).

Fraser, Nancy, 2009: Scales of Justice: Reimagining Political Space in a Globalizing World (New York: Columbia University Press)

Fudge, Judy, 20Io: "A Question of Scale: Justice, Citizenship and Gender", in: Canadian Journal of Women and the Law, 22,I: 267-276.

Fukuda-Parr, Sakiko; Messineo, Carol, 20I2: "Human Security: A Critical review of the Literature", in: Centre for Research on Peace and Development (CRPD) Working Paper No II, Belgium; at: <http://soc.kuleuven.be/ web/files/I2/80/wpII.pdf>,(I5 February 20I2).

Garelli, Glenda; Tazzioli, Martina, 20II: "Esistenze sospese e resistenze al CARA di Mineo"; at: <http://www.storiemigranti.org/spip.php?rubriqueI26> (29 March 20I2).

Gasper, Des, 20I0: "Climate Change and the Language of Human Security”, Working Paper 505 (The Hague: International Institute of Social Studies (ISS)).

Global Detention Project, 2009: "Libya Detention Profile"; at: 〈http://www.globaldetentionproject.org/countries/ africa/libya/introduction.html>, Io February 2012.

Gopalkrishnan, Narayan; Babacan, Hurriyet, 2007: "Introduction: "Race" and Racism", in: Gopalkrishnan, N.; Babacan, H. (Eds.): Racism in the New World Order: Realities of Cultures, Colours and Identity (Cambridge: Cambridge Scholars Publishing): I-8.

Hall, Stuart, 1997: "The Work of Representation”, in: Stuart Hall (Ed.): Representation: Cultural Representations and Signifying Practices (London: Sage Publications).

Hamood, Sara, 2008: "African transit migration through Libya to Europe: the human Cost", in: Journal of Refugee Studies, 2I,I: 19-42.

Harding, Sandra, I993: "Rethinking Standpoint Epistemology: What is 'Strong Objectivity'?", in: Alcoff, Linda; 
Potter, Elizabeth (Eds.): Feminist Epistemologies (New York: Routledge): 49-82.

Heathcote, Gina, 20II: "Feminist Politics and the Use of Force: Theorising Feminist Action and Security Council Resolution I325”, in: Socio-legal Review, 7: 23-43.

Hill, Felicity; Aboitiz, Mikele; Poehlman-Doumbouya, Sara, 2003: "Nongovernmental Organizations' Role in the Buildup and Implementation of Security Council Resolution I325”, in: Signs, 28,4: I255-I269.

Hoogensen, Gunhild; Stuvoy, Kirsti, 2006: "Gender, Resistance and Human Security", in: Security Dialogue, 37: 207-228.

Hooper, Charlotte, 2008: Manly States: Masculinities, International Relations and Gender Politics (New York: Columbia University Press).

Hudson, Heidi, 2005: "Doing Security As Though Humans Matter: A Feminist Perspective on Gender and the Politics of Human Security", in: Security Dialogue, 36,2: 155I74.

Hudson, Natalie, 20I0: "Gender, Human Security, and the United Nations: Security Language as a Political Framework for Women" (London: Routledge).

Huliaras, Astereis, 200I: "Qadhafi's comeback: Libya and sub-Saharan Africa in the I990s", in: African Affairs, IOO: 5-25.

Huysman, J.; Squire, V., 2009: "Migration and Security", in: Dunn Cavelty, M.; Mauer, V. (Eds.): Handbook of Security Studies (London: Routledge).

ICRtoP, 20I2: "Crisis in Libya. International Coalition for the Responsibility to Protect"; at: <http://www.responsibilitytoprotect.org/index.php/crises/crisis-in-libya?format $=\mathrm{pdf}>$ (I3 June 20I2).

IMI, 20II: North Africa in Transition: Mobility, Forced Migration and Humanitarian Crises (Oxford: International Migration Institute).

IOM, 20I2: Migrants Caught in Crisis: The IOM Experience in Libya (Genève, Switzerland, International Organization of Migration)

Johnson, Trevor, 2000: "Ethnic violence and mass deportations of immigrants in Libya"; at: <https://www. wsws. org/articles/2000/oct2000/liby-028.shtml> (I5 February 20I2).

Kristoffersson, Ulf, 2000: HIV/AIDS as a Human Security Issue: A Gender Perspective, Working Paper Expert Group Meeting (city: United Nations Programme on HIV/AIDS).

Koser, Khalid, 20II: Responding to Migration from Complex Humanitarian Emergencies: Lessons Learned from Libya, Briefing Paper (London: Chatham House, Centre on Global Health Security).

Kumar, Richa, 20II: "Not in my Backyard: Externalization Practices of the EU and its impact on the Refugee Protection Regime” (MA Thesis, University of Amsterdam, Graduate School of Social Studies).

Leudar, Ivan; Marsland, Victoria; Nekvapil, Jiri, 2004: “On Membership Categorization 'us', 'them' and 'doing vio- lence' in Political Discourse”, in: Discourse \& Society, I5,2-3: $243-266$.

Lorentzen, Lois Ann; Turpin, Jennifer, I998: “The Woman and War Reader" (New York: New York University Press).

Marshal, Andrew, Gavin, 20II: "Lies, War and Empire: NATO 'Humanitarian' Imperialism in Libya”; at: <http://georgewashington2.blogspot.com/20II/o8/lies -war-and-empire-natos-humanitarian.html> (27 April 20I2).

McKay, Susan, 2004: "Reconstructing fragile lives: Girls' social reintegration in Northern Uganda and Sierra Leone" in: Gender and Development, I2,3: 19-30.

Migreurop, 20II: "At the Margins of Europe: the Externalization of Migration Controls"; at: <http://www.statewatch.org/news/20I2/mar/migreurop-annual-report20IO-20II.pdf> (30 March 20I2).

Mohanty, Chandra Talpade, I991: "Under Western Eyes: Feminist Scholarship and Colonial Discourse", in: Mohanty, Chandra Talpade; Russo, Ann; Torres, Lourdes (Eds.): Third World Women and the Politics of Feminism (Indianapolis: Indiana University Press): 333-358.

Oman, Natalie, 20I0: "Hannah Arendt's 'Right to Have Rights': A Philosophical Context for Human Security”, in: Journal of Human Rights, 9,3: 279-302.

O'Reilly, M; Parker, N., 20I2: "Unsatisfactory Saturation: a critical exploration of the notion of saturated sample sizes in qualitative research", in: Qualitative Research; at: <http://qrj.sagepub.com/content/early/20I2/05/ I7/I468794II2446I06.abstract> (I4 August 20I2).

Paoletti, Emanuela, 20II: "Migration and foreign policy: the case of Libya", in: The Journal of North African Studies, I6,2: 2I5-23I.

Pezzotti, Maddalena, 2005: "Women, Peace Processes and Peacekeeping Operations: A Conflict Management Perspective", in: Conflict Trends, I: I9-22.

Reisigl, Martin; Wodak, Ruth, 200I: Discourse and Discrimination: Rhetorics of racism and anti-Semitism (London - New York: Routledge)

Ronzitti, Natalino, 2009: “The Treaty of Friendship, Partnership and Cooperation between Italy and Libya: New Prospects for Cooperation in the Mediterranean?", Paper presented at the Mediterranean Strategy Group Conference on "Is regional cooperation in the Maghreb possible? Implications for the Region and External Actors", Genoa, II-I2 May.

Saxer, Marc, 2008: "The Politics of Responsibility to Protect”, in: Dialogue on Globalization, Briefing Paper, No. 2 (Berlin: Friedrich Ebert Stiftung [FES]).

Scheffran, Jurgen; Brzoska, Michael; Brauch, Hans, Gunter; Link, Peter, Michael; Schilling, Janpeter (Eds.), 20I2: Climate Change, Human Security and Violent Conflict: Challenges for Societal Stability. Hexagon Series on Human and Environmental Security and Peace, vol. 8 (Heidelberg - Dordrecht-London-New York: Springer).

Titscher, Stefan, 2000: Methods of Text and Discourse Analysis"(London: Sage). 
Truong; Thanh-Dam, 2009: Feminist knowledge and Human Security: Bridging Rifts through the Epistemology of Care, Working Paper No. 48I (The Hague: International Institute of Social Studies [ISS]).

Tucker, Bruce; Triantafyllos, Sia, 2008: "Lynndie England, Abu Ghraib and the New Imperialism”, in: Canadian Review of American Studies, 38,1: 83-100.

United Nations, 20II: "Security Council SC/IO200: $6498^{\text {th }}$ Meeting” (New York: United Nations, Department of Public Information); at: <http://www.un.org/News/ Press/docs/20II/scIO200.doc.htm> (I5 February 20I2).

UNCHR, 20I2: "More than I,500 drown or go missing trying to cross the Mediterranean in 20II", in: News Stories, 3I January 20I2; at: 〈http://www.unhcr.org/4f280 3949.html> (23 May 20I2).

UNCHR, 20II: "Internal displacement on the rise in Libya, UNHCR sending aid to Benghazi”, Briefting Notes, 22 March 20II; at: <http://www.unhcr.org/4d888f3d9. html>, 30 March 2012.

UNCHR, 20IIa: "UN High Commissioner for Refugees appeals for safety of third-country nationals in Libya", Press Release, 22 August; at: <http://www.unhcr.org/ 4e526I069.html> (I5 April 20I2).
UNHCR, 20Irb: "UNHCR concerned as sub-Saharan Africans targeted in Libya”, Press Release, 26 August 20II; at: <http://www.unhcr.org/4e57dicb9.html> (I5 April 20I2).

Yuval-Davis, Nira, 2006: "Intersectionality and Feminist Politics", in: European Journal of Women's Studies, I3,3: 193-209.

Vassallo Paleologo, F., 20II: "Dall'emergenza umanitaria allo Stato d'eccezione” (city: Associazione Studi Giuridici sull'Immigrazione); at: <http://www.asgi.it/public/parser _download/save/commento.dall.emergenza.umanitaria. allo.stato.di.eccezione.fulvio.paleologo.pdf > (27 August 20I2).

Walby, Sylvia; Armstrong, Jo; Strid, Sofia, 20I2: "Intersectionality: Multiple Inequalities in Social Theory" in: Sociology, 46,2: 224-240.

Zarkov, Dubravka, 20II: "Exposures and Invisibilities: Media, Masculinities and the Narratives of War in an Intersectional Perspective," in: Lutz, H.; Herrera, M.T. Vivar; Supik, L. (Eds.): Framing Intersectionality: Debates on a multi-faceted Concept in Gender Studies (Farnham: Ashgate): I05-I2O.

Open Access. This chapter is distributed under the terms of the Creative Commons Attribution Non-commercial License, which permits any noncommercial use, distribution, and reproduction in any medium, provided the original author(s) and source are credited. 


\title{
14 Complexity of Gender and Age in Precarious Lives: Malian Men, Women, and Girls in Communities of Blind Beggars in Senegal
}

\author{
Codou Bop ${ }^{1}$ and Thanh-Dam Truong ${ }^{2}$
}

\begin{abstract}
$^{3}$
This chapter provides a perspective on the migration of communities of blind beggars from Mali to Dakar, Senegal. Migration for begging across borders as a way of making a living adopted by persons affected by river blindness involves being guided by non-blind guides - usually a girl or young woman who can be a relative or acquaintance. The patterns of movement are generally seasonal and circular and are based on a variety of social arrangements for guiding, including a modification of 'child fostering' as a tradition, biological kinship and marriage, and employment. Each type of arrangement delineates specific obligations and entitlements between the guides and the beggar according to the relationship involved: parent, guardian, spouse, or employer. The last arrangement applies especially to girls and women who migrate on their own account in search of other types of work but end up as guides. Social justice strategies that address the individual rights of young migrants from Mali to Senegal have yet to recognize the existence of this group of female guides. Understanding the experiences of the migrant blind beggars from the perspective of multiple conditions of 'disability' may help towards an appreciation of how mutual dependency based on gender and age can be interwoven into layers of culturally defined inter-generational obligations, for which social justice strategies built only on the idea of the individual rights of women or children may not necessarily be appropriate.
\end{abstract}

Keywords: Circular migration, Senegal, Mali, West Africa, children, gender, generation, begging, livelihood, disability, river blindness, social justice.

\subsection{Introduction}

A large body of literature on migration in West Africa tells of the complexity of migratory movements at lo-

1 Codou Bop is a researcher and activist on women's human rights and the coordinator of Groupe de Recherche Femmes et Lois au Sénégal (GREFELS) based in Dakar, Sénégal.

2 Thanh-Dam Truong is Associate Professor at the International Institute of Social Studies, Erasmus University Rotterdam, The Netherlands.

3 This chapter draws on the results of a broader study funded by IDRC, project number I0489I-0oI, and entitled: "Femmes, Migrations et Lois au Mali et Sénégal" (Women, Migrations and the Law in Mali and Senegal) implemented by the Research Group on Women and Laws in Senegal (Groupe de Recherche Femmes et Lois au Sénégal). The members of the research team are: Codou Bop, Fanta Cissé, Fatou Binetou Dramé, Aissa Haidara Touré, Ndeye Sokhna Guèye, and Cheikh Ibrahima Niang. cal, national, and international levels, and of its especial role in sustaining and expanding people's livelihoods (Adepoju 2004; De Haan/Brock/Coulibaly 2002). With some exceptions (Sy I99I; Findley I99I; Brockerhoff/Eu 1993; Gondola 1997a, 1997b), this body of literature generally emphasizes the experience of the male migrants. In recent years some attention has been given to the autonomous migration of women and people under eighteen years of age (Findley I99I; Bocquier/Traore 2000). Within this subset of the migration literature, much attention has been given to practices of child trafficking and fosterage for economic exploitation (Kielland/Tovo 2006), and to the migration of children as soldiers in the context of armed conflicts (Machel 1996). Analyses of child labour migration that place emphasis on 'gender' distinguish between the types of work that boys and girls do - domestic work and sexual services for young girls and agricultural work and fishery for young boys (UNICEF 2002; Truong 2005; de Lange 2007). The 
relationship between gender, child migration, and 'streetism' as a mode of life has also recently been looked into. This has demonstrated not only that there are multiple causes behind children's moving to the street to make a living, pointing to the need to treat 'gender' and 'age' as power relations rather than merely ascriptive characteristics (Awumbila/ArdayfioSchandorf 2008), but also that the term 'street children', being associated with delinquent behaviour, can have a stigmatizing effect. Caution should be exercised to avoid further discrimination against girls and young women, and instead the causes related to structural inequality should be examined (Eshia 20IO).

This chapter provides a perspective on the situation faced by Malian girls and young women who migrate from rural and peri-urban areas to Dakar, the Senegalese capital city, to guide beggars who are relatives or acquaintances affected by Onchocerciasis and Trachoma. ${ }^{4}$ People affected by these insidious and non-fatal diseases must endure lifelong suffering and grave socio-economic problems as regards their identity and relations with family and community. Begging is one way of earning a living while maintaining a sense of self-worth and dignity, but requires the crucial assistance of a guide, especially when the activity is conducted across borders. The activity can be lucrative, but beggars and their communities must endure harsh conditions when on the move and as transient migrants.

As section I4.2 shows, migration in West Africa is showing trends of increased feminization (a higher proportion of women) and precociousness or increasingly younger chronological age. The perspective on the migration of beggars and their guides presented in section I4.3 is based on the findings of multi-sited research in Mali and Senegal. The aim is to provide insights into the prevailing practices of migration,

4 Commonly known as river blindness, Onchocerciasis is caused by Onchocerca volvulus, which is transmitted to humans by the bite of infected black flies which breed in fast-flowing streams and rivers; it often blinds people, as well as causing a debilitating skin disease. Onchocerciasis can be cured by a drug called Mectizan which kills the parasite's larvae in the human body, preventing blindness and transmission of the disease to others (Remme 1995). Trachoma, also known as river blindness, is the result of infection of the eye with Chlamydia trachomatis. Infection spreads from person to person, and is frequently passed from child to child and from child to mother, especially where there is a shortage of water, many flies, and crowded living conditions (Mufioz/West I997). their gender and age dimensions, and the layers of vulnerability experienced by women and girls as guides. Migrating to Dakar in the dry season is based on interrelated considerations, such as Ramadan - a holiday linked with the giving of alms and demonstrating Muslim piety - and the fact that the spaces they occupy in the city are not flooded, and so are habitable even on the streets. The preference for girls rather than boys as guides is both social and economic. Five types of social arrangements applicable to girls and young women who guide the blind are identified, demonstrating the key relationships that shape their migration and the scope for them to assert control over their own life.

In section I4.4, the legal and institutional frameworks for the protection of child migrants in Mali and Senegal are discussed, demonstrating a misfit between the social constructions of 'children' and 'gender' upon which current migration and human trafficking policies in the region are based, and the reality as lived by blind beggars and their guides. This calls for a re-evaluation of the ideal notion of 'childhood', the interpretation of 'gender' in migration, and the dominant notion of 'disability' as physical or mental impairment.

Understanding the situation faced by the blind beggars from the perspective of multiple conditions of 'disability', as well as the situation faced by their female guides from a perspective of multiple-layered vulnerability, can help identify the specific aspects of gender as an adaptive structure in a web of culturally defined intergenerational mutual dependence.

\subsection{Contextualizing the Migration of Men, Women, and Children in Senegal and Mali}

Well before West Africa was colonized by the European powers, migration had taken diverse patterns, driven by a multiplicity of causes, such as long-distance trade and search for pastures and work (Cordell/Gregory/Piché 1996). Subregional migration, intensified under colonization owing to urbanization, the growth of administrative and industrial centres, and plantation agriculture, continues today with little regard for post-colonial borders (Colvin I98I; Diop 2008). In the last few decades, rural-urban migration patterns have changed from seasonal and circular movements by individual men to more permanent migrations, frequently involving part of or the entire family unit (Riddell 1980). These migrations, studied 
by Findley (1989, I99I, 1997), Sy (199I), Bâ (1996), and Lambert (2007), are progressively more feminized, with women increasingly migrating autonomously. This may be a response to the combined effects of drought and the structural adjustment policies implemented since 198I, both of which have led to a worsening of living conditions in rural areas (Toulmin/ Guèye 2003; Truong 2006); it is also possible that women left rural areas to escape not only from poverty but also from dependency on their men. Migration by unmarried women can now arguably be viewed more as an individual endeavour than a family strategy (Bocquier/Traoré 2000; Lesclingand 2004).

The presence of Malians in Senegal has been fostered both by a common political history and by administration as a unified territory during the colonial period. ${ }^{5}$ The Senegalese Navetanat system of seasonal labour ${ }^{6}$ was also a factor. Navetanat is characterized by a massive short-term migration of young people - generally from the areas where subsistence agriculture predominates - for intensive and temporary work on commercial groundnut farms (David 1980). The system was consolidated by the close ties with the areas of origin through social and financial remittances. For young people the Navetanat was often a means to escape the power of, and abuse by, the elders that the colonial authorities ignored (Bourgeot I977). The Navetanat developed rapidly following the expansion of trade in agricultural commodities until the economic crisis of the I970s, declining only through the combined effect of drought and falling global prices, particularly for groundnuts (Ndiaye 2OI2). Migrants seeking longer-term and more remunerative temporary urban employment gradually abandoned the system (Gubert 2007).

At the peak of the Navetanat system in the I96os and I970s, many migrants originated in the Kayes region in the western part of Mali, bordering Senegal and Mauritania. Their movement was facilitated by the Kayes-Dakar rail connection as well as by social connections, with two-way movements being so common that they did not, and do not, carry the meaning

5 The Malian Federation was founded on 4 April I959, uniting Senegal and the Sudanese Republic (formerly French Sudan), and became entirely self-governing when it gained independence from France on 20 June 1960. The federation collapsed shortly after independence, on 20 August 1960, when Senegal withdrew, due to political disagreements. The Sudanese Republic was renamed the Republic of Mali on 22 September 1960. See Foltz (1965).

6 Navet means rainy season in Wolof. of crossing a national border for the people involved (Fall 2003). Today, long-lasting or permanent settlements by Malians in the city of Dakar can be found in communities specializing in particular economic activities. These communities, particularly those formed from people of Soninke origin from the valley of the upper Senegal river and from the Bambaras of the Kayes region, have mostly traded cola nuts (especially the men) and dyed fabrics and food (especially the women) and settled in Dakar, Thies, Saint-Louis, and Mbour. The first and second generations of migrants act as hosts to the latecomers (Fall 2003). Today, internal and cross-border migrations in search for work - whether seen from the perspective of a strategy to diversify household livelihoods or as a path to 'modernity' - are showing signs of being undertaken more and more by those who are increasingly younger in chronological age (ILO 2007; BIT/LUTRENA 2007; Moens/Zeitlin/Bop/Rokhaya 2004).

\subsection{Circular Migrations for Begging}

\subsubsection{Research Methodology}

This study is among the first multi-sited research projects on the migration of adult blind beggars and their female guides. Its results are to be considered as preliminary. Its aim is to raise new questions for research on the links between disability, gender, and age in migration and the appropriateness of human trafficking and children's rights as a policy field in West Africa. In Mali three regions (Bamako, Koulikoro, and Kayes) were chosen as research sites with the help of resource persons, including (ex)-migrants and officials. All three regions are known to have been affected by river blindness. In addition, Kayes City is known to be the main transit point for Malian children before they leave for Senegal. Interviews (with bilingual Bambara-Wolof translation) were conducted with twenty-two blind beggars and forty-one adolescent returnees from Senegal who were being assisted by a civil society organization for reintegration. In addition, interviews were attempted with seventeen persons working in a wide range of institutions active in the migration field (specialized agencies of the United Nations, non-governmental organizations, and women's organizations), but they were unaware of the existence of female guides within the flow of blind beggars across the border.

A key message that emerged from interviews with Malian beggars at the different research sites con- 
Figure 14.1: Map of Mali with indication of the research sites (Bamako, Koulikoro, Kayes). Source: United Nations (2012; permission granted 12 November 2012).

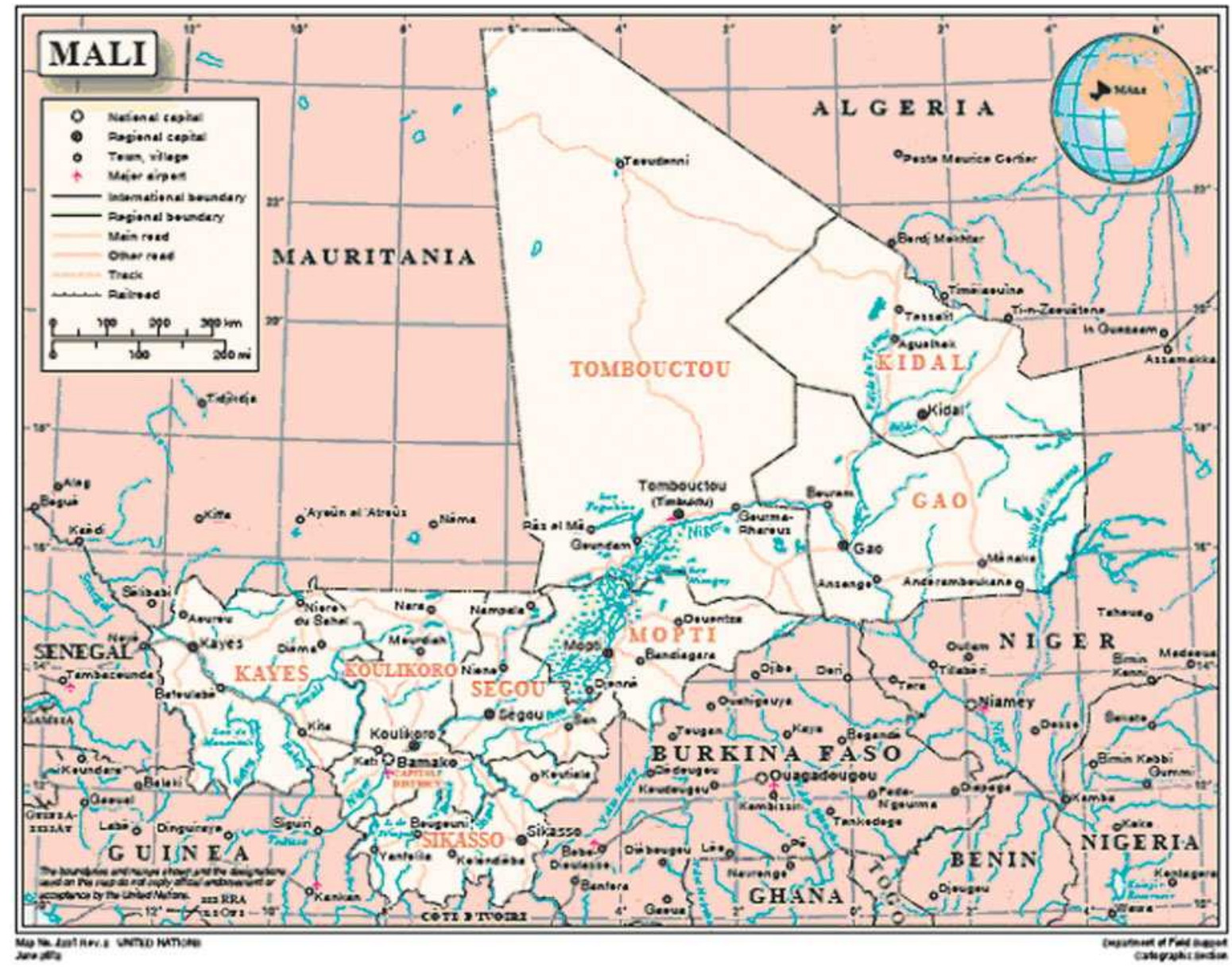

cerned economic motivation, namely the belief that Senegalese people are more pious and make higher donations than Malians, and that girls inspire pity and are more likely to bring in large donations. Socially, girls are also preferred as guides because they are thought to be more 'courageous' and able to accept the strenuousness of their occupation without complaining. Further, the adolescent returnees provided insights on the trajectories of migration and modes of adaptation in transit and destination, highlighting how border porosity, the railroad, and new developments in public transport facilitated their journey between Mali and Senegal.

Being both the main destination and accessible for research, Dakar was chosen as a research site on the receiving end. Within Dakar, research sites were the Dakar-Bamako train station, the mosque on Fleurus Street (Grand-Yoff), and Castor, all areas that host communities of blind beggars from Mali. Because the use of the survey method to obtain disaggregated socio-demographic information about the target population was unsuccessful due to non-cooperation, this information was gathered during one-to-one and semi-structured interviews.

It should be noted that Senegalese law forbids begging, and a few months before the study began there were several police and municipal raids. Beggars were thus anxious to avoid attention from the authorities, fearing forced repatriation to Mali if their identity was revealed. The ethics of research also had to be taken into consideration, because normally children should only be interviewed in the presence of their parents or guardians, or with the latter's authorization. Where this was impossible, a retired female Malian teacher who has lived in Senegal for many years was hired as a facilitator and translator. The fact that she was an elderly person with a respected position also helped temper the concerns of the blind beggars. The use of "la parenté à plaisanterie"7 greatly helped improve the relationship between the researchers and the participants. 
Figure 14.2: Map of the Communes d'Arrondissement of Dakar Department with indication of research sites: Plateau; Grand-Yoff; Castor; Liberté; Grand Dakar. Source: Wikimedia Commons.

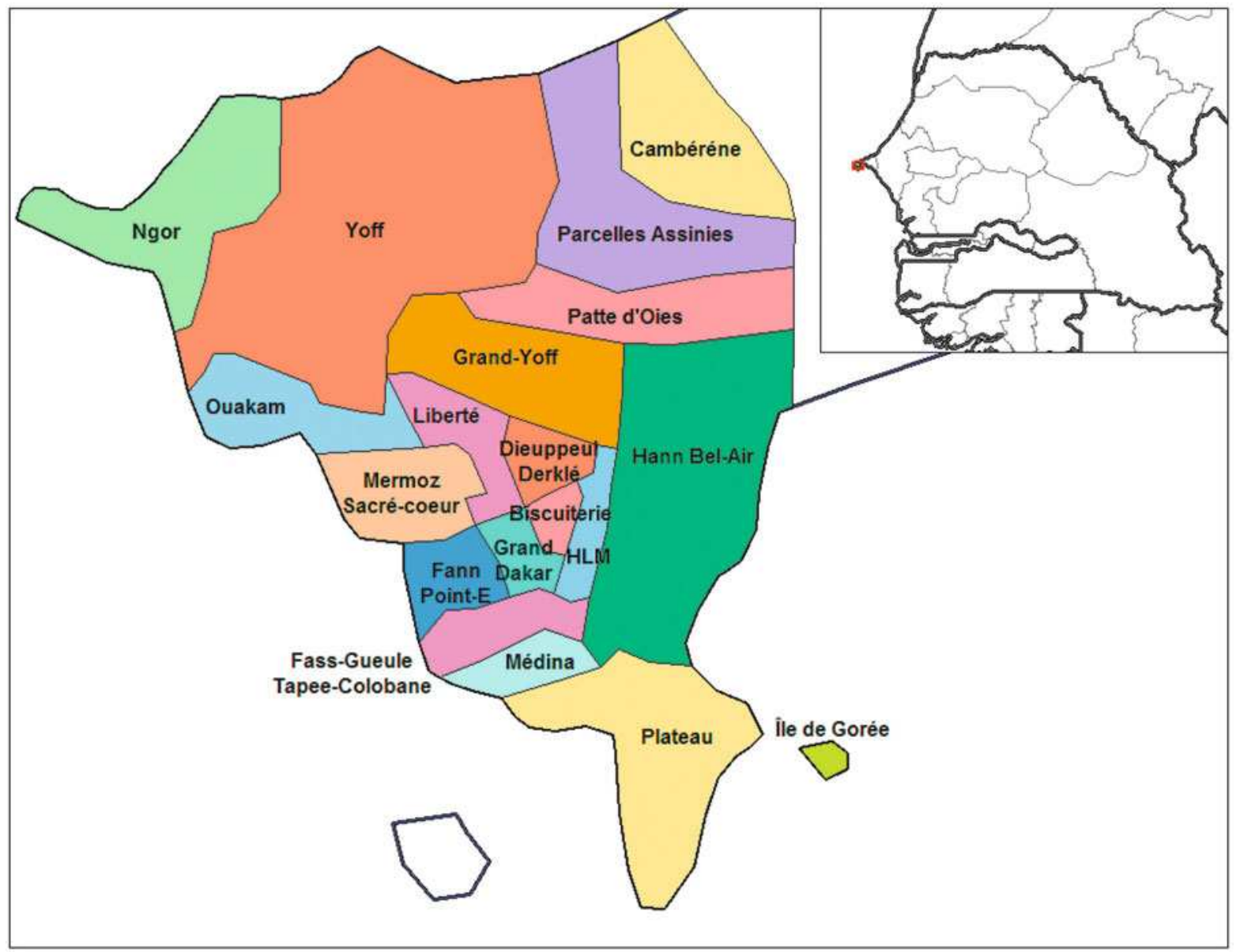

The interviewers placed the blind beggars in the position of 'resource persons', together with a few people in the Senegalese communities. Through this technique, information could be gathered from the migrant young women and girls as research subjects, as well as from beggars as migrants who also shared their own personal experiences. In total, twenty-five male and one female blind beggars (between 24 and 70 years of age) and fifteen female guides (between the ages of Io and 26) were interviewed, some in the presence of their father, mother, husband, or guard-

7 This social practice, known as a kind of joking relationship, is unique in West Africa. Known as Sinankunya in Mali, Rakiré in Mossi of Burkina Faso, Toukpê in Ivory Coast, and $\mathrm{Kal}$ in Wolof Senegal, the practice allows, and even requires, members of the same kin group and ethnic groups to mock or insult without consequence. The practice is a means of easing tension and reinforcing alliances between clans whose members are obliged to help each other (Labouret 1929). ian. Age was found to be an arbitrary measure, given that many children began guiding the blind when under ten in their home country and now practise it as cross-border migrants.

The semi-structured questionnaire was designed to elucidate, from respondent biographies, the process of becoming migrant beggars or guides, their trajectories of migration, and their means of coping in Dakar. This provided an opportunity for the respondents to relate in great detail their migration experiences, and through these the researchers were able to gain an indepth understanding of the social meanings of disability and the notion of masculinity as the provider. This examination of the migration of children and young people within a social enclave of poverty shows the significance of gender and intergenerational mutual dependency, and thus may help to raise more awareness about the links between gender, disability, migration, and life choices. 


\subsubsection{Multiple Conditions of Disability and Migration for Begging as a Livelihood}

The medical anthropologist Kaplan-Myrth (200I) suggests that where the conditions of everyday life are disabling, as in the case of rural Mali, ${ }^{8}$ the modes of coping adopted by people suffering from river blindness should be seen from the perspective of multiple and interwoven disabilities. This perspective involves a shift away from the logic of disability prevention that sees ignorance of the origin of river blindness as the main cause. It focuses on how people deal with the disease as a given, something that diminishes their capabilities but not necessarily their social roles and obligations. When prevention programmes do not reach them, they continue to cope with their everyday life and their insidious illness.

In Mali, most of the health care centres that have treatment/medicine to offer for river blindness are located in Bamako, the capital, or in towns and villages along the Niger river. There are also programmes for prevention (eye examination, specialized procedures, distribution of drugs, provision of supplies and information) in health posts in villages throughout the country. However, poor accessibility due to poor infrastructure, lack of motivation, and poor organization preponderate in many infected areas (Thylefors 1985; Sommer 1989). This reduces prevention and, as Kaplan-Myrth (200I) noted, in remote areas people suffering from river blindness simply refer to the illness as a 'disabling fact of life', 'the worst possible fate', 'the will of Allah', and as a destiny that must be coped with. Since blindness diminishes their ability to work in their fields and homesteads, begging is considered an acceptable means of survival, though many undertake other manual tasks for a living as much as possible, such as spinning cotton rope, shelling peanuts, and weaving plastic to make cots and chairs (Kaplan-Myrth 200I: 99-I02). This perspective resonates with the findings of this research, with one additional feature: crossing borders to beg requires the sustained support of a guide and a caretaker of daily needs in an alien environment.

Interviews conducted in Mali revealed that the majority of women and girls and the blind beggars they guide come from remote rural areas in the Kayes region (Bafing, Mahina, Kita, and Brigo towards Kar-

8 By 'disabling', Kaplan-Myrth refers to the lack of basic infrastructure such as access to clean water, adequate housing, roads, electricity, health care, and education, combined with malnutrition and infectious disease. amokola). The others come from Koulikoro, Segou, and other rural areas. Many of these villages are close to one of two dams, the Manantali in the Kayes region and the Tienfala in the Koulikoro region, with the proximity of the dams linked to river blindness. Begging across the border, which seems to have begun around the 2000 s or possibly before, involves circular and seasonal migration. They usually travel during Ramadan and stay through the dry season. This pattern is closely related to the availability of housing and the living conditions in the street. During the rainy seasons, the areas they occupy are flooded and become uninhabitable.

The most common means of transport is the Bamako-Dakar train. Blind beggars are often allowed to travel by rail for free, being seen as destitute. The girls who accompany them sit between the cars in front of the toilets, a location considered dangerous by the railroad employees and ignored by the ticket collectors because of the risk of accident. As the railways become increasingly privatized, travelling by bus, truck, or canoe for some parts of the trip, or walking for some stretches, have become more common. Such trips do not happen in one go. Beggars generally stay (in transit) in the big cities, especially Bamako and Kayes. While in transit, children and young people may take up small jobs such as load carriers or shoe polishers to earn their fare. They then move from Kayes, hundreds at a time, towards Kidira, Bakel, Tambacounda, Goudiri, or Diawara. Some beggars and their guides travel on foot to Kayes. Once in Kayes they go to Berola in the Kenieba circle and cross the river which forms the border between Mali and Senegal in order to get to Sayanssou; from there they continue to Kedougou. In Senegal, for those who decide to go on to Banjul in The Gambia, the transit cities are Kidira, Tambacounda, Kaolack, Thies, and Dakar.

Senegal is attractive for beggars from neighbouring countries partly because the standard of living is higher, but mainly because the Senegalese are reputed among Malians to be pious and to diligently honour the Islamic requirement to give alms. A resource person in Mali explained:

A beggar who is a head of his household may get to hear from other Malian beggars telling of their experience in Senegal and of how much money can be made and may decide to travel with his family.

Interviewees, including resource persons and the girls themselves, explained that at the moment of departure the girls becoming guides were happy to be doing so because they thought they would be able to shop for their marriage trousseau. Their parents also prom- 
ised them presents and explained that their father would be able to build a house for the family. According to the imam of the mosque at Fleurus Street in Dakar, who is a Malian:

Begging is a job for disabled Malians in Senegal. It's a lucrative business, as shown by their large communities. Although some end up doing this all their lives, for others it is a necessary but short-term means of acquiring funds for various projects - such as starting a business, buying supplies, buying and/or building a property. Several beggars and adult guides have managed to own a house from what was earned by begging.

Migrating to beg as a means of livelihood has also been associated with declining community support in the home villages. A 44-year-old blind male beggar explains:

We have to feed and clothe our children. The community does not do anything for the children of the blind and each blind beggar must look after his children, so that they can look after themselves in the future. I want to buy a house for my family and have been sending money to my brother, but the amount is not yet sufficient.

The way in which beggars make their living is not really offensive to the Senegalese population, even when practised by children. Interviewees related that earnings from begging can be twice or three times as high in Senegal as in Mali. In Mali, daily earnings may be between 300 and 3,000 Communauté Française d'Afrique (CFA) francs, equivalent to less than US\$I to 6. In Dakar the daily amount can be as high as Io 000 to 20000 CFA francs (US\$20 to 40). These earnings are used in various ways: remittances to family members who stay behind in Mali; basic living costs of the beggar and his/her family in Senegal; and purchasing personal effects, cereals, and other foodstuffs to be taken back to the village upon the beggar's return home.

\subsubsection{Gender and Age in Guiding and Living Conditions}

According to adult respondents in a village in Mali, once a daughter is 'mentally competent' to guide her blind father, she is required to accompany him. Boys generally refuse to guide their blind parents when they reach a certain age (between nine and twelve) because of shame. When they join the flow of migrant beggars, they beg for themselves. Some beggars keep their own daughters in Mali, and once in Senegal they hire girls of the same ethnic group to guide them.

Five main types of arrangements for the girl children and women as guides were discerned from the interviews. The first type involves the girl who serves as guide for her biological father or mother who is blind. In the words of a thirteen-year-old girl:

I came here with my blind father six months ago. He first went to Bamako with my mother to beg. My two older brothers work in the fields. But my younger brother fell ill and my mother returned to take care of him. So my father took me with him [on his next trip]. I miss my mother and brothers. But my father says that we will return at the beginning of the rainy season and we can bring them money and lots of things. Here people give us food and clothing and we sleep in front of the mosque.

A sixteen-year-old girl told the following story:

My father has passed away. I am the second child. My elder sister is married and looks after my younger brother. My blind mother and I came from a rural area and I guide her to beg. My mother heard from other people that earnings during one day here [in Dakar] can be as much as earnings during one month of begging where we come from. My mother used her savings and with the help of her brother we took the train to come here.

A blind male beggar, forty years of age, explained how his daughter became his guide:

My wife has our baby on her back. I feel sorry for her. Guiding me is very tiring for her because we have to walk a lot. So I ask my little girl to guide me and let my wife beg on one spot. When daughter guides me I notice that my earning is higher than when I ask one of the girls from our community to guide me. These girls scam us because they practise the tontine and save for a house upon their return to Mali.

The second type involves girls who were required by their parents to travel to Senegal to guide a blind beggar in exchange for financial or material resources for the parents. The beggar may not be related to the girl and her family, but comes from the same village in Mali. The girl may be the niece or daughter of a friend or neighbour of the beggar. The arrangement between the girl's parents and the beggar is called 'lending'. In the words of a ten-year old girl:

My father has 'loaned' me to my uncle. My father made the decision and my uncle asked me if I wanted to come along with him. I knew what I have to do once in Dakar and I agreed. My uncle paid my transport. We came here four months ago and I have no contact with my family since. I have no idea if he has sent money to my parents.

The third type involves those who were married to the beggar they guide before leaving Mali. Resource persons also told us about some women being married to blind beggars under the custom of levirate, ${ }^{9}$ 
sometimes by force - especially the younger ones. A forty-four-year-old blind beggar on Fleurus Street explained:

My young wife guides me. My friend, Sékou Konaté, gave away his daughter to me in marriage. She is my fifth wife. The others have left me because I fell ill. I have been coming here to beg since 2003 . I had been saving to buy salt for trade. Two years ago, I was able to buy two tonnes of salt. I was counting on buying a grinding machine with the money earned from selling the salt. But the customs officer demanded a sum of 200000 CFA francs (US\$400) for clearance. I did not have the money so I lost my merchandise. If it were not for this customs officer I would have stopped begging and returned home with a business.

The fourth type involves those who are 'rented out' on a daily basis by their mothers (also blind beggars) to a blind male beggar with whom they share the same sites. Being old, widowed, or divorced, these women ${ }^{10}$ earn through their own begging in addition to the services provided by their girl children to the adult male beggars; the children do not receive any compensation due to the fact that the agreement is made between adults. A seventy-year-old blind beggar explained:

There are blind beggars who come without their wives or children. They hire girls to guide them and they divide the earnings in half at the end of the day with the girl's father or mother. Often the girls themselves also come to the beggars looking for work.

The fifth type involves young women who independently migrated to Senegal in search for work, often as housemaids, but could not find work and have ended up becoming guides for beggars. Unrelated to the beggars through kinship, they work for earnings in a strictly economic relationship without the intervention of a parent.

A twenty-year-old female guide explained:

I have lost both of my parents and I live with my grandmother. My grandmother convinced me to go with her to Senegal because she had been there and knows the place. I guide blind beggars who need me and we share the earnings at the end of the day. It is a professional relationship and I keep my share of the earnings. People give us clothes here and I don't have to buy them. I want to save money to buy merchandise and sell it upon our return to Mali. That way I don't have to guide beggars any more.

9 Levirate marriage is a marriage in which a man takes over the widow of a family member.

10 These were Senegalese women who live and beg in the same area as their Malian counterparts.
Those who provided guiding services in return for a share of earnings admitted that begging could be lucrative - particularly when their beggar employers paid for their meals. Resource persons in Mali and Dakar confirmed that some of these young women, as returnees, were able to buy goods (televisions, furniture, foodstuffs) to take back to their home towns or villages. Some have managed to use their savings to buy land or set up an income-generating activity in their home country. In Dakar, there were also cases in which the companionship between these independent women and the beggars has led to a relationship of affection and love, and even marriage. In these cases the pair continues the same arrangement for their work, though the guides can be more independent since they have become indispensable partners for the beggars. Some can negotiate a position as an equal partner, gain autonomy, and achieve a position of authority vis-à-vis their blind husbands. ${ }^{11}$

In Dakar, the main problems the beggars encounter are housing and personal security, though newly arrived people fairly quickly integrate into migrant begging communities. Those who do not immediately find a place to stay often share the shelter of another couple until an alternative can be found. The lucky ones are those who can find a tiny room built from cardboard and sheet metal in Grand-Yoff, Hann village, or Castor. These housing arrangements are privately owned and managed by the local population and rented to the beggars. They are situated close to water discharge canals. On Valmy Street, a part of the begging community lives in a run-down building, paying on average Io 000 CFA francs (US\$20) per month; but the majority sleep in the street 'en famille' around the mosque in Fleurus Street or the mosque of Grand Dakar or inside the Dakar train station. A Malian women trader in the Malian market at the Dakar train station describes these shelters as follows:

The girls and the beggars live in rooms made of wood, metal sheets, or rice bags or plastic sheets with many holes. The rooms are overcrowded with adults and children, bags of clothes, and other belongings. To sleep, they place mats on the ground and fold them up during the day. The building belonging to the Cité des Eaux near Bignona in Grand-Yoff has many rooms in a row,

11 The researchers once witnessed a marital dispute over the amount of money obtained from selling a donated piece of meat. The husband complained that the amount appeared too low and was met with rather defensive behaviour on the part of his wife. The young wife had to be calmed down by neighbours to prevent escalation of the dispute. 
with narrow doors and without windows. The rooms have quite high ceilings but there is no electricity or water. Apart from these, there are even more dicey shelters, with doors that cannot be closed properly, or no door at all. A number of abandoned trucks are also used as shelters.

In these conditions, personal security and poor sanitation are problems. The beggars have no information about or access to banking services; they keep their money to themselves and are therefore vulnerable to attack and robbery (in their rooms or on the streets), particularly when it is publicly known that they have electronic equipment of value - radios, televisions, or mobile phones. Poor sanitation leaves the beggars and their guides vulnerable to many types of illnesses such as malaria, rheumatism, bronchitis, and skin diseases. Self-medication is practised; they buy medicines that come illegally from Mali or Nigeria and are sold nearby. In cases of serious illness they go to the local health centres or private clinics where they have to pay the full costs. A beggar complained:

To ensure that my second wife got proper care when she had problems during her pregnancy, I had to spend about 250000 CFA francs (around US\$500).

As circular migrants, girls who are guides do not have access to schools in Senegal and are kept entirely within the Malian beggars' communities. Few of them speak Wolof, the principal language in Senegal, and thus most are unable to make friends with a Senegalese. Some of those interviewed had been victims of sexual violence, or were in conflict with boys living in the neighbourhood. The young women and girls who guide the beggars spend their days walking with the beggars without a rest, and sometimes they have to go begging at night. They have little to eat, surviving on leftovers from cheap restaurants or bits of meals left by their Senegalese neighbours. Under these circumstances the burdens on the girls are more intense particularly for the biological daughters, wives through forced marriage, or 'loaned' guides. As conditions are harsh some wives have left their husbands. A wife of a beggar tells:

I guide my husband in the morning, and in the afternoon I must guide my mother. In the night I sell attiéké $e^{12}$ and fish.

In sum, young Malian female guides are frequently exposed to hazardous living conditions and strenuous work, and to all types of violence - including sexual vi-

12 Attiéké is a grain-based product processed for urban use. olence leading to unwanted pregnancy. Their ability to gain some autonomy varies, depending on their age, the type of guiding arrangement, and the relationship with the beggar which defines the term of mutual dependency: whether this is an inter-generational obligation within kinship or an employment relationship, marriage with the wife in a commanding role as the non-blind party, and so on.

\subsection{Legal and Policy Responses: The Exclusion of Young Migrant Malian Guides of Beggars}

In the context of cross-border migration today in West Africa, human trafficking, including child trafficking, becomes pertinent. There is an important legal and administrative arsenal with provisions protecting children who are victims of malpractices in crossborder migration and trafficking in West Africa and a great number of intra-regional and bilateral programmes to counter child trafficking. The most important is the United Nations Convention against Transnational Organized Crime (UNCTOC) and its Protocol to Prevent, Suppress and Punish Traffic in Persons Especially Women and Children.

The Senegalese and Malian legal and policy instruments on child trafficking follow the definition of the Protocol on human trafficking of UNCTOC (see Bop/Cissé/Touré/Niang 20I2). According to article 3 (a) of this protocol:

\footnotetext{
'Trafficking in persons' shall mean the recruitment, transportation, transfer, harbouring or receipt of persons, by means of a threat or use of force or other forms of coercion, of abduction, of fraud, of deception, of the abuse of power or of a position of vulnerability or of the giving or receiving of payments or benefits to achieve the consent of a person having control over another person, for the purpose of exploitation. Exploitation shall include, at a minimum, the exploitation of the prostitution of others or other forms of sexual exploitation, forced labour or services, slavery or practices similar to slavery, servitude or the removal of organs (UNODC 2008: 2).
}

Regarding consent, article 3 (b) states that

if a victim's consent to the intended exploitation is obtained through any improper means (threat, force, deception, coercion, giving or receiving of payments or benefits, abuse of power, position of vulnerability) then the [apparent] consent is negated and cannot be used to absolve a person from criminal responsibility. Regardless of whether their consent was obtained without use of any prohibited means, children have special legal sta- 
tus. A 'child' shall mean a person under the age of eighteen years [emphasis added] (UNODC 2008: 5).

Senegal has harmonized this Protocol with its national laws. Mali has instituted a mandatory exit visa for children, but this has not yet produced the expected results. Many children continue to move across borders by train, bus, and boat, sometimes with the full awareness of the security forces responsible for ensuring the implementation of this new measure. The only instrument between Senegal and Mali with respect to the issue of child trafficking is a bilateral agreement signed on 22 July 2004 in Dakar.

Other related international instruments include the conventions of the International Labour Office (ILO) relating to the Rights of Women and Children, the Convention on the Elimination of All Forms of Discrimination against Women (CEDAW), and the Convention on the Rights of the Child (CRC), which West African countries have signed and/or ratified. There are also regional instruments, such as the African Charter on the Rights and Welfare of the Child that came into force on 29 November 1999, and the Protocol to the African Charter on Human and Peoples' Rights on the Rights of Women adopted in Maputo in 2003. At the regional level, the Economic Community of West African States (ECOWAS), of which Senegal and Mali are members, adopted the Declaration to fight against Trafficking in Persons during the twenty-fifth Ordinary Session of Authority of Heads of State held in Dakar on 20-2I December 200I (see appendix I).

At the national level, both countries prohibit begging, although the tradition of giving alms and begging as a way of making a living are socially accepted. From the perspective of the young guides, there are discrepancies between the legal definition of 'trafficking', 'age', and 'consent' and the social reality of their migration. These discrepancies should be of concern for national institutions and organizations responsible for controlling child trafficking. Different cultural and sociological interpretations of 'childhood' are at play, especially under conditions of dire poverty. A major point of contention revolves around the question of labour exploitation and the links between practices of 'child fostering' and trafficking.

In West Africa, child fostering is an age-old practice that involves the parents' placing their child (or sometimes 'giving' the child to a childless relative) in a family, workshop, or business of a relative for apprenticeship and education. In the context of child migration today, fostering may have become a way to access child labour for which gains can be made for both parents and fosterers, given the increasing role of intermediaries who facilitate these arrangements in exchange for personal profits (Truong 2005). Research from a child-centred perspective shows that the children themselves view migration as a valuable means of improving their status and learning new skills and that they can actually benefit from its educational impact (Hashim/Thorsen 20II). Given the mixed evidence on the effects of fostering on children's well-being and education, caution should be exercised against a general demonization of the system (Serra 2009).

Furthermore, the traditional perception of the child as 'capital' to ensure the parents' old age is very much alive, not only in families but also among institutions responsible for the promotion of children's rights. A child also may not be defined solely and exclusively by chronological age. Other criteria come into play in determining the status of childhood or adulthood: capacity, strength, size, level of economic dependence, marital status, having been (or not been) subject to an initiation rite. This means that adjusting policy to local contexts may have to involve thinking about 'social age' (Clark-Kazak 2009) instead of 'chronological age'.

Thus, applying the UN definition of human trafficking has met with both local resistance (Truong 2005: 7I) and with resistance among socially engaged scholars, since a strict crime-oriented approach introduces new risks. These risks include the wrong people being punished, or the further tightening of control over the mobility of people under the age of eighteen (Busza/Castle/Diarra 2004). The puzzle regarding interaction between 'culture' and socio-economic relations, its outcome in relation to children's rights, and the question of the stage at which child labour migration can be considered as trafficking is yet to be solved. There continues to be a great deal of uncertainty, both when defining the target group and when determining the means of intervention (De Lange 2007).

Where policy concerns for child beggars are explicitly expressed, so far girls have been hardly visible to researchers. A survey conducted by the United $\mathrm{Na}$ tions Children's Fund (UNICEF) in cooperation with the project Understanding Children's Work (UCW) (2007: 2-4) on child beggars in the Dakar region asserts that boys constitute the quasi-total population of child beggars, and that ninety per cent of the child beggars in Dakar are talibés or boys who have been sent away to religious schools (daaras) for an Islamic education. ${ }^{13}$ The survey covered 7,600 child beggars, 
among whom no single girl was included, based on the belief that girls are 'marginal' in the activity of begging. Boys work up to six hours per day begging in addition to other jobs they manage to find such as carrying loads or collecting garbage. The need for special protection of the girl guides of blind beggars has to date been neither acknowledged by their families nor recognized by responsible institutions. Ironically, despite their visibility in public spaces - in the streets, at crossings, in front of filling stations and mosques -, the relevant policymakers seem unable to recognize their presence. This lack of awareness of the presence of female children in begging communities is also the case with staff at regional offices of UN agencies and at non-governmental organizations (NGOs) in Dakar whose mandate is the protection of vulnerable children.

It can be said that this invisibility in the eye of policymakers may have been reinforced by two kinds of bias. First, there is a sectoral bias in campaigns against child trafficking, leading to the targeting of particular sectors that have received public attention and dominate the global agenda. For example, cocoa production (known to employ more boys than girls) has been subject to multi-level pressure and collaborative action: consumer brands, strategic government intervention, and geographic concentration (Schrage/Ewing 2005; Ndiaye 2009). Likewise sex trafficking - believed to generate US\$7-I2 billions annually (Yen 2008: 659) and estimated at seventy per cent of all human trafficking (Adepoju 2005) - has been subject to many different types of collaborative action.

Second, there is a cognitive bias based on gender beliefs held by officials, civil society organizations, and researchers on who does what 'work' and what counts as 'work' for children. Child beggars are considered to be rare (or a small fraction of the population of children in most countries) and difficult to reach (UNICEF/UCW 2009). For the girls who guide beggars, the multiple layers of disadvantage derived from being young, female, and a member of an eco-

13 The survey method used in this study defines talibés as any child who has spent the night before the survey in a Koranic institution and has declared himself to have received religious education. It should be noted that in the past many talibés lived at home and studied at a daara in their village, while some were entrusted to marabouts (Koranic teachers) in distant villages. Today with the deterioration of rural daaras it has become common for parents to confide their boys to the care of marabouts far away and often without contact for several years. nomically insignificant group of migrants may have shut them out from the realm of policy relevance.

These biases are laid bare in the defining of 'target groups' for policy and support programmes. Under the various programmes designed to help children in difficult circumstances implemented by the UN agencies or NGOs, a number of terms have been introduced, such as street children, children in danger, trafficked children, little beggars, vulnerable children, children in vulnerable circumstances, and children in distress. None of these definitions captures the multiple conditions of vulnerability and difficulty experienced by the girls who guide blind beggars. Their difficult conditions are reinforced by a combination of power dynamics mediated through a range of social institutions (the family, child fostering for economic gain, levirate marriage) not easily captured under the category of a single target group.

In Senegal, despite the existence of many national and international institutions that support vulnerable children, most of them have as yet little knowledge of the presence of girls guiding beggars, or of the migration routes they take or their living conditions. Following an advocacy initiative, several donors agreed to fund a voluntary return migration programme involving hundreds of Malian children trafficked into Senegal, paying for the journey and providing initial moneys for income-generating activities once back in Mali. No female child was considered. There is no specific or positive discrimination policy for the families these children come from. The girls guiding beggars are also excluded from the Senegalese government's antipoverty measures, which cover children's needs and do pay special attention to the rights of the girl child in education and health.

Finally, there is little political will in either the Senegalese or Malian states to protect the rights of migrant children. Following the 2004 bilateral agreement of cooperation between Senegal and Mali, a Joint Standing Committee was set up with administrative focal points for monitoring child trafficking. But as neither country has arranged for the financial and human resources to translate commitments into action, this Committee is not functional and no meetings of the focal points have been held.

\subsection{Conclusion}

Knowledge about the situation of girls who guide beggars is sparse. The insights obtained from this research underscore the importance of recognizing the 
presence of these girls among the population of children and young people who move across borders. The fact that most of them were persuaded to leave their biological family and their village and cross the Senegal-Mali border to carry out such strenuous activity proves they are not only victims. Although their agency is circumscribed by the relationships that organize their migration, they can be agents having unique personhood. They face major constraints in achieving personal well-being and in maintaining personal security with regard to health, housing, and income.

In this respect, the view that children's rights programmes should have an approach that is person-centred (White 2002) rather than one merely categorycentred (based on an identity arbitrarily fixed by gender or a given age limit) seems to make sense. The multiple forms of vulnerability faced by girls who guide beggars suggest that in their situation, many structural inequalities have been reinforced and/or produced. Micro-processes of social transformation that are gendered and generation-based are such that the normative distinction between the categories of 'migration' and 'trafficking', 'childhood' and 'adulthood', 'ability' and 'disability' may not always be appropriate. Improvement of this knowledge should be a priority for researchers.

Understanding the reality of begging communities from the perspective of multiple conditions of disabil- ity and vulnerability may open up new avenues for research and action. Viewing adults and children as two fixed categories can constrain an understanding of the multiple relations amongst, and between, adults and children, and the changing nature of power that underpins these relationships in matters of both mutual interest and resistance (White 2002). Studying children in relation to migratory processes must go beyond viewing them as only passive extensions of adult actors to ensure a better understanding of their being active agents in their own efforts and imaginaries of the world in relation to the varying circumstances under which they migrate. This has implications for legal as well as policy practices.

Finally, given the context of a multidimensional crisis (economic, social, and environmental) facing West Africa and the relatively lucrative benefits of migration for begging as a livelihood, the migration of children and young people in this context is unlikely to stop unless sustainable alternatives for the blind can be found. Only a bold policy aimed at greater social justice that also gives a cognitive dimension to the quotidian aspects of human security as intergenerational mutual dependence generally and in communities affected by river blindness could change this situation. A new prism on social justice is needed to help overcome the tendency to disaggregate social problems into discrete challenges facing specific groups rather than to define them as being interrelated.

\section{Appendix: Legal and Institutional Frameworks to Combat Child Trafficking relevant to Mali and Senegal}

\section{International Instruments}

11. Convention against Transnational Organized Crime and its Protocol to Prevent, Suppress and Punish Trafficking in Persons, Especially Women and Children

12. Convention on the Rights of the Child, adopted by the General Assembly in its resolution 44/25 of 20 November 1989, United Nations, Treaty Series, vol. 1577, no. 2753 I.

13. Optional Protocol to the Convention on the Rights of the Child on the sale of children, child prostitution and child pornography, adopted by the General Assembly in its resolution 54/263 (annexe II) of 25 May 2000, United Nations, Treaty Series, vol. 2I7I, no. 2753I.

14. Convention concerning Forced or Compulsory Labour, I930 (Convention No. 29), of the International Labour Organization Convention, United Nations, Treaty Series, vol. 39, no. 6r2.

15. ILO Convention 182óThe Worst Forms of Child Labour Convention, adopted in I999 and ratified by I73 nations by 20IO. Article 2 defines a child as someone under the age of I8.

16. Convention on the Elimination of All Forms of Discrimination against Women, adopted by the General Assembly in its resolution 34/I80 of I8 December I979 (article 6 refers to traffic in women and exploitation of prostitution of women), United Nations, Treaty Series, vol. I249, no. 20378

\section{Regional Instruments}

1. The African Charter on the Rights and Welfare of the Child entered into force on 29 November 1999. Article 29 of this Charter states that States parties shall take appropriate measures to prevent: (a) the abduction, the 
sale of, or trafficking of children for any purpose or in any form, by any person, including parents or legal guardians of the child; (b) the use of children in all forms of begging.

2. The African Charter on the Rights and Welfare of the Child that came into force on 29 November I999.

3. The Protocol to the African Charter on Human and Peoplesí Rights on the Rights of Women, adopted in Maputo in 2003.

4. Economic Community of West African Statesí Declaration on the Fight against Trafficking in Persons (the twenty-fifth Ordinary Session of Authority of Heads of State, held in Dakar on 20-2I December 200I, with a Plan of Action against Trafficking in Persons (2002-2003) annexed to the Declaration.

\section{Bilateral Agreement}

A bilateral agreement on the struggle against trafficking and trafficking of children signed between Senegal and Mali, 22 July 2004 in Dakar.

\section{References}

Adepoju, Aderanti, 2004: "Trends in international migration in and from Africa", in: Massey, Doris. S. and Taylor, J. Edward (Eds.): International Migration Prospects and Policies in a Global Market (Oxford: Oxford University Press): 59-I03.

Adepoju, Aderanti, 2005: "Review of Research and Data on Human Trafficking in sub-Saharan Africa”, in: International Migration, 43,I-2: 75-98.

Awumbila, Mariama; Ardayfio-Schandorf, Elizabeth, 2008: "Gendered poverty, migration and livelihood strategies of female porters in Accra, Ghana”, in: Norwegian Journal of Geography, 62,3: I7I-I79.

Bâ, Cheikh, Oumar, 1996: "Migrations régionales et relations de genre dans la vallée du fleuve Sénégal”, in: Africa Development, 23,3: 95-II9.

BIT/LUTRENA, 2007: Etude sur la traite des enfants au Mali: Dimensions internes, phénomènes transfrontaliers, rôle et responsabilités du secteur privé. Rapport final (Dakar: Bureau International du Travail (BIT)/Programme de Lutte Contre La Traite des Enfants a des Fins d' Exploitation de leur Travail en Afrique de l'Ouest et du Centre (LUTRENA)).

Brockerhoff, Martin; Eu, Hongsook, I993: "Demographic and Socioeconomic Determinants of Female Rural to Urban Migration in Sub-Saharan Africa", in: International Migration Review, 27,3: 557-577.

Bop, Codou; Cissé, Fanta; Touré, Aissa; Niang, Cheikh Ibrahima, 20I2: Femmes, Migration et Droits au Mali (Dakar: Centre de Recherches pour le Développement International (CRDI) Groupe de Reserche sur les Femmes et Lois au Senegal (GREFELS)).

Bocquier, Philippe; Traoré, Sadio, 2000: Urbanisation et dynamique migratoire en Afrique de l'ouest: la croissance urbaine en panne (Paris: L'Harmattan).

Bourgeot, André, 1977: "Observations critiques sur "Les Migrations africaines”, in: L'Homme, I7,2-3: II7-I23.

Busza, Joanna; Castle, Sarah; Diarra, Aisse, 2004:"Trafficking and Health", in: British Medical Journal, 328: I369-I37I.
Clark-Kazaka, Christina Rose, 2009: “Towards a Working Definition and Application of Social Age in International Development Studies", in: The Journal of Development Studies, 45,8: I307-I324.

Colvin Lucie, Editor, 1981: The Uprooted of the Western Sahel: Migrants' Quest for Cash in Senegambia (New York: Praeger Publishers).

Cordell, Dennis D.; Gregory, Joel W.; PicheÏ, Victor, I996: Hoe and wage: A social history of a circular migration system in West Africa (Boulder: Westview Press).

David, Phillipe, I980: Les navétanes. Histoire des migrants saisonniers de l'arachide en Sénégambie des origines à nos jours (Dakar: Nouvelles Editions Africaines (NEA)).

De Haan, Arjan; Brock, Karen; Coulibaly, Ngolo, 2002: "Migration, Livelihoods and Institutions: Contrasting Patterns of Migration in Mali”, in: Journal of Development Studies, 38,5: 37-58.

De Lange, Albertine, 2007: "Child labour migration and trafficking in rural Burkina Faso", in: International Migration, 45,2: I47-I67.

Diop, Momar Coumba 2008: Le Sénégal des Migrations, Mobilités, Identités et Sociétés (Paris: Khartala).

Eshia, Owusuaa, 2010: Streetism: The Lived Experiences of Unaccompanied Migrant Children and their right (Master Thesis in Philosophy in Childhood Studies, Norwegian University of Science and Technology Faculty of Social Studies and Technology Management Norwegian Centre for Child Research, Trondheim).

Fall, Papa Demba, 2003: Migration internationale et droits des travailleurs au Sénégal, SHS/2003/MC/5 (Paris: UNESCO).

Findley, Sally, I989: "Les migrations feminines dans les villes africaines: une revue de leurs motivations et experiences", in: Philippe, Antoine; Coulibaly, Sidiki (Eds.): L'insertion urbaine des migrants en Afrique. (Paris: ORSTOM).

Findley, Sally E., I99I: "Sécheresse et migration dans la vallée du fleuve Sénégal .Les femmes et les enfants dominent le nouveau type du migrant", in: Pop Sahel, i6 (April): 19-28. 
Findley, Sally E. 1997: "Migration and family interactions in Africa”, in: Aderanti, Adepoju (Ed.): Family, population and development (London: Zed Books): Io9-I38.

Foltz, William J., I965: From French West Africa to the Mali Federation (New Haven CN: Yale University Press).

Hashim, Iman; Thorsen, Dorte, 20II: Child Migration in Africa (New York: Zed Books).

Gondola, Charles Didier, I997a: "Unies pour le meilleur et pour le pire - Femmes africaines et villes coloniales: une histoire du métissage", in: Cli-Histoire, femmes et societies, 6: 87-IO4.

Gondola, Charles Didier, I997b: Villes Miroirs: Migrations et identités urbaines à Kinshasa et Brazzaville I930-1970 (Paris: Editions L'Harmattan).

Gubert, Flore, 2007: "Migration and Development: Mixed evidence from western Mali”, in: Development, 50,4: 94-Ioo.

Kaplan-Myrth, Nili, 200I: "Blindness Prevention in Mali: Are Improvements in Sight?", in: Disability Studies Quarterly, 2I,3: 9I-IO3.

Kielland, Anne; Tovo, Maurizia, 2006: Children at Work: Child Labor Practices in Africa (Boulder, CO: Lynne Rienner Publishers).

Labouret, Henri, 1929; "La Parenté à Plaisanteries en Afrique Occidentale", in: Africa: Journal of the International African Institute, 2,3: 244-254.

Lambert, Michael, 2007: "Politics, patriarchy, and the new traditions: understanding female migration among the Jola (Senegal, West Africa)”, in: Hahn, Hans P.; Klute, George (Eds): Cultures of Migration: African Perspectives (Berlin: Lit Verlag): I29-I46.

Lesclingand, Marie, 2004: "Nouvelles stratégies migratoires des jeunes femmes rurales au Mali: de la valorisation individuelle à une reconnaissance sociale”, in: Sociétés contemporaines, 55: 2I-42.

ILO, 2007: Combating the trafficking of children for labour exploitation in West and Central Africa (Geneva: International Labour Organization (ILO)/ International Programme on the Elimination of Child Labour (IPEC)).

Machel, Graça, 1996: The Impact of Armed Conflict on Children (New York: United Nations).

Moens, Bruno; Zeitlin, Veronica; Bop, Codou; Gaye, Rokhaya, 2004: A Study of the Practice of Trafficking in Persons in Senegal, A Report (Dakar: United States of Agency for International Development (USAID)).

Mufioz, Beatriz; West, Sheila, 1997: "Trachoma: The Forgotten Cause of Blindness", in: Epidemiologic Reviews, I9,2: 205-2I7.

Ndiaye, Amadou, 20I2: "Agricultural Non-family Workers (Sourga) in Senegal River Valley", Paper presented at an international conference on the future of the agrifood sector in Africa: Young People, Farming and Food, I9-2I March, 2OI2, Accra, Ghana, co-hosted by the Future Agricultures Consortium and the Institute of Statistical Social and Economic Research (ISSER), University of Ghana.

Ndiaye, Ababacar, 2009: La traite et le trafic des filles entre le Mali et le Sénégal: Analyse juridique de la situation des filles guides de mendiants et domestiques au Sénégal au regard de l'Accord de coopération, de la loi et des instruments juridiques, (Dakar: Groupe de researche sur les femmes et Lois au Senegal (GREFELS)).

Remme, J. F. H. 1995: "The African Programme for Onchocerciasis Control: Preparing to Launch", in: Parasitiology Today, I,II: 403-406.

Riddell, J., Barry, I980 "Is Continuing Urbanization Possible in West Africa?", in: African Studies Review, 23,1: 69-79.

Schrage, Elliot J.; Ewing, Anthony P., 2005, "The Cocoa Industry and Child Labour", in: The Journal of Corporate Citizenship, I8 (Summer): 99-II2.

Serra, Renata, 2009: "Child fostering in Africa: When labor and schooling motives may coexist", in: Journal of Development Economics, 88,I: 157-I70.

Sommer, Alfred, I989: "Organizing to Prevent Third World Blindness"”, in: American Journal of Ophthalmology, IO7,5: 544-546.

Sy, Maimouna, I99I: "Les migrations féminines selon les ethnies du Sénégal” communication à la Conférence: Femme, Famille et Population (Ouagadougou: Burkina Faso Union Africaine pour l'Etude de la Population).

Thylefors, Bjorn, 1985: "Development of Trachoma Control Programs and the Involvement of National Resources", in: Reviews of Infectious Disease, 7,6: 774-776.

Toulmin, Camilla; Guèye, Bara, 2003: Transformations in West African agriculture and the role of family farms (London: International Institute for Environment and Development (IIED).

Truong, Thanh-Dam, 2005: Poverty, Gender and Human Trafficking: Rethinking Best Practices in Migration Management (Paris: United Nations Educational, Scientific and Cultural Organization (UNESCO).

Truong, Thanh-Dam, 2006: "Governance and poverty in sub-Saharan Africa: rethinking best practices in migration management", in: International Social Science Journal; 58,190: 697-7I4.

UNICEF, 2002: Child Trafficking in West Africa: Policy Responses (Florence: Innocenti Research Centre, United Nations Children's Fund).

UNICEF; UCW, 2009: Comprendre le travail des enfants au Mali: Rapport sur le travail des enfants (Rome: Understanding Children Work (UCW), United Nations Children's Fund (UNICEF).

UNODC, 2008: Toolkit to Combat Trafficking in Persons Global Programme against Trafficking in Human Beings (Vienna: United Nations Office on Drugs and Crime (UNODC)).

White, Sarah, 2002: "Being, becoming and relationship: conceptual challenges of a child rights approach in development", in: Journal of International Development, I4, 8: I095-IIO4.

Yen, Iris, 2008: "Of vice and men: A new approach ro eradicating sex trafficking by reducing male demand through educational programs and abolitionist legislation”, in: Journal of Criminal Law and Criminology, 98,2: 653686.

Open Access. This chapter is distributed under the terms of the Creative Commons Attribution Non-commercial License, which permits any noncommercial use, distribution, and reproduction in any medium, provided the original author(s) and source are credited. 
Part V Liminal Legality, Citizenship and Migrant Rights Mobilization

Chapter 15 Migrants' Citizenship and Rights: Limits and Potential for NGOs' Advocacy in Chile Claudia Mora and Jeff Handmakert

Chapter 16 Diminished Civil Citizenship of Female Migrant Domestic Workers in Saudi Arabia and the United Arab Emirates Antoinette Vlieger

Chapter 17 The Right to Education for Migrant Children in Thailand: Liminal Legality and the Educational Experience of Migrant Children in Samut Sakhon

Kamowan Petchot

Chapter 18 Challenges of Recognition, Participation, and Representation for the Legally Liminal: A Comment

Cecilia Menjívar and Susan Bibler Coutin 
 Migrants' Citizenship and Rights: Limits and Potential for NGOs' Advocacy in Chile
}

\author{
Claudia Mora and Jeff Handmaker ${ }^{1}$
}

\begin{abstract}
In this chapter we address the structural and institutional constraints faced by non-governmental organizations (NGOs) assisting Peruvian migrants in Chile to advocate for migrants' rights. We argue that these constraints have provoked reactive rather than proactive strategic responses by NGOs in their promotion of migrants' rights. In addition, the unchallenged acceptance of a traditional notion of citizenship has placed Chilean NGOs as short-term service providers rather than as long-term advocates. We propose that a conscious recognition of the possibilities opened up by international legal regimes to confront nation-states' regulation of migrants' rights offers a pragmatic approach to navigating such limits.
\end{abstract}

Keywords: citizenship, liminal legality, migrant advocacy, rights translation, stratification.

\subsection{Introduction}

The Southern Cone of Latin America has undergone significant shifts in the migration of people during the last few decades. The direction of movement has traditionally been south to north, in particular to North America and Europe. However, the movement of people to countries in the global North has given way to an increasingly intraregional south-south migration. This diversification of flows has not only followed economic and political crises, but has also resulted from border containment policies in the north, weighing on migration's costs and the length and purpose of the entire migration project.

1 Dr. Claudia Mora is a faculty member of the Department of Sociology at Universidad Alberto Hurtado, Chile. Dr. Jeff Handmaker is a senior lecturer in Law, Human Rights and Development at the International Institute of Social Studies, Erasmus University, The Netherlands and Honorary Senior Research Fellow in the School of Law, University of the Witwatersrand, South Africa. The authors would like to thank Hugo Sir for his invaluable help as research assistant. Correspondence can be e-mailed to cmora@uahurtado.cl and handmaker@iss.nl. Funding for this research was provided by IDRC, Canada, Grant number 104785-006 and FONDECYT, Chile, Grant number IIo0793.
Migration to neighbouring countries demands lower monetary and time investments, given the proximity to migrants' countries of origin and flexible entry requirements. Today, more than ten per cent of Latin American migration happens within the region (Martinez 20II). As in other parts of the world experiencing similar dynamics, the rapid increase in intraregional migration has been accompanied by migrants' social exclusion and structural constraints on their ability to claim rights, taking place on two levels: first, based on the territorially based normative regimes in the country of destination; and second, related to migrants' location in social hierarchies of gender, race, and social class, which constitutes differentiated notions and exercise of rights, in both the countries of origin and of destination.

In this chapter, we focus on a case study of Peruvian migration to Chile in order to assess the conditions forging civil society organizations' capacity to respond to these challenges in their promotion of migrants' rights. We explore the incongruence of nation-state rights' addressing globally based justice issues pertaining to the movement of people around the globe, and the possibilities for advocacy on behalf of migrants by civil society organizations. In the case of Chile, an increase in Peruvian migrants has not changed the policy framework in a way that supports broader protection of migrants' rights, and the advo- 
cacy response of civic organizations has been correspondingly limited. This has left the growing Peruvian migrant population with a liminal legal status (Menjivar 2006), including restricted access to social services and almost no participation in the public sphere.

Peruvians in Chile form a distinct flow of migrants. They amount to 138,000 according to the Immigration Department of Chile, and this number has continued to grow since the I990s. Migrants from Peru consist, by and large, of predominantly labour migrants travelling on an individual basis, at least in their initial stages of migration. Peruvian migrants are mostly women (sixty per cent according to the last 2002 census), which is in part explained by the fewer resources required for intraregional migration, and the proximity of the country of origin that permits the continued fulfilment of gender responsibilities with family and community in Peru.

While they average over ten years of education, Peruvians are concentrated in precarious, low-paid, lowstatus occupations in Chile, largely due to prejudice and stereotypes held by employers and society at large (Mora 2009, 20II). Most migrants are recruited through informal channels to work in domestic service and construction work, in conditions that do not substantially alleviate their economic and social marginalization. The effects of these conditions on migrants' awareness and the exercising of their rights have been explored elsewhere (Mora/Piper 20II). Our research has drawn attention to the relevance of social stratification and its influence on notions and claims of rights, linking migrants' understanding and practice to a combination of their social and cultural capital, the length of their stay in the host society, and their understanding of rights vis-à-vis their country of origin and destination (Mora/Piper 20II).

In this chapter, we will address the structural and institutional constraints faced by non-governmental organizations (NGOs) assisting Peruvian migrants in Chile to advocate for migrants' rights. We will argue that these constraints have provoked NGOs' reactive rather than proactive strategic response to advocacy. We propose that a conscious recognition of the possibilities opened up by international legal regimes to confront nation-states' regulation of migrants' rights offers a pragmatic approach to navigating such limits and to translating entitlements into a locally relevant context (Merry 2006a, 2006b).

We will begin by assessing the implicitly prescribed notion of citizenship that defines the category 'migrant', which precludes the recognition of certain rights. We will argue that the boundaries of citizen- ship set by the nation-state not only contradict the realities of migration, but that the unquestioned acceptance of this bounded notion by civic actors, and particularly NGOs, is a significant obstacle to social advocacy for migrants. NGOs are, broadly speaking, not a network capable of safeguarding the human rights of peoples (Ong 2006). However, their unquestioned acceptance of such a limited definition of citizenship has resulted in NGOs' intensifying their position as service-providers to migrants, rather than as representatives of migrants in legal and social processes that define social belonging and economic distribution (Fraser 2003). This has consequently restricted the scope of their activities and their potential as advocates. Furthermore, this positioning of NGOs as service-providers rather than critical advocates has confirmed the Chilean state's approach to individual responsibility and autonomy in the resolution of migrants' needs and demands. This becomes particularly relevant in the case of Peruvian migration to Chile, which involves a great number of women. Women migrants are mostly segregated into care work, a low-status position in the occupational hierarchy, which tends to reproduce their social and economic marginalization in Chile. In addition, Peruvian migrants' life conditions and trajectories are shaped by their limited access to social resources on the grounds that they 'lack citizenship' and experience liminal legality (Mora 2008, 2009).

Our critique of traditional notions of citizenship espoused by Chilean NGOs is intended to shed light on alternative models of representation that would broaden the service approach of NGOs to one of informed advocacy for the rights of migrants. In reaching these findings, we draw on research carried out in Santiago de Chile between 2008 and 2009 and on interviews with thirty-five key informants from organizations which provide at least one service to immigrants, in order to explore the constraints placed on NGOs should they ultimately fulfil a more prominent advocacy role.

\subsection{Citizenship in a Globalized World}

Migration poses many challenges to traditional notions of citizenship - understood as the bond between individuals, their rights and responsibilities, and a nation-state - since the growing scale of people's movement around the globe confronts people's claims to universal citizenship with the actual boundaries of citizens' inclusion within a nation's frontiers. The 
breadth of contemporary migration draws attention to at least three aspects of this challenge. First, to the unyielding hold of the nation-state on the political system, which narrowly defines the parameters of inclusion. Second, to the need for recasting membership of a political community as an issue of social justice. And third, to the possibilities for a redefinition of citizenship's emerging out of clashes between different levels of regulatory regimes. These three aspects help us explore some of the contradictions of citizenship in a globalized world.

\subsubsection{The Restrictiveness of Citizens' Inclusion}

Citizenship can be a mark of belonging as well as of exclusion. It warrants entitlement to social benefits to all those considered part of the political community by birth, by ancestry, or by ascription through a formal procedure established by the state. In contrast, the category of migrant is possible only to the extent that it is conceived as the other in relation to the category of citizen. Non-citizens, generally, lack membership of the political community. It is this negation that signals the impervious hold of the nation-state on the political system, in that it defines the limits of access to social rights and entitlements. This power of the nation-state has clearly diminished in other spheres, most notably in economic activities and regulations, but not in the definition of membership (Halfmann I998).

Even though citizenship has been thought of as a neutral political space, unmarked by social stratification, this idea of universalism contained in a homogeneous community of citizens has served to obscure material differences and inequalities among nationals and migrants alike (Barber 2006). Indeed, the concept of social inclusion professed by the notion of citizenship disregards the material and symbolic differences among nationals by gender and class, and it also determines the particular forms of exclusion faced by immigrants as non-members of a political community and 'aliens' to the distribution of social benefits.

The conventional distinction between citizens and non-citizens is becoming increasingly contested in a globalized and conflict-ridden world, involving large and often sudden movements of people. Related to these developments, in terms of human rights law, and especially with regard to the International Convention on the Protection of the Rights of All Migrant Workers and Members of Their Families (I990) which Chile ratified on 2I March 2005, is the fact that migrants are entitled to demand social benefits, includ- ing access to health ${ }^{2}$ and education ${ }^{3}$. A core objective of the 1990 Convention provides that migrant workers should be guaranteed decent work conditions. Article 70 of the Convention states that:

States Parties shall take measures not less favourable than those applied to nationals to ensure that working and living conditions of migrant workers and members of their families in a regular situation are in keeping with the standards of fitness, safety, health and principles of human dignity.

These entitlements provided by the I990 Convention form part of a social dimension of citizenship, guaranteeing as a minimum the opportunity to live a 'dignified life' according to the means and capacities in the host society. In this context, the reinforcement by international regimes of the protection of migrants' basic rights acquires great relevance.

The intensity and speed of people's movement have therefore exceeded the boundaries of citizenship, which has been recast as not the sole path to the recognition of membership. In a highly mobile world, immigrants do not always become, or even want to become, citizens of a nation-state. Indeed, for many migrants, citizenship status is less relevant than their entitlement to social services such as health, education, and welfare benefits (Basok 2004). This means that, to migrants, formal political recognition may be secondary to the legitimacy of social rights provided by the international regime of human rights, of rights located in the individual rather than in the nationstate.

Migrants' experiences and demands are shaped by interactions between different types of agents and institutions, framed by conflicting norms and symbols, and within a structural context. This is why different stages of migration may intensify the relevance of migrants' access to social services or to formal recognition (Basok 2004; Mora/Piper 20II). And, to fully understand the relevance of different degrees of migrants' entitlements, and the way they are constructed through interaction, it is necessary to also consider citizenship as a process (Nakano Glenn 20II). This means that practices of citizenship are shaped by different forms of social hierarchies which unevenly position migrants in relation to entitlements and their exercise of rights (Basok 2004). Hence, to go beyond paper rights, or 'law in the books', which may be accorded by formal citizenship, migrants must

2 Provided for in articles $25(\mathrm{I})(\mathrm{a}), 28,43(\mathrm{I})(\mathrm{a}), 45(\mathrm{I})(\mathrm{e})$ and 70 of the Convention.

3 Provided for in articles 30, 45(I)(a) and 45(4). 
be able to formulate claims to these rights in terms of the 'living law' (Hertogh 2009), and such claims are likely to be precluded by forms of social exclusion of gender, class, and race.

As we have argued elsewhere, there are key factors triggering migrants' sense of entitlement: the nature of their legal (i.e. documented or undocumented) status; the length of migrants' stay in the country of destination; migrants' human and social capital, which provide the resources for consciousness and claims; and their understanding of rights compared to their country of origin (Basok 2004; Mora/Piper 20II). A processual approach allows one to correlate different stages of migration with changing grievances and notions of rights, as well as the centrality of access to formal citizenship. For example, the first stage of migration is often governed by migrants' search of employment. Hence, it is likely that, even if conscious of their rights, migrants' need for a job may take precedence over other grievances and demands. Migrants may fear losing their job if they claim labour rights or fear stigmatization as 'problem workers', which would not only affect their situation as family providers, but that of the network of migrants often involved in their labour recruitment, 'contaminating' the network for future referrals (Mora/Piper 20II). Recently arrived migrants are, on the whole, more socially vulnerable compared with experienced migrants. In this first stage of migration, consciousness of needs and a capacity to formulate demands for social services may be more relevant than acquiring formal citizenship.

This differentiated position does not mean migrants' experiences are similar in every stage of migration. The notion of 'migrants' also suffers from the dangers of essentialization, given that people's possession of economic, social, and cultural capital marks different paths and experiences of migration. As Sassen (I998) notes, there are two different circuits of people's movement. Firstly, there are highly skilled professionals who more closely resemble the relatively free movement of capital, and for whom citizenship may be irrelevant and/or an accessible resource. Secondly, there are migrant workers in search of better economic and life chances through marginal and often precarious work. This second group is subject to increasing constraints of movement and while relevant, their membership in a political and/or economic community is equally elusive. We deal with the second group, for whom human dignity and access to basic services constitute an aspiration in their first migratory stage.

\subsubsection{Rights and Social Justice Beyond Formal Citizenship}

Related to the perceived, albeit contested importance of citizenship status for migrants, there has also been an increasing questioning of the very concept as anachronistic and surpassed by actual developments in the international arena. In this vein, Yasemin Soysal (I997), for example, has argued that the notion of citizenship assumes rights and identities presaged by the boundaries of the nation-state, without taking into account that the public sphere is constituted transnationally and hence that claims emerge 'within' and 'beyond' the nation-state (Soysal I997: 5IO-5II). In this regard, Fraser (2009) proposes to go beyond conceptualizing justice as pertaining to all those affected nationally or transnationally, to a notion where it pertains to all those subjected to the same governance structure.

Human rights and international law, including specifically articles 23 and 24 of the Universal Declaration of Human Rights (I948); article 5(e)(i) of the Convention on the Elimination of All Forms of Racial Discrimination (1965); the broad protection afforded by the Convention on the Rights of the Child (I989); and especially the Convention on the Protection of the Rights of All Migrant Workers and Members of Their Families (I990), as well as various Conventions passed under the auspices of the International Labour Organization, potentially provide a broad normative basis for the advancement of migrants' rights in the countries and societies in which they settle. Claims based on human rights are not tied to a territory but located in individuals. Hence, states are less able to arbitrarily deny rights to non-citizens. This form of individualized citizenship captures the aspirations of millions of migrants who, while not citizens of a nationstate, invoke universal norms to claim or advocate for the recognition of their basic social rights. In practical terms, citizenship is surpassed by the contestation of global regimes placing claims of rights beyond the boundaries of the nation-state.

The limits of nation-state citizenship in a globalized world are that this conventional notion of citizenship has ceased to explain the relations between the state and the political community, precisely because, as Soysal (I997) argues, the public sphere is constituted within and beyond the boundaries of the state. The persistence of the state's hold on the political sphere with its corresponding normative framework of what is distributed and to whom has made migration and membership in a political community 
pivotal to an issue of social justice that is not always territorially based. Indeed, as Fraser (2003) has argued, the effects of such framework are mediated by non-territorial and extra-territorial forces. That is, in answering the questions of what, whom, and how the distribution of resources is accomplished, the framework for justice needs to be rethought to include postWestphalian principles (Fraser 2003).

At the same time, a stumbling block on the path to social justice is a definition of belonging using territorial parameters for a process where they are irrelevant. A critical assessment of citizenship and of the limits of a territorially bound justice frame allows one to explore an understanding of different facets of the vulnerability and social exclusion on the grounds of gender, race, and class confronted by the majority of labour migrants. In this scenario, civil society and especially NGOs assisting migrants have the potential to connect different political levels. These include the level within and beyond a nation-state and interrelated regulatory regimes and the level of different social actors within the nation-state. Civil society organizations are key agents in the representation of migrants' interests and in the promotion of measures that advance the recognition of migrants, such as the gathering and dissemination of information to migrants; advocacy, particularly for the most vulnerable; legal aid services; lobbying for legal change; and education on immigrant rights (Battistella I993; Klaaren/ Dugard/Handmaker 20II). More importantly, a willingness among organizations to question a territorially based frame of justice can help facilitate their bridging role between migrants and the society in countries of destination, which in turn enhances their advocacy for migrants' interests.

\subsubsection{Clashes between Different Regulatory Regimes}

Regulating who may enter and remain within a country has conventionally been one of the principal features of a state's exercise of territorial sovereignty in terms of well-established principles of international law. More importantly, "the right to leave and the right to enter a country are not symmetrically protected" (Cornelisse 20IO: I75). This principle of territorial sovereignty in international law has, however, been seriously undermined as different legal systems and social normative structures, both national and international, coexist within nation-states, leading to theoretical and actual clashes that have the potential to either limit or advance a person's social protection.
In this plurality of legal systems, a national law may, for example, prescribe that no one of a particular nationality be entitled to health care, whereas a health care clinic financed by the municipal government may observe a policy of opening its doors to anyone, regardless of legal residential status. Clashes also arise between different national laws. For example, a country's immigration law may forbid the possibility of a long-term migrant guest-worker being joined by her family members, while the same country's constitution may extend to all the right to enjoy one's family life.

Migration policy regimes that emanate from multilateral systems often clash with a state's national (im)migration law system. In the case of a treaty, the juridical implications of these clashes are explicitly negotiated and agreed in terms of another international law principle, pacta sunt servanda. ${ }^{4}$ At the global level, multi-lateral policies aimed at restricting the movement of people across borders may contradict policy regimes aimed at the protection of migrants.

In terms of global protective measures, the International Labour Organization (ILO) oversaw the development and ratification of a comprehensive $\mathrm{Mi}$ grant Workers Convention (I990), which came into force in 2002 . While the treaty has been ratified by large numbers of states from which migrant workers originate, virtually none of the host states where migrant workers obtain employment have ratified the treaty and the Convention is therefore not binding in these countries. As mentioned earlier, Chile is an exception, having ratified the Convention on 2I March 2005. A state's ratification of an international treaty designed to protect an individual raises the possibility of individuals, either on their own or via an intermediary organization, making a direct or indirect claim against a state (Handmaker 2009: 32). For example, NGOs in Chile could raise issues of concern with the Committee on the Rights of Migrant Workers, which was established in terms of article 72(I) of the 1990 Convention. The Committee in fact reviewed Chile in its ${ }^{\text {th }}{ }^{\text {Sh }}$ Session in September 20II. Among its conclusions, the Committee expressed concern "about reports on the existence of discriminatory attitudes and social stigmatization of migrant workers and members of their families" in Chile (Committee on Migrant Workers 20II).

4 Meaning: "agreements must be kept". This refers to the collective, binding effect of treaties on all contracting states, against whom claims may be brought by migrants and/or representative organizations. 
As an inherently global issue, governments and multilateral organizations have been encouraged to harmonize or codify many different efforts to regulate transnational migration. Consultative policy processes have sought a middle ground between the different levels and types of regulatory regimes, according due attention to state security concerns as well as promoting the humane treatment of migrants.

In the course of these efforts at global codification, states have tended to privilege and indeed encourage people to migrate for study purposes as well as to take up key jobs in certain employment sectors. International organizations and NGOs have meanwhile sought to promote and protect the rights of refugees as an exceptional category of migrant. Consequently, this category of migrants, together with knowledge migrants, has benefited more from these regimes in terms of their level of legal protection and social acceptance (Handmaker 20II). Labour migrants are, in this sense, the category most likely to benefit from an active role being taken by civil society organizations, and their strategic use of international versus national norms in the promotion of migrants' rights and entitlements.

\subsubsection{Civic capacity to hold states accountable}

The capacity of civic actors to promote and, sometimes, impose state accountability for meeting national and international legal obligations has been shaped by concomitant global, regional, and national legal frameworks. With the introduction of human rights instruments at the international and, by extension, regional level, the legal scope for advocating individual and group rights at the national level has been enhanced. As illustrated earlier, treaty-based rights, such as those provided by the Convention on Migrant Workers and Their Families, may not only be directly enforceable through a relevant international treaty body or international tribunal, but also through a state's national court system, depending on whether or not a state's domestic legal system regards a treaty as self-executing. Legal remedies in direct relation to the Convention may be difficult, although migrants would still be able to make claims through the state's labour law, insisting on the enforceability of the Migrant Workers Convention (Satterthwaite 2005: 63).

Ignatieff (I999) has referred to these developments as components of a human rights 'revolution' with juridical, enforcement, and advocacy dimensions; as part of a human rights 'spiral' (Risse/Ropp/ Sikkink 1999); or as the product of a 'curious grape- vine of interests' in which non-state actors, NGOs, have played a key role (Korey 2003). As participants in international legal and political processes, individuals and civic organizations have played key roles, from the framing of juridical standards to human rights enforcement and the expanding of public consciousness about migrants' rights, and these have shifted the relationship between civic actors and the state (Handmaker 2009: 57).

\subsubsection{Civic Actors as Translators}

Civic actors also fulfil a crucial role in mediating the translation of international legal norms into local contexts. The role of these translators can be a powerful force in reinforcing social justice claims through other, non-legal means (Abel 1995, Merry 2006b). In order to be effective translators, civic actors must possess a 'double consciousness' of the content of international law and the circumstances and institutions through which it is enforced, as well as the local or national context in which international norms find expression (Merry 2006a, 2006b). NGOs are situated at a place where they can be brokers or 'translators' of human rights and social justice claims: a bridge between the human rights world, activists, and migrants (Merry 2006a, 2006b).

\subsection{Migrant NGOs in Chile: From Service Providers to Potential Advocates}

The vulnerability characterizing most labour migration means it is decisive that organizations lobby for their interests, considering that migrants have limited structures of representation. In this section, we will examine the role migrant NGOs have played as civic actors and in the challenging of social, cultural, legal, and political contexts in which they operate. In the case of Chile, migrant organizations have not taken a strong advocacy role, and services provided tend to be specific and uncoordinated with other organizations or services. Some of these organizations are sponsored by the Catholic Church and function as shelters for recently arrived migrants as well as placement agencies for domestic service work. Some are affiliated to universities in Santiago and provide basic legal and psychological services. There are also organizations that focus on the 'cultural integration' of Peruvian migrants, and a few other organizations, born out of the political exile of Peruvians under former 
president Fujimori, which provide legal and financial assistance to the community.

We suggest that these organizations are limited by structural and organizational constraints to become agents of social justice for migrants, and especially women migrants, in Chile. Some of these barriers are institutionally based, while others are outcomes of an insufficient normative framework (political, social, and juridical), precluding the development of an active role by civic society agents. Organizational and normative constraints compel NGOs' tactical or reactive approach to social demands, which in turn impedes the capitalization of NGOs' achievements; the accumulation of institutional knowledge; and the establishment of NGOs as relevant actors in the promotion of migrants' rights.

New forms of citizen participation are, no doubt, promoted by Chilean civil society organizations. Their work in providing immigrants with basic tools to navigate and understand novel structures, institutions, and experiences in a receiving society that is often hostile reveals an understanding of their potential role as advocates, grounded in deep beliefs in humans' right to have rights. However, Chilean organizations have not been able to represent migrants' interests and promote their full access to social and political rights and have rather targeted migrant women in their reproductive role, focusing on the provision of necessary though unrelated services insufficient to broaden the sense of belonging and entitlement in the new society. Certainly, the provision of services is fundamental on immigrants' arrival in Chile; however, organizations fall short in their support of needs emerging along a wider trajectory, and often fail to incorporate the knowledge and empowerment migrants are likely to accumulate over time.

In addition, a lack of understanding of migration as a process that is also transnational has limited services to migrants' arrival, in some ways naturalizing conditions that may not reflect migrants' needs over time. In our research into organizations in Santiago, we found that most pay sole attention to individual and care-related needs, rather than taking on an advocacy role in demanding the advancement of collective rights. Perhaps a more important form of naturalization of immigrants is organizations' unchallenged reproduction of the labour segregation of Peruvian migrants in Chile. Migrant civil society organizations in Chile tend to foster the inclusion of Peruvian migrants, especially women, in their gendered role. Many provide services tailored to women as the fam- ily care-taker, and workshops to prepare them for domestic work (Mora/Piper 20II).

We have argued elsewhere (Mora/Piper 20II) that migrants differ in the relevance they attribute to rights, and that their evaluation shifts with their migratory experience and with their acquired capital (social and cultural), widening the scope of rights claims as these features increase. Hence, migrants' involvement with NGOs is limited, partly because their notions of rights are tied to improving their conditions of employment, using NGOs' legal services, or securing access to medical attention and education for their children. This does not, however, mean that organizations are silent on the collective harnessing of rights; rather their work is just beginning to focus on migrants' access to legal information as well as to information on housing, employment, and educational rights. Nevertheless, the dominant perspective that has resulted is one that naturalizes the positioning of Peruvian migrants, and of women in particular. Consequently the promotion of rights has translated mostly into information workshops on labour law and the filing of migrants' visa applications, or on the know-how of domestic service, reinforcing the low status of migrant women.

\subsection{Chilean NGOs' Possibilities for Agency}

As mentioned, many migrant organizations have emerged in the last decade in Santiago, a number of them sponsored by the Catholic Church, others under the auspices of universities, such as legal aid and psychological clinics, and a few volunteer-based political and cultural organizations. However, there are a number of barriers preventing a strategic approach to advocacy, limiting the development of practices that would allow civic agents to consolidate a sphere of action and to capitalize on their achievements. The first stumbling block for NGOs is the absence of continuous funding. The majority of these organizations rely exclusively on volunteers and short-term funds. The consequences of this financial uncertainty are negative and widely felt, ranging from charging migrants for services to employee and volunteer rotation. The effects of this unmanaged risk prevent the accumulation of organizational knowledge and, in the long run, the achievement of long-term goals.

A second issue, arising from the above, is that Chilean organizations tend to offer only services requested by migrants. Hence, their goals are defined in 
a reactive fashion, narrowly limited to the particular demands for services made by migrants. Most do not include a questioning of the denial of citizenship status to migrants, but rather naturalize the restrictive legal, institutional, and structural limits of the Chilean state, where 'help' is provided to 'aliens'. The networks established among NGOs are scarce too, and for this reason they are rarely able to capture an agenda beyond pressing demands to incorporate planning for broader citizenship and rights claims.

But perhaps the most compelling barrier faced by civil society organizations is the rigid legal framework of the Chilean nation-state. Current immigration law dates back to the dictatorship the country endured from I973 until I990. The focus of the national juridical regime is on national security threatened by migration, rather than on taking into account the reality of increasing migration flows and the need for recognition of migrants' rights. NGOs have worked under this normative framework with its limited focus on assimilation rather than fostering an understanding of migratory flows as part of an all-encompassing transnational dynamic.

Given that many barriers to advocacy emerge from nationally based structural constraints, including a migration law that cannot address citizenship and rights, it is only opposition by international regimes that can open the possibilities for a recognition of migrants' rights and for NGOs' legitimation as advocates. The capacity of civic actors to promote and sometimes impose state accountability for meeting national and international legal obligations has been shaped by the introduction of human rights instruments at the international level. By extension, the legal scope for advocating individual and group rights at the national level has been enhanced. Treaty-based rights are not only directly enforceable through a relevant international treaty body or international tribunal, but also through a state's national court system. To advocate migrants' rights in Chile by way of legal-and social-mobilization would represent a significant departure from their current service orientation.

\subsection{Conclusions}

Dignity and social esteem are integral parts of social justice that often elude Peruvian migrants in Chile, whose share in the distribution of social benefits is often exiguous due to their lower status in Chilean hierarchies of gender, class, and the racial othering taking place in day-to-day interactions, as well as by Chilean institutions. Peruvian migrants' life chances are diminished by gender roles and stereotypes. Peruvian women tend to show a circular pattern of migration when care at origin is involved, affecting their labour trajectory and benefits. Gender stereotypes also direct migrants into a highly segregated labour market, where 'domestic servant' and 'Peruvian immigrant' are becoming symbolically interchangeable. The intersection of migrants' class and gender, and their perception as a racial other - elaborated on the basis of national origin - also contribute to migrants' lack of recognition, and hence, of social justice in Chile. This is why NGOs are central to the promotion of social respect of migrants.

NGOs' potential to advocate for migrants' rights in Chile through legal and social mobilization would represent a significant departure from their current service orientation. Advocacy is a confrontational expression of civic agency that is, generally speaking, more limited in scope than cooperative interactions, such as helping the government cope with implementation challenges, but also potentially more effective in widening the understanding of who counts as a subject of rights (Fraser 2003). NGOs are best positioned to contribute to an effective transnational public sphere that would permit the demand of rights within and beyond the nation-state (Fraser 2003). However, in the case of Chilean NGOs, organizational barriers - such as limited funding, short-term goals and activities, and the absence of networks and structural barriers - such as a dated, national-security-inspired legislation - erode the potential of Chilean NGOs to articulate different levels of legal regimes, to advocate for a notion of citizenship that is not territorially based, and to act as brokers or 'translators' between international human rights regimes and local migrants' demands.

Here, we have suggested the need for civic actors' appropriation of a social space that will allow them to anticipate and manoeuvre power relations-the idea of strategy proposed by de Certeau (2000). And planning, as an effect of the accumulation of NGOs' knowledge and observation, is preceded by a consciousness of the field, its possibilities, and the actors and positions involved. Only then will Chilean NGOs be able to challenge narrowly defined notions of membership and entitlement, especially given the breath of migratory flows and the potential for legitimation in international regimes. For this, civic actors must also understand the potential to mobilize migrants' rights in Chile. They have an inherent capacity to hold states accountable to their national and inter- 
national legal obligations through legal and social mobilization strategies, and civic actors can fulfil a central role in the translation of international rules in local legal contexts.

Our research shows that while Peruvian migrants do use NGOs' services at different times, they mostly rely on informal networks and sources of knowledge,

\section{References}

Abel, Richard, 1995: Politics By Other Means: Law in the Struggle Against Apartheid, I980-1994 (New York: Routledge).

Barber, Pauline Gardiner, 2006: "Locating Gendered Subjects in Vocabularies of Citizenship", in: Tastsoglou, Evangelia; Dobrowolsky, Alexandria (Eds.) Women, Migration and Citizenship (Aldershot, Ashgate): 6I-84.

Basok, Tanya, 2004: "Post-national Citizenship, Social Exclusion and Migrants Rights: Mexican Seasonal Workers in Canada”, in: Citizenship Studies, 8, I: 47-64.

Battistella, Graziano, 1993: "The Human Rights of Migrant Workers: Agenda for NGOs”, in: International Migration Review, 27, I: I9I-20I.

Committee on Migrant Workers, 20II: "Concluding Observations", Heard at the $15^{\text {th }}$ Session, I2-23 September 2oII, CMW/C/CHL/CO/I.

Convention on the Elimination of All Forms of Racial Discrimination, I965: Passed by the UN General Assembly on 21 December 1965, in: UN Treaty Series, 660: 195.

Convention on the Rights of the Child, I989: Passed by the UN General Assembly on 20 November 1989, UN Treaty Series, I577: 3.

Cornelisse, Galina, 20I0: Immigration detention and human rights: rethinking territorial Sovereignty (Leiden: Martinus Nijhoff).

De Certeau, Michel, 2000: La Invención de lo Cotidiano: I. Artes de Hacer (Mexico City: Universidad Iberoamericana).

Fraser, Nancy, 2003: "Social Justice in the Age of Identity Politics: Redistribution, Recognition, and Participation”, in: Fraser, Nancy and Honneth, Axel (Eds.) Redistribution or Recognition: A Political - Philosophical Exchange (London: Verso): 7-Io9.

Fraser, Nancy, 2009: "Who Counts? Dilemmas of Justice in a Postwestphalian World”, in: Antipode, 4I: 28I-297.

Halfmann, Jost, 1998: "Citizenship Universalism, Migration and the Risks of Exclusion", in: The British Journal of Sociology, 49, 4: 513-533.

Hertogh, Marc, 2009: Living Law: Reconsidering Eugen Ehrlich (Oxford: Hart).

Handmaker, Jeff, 2009: Advocating for Accountability: Civic-state Interactions to Protect Refugees in South Africa (Antwerp: Intersentia).

Handmaker, Jeff, 20II: "State security and the mantra of irregular migration”, Paper for the Conference on Irrelevant, Advisors or Decision-Makers? The Role of which suggests that the limits to organizations' advocacy have indeed prevented this role beyond basic assistance to migrants. Civic actors can be a powerful force in the advancement of migrants' rights in Chile, but the necessary conscious recognition of these possibilities is contingent upon their own strategic, rather than reactive, positioning.

'Experts' in International Decision-Making, Rotterdam, 24-26 June.

Ignatieff, Michael, I999: Whose Universal Values? The Crisis in Human Rights (Amsterdam: Stichting Praemium Erasmianum).

International Convention on the Protection of the Rights of All Migrant Workers and Members of their Families, I990: Passed by the UN General Assembly on I8 December I990, A/RES/45/158.

Klaaren, Jonathan; Dugard, Jackie; Handmaker, Jeff (Eds.), 20II: South African Journal on Human Rights (Special Issue on Public Interest Litigation), 27, I.

Korey, William (Ed.), 2003: NGOs and the Universal Declaration of Human Rights: 'a curious grapevine' (New York; Basingstoke: Palgrave Macmillan).

Martinez Pizarro, Jorge (Ed.), 20II: Migración internacional en América Latina y el Caribe Nuevas tendencias, nuevos enfoques (Santiago de Chile: CEPAL).

Menjivar, Cecilia, 2006: "Liminal Legality: Salvadoran and Guatemalan Immigrants' Lives in the United States”, in: American Journal of Sociology, III, 4: 999-I037.

Merry, Sally Engle, 2006a: "Transnational Human Rights and Local Activism: Mapping the Middle”, in: American Anthropologist, I08, I: 38-5I.

Merry, Sally Engle, 2006b: Human Rights and Gender Violence: Translating International Law into Local Justice (Chicago: University of Chicago Press).

Mora, Claudia, 2008: "The Peruvian community in Chile as a response to discrimination and exclusion", in: Peace Review, 20, 3: 339-347.

Mora, Claudia, 2009: "Estratificación Social y Migración Intrarregional: Algunas Caracterizaciones de la Experiencia Migratoria en Latinoamérica”, in: Revista Universum, 24, I: I28-I43.

Mora, Claudia, 20II: "Global Inequalities - Local Hierarchies. Peruvian Migrants' Labour Niches and Occupational Mobility in Chile", in: Boike Rehbein, (Ed.) Globalization and Inequality in Emerging Societies (New York: Palgrave Macmillan): 256-269.

Mora, Claudia and Piper, Nicola, 20II "Notions of Rights and Entitlements Among Peruvian Female Workers in Chile”, in: Diversities, I3, I: 5-I8.

Nakano Glenn, Evelyn, 20II: "Constructing Citizenship: Exclusion, Subordination, and Resistance”, in: American Sociological Review, 76, I: I-24.

Ong, Aihwa, 2006: Experiments with Freedom: Milieus of the Human (Oxford: Oxford University Press). 
Risse, Thomas; Ropp, Stephen; Sikkink, Kathryn, 1999: The Power Of Human Rights: International Norms and Domestic Change (New York: Cambridge University Press).

Sassen, Saskia, 1998: Globalization and Its Discontents: Essays on the New Mobility of People and Money (New York: New Press).

Satterthwaite, Margaret, 2005: "Crossing Borders, Claiming Rights: Using Human Rights Law to Empower Women
Migrant Workers", in: Yale Human Rights and Development Law Journal, 8: I-66.

Soysal, Yasemin, I997: "Changing Parameters of Citizenship and Claims-making: Organized Islam in European Public Spheres", in: Theory and Society, 26: 509-527.

Universal Declaration of Human Rights, 1948: Passed by the UN General Assembly on Io December I948, 2I7 A (III).

Open Access. This chapter is distributed under the terms of the Creative Commons Attribution Non-commercial License, which permits any noncommercial use, distribution, and reproduction in any medium, provided the original author(s) and source are credited. 


\title{
16 Diminished Civil Citizenship of Female Migrant Domestic Workers in Saudi Arabia and the United Arab Emirates
}

\author{
Antoinette Vlieger ${ }^{1}$
}

\begin{abstract}
This chapter discusses the positions of domestic workers and their employers in Saudi Arabia and the United Arab Emirates in relation to different conceptions of citizenship. Scholars studying domestic workers commonly use concepts of citizenship to situate the vulnerable position of domestic workers. This chapter elaborates on existing theory in specifying the connection between the concepts of access to justice, citizenship, and legal liminality. Specifically, this chapter shows how the theory of diminished citizenship, developed to analyse the position of domestic workers elsewhere, also applies to domestic workers in Saudi Arabia and the Emirates. Interviews and fieldwork show that in the case of a conflict, these workers have no proper access to justice; this results in severely diminished civil citizenship and is related to the fact that domestic workers are both migrants and women. This chapter then examines to what extent the position of the employers can be conceptualized within the same citizenship framework. The results suggest that the position of the employers cannot be framed using the same conceptions of citizenship. A more detailed look at Saudi and Emirati societies reveals new concepts, but also shows there may be an interconnection between the various concepts of citizenship. The study finally opens the discussion on possible connections between civil citizenship, social citizenship, and the position of women. As such, this chapter is relevant not only for the more than two million domestic workers in these two countries but also for reaching a better understanding of the importance of full citizenship for women worldwide.
\end{abstract}

Keywords: Access to justice, civil citizenship, domestic workers, gender, legal liminality, migrant workers, Saudi Arabia, social citizenship, United Arab Emirates.

\subsection{Introduction}

This chapter discusses the positions of more than two million female, migrant, live-in domestic workers ${ }^{2}$ in Saudi Arabia and the United Arab Emirates (the Emirates) who suffer from a lack of access to justice. Female domestic workers are live-ins who perform tasks in private households, such as cleaning, cooking,

1 Antoinette Vlieger studied Dutch law, international law, cultural anthropology, and sociology of the non-Western world. She has lectured in corporate law, introduction to law, argumentation theory, contract law and penal law from meta-legal perspectives, and liability law at the University of Amsterdam, where she obtained her Ph.D. in 2OII.

2 Male domestic workers are notably rare and Saudi or Emirati domestic workers have not been found and according to interviewees no longer exist; see below. childcare, and care for the elderly, in exchange for food, lodging, and money. In earlier historical periods, there was often a life cycle of domestic work: girls who worked as domestic workers during their younger years would hire one after marriage. Upon the introduction of the minimum wage in western Europe, domestic workers became too expensive for the average household. Furthermore, other jobs became available for women, and therefore paid domestic work almost vanished from many European countries. In the I970s, several scholars predicted the demise of paid domestic work (Moors 2003), but developments during the decades that followed have proven them wrong; in both the northern and the southern hemispheres, the number of those engaged in paid domestic work has grown rapidly, causing a feminization of the migrant labour force. Whereas in the I970s women formed approximately fifteen per cent of the 
migrant labour force, in the mid-I99os they constituted the majority of migrant workers in several countries-almost sixty per cent in the Philippines and approximately eighty per cent in Sri Lanka and Indonesia (Vlieger 20I2: 45-49).

Similarly to migrants on the Arabian peninsula in general, domestic workers have migrated to Saudi Arabia and the Emirates in large numbers only since the I970s (Silvey 2006: 23). On average, there is one domestic worker for each household in Saudi Arabia, making a total of between I.4 and 2 million. The United Arab Emirates report a higher rate of at least one domestic worker for every citizen (Strobl 2009: I67), with estimates ranging from two to five hundred thousand (Ali 20I0: 95, among others). The women concerned come mainly from the Philippines, Indonesia, Nepal, India, Somalia, Ethiopia, and Morocco. Embassies from these labour-sending countries in both Saudi Arabia and the Emirates report that abuses against domestic workers account for the vast majority of the complaints they receive (Human Rights Watch 2008a: 2). The number of runaways is considerable. Staff at embassies that were interviewed reported that there were many urgent requests for help on a daily basis. Most safe houses are filled beyond their capacity. For instance, the Jeddah deportation centre houses 8,000 people in a facility designed for 5,500 (Human Rights Watch 2008a: 104). Tens of thousands of workers run away each year because of claimed serious breaches of their rights. However, most domestic workers who claim infringement of their rights do not run away, as they are generally well aware of the fact that in conflict, they have almost no one (or no place) to turn to for the protection of their rights. A Filipina domestic worker employed in Riyadh, for instance, stated:

Really they are good to me. If I say I need rest, they give me rest.

Asked if they were not good to her, if she had some problem with her employer, where she would go, she replied:

Madam, I cannot go anywhere, I am not allowed to go outside. I cannot go to the embassy. I will just cry in my room and pray. ${ }^{3}$

This short excerpt illustrates the empirical facts that form the basis of this chapter. These findings are derived from an extended study of all the factors that in-

3 Interview by the author with a Filipina domestic worker (2008); name, place, and details allowing cross-reference withheld for security reasons. fluence the conflicts between female, migrant, live-in domestic workers and their employers in Saudi Arabia and the United Arab Emirates from the perspective of the sociology of law with many aspects of legal anthropology included and applied. Sociology of law (or legal sociology) is the systematic, empirical study of law and conflicts as a set of social practices. As such, it draws on the whole range of methods and theories generally associated with sociological research (Clark 2007: I4I3). Legal anthropology scholars study legal systems, law, and law-like social phenomena, and take as fundamental that law cannot be meaningfully understood apart from the wider culture and society. Scholars in this area share a commitment to intensive and rigorous field methodologies requiring extensive involvement in the communities under study (Clark 2007: 68).

The results of this extended study of the factors that influence the conflicts between female, migrant, live-in domestic workers and their employers in these two countries showed, among other things, that if a domestic worker is lucky, her employer is good to her; if she is not so lucky, she has nowhere to go. Even under the best of circumstances, a domestic worker in Saudi Arabia or the Emirates may be treated well, but she has no rights - she may have some rights on paper, but without any possibility of realizing them, she has no rights in practice (Vlieger 20I2).

An often-used framework of analysis for the position of domestic workers is provided by Bosniak $(2006),{ }^{4}$ who frames the vulnerable position of domestic workers in terms of diminished citizenship. This chapter elaborates on her work, hoping to offer a contribution to our understanding of the importance of citizenship for domestic workers in these two countries in particular and women worldwide in general. Other theories and perspectives on these two million domestic workers were covered in an earlier work, including the minimal influence of both Sharia law (Vlieger 20I2: 85-IO2) and the Western human rights discourse (Vlieger 20I2: I44-I74), and the habit of not regarding their jobs as work because they are performed in the private sphere of the house (IO4IO5, I4I, 203-205). This chapter focuses on concepts of citizenship.

4 This work does not elaborate a particular hypothesis, but gathers together the knowledge that Bosniak has accumulated over the years on the citizenship of migrants in general and of domestic workers in particular. 
This chapter first elaborates on the theory of Bosniak in specifying the connection between the concepts of access to justice, civil citizenship, and legal liminality. Specifically, this chapter shows how the theory, developed to analyse the position of domestic workers elsewhere, also applies to domestic workers in Saudi Arabia and the Emirates. Thereafter, the chapter advances the analysis by posing the question of to what extent the position of the employers can be framed in these same concepts. The results suggest that the position of the employers cannot be framed in the same concepts, which opens new perspectives on what citizenship is and on how different concepts of citizenship may be interrelated. This approach leads to a better understanding of the importance of full citizenship for women worldwide.

\subsection{The Conflicts That Domestic Workers Face}

Domestic workers in the two countries concerned are nearly all female and are currently, according to all interviewees, exclusively migrants. These workers generally live in their employer's private household, where they perform several tasks, such as cleaning, cooking, childcare, and care for the elderly, in exchange for food, lodging, and money (usually approximately US\$200 per month). The conflicts that domestic workers in Saudi Arabia and the Emirates regularly face are numerous and diverse. These conflicts can be divided into three types (Vlieger 20I2: I6-I9). First, there is often disagreement from the outset of employment about the norms that have been agreed to. Both parties agree to work conditions set out by a recruitment agency, and presume that the other party agrees to the same conditions, although this is often not the case. This first type of conflicts concerns salary, specific tasks, days of work per week (usually seven), hours of work per day (the average is seventeen), ${ }^{5}$ whether a domestic worker has a right to salary payments during the first three months, whether payments should be made monthly or at the end of the two-year contract, or even if she is supposed to work as a domestic worker (she may have initially agreed to become a waitress or nurse). Furthermore, domestic workers often disagree with their employer

5 This is hard to believe for many Westerners, but during Ramadan even this average rises, causing even more domestic workers to run away simply because they are exhausted. from the start of their employment when they are not allowed to leave the house on their own, if at all.

In a second type of conflict, domestic workers and employers disagree on behaviour or on a preferred outcome without clear, preliminary ideas about applicable norms. For example, in one documented conflict as to whether a domestic worker had the right to join her employer's family on a trip to Mecca, the parties did not seem to have had clear norms at the start of the conflict but merely a goal or preferred outcome. In a third type of conflict, both parties agree on norms at first, but one party nevertheless acts in a way contrary to these norms. Such conflicts concern alleged theft, child abuse, consensual sexual relations with a male employer either with or without payment, and physical, psychological, or sexual violence, including but not limited to rape and murder. ${ }^{6}$

The common factor in all of these conflicts is that they are generally not dealt with outside the households in a conflict resolution forum (in both countries norm enforcement is generally limited; see the section on the citizenship of employers below). These conflicts are only dealt with in such forums in cases where (i) a domestic worker is the accused party and (ii) the employer wants her removed from his household. These cases concern conflicts in which a domestic worker is, for example, accused of having a boyfriend, of stealing, of abusive behaviour, or of acts of occultism. In such instances, and usually without evidence, the domestic workers are either sentenced or instantly deported. In all other conflicts, domestic workers generally remain within the household, where the employers are able to enforce their own norms and preferred outcomes.

\subsection{Data and Research Methods}

The data forming the background of this chapter on citizenship are derived from research using grounded theory methods (Charmaz 2006: 2-3). A combination of qualitative and quantitative methods was applied during fieldwork throughout 2008 and 2009 in Saudi Arabia and the Emirates and in two countries of origin, Indonesia and the Philippines. ${ }^{7}$ In the early stages of the research, Human Rights Watch published a report on the position of domestic workers in four

6 The frequency of the different conflicts could not be established; see below under data and research methods for the problems of carrying out qualitative research in dictatorships. 
countries, the Kingdom of Saudi Arabia, the United Arab Emirates, Kuwait, and Lebanon, which led to a focus on these four countries (Human Rights Watch 2007). The research was thereafter restricted to Saudi Arabia and the Emirates because, due to time and financial restrictions, it was not possible to study all four countries described in the report. The two selected countries were chosen because Saudi Arabia and the Emirates are considered to be, respectively, the most conservative and the most open countries in the Gulf region. Saudi Arabia is difficult to enter due to strict visa regulations, so the world has comparatively little information about the country. In Saudi Arabia, women have to cover themselves entirely and are segregated from the larger parts of public life. They are not allowed to enter most government buildings and are separated from men in restaurants. Furthermore, women are not allowed to drive and are not allowed to travel or study without the permission of a male relative. They are treated legally as minors and still run the risk, among others, of being convicted for practising magic or of being imprisoned in their families' houses for life for talking to men. Alcohol, music, and fun in general are strictly prohibited, and such punishments as flogging and beheading still occur. Dubai, on the other hand, is an international hub with a large tourist industry. In Dubai, tourists openly walk around in bikinis, drink alcohol, and visit sex workers. While most Emirati women wear the traditional abaya, they can currently work in all sectors of the economy, and they can become lawyers and judges. Therefore, while the countries were neighbours, the differences at first sight seemed stark, and this raised the question of whether that would influence the position of domestic workers. Indonesia and the Philippines were later added as research locations because a comparatively large proportion of the domestic workers comes from these two countries. Furthermore, persons from these two countries of origin were more easily researched because their embassies had safe houses that cooperated extensively in this study. ${ }^{8}$

The data in this chapter was gathered primarily through seventy-three interviews with domestic workers. These interviews were half-open interviews, con-

7 Almost four months in the United Arab Emirates and three months in the Kingdom of Saudi Arabia, four weeks in Manila, and three weeks in Jakarta in the years 2008 and 2009.

8 These safe houses opened their doors, answered questions, and even provided interpreters when necessary. ducted door-to-door, in safe houses run by embassies and in the countries of origin, at the airport upon returning home, via employers and taxi-drivers, and in several waiting rooms for the processing of papers. Other interviews were held with thirty-three employers regarding the subject of domestic workers and with fifteen Saudi and Emirati women regarding the legal system. Additional interviews were held with thirty-two government officials, nine lawyers, six persons from international governmental organizations, seventeen persons from non-governmental organizations (NGOs), twenty-six diplomats, eleven lowerstrata male migrant workers, seven agency owners, two Saudi experts on domestic violence, four nurses, and three judges.

Questionnaires were used at different locations and were completed by both departing and returning domestic workers. Domestic workers in Manila and Jakarta who were about to leave for employment in Saudi Arabia or the Emirates completed one hundred and sixty questionnaires; they were contacted during different, pre-departure orientation courses. One hundred questionnaires were completed by domestic workers who had been employed in Saudi Arabia and the Emirates and who were contacted (i) at their embassies in Saudi Arabia; (ii) at the airport upon their return to Manila and Jakarta; (iii) at government- or NGO-run safe houses in Dubai, Manila, and Jakarta; (iv) in offices where domestic workers arrange for their paperwork upon contract renewal; and (v) in the houses of their employers.

The data drawn upon for this chapter mainly concern the question of where, in the event of a conflict, domestic workers have turned or would turn to for help, as illustrated above. Questions asked included whether and why they would or would not turn to the police, the embassies, or the Saudi or Emirati governments. Government officials, diplomats, NGO members, and lawyers were interviewed regarding available conflict resolution mechanisms for migrant domestic workers. Because several domestic workers mentioned that they had asked taxi drivers for help, taxi drivers were asked where they would take a person who was seeking assistance. Almost all of the locations mentioned by interviewees were visited, such as labour offices, police stations, law offices, shelters, embassies, and the Governor's Office in Riyadh. Several locations had different functions from those officially stated, while other locations simply did not exist at that time. If a conflict resolution mechanism did exist, attempts were made to determine the number of cases concerning domestic workers handled there and 
what their typical outcomes were. At some locations, where previous visits or interviews had raised suspicions about the actual availability of conflict resolution mechanisms, attempts were made to file a case on behalf of a (hypothetical) domestic worker. The discussion on the citizenship of Saudi and Emirati employers is based both on the answers provided to questions regarding the actual functioning of their legal systems in numerous types of conflicts, such as car crashes and divorce cases, and on the relevant literature on this topic.

The problems of finding and gathering quantitative data were considerable. Auwal (20I0: 89) writes:

Political realities in this region limit the ability of individuals and groups to collect and publish solid 'scientific' data on labour issues. With broad quantitative data unavailable, qualitative inquiry and anecdotal analyses provide the best opportunity to develop an understanding of how migrant labourers are treated or victimized in this region (Auwal 20I0).

In this study, the main hurdles that I faced were the inaccessibility of certain types of domestic workers and the unwillingness of most employers to be interviewed. These problems could not be solved within the given time frame and budget. Thus, the questionnaires were used largely in a qualitative way, and most results have been restricted in their presentation to broad categories, such as many and some.

Sampling bias occurred due to language issues and location problems. For example, Filipina domestic workers who were interviewed had run away from their employers and gathered in safe houses, but for many other nationalities, such an option was not available. Furthermore, domestic workers who were content with their employers, even though they were not allowed to leave the house, were often inaccessible or unwilling to talk for fear of losing employment. Again, in analysing the data, caution was applied by continuously questioning the consistency of the results, asking whether the results may have been different for other groups, and if so, why this might have been the case. Researcher bias, the sensitivity of the topic, and the highly protected privacy of the average Saudi or Emirati household severely limited the possibilities of participatory observation within the households. Furthermore, researcher bias was created by the fact that I, as a woman, had certain access to places where males could not enter, while there were many other places where only males could enter (research methods in Vlieger 20I2: 2I-27).

\subsection{Literature on Migrant Domestic Work}

Domestic work is a topic that has received increasing scholarly attention from economists, sociologists, anthropologists, and demographers (Santos 2005: 9). The last two decades have witnessed an impressive growth in the academic literature relating to women, human rights and development, economic migration, trade, migration and globalization, transnationalism, immigration and racism, and the politics of care-giving (Moors 2003). The studies on domestic work by Colen 1990, Constable 1997, Parreñas 200I, and Lindio-McGovern 2003, have theorized citizenship as a new marker of inequality connected to the national, class, and racial politics that organize domestic work (Hondagneu-Sotelo 200I). The peculiarities of paid domestic work in what can be regarded as a relatively new form of 'global apartheid' (Richmond 1994) have led to the dependency of domestic workers as the result of diminished citizenship, which is related to the lack of sufficient legislative protection against exploitative working conditions. This diminished citizenship, along with race and class, generates an additional axis of inequality (Bakan/Stasiulis I995a, I995b; Parreñas 200I; Chang 2000).

Citizenship as a prerequisite for the effectiveness of rights has been a topic of discussion since I95I, when Arendt first published on the problem of individuals who are not members of a political community (persons but not citizens) and therefore are not granted access to the legal system (Arendt 195I). Walzer further added that community members distribute power to one another and avoid, if possible, sharing it with anyone else (Walzer 1983). According to the German philosopher Hamacher, citizenship grants a privi-legium, a right to have rights (Hamacher 2004). However, the existing literature does not clarify how diminished citizenship could be more of a constraint or different for domestic workers in Saudi Arabia and the Emirates than in, for instance, Canada, as researched by Bakan and Stasiulis (1995a, I995b). Therefore, the dilemma of assessing how citizenship was specifically related to the position of domestic workers in the two countries studied became a specific research question.

Many scholars writing on the citizenship of domestic workers apply Bosniak's theory, which is the reason why it was used for this study as well. As Bosniak rightly concludes, a distinction must be made between different types of citizenship (Bosniak 2006). Bosniak distinguishes three types of citizenship, which 
are helpful in an analysis of domestic workers' positions. In the formative periods of most democratic countries, no mention was made of the fact that the right to vote would be limited to men, as this was assumed. Women were not supposed to take part in public decision-making, which can be referred to as political citizenship. Throughout many periods of premodern history, women often lacked the opportunity to work outside their own house and to gain financial independence, which can be referred to as economic citizenship (Bosniak 2007: 38). Furthermore, in most countries, women are not supposed to defend their own rights. Male relatives are supposed to defend women's rights, while women (like children) are not supposed to have an individual right to request and receive governmental protection of their rights. This right to legal protection provided by a government can be referred to as civil citizenship. As will be shown, in both Saudi Arabia and the Emirates domestic workers suffer from diminished civil citizenship. Before we turn to that, the next section will first provide a short introduction to the legal systems of both countries studied in order to provide proper context.

\subsection{The Two Legal Systems}

\subsubsection{The Emirates}

An important body of law in the Emirates is Islamic law or Sharia, applied mainly in personal status issues and criminal cases. However, the applicability of this body of law creates confusion, as it is unclear to what extent its rules apply to non-Muslims as well. For instance, the rule that drinking alcohol is not allowed is generally expected not to be applicable to non-Muslims, as alcohol is served in practically all restaurants and bars in Dubai. However, anyone who comes into contact with the police, for instance, upon filing a complaint against a local for molestation, as one interviewee did, can face charges for alcohol abuse. Furthermore, Sharia is not a codified body of law, which makes it difficult to determine what the exact contents of the Emirati version of this body of law are and what one's rights and duties are.

Next to Sharia, there are increasing numbers of law codes oriented towards Swiss, English, and French law. ${ }^{9}$ These laws include the Emirati labour

9 See for the English version of most important laws at: <http://www.lexadin.nl/wlg/legis/nofr/oeur/lxweuae. htm> (accessed in 2009). law, which explicitly excludes domestic workers from its protection (Emirati Labour Law article 3, sub-section 3). Instruments of the International Labour Organization are also generally not applied to domestic workers. Interviewees from the government stated that this difference is related to the fact that domestic workers are not considered to be workers, as they work in the private sphere of the household. While the government attempts to implement certain laws, it is not always equally capable of or interested in doing so. Certain laws, according to government interviewees, are not intended to be implemented. They are only meant as a hint of what is considered proper behaviour. ${ }^{10}$ Other laws are intended to attract direct foreign investments by giving the (false?) impression of a system demonstrating the rule of law. ${ }^{11}$

While attempts to establish a proper functioning legal system are evident, not all courts and not all judges reach the standards of the inhabitants of the Emirates. The general opinion is that there is no rule of law and that the system functions instead on wasta or connections, as discussed later in this chapter.

Most of the Emirates have joined the federal system, with the courts being organized into two main divisions, specifically, civil and criminal, and generally divided into three stages of litigation. Dubai and Ras al-Khaimah initially organized their courts into two stages, but later Dubai expanded this by establishing the Dubai Court of Cassation. ${ }^{12}$ In Dubai, the Emirates labour law is applied by special labour courts, which are to be consulted only after an attempt at mediation by the Ministry of Labour has failed. ${ }^{13}$ Until quite recently the judges in the different courts were mainly foreigners. For the application of Sharia, scholars mainly from Sudan, Egypt, and Pakistan were invited into the country. For the application of Westernoriented laws, retired Western judges have been and still are being invited. ${ }^{14}$ All of these judges, however, fall under the regulations of the sponsorship or visa system, which, according to interviewees from embas-

10 For instance, a governmental interviewee stated that during the first years of the law concerned, the obligation to wear seat belts while driving was only intended to promote, not to enforce the law.

11 Stated by government critics and by government officials in informal interviews.

12 See at: 〈http://gulf-law.com/uae_judicial.html> (accessed in 2009).

13 This was explained by an interviewee from the Ministry of Labour.

14 This was the explanation provided by several interviewees. 
sies and NGOs, undermines their independence, as they are constantly under threat of deportation. Currently, more Emiratis are being appointed as judges, although they are generally young and inexperienced. The first female judges have also recently been appointed.

\subsubsection{Saudi Arabia}

In most Muslim countries the workings of Sharia are currently limited to status and family and inheritance law, to which banking and penal law are added in some countries. For centuries, governments have been allowed to write secular laws concerning public administration, taxes and, less regularly, penal law. Opposition to secular laws arose in the fourteenth century from Ibn Taimiya, who stated that politics should be conducted entirely according to the Sharia. Ibn Taimiya's work has had a great influence in Saudi Arabia, especially within the Hanbali school of law ( $\mathrm{Zu}-$ baida 2005: 93). In the eighteenth century, al-Wahhab built on these teachings, so starting the movement of Wahhabism. This movement is closely related to Salafism, the radical ideology of resistance as formulated by Sayyid Qutb, whose Egyptian followers were welcomed in Saudi Arabia.

The essence of both Wahhabism and Salafism is that governments should be subject entirely to the principles of Islam-which severely restricts both their executive and legislative powers. These movements can therefore only properly be understood as movements against the establishment. This characteristic is particularly true within the Kingdom of Saudi Arabia, where the Saud family is eager to gain legislative and judiciary power and where the religious leaders oppose the growing power of the Sauds by reference to the teachings of the conservative scholars mentioned above. The religious leaders have a considerable influence on public opinion through their teachings, both in the mosques and on television. However, they are losing power to the royal family of the Sauds, who are creating more and more statutory laws (Abukhalil 2004: 86).

Apart from the work of the Mutawwa, often referred to as the religious police, the implementation of law in Saudi Arabia is notably poor. Furthermore, while most judges are Saudis and therefore do not fall under the sponsorship system, many lawyers are foreign and therefore cannot operate independently. Interviewees in Saudi Arabia were in agreement on this point with interviewees in the Emirates. They stated, among other things, that foreign lawyers generally provide advisory services only for contract, banking, and corporate law.

There is not much additional information available on the laws and courts in Saudi Arabia, either in their theoretical or actual functioning. In part, this lack of information is due to the fact that members of the legal-religious elite are generally not keen on granting individuals the right to interview them or to provide access to courts and other legal institutions. Several laws referred to by interviewees, such as a law that forbids employers to take away an employee's passport, could not be found, and their existence is questionable. Nevertheless, there is a Saudi labour law that, like its Emirati counterpart, explicitly excludes domestic workers from its protection (Saudi Labour Law article 7 sub-section 2). The Saudi government has written a draft law concerning the position of domestic workers, but it has been pending for years. Nor are instruments of the International Labour Organization (ILO) generally not applied to domestic workers in Saudi Arabia. Thus, while the position of workers in general and domestic workers in particular is not strong from a legal perspective, it is even worse from a sociolegal perspective, as the implementation of laws is generally poor (Vlieger 20I2: 3I-43).

\subsection{Access to Justice by Domestic Workers}

The concept of access to justice here refers to more than what is usually meant in Western law schools. Access to justice in the West is commonly perceived as the availability of free legal aid (Clark 2007: I3-I4). According to Llewellyn and Hoebel (Clark 2007: 24I244), access to justice means the availability of any type of dispute resolution procedure for conflicts, including negotiation, mediation, arbitration, and adjudication. Therefore, these broader categories have been examined along with the extent to which domestic workers could actually realize what they perceived as their rights through these forums.

In the Emirates, as stated, domestic workers are excluded from the labour law, and so they have no access to the attached labour courts. Unlike the labour courts in Saudi Arabia, the labour courts in the Emirates do not make any exceptions to that rule: no interviewed diplomat had been able to file a case for a domestic worker at a labour court. During a conflict, domestic workers were officially supposed to turn to the mediation offices falling under the Ministry of the Interior because domestic workers are regu- 
lated under the sponsorship or visa regulation system, and they are not considered to be the responsibility of the Ministry of Labour.

In Dubai, however, this mediation office of the Ministry of the Interior turned out not to exist. Although it officially did exist as of 2008 , the Ministry of the Interior's reception desk had no knowledge of this office or its function. The media department of the Ministry mentioned the existence of a human rights department, but other interviewees stated that this department did not address the issues of domestic workers. According to several interviewed diplomats, the mediation office had indeed been established by 2009, although nobody to date had successfully filed a complaint on behalf of a domestic worker.

In Abu Dhabi, a mediation office at the immigration office did indeed exist, and it functioned fairly well according to interviewed diplomats. This finding notwithstanding, not one of the domestic workers who was either interviewed or who completed a questionnaire for this study was aware of the existence of this office. Diplomats in the Emirates also reported that they occasionally took cases to the Sharia court or the attached reconciliation committee if a rule of religious law had been broken. However, the diplomats all complained about the extremely remote chance of winning a case.

Domestic workers in Saudi Arabia are also officially not allowed to turn to the labour offices, but in exceptional circumstances these labour offices do sometimes accept cases of domestic workers. The Human Rights Commission stated in its Universal Periodic Review of 2009 that in Saudi Arabia domestic workers officially do have the right to go to the labour offices. ${ }^{15}$ However, the labour office in Riyadh was unaware of this report. This office claimed not to accept cases from domestic workers and explicitly stated that women, including me, were not even allowed to be there.

With no access to the labour offices, some domestic workers write letters to the Governor's Office, the National Society for Human Rights, or the Human Rights Commission. ${ }^{16}$ As all three entities function as a sort of ombudsman, these institutions may officially

15 See at: <http://lib.ohchr.org/HRBodies/UPR/Documents/Session4/SA/A_HRC_WG6_4_SAU_I_E.PDF section 38> (accessed in 2009).

16 All three are governmental institutions, although the National Society for Human Rights seems to be slightly more independent. take action by contacting the employer to ask for unpaid salary, passports, exit visas, or plane tickets. When interviewed about this matter, the Governor's Office (or Imara) reacted with hostility to the presence of non-Saudi visitors. This reaction could possibly be because the office preferred written requests, but another interviewed diplomat denied the possibility of foreigners' writing letters to the Governor's Office.

At the Human Rights Commission, a governmental body that officially claimed to handle many cases concerning domestic workers, several officials made such statements during interviews as "Domestic workers don't have problems, they are problems", and "Indonesian domestic workers are prostitutes, all of them." These officials were neither able nor willing to show evidence of cases in which they had actually settled a conflict. The National Society for Human Rights, an institution working directly under the King, was the only other institution where there was a degree of indication that occasional actions were taken on behalf of domestic workers. ${ }^{17}$

Another possibility for migrant workers in Saudi Arabia would be to refer complaints to the Sharia courts. Because domestic workers were not allowed to go to the labour offices, based on the argument that they were part of the family, it would make sense to refer to the court that applied family law. However, Sharia judges, according to interviewed diplomats, generally refused to look into cases concerning domestic workers. Both the courts and the Ministry of Justice were approached for interviews but declined the requests.

It is worth mentioning that the lack of recourse for migrant domestic workers to make a complaint is contrary to Article 47 of the Saudi Basic Governance Act that states the right to bring action in a court of law is guaranteed equally among citizens and residents. The lack of recourse is also contrary to Article I2 of the Arab Declaration of Human Rights, which demands that each member state, including both Saudi Arabia and the Emirates, guarantees the right of every person to bring an action in a court of law. Most interviewed Saudis openly agreed that their le-

17 Several newspaper articles report that these actions occur, although no domestic worker, diplomat, or lawyer was able to confirm this finding. Such confirmation is necessary because the lack of press freedom and inadequate education of journalists makes Saudi newspapers unreliable sources. 
gal system had severe shortcomings with ramifications extending beyond domestic workers.

Thus, it can be concluded that access to justice for domestic workers is severely limited, and as such, these workers suffer from extremely limited access to justice, connected to the following three issues: the issue of khulwa, or gender segregation, the requirement of women to be accompanied by their mahram, and problems specifically associated with the sponsorship system.

\subsubsection{Khulwa}

While the concept of khulwa has officially been abolished in the Emirates, is still has influence. In Saudi Arabia, a woman is officially not allowed to be alone in one place with a man who is not her father, brother, son, or husband (her mahrams). This rule leads to the exclusion of women from the larger parts of public life. As many public buildings are restricted to men, women do not have many places to go outside their own house and the houses of direct relatives. Some policemen and many judges in Saudi Arabia simply refuse to communicate with women. This situation is worsened by the fact that women in this country are not allowed to drive. They are officially not allowed to share a car, such as a taxi, with somebody who is not a mahram, and there is hardly any public transport in Saudi Arabia. Therefore, the lives of women remain largely restricted to the house, although because of the presence of domestic workers, many women have little to do there. Domestic workers, who are not used to seclusion, explained that their employers forced them into following this same rule by several means, including by closing all doors and windows, by not providing any information on the location of the house in relation to other locations, and by making domestic workers fear the outside world.

\subsubsection{Women and their Mahram}

Women in Saudi Arabia are not permitted to mingle with men who are not their mahram, that is, their husband or close male relative. Women are therefore not permitted to have contact with the police, mediators, or judges by themselves, but are to be represented by one of their mahrams. While this patriarchal rule is not connected to Islam and officially is no longer applied in the Emirates, it is still reported to be in effect. For domestic workers, this practice is even more complicated because as migrants they do not have any mahram around. While the male members of the household in which they are employed usually refer to domestic workers as family, the male employers do not consider themselves to be mahram and, as such, they neither feel capable of nor responsible for legally representing their domestic workers. In the rare cases that domestic workers' conflicts are handled through official conflict resolution mechanisms, they are represented by diplomats from their own countries. The women, however, must take shelter in the overcrowded embassy before such representation is possible, and certain embassies either do not have such shelters or lack the knowledge of how to file these types of legal complaints. For instance, one labour attaché interviewed was not even aware of the existence of a labour law or labour court.

\subsubsection{Sponsorship System}

The main obstruction to access to justice by any migrant worker is the sponsorship system. These visa regulations tie the residence of domestic workers, and any other migrant, directly to their employers. The workers cannot change employers, and upon cancellation of the labour agreement for whatever reason, the visa is cancelled. Without protection against arbitrary dismissal, employers can have their migrant domestic workers deported at will. As soon as an employer reports to the authorities that his domestic worker needs to go home, the government arranges the deportation without asking questions. ${ }^{18}$ Additionally, as soon as a domestic worker leaves the house or premises of the employer without permission, she is considered to have terminated the labour agreement. As such, her visa is no longer valid, and she is considered to be a criminal. In these respects, the sponsorship system makes it almost impossible for migrant domestic workers to file complaints against employers (Vlieger 20I2: I79-2IO).

\subsection{Civil Citizenship of Domestic Workers}

According to Bosniak's definition of citizenship, political citizenship encompasses the rights to take part in public decision-making, while economic citizenship is the right or opportunity to work outside one's own

18 According to most interviewees and other fieldwork data, the only exceptions are cases concerning extremely severe abuse of the domestic worker or murder. 
household to gain financial independence, and civil citizenship is the right to legal protection of one's rights by a government. Political citizenship is the type of citizenship that most Saudis and Emiratis do not want domestic workers to gain, and it is this type of citizenship that Saudi and Emirati interviewees seem to have in mind when they say that the visa regulations or sponsorship system cannot be changed because of the number of migrant workers (over ninety per cent in the Emirates; in Dubai, the indigenous population has been reduced to less than five per cent). This form of citizenship, however, has not been requested by any of the interviewed domestic workers. The same applies for migrant workers in the United Arab Emirates in general (Davidson 2008: 190). Economic citizenship is not the issue here, either. Some scholars argue that in most countries women can only join the political community and gain full citizenship by hiring a domestic worker (Bosniak 2006: 15). In other words, economic citizenship, or the opportunity to gain an income through decent work outside one's own household, and political citizenship, or the right of women to join in public decision-making, is gained at the expense of citizenship for domestic workers. This finding is only true concerning the political citizenship of domestic workers as they are paid labourers and thus economic citizens but are bound to the private sphere and are thereby excluded from public decision-making. Thus, their economic citizenship is not diminished, while political citizenship is not what domestic workers seek. What they lack is civil citizenship, which is the right to actual legal protection by a government.

Domestic workers lack this civil citizenship, according to Bosniak, on two grounds. Bosniak makes a distinction between (i) those who lack citizenship based on their bureaucratic status or their lack of membership in a community and (ii) those who lack citizenship based on their lack of membership in the public community (Bosniak 2006). The first addresses those illegal migrants who officially have no right to reside in a country. In many countries, illegal migrants either have no rights or cannot enforce them, whereas in other countries, they have limited rights. The second includes those members of the community who have diminished membership in the public community, including women and all others whose lives are largely contained within the private sphere of the household, such as children and domestic workers (Bosniak: 2006). The previous section demonstrates that both in Saudi Arabia and in the Emirates, these two factors-the lack of membership in a community, and the lack of membership in the public community-greatly diminish domestic workers' civil citizenship. First, because migrants work and reside under the sponsorship or visa regulations, they do not and never will belong to the Saudi or Emirati state. These migrants lack membership in the community. This is the type of diminished citizenship to which Arendt referred. During World War II, stateless refugees (or indésirables) received no protection whatsoever from any state. The second factor shaping diminished civil citizenship, the lack of membership in the public community, is a status that domestic workers in Saudi Arabia and the Emirates share with many women worldwide. In the Emirates and especially in Saudi Arabia, women in general suffer from diminished citizenship as they are supposed to be legally presented by males who may be the ones they are in conflict with.

Thus, the reason that domestic workers in Saudi Arabia and the Emirates suffer from a lack of enforceable rights is that the two factors appointed by Bosniak as diminishing civil citizenship, visa regulations and the seclusion of women, are particularly acute in these countries. The result is severely diminished civil citizenship, which materializes as a near-complete lack of access to justice. Diminished civil citizenship and the related lack of access to justice is referred to by others as legal liminality or liminal legality (see for instance Menjívar 2006). These concepts are all used to analyse the position of undocumented workers in Europe and the United States of America. In the Middle East, due to the visa regulations referred to as the sponsorship system, the literature largely applies to documented workers as well. The diminished civil citizenship of domestic workers is connected with the larger political structures shaped by the exploitation of oil (Vlieger 20I2: 2II-230). Based on this connection, social transformation can be expected to take place in the Emirates earlier than in Saudi Arabia, as the Emirates are running out of oil.

\subsection{Citizenship and Saudi and Emirati Employers}

The previous section argued that domestic workers suffer from diminished civil citizenship, which is caused by the fact that they are both women and migrants. Bosniak's theory, developed for domestic workers in Europe, applies on the Arabian peninsula as well. This finding, in itself, is not surprising. Nevertheless, comparing the situation in Saudi Arabia and the Emirates with issues in Europe is problematic in 
the light of postcolonial theory, postmodernism, and legal culturalism. Postcolonial theory concerns an (often Marxist) literary theory, mainly from Said, Spivak, and Bhabha, that focuses on the legacy of colonialism and the question of how knowledge about the world is generated under specific relationships between the (ex-)colonizers and the (ex-)colonized (Ashcroft/Griffiths/Tiffin 1998; Krishna 2009). Postcolonial theorists state that one should recognize the uniqueness of each culture's development. In this way, postcolonial theory resembles postmodernism, which states that there is no objective basis for knowledge (or at least not a knowable one). From this perspective, theories are merely human constructs that are never value-free, and therefore, postmodernism emphasizes diversity and relativism. The legal version of this line of thinking is legal culturalism, of which Legrand is the most important proponent. Hesselink explains Legrand's position that legal systems cannot be analysed outside of their historical and cultural context, and therefore comparisons in law are only possible by searching for differences (Hesselink 2004: 32-36).

Indeed, while Bosniak's theory can fruitfully be applied to domestic workers, it cannot be applied to the position of Saudi or Emirati employers, as the differences are vast. For instance, Halfmann (1998) states that citizenship offers inclusion into the political system, but Saudi and Emirati citizens in general suffer from a lack of political citizenship as they cannot participate in any public decision-taking. Second, as stated above, the female citizens in both of these countries suffer from diminished economic citizenship. While in the Emirates access to the labour market for women is not officially restricted, it is in Saudi Arabia. Saudi women are in general only allowed to work in the segregated sectors of education and health care, or in their family company. As such, their economic citizenship is severely diminished. Furthermore, unemployment among citizens is a problem in both countries, and pushes women further out of the labour market. As for civil citizenship, this is heavily diminished for nationals as well, not because they as citizens have no rights on paper, but because in practice the government does not properly protect these rights. Several interviewed employers and government officials made such statements as "Why is the whole world so upset about these domestic workers? Nobody has rights in this country."

In Saudi Arabia, civil citizenship of women is severely restricted through the concept of the mahram, which states that a woman must be represented by a husband or a close male relative. As her life is largely restricted to the private sphere of the house, her mahrams are most often the ones with whom she will have a conflict, thus making the realization of rights problematic. Women claim to often lose conflicts based on their gender if they try to ask for protection of their rights. A Saudi female interviewee stated: "It all really depends on who is the judge. Some are very strict in the religion: they are always on the men's side." Extensive problems may arise. For instance, one interviewee explained that:

My wife's sister has been trying for six years now to get a divorce because her husband is sleeping with the maids all the time. However, they don't allow her to get a divorce. He plays the smart guy in court, educated, well-dressed, and then they refuse her the divorce. She supports the children on her own now, doesn't get alimony or anything and doesn't get a divorce either.

A female interviewee who filed for divorce lost custody of her four-year-old child, something which occurs regularly in Saudi Arabia (Sasson 2004: 276277), even though Sharia states that in a divorce, children must stay with their mother until at least the age of seven and, according to other interpretations of Sharia, even longer. Some argue that this is a right to custody; others that it is a right to take care (Schacht 1964: 167). When this interviewee appealed to a higher court for proper application of the Sharia, she was told to go home and stop bothering them: "You already have a court ruling, deal with it."

For men also, the realization of rights is problematic, as neither country has anything resembling the concept of the rule of law. All Saudi and most Emirati interviewees stated that in general, rule implementation or realization of rights is highly problematic, and rules are often simply unknown. The Saudi government, in particular, seems not inclined to clarify rules. The government distributes an English translation of the Labour Law, but concerning the rule that employers are not allowed to take away domestic workers' passports, the Saudi Deputy Minister of Labour, for instance, stated: "If the law is not imposed, it is not the fault of the Ministry" and "It's not our responsibility to make sure that the employers know". In response to the suggestion that they set up a website with all Saudi laws in Arabic and English, an interviewee at the Saudi Human Rights Commission stated, "No, if we tell them all immediately about all the rights they have, it will be a disaster". Other wellknown rules are simply not applied. Many migrants are sentenced to punishments of 3,000 or even I0,000 lashes for zina, or extramarital sex, even though Sharia prescribes a maximum of Ioo lashes. 
This same crime requires four witnesses, which judges rarely ask for in the case of migrants. Examples are so common that the non-application of Sharia seems to be the rule instead of the exception.

Interviewees almost all stated that the legal system functions around the concept of wasta, a system that is not based on rules that apply equally to everyone. Yet there is a hierarchy involved in the issue of who usually wins in a conflict. This hierarchy is shaped by how much power the concerned parties have. Their power, in turn, depends on connections, or wasta. Wasta is determined by patriarchy, tribalism, cronyism, and the power to corrupt or bribe (Vlieger 20I2: 2II-230). According to almost all interviewees, the party that wins a case or conflict is usually the more powerful one. In both countries, but especially in Saudi Arabia, several interviewees complained about the fact that the elite seemed to be above the law entirely. An interviewee stated, for example: "My uncle was a contractor here. He was doing very well, until he got a contract with a prince. He had all these subcontractors and when the prince didn't pay him, nobody helped him: no judge, nobody. So he went bankrupt." Other interviewees made more general statements, such as "If you have a company and some prince decides he wants to have half the shares, there is nothing you can do to stop him." Well-connected non-royalty can also get away with many crimes, interviewees stated. One interviewee summarized the situation: "If they like you, there are no rules. If they don't like you, there is nothing but rules."

Because of the poor functioning of the legal system, including the absence of the rule of law, it can be concluded that employers, or at least those employers who are lower in the societal hierarchy, suffer from diminished civil citizenship (Vlieger 20I2: 2II-230). If civil citizenship concerns governmental protection of rights and the actual realization of rights depend on wasta, then only those with a decent level of wasta can be said to have civil citizenship. However, if Saudi and Emirati citizenship in general is not meant to include civil, political, or economic citizenship, then what does it mean? Unfortunately, little has been written on the question of what citizenship entails for the citizens of the Arabian peninsula. The gathering of data in support of such theories faces the same problems as the gathering of qualitative data on migrant workers, as discussed above. ${ }^{19}$

Based on the data from this research, I propose an analysis of citizenship in Saudi Arabia and the Emirates using three other concepts of citizenship: residency citizenship, welfare citizenship, and social citi- zenship, of which the first two are proposed here for analysis, while the third concept is more often used, among others, by Bosniak herself (2007).

First and foremost, having Saudi or Emirati citizenship means having residency citizenship. Unlike all of the migrant workers, Saudi or Emirati citizens do not live under the constant threat of instant deportation. Second, Saudi and Emirati citizenship generally comes with the right to partake in the welfare of the country. Whereas in Europe, this right to welfare is directly connected to the duty to contribute to society in the form of taxes, in these two Gulf countries, this connection is not the case. The third concept that describes Saudi and Emirati citizenship is used in the European context as well. Social citizenship refers to the social ties that individuals are either born with or develop. To complicate matters, many sociologists tie this phenomenon to the concept of social capital and preserve the term social citizenship for what is defined in this study as welfare citizenship. The concept of social citizenship as used by Walsum and in this chapter is associated with self-fulfilment, social interaction, and civil movement (Walsum 2007: 3). While there is very little civil movement in either Saudi Arabia or the Emirates, citizens do have social ties. These are either those with which they have been born (tribal and familial ties) or the ones that they develop over the course of their lives (friends and work ties). Interestingly, these social ties are what largely define an individual's wasta. Wasta is the combination of tribalism, cronyism, and corruption, while social ties or social citizenship are largely defined by tribal ties and cronies.

\subsection{Connections Between Social and Civil Citizenship}

Neither Saudi nor Emirati citizens, at least not the ones without wasta, have civil citizenship as defined by Bosniak. The government does not generally protect their rights. Rather, these citizens usually defend their position through the use of their connections through wasta. However, as wasta is closely related to the concept of social citizenship, this finding seems

19 There is no freedom of opinion in general, and for scientists in particular. Basically, a choice needs to be made between political acquiescence and a rather problematic career. Scientists from outside the Arabian peninsula run the risk of being blacklisted, meaning they will not be able to return to the countries in which they have specialized. 
to reveal a relationship between social and civil citizenship. If it is wasta that compensates for the lack of the rule of law, it seems that social citizenship compensates for diminished civil citizenship. As such, there seems to be a connection between the two concepts of social and civil citizenship, based on the current functioning (according to interviewees) of their legal systems.

This possible connection between social and civil citizenship is all the more interesting in the light of the two groups that, according to Bosniak, suffer from diminished civil citizenship: (i) those who lack citizenship based on their bureaucratic status or their lack of membership in a community, and (ii) those who lack citizenship based on a lack of membership in the public community (Bosniak 2006). Those who lack civil citizenship because they lack membership in the community are often the ones who have not been born in the community (jus soli) and those who have no blood ties to the community (jus sanguini). These individuals are thus the ones who have not been born with a network of social ties in the community. In Saudi and Emirati society, this means that one is born without any familial or tribal ties. As such, these people have less wasta and less social citizenship, while, according to Bosniak, they also form a category lacking civil citizenship.

The second group that, according to Bosniak, suffers from diminished civil citizenship are those individuals whose lives are largely restricted to the private sphere of the household. The effect of this restriction in movement is a less developed network of social ties, other than familial and tribal ties. As Walsum argues, involvement in the reproductive or private sphere provides little or no credentials for integration into social citizenship such that women who are heavily committed to responsibilities in the private sphere receive, at best, marginal support from the welfare state (Walsum 2007: 3). In Saudi Arabia and the Emirates, this condition means that both men and women are born with tribal ties and, as such, can defend their position through these ties. However, men, unlike women, also become part of the public community in which they develop new ties and new connections. As a result, men's further developed social network opens possibilities for making better use of cronyism. Women, both nationals and migrant domestic workers, develop fewer of these ties throughout their lives. This leads to a second interesting connection. First, because of diminished civil citizenship through the lack of a government that actively protects an individual's rights, Emirati and Saudi citizens protect their positions through social citizenship (a connection based on current functioning). Secondly, the two groups that, according to Bosniak, have diminished civil citizenship in practice are exactly the same as the groups that in principle have fewer options with regard to a growing network of social ties and to developing social citizenship (a connection based on Bosniak's theory).

Also, there is a third clue to a connection between the concepts of civil and social citizenship. Several interviewees stated that before industrialization, which was no more than half a century ago in these two countries, communities were small, and social control was sufficient as the normative enforcement mechanism (Vlieger 20I2: 2II-230). However, social control functions only if individuals have connections with persons who are willing to stand up against infringement of their position. In other words, interviewees stated that in the old days the legal system largely functioned around social citizenship. Again, there is an observable connection between the two concepts: while social citizenship diminished due to industrialization and the connected trend towards urbanization, according to interviewees civil citizenship, or protection of rights by a governmental body, became necessary (a connection based on the historical development of the legal systems).

Based on these three connections, it seems that civil citizenship is intended to compensate for a lack of social citizenship. Social citizenship, if defined as one's network of connections, or one's wasta, defines one's power, and that is what renders government protection unnecessary. Because migrants and women have a less developed network of social connections, as they have less access to the community or less access to the public community, they are more in need of a protective government: they are the ones in need of civil citizenship and of the rule of law.

\subsection{Conclusions}

Domestic workers are excluded from the Saudi and Emirati labour laws, and they correspondingly have no official access to the labour courts that are designated to address conflicts between employers and employees. As the data show, there are no other conflict resolution mechanisms to compensate for this exclusion. Therefore, domestic workers' access to justice is extremely limited. Bosniak discusses three concepts of citizenship: political citizenship, economic citizenship, and civil citizenship (Bosniak 2006). Because of their 
limited access to justice, domestic workers in Saudi Arabia and the Emirates suffer from diminished civil citizenship. This situation is caused by the fact that the workers are both women and migrants. In Saudi Arabia especially, women are secluded to the private sphere of the household. Additionally, because of the sponsorship system or visa regulations in the two countries, migrant domestic workers cannot realize their rights. As such, the workers' diminished civil citizenship is comparable to the position of undocumented workers in the West, which is referred to as liminal legality or legal liminality.

While Bosniak's theory applies closely to the position of domestic workers in Saudi Arabia and the Emirates, her concepts of political, economic, and civil citizenship are less suitable for describing the position of the Saudi and Emirati employers. These employers hold a not entirely unrestricted but similar residency citizenship: a right to reside. The employers also hold a certain welfare citizenship, although it is different from the Western concept. This citizenship is a right to partake in the welfare of the country, regardless of one's contribution to this welfare, although critics of the two regimes state that this right depends on the acquiescence of citizens. Furthermore, this welfare citizenship certainly would not have existed in this form without oil revenues.

Citizenship as discussed by Arendt (Arendt I95I) and Hamacher's concept of a privi-legium (Hamacher 2004), the right to have rights, refer to access to the legal system or civil citizenship. As the data in this research show, this concept is not universal. Walzer stated that community members distribute power to one another and avoid, if possible, sharing it with anyone else (Walzer 1983). Such sharing indeed applies in the two countries studied. Saudi and Emirati citizens are not inclined to share their residency citizenship or welfare citizenship with outsiders.

The concept of social citizenship concerns the actual social ties developed by members of the community. This concept is regularly referred to as social capital and applies equally to the Saudi and Emirati employers. In fact, social citizenship seems to be the only citizenship concept that applies equally, next to the concept of residency citizenship. Hence, the general concept of citizenship, or membership in a community, in countries that lack both welfare and a system of the rule of law, may not encompass more than the right to reside, plus the actual social ties one develops.

Furthermore, the concepts of social citizenship and civil citizenship seem to be interrelated in three distinct ways. The data of this research suggest the following connections. First, in Saudi Arabia and the Emirates, where a rule of law exists on paper but not in practice, citizens protect their position through wasta, or connections. Where there is no proper civil citizenship provided by the government, people use social citizenship to protect their positions. Second, while Bosniak argues that it is those who are excluded from the community (migrants) and those who are excluded from the public community (women and children) who suffer from diminished civil citizenship, it is also migrants, women and children who, in general, have fewer connections and less social citizenship. Finally, according to interviewees, social control was largely enough to enforce norms in the past. However, now that people in the Arabian peninsula have moved from villages to cities, government organizations have become necessary for the enforcement of norms. In other words, the effectiveness of social citizenship has diminished due to industrialization, which has made civil citizenship necessary.

However, the two governments have not properly developed the rule of law, and by extension civil citizenship, and this leads to destructive effects for those with the least social citizenship. Therefore, because migrants and women have less social citizenship, as they have less access to the community and less access to the public community respectively, they are most in need of a protective government: they are the ones in need of civil citizenship and of the rule of law. Inversely, as migrants and women suffer from diminished civil citizenship, they are the ones most in need of social citizenship.

In the two countries researched, a large number of domestic workers have taken on the largest share of household tasks. In this light, the concept of khulwa, or seclusion of women to the private sphere of the house, makes no sense. However, in a country without the rule of law, which is particularly the case in Saudi Arabia, where women lack civil citizenship, social citizenship could compensate for that seclusion by offering other means of protection. Therefore, in those instances where Saudi or Emirati women have little to do at home, it is the connection between the concepts of civil citizenship and social citizenship that actually explains the strong adherence of men to the concept of khulwa, of seclusion of women to the private sphere of the house, for it will prevent womendomestic workers and wives and daughters alikefrom developing any protection against the men in the house. 


\section{References}

Abukhalil, As'ad, 2004: The Battle for Saudi Arabia: Royalty, Fundamentalism and Global Power (New York: Seven Stories Press).

Ali, Syed, 20ro: Dubai: Gilded Cage (New Haven: Yale University Press).

Arendt, Hannah, 1951: The Origins of Totalitarianism (San Diego: Harcourt).

Ashcroft, Bill; Griffiths, Gareth; Tiffin, Helen, I998: Key Concepts in Post-Colonial Studies (New York: Routledge).

Auwal, Mohammad, 20I0: "Ending the Exploitation of Migrant Workers in the Gulf", in: The Flechter Forum of World Affairs, 34,2: 87-108.

Bakan, Abigail; Stasiulis, Daiva, I995a: "Domestic Placement Agencies and the Racialization of Women's Household Work", in: Signs, 20,2: 303-335.

Bakan, Abigail; Stasiulis, Daiva, I995b: "Negotiating Citizenship: The Case of Foreign Domestic Workers in Canada", in: Feminist Review, 57: II2-I39.

Bosniak, Linda, 2006: The Citizen and the Alien: Dilemmas of Contemporary Membership (New Jersey: Princeton University Press).

Bosniak, Linda 2007: "Citizenship, Non Citizenship and the Status of the Foreign Domestic", in: Walsum, Sara (Ed.), 2007: Women and Immigration Law: New Variations on Classical Feminist Themes (Oxford: Routledge-Cavendish): $35-43$.

Charmaz, Kathy, 2006: Constructing Grounded Theory: A Practical Guide Through Qualitative Analysis (Los Angeles: Sage).

Chang, Grace, 2000: Disposable Domestics: Immigrant Women Workers in the Global Economy (Cambridge, MA: South End Press).

Clark, David (Ed.), 2007: Encyclopedia of Law \& Society; American and Global Perspectives (Los Angeles: Sage Publications).

Colen, Shellee (Ed.), I990: At Work in Homes: Household Workers in World Perspective (Washington DC: American Anthropological Association).

Constable, Nicole, I997: Maid to Order in Hong Kong: Stories of Filipina Workers (New York: Cornell University Press).

Davidson, Christopher, 2008: Dubai: The Vulnerability of Success (New York: Columbia University Press).

Halfmann, Jost, I998: "Citizenship Universalism, Migration and the Risk of Exclusion", in: The British Journal of Sociology, 49,4: 5I3-533.

Hamacher, Werner, 2004: "The Right to Have Rights: Fourand-a-Half Remarks", in: South Atlantic Quarterly, IO3,2-3: 353 .

Hesselink, Martijn, 2004: Contractenrecht in Perspectief (Den Haag: Boom Juridische Uitgevers).

Heyzer, Noalleen; Lycklama à Nijeholt, Geertje; Weerakon, Nedra, I994: The Trade in Domestic Workers: Causes,
Mechanisms and Consequences of International Migration (London: Zed Books Ltd).

Hondagneu-Sotelo, Pierrette, 200I: Domestica: Immigrant workers and their Employers (Berkeley: University of California Press).

Human Rights Watch, 2007: Exported and exposed; abuses against Sri Lankan Domestic Workers in Saudi Arabia, Kuwait, Lebanon and the United Arab Emirates (New York: Human Rights Watch); at: <http://www.hrw.org/ sites/default/files/reports/srilankaIı_webwcover.pdf〉.

Human Rights Watch, 2008a: As if I am not human: Abuses against Asian Domestic Workers in Saudi Arabia (New York: Human Rights Watch); at: <http://www.hrw.org/ reports/2008/07/I4/if-i-am-not-human>.

Human Rights Watch, 2008b: Perpetual Minors; Human Rights Abuses stemming from Male Guardianship and Sex Segregation in Saudi Arabia (New York: Human Rights Watch); at: <http://www.hrw.org/reports/2008/ 04/I9/perpetual-minors>.

Human Rights Watch, 2008c: Precarious Justice. Arbitrary Detention and Unfair Trials in the Deficient Criminal Justice System of Saudi Arabia (New York: Human Rights Watch); at: <http://www.hrw.org/reports/ 2008/03/24/precarious-justice>.

ILO (International Labour Organization), 2006: Protection of Migrant Domestic Workers in Destination Countries: ILO Human Rights Training Manual for Consular Officials and Labour Attaches (Geneva: ILO); at: <http://www.ilo.org/jakarta/whatwedo/publications/ WCMS_I223I3/lang-en/index.htm>.

Krishna, Sankaran, 2009: Globalization \& Post-Colonialism; Hegemony and Resistance in the Twenty-First Century (Lanham: Rowman \& Littlefield Publishers Inc).

Lindio-McGovern, Ligaya, 2003: "Labour Export in the Context of Globalization. The Experience of Filipino Domestic Workers in Rome", in: International Sociology, I8,3: 5I3-534.

Menjívar, Cecilia, 2006: "Liminal Legality: Salvadorian and Guatemalan Immigrants' Lives in the United States", in: American Journal of Sociology, III,4: 999-IO37.

Moors, Annelies, 2003: "Migrant Domestic Workers: Debating Transnationalism, Identity Politics and Family Relations", in: Comparative Studies in Society and History, 2003,45: 386-394.

Nader, Laura (Ed.), I969: Law in Culture and Society (Berkeley: University of California Press, Paperback version of 1997).

National Society for Human Rights, 2006: The First Report on Human Rights Conditions in the Kingdom of Saudi Arabia (Riyadh).

Parreñas, Rhacel, 200I: Servants of Globalisation, Women, Migration and Domestic Work (California, Stanford University Press).

Richmond, Anthony, I994: Global Apartheid: Refugees, Racism, and the New World Order (New York: Oxford University Press). 
Sasson, Jean, 2004: Daughters of Arabia (London: Bantam Books).

Schacht, Joseph, I993: An Introduction to Islamic Law (Oxford: Clarendon Press).

Santos, Maria, 2005: Human Rights and Migrant Domestic Work; a Comparative Analysis of the Socio-Legal Status of Filipina Migrant Domestic Workers in Canada and Hong Kong (Leiden: The Raoul Wallenberg Institute Human Rights Library).

Silvey, Rachel, 2006: "Consuming the Transnational Family; Indonesian Migrant Domestic Workers in Saudi Arabia”, in: Global Networks 6,r: 23-40.

Strobl, Staci, 2009: "Policing Housemaids. The Criminalization of Domestic Workers in Bahrein", in: British Journal for Criminology, 49: 165-I83.
Vlieger, Antoinette, 20II: "Dienstbodes in Saoedi-Arabië: Intersectionaliteit en Toegang tot het Recht", in: Recht der Werkelijkheid, 32,2: 47-64.

Vlieger, Antoinette, 20I2: Domestic workers in Saudi Arabia and the Emirates: a Socio-Legal Study on Conflicts (New Orleans: Quid Pro Books).

Walsum, Sara (Ed.), 2007: Women and Immigration Law; New Variations on Classical Feminist Themes (Oxford: Routledge-Cavendish).

Walzer, Michael, I983: Spheres of Justice; a Defense of Pluralism and Equality (New York: Basic Books).

Zubaida, Sami, 2005: Law and Power in the Islamic World (London: Tauris).

Open Access. This chapter is distributed under the terms of the Creative Commons Attribution Non-commercial License, which permits any noncommercial use, distribution, and reproduction in any medium, provided the original author(s) and source are credited. 


\title{
17 The Right to Education for Migrant Children in Thailand: Liminal Legality and the Educational Experience of Migrant Children in Samut Sakhon
}

\author{
Kamowan Petchot ${ }^{1}$
}

\begin{abstract}
For decades, Thailand has experienced an influx of a large number of migrants from Myanmar who have come in search of better economic opportunities. This influx has led to a sizeable migrant population residing in Thailand, of which children make up a significant percentage. Providing education for large numbers of migrant children has become a matter of national concern, both because of Thailand's international human rights obligations and as a matter of national security. Responding to these concerns, the government of Thailand has adopted a policy of providing free and compulsory education for every child within its territory, including migrant children. However, despite the efforts of the Thai government to provide education for all, many migrant children are still unable to benefit from this policy.

In this chapter, the challenges of realizing the right to education for migrant children in Samut Sakhon, a coastal province in central Thailand, are studied. Schools are regarded as institutional duty bearers that are obliged, on behalf of the state, to fulfil their legal obligation in terms of Thai government policy. These obligations emanate from the Convention on the Rights of the Child, to which Thailand is a state party. In addition, the research analyses the precarious status of migrant children. The concept of 'liminal legality' is used to conceptualize the in-between status of migrant children and families, and to illustrate how this liminal status shapes the opportunity structure of migrant children in education by influencing household decision-making. In this chapter, it is argued that addressing the liminal status of migrants is essential in addressing not only the issue of migrant children's education, but also that of their incorporation into Thai society in general.
\end{abstract}

Keywords: Burmese migrants, migrant children, right to education, liminal legality, Thailand.

\subsection{Introduction}

Since the I980s, the expansion of Thailand's economy has created a large national demand for labour, and especially for unskilled labour. Unskilled work has been shunned by local Thai workers, partly because of improvements in the level and availability of basic education through to secondary school. This has resulted in Thai workers moving from semi-skilled to skilled jobs. In addition, the preference of Thais to work in

1 Kamonwan Petchot (Thailand) holds an MA in Development Studies from the International Institute of Social Studies (ISS) of Erasmus University Rotterdam. She is currently a consultant to the Asia Pacific Forum on Women, Law and Development (APWLD). the service sectors as well as a decline in the birth rate has resulted in an acute domestic labour shortage, especially in labour-intensive industries (Chantavanich 2007a: I). Consequently, Thailand has become a destination for many migrants from neighbouring countries throughout South-East Asia, and in particular from Myanmar, Cambodia, and Laos, who fill the gap in unskilled jobs. A sizeable community, migrants in Thailand have fuelled the country's economic growth. According to a report by the International Labour Organization (ILO), out of thirty-six million Thai workers in 2007 , five per cent or I.8 million were migrants, and their contribution to the Thai gross domestic product (GDP) was estimated at I.25 per cent or US\$2 billion. The number of migrants and the 
range of occupations in which they have been employed has further expanded (Martin 2007: xi-xii).

Children make up a significant percentage among those migrants who come to Thailand. Article I of the UN Convention on the Rights of the Child (CRC I989) defines a child as "every human below the age of I8 years unless under the law applicable to the child, majority is attained earlier”. A 2008 report by the International Organization for Migration (IOM) estimated that there were 200,000 migrant children under the age of I7 years in Thailand (IOM 2008: I84). Migrant children in Thailand are a heterogeneous group, differentiated by age, ethnicity, their legal status, and the patterns of mobility of their parents. For the purposes of this chapter, migrant children can be divided into those who are (I) migrants themselves who came to Thailand without their parents in search for work; (2) those who accompanied their family, and (3) children who were born to migrant parents in Thailand (Huguet/Punpuing 2005: I24, Thu 2006: I4).

From the perspective of the Thai government, providing education to migrant children is a response to its international obligations under the UN Convention on the Rights of the Child (CRC), which obliges Thailand to provide for all children, including the children of migrants, with the right to education. It is regarded by the government as a measure to ensure national security in the long term, since a large number of uneducated migrant children without access to formal employment could join in illegal activities that would harm national security, such as drug trafficking or the sex industry. There is much public concern that the lack of access to education by migrant children can lead to their marginalization and prevent their assimilation into Thai society. Without access to education, migrants remain an uneducated underclass vulnerable to exploitation and illegal activities. This is confirmed by Caouette, who argues thatmigrants' cultural and economic marginalization may lead to drug trafficking or human trafficking for labour or sexual exploitation in the sex industry (Caouette 200I: 92, I07).

As a state party to the CRC, Thailand is obliged to respect, protect, and fulfil the right to education for all children, including migrant children. Article 28 of the CRC provides that all children have a right to education. Responding to this international obligation, the Thai government has adopted various policies to ensure universal education for every child within its territory. The 'Education for All' campaign, which was supported by the United Nations Educational, Scien- tific and Cultural Organization (UNESCO), was adopted by Thailand in I990 (MFA 20II). In 2004, the Office of Education Council (OEC) created the 'Education Provision for Disadvantaged Children' (MFA 20II; ILO/OEC 2008: II). In addition, the 'Education for All Cabinet Resolution' of 2005 provided for universal access to education for all children in Thailand, regardless of their nationality or legal status (MFA 20II; ILO/OEC 2008: II).

However, there is a gap between law and implementation. This is evidenced through the very low number of migrant children who actually enrol in school. According to the Foundation for Rural Youth (FRY), a non-governmental organization (NGO) that promotes access by migrant children to Thai public schools, Thailand has accepted less than sixteen per cent of registered migrant children into its education system. In some areas, such as Bangkok, the situation is critical, with fewer than four per cent of migrant children enrolled in schools. ${ }^{2}$

Studies of access to education by migrant children have pointed to three interconnected problem areas, namely policy issues, the school system, and problems at the household level (Thu 2006: I8). At the level of policy, the 2005 'Education for All Cabinet Resolution' requires that migrant children be afforded the same rights as Thai children, including government funding. However, schools cannot receive government funding for migrant children who are undocumented (Thu 2006: 60). Therefore, schools bear the financial burden of accepting the children of undocumented migrants. This runs contrary to the government policy of offering education to all children, irrespective of their nationality or documented status.

At the level of the school system, legal consciousness among school administrators, or the way in which they perceive and interpret their obligations as stated by law, also appears to be a major issue. Amanda Bissex, chief of the child protection section of the UN Children's Fund (UNICEF) Thailand has pointed out that "access to education for migrant children is impeded by understanding of the cabinet decision at the local level" (Irinnews 2009). Thu's study (2006) revealed that the government budget was misused, for example by using the per-head budget, which is aimed directly at students to cover their edu-

2 Nicola Hoyne, 20II: "Thailand: Education desperately needed for migrant and stateless children"; at: <http:// www.minorityvoices.org/news.php/fr/693/thailandeducation-desperately-needed-for-migrant-and-statelesschildren> (accessed I5 June 20II). 
cational costs (e.g. uniforms, shoes, and books), and for other school expenditure (e.g. electricity and water). Consequently, many schools did not receive the supporting budget as stated in the Cabinet Resolution (Thu 2006: 60).

At the household level, factors that affect the educational opportunities of migrant children are the attitude of migrant parents towards education in general and the Thai educational system in particular. Migrant parents with a positive attitude towards education tend to keep their children in school for a longer period of time. Other factors include the direct costs (e.g. fees, books, clothes) and indirect costs (e.g. child labour) of attending school, an uncertain future in Thailand, lack of information about Thai education, gender, the duration of their stay in Thailand, and proficiency in the Thai language, all of which can have negative impacts on migrant children's opportunities for pursuing education (Thu 2006: I8).

This study explores the challenges of accessing education, faced by the children of migrants in Thailand. The rights of migrants derive from the international legal obligations of the state, although an explicit, national recognition of their legal status is important in defining who is entitled to what level of rights protection. Migrant children are not entitled to the same rights and protection as those who are citizens. The law requires that each child, including migrant children, residing on Thai territory is legally entitled to the right to education; however, there are some legal gaps or difficulties for migrant children in obtaining an education. Their presence in Thailand is only temporarily legal or even illegal in some cases but they are legally entitled to education, while the future of their career or status in Thailand remains unclear. The in-between or 'liminal' legal status of migrant children makes it difficult for the state to realise the right to education. Furthermore, the framing of children's education as an issue of human security (reduced to the idea of the costs and benefits of providing education) can be confused with matters of national security (viewing migrants as a potential threat), which may generate fear and mutual suspicion among members of a community and further undermine efforts to provide education for migrant children. This is a grey area of the law. Migrant children's experiences are shaped in a different way from the experiences of other groups of children.

\subsection{Methods and Scope of Study}

The research project used qualitative methods. Data was collected through different methods, including documentary research, semi-structured interviews, and field observation. My main method was semistructured interviews with three groups of informants: (I) migrant students, (2) migrant parents, and (3) teachers and educators. Fifteen informants from each group (forty-five in total) were selected from three schools (two public schools and an NGO learning centre). The community of Samut Sakhon in central Thailand was selected as a field for research study because of the large number of Burmese migrant children who live there; in addition, the local governor has made an effort to provide education for migrant children in the community. Based on a case study of this community, this chapter documents how Thailand deals with the education of migrant children.

\subsection{Thai Policy on Labour Migration}

Due to a domestic labour shortage in Thailand from the late I980s until the early I990s, the business sector asked permission to employ foreign workers in order to overcome their labour shortage. In 1992, the Thai government developed an immigration policy for unskilled labour migrants, mostly directed towards the fishing, construction, agricultural, and other industrial sectors.

In Thailand, the rights of workers and the obligations of employers are covered by the Labour Protection Act of 1998 (B.E.254I), which deals with working hours, holidays, notice, overtime, and sick pay. However, as Muntarbhon (2005: I3) argued, the "national law with the greatest impact on migrant workers are not the labour laws themselves but the national immigration law". Immigration policies governing migrant workers' lives in Thailand rely on two major acts, the Foreign Employment Act 2008 (B.E.255I) and the Immigration Act 1979 (B.E.2522). The latter states that unauthorized entry or breach of immigration law or both is illegal and may lead to deportation or other penalties or both. However, Section I7 gives the Ministry of the Interior some flexibility to exempt irregular migrants from being deported if they present themselves for registration. Additionally, the employment of migrant workers is regulated by the Foreign Employment Act 2008, which requires that an alien must have a work permit and that aliens are allowed to work only in activities designated by law or by the 
relevant governmental authority (i.e. the Ministry of Labour) (Muntarbhon 2005: 13).

Thailand had never allowed the employment of unskilled foreign workers in the country before; its existing legal framework did not provide clauses for such initiatives, so the government decided to use a cabinet resolution as the mechanism to establish a new legal framework. The cabinet resolution is an ad hoc type of policy formulation based on the belief that the employment of migrant workers would be a temporary event and the situation would change after some years (Chantavanich 2007a: I-2).

This belief in the 'temporariness' of migrant labour has proven to be misplaced. Many economic sectors in Thailand have relied continuously on migrant workers for more than three decades and there appears to be no prospect that Thai workers will return to these labour-intensive jobs. On the contrary, a research study suggested that the structural dependence on migrant workers tends to persist in the medium- to long-term since there is little evidence of alternatives such as a mechanization or re-structuring of the national workforce to attract Thai workers (Martin 2004: 3).

\subsubsection{Administration of Thai Labour Migration Policy}

The main administrative bodies involved in migrant management in Thailand are the Ministry of the Interior (MOI) and the Ministry of Labour (MOL). The MOI manages the regularization of migrants through civil registration and issues a thirteen-digit identification (ID) number, which grants migrants a temporary residence. The MOI's primary concern has been to protect national security, and therefore it has supported strict migrant policies, from confining migrants to the employers with whom they had registered to restrictions on their freedom of movement (Pollock/Pearson/Kusakabe 2009: 3-4). The MOI introduced policies that assumed that the need for migrant labour in Thailand was temporary. Consequently, migrant workers are 'working migrants' who will eventually return to their countries of origin.

The MOL is responsible for issuing work permits, which will allow migrant workers to legally obtain employment in Thailand. The primary concern of the MOL is the demand for migrant workers to meet the country's domestic labour shortage, and since the Ministry works directly with the domestic labour market and business sectors, the MOL recognizes the importance of migrant workers and the prospect that
Thailand will continue to depend on migrant workers in many sectors in the future. Thus, the policies of the MOL tend to be more generous, and it has worked with other related agencies on policies to grant welfare assistance and other forms of social and legal protection to migrant workers, including health care and decent working conditions, although these policies are limited to workers only and do not necessarily imply protection for the children of migrants (Rukumnuaykit 2009: 27).

The first migrant workers registration programme was introduced through a cabinet resolution in 1992 that allowed registered migrants to temporarily work in Thailand instead of facing deportation. Initially, the registration was limited only to Burmese migrants and to certain types of jobs (fishing, construction, agricultural, and some industries) in particularly designated provinces (Chantavanich 2007a: 1). A big demand from the business sector for migrant workers pushed the government to introduce additional categories for registration, which gradually expanded to migrants from Cambodia and Laos and to additional provinces, and also gradually expanded the number of job types to seven, then eleven, then forty-seven, and then to eighteen sectors in five industries, before it eventually expanded to all types of jobs and sectors in 200I (Chantavanich 2007b: 2, 4).

Later, in an attempt to manage migration differently, the registration shifted from an area-based system to one that was area- and quota-based. The government limited the number of registered migrants following a recommendation by scholars (Chantavanich 2007b: 5). However, this amendment has been of limited relevance since the number of registered workers has been lower than the quota. This was due to the fact that many workers have been employed in sectors that were not permitted to hire migrants. Nevertheless, some employers have been unwilling to pay high registration costs, although they have avoided prosecution by paying bribes to the police (Chantavanich 2007a: 6).

In 200I, the Thai government changed its policy again to permit an open registration nationwide in all occupations, without any limiting quotas. The intention was to 'regularize' all underground irregular migrant workers, so that the government could have an accurate figure of the number of migrants to guide future policy measures. The registered number of migrants in $200 \mathrm{I}$ was 568,000 , the highest number ever recorded, before the number dropped to 409,339 in the following year when the registration programme was renewed (Rukumnuaykit 2009: 20). At the same 
time, the government concluded memoranda of understanding (MOUs) with Myanmar, Laos, and Cambodia to legalize migrant workers, based on a government-to-government recruitment of migrant workers for specific periods of employment in Thailand. Placing conditions for this registration was intended to motivate the workers to return home after the completion of employment, although the MOUs also covered matters of labour protection and dispute settlement, and measures aimed at eliminating illegal employment (Chantavanich 2007a: 7).

In 2004, another major shift in migrant policy occurred which required that migrant workers, their dependents, and their employers must all be registered. Migrant workers and their dependents were to receive a thirteen-digit ID number for better migration management. These IDs were only valid for one year, however, and since then there has been no systematic effort to register migrants, other than those applying for work permits. In addition, the 20 II work permit registration with the MOL was opened for dependents (family and children) of migrant workers to apply for a temporary status.

In short, most laws and policies regulating migrants have been concerned with the working conditions, wages, and welfare of migrant workers. There has never before been an immigration law or policy concerning migrant children in Thailand. Furthermore, the government of Thailand sees a key linkage between immigration law, national security, and national policy, with national security in particular shaping the application of the Immigration Act. Consequently, a series of cabinet decisions since 1992 have resulted in a 'half-open door' policy towards migrant workers (Muntarbhon 2005: I3).

\subsubsection{Thai Policy on Migrant Children}

Since the early 2000 s, the government has responded to the concerns raised by international organizations (e.g. ILO) over migrant children with regard to child trafficking and exploitation of migrant child labour in the commercial sexual industry, the fishery industry, and seafood processing factories. ${ }^{3}$ At the same time, the increasing numbers of migrant children raised challenges of integration which were perceived by the Thai government as a potential threat to national

3 See: United States Department of Labor, 20I2: Thailand: Incidence and Nature of Child Labour; at: <http:// www.dol.gov/ilab/media/reports/iclp/tda2004/thailand. htm> (accessed I5 May 20I2). security (ILO/OEC 2006: I, 2008: 8). The Thai government and international agencies (e.g. ILO and Save the Children) regarded education as the best solution for reducing poverty and child labour. Education was also regarded as assisting in the integration of migrant children into Thai society, thereby reducing the (perceived) national security threat.

In addition, based on the norms of international treaties to which Thailand is a party, the Ministry of Education (MOE) introduced the 'Education for All' policy, which aimed to expand universal education in order to reach all children from every group in society, including migrant children. In 2005, based on the 'Education for All' policy, the MOE began working in cooperation with other relevant stakeholders to provide education for migrant children, irrespective of whether or not they were documented. This included cooperation with the Ministry of Interior (MOI), which started issuing a civil status that granted temporary residence to migrant children. However, as there was no clear and coherent policy in place for migrant workers in Thailand, and as each organization involved in migrant management had different interests and agendas, the possibility for misunderstandings between policies at the local and national levels was high.

Thus, while the Thai government openly recognized the right to education, at the same time the restrictions of Thai immigration law meant that it was almost impossible to acquire a permanent residence, let alone citizenship. Hence, the migrant assimilation process has relied greatly on how migrants manage to deal with their precarious status.

\subsubsection{Migrant Labour in Samut Sakhon Province}

The Samut Sakhon province, has experienced rapid economic growth, which has in turn expanded the labour market in three key sectors (fishery, industry, and agriculture), but this work has been unattractive to Thai workers. A high and growing demand for labour, coupled with inadequate local labour, created an acute labour shortage, paving the way for migrant workers from neighbouring countries to fill the gap. Half of the workers in these sectors are now migrants. Responding to the pressure from the private sector for a sustainable labour supply, in 1992 the Thai government eased the procedure for registration of undocumented migrants from Myanmar, Laos, and Cambodia to temporarily work in the province. Initially the law allowed them to work only in fishery 
and fishery-related factories, construction, farming, and domestic service, before it gradually expanded to nineteen other sectors by 2009 (Chantavanich 2007a: 2; Thai Cabinet Resolution of 26 May 2009). The actual number of migrants in Samut Sakhon, taking into account unregistered migrants, is estimated to be 200,000, compared to the local Thai population of 543,302 (ILO/OEC 2006: 5; Thu 2006: 3I).

Samut Sakhon is also an attractive destination for migrant workers due to relatively high wage levels compared with other provinces. As of I April 20I2, the minimum wage in Samut Sakhon is 300 baht per day, whereas in other provinces with a high concentration of migrant workers such as Tak, Chiang Rai, and Ranong, the minimum wage is 226, 232, and 259 baht respectively. ${ }^{4}$ However, undocumented workers often receive less than the minimum wage, and have no negotiating power (Martin 2004: 20). Even when workers are legally documented, they still have very little negotiating power over their wages as the registration system ties the migrants to the employers with whom they have registered. Migrant workers who quit or leave without the employer's or the authority's permission will immediately lose their work permits, a situation that leaves them with little room for wage negotiation.

The majority of migrant workers in Samut Sakhon are from Myanmar. Out of 76,059 registered migrants in 2008, 75,6I4 (99.4I per cent) were from Myanmar while 378 (0.5 per cent) were from Laos, and 67 (0.09 per cent) from Cambodia. Among the various ethnic groups that enter Thailand, Mon and Burmese are the majority. Samut Sakhon also has old Mon-Thai communities who migrated to Thailand a long time ago and are now Thai citizens of Mon ethnic origin. Mon is an ethnic group from Myanmar who have a long history of migration to Thailand because of an ongoing ethnic conflict in Myanmar. Their first migration dates back to as early as the sixteenth century. The majority of migrant workers are concentrated in the Muang Samut Sakhon district, and especially in Mahachai, where seafood processing and fishery-related factories are located. As will be argued next, this situation for migrants in Thailand represents a clear example of 'liminal legality' or a 'segmental assimilation', where the outcome of the assimilation varies due to personal and interpersonal factors.

4 Department of Employment, 20I2: Ministry of Labour Statistics, Government of Thailand; at: <http://www. doe.go.th/Page/interesting/interesting3.html> (accessed 28 June 20I2).

\subsection{Liminal Legal Status}

Legal status has been recognized by scholars as one of the most essential aspects of migrants' lives. Immigration law governs and shapes vital spheres of migrants' existence, from health care, vulnerability in the streets, the ability to combat domestic violence, and access to the labour market and wage levels, to their identity, self-recognition, and, more importantly, incorporation in the receiving country (Menjivar 2006: 1000). The impact of legal status on the lives of migrants has been stressed as very influential, to the point that it creates different classes of immigrants with different rights and privileges. These differences in turn contribute to the experiences faced by migrants from different legal categories (Freeman 2004: 950).

In their study on 'segmented assimilation', Portes and Zhou (1993) pointed to the different contexts of reception in the lives of migrants, which may consequently lead them in different directions. According to Menjivar, migrants do not form homogeneous groups and they have different access to resources (economic, social, and legal status) as well as to conditions in destination areas. Therefore, the outcomes of the integration of migrants into the host society vary. Conditions in the receiving country include personal factors such as skills, and extra-personal factors such as immigration law and access to the labour market, which work together to shape the opportunity structure for migrants in a receiving country (Menjivar 2006: I002). Immigration law determines which legal categories the migrants belong to (regular/irregular or documented/undocumented), as well as the status and participation of migrants in society; these are closely linked to their entitlement to resources, 'with little to share with others' (Menjivar 2006: IO23). Immigration law can be a constraining factor affecting the opportunities of migrants in the labour market by determining who can or cannot do certain kinds of jobs and for how long. For migrant workers in Thailand, immigration law strictly governs their work conditions. Moreover, immigration law and legal status also govern the interaction of migrants with welfare and cultural regulations (Freeman 2004: 950).

Legal status is closely linked to the concept of citizenship, which not only forms the domestic legal basis for access to individual rights, but also frames the social obligations between the individual and the state. Citizenship furthermore shapes immigrants' membership in society and their understanding of their place in it (Menjivar 2006: I003). As noted by Calavita, "[t]he immigrant is a stranger, physically 
present but not a member of a community" (Calavita I998: 40I). The legal status of migrants is conventionally divided in a binary way between regular and irregular or documented and undocumented. However, as globalization has brought about changing patterns of movement and migration as well as variable migration policies in different contexts and historical periods, the boundaries of legal categories between the black area of illegality and the white area of legality have become blurred. A new category of immigration status has emerged in the grey area in between these two conventional categories. This in-between status has been explored by different scholars, and referred to variously as "liminal legality" (Menjivar 2006), "permanent temporariness" (Bailey/Wright/Mountz/Miyares 2002: 125), "legal non-existence" (Coutin 2002: 34, 47), "precarious status" and "less-than-full status" (Goldring/Berinstein/Bernhard 2009: 240).

Using the concepts of "liminality" and "legal nonexistence", Cecilia Menjivar developed the concept of "liminal legality" to explain the social impact of Central American immigrants' uncertain status. Victor Turner's concept of "liminality" was used to conceptualize the "becomingness-state" or the transitional period between two relatively fixed or stable conditions (Turner 1967: 93). Susan B. Coutin's concept of "legal non-existence" captured the experiences of undocumented Central Americans as being "physically present and socially active but lacking legal recognition” (Menjivar 2006: I008). Undocumented migrants living in legal non-existence fall under a state of subjugation, which makes them "vulnerable to deportation, confinement to low wage jobs and denial of basic human needs, such as decent housing, education, food and healthcare" (Menjivar 2006: I008). Coutin stresses the negative impact of legal non-existence as an "erasure of rights and personhood thus making violence against people in this condition not only legitimate but sometimes even required" (Coutin, cited in Menjivar 2006: I008). Without legal recognition by the state, the rights of people who live under this situation become ambiguous and are usually violated (Coutin 2000, cited in Menjivar 2006: I008).

Liminal legality is therefore characterized by its ambiguity; it is neither a regular nor irregular status but may have characteristics of both. It is neither onedimensional nor a linear process; it is not simply a changing phase from undocumented to documented status - the transition is never complete as the migrants' legal status usually fluctuates (Menjivar 2006: IOOI). Migrants who register and become regularized in Thailand are granted temporary residence and work permits, which are generally valid for no more than two years. Their status is thus one of temporary legality. In addition, migrants may return to an irregular (undocumented) status in different ways: when their temporary status ends, when their work permits expire, or if they violate the immigration law and regulations such as changing employers without either the employer's or the authority's permission, or when migrant workers leave the province in which they are registered without authorized permission (Vasuprasat 20I0: 20).

\subsubsection{Liminal Legality and Migrant Children's Access to Education}

Migrant children in Thailand are a heterogeneous group, differentiated by age and ethnicity, as well as by the legal status and the patterns of mobility of their parents. They can be divided into three groups: children who accompany their parents in migration to Thailand; unaccompanied migrant children; and children born to migrant parents in Thailand (Huguet/ Punpuing 2005: I24).

The liminal legal status of migrants leads to specific kinds of vulnerability that significantly affects their experiences of assimilation in Thailand in general, and their attitude towards education in particular. Burmese children born to migrant parents in Thailand cannot obtain citizenship of either Myanmar or Thailand. Myanmar law requires a child born to Burmese parents to be registered within a month of birth. Parents must use the birth certificate to apply for a household certificate. Burmese migrant parents cannot fulfil this requirement while working in Thailand since many undocumented migrant parents may have left Myanmar without a proper document or they may be afraid that if they return, their re-entrance to Thailand could be difficult and costly.

Most workers from Myanmar are reported to have a Myanmar ID, but in order to legally leave the country they also need to have a passport, which is also very costly. Therefore, many migrants from Myanmar leave their country illegally, even though returning without a proper document may lead to a penalty of up to one year's imprisonment and a fine (Rukumnuaykit 2009: IO-II). As a matter of principle, Thai nationality may be obtained by birth for all children born in Thai territory but according to Thai law undocumented migrants are exceptions to this principle (Yang 2007: 523). Without Thai or Burmese citizenship, these children are left stateless, and are what Bhabha calls "Arendt's children", a situation when 
"supposedly inalienable rights are unenforceable for individuals who lack their government" (Bhabha 2009: 4II). Bhabha has further observed that, according to Article I.I of the Convention Relating to the Status of Stateless Persons of 28 September I954, statelessness refers to when a person is "not considered as a national by any State under the operation of its law" (Bhabha 2009: 4II).

Though migrant children in Thailand are granted temporary status, their future is still very uncertain. There is no clear implication for their legal status after they complete basic education. This means that there is no clear expectation of obtaining Thai citizenship or permanent residency. Migrant children are subject to the same procedures as their parents in that they may only attain a temporary or precarious legal status. Due to their liminal legal status, job opportunities are limited to manual jobs, as restricted by the law. ${ }^{5}$ These jobs require no educational qualification, but workers who are proficient in Thai might have a better chance to work in a higher position with higher wages than workers who cannot speak Thai. The opportunity for Burmese labour migrants to legalize their residential status is further limited as the law requires that aliens must demonstrate 'good behaviour' (Thailand's Nationality Act B.E.2508 amended by Act B.E.2535 and Act B.E. 255I, Section IO.2). In practice, this excludes most migrants (as well as their children) who have entered the country illegally (Yang 2007: 526). Since there is no clear policy or prospect for the future of migrant children, migrant parents and their communities view the efforts of the government to provide education to their children with suspicion. Moreover, a series of shifts in immigration policies in the last decade have exacerbated their already insecure feeling about their future in Thailand and this significantly affects their attitude towards education.

The precarious status of migrant children as well as their families brings about ambiguity in their entitlement to education. As mentioned earlier, the state's decision to provide rights to education for migrant children is based on national security concerns, and the benefits of providing education to migrant chil-

5 Ekachai, Sanitsuda, 2003: Shattered Dream: Immigrant Workers' Fact and Figure, The Human Rights Sub-Committee on Ethnic Minorities, Stateless, Migrant Workers and Displaced Persons, The Lawyers Council of Thailand; at: <http://www.statelessperson.com/www/?q $=$ node $/ 607 \mathrm{I}>$ (accessed 2 May 20I2); and Thai Cabinet Resolution of 26 May 2009. dren are weighed against the costs of not providing it (ILO/OEC 2008: 8).

\subsubsection{Migrant Children's Education in Samut Sakhon}

While Samut Sakhon has been experiencing rapid growth, especially in the fishery sector, the province has employed a large number of migrant workers to take over low-skilled labour jobs that have been abandoned by local Thais. Since it is unlikely that Thai workers will return to these jobs, there is an expectation that Thailand, and especially the Samut Sakhon province, will continue to depend on migrant workers in many sectors, especially fishery and fishery-related industries. Hence, there have been some shifts, not only in migration policies, but also in relation to social welfare, and in particular to education and health care.

According to the registration statistics provided by the Ministry of Labour, in 2OII there were I,2I8 migrant children under fifteen years of age registered as dependants of migrant workers in Samut Sakhon. However, this number does not reflect the reality of migrant children since a short period of registration (I5 June-I4 July 20II), inadequate publicity about government registration, and complications with the system led to only a small number of children being registered. $^{6}$

The Labour Rights Promotion Network (LPN), an NGO working with migrant children in Samut Sakhon, estimates that every year there are 2,000 children born to migrant parents in Samut Sakhon. Furthermore, given that some children were sent home and some accompanied their family to other provinces in search of work, the estimated number of migrant children in Samut Sakhon who arrived between 2004 and $201 \mathrm{II}$ is 7,000-I0,000. ${ }^{7}$ This situation is further described by an official from the Education department:

We are aware of the 'Education for All Cabinet Resolution' which is the policy of the government that states that migrant children, regardless of their status, can go to school. Therefore we have tried to improve the situation of migrant children in our area. We have worked with our sample school, the Sirimongkol School, to promote the school enrolment of migrant children. We try to publicize this to inform the migrant parents that their

6 Interview by Kamowan Petchot with Sompong Srakaew, Organization Director at Labour Rights Promotion Network (LPN), Thailand in July-August 20II.

7 Interview by Kamowan Petchot with Sompong Srakaew. 
children can come to school. Most of them go to Sirimongkol School, our sample school. The number of migrant children enrolling in schools has increased over time although we still face problems of student drop-out. ${ }^{8}$

Table 17.1: Number of migrant students enrolling in the public school in Samut Sakhon during the academic years 2005-2009. Source: Samut Sakhon Educational Service Area (2012).a)

\begin{tabular}{|c|c|}
\hline Academic Year & No. of Migrant Students \\
\hline 2005 & 177 \\
\hline 2006 & 287 \\
\hline 2007 & 493 \\
\hline 2008 & 526 \\
\hline 2009 & 1,039 \\
\hline
\end{tabular}

a) Samut Sakhon Educational Service Area, 2012: "Number of Migrant Students Enrolling in Public School in Samut Sakhon from Academic Year 20052009"; at: <http://www.km.skn.go.th/?name= research \&file=readresearch\&id=27> (accessed 28 June 2012).

While the Samut Sakhon Educational Service Area has devoted a lot of attention to education for migrant children, policy implementation has also been driven and supported by international organizations such as the ILO's International Programme on the Elimination of Child Labour (ILO-IPEC), IOM, and Save the Children. These organizations operate their own projects as well as others in partnership with local organizations, both governmental (e.g. Samut Sakhon Educational Service Area) and non-governmental (e.g. LPN and the Rak Thai Foundation). The main objectives of these international organizations in Samut Sakhon range from education as a key mechanism for bringing children out of child labour (ILO/OEC 20IO) to education as a means of protecting children from trafficking and exploitation (Save the Children UK). As a result of the convergence of objectives and interests from various parties at the local, national, and international levels in providing educational opportunities for migrant children in Samut Sakhon, the educational situation of migrant children has improved. However, there still remain some challenges faced by schools, as well as barriers caused by migrant children's liminal status.

At the local level, schools have adopted different interpretations of the 2005 'Education for All' Policy,

8 Interview by Kamowan Petchot with Mr Pongdhep, Education Service Area Officer at Sirimongkol School, Thailand in July-August 20II. resulting in different practices. At the same time, at the national level, there is a lack of effective coordination of priorities and interest between the different agencies that are involved in migrant management (e.g. MOE, MOI, MOL, and the Royal Thai Police). Ineffective communication and coordination between different agencies, such as MOE and MOI regarding students' ID numbers and budget allocation, exacerbates not only the vulnerability of uncertain status for migrant students, but is also a financial burden for schools.

\subsubsection{Tracking Differences and Commonality}

Migrant children have two main educational options, namely formal (public school) and informal (e.g. a migrant learning centre). The challenges these schools face in providing education for migrant children must be specially emphasized. Interviews were conducted in two public schools, one of which had a majority of migrant students while the other had a majority of Thai students. In addition, one migrant school/learning centre was selected for interview. There are many actors involved in the provision of education for migrant children, ranging from the staff of the schools, educational authorities, NGOs, and learning centres to communities. Data were collected from three main groups of stakeholders, namely teachers, students, and parents/guardians, with some additional interviews with education officials from Samut Sakhon Educational Service Area and NGO workers from LPN. The first school is the Wat Sirimongkol School, which provides education from preprimary to primary level (grade 6). There are 604 students: 59I migrants and ten Thai students. The school has the largest number of migrant students, with a cluster of more than thirty per cent of the migrant students who enrol in public schools in Samut Sakhon. It was also the only school where migrant students outnumbered Thai students. The openness of the school's policy allows for the registration of students regardless of their nationality and legal documents. This school has furthermore an ethnic affinity with the local community. The school is located in the old Mon-Thai community, which is quite open to newcomers from Myanmar. The community still shares some ethnic identity with the newcomer Mons, such as language, cultural practices, and beliefs, although they are also open to people of other ethnic groups as well. Most people in this community work in the agricultural sector. 
Table 17.2: Number of students at the primary and upper secondary levels in Samut Sakhon during the academic year 2010. Source: Ministry of Education (2012). ${ }^{\text {a) }}$

\begin{tabular}{|c|c|c|c|}
\hline Grade & Male & Female & Total \\
\hline $\begin{array}{l}\text { Grade } 1 \\
\text { Grade } 2 \\
\text { Grade } 3 \\
\text { Grade } 4 \\
\text { Grade } 5 \\
\text { Grade } 6\end{array}$ & $\begin{array}{l}3,779 \\
3,550 \\
3,584 \\
3,577 \\
3,501 \\
3,690\end{array}$ & $\begin{array}{l}3,578 \\
3,324 \\
3,336 \\
3,330 \\
3,253 \\
3,557\end{array}$ & $\begin{array}{l}7,357 \\
6,874 \\
6,920 \\
6,907 \\
6,754 \\
7,247\end{array}$ \\
\hline Total of Primary Ed. & 21,681 & 20,378 & 42,059 \\
\hline $\begin{array}{l}\text { Grade } 7 \\
\text { Grade } 8 \\
\text { Grade } 9\end{array}$ & $\begin{array}{l}3,762 \\
3,393 \\
3,038\end{array}$ & $\begin{array}{l}3,331 \\
3,272 \\
3,057\end{array}$ & $\begin{array}{l}7,093 \\
6,665 \\
6,095\end{array}$ \\
\hline Total of Lower Secondary Education & 10,193 & 9,660 & 19,853 \\
\hline $\begin{array}{l}\text { Grade } 10 \\
\text { Grade } 11 \\
\text { Grade } 12\end{array}$ & $\begin{array}{l}779 \\
699 \\
584\end{array}$ & $\begin{array}{l}1,272 \\
1,158 \\
1,027\end{array}$ & $\begin{array}{l}2,051 \\
1,857 \\
1,611\end{array}$ \\
\hline Total of Upper Secondary Education & 2,062 & 3,457 & 5,519 \\
\hline
\end{tabular}

a) Ministry of Education, 2012: "Number of Students at Primary-Upper Secondary Levels in Samut Sakhon: Academic Year 2010" (Bangkok: Government of Thailand); at: <http://www.moe.go.th/data_stat/\#\% E0\%B8\%82\% E0\%B9\% 89\%E0\%B8\%AD\%E0\%B8\%A1\%E0\%B8\%B9\%E0\%B8\%A5-\%E0\%B8\%AA\%E0\%B8\%96\%E0\%B8\%B4\% E0\%B8\% 95\%E0\%B8\%B4\%E0\%B8\%94\%E0\%B9\%89\%E0\%B8\%B2\%E0\%B8\%99\%E0\%B8\%81\%E0\%B8\%B2\%E0\%B8\%A3 \%Е0\%B8\%A8\%E0\%B8\%B6\%E0\%B8\%81\%E0\%B8\%A9\%E0\%B8\%B2> (accessed 28 June 2012).

The school receives funding from the Ministry of Education (MOE). The school had applied for a per head budget by sending the total number of students and school registration documents without applying for the thirteen-digit numbers for their students; the Ministry left this requirement to the discretion of the secondary school. The rationale behind this practice is the minimum age for legally working. If the school had applied for civil registration for their students, it might have contributed to a drop-out of students before grade 9. It was felt that some migrants might just have used school as a means to obtain civil registration and legal status in order to stay in the country, after which they would get the thirteen-digit number and take their children out to work. ${ }^{9}$

The school was popular among migrant students because of a flexible curriculum that adjusted to the specific needs of migrant children and provided a migrant-friendly environment. The school has used the core curriculum as assigned by the MOE, but has adjusted some details to suit migrant children's learning needs, such as providing a translator to help the teachers in primary classes so that new students can follow

9 Interview with teacher $\mathrm{G}$, a teacher from Sirimongkol School and teacher I, a teacher from LPN Learning Centre, 2OII. the class and gradually learn Thai. The school also has activities that help promote an understanding of Thai culture and values, and this can facilitate the children's integration into Thai society through such things as Thai etiquette and courtesy. The second school, the Srisuttharam School, is a big public school with 583 students, of whom I24 are migrants. The school provides education from pre-primary to lower secondary level (grade 9). The school is located in the same area and is functionally linked to the LPN Learning Centre, which trains and prepares migrant students to join this public school. The students from the learning centre who wish to continue their study in this school have to complete an examination to identify which class fits their academic ability.

The school has a legal duty to provide education to every child, regardless of their legal status. When a child with no legal registration documents enrols, the school registrar issues a personal record for the student, which includes a photograph and the parents' details. This school will also apply for a civil registration (the thirteen-digit ID numbers) for their students. The ID numbers allow for temporary residence up to a maximum of ten years. This school reported that the process of issuing an ID number from the MOI could be very slow, up to two years or more. The delayed procedure has caused budgetary challenges to 
the school because, for the per head budget from MOE, the school needs to send the actual number of enrolled students, with their thirteen-digit ID numbers attached. As a result, the school does not receive the per head budget for those students who are waiting for their ID numbers. As a result, the bureaucratic difficulties of receiving funding for migrant students is in contradiction with the school's legal duty to provide education for migrant children. As confirmed by the school's director:

My school receives the support from the government. When we accept migrant students, school registrar will fill the form for students' information and then send the application for the thirteen-digit number to the district office which will eventually go to the Ministry of Interior who will issue the ID for migrant students but the problem we have here is that sometimes, it takes so long before the students can get their numbers...sometimes up to two years. I'm not sure why it takes them so long. We need that number to apply for a budget per head from the Ministry of Education. We cannot get the budget for students who don't have an ID or are still in the process of applying so we have to share with them the budget of other students, Thai students and those students who already received their ID numbers...I think maybe the long and complicated procedure and financial problems might be one of the reasons why many public schools don't want to accept migrant students but here we accept all children who applied. The law clearly states that we have to do so. ${ }^{10}$

There are two ways for migrant children without legal residential documents to obtain some form of legal status, through their registration as dependents of migrant workers and/or through registration by the school. If migrant children apply through schools, they will be granted a different status and a longer temporary residence permit of up to ten years, while registering as a dependent will grant them the same status as their parents, with a residence permit for up to two years. Mostly, migrants can only obtain a oneyear amnesty to legally stay in the country through a work permit renewal with the MOL. Accordingly, a number of migrant parents have decided to send their children to a public school to obtain a longer legal status.

Migrant children without ID numbers face arrest and deportation, and they are charged with entering the country illegally. However, if the migrant children are students of a public school, whether children who have not applied for an ID number, or those who

10 Interview by Kamowan Petchot with Mr Pisarn, School Director, at Srisuttaram School, Thailand in July-August $20 I I$. were waiting for one, then their teachers may provide the police with evidence that they are students in order to get them out of custody. Some migrant parents send their children to school just to obtain the legal status, for fear of police harassment, arrest, and deportation.

I and most parents send our children to school because we are afraid that the police could arrest our children. Now we are mostly registered at the new registration this year so police cannot arrest us any more but for many children who did not know about the registration or the employer did not take them to registration, they still have no documents. But if children come to school, the police cannot arrest them. ${ }^{11}$

Besides the budgetary challenge faced by Srisuttharam School due to the delay in issuing ID numbers, the school also experiences the problem of student dropout. Many students have to move when their parents change jobs, and this makes it difficult for students to continue their studies as they might leave before they receive the ID card, and they cannot reapply for it from the new school. Public schools are only open for enrolment twice a year, at the beginning of each new semester, while the pattern of mobility of migrant families varies throughout the year. Migrant children might arrive in the middle of the school semester, and be unable to immediately continue their study in a new school, or may end up repeating classes. Poverty and debt was mentioned by those interviewed as the main factor that caused students to drop out. ${ }^{12}$ Another teacher emphasized this point:

Basically, learning Thai is important since they live here but some of their parents don't think like that. They don't think about how useful an education for their kids is nor do they pay any attention. However, there are some that care about the education of their children and send their kids to school although there are a lot of problems due to the expenses, for example for school uniform, daily allowances, transportation, etc. Even if they don't have to pay tuition fee, but for some, still out of hand. In this classroom as well, there are many poor kids whose parents work for a shrimp peeling factory. Some families have only a mother who is living with the children while the father has sailed with the fishing boat. Many children left school to work. ${ }^{13}$

11 Interview by Kamowan Petchot with A, a migrant parent at Srisuttaram School in July-August 20II.

12 Interview by Kamowan Petchot with Vava, a student, with teacher W, and with Mr F at Srisuttaram School, Thailand in July-August 20II.

13 Interview by Kamowan Petchot with Tan, a teacher, at LPN Learning Centre, Thailand in July-August $20 I I$. 
Even though there was no school fee and there were subsidies for uniforms and textbooks, parents still have to pay some additional expenses such as transportation costs and a daily allowance. The income of some migrant families is too low for them to be able to afford their children's education. To send a child to school, parents have to spend at least 300 baht for their lunch and at least 500 baht on transport every month, while the average monthly income of a worker in the seafood processing factories is about 2,000 baht. When added to other necessary expenses such as housing and food, the educational expenses are beyond the financial means of migrant families. Apart from their low income, many migrant families are also in debt bondage, arising from their journey across the border and sometimes through job seeking, as was confirmed by one migrant child:

When I first arrived here, I joined school but my mother and brother alone cannot work to pay our debt so I left school to work in the shrimp peeling factories...Then when we paid off all our debt I came back to study in school. ${ }^{14}$

Many children leave school to enter the labour market when they reach the age of nine or ten years old, either by working in the informal sector, or by lying to employers about their real age, since the minimum age for employment in Thailand is fifteen. This correlates with the drop-out rate of students in school. According to statistics from the Samut Sakhon Educational Service Area for the academic year 20Io, the educational level that had the highest drop-out rate was grade 2, where a total number of forty-six students became only ten students, who proceeded to grade 3 .

A third school for migrants was set up five years ago by LPN and it is solely funded by foreign donors. Currently there are I40 migrant students in the learning centre, ranging from pre-primary to primary level (grade 2). The majority of the migrant children are Burmese and Mon from Myanmar. As mentioned, the learning centre is linked to the Srisuttaram School, both institutionally and by location, at the back of the Srisuttaram School. Their classes prepare migrant students to enter the public school system. The school tries to create a public school environment, such as requiring students to wear a uniform, as well as singing the national anthem, praying every morning, and using the same curriculum and textbooks. Although the

14 Interview by Kamowan Petchot with Min, a migrant student at Srisuttaram School, Thailand in July-August 2OII. learning centre uses the same curriculum as the public school, they are more flexible and sensitive to the situations and specific needs of migrant children. The main language of instruction is Thai with some additional use of Burmese and Mon so that the new students can follow the lesson and don't feel isolated from their classmates.

Sending children to the learning centre rather than the public school involves additional costs. Although the centre does not require a school fee, parents still have to cover transport costs, lunch, uniforms, textbooks, and stationery. Despite this, parents still prefer to send their children to the learning centre before they enter the Thai public school in order to prepare their children mentally and academically for the formal school system. The Thai public schools provide no preparatory classes for migrant students. Furthermore, the learning centre has a more flexible acceptance period for new students, which better suits the pattern of migrant families' mobility. They accept new students all year round. Although many people call the LPN school a migrant school, the law does not recognize its status as a school. For this reason, the school receives no support from the government. Lack of support from government poses the main challenge. The school does not require a school fee as all school expenses come from foreign donors. However, it is running out of funds after five years of external support and is facing difficulties in operating. The school has already had to cut many expenses. Free lunches have been cancelled, while textbooks and some stationery have been scarce. Moreover, the lack of funding leads to a lack of teachers. Apart from financial difficulties, the status of teachers in the learning centre is another issue. The learning centre has a problematic status. Teachers in the learning centre are considered to have a lower status than teachers in formal schools. They also receive lower wages, are seen as having lower social status, and there is no legal recognition of their status. As a result, people who are qualified for the job would prefer to work for formal schools.

\subsubsection{Impact of 'Liminal Legality' on the Experience of Migrant Children in the Thai Education System}

The 'liminal legality' of migrant children and their families affects the experiences of children in the education system. The combination of immigration laws, migrant children's socio-economic status, and their parents' preferences affect both migrant children's 
educational lives and by extension their incorporation into Thai society.

Most migrant children are living in 'mixed legal status' families, where each family member has a different status in terms of the immigration law (Fix/ Zimmerman 200I). Registered migrants possess a temporary amnesty from deportation. However, the registration which allows undocumented migrants to temporarily stay and work in Thailand involves multiple and confusing deadlines, which are often not well communicated to the migrants. Migrant children who apply for an ID number through the school are granted a temporary residence permit of not more than ten years, whereas registered parents and dependants are granted a residence permit and a work permit of no more than two years.

Sometimes one family has members with both statuses in relation to the law. For example, a migrant child might live in a family where one of the parents is registered while the other is unregistered, or had been registered at an earlier stage but fell back into irregularity. At the same time, migrant children may have siblings who are too young to join school and register through the school system, and thus still do not have a legally-protected status. Among migrant children, some have received the ID number through the school, while others will have been on a waiting list for years before they receive their ID number. A further group of migrant children cannot apply through their school since not all primary schools concern themselves with the registration of their students, but leave the burden to secondary schools.

Living in the grey area of precarious legal status, the mixed status of migrant children leads to sceptical attitudes toward education, and this further impacts on the long-term opportunities of migrant children. As parents and other guardians move in and out of legality and fear deportation, their children and their children's education are also affected. For example, some parents feel that contact with a state authority, like a public school, can lead to an inquiry about their legal residence status, and therefore prefer to send their children to learning centres, which generally provide only a basic education up to primary or lower secondary level. Alternatively, parents choose to end the education of their children altogether at the basic level due to their fear of contact with government authorities. Consequently, as migrant parents do not perceive a secure future in Thailand, they are reluctant for their children to engage in the Thai education system. The concern of parents is that, following their education, their children will end up in the same situ- ation as themselves, with a 'liminal legal status' and access to the same low-paid jobs. ${ }^{15}$ Another migrant parent elaborated on this point:

I think it is very good that my granddaughter goes to school. Now she speaks Thai much better than before and she can read signs on the street and medicine labels for me. [When asked: What did she plan for her granddaughter's education? How long does she plan to keep her grandchildren in school?] No, I don't want her to stay in school for too long...maybe not more than Por 3 [Prathom 3, first level of elementary school equivalent to grade 3]...or Por 6 [Prathom 6, second level of elementary school equivalent to grade 6]. I don't work any more these days ... Only their parents earn for the whole family now and if they have to change workplace or if we have to go back to Myanmar, she will have to get out of school anyway. It is better that after she gets necessary skills, she works to earn and help her family. ... [After a long pause] Even if she finishes high school, she will work like her parents. That doesn't require a school certificate. ${ }^{16}$

Moreover, frequent shifts in immigration law and other regulations lead to an uncertain feeling among both parents and children about their future in Thailand, as deportation back to their country of origin can happen at any time. Consequently, there has been a trend towards taking children out of schools as parents weigh the possible gains from education in the future against the likely income from child labour, since they do not have a secure feeling anyway about their future in the country, including that of their children.

This is also partly a result of the experiences of migrants in their country of origin. One respondent recalled her mother telling her of the situation of underemployment in Myanmar; this leads to attitudes to the value of education, which are different from that of Thai society, where a higher level of education is valued as providing better opportunities in the labour market. ${ }^{17}$

For some parents with previous experiences in Myanmar, a higher level of education does not necessarily translate into better-paid jobs since the economy

15 Interview by Kamowan Petchot with Mrs S, a migrant parent, at LPN Learning Centre, Thailand in JulyAugust 20II, and interview by Kamowan Petchot with Yu, a student at Srisuttaram School, Thailand in JulyAugust 20II.

16 Interview by Kamowan Petchot with Mrs S, a migrant parent, at LPN Learning Centre, Thailand in JulyAugust 20II.

17 Interview by Kamowan Petchot with Vava, a student, at Srisuttaram School, Thailand in July-August $20 I I$. 
does not offer this and the majority of migrants face unemployment or underemployment. The parents' level of education and length of time in Thailand also makes a difference in their attitude towards the value of education, since parents who have more education and have lived for a longer period of time in Thailand tend to value education more than just language literacy and tend to keep their children in schools for longer:

I want my son to get an education as high as he could... I have been here for a long time (more than 15 years). I have seen things and know more than others [migrant parents] who work in seafood factories here. I know that the school is good for my son's future. He will have a better opportunity, a better future than others without education. Many migrant parents don't think like me. They just want their children to have basic Thai language and keep their young children at school so that the teachers can take care of their children while they go to work. But I want my son to go to school and maybe to university and get a nice job. ... But this also depends on the government. ${ }^{18}$

Mr. Mihn has been in Thailand for fifteen years and employs people in his own shop. His situation is different from many other migrant parents who mostly work in fishery or fishery-related factories and have been in Thailand for less than ten years. Therefore his financial situation is also better than that of most other migrant parents. The family lives in a rented house while most migrant families live in rented shared rooms in an apartment.

Immigration law restricts migrants to remaining in the area where they have registered; movement out of that area without the permission of the authorities is a violation of the law. As a result, many families are separated and are not able to meet each other often. Most migrant children in Thailand have had experience of family separation, both in relation to family members who still live in their country of origin, and of the separation caused by immigration laws that restrict the freedom of movement of migrants, as well as the deportation of some family members who lack (or lose) their regular legal status. Family separation can have an important impact on the performance of migrant children in school as well as their integration into Thai society. In short, immigration law dictates whether migrants will have access to education or not, and to what level. By extension, immigration law shapes migrants' expectations and goals.

18 Interview by Kamowan Petchot with Mihn, a migrant parent, in Thailand (place withheld) in July-August $201 \mathrm{I}$.
A further important factor affecting migrant children's access to schools is their insecure financial situation. Even though education is provided by the state free of charge, parents need to pay additional direct and indirect costs of education, such as transport and daily allowances, which can be considered unaffordable for low-income migrant families. Migrant families are bound by their 'liminal legality'. Due to their inability to find better-paid jobs, a lack of negotiating power to improve their wages, and the need to pay high registration fees, migrant families also face economic difficulties. Without access to other resources, children are sometimes forced to enter the labour market in order to support their families. The opportunity cost of child labour outweighs the value of receiving an education, particularly when families are in debt, acquired through making the journey to Thailand or sending remittances to other family members back home.

The socio-economic status of migrants is the most significant factor that dictates access to education and that shapes the opportunity structure in the education system. This is exacerbated by an uncertain legal status, which itself moulds migrants' access to financial resources (for example, funding for education, and bank loans). Without access to financial resources, migrant children are pushed into child labour. Marginal legal status also shapes their interpretation of opportunities in the market, of school and of the education system in general.

Apart from the household composition and the financial situation of migrant children, their parents' preference determines the access to education of migrant children. Parents decide the type of education (formal, informal, or non-formal education), schools, duration of time in school, and level of education their children should receive.

As mentioned earlier, migrant families feel insecure about their future in Thailand due to their precarious status and frequent shifts in immigration policy. As a result, they adjust their educational aspirations to their life conditions. Their expectation from education is mainly oriented to acquiring basic skills, such as rudimentary mathematics and language literacy for the purpose of communication in the workplace and everyday life, rather than aiming at attaining a degree certificate or level of education higher than their basic communication needs.

However, as mentioned earlier, there is an exception to this general trend. Parents who have received a higher level of education or have spent several years in Thai schools tend to recognize the value of educa- 
tion more, and tend to keep their children in school for a longer period. This group of parents has developed higher aims for and expectations from the education of their children. They believe that, with a higher level of education, their children will be able to find better jobs at a skilled level, which will lead them out of poverty and to a better future. However, parents still expressed concerns about the frequent shifts in policies and their uncertain future and recognize that their 'liminal status' serves as a barrier preventing them from access to educational loans or bank loans in order to pay for a higher level of education. One of the prior conditions in requiring an educational loan is Thai nationality, a condition which migrant children lack.

Schools and teachers seem to ignore the situation of migrant children at home as well as ignoring the specific need as migrants who have to live with an uncertain legality:

We use the core curriculum as assigned by the Ministry of Education. Here we don't adjust the curriculum to the student. The student must adapt themselves towards us. We treat them just like Thai students. Everything is equal. ... Here we only use Thai. ... Everything is the same, no divide... If they violate school rules they will be punished just like Thai students. ... Some [migrant] students often come to school late or missed classes often. ... [When asked about differences in performances between Thai and migrant students] They are good at mathematics and English but most of them are bad at science or social study, those subjects that require Thai language skills. They will be quiet but they are diligent and obedient students. ${ }^{19}$

Meanwhile, a school official responded:

Of course, I think it [the class and curriculum] is very useful and appropriate for them. I don't think we have to adapt to their needs. I think it's them that need to adapt to our curriculum because they get many benefits from coming to school. ... It's them who benefit from coming to school so they need to adjust themselves to school rules as well as to the curriculum. ${ }^{20}$

This lack of consideration about the effect of an uncertain legal status on the performance and educational objectives of migrant children leads to a feeling of isolation or exclusion in migrant children at school, and this can form an additional reason for children to drop out of school.

19 Interview by Kamowan Petchot with Noi, a teacher, at Srisuttaram School, Thailand in July-August 201 II.

20 Interview by Kamowan Petchot with an Education Service Area Officer at Sirimongkol, Thailand in July-August $20 I I$.
In summary, while education is made available to migrant children by way of government policy, migrant children's lack of access to education is due to their problematic legal status. Legal status reinforces and exacerbates the negative impacts of other forms of discrimination such as race, gender, and socio-economic status.

\subsection{Conclusion}

The Thai government has made an effort to ensure the availability of education by granting free and compulsory education for every child within its territory, and has tried to reduce discrimination against migrant children by requiring that schools accept all children regardless of their legal status. However, discrimination still takes place through the implementation of this policy, where migrant children are prevented from accessing education for various reasons. Discrimination is mainly based on the 'liminal legal status' of migrant children.

Because of the long bureaucratic procedure in applying for a budget for migrant children, many schools face financial difficulties. This procedure discourages most schools from accepting migrant students, and leads to a concentration of migrant children in a few schools. In addition, insensitivity on the part of schools to migrant children's difficult socioeconomic conditions and their specific needs, such as language barriers, leads to formidable challenges for schools in providing quality education. Furthermore, learning centres with an unrecognized status receive no support from government and face even more significant financial problems, including the low wages and status of teachers, and ultimately an even lower quality of education. However, 'liminal legality' is the main factor preventing children from enjoying their rights to education, by shaping migrant children's experiences in the education system as well as their educational aspirations, and in general shaping the opportunity structure of migrant children in education. This can also explain the low enrolment rate of migrant children in public schools and their early dropout rate. This situation of 'liminal legality' not only affects the educational opportunities for migrant children, but also has significant implications for their integration into Thai society. Without addressing the problematic legal status of migrant children, it will be impossible for migrant children to fully realize their right to education. 


\section{References}

Bailey, Adrian; Wright, Richard; Mountz, Alison; Miyares, Ines, 2002: "(Re)producing Salvadoran Transnational Geographies", in: Annals of the Association of American Geographers, 92,I: I25-I44.

Bhabha, Jacqueline, 2009: “Arendt's Children: Do Today's Migrant Children Have a Right to Have Rights?", in: Human Rights Quarterly, 3I,2: 4IO-45I.

Calavita, Kitty, I998: "Immigration, Law and Marginalization in a Global Economy: Notes from Spain”, in: Law \& Society Review, 32,3: 529-566.

Caouette, Therese, 200I: "Small Dream Beyond Reach: The Lives of Migrant Children and Youth along the Borders of China, Myanmar and Thailand', A Participatory Action Research Project, Save the Children (UK); at: <http://www.childmigration.net/STC_Caouette_O2> (I5 July 20II).

Chantavanich, Suphang 2007a: "Thai Policies Towards Migrant Workers from Myanmar", Paper presented at the APMRN Conference at Fujian Normal University, Fuzhou, 26-28 May.

Chantavanich, Suphang, 2007b: "Factors Affecting Thailand Immigration Policies During 1992-2004', Paper presented at the Conference on International Migration, Multi-local Livelihoods and Human Security: Perspectives from Europe, Asia and Africa at the Institute of Social Studies, the Hague, 29-30 August.

Convention on the Rights of the Child, I989: Passed by the UN General Assembly on 20 November 1989, UN Treaty Series, I577: 3.

Coutin Susan, 2002: Legalizing Moves: Salvadoran Immigrants' Struggle for U.S. Residency (Ann Arbor: University of Michigan Press).

Freeman, Gary, 2004: "States and Modes of Political Incorporation: Immigrant Incorporation in Western Societies", in: International Migration Review, 38,3: 945969.

Fix, Michael; Zimmerman, Wendy, 200I: "All Under One Roof: Mixed Status Families in an Era of Reform', in: International Migration Review, 35,2: 397-4I9.

Goldring, Luin; Berinstein, Carolina; Bernhard, Judith, 2009: "Institutionalizing Precarious Migratory Status in Canada", in: Citizenship Studies, 13,3: 239-265.

Huguet, Jerry; Punpuing, Sureeporn, 2005: "Child migrants and children of migrants in Thailand", in: Asia Pacific Population Journal, 20, 3: I23-I42.

ILO (International Labour Organization); OEC (Office of Education Council), 2006: Research study on Educational opportunity of migrants and stateless children in Samut Sakhon; at: <http://www.ilo.org/public/english/ region/asro/bangkok/apec/download/th_study_edu. pdf> (II April 20II).

ILO (International Labour Organization); OEC (Office of Education Council), 2008: Education Provision for Stateless and Cross National Migrant Children in Thailand.
ILO (International Labour Organization), 20I0: Good practice notes: Serving the unserved: How government agencies and $\mathrm{NGOs}$ learned to reach migrant children with educational opportunities, at: <http://www.ilo. org/global/topics/WCMS_I42095/lang-en/index.htm> (I2 September 20II).

IOM (International Organization of Migration), 2008: Situation report on international migration in East and South East Asia, at: <http://www.iom.int/jahia/webdav/ site/myjahiasite/shared/shared/mainsite/published_ docs/books/IOM\%20Situation\%20Report $\% 20-\% 20$ Final.pdf> (I5 June 20II).

Martin, Philip, 2004: Thailand: Improving the Management of Foreign Workers, Bangkok: International Labour Office and International Organization for Migration.

Martin, Philip, 2007: The Contribution of Migrant Workers to Thailand: Towards policy development, Bangkok: International Labour Organization; at: <http://phamit. org/download/Migrants\%2oeconomic\%2ocontribution. pdf $>$ (I4 June 20II).

Menjivar, Cecilia, 2006: "Liminal Legality: Salvadoran and Guatemalan Immigrants' Lives in the United States”, in: American Journal of Sociology, III,4: 999-I037.

MFA (Ministry of Foreign Affairs), 20II: Right to Education for Migrants, Refugees and Asylum Seekers, Bangkok: Government of Thailand; at: <http://www.mfa.go. th/ humanrights/index.php?option=com_content\&view= article\&id $=72$ :right-to-education-for-migrants-refugeesand-asylum-seekers- $\&$ catid $=35$ :un-resolution $\&$ Itemid $=73>$ (2 May 20I2).

Muntarbhon, Vitit, 2005: The Mekong Challenge - Employment and Protection of Migrant Workers in Thailand: National Law/Practices Versus International Labour Standard, International Programme on the Elimination of Child Labour, Bangkok: International Labour Office.

Pollock, Jackie; Pearson, Ruth; Kusakabe, Kyoko, 2009: "Policy Brief and Recommendation on Undocumented Labour Migration in Thailand", Paper presented at the International Workshop on Gender, Migrant Workers and Citizenship in the Greater Mekong Sub-region at the Asian Institute of Technology, Pathumthani, I-3 June.

Portes, Alejandro; Zhou, Min, I993: "The New Second Generation: Segmented Assimilation and its Variants", in: The Annals of the American Academy of Political and Social Science, 530,I: 74-96.

Portes, Alejandro; Zhou, Min, I993: 'The New Second Generation: Segmented Assimilation and its Variants', in: The Annals of the American Academy of Political and Social Science, 530, r: 74-96.

Rukumnuaykit, Pungpond, 2009: A Synthesis Report on Labour Migration Policies, Management and Immigration Pressure in Thailand, Geneva: International Labor Organization, at: <http://www.ilo.org/asia/whatwedo/ publications/WCMS_IO3923/lang-en/ index.htm> (7 August 20I2). 
Thai Cabinet Resolution of 26 May 2009, 'Registration of Irregular Migrants from Myanmar, Laos and Cambodia' (in Thai); at: <http://www.cabinet.soc.go.th/soc/ Program2-3.jsp?top_serl=220064\&key_word=\&owner_ dep $=\&$ meet_date_dd $=268$ meet_date_mm $=5 \&$ meet_da te_yyy $=2552 \&$ doc_idI $=\&$ doc_id $2=\&$ meet_date_dd $2=\&$ meet_date_mm2=\&meet_date_yyyy2=> (I5 May 20I2).

Thu, Zeya, 2006: "Migrant Children's Access to Education in Thailand: A Case Study of Myanmar Children in Samut Sakhon Province”, Masters thesis (Bangkok: Chulalongkorn University).
Turner, Victor, 1967: The forest of symbols: Aspects of Ndembu ritual (Ithaca: Cornell University Press).

Vasuprasat, Pracha, 20Io: Agenda for labour migration policy in Thailand: Towards long-term competitiveness, International Labour Organization/Japan Project on Managing Cross-border Movement of Labour in Southeast Asia, Regional Office for Asia and Pacific.

Yang Bryant, 2007: "Life and death away from the golden land: The plight of Burmese migrant workers in Thailand", in: Asian-Pacific Law and Policy Journal, 8,2: $486-535$.

Open Access. This chapter is distributed under the terms of the Creative Commons Attribution Non-commercial License, which permits any noncommercial use, distribution, and reproduction in any medium, provided the original author(s) and source are credited. 


\title{
18 Challenges of Recognition, Participation, and Representation for the Legally Liminal: A Comment
}

\author{
Cecilia Menjívar and Susan Bibler Coutin ${ }^{1}$
}

\begin{abstract}
Following the approach to social justice taken in this book, we would like to bring attention to issues of recognition, participation, and representation as these are linked to migrants' legality and their rights in the chapters by Petchot (I7), De Vlieger (I6), and Mora and Handmaker (I5). These three issues are closely intertwined. In this review chapter, we start by recognizing the implications of migrants' liminal legality, of migrants' rights as workers, and of their right to access goods and benefits in society as key to advancing projects of equality and justice more generally. As Fraser (2007) observes, misrecognition is fundamental to inequality, particularly gender inequality.
\end{abstract}

Keywords: Access to goods and services, liminal legality, migrants, statelessness.

\subsection{Comment on Chapter 17 by Petchot}

Petchot describes various 'legal grey areas' in the experiences of Burmese migrant children in Thailand. One is the liminal legal status of the migrants themselves; another comes from the different understandings of these children's rights by governing bureaucracies, and a further grey area is found at the intersection of national and supranational legal orders. At the centre of each area lies a tension between the conferral of rights in principle and the difficulty in accessing them in practice. Importantly, Petchot reminds us that the state is far from a monolithic entity, as its various bureaucracies often clash in terms of purpose and even in definitional questions of who is deserving and who is not. Whereas the Thai government acknowledges the need for educating migrant children out of security concerns and assimilation projects, and seeks to comply with international treaties to extend rights to these children, it does not nec-

1 Cecilia Menjívar is Cowden Distinguished Professor in the T. Denny Sanford School of Social and Family Dynamics at Arizona State University. Susan Bibler Coutin is Professor in the Departments of Criminology, Law and Society and Anthropology at the University of California, Irvine, and Associate Dean of the Graduate Division. essarily recognize these children's right to education from a liminal legal position. The universal rights in international treaties clash with the national realities of the immigration and educational bureaucracies and can give way to new forms of inequality. Rather than facilitating access to rights, new social hierarchies emerge, particularly as social positions, such as age and ethnicity in the case of Burmese immigrant children in Thailand, intersect with migrants' legality. Petchot's piece invites reflection about similar cases in other parts of the world, particularly where the presence of migrants is compartmentalized, recognizing their benefit to society while simultaneously curtailing their rights.

\subsection{Comment on Chapter 16 by De Vlieger}

Projects of recognition to advance migrants' rights do not pertain solely to the recognition of how migrants' legality, regulated by national governments, can curtail access to universal rights, but also on the recognition of the contributions of migrants to the receiving society as workers. This is the case in the piece by De Vlieger, in which she documents the experiences of women domestic workers in Saudi Arabia and the United Arab Emirates. A key factor that shapes the ex- 
periences of the migrant domestic workers as well as their lack of access to their rights as workers is the belief that their work does not represent 'employment' because it is performed within the private sphere of the household. Within a context of deep class, gender, and ethnic inequalities, the work these migrant women perform becomes particularly exploitable and disposable because these workers are women and because the work they perform is not fully considered 'employment'. Indeed, the lack of recognition of domestic work as an occupation in which workers can claim rights and the informality associated with work performed within the home, together with ideas of servility associated with domestic work, set the conditions for rights violations and exploitation. In spite of the formal legal arrangements through which the migrant women depicted by De Vlieger enter this occupation, the organization of the work as a private affair in the home, couched within personalized understandings between two individuals, curtails the women's rights and leaves them socially and economically vulnerable. Importantly, although these women's legality is formalized, the organization of work and expectations of the servility attached to it contribute to diminish the women's citizenship and they end up as vulnerable as liminally legal migrants in other contexts. Even though the cases De Vlieger describes demonstrate extremely limited access to rights and justice, the lack of recognition of domestic work as an occupation like any other and the informality associated with it parallel the cases of migrant women in other societies. Indeed, Hondagneu-Sotelo (2007) argues that a first step in addressing injustices and rights violations among Latina domestic workers in the USA is the formalization of employment arrangements in paid domestic work so that labour protections can be integrated in this occupation. Rights claims and even the recognition of rights can be particularly challenging among these workers because of the isolation they experience in their place of work. As Nakano-Glenn (I988: 6I) notes about JapaneseAmerican domestic workers, "her work is unrelated to the activities of other workers".

\subsection{Comment on Chapter 15 by Mora and Handmaker}

The clash between different regulatory regimes and between the social rights extended by the international regime of human rights and those that are located in the nation state is also central to the case of
Peruvian migrants in Chile discussed by Mora and Handmaker. This tension often serves to exacerbate regimes of inequality to create new forms of stratification based on the migrants' legality, as also described by Massey (2007) in relation to the USA. In the case of Peruvian migrants in Chile, non-governmental organizations (NGOs) that assist them have responded to restrictions imposed by the receiving country's immigration laws through the recognition of the migrants' universal rights and of the limited structures within which to exercise them as workers. However, the NGOs' efforts to recognize these migrants' rights (both their rights as workers and their social rights as human beings) fall short because they act within the same confining structures and inadvertently reproduce the segregation of Peruvian workers in Chile. It should be noted, however, that like the domestic workers whose isolation often prevents them from relating to others as workers (and becoming conscious of their rights), the Peruvian migrant workers in Chile might engage themselves in projects of recognition of their own rights and advocate for justice and humanity from their own social locations. There are parallels to successful movements that migrants have organized. Notable among them are those of day labourers in the USA (Cordero-Guzman/Martin/Quiroz-Becerra) Theodore, 2008), the youth organized around the Development, Relief, and Education for Alien Minors (DREAM) Act (Nicholls 20I2), and the political demonstrations organized by migrants in uncertain legal statuses (Pantoja/Menjívar/Magaña 2008) who otherwise have been inhabiting legitimate spaces in society (Coutin 2000). Such mobilizations by the migrants themselves not only lead to a recognition of their presence but also of their rights as workers and as human beings.

\subsection{Factors facilitating or precluding migrants' mobilization}

By analysing factors that facilitate or preclude migrants' mobilization, these three chapters shed light on the possibilities that migrants have to achieve greater participation and thus increased levels of social inclusion. Mora and Handmaker suggest that international forums provide a vehicle through which the Chilean government can be called to account for failing to prevent the discrimination experienced by Peruvian migrants. Filing a complaint before the International Labour Organisation, they argue, would be a proactive step that would sharpen NGOs' rights focus 
and enable them to develop more expansive notions of citizenship and of gender, notions that denaturalize Peruvian women's participation in domestic labour.

Petchot argues that the Thai state's failure to address the liminality of migrant children prevents educational structures from meeting these children's educational needs. Though migrant children have the right to education, they are unable to participate in the educational system at rates comparable to Thai children. De Vlieger documents a strikingly blatant institutional insensitivity on the part of Saudi officials who are responsible for human rights issues. These officials denied the possibility that domestic workers could experience problems, instead depicting these women as problems and as sexually deviant. Furthermore, the very offices to which domestic workers were supposed to bring complaints did not actually exist. A common feature of all the cases discussed by these authors is a level of institutional unresponsiveness that, far from recognizing the migrants' rights, misrecognizes them, in Bourdieu's (2004) conceptualization of misrecognition and its implications. Hence, migrants' rights are mislabelled as something else, rendering the realities of migrant women and children invisible.

\subsection{Racialization and Stigmatization of Migrants in Popular Imaginations}

Closely linked to state and even NGO unresponsiveness are limitations in the ways that migrants are represented in the popular imagination. Mora and Handmaker point out that Peruvian migrants in Chile experience a form of racialization according to national origin, setting them apart from Chileans as a distinct population. Racialization is common in the USA case as well, where Latinos are accused of being foreign 'invaders' even in areas of the country that historically were part of Mexican territory and where some residents' roots pre-date these territories being annexed by the USA (Chavez 2008). The racialization of Peruvian migrants in Chile presumably takes different forms, perhaps linked to shifts in or redefinitions of the composition of migrant populations, for example from students and refugees to domestic and other workers. Similarly, international discourses and legal structures that are used to criminalize unauthorized movement (Walters 2002) may contribute to a deeper stigmatization of migrants there. Mora and Handmaker contend that social recognition, such as access to health care and employment opportunities, may be more important to Peruvian migrants than political integration. This position is echoed by Kamal Sadiq (2009), who critiques migration theorists for focusing on south-to-north movements, to the exclusion of regional and other migrations. Sadiq stresses that political integration and voting rights, which are often taken as the key marker of citizenship within immigration studies, are less important in flows that move in other directions. By redefining citizenship as a process rather than as a status, Mora and Handmaker help to refocus attention on these multiple dimensions of integration.

\subsection{Concerns about Migrant Children's Education and Migrants' Liminal Legality}

Likewise, the public representation of migrant children in Thailand is at issue in efforts to meet these youths' educational needs. It is significant that public concern in Thailand focuses on the need for public education of migrant children, rather than regarding such education as a public burden, as is sometimes the case in the USA (Abrego/Gonzalez 20IO). And yet Petchot indicates that the Thai concern seems to stem from the sense that if they are not educated, children may pose a security risk, and is therefore an instance of a more widespread slippage between concerns for children at risk and the anxiety that children pose a risk. Once again, this is certainly an issue in the USA and in other countries in which key facets of youth culture have been criminalized (Ferrell I999). There is therefore a clash between the educational priorities of the Thai state and the ostensible purpose of education. Migrant children in Thailand are granted the right to education in order to keep children occupied and out of trouble, to integrate these children into Thai society, and to comply with treaty obligations. Education does not seem designed to equip children for success in life, which presumably is the rationale for making education a right. Instead, school officials interviewed by Petchot appear as begrudging, suggesting that the youth are the ones who need to adapt to Thai educational standards and that migrant children are fortunate to have educational opportunities. The representation of migrant children as interlopers appears to be significant here as well.

These representations of Peruvian domestic workers and of Thai children derive, ultimately, from their liminal legality, a form of liminality experienced by 
domestic workers in Saudi Arabia and the United Arab Emirates as well. Liminal legality is produced by national laws in receiving states that with increasing frequency grant new migrants nothing more than temporary statuses that limit their social rights and access to justice (Menjívar 2006). Calavita (2005) has documented the cases of Spain and Italy, in which seemingly generous immigration laws were, in practice, unworkable, thus enabling nation states to appear to satisfy demands for rights and calls for restriction (see also De Genova 2002). The papers discussed here, however, demonstrate that liminal legality can also be produced through other means, including clashes between national and supranational legal orders, tensions between state bureaucracies of the same government, or even ideologies regarding gender, race, and ethnicity, also in conjunction with formal legal orders. Mora and Handmaker, for example, examine the multiplicity of legal regimes that are relevant to migrants' lives and that produce the grey areas in which the liminally legal live. Petchot examines how the liminal legality of Burmese migrant children is produced by tensions between the Thai immigration and education bureaucracies around recognizing the rights of children. De Vlieger demonstrates that even when migrants are recognized formally as migrants by receiving states, ideologies of gender and race and ethnicity create marginal spaces of legality and vulnerability and constrain access to justice. By investigating not only different orders (local, state, international), but also different areas of law (family, health, citizenship) and different regulatory mechanisms (policing, providing health care, registering a birth or marriage) these chapters broaden our understandings of the legal frameworks within which immigration is conceptualized and offer new avenues of theorizing migrant legality. The chapters also show how civil society actors respond to the exclusions associated with liminality. We wonder whether there are also other, less formal ways to respond - a point to which we return below.

The liminal legality experienced by domestic workers in Saudi Arabia and the United Arab Emirates is, according to De Vlieger, a form of quasi-statelessness. Domestic workers' diminished citizenship stems from their lack of access to the public sphere, exacerbated by their dependence on employers, who frequently are the very men about whom they may have a complaint and who may be the ones who would have to represent them in any formal legal proceeding. This situation creates a crippling double bind for women, whose only recourse to formal justice requires representation by the very person about whom they complain. This double bind, De Vlieger argues, is a more extreme version of a diminished citizenship that is common to (a) all women and (b) to a lesser extent, to all citizens (including men), due to the seemingly poor functioning of the legal system, a system in which even the requirements of sharia law are ignored. Men, particularly those who are employers, are nonetheless able to compensate for their diminished citizenship through social capital derived from their ties to others. We wondered, however, whether women are able to develop informal ties and strategies for at least trying to improve their situations. Legal anthropologists who are attentive to gender issues have sometimes documented ways that women are able to work behind the scenes, strategizing even in seemingly stark or impossible conditions (see, for example, Hegel-Cantarella 20II on legal strategies that underlie Egyptian marriage contracts). The circumstances of the domestic workers analyzed by De Vlieger are certainly dire; however, we wondered how these women respond, and whether their responses are ever communicated to other potential migrant domestic workers in their homelands.

\subsection{Migrants' de Facto and Formal Statelessness}

The de facto statelessness discussed by De Vlieger is paralleled by the formal statelessness documented by Petchot. Some migrant children born in Thailand fail to acquire citizenship either there or in their parents' country of origin. This statelessness is brought about by bureaucratic challenges (for example, children's births have to be registered in their parents' country of origin within one month in order for them to receive citizenship) and thus seems to be administratively imposed, rather than treated as a deliberate exclusion. Children's liminal legality in Thailand is exacerbated by different institutional priorities (procontrol or pro-employment) of Thai ministries. Echoing Mora and Handmaker's account of the contradictions between different legal regimes that govern migrants' lives, Petchot details the ways that migrant children fall between legal orders. These children are protected by the Convention of the Rights of the Child, but are vulnerable in that most do not actually receive the education that the Thai state recognizes as their right. The multiple legal orders that produce liminality include illegalities that develop around unauthorised movement. Even the state, through police who accept bribes and through other forms of cor- 
ruption, participates in such illegalities. Petchot's analysis of the registration system to which migrant youth are subject is fascinating; their experiences parallel the bureaucratic maze that USA-born children of Mexican immigrant parents navigate when their parents are deported from the USA to Mexico and the children enter the Mexican school system (Medina 20II). School officials, parents, and youth themselves experience dilemmas about whether or not to register, when to register, what registering means, and what rights and obligations are conferred by registration. Importantly, Petchot discusses a range of statuses that individuals may have, thus helping to overcome the limitations of seeing legality as binary, as either being 'legal' or 'illegal' (Menjivar 2006). This status continuum has also been documented by legal scholars such as Hiroshi Motomura (2006), who points out that in the USA, mere presence confers a form of territorial personhood that merits legal recognition (see also Bosniak 2006). We suspect that, though tragic for migrants themselves, liminality is also productive for employers, markets that thrive on migrant illegalities, and perhaps the state itself, in terms of the potential for social control of various populations. Therefore, in addition to seeing liminality as a form of social exclusion, as a lack or a gap, we suggest also examining what liminality generates or enables, and for whom.

\subsection{The Case of Refugees from El Salvador and the US 'Deferred Action' Programme}

Lastly, we cannot conclude our comment without noting parallels to the case of El Salvador, with which we both are familiar through our own research and advocacy work. Those who left El Salvador during the I980-I992 Salvadoran civil war experienced a form of quasi-statelessness not unlike that documented by these authors. Denied protection, or actively persecuted by Salvadoran authorities, migrants who travelled to the USA experienced social exclusion there as well, through legal processes that represented Salvadoran migrants as 'economic migrants' rather than as 'political refugees' deserving of asylum. Migrants nonetheless participated in social life to some degree in both the USA and El Salvador, obtaining jobs, often in the shadow economy, having families, and sending remittances to relatives in El Salvador. Additionally, migrants launched social movements opposing US military assistance to the Salvadoran government and advocated on behalf of Salvadoran and
Guatemalan asylum seekers (Perla/Coutin 20I0). In the post-war period, even Salvadoran authorities, including the Procuraduría de Derechos Humanos, a human rights office established through the Salvadoran peace accords, joined the effort to secure immigrants' rights to remain in the USA. This informal participation and formal organizing led to legal victories that gave some Salvadoran migrants the ability to become legal permanent residents and eventually US citizens, while others remained temporary or undocumented residents, and thus liminally legal. Thus, the challenges posed by the Thai registration system sound very familiar to us, given our knowledge of the ways that registration for Temporary Protected Status (TPS) has worked in the USA (Mountz/Wright/Miyares/Bailey 2002). Furthermore, we have found that it is not uncommon for one family member to apply for TPS and thus assume a risk of exposure to authorities, leaving other family members undocumented and, in the long run, legally unprotected. Such strategies, though logical in the short run, result in the sort of mixed-status families described in the chapters of this section.

At the time of writing, migrant youth in the USA have been facing a new set of documentary challenges given the Obama administration's new 'Deferred Action' programme, which permits individuals who entered the USA before the age of I6, lived continuously in the USA for at least five years, graduated from a US high school or served in the US military, and have no criminal convictions, to obtain a work permit (Department of Homeland Security 20I20mHh). Though certainly a step forward for migrant youth, it is not yet clear what documentation will be required to demonstrate eligibility, or whether this programme will survive the 2012 presidential elections. Furthermore, the programme grants only employment authorization, not a path to citizenship, and thus constitutes a new form of liminal legality.

\subsection{Concluding Remark}

The cases documented in the chapters in this section, as well as parallel cases we have referenced in our comments, remind us that as more immigrant receiving governments adopt new forms of temporary statuses that 'irregularize' immigrants (Calavita 2005), migrant workers' social rights are simultaneously diminished. Strategies to keep immigrants as guests and temporary workers may appear as solutions that confer migrants the right to work, but at the same time 
encode restrictions on migrants' rights. Projects that advocate for immigrants' welfare can be critical in also pointing to the inequalities and injustices that the legal regimes of receiving governments create. These projects start with recognizing the fundamental hu-

\section{References}

Abrego, Leisy J.; Gonzales, Roberto G., 20Io: "Blocked paths, uncertain futures: The postsecondary education and labor market prospects of undocumented youth", in: Journal of Education for Students Placed at Risk, I5,I: I44-I57.

Bosniak, Linda, 2006: The citizen and the alien: Dilemmas of contemporary membership (Princeton: Princeton University Press).

Bourdieu, Pierre, 2004: "Gender and Symbolic Violence", in: Scheper-Hughes, Nancy; Bourgois, Philippe (Eds.) Violence in War and Peace: An Anthology (Malden, MA: Blackwell): 339-342.

Calavita, Kitty, 2005: Immigrants at the Margins: Law, Race and Exclusion in Southern Europe (Cambridge: Cambridge University Press).

Chavez, Leo, 2008: The Latino threat: Constructing immigrants, citizens, and the nation (Stanford: Stanford University Press).

Cordero-Guzmán, Hector; Martin, Nina; Quiroz-Becerra, Victoria; Theodore, Nik, 2008: "Voting with their Feet: Nonprofit Organizations and Immigrant Mobilization", in: American Behavioral Scientist, 52,4: 598-617.

Coutin, Susan Bibler, 2000: Legalizing Moves: Salvadoran Immigrants' Struggle for U.S. Residency (Ann Arbor, MI: University of Michigan Press).

De Genova, Nicholas P., 2002: "Migrant 'illegality' and deportability in everyday life", in: Annual Review of Anthropology, 3I: 4I9-447.

Department of Homeland Security, 20I2: "Secretary Napolitano Announces Deferred Action Process for Young People Who Are Low Enforcement Priorities", Press Release on I5 June; at: <http://www.dhs.gov/ynews/ releases/20I206I2-napolitano-announces-deferred-actionprocess-for-young-people.shtm> (8 July 20I2).

Ferrell, Jeff, I999: "Cultural Criminology", in: Annual Review of Sociology, 25: 395-418.

Fraser, Nancy, 2007: "Transnationalizing the Public Sphere - On the Legitimacy and Efficacy of Public Opinion in a Post-Westphalian World", in: Theory Culture and Society, 24,4: 7-30.

Hegel-Cantarella, Christine, 20Ir: "Kin-to-be: Betrothal, Legal Documents, and Remaking Relational Obligations man rights of migrants, their rights as workers, and their social rights in the countries in which they reside so as to align national and supranational orders and various state bureaucracies to produce lasting conditions of justice for the immigrants.

in Egypt", in: Law, Culture and the Humanities, 7,3: 377-393.

Hondagneu-Sotelo, Pierrette, 2007: Doméstica: Immigrant Workers Cleaning and Caring in the Shadows of Affluence (Berkeley: University of California Press).

Massey, Douglas S., 2007: Categorically unequal: the American stratification system (New York: Russell Sage Foundation).

Medina, Dulce, 20II: Return Migration: Modes of Incorporation for Mixed Nativity Households in Mexico (M.A. thesis, Arizona State University, School of Social and Family Dynamics).

Menjívar, Cecilia, 2006: "Liminal Legality: Salvadoran and Guatemalan Immigrants' Lives in the United States”, in: American Journal of Sociology, III,4: 999-I037.

Motomura, Hiroshi, 2006: Americans in waiting: The lost story of immigration and citizenship in the United States (New York: Oxford University Press).

Mountz, Alison; Wright, Richard; Miyares, Ines; Bailey, Adrian J., 2002: "Lives in Limbo: Temporary Protected Status and Immigrant Identities", in: Global Networks 2,4: $335-356$.

Nakano-Glenn, Evelyn, 1988: "A Belated Industry Revisited: Domestic Service Among Japanese-American Women”, in: Statham, Anne; Miller, Eleanor M.; Mauksch, Hans O. (Eds.) The Worth of Women's Work: A Qualitative Synthesis (Albany, NY: SUNY Press): 57-75.

Nicholls, Walter J., 20I2: "Voice and Power in the Immigrant Rights Movement: The Case of the Undocumented Student Movement (aka, the DREAMers Movement)", Unpublished (University of Amsterdam, Department of Sociology).

Pantoja, Adrian; Menjívar, Cecilia; Magaña, Lisa, 2008: "The Spring Marchers of 2006: Latinos, Immigration, and Political Mobilization in the 2Ist Century", in: American Behavioral Scientist, 52,4: 499-506.

Perla, Hector; Coutin, Susan Bibler, 20I0: "Legacies and Origins of the U.S.-Central American Sanctuary Movement", in: Refuge, 26,I: 7-19.

Sadiq, Kamal, 2009: Paper Citizens: How Illegal Immigrants Acquire Citizenship in Developing Countries (Oxford: Oxford University Press).

Walters, William, 2002: "Deportation, Expulsion, and the International Police of Aliens", in: Citizenship Studies, 6,3: 265-292.

Open Access. This chapter is distributed under the terms of the Creative Commons Attribution Non-commercial License, which permits any noncommercial use, distribution, and reproduction in any medium, provided the original author(s) and source are credited. 


\section{Part VI Migration Regimes, Gender Norms, and Public Action}

Chapter 19 Gender, Masculinity, and Safety in the Changing Lao-Thai Migration Landscape Roy Huijsmans

Chapter 20 Public Social Science at Work: Contesting Hostility Towards Nicaraguan Migrants in Costa Rica

Carlos Sandoval-García 


\title{
19 Gender, Masculinity, and Safety in the Changing Lao-Thai Migration Landscape
}

\author{
Roy Huijsmans ${ }^{1}$
}

\begin{abstract}
Recent policy debates on migration in the Greater Mekong Subregion have put increasing emphasis on migrant safety, which has taken the form of opening legal channels of migration. Whereas the discourse on migrant safety revolves around gendered emphases in vulnerability, foregrounding female migrants' vulnerability and muting male migrants' vulnerability, policy interventions to make migration safer are too often framed as gender-neutral. In this chapter I focus on Lao employment agencies as a key technique in the management of LaoThai cross-border migration. I argue that employment agencies are embedded in a masculine policy landscape and I contest them as gender-neutral techniques by demonstrating how these agencies and the policy architecture in which they are situated produce significant degrees of male privilege when it comes to accessing supposedly safe forms of migration. Yet male privilege is limited, as migrating through these supposedly safe channels of migration may in fact increase male migrants' vulnerability. However, I argue that young men's motivations for migrating through these expensive legal channels can only in part be understood by looking at their material effects on migrant vulnerability. Instead, this practice should rather be interpreted as a modern version of the cultural style of hegemonic masculinity through which young men deal with protection from danger in the risky exercise of migration.
\end{abstract}

Keywords: Gender, Lao PDR, masculinities, migration, policy, Thailand.

\subsection{Introduction}

Recent policy debates on migration have put increasing emphasis on improving migrant safety. This is driven by strongly gendered constructions of migrant vulnerability in which female migrants' vulnerability is emphasized and often essentialized and male migrants' vulnerability is silenced or ignored. Concerns about a pattern of so-called feminization of migration (e.g. Gaetano/Yeoh 20I0) have further contributed to a lack of attention to male migrants' vulnerability, despite the fact that men still constitute a large share of the migrant population-including in the Greater Mekong Subregion (GMS).

The GMS is frequently highlighted in relation to concerns about migrant vulnerability. This is most evident in the portrayal of the GMS as a trafficking

1 Roy Huijsmans is Lecturer in Children and Youth Studies at the International Institute of Social Studies (ISS) in the Hague, the Netherlands. hotspot (UN-ESCAP 2000; ILO 2003b: 29; David/ Gallagher/Holmes/Moskowitz 20II: I). Human trafficking is one of the most dramatic representations of migrant vulnerability and the explicit emphasis on 'women and children' ${ }^{2}$ highlights how constructs of migrant vulnerability are strongly gendered and generational. Recent attempts to broaden anti-trafficking legislation and interventions, in order to make them inclusive of (adult) male victims (e.g. ILO 2008: 6-7; David/Gallagher/Holmes/Moskowitz 20II: II; UNIAP n.d.), have, so far, done little to alter such dominant constructs of migrant vulnerability.

Sparse attention to male migrant vulnerability in the context of both anti-trafficking and migration policy is substantially due, I will argue, to the social con-

2 This is evident from the Protocol to Prevent, Suppress and Punish Trafficking in Persons, Especially Women and Children, of the United Nations Convention against Transnational Organized Crime (2000), also commonly known as the 'Palermo Convention'. 
struction of masculinity. Hegemonic notions of masculinity construct hardships experienced by male migrants as something to overcome and conducive to the formation of masculinity as conceived in the hegemonic notion. This disassociates the vulnerability of male migrants from questions about the social production of male vulnerability and, specifically, the role of seemingly gender-neutral 'safe migration' policy frameworks in producing degrees of male vulnerability.

Policy efforts to address migrant vulnerability have over recent years undergone a gradual shift. The initial exclusive focus on the (potential) migrants deemed most vulnerable (young girls), through the human trafficking discourse, is now increasingly combined with broader efforts to make migration 'safer' (ILO 2003a; Dottridge 2006: II). In this chapter I concentrate on a key policy area that is presented as making migration safer. This concerns the "improving, enlarging and creating [of] additional legal labour migration channels that may substitute for the trafficking of children and women into exploitative situations" (ILO 2003a: 2).

In this chapter I unravel the apparent gender neutrality in the architecture of the legal channels of migration. In addition, I shed light on the practice dimension of migration policies presented as improving migrant safety, by analysing how such policies play out in particular, often deeply gendered, migrant landscapes. These two lines of analysis illuminate the male privilege embedded in policy approaches to safe migration. Yet the analysis also shows male privilege to be limited, as men's privilege in accessing supposedly safe channels of migration in fact increases rather than decreases the condition of migrant vulnerability. Lastly, by highlighting a number of 'mistranslations' of policy in local contexts I stress the importance of ethnography in policy-related research. This shows that policy as manifesting in local contexts is never static, given, or uniform, but always and necessarily in the making, negotiated, and plural.

In making this case I will focus on Lao-Thai migration in the middle Mekong Valley and on the role of 'employment agencies' specifically. ${ }^{3}$ In global policy discourses on the creation of legal channels of migration, employment agencies play a key role (Rudnyckyj 2004; Martin 2005; World Bank 2006; Chantavanich 2008; Pijpers 20IO; Xiang 20I2). These agencies are

3 In this chapter the term "employment agencies" is used. These agencies are also referred to as "human resources companies" (Rudnyckyj 2004) or "employment services agencies" (Martin 2005). envisioned as actors who help to improve migrant safety in various ways, including equipping migrants with a documented status, transparent recruitment practices, providing pre-migration training sessions for migrants, establishing contractual arrangements between employers and migrant workers in accordance with relevant laws, and protecting migrant workers from exploitation by ensuring that contractual arrangements are respected (e.g. Ministry of Labour and Social Welfare, Lao PDR 2002a).

Lao employment agencies are relatively new actors in the emerging Lao migration regime, hence the empirical prevalence of migration through employment agencies remains low. Yet a focus on this particular intervention is justified by the important role attributed to such agencies globally and within the Lao People's Democratic Republic (Lao PDR). In addition, the Lao-Thai case fits the purpose of this chapter since it constitutes a case in which concerns about migrant safety are highly gendered, yet responded to in seemingly gender-neutral terms. Moreover, a focus on Lao PDR contributes to filling important knowledge gaps on migration research in the GMS, which has so far paid little attention to Lao migration. The few studies doing so typically focus on Lao migrants at their destination in Thailand without linking this to research at their sites of origin.

The chapter is organized as follows. The next section briefly explains the methodology and data sources before moving on to a discussion of the emerging body of work on masculinities and migration and its relevance for the Lao case discussed here. This is followed by a multi-scalar analysis of the introduction of Lao employment agencies as situated in the emerging Lao migration regime. Having mapped the discursive and politico-economic architecture of the Lao migration regimes, the final sections of the chapter unravel the gendered working of employment agencies. This is done by focusing on the gendered construction of categories of migrants and legitimate migrant work, complemented with analyses of the lived experience of migrating through employment agencies.

\subsection{Methodology and Data}

The empirical material presented in this chapter stems from two sources. First, material collected for an overview report sponsored by the International Labour Organisation (ILO), using semi-structured interviews predominantly (Huijsmans/Phouxay 2008). Second, 
data obtained through a long-term ethnographic research project focusing on young migrants from one predominantly ethnic Lao village in lowland Lao PDR (Huijsmans 20IO).

The ILO report forms a component in a regional ILO-sponsored study on recruitment practices finalized in 2008. ${ }^{4}$ Together with a UNIFEM report (Phetsiriseng 2007), this is the only study to date that empirically addresses the phenomenon of migration through Lao employment agencies. The ILO report suffers, however, from important methodological limitations (outlined in Huijsmans/Phouxay 2008: I920). First, due to the timing of the study the sample consisted of early returnees only and does not include any migrants who have completed their two-year contract. Second, the study was conducted in a short period of time, which did not allow building up any form of rapport with the respondents or any followup research. The latter is particularly pressing since cross-border migration into Thailand remains a highly sensitive topic in Lao PDR (see for example Thammavongsa 2006; Pongkhao 2007). The shortcomings of the ILO report are to some extent offset by incorporating material obtained through a long-term ethnographic research project. In that study I succeeded in building a sufficient level of rapport with respondents and conducted multiple interviews between 2007 and 2009 with a purposefully selected set of respondents. Among the respondents were five migrants (four men, one woman) who had migrated through a Lao employment agency. These five were part of the seven total villagers (five men, two women) who had left Baan Naam in the course of 2006 on a two-year contract to Thailand through a Lao employment agency (all through the same agency) and returned in 2008. The men all migrated to an oil palm plantation in southern Thailand (Krabi province) together with thirty-four other male Lao migrant workers. The two women migrated through the same employment agency but were sent to different locations. One was sent to the north-eastern Thai town of Khon Kaen to work in a factory producing fishnets, and the other to central Thailand to work in a pineapple-canning factory. When in Thailand, one of the female migrants and two of the male migrants were interviewed by telephone. This was supplemented with face-to-face in-

4 The Cambodian, Lao, and Thai country reports are synthesized in Chantavanich (2008).

5 Baan Naam is a pseudonym for the research village. Names of respondents presented in this chapter are pseudonyms too. terviews with all but one of the seven migrants upon their return to Baan Naam, and with material obtained from their families.

\subsection{Masculinities and Migration}

For decades, feminist critique of migration theories has expressed concerns about the bias towards the male experience due to the hegemonic construct of 'the migrant' as a male adult breadwinner, which has overgeneralized the experience of women, along with children (Huijsmans 20IIa), as dependants and obliterated the reality of them as agents in migration (Chant I992; Momsen I999; Jolly/Reeves 2005; Donato/Gabaccia/Holdaway/Manalansan IV/Pessar 2006). However, the implicit treatment of "the man" as "the universal, normative subject" (Louie 2002: 5, in: Ford /Lyons 20I2: I) means that in relation to research on men in migration one can also speak of gender blindness since this amounts to a problematic focus "on men as non-gendered humans" (Hibbins/ Pease 2009: 5).

The notion of masculinity is used to gender men. The term refers to "the discourses and [material] practices which indicate that someone is a man, a member of the category of men" (Collinson/Hearn I994: 6). Masculinity, in this sense, is a social construct, which is necessarily plural, hence 'masculinities', as it differs across and within time and space. In addition, masculinities are relational constructs that can only exist in relation to something else like femininity or certain other notions of masculinity (Connell 2005).

Work on masculinities in the context of migration has redressed the gender-blindness that has long characterized the study of men in migration (e.g. Jónsson 2008; Datta/McIlwaine/Herbert/Evans/May/Wills 2009; Donaldson/Hibbins/Howson /Pease 2009; Hoang/Yeoh 20II; Kitiarsa 20I2; McKay/LuceroPrisno III 20I2; Thai 20I2). This body of work has focused mostly on men as migrants (but note: Hoang/ Yeoh 20II), unravelling the interplay between the impact of "global systems of production on the working lives of men" and "the impact of cultural flows on the construction of what it means to be 'a man'" (Ford/ Lyons 20I2: I2). This has yielded research on a wide range of issues including sexual intimacy and migrant men's subjectivity as transnational actors (Kitiarsa 20I2), migrant men's enactment of diverse and conflicting masculinities embedded in the socially constructed spaces comprising the migratory journey (McKay/Lucero-Prisno III 20I2; Thai 20I2), and the 
negotiation and reconstruction of male identities through migration (Datta/Mcllwaine/Herbert/Evans/ May/Wills 2009; Donaldson/Howson 2009: 210).

Work on masculinities and migration has, so far, mostly concentrated on adult men in migration. Relatively little attention has been paid to generational dimensions of masculinities (an important exception includes Jónsson 2008) despite the obvious point that what it means to be a man, as well as becoming a man, is to a great extent shaped by relations of age, whilst migration is also shaped by generational relations (e.g. Haseen/Punpuing 20IO). It is for this reason that I focus in this chapter on a particular generational grouping of men: young unmarried men.

Furthermore, there remains much scope to inform work on masculinities in the context of migration by a gender analysis of policy. Feminist scholars have long pointed out that 'policy' is far from a neutral, genderless activity, and that policymakers, who are often men, are seldom 'neutral' men (Hearn 20II: 159). This would suggest that migration policy is likely to produce a degree of male privilege. At the same time, male privilege in the architecture of migration policy and in the practice of policy does not mean that men are less vulnerable whilst in migration. For example, Donaldson and Howson (2009: 210) have pointed out that whilst it is "usually men who gain more than women from migration", at the same time "it is also men who are more likely to need welfare support, and...who are exposed to greater intolerance, violence and discrimination, in the host country". Even so, hegemonic notions of masculinity frequently leave less space to men than to women in terms of acknowledging vulnerability.

\subsection{Gendered Continuity and Change in the Migration Landscape}

In the years prior to I975 people did not travel a lot like today. People would only occasionally go beyond their village. For example, when I was pen sao (a maturing girl) I never went to Baan Fangthai as young girls do today. However, some other villagers would go to Baan Fangthai in those days (Interview with Mrs Mae Laddavanh in 2008. She was in her forties at the time of interview). ${ }^{6}$

Baan Fangthai, Baan Naam's neighbouring village on the Thai side of the Mekong River, is for many villagers of Baan Naam the gateway to migration further into Thailand. The phrase 'going there' (pai phoun) complemented with a nod towards the Mekong River (and all that lies beyond) was indeed commonly used as a cryptic shorthand for cross-border migration. The above interview excerpt is thus not limited to everyday forms of cross-border mobility, but includes larger migration projects.

Mae Laddavanh makes the striking point that the gendered face of mobility and migration in the middle Mekong valley has transformed dramatically over the past decades. In $\mathrm{Tai}^{7}$ Theravada Buddhist societies mobility has long been part of important rites of passage for young men and contemporary labour migration can thus be seen as a historical continuity in the cultural production of hegemonic masculinity. However, the over-representation of young women in contemporary labour migration in both Thailand and Lao PDR (Mills 1999; MoLSW/Committee for Planning and Cooperation National Statistical Center/ILOIPEC/TICW 2003) presents a sharp break with the very limited mobility experienced by young unmarried women only a generation ago, as commented upon by Mae Laddavanh above.

Kirsch (1985) analyses the masculine and feminine scripts underpinning the gender differences in mobility that were long observable among young people in Tai societies. For young men the practice of pai thiaw (literally: to go around) constituted an "opportunity to wander around, to test themselves in new locales and different styles of life" (Kirsch 1985: 313). Mobility in the past, like labour migration today, was not riskfree and young men were not oblivious to those risks. Fordham (1998: 107) observes in this respect that risktaking behaviour constitutes a key element of hegemonic masculinity in Tai Theravada Buddhist societies because "a man's ability to pull off these sometimes highly dangerous acts [referring to drink-driving,

6 Baan Fangthai is the (pseudonymous) name of the village across the river from Baan Naam on the Thai side of the border and a popular destination for contemporary cross-border wage labour and point of departure for migration further into Thailand by Baan Naam villagers.

7 The term 'Tai' (also 'Tai-Kadai') refers here to the one of the five indigenous South-East Asian language groups. The Tai language group is scattered across South-East Asia (including southern China) and includes 'the national language of Thailand and Laos, as well as the tongues spoken by some upland groups found in those countries' (Ricklefs/Lockhart/Lau/Reyes/AungThwin 20IO: 2). According to the 2009 Lao National Human Development Report, $64.9 \%$ of the total population of Lao PDR belongs to the Tai language group (Souksavath/Acharya 2009: 42). This numerical majority is also the politically and socioculturally dominant group. 
speeding, unsafe sex, etc.] is concrete evidence of his merit, his prowess, and his control over his body and the immediate environment".

The actual experience of vulnerability, understood as the failure to overcome the hardships of migration, greatly undermines one's credibility as a man according to such a hegemonic masculine script (Fordham I998: I06). Furthermore, the emphasis on female vulnerability and the muting of male vulnerability in migration can be understood as an important act of cultural production which serves to maintain gender boundaries in times in which male monopoly over migration as a source of prestige is greatly undermined by the rapid feminization of migration (Mills 1995: 258).

Hegemonic femininity is constructed in terms of motherhood and nurturing, and this has long contributed to limiting women's social and spatial mobility in Tai societies (Keyes 1984; Keyes I986). In the current era of widespread involvement of young women in labour migration the construct of 'dutiful daughter' constitutes a cultural continuity, legitimizing young women's dramatically expanded spatial mobility. Still, young women's involvement in labour migration is met with much greater concern than that of men due to the highly gendered ways in which sexuality is constructed. As Mills (1995: 258) argues: "parents worry about the physical safety of absent sons and daughters alike but usually only daughters are considered at risk of inappropriate sexual activity".

\subsection{The Emergence of a Lao Migration Regime}

In the decades following the establishment of the communist Lao PDR in 1975, migration by Lao nationals to capitalist Thailand was a highly sensitive subject. Official Lao responses boiled down to either ignoring the evidence of irregular Lao migrants working in Thailand, or of condemning it as unpatriotic behaviour concerning only a few isolated individuals. In the r 990 s this position became increasingly untenable mainly because Thai authorities started conducting rounds of registration of unregistered migrant workers on Thai soil (Muntarbhorn 2005: 5). In addition, Lao PDR's entry to the Association of Southeast Asian Nations (ASEAN) in 1997, part and parcel of the Lao state's reorientation towards a politics of regional integration and market economic principles, paved the way for Lao involvement in bilateral and multilateral responses to cross-border migration in the GMS.

The Bangkok Declaration on Irregular Migration of April 1999 forms an important starting point for analysing the emergence of a Lao migration regime. ${ }^{8}$ The Declaration acknowledged cross-border migration as a here-to-stay reality presenting challenges but also opportunities, and requiring "orderly management" based on "concerted efforts of countries concerned, whether bilaterally, regionally or otherwise". The subsequent 2002 Memorandum of Understanding $(\mathrm{MoU})$ on Employment Cooperation between the Royal Thai Government and the Government of Lao PDR can be seen as an expression of the Bangkok Declaration. ${ }^{10}$

In this $\mathrm{MoU}$ the two states agreed upon taking action to realize the following:

I.I Appropriate procedures in employment [of migrant labour]

I.2 Effective deportation and return of migrant workers who have completed the duration of their work permit

I.3 Appropriate labour protection

I.4 Prevention and intervention in illegal border crossing, illegal employment services and illegal employment of migrant workers

(Article I of MoU on Employment Cooperation; in: Muntarbhorn 2005: 6I).

These four key objectives of the MoU illustrate the double-edged sword of the new Lao-Thai approach to migration management and the contradictions between discourses and conditions of 'safety' and 'vulnerability'. The creation of legal channels of migration is legitimized in the name of making migration safer through 'appropriate procedures' and reducing migrant vulnerability through 'appropriate labour protection'. Intertwined with the discursive coupling of the creation of legal channels of migration to migrant safety, point I.4 foreshadows increased efforts to crack down on all forms of migration taking place outside these supposedly safe channels of migration. Given that the majority of Lao migrants migrate in an undocumented manner, and will no doubt continue

8 This Declaration was signed by representatives of the Lao state alongside representatives of twenty-eight other Asia-Pacific countries.

9 With reference to Preamble note (I), (2), and (5), and Declaration note (2) of the Bangkok Declaration on Irregular Migration.

10 Followed in 2005 by an MoU on combating human trafficking. 
doing so in the near future, the condition of migrant vulnerability actually increases for undocumented migrants, thus making migration more unsafe for the majority of Lao cross-border migrants despite discourses of migrant safety.

The problematic interplay between different categories of migration with regard to migrant safety has been commented upon in the Lao and Thai context. From a Thai perspective, Muntarbhorn (2005: iv-v) has argued that Thai migration policies have certainly become more liberal, yet this "more open door policy" is subject to various conditions, most importantly the need "on the part of migrant workers to use open rather than clandestine channels to enter Thailand". Similarly, from a Lao perspective, scholars (e.g. Huijsmans 20Irb; Molland 20I2) have also emphasized that policies addressing irregular migration (especially antitrafficking initiatives) need to be analysed in relation to policies concerning the regularization of migration. It is the interplay between policies addressing seemingly different categories of migration, which are set apart by their opposing relation to constructs of migrant safety, that constitutes the essence of the governmentality, the methods of governance, of Lao-Thai migration.

The establishment of employment agencies constitutes a principal way in which legal channels of migration are expanded. Following Xiang's (2OI2: 5I) work on China, the Lao state too "relies on agents to turn flesh and blood migrants into 'paper migrants', to transform unpredictable individual mobility into legible, aggregate flows, and to hold agents as scapegoats if needed". Lao employment agencies can thus be understood as technologies in the governmentality of Lao-Thai migration. In the Lao context, this notion of governmentality does not take the form of the meticulously orchestrated disciplining in the form of the compulsory pre-departure training as described by Rudnyckyj (2004) in the Indonesian context. ${ }^{11}$ Rather, referring to Lao employment agencies as technologies of governmentality highlights the key role

11 In fact, interviews with representatives from Lao employment agencies conducted in 2007 revealed that in the Lao context such pre-departure training typically lasted two to three hours only and was little more than briefing sessions, often organized at provincial level and conducted by local officials of the Ministry of Labour and Social Welfare. Furthermore, of twenty early returnees interviewed in 2007 who had migrated through Lao employment agencies to Thailand, eight had not received any such pre-departure training/briefing at all (Huijsmans/Phouxay 2008). played by these agencies in the newly emerging Lao migration regime which is making Lao migration into Thailand legible, profitable, and manageable, whilst discursively framing such agencies as a promotion of migrant safety. In addition, the notion of governmentality also highlights the transnational nature of the conduct of conduct in migration management. This allows the analysis of Lao employment agencies to be connected to shifts in transnational migration discourses.

\subsection{Employment Agencies and the Changing Political Economy of Migration}

The creation of legal channels for migration is not something new (Martin 2005), and originally emerged at a time when migration was firmly associated with the construct of the male migrant as the breadwinner. At present, the opening up of legal channels of migration is growing rapidly as a form of migration management. However, unlike when this approach to migration management was first promoted in Western Europe in the years after the Second World War, it is now implemented in a context in which social rights of migrants are being undermined by market forces, and is situated in a migrant landscape that is increasingly recognized as feminizing. ${ }^{12}$ Moreover, in the present-day promotion of the opening up of legal channels of migration, an increasingly important role is attributed to the private sector in recruiting and dispatching migrant labour (for examples in East and South-East Asia see: Rudnyckyj 2004; Anh 2007; Xiang 20I2). This current trend contrasts with earlier approaches in the I950s and I960s in Europe and North America and until several decades later in various socialist states, where it was the state that, on the basis of bilateral agreements, played an active role in dispatching migrant workers (Martin 2005).

This historical shift in the political economy of recruitment of migrants, away from the state and towards the market, can be seen from changes in ILO conventions (Peck/Theodore/Ward 2005: 6). ILO Convention 97 on Migration for Employment (I949)

12 Feminization of migration refers here not only to the growing prevalence of women as migrants, but also to the reduction in, and partiality of forms of, social protection available to female migrants especially compared with what was prevalent under the 'male-breadwinner' model of migration. 
is primarily state-centred and mentions migration through other than "government-sponsored arrangements" only in its annexes. Moreover, it states in Article 2 that:

Each Member for which this Convention is in force undertakes to maintain, or satisfy itself that there is maintained, an adequate and free service to assist migrants for employment, and in particular to provide them with accurate information (emphasis added I949: Article 2).

This Article reflects the ILO's concern, at the time, with for-profit employment agencies which it sought to regulate, if not abolish. With Convention I8I on Private Employment Agencies (I997), the ILO definitely departed from this earlier concern and paved the way for private sector involvement in matching demand and supply in transnational labour markets. This approach has received broad support from influential global players such as the World Bank (e.g. World Bank 2006).

The governments of Lao PDR and Thailand have not ratified any of the ILO conventions mentioned above, yet employment agencies are firmly situated in the newly emerging Lao migration regime. The MoU on Employment Cooperation assigns an important role to "competent authorities" in the management of migration. Later policy documents reveal these "competent authorities" as migration employment agencies. $^{13}$

\subsection{Uncovering Gender in Migration through Lao Employment Agencies}

In the Lao context, it was only in late 2005 that the first batch of Lao migrants was sent to Thailand through employment agencies (Vientiane Times 2005). ${ }^{14}$ Following an initial trial with 30-50 workers, sent out on a one-year contract, subsequent migrant workers were sent out on two-year contracts by a total of nine different employment agencies, including three state-run agencies (Huijsmans/Phouxay 2008). These employment agencies are situated in a highly

13 Note particularly Prime Minister Decree 68/2002 (2002) and Directive of the Minister of Labour and Social Welfare 24I7/MoLSW (2002a).

14 Note however that Phetsiriseng (2007: 43) observes that the State Employment Enterprise has existed since 1995 in Lao PDR, and has over the years recruited a few Lao workers for international migrant work. bureaucratic and gendered regulatory landscape involving two different ministries in both Lao PDR and Thailand, as well as the Lao embassy in Bangkok (for a detailed analysis see: Phetsiriseng 2007; Huijsmans/ Phouxay 2008).

This highly complex structure partly explains why Lao employment agencies lagged considerably behind in meeting the Thai demand for Lao labour. By August 2007 the total request for Lao migrant workers had accumulated to 59,700 while Lao employment agencies had only been able to respond with a total of 6,546 workers (Pongkhao 2007). ${ }^{15}$ Next to the delay caused by the bureaucratic architecture of the recruitment process, the mismatch between Thai demand and Lao supply of formal migrant labour is also caused by the relative expense of this form of migration. Migrants are typically confronted with recruitment fees of I5,000-20,000 Thai Baht (US\$484-645) (Phetsiriseng 2007; Huijsmans/Phouxay 2008: 36). ${ }^{16}$ Paying large sums of money in order to get access to particular forms of employment is fairly common in Lao PDR. ${ }^{17}$ Still, most Lao migrants are unable to meet such expenses prior to migration and these costs are typically deducted from the subsequent migrant's wage. Hence, most migrants find themselves in a situation of debt-bondage since their contracts do not allow them to change employers once in Thailand, yet make them, or their households in Lao PDR, principally responsible for recovering the expenses, as discussed below.

Recruitment practices differ between agencies and include advertising of migrant work over the radio and in printed media, and recruitment through formal channels of command. The latter was the dominant mode of recruitment in Baan Naam, taking the following shape: first, the village head would travel to the district centre to be briefed about migration

15 It should be emphasized that the number of migrants migrating through employment agencies is only a fraction of those thought to have migrated through undocumented channels. The large gap between demand and supply was also caused by the fact that Lao employment agencies were prohibited from sending Lao migrants abroad between January and August 2007 as the Lao state was looking into a range of problems with this form of migration (Huijsmans /Phouxay 2008: 30).

16 This is considerably more expensive than migration through irregular channels (Huijsmans /Phouxay 2008).

17 For example, in 2012 young urban Lao would reportedly pay sums of 20 million Lao Kip (US\$2,500) for a job in the booming Vientiane banking sector with a starting salary of about I.5 million Lao Kip (less than US\$200) per month. 
through employment agencies. He, in turn, would announce a 'call for migrant workers' over the village speaker system and invite interested villagers to attend a meeting in the village temple where he would elaborate on further details. After the meeting interested villagers would register with the village head for a particular form of migrant work in Thailand and pay an initial fee to start processing the required documents (e.g. passport). The village head would report these details at the district centre and documents would then be processed. Once passports were ready, the prospective migrants would be invited to the employment agency in Vientiane for a briefing and to sign the contract that tied them to a Thai employer.

Migration policy in practice provides fertile ground for 'mistranslation' of policy. Due to this grapevine structure of communication many Lao migrants enter migration through employment agencies with vague or plainly wrong information, which seriously undermines the migrant safety these channels of migration are meant to contribute to. In addition, by bringing recruitment into the formal domain it becomes associated with masculine institutions. This shift in the field of recruitment affects, even at village level, potential migrants in a gendered fashion. The five young migrants interviewed all claimed it was they who took the initiative for migration through an employment agency. Yet only the four young men attended the meetings at the village temple in person. Nalintone, the only female migrant interviewed, did not attend these meetings in person. In her case one of her parents attended the concerned meetings. This no doubt explains why Nalintone was most articulate about the lack of information she had received prior to migration. For this reason she described migration through Lao employment agencies as 'pai dao' (go guessingly).

\subsubsection{Gender and the Construction of Legitimate Migrant Labour}

Whereas in the recent past cross-border migration into Thailand was framed by the Lao state as undermining national development, the Prime Minister's Decree No. 68/2002 (2002) reframes it as a positive contribution to national development. It does so by emphasizing its potential for "upgrad[ing] the skills of Lao citizens" in terms of "knowledge" and "technicalprofessional" skills (ibid.: Article I). Policy note $30 \mathrm{II}$ of the Minister of Labour and Social Welfare of the Lao PDR (2007) adds a further range of migration bonuses, including its supposedly poverty-reducing im- pact and a reduction of national unemployment; and through the skill-upgrading envisioned taking place through migration the returnees are considered more capable of participating in Lao national development. This justification of the Lao state's new position on the issue of cross-border movement into Thailand is underpinned by a discourse of development as modernization (Vijayan 2002). Vijayan argues, on the basis of the Indian case, that this development discourse constitutes a "silent privileging of the masculine" (Vijayan 2002: 34).

This gendered justification of the state's promotion of cross-border labour migration maps onto a gender-segregated migrant labour market, gender differences in the valuing of forms of work, and notable gender differences in the experience of being young. This becomes evident from the list composed by the Lao state that employment agencies need to abide by. It is at this level that the construction of legitimate cross-border migration and migrants to Thailand starts translating into highly gendered realities. First, potential migrants need to meet a series of minimum requirements. This includes minimum age requirements (I8 years), completion of at least primary education, good health, and good citizenship (Ministry of Labour and Social Welfare 2002a: Article 3). Seemingly gender-neutral, these requirements play out in a gendered social reality and, thereby, come to reinforce gender inequalities.

With regard to the education requirement, for 2004-2005 a 44.2 per cent national primary school completion rate was reported. The main variation within this national average is by province (correlating with ethnicity). However, for virtually all provinces the average number of years of schooling differs between men and women, with the male population, on average, having spent more years in education than their female counterparts (Souksavath/Acharya 2009: 227). These gender differences in educational requirements were also observed in the migrant population surveyed by the 2003 Labour Migration Survey. Although on average the migrant population was found to be educated to a slightly higher level than the total population, the share of female migrants who had not completed primary education was, at I2.5 per cent, a fraction higher than the corresponding share (9 per cent) among the male migrants (ILO 2007: 24).

The minimum age requirement also plays out in a gendered manner. As observed above, several studies (e.g. MoLSW/Committee for Planning and Cooperation National Statistical Center ILO-IPEC/TICW 2003; Huijsmans 20IO) have shown that in the Lao 
context, migration is shaped by the combined working of gender and generation. At the aggregate level Lao migration data show some gender disparity, yet this disparity becomes far more pronounced if a generational dimension is added. The 2003 Labour Migration Survey data illustrate this point most clearly (MoLSW/ Committee for Planning and Cooperation National Statistical Center/ILO-IPEC/TICW 2003). Based on a survey using statistically representative methods employed in three Lao provinces, and covering 5,966 households, a total outmigration rate of 6.9 per cent was found, with the vast majority of observations (over 80 per cent) concerning cross-border migration to Thailand. The total cross-border migrant population breaks down as 4I per cent male migrants and 59 per cent female migrants. However, gendered patterns are far more pronounced if we concentrate on migrants below I8 years of age, comprising 2I.5 per cent of the total migrant population. ${ }^{18}$ This sub-sample is disproportionally female (over 70 per cent), reflecting the fact that 25.4 per cent of all female crossborder migrants were younger than I8 years of age, whereas this figure is only 15.6 per cent for all male cross-border migrants.

The discussion above illustrates that seemingly gender-neutral requirements such as minimum age and minimum educational requirements operate in gendered terrains and thereby come to reinforce gender inequalities, as potential male migrants are, on average, more likely to meet these requirements than potential female migrants. In addition to the gendered working of requirements imposed at the level of the individual, gender can also be observed in relation to the categories of migrant work prohibited from recruitment. In a Ministerial Regulation (Labour and Social Welfare) issued in December 2002 by the Lao PDR (2002b), three categories of work were prohibited from recruitment. These were:

1. plain jobs that do not require the assistance of mechanical machines in the workplace, do not develop skill levels, and do not provide technical knowledge (e.g. cleaning, sweeping, portering, digging canals/fishponds);

18 This concerns cross-border migration predominantly (over 80 per cent), and mostly older children. Note further that the migration survey does not explain whether the age concerned was the first age of migration or the current age of migration. Neither is the study clear about the precise definition of migration that was employed (e.g. in terms of duration).
2. jobs that are contradictory to customs and traditions, culture, or law (e.g. prostitution, pimp, spy, terrorist, drug dealer, selling sexual equipment, nude shows);

3. jobs that are dangerous to the health and life of the workers (e.g. exposure to chemicals, radiation, explosive substances, open-sea fishing in small boats, catching wild animals such as tigers, lions, or crocodiles).

(Adapted from Phetsiriseng 2007: 56-57.)

We limit ourselves here to the first category of 'plain jobs' and focus on domestic work in particular. ${ }^{19}$

Due to its largely undocumented nature, the magnitude and sectoral distribution of Lao migrant work in Thailand is only known by approximation. Yet Thai data on the application for work permits by eligible Lao migrant workers following the Thai 2004 round of registration is instructive here, despite its limitations (Table I9.I).

Table 19.1: Work permits issued to Lao workers already in Thailand by mid-December 2004 (following the 2004 round of registration), by sector. Source: Adapted from World Bank (2006: 56).

\begin{tabular}{|l|c|c|}
\hline Type of work & $\begin{array}{c}\text { Number of } \\
\text { Permits Issued }\end{array}$ & Per cent \\
\hline On fishing boats & 2,634 & 2.7 \\
\hline Fish processing & 1,013 & 1.0 \\
\hline Agriculture & 16,795 & 16.9 \\
\hline Construction & 8,442 & 8.5 \\
\hline Domestic service & 31,449 & 31.7 \\
\hline Other & 39,019 & 39.3 \\
\hline Total & 99,352 & 100 \\
\hline
\end{tabular}

Table I9.I shows that domestic work is by far the single largest occupation of Lao migrant workers in Thailand. Since Lao migrant domestics are predominantly female (see e.g. Muttarak 2004; Phetsiriseng 2007: 78), the gendered impact of omitting 'plain work' from recruitment is significant, and far more pronounced than the exclusion of, for example, jobs in the 'dangerous to health' category such as open-sea fishing, which will affect Lao men primarily but in much smaller numbers.

19 However, a similar argument could be made for migrant sex work, which is also done mostly by women and excluded from these supposedly safe channels of migration. 
Constructing domestic work, cleaning work, etc., as 'plain work' that does not contribute to the development of any skills makes it incompatible with the highly gendered legitimization of cross-border migrant work mentioned above: skills upgrading of the Lao workforce with the ultimate goal of realizing an implicitly masculine project of development as modernization. This framing of domestic work indeed misrecognizes the very real skills this work requires at a professional and interpersonal level. Moreover, the absence of women's domestic and cleaning work from legitimate migrant labour can also be explained by efforts to preserve the dominant feminine value of 'mother-nurturer', which underpins the official discourse on women's role in Lao national development as wives, mothers, and preservers of traditional culture (e.g. Sangsomboun 2008). ${ }^{20}$ Acknowledging the reality of the earnings from Lao women's migrant domestic work sustaining numerous livelihoods and thus being an important foundation of Lao national development would require a profound reworking of this dominant feminine ideal. Lastly, omitting Lao women's domestic work from legitimate forms of migrant work also needs to be appreciated against a lingering sense of inferiority on the part of the Lao in Lao-Thai relations (Ngaosyvathn /Ngaosyvathn I994; Theeravit/Semyaem 2002; Pholsena/Banomyong 2006: 60-6I). Lao women cleaning the houses of Thai nationals can be viewed as the very articulation of a masculine sense of Lao inferiority which the Lao state seeks to overcome, and this sheds yet another light on the exclusion of domestic work from legitimate migrant work.

20 At the first Women's Congress of the Members of the Women's Association Central Committee of Lao PDR in 1984 the motto of "three goods and two duties" was coined. The three goods include being a good citizen, a good mother, and a good wife, and the two duties include a duty of national defence (socialist construction) and women's emancipation (Ngaosyvathn 1995: I05-I07; Ireson-Doolittle/Moreno-Black 2004: 27). Such mottos have never been applied to men, who were simply seen as already 'good' and 'dutiful' (Ngaosyvathn I995: 107). With the socialist rhetoric quickly fading and a widespread return to 'traditional' Lao values, being a 'good citizen' is in relation to Lao women increasingly translated into preserving ethnic Lao traditional culture such as wearing traditional dress, traditional hairstyles, etc.

\subsubsection{Gender and Generation in Entering Migration through Employment Agencies}

In a similar way to the limitations imposed on potential migrants and migrant work, the high costs attached to migration through employment agencies do not play out in a socially undifferentiated manner. Most importantly, Baan Naam data illustrate that this ensures that only those from relatively better-off families would even consider becoming involved in this form of migration (Huijsmans 20I0: I78). Next, it also ensures that only one household member at a time can become involved in this form of migration. ${ }^{21}$ In the demographic context of fairly large household sizes, it is then of interest to observe how entry into employment agencies is shaped by relations of gender and generation.

Among the seven migrants from Baan Naam who had gone through an employment agency to Thailand all but one migrant were 'dependants' at the time of migration in the sense that they had not yet established their own households. This means that despite the fact that these young migrants claimed it was they who initiated the decision to migrate, such claims should not be read as the unconstrained exercising of young people's agency. Importantly, as dependants, these sons and daughters lack the collateral to sign up for migration through employment agencies. Hence, at the end of the day it is their parents who act as gatekeepers, which means that migration decisionmaking is here shaped by generational relations. Research in Baan Naam showed that this dimension even gained contractual status as employment agencies would enter separate contracts with the head of household of the migrants concerned, making the Lao household responsible for recovering the expenses associated with recruitment should the migrant concerned fail to do so him/herself (Huijsmans 20IO).

The two most comprehensive studies on migration through employment agencies (Phetsiriseng 2007; Huijsmans/Phouxay 2008) fail to present statistical data on recruitment through agencies in a gender-disaggregated form. Doneys (20II: 56) reports, however, that in 2008 most Lao migrants who had entered Thailand through employment agencies were

21 The one exception included a household in which both the father and the second-born (son) signed up for migration, leaving behind the mother and three children. 
male (62 per cent). This pattern is indeed reflected at the micro-scale of Baan Naam. ${ }^{22}$ Importantly, this gender pattern of migration through employment agencies contrasts with the overall pattern of crossborder migration of Lao nationals into Thailand in which men constitute a minority (4I per cent, as stated above). Part of the explanation of this divergence may be found in the gendered construction of legitimate migrant work discussed above which produces a degree of male privilege.

Male privilege is further aggravated by the intersection of relations of gender and generation at the scale of the household. Three factors are at stake here. First, women tend to marry at an earlier age than men. Because it is primarily unmarried young people that become involved in migration and since there is a minimum age of recruitment of I8 years, the supply of potential male migrants outstrips that of potential female migrants. Second, the daily presence of daughters is, in general, of greater value to rural households than the daily presence of sons. Daughters are not only involved in a far greater range of everyday forms of work that are of significant importance for the production and reproduction of rural households, but parents are, in general, also more successful in directing their daughters' labour towards the household economy than that of their sons (Huijsmans 20IO: I4I). Hence, parents may be keener to approve of, and finance, the absence of a son than a daughter. In relation to the above, and thirdly, whereas daughters' involvement in migration is often met with parental concern (Rigg 2005: 150), in relation to sons it is local idleness that worries parents. Motivating sons to become involved in migration through employment agencies should thus not only be interpreted from an economic perspective, but also as a gendered form of parental discipline. Stemming from a hegemonic notion of masculinity which values risk-taking behaviour (Fordham I998), sons' idleness is associated with drinking, getting into fights, and impregnating girls, whereas migrant work through formal channels is seen as mitigating these possible troubles. Moreover, encouraging sons into two-year migrant contracts may also constitute a parental strategy of postponing possible marriages of their sons and the financial implications of this. ${ }^{23}$

22 Note that one of the two young women who migrated through an employment agency comes from a household with daughters only, rendering the gender question largely irrelevant.
I was afraid that if he were to stay in Baan Naam he would find a girl and get married. Yet, right now we don't have the money for a wedding [their first-born [son] had just married]. Also, he should first earn money himself before getting married, that's why I think it is good that he went again (Notes from interview with a mother whose second-born (son) was about to migrate for a second time through an employment agency on a two-year contract to Thailand; 2008, Baan Naam).

\subsection{Masculinity and the Limitations of Male Privilege}

The previous sections have shown that the gendered construction of the functioning of Lao employment agencies produces male privilege; men are more likely to become involved in this form of migration than women. This is potentially in tension with the policy rhetoric that presents migration through legal channels as contributing to migrant safety based on a dominant discourse of female migrants' vulnerability which is widespread in the activist and academic literature but also clearly identifiable in everyday village life:

It would have been different. Girls would have listened and stayed. For example, I also wouldn't want my younger sister to go and work elsewhere because for girls it is more dangerous than for men. Men look stronger than women and are, therefore, safer. Also when we see the news, it is always girls to which bad things happen. Therefore, I also don't want my younger sister to go (Excerpt from interview with Jonnie (male, 2I years), Baan Naam, 2009, about why he and not his sister became involved in migration through employment agencies).

Jonnie's remark reflects a widespread perception about female migrants' vulnerability, and in Jonnie's case this remained 'fact' even though his own experience stands out as a case in point of male vulnerability, as is discussed in more detail below. The governmentality of the Lao migration regime, which may be summarized as bringing about a 'conduct of conduct' that discourages potential migrants from migrating through irregular channels by emphasizing the associated 'risks' and stimulating migrating in a documented fashion through the promotion of 'safety', can be assessed as relatively successful based on the observation that security considerations indeed emerged as an important motivation for migrants to opt for employment agencies despite the considerable costs $(\mathrm{Hu}-$

23 Note that in the matrilocal ethnic Lao context bridegrooms or their family pay a bride price. 
ijsmans/Phouxay 2008). Importantly, this governmentality of migration has also shifted the cultural styles of hegemonic notions of masculinity. While we have earlier observed that risk-taking behaviour constitutes an important element in hegemonic forms of masculinity among Tai men, so does a "preoccupation with protection from danger" (Tambiah 1984, in: Fordham I998: 107). Whereas in the past this concern with protection from danger manifested itself primarily in the form of the accumulation of amulets, performance of rituals, and the search for blessings (e.g. Mills 1995; Fordham 1998), statements like the one below suggest that performing a modern form of citizenship, by migrating through state-related institutions in a documented manner, has become part of the cultural style of seeking protection from danger among young men.

I went through an agency because I thought that if something would happen the agency would take care of it. Also, this is a comfortable way of going since all the documents are in order. This was important since I was a bit afraid to go abroad for such a long time because I had not done so before (Notes from interview with Som (male, mid-twenties) upon return from two years in Thailand; Baan Naam, 2009).

These young men paid large sums of money or became indebted to the employment agency as a means to secure a certain degree of protection from danger when engaging in an activity (cross-border migration into the deep South of Thailand) they clearly understood as risky. The question remains, however, whether migration through Lao employment agencies as a means to protect oneself from danger actually contributes to making migration safer in a material sense, or should indeed be viewed as a cultural style? A first point of concern in addressing this question is whether migrants migrating through employment agencies actually know what they are stepping into. A survey among twenty migrants showed that virtually all had received information about the nature of work, wages, working hours, health care, and termination of employment prior to migration, which, indeed, compared favourably with migrants who had migrated through informal channels (Huijsmans/ Phouxay 2008: 40). However, when asked how predeparture and contractual information compared with the actual reality at the migration destination a significant discrepancy was observed, as illustrated in Table 19.2.

The data presented in Table 19.2 was collected among early returnees and as observed in the methodology section contains an important element of bias.
Table 19.2: Areas in which the reality of migration differed from the pre-departure information. Source: Adapted from Huijsmans and Phouxay (2008: 41).

\begin{tabular}{|l|c|}
\hline Category & Formal recruits $(\mathbf{n = 2 0})$ \\
\hline nature of work & 15 \\
\hline salary & 16 \\
\hline working hours & 14 \\
\hline overtime & 6 \\
\hline rest days & 9 \\
\hline living conditions & 15 \\
\hline risks and dangers & 10 \\
\hline
\end{tabular}

However, the qualitative data from Baan Naam confirms the above picture:

Research Assistant: Before you went, did you know exactly about the kind of work you were to do?

Jonnie: When the village head announced the possibility of working in Thailand over the village speaker system, he said there were two types of jobs: work in a fish canning factory and work in a pineapple canning factory... we were preparing to go there [to one of the factories] and our passports were processed. But then the factories did no longer need workers, and a palm oil plantation needed workers urgently, so we went there but we had no idea what we would be doing there.

RA: Did you go to all the meetings?

Jonnie: Yes I went to all the meetings, but during these meetings they didn't talk about the palm oil plantations, only about the pineapple and fish canning factory. It was only in the very end that we heard a little bit about plantation work...I wanted to work in one of the factories... but in the end this work was not available. So I went to the palm oil plantations...I went [there] because my passport was already issued and I was indebted for I5,000 Baht with the employment agency and had spent about 5,000 Baht myself in the district level to prepare documents (Excerpt from interview with Jonnie (male 2I years), upon return in Baan Naam, 2009).

Since passports were already issued and valid for three years only, Jonnie and the other young men from Baan Naam felt they could not take their chances. Rejecting a migrant opportunity without knowing when and what would come up was playing with their chances which could lead to a situation in which their passport would run out before having completed a standard two-year contract. For this reason they were ready to accept entirely different work from the sort of migrant work they had initially registered for without knowing much about what this work entailed. 
This indeed constitutes another form of 'mistranslation' of policy.

Next to pre-departure information about the type and nature of work, information about prospective salaries was also unclear. Salaries were typically presented as a range in the migrant contracts. Yet upon arrival the migrants were soon to discover that their actual salaries rarely went beyond the low end of this range. This practice left Som, a young man in his midtwenties, to observe ironically that "everything they [employment agencies] had said was true", meaning that the agency had emphasized the most rosy reading of the contract, without highlighting the fact that there were no guarantees that these conditions would be met.

Consequently, salaries and conditions of work quickly became a main point of contestation for the Baan Naam men who had migrated to the southern Thai palm oil plantations. Once at the plantation the Lao workers found themselves allocated lowly paid tasks like weeding and applying pesticides and excluded from better-paying types of work like harvesting the palms, which were reserved for Thai labour teams. ${ }^{24}$ Following the pre-departure recommendations of the Lao employment agency, the men got in touch with the agency in order to have their concerns addressed:

Before we left we were told to get in touch with the employment agency in case of any problems. And so we did, but the employment company did not like it when I called them and they did nothing with our complaints. Whenever we called, the Lao employment company would just get in touch with a Thai middleman. The middleman would then say that the Lao workers were just too lazy. You know, the Thai middlemen and the Lao employment agency eat and drink beer together, so they believe each other no matter what we say. Also, the Lao employment agency got their money already from the palm plantation so they didn't care anymore. (Notes from interview with Sukan's father in Baan Naam, 2008. He was the only adult in a group of five male workers from Baan Naam, including his second-born son (Sukan), working at the oil palm plantation. As the only adult he acted as the group leader.)

24 Work in the palm oil plantations is at piece rate. A main difference between harvesting the palms and work like weeding and applying chemicals was that the former allowed workers to put in many hours of work with the possibility of earning much higher wages than they could earn by weeding and applying chemicals-which was seen as a single task of fixed magnitude and was often completed in less than a working day.
Over time, two of the young Lao men managed to get out of these lowly paid tasks. Based on their physical strength, they were asked to join a Thai work team on the plantation, which allowed them to enter the more profitable work of harvesting palms. Bodily performance contributes here to the constitution of a hegemonic notion of masculinity, which makes, however, gender vulnerable on two accounts. First, it immediately renders gender vulnerable for the five men whose bodily performance fell short, particularly since the alternative strategies for improving their fate (repeatedly bringing up their complaints) proved futile. Second, the hard labour of harvesting palm trees does not contribute to skill formation. Hence, the immediate improvement achieved through the bodily performance of physical strength is likely to render these men's gender vulnerable in the long run because labour under 'the regime of profit uses up the workers' bodies, through fatigue, injury and mechanical wear and tear', a process which is here not offset by the growth of skill (Connell 2005: 55).

The Lao migrants who have migrated through employment agencies are, by contract, tied to a specific employer, and their indebtedness to the Lao employment agency means that these migrant workers have little other choice than to stick to their job despite problems remaining unresolved. It is only when the worst comes to the worst that migrants who had migrated through employment agencies would resort to quitting without notice. $^{25}$

After about one and a half year into his contract Jonnie fell ill, which he believed was due to his daily work with pesticides in the palm oil plantation. After a period of tiredness and dizziness he could at some point no longer stand and walk and was hospitalized for eight days. After being discharged from the hospital his fellow workers from Baan Naam advised him to quit, as they feared continuing the work might kill Jonnie. Since Jonnie had paid off his debts he decided to quit. Without bothering to ask for his passport (which was kept by his employer) he travelled independently and in an undocumented fashion back to Lao PDR (Notes from interviews with Jonnie; Baan Naam, 2009).

Quitting without notice and leaving one's passport and documented status behind constituted in this case a form of dealing with the migrant vulnerability created by the conditions of migrating through em-

25 Free transport back to Lao PDR at the end of the contract is another motivation for Lao migrants to try to complete their contracts rather than quit prematurely. 
ployment agencies. Ironically, even this strategy, which is frequently employed by undocumented Lao migrants in Thailand as an act of agency in response to dissatisfaction with their migrant work conditions (Huijsmans 20IO), is more risky for documented migrants than for undocumented migrants as the former leave a traceable identity behind.

\subsection{Conclusion}

In this chapter I have shown that notions of risk and safety feature prominently in discourses underpinning transformations in the architecture of migration regimes. In the Lao-Thai case presented in this chapter, migration through irregular channels is constructed as risky and dangerous and this provides an important justification for interventions aimed at preventing, discouraging, and even criminalizing such forms of migration. At the same time, the creation of legal channels of migration is presented and promoted as making migration 'safe'. Employment agencies are key actors in the newly established formal channels of migration and are assigned the 'duty' of safeguarding migrant safety by ensuring protection of migrant workers in accordance with relevant laws and regulations (Prime Minister's Office, Lao PDR 2002).

Concerns about migrant safety are often highly gendered, revolving around female migrants' vulnerability, whereas hardship experienced by male migrants is only seldom problematized due to hegemonic notions of masculinity. Despite such gendered constructs of vulnerability, interventions promoted as improving migrant safety are typically presented as gender-neutral. This is especially true for employment agencies, which are presented as making migration safer and are envisioned doing so in a gender-neutral fashion.

I have, however, shown employment agencies to be distinctly gendered. Firstly, these agencies are embedded in the gendered terrain of the emerging Lao migration regime. The latter is underpinned by a discursive re-appreciation of cross-border migration as

\section{References}

Anh, Dang Nguyen, 2007: "Labour Export from Viet Nam: Issues of policy and practice”. 8th International Conference of Asia Pacific Migration. Fuzhou, China, 25-29 May 2007.

Chant, Sylvia, Ed., I992: Gender and Migration in Developing Countries. New York, (London: Belhaven Press). something that is conducive to the implicit masculine discourse of development as modernization embraced by the Lao state. I have argued that hegemonic notions of masculinity and femininity underpin the construct of legitimate cross-border migrant work, which effectively excludes large parts of the Lao female migrant labour population from these supposedly safe channels of migration. Furthermore, the seemingly gender-neutral selection criteria applied by employment agencies produce significant degrees of male privilege in accessing safe migration because they inevitably play out in the highly gendered social terrain of contemporary Lao society.

Whilst young Lao men may be privileged in accessing these supposedly safe forms of migration, I have argued that the male privilege is highly limited. In fact, the conditions of migration through employment agencies may well contribute to an increase in migrant vulnerability, as the case of Jonnie illustrated. Furthermore, under the highly constraining conditions of contractual labour migration young men typically had to rely on the bodily performance of sheer physical labour power in order to improve their individual situation. I have argued, however, that such bodily performance renders gender vulnerable regardless of whether male migrants are able to contribute to this dimension of the constitution of a hegemonic notion of masculinity.

Lastly, I have argued that evaluating young Lao men's motivations to migrate through these very costly employment agencies in purely material terms loses sight of how it may rather constitute a modern version of a cultural style of hegemonic masculinity. Acknowledging young men's migration through employment agencies as the seeking of protection from danger through the performance of a modern form of citizenship explains, for example, the paradoxical observation that the young men from Baan Naam (and none of the young women) decided, with the exception of Jonnie, to remigrate through the very channels of migration that had already failed them once.

Chantavanich, Supang, 2008: The Mekong Challenge: An honest broker-improving cross-border recruitment practices for the benefit of government, workers and employers (Bangkok: International Labour Office-ILO, Mekong Sub-Regional Project to Combat Trafficking in Women and Children, International Programme on the Elimination of Child Labour). 
Collinson, David; Hearn, Jeff, I994: "Naming Men as Men: Implications for work, organization and management", in: Gender, Work and Organization, I,I: 2-I9.

Connell, R.W., 2005: Masculinities (2nd edition). (Cambridge: Polity Press).

Datta, Kavita; Mcllwaine, Cathy; Herbert, Joanna; Evans, Yara; May, Jon; Wills, Jane, 2009: "Men on the Move: Narratives of migration and work among low-paid migrant men in London", in: Social \& Cultural Geography, Io,8: 853-873.

David, Fiona; Gallagher, Anne; Holmes, Paul; Moskowitz, Albert, 20II: Progress Report on Criminal Justice Responses to Trafficking in Persons in the ASEAN Region (Jakarta: Association of Southeast Asian Nations (ASEAN)).

Donaldson, Mike; Hibbins, Raymond; Howson, Richard; Pease, Bob (Eds.), 2009: Migrant Men: Critical studies of masculinities and the migration experience (New York, Oxon: Routledge).

Donaldson, Mike; Howson, Richard, 2009: "Men, Migration and Hegemonic Masculinity", in: Donaldson, Mike; Hibbins, Raymond; Howson, Richard; Pease, Bob (Eds.): Migrant Men: Critical studies of masculinities and the migration experience. (New York, Oxon: Routledge): 210-2I7.

Donato, Katharine M.; Gabaccia, Donna; Holdaway, Jennifer; Manalansan IV, Martin; Pessar, Patricia R., 2006: "A Glass Half Full? Gender in migration studies", in: International Migration Review, 40,I: 3-26.

Doneys, Philippe, 20II: "En-gendering Insecurities: The case of the migration policy regime in Thailand", in: The International Journal of Social Quality, I,2: 50-65.

Dottridge, Mike, 2006: Action to Prevent Child Trafficking in South Eastern Europe: A preliminary assessment (Lausanne, Geneva: Terre des Hommes, UNICEF).

Ford, Michele; Lyons, Lenore, 20I2: "Introduction", in: Ford, Michele; Lyons, Lenore (Eds.): Men and Masculinities in Southeast Asia (London, New York: Routledge): I-I9.

Fordham, Graham, 1998: "Northern Thai Male Culture and the Assessment of HIV Risk: Toward a new approach", in: Crossroads: An interdisciplinary journal of Southeast Asian studies, I2,I: 77-I64.

Gaetano, Arianne M.; Yeoh, Brenda S.A., 20IO: "Introduction to the Special Issue on Women and Migration in Globalizing Asia: Gendered experiences, agency, and activism”, in: International Migration, 48,6: I-I2.

Haseen, Fariha; Punpuing, Sureeporn, 20I0: "Impact of Ageing on Migration in Asia”, in: Hofmeister, Wilhelm (Ed.): Ageing and Politics: Consequences for Asia and Europe (Singapore: Konrad-Adenauer-Stiftung): 15-35.

Hearn, Jeff, 20II: "Gender Regimes Changing Men or Men Changing Gender Regimes? Challenges for national and transnational social policy, gender equality and organizing with men”, in: Cornwall, Andrea; Edström, Jerker; Greig, Alan, (Eds.): Men and Develoment: Politicizing masculinities (London, New York: Zed Books): I55-I69.
Hibbins, Raymond; Pease, Bob, 2009: "Men and Masculinities on the Move", in: Donaldson, Mike; Hibbins, Raymond; Howson, Richard; Pease, Bob (Eds.): Migrant Men: Critical studies of masculinities and the migration experience (New York, Oxon: Routledge): I-20.

Hoang, Lan Anh; Yeoh, Brenda S.A., 20II: "Breadwinning Wives and 'Left-behind' Husbands: Men and masculinities in the Vietnamese transnational family", in: Gender \& Society, 25,6: 717-739.

Huijsmans, Roy B.C., 20I0: "Migrating Children, Households, and the Post-Socialist State: An ethnographic study of migration and non-migration by children and youth in an ethnic Lao village" (Unpublished PhD thesis, Durham, UK: Durham University, Department of Geography).

Huijsmans, Roy, 20IIa: "Child Migration and Questions of Agency”, in: Development \& Change, 42,5: I307-I32I.

Huijsmans, Roy, 2orıb: "The Theatre of Human Trafficking: A global discourse on Lao stages", in: International Journal of Social Quality, I,2: 66-84.

Huijsmans, Roy; Phouxay, Kabmanivanh, 2008: "Whether you go illegally or legally in the end it's the same, you're cheated". A study of formal and informal recruitment practices of Lao workers migrating to Thailand (Vientiane: International Labour Organisation, National University of Laos).

ILO (International Labour Organization), I949: Convention Concerning Migration for Employment (1949 Revised), C97. 22-OI-I952.

ILO, 2003a: Legal Labour Migration and Labour Markets: Alternatives to substitute for trafficking in children and women'. Technical Intervention Area Summary Note, TIA-I (Bangkok: Mekong Sub-regional Project to Combat Trafficking in Women and Children, International Programme on the Elimination of Child Labour, International Labour Organization).

ILO, I2003b: Trafficking in Human Beings: New approaches to combating the problem (Geneva: International Labour Office, Special Action Programme to Combat Forced Labour).

ILO, 2007: The Mekong Challenge - Winding Roads: Young migrants from LaO PDR and their vulnerability to human trafficking. An analysis of the 2003 Lao PDR migration survey with a new introduction and foreword (Bangkok: International Labour Office, Mekong Sub-Regional Project to Combat Trafficking in Children and Women, International Programme on the Elimination of Child Labour).

ILO, 2008: Meeting the Challenge: Proven practices for human trafficking prevention in the Greater Mekong Sub-region (Bangkok: International Labour Organization, Mekong Sub-regional Project to Combat Trafficking in Women and Children, International Project on the Elimination of Child Labour).

Ireson-Doolittle, Carol; Moreno-Black, Geraldine, 2004: The Lao: Gender, power, and livelihood (Boulder, Colorado: Westview Press). 
Jolly, Susie; Reeves, Hazel, 2005: Gender and Migration: Overview Report (Brighton: IDS-BRIDGE).

Jónsson, Gunvor, 2008: Migration Aspirations and Immobility in a Malian Soninke Village. Working Paper, No. Io (Oxford: University of Oxford, James Martin 2Ist Century School, International Migration Institute [IMI]).

Keyes, Charles F, 1984: "Mother or Mistress but Never a Monk: Buddhist notions of female gender in rural Thailand", in: American Ethnologist, II,2: 223-24I.

Keyes, Charles, F, I986: "Ambiguous Gender: Male initiation in a Northern Thai Buddhist society", in: Walker Bynum, Caroline; Richman, Paula; Harrell, Stevan (Eds.) Gender and Religion: On the complexity of symbols (New York: Beacon Press): 66-96.

Kirsch, A. Thomas, 1985: "Text and Culture: Buddhist sex roles/culture of gender revisited”, in: American Ethnologist, I2,2: 302-320.

Kitiarsa, Pattana, 20I2: "Masculine Intent and Migrant Manhood: Thai workmen talking sex", in: Ford, Michele; Lyons, Lenore (Eds.) Men and Masculinities in Southeast Asia (London, New York: Routledge): 38-55.

Louie, K., 2002: Theorizing Chinese masculinity: Society and gender in China (Cambridge: Cambridge University Press).

Martin, Philip, 2005: Merchants of Labor: Agents of the evolving migration infrastructure. Discussion Paper, DP/I58/2005 (Geneva: International Labor Organization, International Institute for Labor Studies).

McKay, Steven; Lucero-Prisno III, Don Eliseo, 20I2: "Masculinities Afloat: Filipino seafarers and the situational performance of manhood", in: Ford, Michele; Lyons, Lenore (Eds.) Men and Masculinities in Southeast Asia (London, New York: Routledge): 20-37.

Mills, Mary Beth, 1995: "Attack of the Widow Ghosts: Gender, death, and modernity in Northeast Thailand", in: Ong, Aihwa; Peletz, Michael G (Eds.): Bewitching Women, Pious Men: Gender and body politics in Southeast Asia (Berkeley, Los Angeles, London: University of California Press): 244-273.

Mills, Mary Beth, 1999: Thai Women in the Global Labor Force: Consuming desires, contested selves (New Brunswick, New Jersey, London: Rutgers University Press).

Ministry of Labour and Social Welfare, Lao PDR, 2002a: Directive of the Minister of Labour and Social Welfare on the Implementation of the Prime Minister's Decree on Sending Lao Workers to Work Abroad (unofficial translation), 24I7/MoLSW 29 July 2002.

Ministry of Labour and Social Welfare, Lao PDR, 2002b: Regulation of the Minister of Labour and Social Welfare on the Types of Jobs Prohibited for Sending Lao Workers to Work Abroad (unofficial translation), 3824/ MoLSW I9 December 2002.

Minister of Labour and Social Welfare, Lao PDR, 2007: Continuation of sending of Lao workers abroad (unofficial translation), 30II/MoLSW, 8 August 2007. (Policy Note 30II/2007)
Molland, Sverre, 20I2: "Safe Migration, Dilettante Brokers and the Appropriation of Legality: Lao-Thai 'trafficking' in the context of regulating labour migration", in: Pacific Affairs, 85,I: II7-I36.

MoLSW, Committee for Planning and Cooperation National Statistical Center and ILO-IPEC/TICW, 2003: Labour Migration Survey in Khammuane, Savannakhet and Champasack 2003 (Vientiane: Ministry of Labour and Social Welfare, Department of Labour [Lao PDR], Committee for Planning and Co-operation of the National Statistical Center, International Labour Organisation-IPEC/TICW [International Programme on the Elimination of Child Labour/Project to combat Trafficking in Children and Women]).

Momsen, Janet Henshall (Ed.), I999: Gender, Migration and Domestic Service (London, New York: Routledge).

Muntarbhorn, Vitit, 2005: The Mekong Challenge. Employment and Protection of Migrant Workers in Thailand: National Laws/Practices versus International Labour Standards? (Bangkok: International Labour Organization).

Muttarak, Raya, 2004: "Domestic Service in Thailand: Reflection of conflicts in gender, class and ethnicity", in: Journal of Southeast Asian Studies, 35,3: 503-529.

Ngaosyvathn, Mayouri, 21995: Lao Women Yesterday and Today (Vientiane: Lao State Printing Enterprise).

Ngaosyvathn, Mayouri; Ngaosyvathn, Pheuiphanh, 1994: Kith and Kin Politics: The relationship between Laos and Thailand (Manila: Journal of Contemporary Asia Publishers).

Peck, Jamie; Theodore, Nik; Ward, Kevin, 2005: "Constructing Markets for Temporary Labour: Employment liberalization and the internationalization of the staffing industry”, in: Global Networks, 5,1: 3-26.

Phetsiriseng, Inthasone, 2007: Gender Concerns in Migration in Lao PDR. Migration mapping study: A review of trends, policy and programme initiatives (Bangkok: UNIFEM East and Southeast Asia, and Unifem Lao PDR).

Pholsena, Vatthana; Banomyong, Ruth, 2006: Laos: From buffer state to crossroads? (Chiang Mai: Mekong Press).

Pijpers, Roos, 20I0: "International Employment Agencies and Migrant Flexiwork in an Enlarged European Union", in: Journal of Ethnic and Migration Studies, 36,7: 1079I097.

Pongkhao, Somsack, 2007: "Lao Authorities Demand Legalisation of Workers", in: Thailand' Vientiane Times, 3 September 2007 (issue 206), Vientiane.

Prime Minister's Office, Lao PDR, 2002: Decree of the Prime Minister on Sending Lao Workers to Work Abroad [unofficial translation], No. 68/2002 28th May 2002.

Ricklefs, M.C.; Lockhart, Bruce; Lau, Albert; Reyes, Portia; Aung-Thwin, Maitrii, 20I0: A New History of Southeast Asia (Basingstoke: Palgrave MacMillan). 
Rigg, Jonathan, 2005: Living with Transition in Laos: Market integration in Southeast Asia (London: RoutledgeCurzon).

Rudnyckyj, Daromir, 2004: "Technologies of Servitude: Governmentality and Indonesian transnational labor migration”, in: Anthropological Quarterly, 77.3: 407-434.

Sangsomboun, Phonesavanh, 2008: "Traditional Dress Key to Preserving Culture”, in: Vientiane Times, 59,Io (Vientiane: Io March 2008).

Souksavath, Phonesaly; Acharya, Sarthi, 2009: Employment and Livelihoods: The 4 th national human development report (Vientiane: Ministry of Planning and Investment, UNDP).

Tambiah, S.J., 1984: The Buddhist saints of the forest and the cult of amulets (Cambridge: Cambridge University Press).

Thai, Hung Cam, 20I2: "Low-wage Vietnamese Immigrants, Social Class and Masculinity in the Homeland", in: Ford, Michele; Lyons, Lenore (Eds.) Men and Masculinities in Southeast Asia (London, New York: Routledge): 56-67.

Thammavongsa, Panyasith, 2006: "Permit system vital to control migration”, in: Vientiane Times, I6 January 2006 (Vientiane).

Theeravit, Khien; Semyaem, Adisorn, 2002: Thai-Lao Relations in Laotian Perspective (Bangkok: Institute of Asian Studies, Chulalongkorn University).

UN General Assembly, 2000: Protocol to Prevent, Suppress and Punish Trafficking in Persons, Especially Women and Children, Supplementing the United Nations Convention against Transnational Organized Crime, I5 November 2000; at: 〈http://www.unhcr.org/refworld/ docid/4720706co.html> (I7 March 2009).

UN-ESCAP, 2000: Sexually Abused and Sexually Exploited Children and Youth in the Greater Mekong Subregion: A qualitative assessment of their health needs and available services. ST/ESCAP/2045 (New York: United Nations Economic and Social Commission for Asia and the Pacific).

UNIAP, (n.d.): "Initiatives: Support to underserved victims"; at: <http://www.no-trafficking.org/init_underserved. html> (3I August, 20IO).

Vientiane Times, 2005: "Laos to Export Legal Labour to Thailand", in: Vientiane Times, 5 August 2005 (Vientiane).

Vijayan, Prem, 2002: "Nationalism, Masculinity and the Developmental State: Exploring Hindutva masculinities”, in: Cleaver, Frances (Ed.): Masculinities Matter! Men, gender and development (London, New York: Zed Books): 28-56.

World Bank, 2006: Labor Migration in the Greater Mekong Sub-region. Synthesis report: Phase I (Washington, D.C.: The World Bank).

Xiang, Biao, 20I2: "Predatory Princes and Princely Peddlers: The state and international labour migration intermediaries in China", in: Pacific Affairs, 85,I: 47-68.

Open Access. This chapter is distributed under the terms of the Creative Commons Attribution Non-commercial License, which permits any noncommercial use, distribution, and reproduction in any medium, provided the original author(s) and source are credited. 


\title{
$20 \quad$ Public Social Science at Work: Contesting Hostility Towards Nicaraguan Migrants in Costa Rica
}

\author{
Carlos Sandoval-García ${ }^{1}$
}

\begin{abstract}
$^{2}$
Nicaraguan migration to Costa Rica is one of the most salient cases of South-South migration in Latin America. Despite Costa Rica's self-representation as a peaceful and democratic society, Nicaraguan migrants in Costa Rica, the main foreign-born community in the country, are widely portrayed in derogatory terms, for example as violent and criminal and in general as "threatening Others" (Sandoval 2004). This chapter explores a set of examples of analyses of critical interventions - regarding immigration law, social imaginaries around which representations of Nicaraguans are framed, and participatory work carried out with impoverished communities in order to reflect on the ways in which social sciences in Costa Rica attempt to intervene both in the everyday hostility of Costa Rican society and in the ways in which Nicaraguans contest that hostility. Responding to Michael Burawoy's call for a "public sociology" $(2005,2007)$, the chapter reflects on how debates around public social sciences could enrich the political, institutional, and conceptual location of migration studies in Costa Rica.
\end{abstract}

Keywords: migration, Nicaraguans, Costa Rica, immigration law, social imaginaries, community work, public sociology.

\subsection{Introduction}

This chapter ${ }^{3}$ reflects on the scope and limitations of endeavouring as social researchers and social activists to intervene in three specific arenas of the debate on immigration in Costa Rica. One refers to the possibilities of influencing public policy in the field. The experience of analyses of Costa Rica's new Migration and Alien Affairs Law, which came into effect in March 20IO, is discussed. The main challenge has

1 Carlos Sandoval-García is professor at the Media Studies School and the Institute for Social Research, both at the University of Costa Rica. He is also editor of the Anuario de Estudios Centroamericanos (<www.anuario.ucr. ac.cr $>$ ).

2 This chapter draws on the findings of an IDRC-funded project 'Advancing the Rights of Migrant Women in Latin America and the Caribbean', project number I04785-003.

3 An earlier version of this chapter (Sandoval, 20I2a) was published in Entreverse. Teoría y metodología práctica de las Fuentes orales, edited by Miren Llona (Bilbao, University of the Basque Country). been how to translate the analysis of social sciences into a legal submission to the Constitutional Court. A second area is how to respond to the imaginaries of immigration, which are usually characterized by an exaggeration of the number of immigrants and by imputing to them the weakening of public services and the rise of insecurity. A third area of intervention refers to work with migrant communities and the ways they position themselves with respect to the criminalizing discourses they are questioning.

Reflection about the challenges, institutionalization, and links with the social sciences has been present in different periods and sociocultural contexts. Often it has involved critical observations growing out of the context of power relations that privilege certain perspectives and institutional contexts to the detriment of others (see, for example, Fanon (1986), Mills (1987)). Some of these initial concerns have continued to be debated more recently. Pierre Bourdieu and Wacquant (I992: 37), for example, suggest at least three angles of inquiry. One refers to the social origins and social conditions (e.g. class, gender, generation) from which a researcher envisions a project; the 
second asks about the institutional conditions from/ in which it is worked on; and the third refers to the concepts and tools from which and with which it is conceptualized and developed. The three demand an effort of distancing capable of converting the biography and premises of work into an object of inquiry. Boaventura de Sousa Santos (2009: I25) offers a second contribution, suggesting that reality cannot be reduced to what exists, but requires also a sociology of what is missing and a sociology of what is emerging. ${ }^{4}$

A third perspective, upon which this chapter is mainly based, is Michael Burawoy's call for public sociology, a sociology which addresses wide publics and asks for whom and for what knowledge is being produced. Burawoy (2007: 243) identifies four spaces of sociology: professional sociology, written for other specialists, which has the greatest legitimacy and recognition; the sociology of public policies; critical sociology; and the one he underscores as the main challenge, public sociology. Some critics have reservations about whether public sociology will effectively be able to subvert the hierarchies within the discipline (Hays 2007); others ask how far public sociology recognizes the asymmetries between sociology and subordinate fields of knowledge, such as Latino studies or ethnic studies (Nakano Glenn 2007). A greater doubt is to what degree this debate about public sociology enters into a dialogue with similar perspectives in the global South (see Burawoy 2007: 254 for an exception).

Following Patricia Hill Collins (2007: 2I), this chapter asks whether and how we who work critically in migration have "been making public sociology without knowing it" (emphasis in the original). It asks too in what ways these debates are enriching our work in a period in which the institutional weaknesses of the Central American universities and the predominance of international cooperation priorities leave few possibilities for new generations of social scientists to be able to enjoy stable work options from which they can respond to the needs for knowledge of the dispossessed peoples in the region.

Both the views of de Sousa Santos and Burawoy require us to reflect on the ways in which power/ knowledge relations are forged in migration research.

4 De Sousa Santos (2009: I29) suggests a sociology of absences and a sociology of emergences. "While the sociology of absences moves in the field of social experiences, the sociology of emergences moves in the field of social expectations" (p. I30). "Both grant the present a denser and more substantive content than the fleeting instant between past and future" (p. I3I).
Issues regarding needs of knowledge and political organization of migrant communities and the interplay between research, advocacy, and policy-making are among some of the challenges posed by these attempts to go beyond detached social science research.

The three areas of work considered in the chapter - public policies, social imaginaries, and community work - have been part of research projects carried out at the Institute for Social Research at the University of Costa Rica between 2005 and 20II. ${ }^{5}$ We began working on a project whose title was La Carpio: The experience of urban segregation and social stigmatization, which was supported by a grant awarded by the Wenner-Gren Foundation for Anthropological Research and another from the Central American Jesuit Migration Service (Sandoval/Brenes/Fernández/Paniagua/ Sánchez 2007; Sandoval 2009a; Sandoval/Brenes/ Masís/Paniagua 20Io; see also <www.lacarpioenlinea.ucr.ac.cr >). The La Carpio community is probably the biggest binational community in Central America and the project aimed to contribute towards building collective memories and a grounded political culture.

A second team project was Advancing the Rights of Migrant Women in Latin America and the Caribbean, a regional project that has looked at the lived experience of migrant women and migrant organizations in five Latin American countries, one of which was Costa Rica. This project was funded by the International Development Research Center (IDRC) of Canada (Brenes/Fernández/Paniagua/Sandoval 20Io; Bolaños/Brenes/Paniagua/Sandoval et al. 20II; Sandoval/Brenes/Paniagua 20I2). We aimed not only to research some of the main issues regarding migration, but also to learn how to build cooperative forms of work in which collaboration and not competition could be the main source of inspiration. The challenges of the social sciences not only refer to the formulation of theoretically and empirically (and socially relevant) informed research questions, but also depend on the possibility of forging vibrant, generous, and enriching academic cultures (Green 1997: 195). Meanwhile, these projects have asked the team how to build links: with migrant people who, rather than

5 During this period, a number of colleagues have been active protagonists. Esteban Sánchez-Solano, Mayela Castillo-Villachica, Karen Masís-Fernández, Marcela Montanaro-Mena, and Olman Bolaños have joined several initiatives. Mónica Brenes-Montoya, Laura Paniagua-Arguedas and I have worked together throughout this period. 
being considered as 'objects of research', are recognized as subjects; with organizations that work on advocacy; and with cooperation agencies.

\subsection{Nicaraguan Migrants as 'Threatening Others' in the Costa Rican Social Imaginary}

The Nicaraguan community in Costa Rica is a major case of South-South migration in the Latin American context. The 2000 population census estimated that Nicaraguans who live in Costa Rica represent around 226,374 (5.9 per cent) of the total inhabitants. Eleven years later, in 20II, the population census reported $287,766,6.6$ per cent of the total population. Over the course of a decade (2000-20I0), while there was a 27.I per cent absolute rise there was thus only a very slight increase in the share ( 0.9 per cent), which is much less prominent than the one reported between the census carried out in 1984 and the 2000 census, which was 4.I per cent. In other words, there is a tendency towards stabilization of Nicaraguan immigration in Costa Rica, although in the Costa Rican imaginary the image is that the proportion of immigrants is continuing to grow.

In the second half of the twentieth century, two moments can be distinguished in which the displacements from Nicaragua to Costa Rica intensified. One was the war in Nicaragua financed by the Reagan Administration starting in the early eighties, which demanded the establishment of Patriotic Military Service (conscription) and produced a profound economic crisis in Nicaraguan society. The other was generated by the neo-liberal measures starting in the early nineties that privatized institutions in Nicaragua, eliminated subsidies, and generated enormous unemployment. Additionally, the social disaster produced by Hurricane Mitch in 1998 aggravated the living conditions of hundreds of thousands of Nicaraguans.

The Nicaraguan community in Costa Rica has been thematized as much in the media as in everyday life conversations. Many of the themes will seem familiar in other countries and regions, since while nationalities vary, the narratives do not: Will the immigrants become a majority? Will they impose other customs? Will they take jobs away from the nationals? Are they responsible for the decline of public services and the increase in crime rates and the sense of insecurity? These are some of the recurring questions heard in Costa Rica, just as in the United States or the
European Union (Lipsitz I999; Chavez 200I, 2008; Bhattacharyya/Gabriel/Small 2002).

In the case of Costa Rican society, a weak public sphere impedes a strengthening of reflection about itself and of any recognition that there has been an undermining of key institutions, generated above all by the shrinking of public investment and by a blurring of the collective imaginary that has characterized the country as 'exceptional'. Fantasies about the nation frequently replace debate about the type of society to which one aspires. The anti-immigrant hostility, often fed by the mass media, has been the raw material of the exclusionary fantasies of the nation. In turn, this same anti-immigrant hostility aims to contain and make bearable the anxiety generated by the uncertainty about the effacing of the institutions and the imaginaries (Sandoval 2004).

During the last thirty years, Costa Rica has experienced a number of changes in its economic policies which have configured an export-based economy that has diversified products and increased markets. Under this economic pattern, economic growth has not meant equitable redistribution. While the proportion of those living below the poverty line remains at about twenty per cent, inequality has risen considerably. A new methodology applied to estimating income distribution reported that the Gini Index is about 0.54 per cent (INEC 20II). It locates Costa Rica as one of the Latin American countries in which inequality has risen more sharply in recent years.

Paradoxically, those who are considered 'threatening Others' are indispensable for these new economic patterns. Newer leading agricultural products like watermelons, oranges, melons, and mangoes, as well as traditional products such as coffee and bananas, are produced and processed by Nicaraguan men and women. The case of the construction sector is similar, since Nicaraguans have been indispensable for building the infrastructure that has made possible the tourist boom, especially in the Pacific coast region. Insecurity, which has been considered as the main problem of the country in a number of surveys, has been tempered by private security companies which very often recruit Nicaraguan guards. Throughout this period, 'security' has ceased to be seen as an issue related to the Costa Rican welfare state and has become instead a police concern. Meanwhile, attributing responsibility for this sense of dislocation to Nicaraguans has been a way of making sense of these institutional changes. Last but not least, Nicaraguan women are in charge of (badly-)paid domestic work and responsible for caring for Costa Rica's middle-class children and 
elderly people. In short, those who are considered violent are also the ones responsible for maintaining Costa Rica's sense of security and economic growth. The increase in drug trafficking and political corruption makes this landscape even more unpredictable (Sandoval 20I2c).

\subsection{Understanding and Countering the Legality that Produces Irregularity - Analytical, Normative, and 'Translation' Research}

Seyla Benhabib (2004: 2) has noted that "transnational migrations bring to the fore the constitutive dilemma at the heart of liberal democracies between sovereign self determination claims on the one hand and adherence to universal human rights principles on the other". It is recognized that there are human rights that transcend national policies but it is also recorded that the sovereignty of the state continues to determine who has rights and who does not.

Costa Rica's current General Law of Migration and Alien Affairs (No. 8764) was approved by the Legislative Assembly in July 2009 and went into effect in March 20IO. In general, it presents a series of modifications to the previous law. It eliminates a good part of the vocabulary linked to 'security' which abounded in the earlier law, replacing it with that of human rights, alluding to multiple international agreements ratified and in effect in Costa Rica.

The human rights framing has earned important legitimacy among stakeholders. But the new law combines this framing with specific provisions that make the migratory regularization process even more cumbersome and difficult, and grants competencies to authorities charged with executing the migratory legislation that more properly belong to the judicial branch.

Even though Costa Rican Social Security reports that only 57.4 per cent of the economically active population was covered by social security as of February 2009, mainly because the majority of jobs generated are located in the so-called 'informal' sector, affiliation to the public social security system is one of the new requisites for beginning regularization processes (articles 7, point 7; 78, point 3; and 97). A consequence of this new requisite is that the responsibility for insurance falls on the workers and employers are exempted of their responsibility.

The costs related to documentation are another aspect. The law establishes a series of payments to ob- tain extension periods for the migratory category or to change it. For example, persons categorized as tourists must pay US\$Ioo to prolong their stay in the country (article 90). In addition, those wishing to change their migratory category must, in addition to meeting the requirements to obtain the new category, pay \$200 (articles 96 and I25) unless they leave the country to come in on a visa, in which case they must begin residency proceedings, which costs $\$ 30$.

If one considers that the high costs are one of the factors that impede the steps for regularizing the migratory status or renewing documents, they become a factor that impedes regularization itself. In fact, one of the grounds to cancel a person's permanent residency is failure to renew that person's documentation within three months of its expiry date (article I29, point IO). To this must be added that for every irregular stay in Costa Rican territory, once must pay a US $\$$ Ioo fine for each month of that stay or, "by default, the person's entry will be prohibited for a period equivalent to triple the time of his/her irregular permanence" (article 33, point 3).

The insurance requirement added to the severity of the fines will very probably increase non-documentation. Thus the law would produce the 'illegality' it is claimed it would eradicate; that is, the requisites are such that they foster lack of documentation. The report of regularization requests presented to the General Division of Migration and Alien Affairs (DGME) reveals that there has been a decrease of almost fifty per cent in new permanent visa applications between $20 \mathrm{IO}$ and 20II (Press Conference 20I2). In other words the law's promise, which is regulation, is far from being fulfilled. ${ }^{6}$

The same pattern is underscored in some studies on migratory legislation in various other countries (DeGenova 2002). Mae Ngai, for example, has noted

6 During the second semester of the year 20I2, the DGME announced a number of temporary measures that make some of the requirements for residence more flexible. It coincided with the recognition of the Tratado de la Apostilla, which establishes that when a state recognizes documents expedited by another state, such documents do not need to be certified by the consular authorities of the country in which they are going to be submitted. Currently, Nicaraguans applying for residency in Costa Rica can obtain their documents at the Nicaraguan consulate in Costa Rica. The large queues at the Nicaraguan consulate seem to confirm that most of the undocumented Nicaraguans who live in Costa Rica have already qualified for a visa but have not had the budget to pay for their documents. 
that "the migratory restriction produces an illegal person as a new illegal political subject, whose inclusion within the nation was simultaneously a reality and a legal impossibility". She goes on to say that "being an unauthorized or illegal immigrant is a status conferred by the State and is then incorporated into the bodies of the migrants, because illegality is both produced and experienced" (quoted by Chavez 2008: 23). A law that claims to be inspired in the name of human rights ends up reducing the practical possibilities of achieving migratory regularization.

A second set of provisions foreseen by the law refers to the powers granted to migratory authorities. The detentions that the Migration Police may make are for twenty-four hours, but they can be extended with the authorization of the DGME director without specifying a limit, as established in articles I2 and 3I, points $5 \mathrm{a}$ and $5 \mathrm{~b}$. In this context, doubt arises as to whether the detentions could be indeterminate and prolonged by an administrative authority or are expressly reserved for a judicial authority, as the Political Constitution of Costa Rica makes explicit in its article 37. The provision in article $\mathrm{I} 6$ of the existing Law of Migration and Alien Affairs must be understood in the same sense, namely that "the Professional Migration Police will investigate the trading and trafficking in persons, as well as any infraction of a migratory nature". The administrative police would be given the power of making arrests, but this should not be for the purpose of investigating cases, as this would usurp a power of the judicial branch as established in article I53 of the Political Constitution.

From a more long-range perspective, this discretion granted to administrative authorities coincides with changes in the legislation of a large number of countries, which have meant the erosion of a number of aspects of the rule of law through the greater discretion granted to police authorities and the reduction of the presumption of innocence and of the separation of powers (Bhattacharyya 2008). In the migratory sphere then, changes are taking place whose nature and consequences could be far-reaching.

The construction of links between the different kinds of knowledge, agents, and social practices around the demand for justice and rights in the field of migration requires a search both for ways to articulate perspectives of a more analytical type, which for example describe the increase in policies to control migratory flows, and for approaches whose main attention is applied to a normative perspective and whose priority is to imagine possible modes of transformation.
Spanning the analytical and the normative, one of the tasks still pending is to conceive a public policy on migration that starts by recognizing the profound interdependence between migrants, their relatives, and the receiving communities. Thousands of people have found employment and residence in Costa Rica, providing services to Costa Rican citizens; for example, many Costa Ricans can work at paid jobs because a Nicaraguan is caring for their children or for older adults. Some economic activities, such as construction, export agriculture, private security, and of course paid domestic work structurally depend on the participation of Nicaraguans. Although, as Benhabib (2004: 93) notes, "peoples are radically and not merely episodically interdependent", she emphasizes that "citizenry and the practices of political membership are the rituals through which the nation spatially reproduces itself. The control of territorial borders, which is coeval with the sovereignty of the modern nation state, seeks to ensure the purity of the nation in time through the policing of its contacts and interactions in space" (Benhabib 2004: I8).

For normative-cum-transformative work, rather than suggesting new totalities Boaventura de Sousa Santos (2009: I25) favours the work of 'translation', which he specifies as "the procedure that permits the creation of reciprocal intelligibility among the experiences of the world, both the available and the possible, revealed by the sociology of absences and the sociology of emergences" (de Sousa Santos 2009: I36). Translation involves links between various kinds of knowledge, agents, and social practices and is particularly necessary in the search for links between perspectives of a more analytical kind and those more focused on regulatory approaches. The importance of this link acquires more relevance if one recognizes, as Jonathan Rutherford (2007: I9) has noted, that the predominating theories that emphasize the de- and reconstruction of social identities, generally related to post-structuralism, have lacked the ethical references to generate new, more egalitarian social relations than the ones they seek to deconstruct. The emphasis on the possibility of reconstruction has not been accompanied by a similar impetus in terms of articulating emerging worlds.

Translation also facilitates the configuration of "contact zones" (Sandoval 2009b) between kinds of knowledge, perspectives, and actors who do not frequently encounter each other. Law, says de Sousa Santos (2OIO: I2), "can be emancipating when it is used counter-hegemonically". In other words, the lonely academic critique or the communications from organi- 
zations that recognize discriminations in such law need to be transcended in order to advance the recognition of "citizenries in practice" (Brenes/Fernández/ Paniagua/Sandoval 20ro). The public social sciences, in the Burawoy sense, can contribute to this task.

It is in this context that the challenge arises to try to contest some articles of this law in the Constitutional Court on the grounds of unconstitutionality or because they go against international agreements to which the Costa Rican State is a signatory, arguing, for example, that some of the requisites, costs, and fines violate the principles of reasonableness and proportionality which underpin the rule of law, or that the powers assigned to the DGME and the Migration Police violate the principle of independence of the branches of government.

This involves not only systematizing some of the criticisms of the existing legislation, but also consolidating capacities to persuasively contest the need to make justice and citizens' rights prevail beyond nationality. Based on this concern, the team who worked in the project Advancing the Rights of Migrant Women in Latin America and the Caribbean invited colleagues working in NGOs and churches to reflect on the scope of the law and on the possibilities of engaging in advocacy. In the framework of these initiatives, a document with the main concerns was delivered to the then director of the DGME, in which it was suggested, for example, that the charges for obtaining documents should not be reduced but that the documents should be valid for longer. As a product of this initiative, the DGME agreed to extend the validity of residence permits from one year to two at first issue and to three or four years for revalidations, as verified by article 56 of the Regulations of Alien Affairs published in the official daily La Gaceta in January 20II (Asamblea Legislativa de la República de 2009).

A second stage of the work consisted of convening a group that met over a longer period for a more careful reflection on the law and on the possibilities of preparing a writ of unconstitutionality. By September 20II, a final version of the writ was submitted to the Constitutional Court, which in April 2012 partially admitted it. Overall, the Court admitted the claims against those articles in which the distinctions between faculties of the Judicial and the Executive powers were blurred. But it did not accept that serious criminal charges were a matter of constitutional law. If one compares the work done when the previous law went into effect in 2006 and what happened with the current one, an important difference is that this time there is a greater collective critical effort and ca- pacity for detailed and informed analysis. In fact, in 2006 , the possibility of writing a writ of unconstitutionality was unthinkable. Now the possibility of getting together colleagues from the social sciences and law (a social science that is unfortunately usually far away from the rest of the camp) is a substantive step forward. Even though at the time of writing this chapter (May 20I2), the Court has not provided a final decision, this experience is without doubt a step forward both in terms of cooperative work and translating social science findings into legal claims. Following de Sousa Santos, the writ of unconstitutionality that was presented in 20II might be thought of as a team experience of translating empirical research into a normative perspective through which what was absent (a Constitutional claim) was made possible. Although international cooperation in migration research is frequent and at times abundant, little is invested in promoting advocacy, particularly long-term advocacy. Instead, assessments on diverse themes often overlap. In response to this certainly limited panorama, the experience of analyzing the law introduces more general questions about what the research and advocacy priorities on the migration issue should be in a context characterized by the hardening of migratory legislation in various regions of the world.

A second initiative on the issue of rights has been articulated around the danger that Nicaraguan women with an irregular status do not have access to health services except in emergency situations or during pregnancy. The Costa Rican state is a signatory to the international legislation on sexual and reproductive rights. As a consequence, what is established in these international regulations is obligatory for the Costa Rican state. The challenge is how to make compliance with international regulations enforceable at a national level. A document by the project team $A d$ vancing the Rights of Migrant Women in Latin American and the Caribbean has also been prepared. However, just before submitting the proposal to the authorities, a number of financial and administrative difficulties at the Public Security System (Caja Costarricense de Seguro Social [CCSS]) were revealed which made politically improbable that health provision for non-documented women would be accepted. The Minister of Health even suggested that attention to migrants was one of the factors that explain the financial crisis (La Nación 27.08.20II).

Both the writ of unconstitutionality and the proposal to extend to migrant women in an irregular condition the right of access to health care face hard times due to the conflict over the definition of bor- 
ders between Nicaragua and Costa Rica (Sandoval 20I2c). This ongoing situation involves a considerable step backward in terms of the exercise of migrants' rights. The media have represented the conflict as a confrontation between societies and in Costa Rica flags have even been placed in houses and automobiles to underscore the identification of the population with the position of President Laura Chinchilla. Thus the border conflict has mobilized nationalist speeches and increased anti-migrant hostility. That, together with the exercise of citizenship in practice, presents the enormous challenge of debating the social imaginaries around immigration, some of which are unquestionably a departure point for the legislation that we have discussed in this section. This is the subject of the following section.

\subsection{Social Imaginaries around Immigration -The Absence of Recognition of Interdependence}

In a context of anti-immigrant hostility, one of the challenges facing academic research and social organizations is how to respond to it, both in terms of content and in the cultural forms and means used. This section examines some of the arguments with which an attempt is made to respond to anti-immigrant hostility. A first argument is the 'numbers game,' where it is often suggested that if the number of immigrants drops, the hostility will decrease as well. A second repertoire is instrumental: we must accept the immigrants given that they undertake work the local population does not do. A third way of responding, common among the critical social sciences, is to assume that the hostility is a product of unfounded images about the relationship between the presence of immigrants and insecurity or lack of facilities in the institutions. A fourth way of responding refers to the application of values such as hospitality and solidarity to try and transcend the hostility and exclusion associated with migratory legislation.

The "numbers game" (Hall I98I) is usually used from conservative positions, not so much to refute the hostility as to justify it. Thus the main thesis is that if there weren't 'so many migrants' there would be no hostility. That makes the immigrants responsible for their own discrimination. Ghassan Hage (I998: 92) notes something for the case of Australia that could also be said in the Costa Rican case: when it is considered that there are 'many immigrants', it "represents...the possibility of becoming beyond control and losing the status of being an object of the will of the nationalist manager".

The literature reports that there is not necessarily a correspondence between an increase in immigration and the growth of hostility. It is estimated that international migrants make up three per cent of the total world population, i.e. some 200 million people. It is often considered that such figures correspond to a considerable increase in international migration, frequently explained as a consequence of globalization. Nonetheless, historians (e.g. Hobsbawn 1998) have already noted that in relative terms, taking into account the population at the time, there was greater immigration in the nineteenth century than in the twentieth century. If an analysis of internal migration were integrated into this historical perspective, there might also be some surprising results. From the above, it can be concluded that both in historical terms and in contrasting internal-versus-external migration, greater caution should be used when concluding that we are living in an 'age of migrations', which is often assumed to be a synonym for international migrations. Very probably the most noteworthy aspect of this period is the increase in controls by the developed countries, particularly the United States and the European Union, to avoid the entry of people seen as racially different coming from the countries of Latin America, Asia, and Africa.

The Costa Rican case demonstrates some similarities to what has been noted in international terms. While the 1927 census, for example, reported 6.2 per cent foreign population, the 20 II census reported 8.9 per cent, which means a slight increase in share of 2.7 per cent in 84 years. As was noted above, the increase of the Nicaraguan share between 2000 and 2011 was 0.9 per cent, much less than in the period I984-2000, when the increase was 4.I per cent. In other words, although the local population is falling in Costa Rica, Nicaraguan immigrants are not showing a pronounced increase. Nonetheless, the hostility appears not to be decreasing substantially. In this regard, one of the pending challenges for public social science is how to undertake and communicate a critical reading of the demographic trends with non-specialized audiences.

Instrumental responses, which stress that Nicaraguan men and women take jobs that the local population does not want (Sandoval 2004), are usually the most frequent and advocate tolerance. This vision is based on the premise that crucial economic activities, such as export agriculture (pineapples, oranges, melons, bananas, and coffee, for example), as well as con- 
struction or paid domestic work, depend on the Nicaraguan labour force, and so they must be tolerated. A shortcoming of this concept of tolerance, however, is that those who supposedly propose it retain the right to decide who they exercise their tolerance on; they do not lose the power that allows them to be tolerant. As Hage (1998: 85-86) notes, "When those who are intolerant are asked to be tolerant, their power to be tolerant is not taken away from them. ... the advocacy of tolerance left people empowered to be intolerant".

Recognition of the interdependence between the receiving society and the migrants could be a step forward from a temporary self-interested 'tolerance'. Nonetheless, Costa Rican society is far from being in a condition to recognize how much it depends on those it does not accept. The recognition of interdependence is, in de Sousa Santos' terms, a structuring gap in the Migration Law. In other words, that which is not there tends to shape the part that is. In this regard, the migratory legislation expresses values rooted in the social imaginary, such that trying to change it is not merely a legal issue, although that dimension is very important, but relates to a plane that is more ideological.

The absence of the notion of interdependence also refers to the underdevelopment of the possible narrative or genres from which to represent interdependence. It is symptomatic that in Costa Rica, despite the frequency of references to immigration, only two novels have been published on this theme (Marcenaro 2007; Paniagua 2010), even though novels are possibly the cultural form that best reveals the social reality of a period (Bakhtin I98I; Williams I977; Mora 2000). Nor is there major participation in the public debate about immigration by the first generation of the children of immigrants. They should be among those best prepared to be aware of the centrality of interdependence.

In a context in which the ratio of paid jobs undertaken by women is higher than the proportion of reproductive work done by men at home, a good number of Costa Rican women recognize that without the paid domestic work frequently done by Nicaraguan women, their participation in the job market would be impossible. In a certain way, paid domestic work done by Nicaraguan women has made gender inequalities less explicit in Costa Rican society. However, such recognition does not translate into publicly shared narratives that can frame social imaginaries and policy-making on immigration in terms of interdependence. In such a context, the ways in which Nica- raguan women experience inequalities and misrecognition in Costa Rica is not a publicly recognized issue. For instance, their employers do not affiliate them to the CCSS (it is estimated that only Io per cent of the total paid domestic workers are registered in the CCSS), and so they will not have a chance to obtain health provision and/or a pension.

Despite the fact that most of migrants are not of an age at which they require frequent visits to clinics, 'common sense' hostility in Costa Rica makes sense of the decline in public services (including health) as a consequence of the demand from migrants. The 'Nicaraguan other' is deeply embedded in jokes, emails, interpersonal conversations, blogs, and entertainment programmes. The principal consequence of this conversion is probably that xenophobia and racism have been turned into 'common sense' and few respond to it from a critical perspective in daily life.

These mythologies are not justified by the empirical evidence and instead respond to prejudices that research could reveal. For example, the evidence confirms that there is no causal relationship between the increase in certain forms of criminality and the migrant population. The percentage of incarcerated Nicaraguan men is close to the total percentage of Nicaraguans in the country. The analysis of the association usually established between the decline in public services and the immigrant population has been refuted based on the consideration that this decline forms part of the reduction of public investment, a typical neo-liberal policy that has been in place for nearly three decades (Sandoval 2004).

In this context, nationalist imaginaries seem to be replacing social ones as the main reference for elaborating an understanding of institutional changes and social relations. In this context, two tasks are particularly difficult. One is how to present to non-specialized audiences how this nationalization of politics influences the way in which Costa Ricans in a more vulnerable situation perceive Nicaraguans as the ones who are taking away their jobs, services, and rights.

The second difficulty is that identification with images of a 'nation threatened' by immigrants is characterized by a strong subjective component while explanations rooted in 'hard data' don't usually approximate the most emotive forms of ascription. Perspectives interested in subjectivity, common to psychoanalysis, deal with hostility as a 'projective identification' that condenses around those who are considered 'others' the sense of fragility that individuals experience in the external world (see Rustin 200I; Clarke 2003; Totton 2006). Unfortunately, at least in the case of Costa 
Rica, these forms of understanding hostility and xenophobia have been more used as an interpretive resource than to guide public intervention strategy. For example, we have no experience in translating this notion of 'identificatory projection' into public discussion in daily life. The absence of debate about the preeminence of nationalism as collective identification and the limited public reflection about the subjective dimension leave space for legitimating the right wing. The 20IO election campaign had as one of its variants the consolidation of a kind of authoritarian populism (Hall I979), in which the Right, which is never named as such, promised zero tolerance and maximum punishments for those who committed crimes, rather than emphasizing the opening up of markets - the latter being a promise that would be unfashionable in the context of the economic crisis. The framing of the campaign drew on a populist repertory in which the icon was a semi-naked man who justified his few belongings as the only way to ensure that he wouldn't be robbed (Sandoval 20IO). Despite the fact that throughout the years 2010 and 201 I the percentage of homicides and the perception of insecurity have diminished, the latter is still considered as the most important problem of the country (Sandoval 20I2b).

Probably the most important consequence of the legitimization of populist authoritarianism is that it became the frame around which the political parties organized their campaigns. The Right ended up presenting itself as in the centre of the political spectrum. The centre-left opposition either didn't try or failed to introduce another vocabulary and other imaginaries (Sandoval 20IO).

A fourth way of addressing xenophobia is rather more practical and based on communal experiences, especially in impoverished neighbourhoods where canteens, health clinics, and educational facilities emerge from the links between churches, NGOs, and communities. Most of these initiatives began as a consequence of cooperative links growing out of the experience of exclusion and the attempt to create institutional facilities that help forge a sense of community. In fact, impoverished communities where Nicaraguans and Costa Ricans live together do not exhibit a nationbased divide. Many families in these communities are mixed, and nationality is not an issue in itself.

Despite the conflicts, rivalries, and contradictions present in the community projects, a social fabric of cosmopolitanism from below is given form around the eating establishments, clinics, and schools. These are the cases of binational communities such as $\mathrm{La}$ Carpio, Barrio Nuevo, or El Triángulo de Solidaridad, situated in Costa Rica's capital. As Mark Goodale (2007: 2I) points out: “...many of the most important actors whose encounters with human rights discourse contribute to its transnationalism never physically leave their villages or towns, or countries". Unfortunately, the image these communities have in the public sphere is of criminalized places. Figuring out how to legitimize a place for its cosmopolitanism-from-below in public speeches is a challenge that may possibly require putting it to music, or into literary and audiovisual fiction. For the time being, these are largely tasks that have been postponed by those working in universities, NGOs, churches, etc.

Recognition of how solidarity and hospitality emerge from daily life could be a priority for intellectual perspectives that prioritize deconstruction, but, as Jonathan Rutherford (2007: I9) notes, "lacked the ethical resources to generate new, more egalitarian social relationships and identities to replace those they sought to undo". A far-reaching challenge, particularly relevant in the study of the imaginaries of immigration, is to become more aware of how to articulate efforts and horizons of hope.

\subsection{Seeking Cosmopolitanism-from- below}

The cosmopolitan is usually conceptualized as a citizen of the world (Tomlinson 1999). Although the term is often used as an alternative to the narrow sense of national or provincial belonging, it has also been noted that it is mainly framed as a "[Male] white/First World take on things" (Massey quoted by Tomlinson I999: I87). As Jonathan Friedman (I997: 81; quoted by Morley 2000: 239) asks, "who can afford a cosmopolitan identity?". Nonetheless, there are also "cosmopolitans in spite of themselves" who forge what might be termed "mundane cosmopolitanism" (Hebdige quoted by Morley 2000: I74). Close to the latter, cosmopolitanism from below aims to envision ways of being which emerge from the experiences of displacement and forced migration. Cosmopolitanism from below emerges from those who do not perceive themselves mainly through narratives of belonging, but who are searching for new ways of being. People living in 'glocal' impoverished communities are learning how to share even when they hold few material resources and are often criminalized.

The analysis of legislation and media imaginaries would unquestionably remain incomplete if the experiences of the migrant community were not simultane- 
ously explored. This experience is often the object of external discourses, but is seldom recognized as the subject of its own enunciation.

'Giving voice to those who have no voice', as it was phrased in Latin America thanks particularly to the vitality of Liberation Theology, is being transformed into the need to listen to these 'others', who have always had a voice but are not recognized as equals. Life stories and other tools of ethnography, for example, are indispensable to inscribe part of the life experiences of the millions of men and women forced to leave their countries in search of opportunities. Community work is easily regarded as 'asistencialismo' (a paternalist, dependency-producing handout approach), unable to transcend immediate needs. Sometimes it is suggested that what is required is more political-oriented work. It has meant a certain division of work among those who undertake community work and those who have more mainstream political priorities. This identification of a local focus with asistencialismo, contrasted to what we could call 'public as political', has been a damaging dichotomy. While the community work could be driven by asistencialismo it also can be an opportunity for those excluded to forge a grounded political culture.

The construction of collective memory growing up around community struggles and efforts is an essential task in terms of political culture. Elizabeth Jelin (2002: 2) suggests that memories are subjective processes, anchored in experiences and in symbolic and material frameworks, and are objects of dispute, conflict, and struggle. Thus they change over time and with that the sense of the past varies. "There is an active political struggle around the sense of what occurred, but also about the sense of memory itself" (Jelin 2002: 6), she argues. Memory as socio-historical construction is a referent for the construction of collective subjectivities and identities. "Identities and memories are not things we think about, but things we think with" (Gillis 1994, quoted in Jelin 2002: 25). As Richard Johnson and his colleagues (2004: 264265) also point out, we can only know what we are thinking and feeling when we express it to others, giving it a defined cultural form. That is to say, the lived experience has to be turned into narrative to be communicated.

Collective memory - being able to articulate struggles, efforts, community initiatives - is a precondition for the constitution of political subjects, who are often effaced by the clientelism of traditional political parties and are not considered as peers by the Left. Thus community work, without being named as 'po- litical', is nevertheless so. And what is more important is that, without this grounded political culture, efforts at a national scale cannot go beyond the expression of the critical middle classes. In the terms of de Sousa Santos, collective memory emerges as a way of translating experience into narratives that are to be shared within the local communities. This process of translation seems to require cultural forms (music and videos among others resources) through which new generations would probably be able to reflect creatively on their lived experience.

As well as this, more explicit political work, for instance campaigning for a reform of immigration legislation, needs to be grounded in the local communities. In her critique of the dichotomy between antiracist work, which used to take place more locally, and the anti-globalization initiatives that do not maintain strong links with those displaced by the global forces of capitalism, Alana Lentin (2004: 298) notes:

For these writers, the displacement of the localized refers to the effort to connect local and global which seeks a common project of intellectual and activist resistance against consolidated transnational counterforce: globalization. Nevertheless, their failure to confront the immediacy of the extremely localized difficulties faced by the 'migrant' - conceptualized as a symbol or a movement rather than as an individual - and the negotiations which must take place at the level of the locality in the interests of survival is indicative of the failure of anti-racism to be fully included in the new politics they describe.

So, most of the time the everyday efforts made in local communities are not perceived by mainstream audiences as 'politics'. A major challenge ahead is how to build links between communities through the recognition that sharing experiences would prompt the creation of a variety of networks. Currently, local communities know little of similar efforts in other communities located not far away. On the other hand, proposals to build networks are conceived at national or regional levels and usually are implemented with little reference to local communities. A common consequence is the disposition to 'speak on behalf of migrants' even though migrant communities scarcely know of the organizations that supposedly represent their interests.

This issue of 'who speaks on behalf of whom' introduces the issue of representation. Most of the repertoires intended to contest xenophobia discussed above are part of initiatives undertaken by institutions - NGOs, churches, and UN projects, among others that have weak links with local communities. The few existing organizations of migrants themselves are tiny 
and are characterized by mutual recriminations. It seems that the hostility against migrants and the political polarization of Nicaraguan society has diminished the possibilities of collective action. Additionally, political parties in Nicaragua do not recognize emigration as a challenge for their own agendas and, except in electoral periods, ignore their co-nationals in Costa Rica. What seem to matter are remittances, not those who produce value.

The possibility of larger migrant organizations able to produce their own ways of demanding recognition and distribution in different forums (Fraser 2008) seems to depend on the recognition that any collective action project has to be grounded in the communities. Rather than a fixed agenda and rigid ways of working, collective efforts have to be strategic, based on limits and potentialities. Again, translation, rather than a sort of master plan, seems to be the key. However, translation implies actors who are able to be present at different scales. The intellectual division of work between community work and national or international advocacy is without reservation an impediment for translating agendas and the triangulation of efforts. In other words, the challenge not only refers to ideas or proposals but also to the 'situatedness' of academic, social, and political actors. Migrant communities are impoverished and share a vast number of limitations, but at the same time they are vital to a number of key economic activities. In interviewing women who work in the pineapple industry Costa Rica is the leading world exporter - they recounted how they stopped a pineapple processing plant because they did not receive a minimum wage. Instead their income was based on the amount of fruit selected, and they received very little money if the number of fruits selected for export declined. So they wrote a letter to justify their refusal to continue working. The managers agreed to change the payment scheme (Sandoval/Brenes/Paniagua 20I2). Such experiences have to be channelled into a long-term effort of constituting political subjects, and social science research can contribute to this.

The key may reside in the articulation of efforts and mobilizations rather than in mutual disqualification. One step in the linking work may consist of facilitating possibilities for political formation in communities, so that those who participate in community initiatives may also acquire competencies to participate in national or regional networks. In other words, independent of the migratory condition, pedagogical processes need to be facilitated that strengthen what Davis, Martínez, and Warner (20I0: 87) call "substan- tive citizenship" (in contrast to formal citizenship, according to which people are seen as having an irregular status or are residents, etc.) - initiatives through which people can participate in their barrios, making use of public spaces, as well as participating in political actions on a broader scale.

Cosmopolitanism from below seems to be essential to any larger project of politics, in terms of envisioning ways of work, content, and form. Cultural forms through which contestation can take place have so far been barely discussed. The capacity to identify cultural forms that can appeal to people to recognize what Costa Rica's most vulnerable groups have in common with the migrant community is a key political challenge. The possibility of accomplishing this depends, again, on a close relationship with the local communities.

\subsection{Conclusions}

For the research team that has been involved in studying Nicaraguan migrants in Costa Rica, various challenges have come up in the attempt to intervene in policy formulation, the critique of imaginaries, and community work. The first one refers to the ethical dimension, and relates to the responsibility that follows from listening. In other words, listening does not just involve attentively following what the migrants are saying, but it also involves raising questions about the ways in which what was said could be translated to decision-makers. Here there seems to be an important challenge for the social sciences, since needs assessments are frequent, and most often agree in their main conclusions, but there is usually no great willingness to follow up on the demands that are identified.

A second challenge consists of the possibilities of creating work teams in which colleagues with different backgrounds can contribute to the research work and the ways in which the main findings can influence public policies, but also to the political work in a broader sense. The demands posed by the communities recall the tensions that arise from the relations between those social science perspectives most centred on analytical or comprehensive perspectives and those most interested in normative perspectives. Such tensions become more alive when what they are dealing with is not so much reproducing the analytical/normative distinction, but linking and articulating findings and policy-making (or politics) based on concrete situations and cases. 
A third challenge refers to the possibilities that one can advocate public policy formulation based on research. It is not hard to recognize that there is often mutual resistance between policy formulators and those of us who do academic research, above all at times like today, when policies maintain an accentuated orientation in general neo-liberal terms and academic research defends critical analysis. Nonetheless, based on the work experience around the Migration Law and its regulations, it is worth insisting that advocacy must not be discarded. Although the results are limited, it is even more limiting to assume that the social sciences only consist of critically assessing the country's development style without attempting to use the knowledge gained to influence the course it is taking. While it is possible to intervene in the course of processes, it involves recognizing that those possibilities are limited in certain topics and institutional contexts and are greater in others. It is also important to recognize that in the process of demanding, the collective effort becomes visible, while also making visible the agendas they are trying to legitimize. That is, the stakeholders and agendas are not preconfigured ahead of time; there is a learning process and an

\section{References}

Asamblea Legislativa de la República de Costa Rica, 2009: Ley de migración y extranjería $\mathrm{N}^{\circ} 8764$ (San José).

Bakhtin, Mikhail, 198I: The Dialogic Imagination: Four essays by M.M. Bakhtin [Michael Holquist (Ed.); Caryl Emerson and Michael Holquist (translators)] (Austin: University of Texas Press).

Benhabib, Seyla, 2004: The Rights of Others. Aliens, Residents and Citizens (Cambridge: Cambridge University Press).

Bhattacharyya, Gargi, 2008: Dangerous Brown Men. Exploiting Sex, Violence and Feminism in the War of Terror (London: Zed).

Bhattacharyya, Gargi; Gabriel, John; Small, Stephen, 2002: Race and Power. Global racism in the twenty-first century (London: Routledge).

Bolaños, Olman; Brenes, Mónica; Paniagua, Laura; Sandoval, Carlos, 20II: Un país en donde quepa toda la gente. Derechos y responsabilidades de las personas migrantes en Costa Rica (San José: Lara y Segura).

Bourdieu, Pierre; Wacquant, Loic, I992: An Invitation to Reflexive Sociology (Chicago: University of Chicago Press).

Brenes, Mónica; Fernández, Karen; Paniagua, Laura; Sandoval, Carlos, 20I0: Ciudadanías en práctica. El ejercicio de los derechos de personas migrantes en Costa Rica en la Sala Constitucional (San José: CONAMAJ).

Burawoy, Michael, 2005: "For Public Sociology" in: American Sociological Review, 70: 4-28. accumulation of capacities indispensable to future efforts to legitimate new demands. The translation of international law and constitutional law into the analysis of migration legislation can be mentioned as a case in point. Similarly, ways can be recounted in which social science can call into question public policies that used to be taken for granted. A last example might be the challenge of articulating community projects which give material support to impoverished communities often inhabited by migrants, and political education through which those who join the initiatives can recognize the sources of their everyday misfortunes.

A fourth challenge, incipient in the experiences narrated here, refers to the ways migrants themselves can join with the institutions in advocacy work so that the formulation of demands does not fall exclusively to those who work in universities, NGOs, churches, and other institutions. In some cases more than in others, the participation of community members has been incorporated into some of the initiatives described here. But without doubt, the integration of broader collectives should not be considered a second-rate priority.

Burawoy, Michael, 2007: "The Field of Sociology: Its Power and Its Promise”, in: Clawson, Dan; Zussman, Robert; Misra, Joya; Gerstel, Naomi; Stokes, Randall (Eds.): Public Sociology. Fifteen eminent sociologists debate politics of the profession in the twenty-first century (Berkeley: University of California Press).

Chavez, Leo, 200I: Covering Immigration: Popular Images and the Politics of the Nation (Berkeley: California University Press).

Chavez, Leo, 2008: The Latino Threat. Constructing immigrants, citizens, and the nation (Berkeley: University of California Press).

Clarke, Simon, 2003: Social Theory, Psychoanalysis and Racism (London: Palgrave).

Davis, Stephen; Martínez, Juan; Warner, Stephen, 20I0: "The Role of the Catholic Church in the Chicago Immigrant Mobilization", in: Pallares, Amalia; FloresGonzález, Nilda (Eds.): ¡Marcha! Latino and the Immigrant Rights Movenment (Champaign, IL: University of Illinois Press).

DeGenova, Nicholas, 2002: "Migrant 'illegality' and deportability in everyday life", in: Ann. Review of Anthropology, vol: I4I9-I447.

De Sousa Santos, Boaventura, 2009: Epistemologías desde el Sur (Buenos Aires: CLACSO).

De Sousa Santos, Boaventura, 20I0: "Prólogo", in: Pazmiño Freire, Patricio (Eds.): Del Activismo Social a la Justicia Constitucional (Quito: FLACSO). 
Fanon, Franz, 1986: Black Skin, White Masks (London: Pluto).

Fraser, Nancy, 2008: Scales of Justice. Reimagining Political Space in a Globalizing World (Cambridge: Polity Press).

Friedman, J., I997: "Global crises, the struggle for identity, and intellectual pork-barrelling”, in: Werbner, P.; Modood, T. (Eds.): Debating Cultural Hybridity (London: Zed): 70-89.

Gillis, John, 1994: "Memory and identity: the history of a relationship", in: Gillis, John R. (Ed.): Commemorations: The Politics of National Identity (Princeton: Princeton University Press).

Goodale, Marc, 2007: "Locating Rights. Envisioning Law between the Global and the Local", in: Goodale, Marc; Engle, Merry Sally (Eds.): The Practice of Human Rights. Tracking Law between the Global and the Local (Cambridge, MA: Cambridge University Press).

Green, Michael, 1997: "Working practices", in: McGuigan, Jim (Ed.): Cultural Methodologies (London: Sage).

Hage, Ghassen, 1998: White fantasies (Sydney: Pluto Press).

Hall, Stuart, I979: "The Great Moving Right Show" in Marxism Today, January.

Hall, Stuart, I98I: "The Whites of their Eyes: Racist Ideologies and the Media", in: Bridges, George; Brunt, Rosalind (Eds.): Silver Linings: Some Strategies for the Eighties (London: Lawrence and Wishart). Reprinted 1990 in: Alvarado, Manuel; Thompson, John (Eds.): The Media Reader (London: British Film Institute).

Hays, Sharon, 2007: "Stalled at the Altar? Conflict, Hierarchy, and Compartmentalization in Burawoy's Public Sociology”, in: Clawson, Dan; Zussman, Robert; Misra, Joya; Gerstel, Naomi; Stokes, Randall (Eds.): Public Sociology. Fifteen eminent sociologists debate politics of the profession in the twenty-first century (Berkeley: University of California Press).

Hebdige, Dick, I990: "Fax to the future", in: Marxism Today, January: 20.

Hill Collins, Patricia, 2007: "Doing the Sociology That Had No Name”, in: Clawson, Dan; Zussman, Robert; Misra, Joya; Gerstel, Naomi; Stokes, Randall: Public Sociology. Fifteen eminent sociologists debate politics o the profession in the twenty-first century (Berkeley: University of California Press).

Hobsbawm, Eric, 1998: “The Death of Neoliberalism”, in: Marxism Today, Nov/Dec.

INEC [Instituto Nacional de Estadística y Censos], 20II: Encuesta Nacional de Hogares. Cifras básicas sobre fuerza de trabajo, pobreza e ingresos (San José: INEC, July).

Jelin, Elizabeth, 2002: Los trabajos de la memoria (Madrid: Siglo XXI).

Johnson, Richard; Chambers, Deborah; Raghuram; Parvati; Tincknell; Estella, 2004: The Practice of Cultural Studies (London: Sage).

La Nación, 20II: "Me venía preparando para atender algo muy complicado”, in: 27 August.
Lentin, Alana, 2004: Racism \& Anti-racism in Europe (London: Pluto).

Lipsitz, George, 1999: The Possessive Investment in Whiteness. How White People Profit from Identity Politics (Philadelphia: Temple University Press).

Marcenaro, Petronio, 2007: Al otro lado del Río San Juan (San José: Editorial Costa Rica).

Massey, Doreen, 1994: Space, Place and Gender (Cambridge: Polity Press).

Mills, Charles Wright, 1987: La imaginación sociológica (México: Fondo de Cultura Económica).

Mora, Tatiana, 2000: Poverty matters, but to what extent? Perceptions of poverty through the literary discourse in Costa Rica (The Hague: Institute for Social Studies, Working Paper No. 3IO; <http://repub.eur.nl/res/pub/ I9055/wp3IO.pdf>.

Morley, David, 2000: Home Territories. Media, Mobility and Identity (London: Routledge).

Nakano Glenn, Evelyn, 2007: "Whose Public Sociology? The Subaltern Speaks, but Who Is Listening?”, in: Clawson, Dan; Zussman, Robert; Misra, Joya; Gerstel, Naomi; Stokes, Randall (Eds.): Public Sociology. Fifteen eminent sociologists debate politics \& the profession in the twenty-first century (Berkeley: University of California Press).

Ngai, Mae M., 2004: Impossible Subjects: Illegal Aliens and the Making of Modern America (Princeton, NJ: Princeton University Press).

Paniagua, Flory, 20I0: La embajadora de la ciudad de las naranjas en Costa Rica (Heredia: Litografía Morales).

Press Conference, 20I2: "La Ley de Migración en Costa Rica: A dos años de su entrada en vigencia. Promesas, realidades y desafíos", San José: 28 March.

Rustin, Michael, 200I: Reason and Unreason. Psychoanalysis, Science and Politics (London - New York: Continuum Books).

Rutherford, Jonathan, 2007: After Identity (London: Lawrence and Whishart).

Sandoval, Carlos, 2004: Threatening Others. Nicaraguans and the formation of national identities in Costa Rica (Athens: Ohio University Press).

Sandoval, Carlos, 2009a: "Narrating lived experience in a binational community in Costa Rica”, in: Bhattacharyya, Gargi (Ed.): Ethnicities and values in a changing world (London: Ashgate).

Sandoval, Carlos, 2009b: "Zonas de contacto entre las ciencias sociales", in: Cook, Elizabeth (Ed.): Género y Religión, Sospechas y aportes para la reflexión (San José: Universidad Bíblica Latinoamericana).

Sandoval, Carlos, 20ıо: "Costa Rica: El triunfo de Chinchilla sella veinte años de derechización”, in: Envío, 29,344: 32-39.

Sandoval, Carlos, 20I2a: "Contestar la hostilidad antinmigrante en Costa Rica: Un proyecto de ciencias sociales públicas en curso", in: Mirian Llona (Ed.): Entreverse. Teoría y metodología práctica de las Fuentes orales (Bilbao, University of the Basque Country). 
Sandoval, Carlos, 20I2b: "De Calero a la Trocha. La nueva disputa limítrofe entre los gobiernos de Costa Rica y Nicaragua (20IO-20I2)", in: Anuario de Estudios Centroamericanos, 38: I77-I92.

Sandoval, Carlos, 20I2c: "Presentación", in: Huhn, Sebastian (Ed.): Criminalidad y discurso en Costa Rica. Reflexiones críticas sobre un problema social (San José: FLACSO).

Sandoval, Carlos; Brenes, Mónica; Masís, Karen; Paniagua, Laura; Sánchez, Esteban, 2007: Nuestras vidas en La Carpio. Aportes para una historia popular (San José: Editorial de la Universidad de Costa Rica).

Sandoval, Carlos; Brenes, Mónica; Masís, Karen; Paniagua, Laura, 20Io: Un país fragmentado. La Carpio: Cultura, comunidad y política (San José: Editorial de la Universidad de Costa Rica).

Sandoval, Carlos; Brenes, Mónica; Paniagua, Laura, 20I2: La dignidad vale mucho. Mujeres nicaragüenses forjan derechos en Costa Rica (San José: Editorial de la Universidad de Costa Rica).

Tomlinson, John, I999: Globalization and Culture (Cambridge: Polity Press).

Totton, Nick, 2006: "Conflict, competition and aggression”, in: Totton, Nick (Ed.): The Politics of Psychotherapy (Berkshire: Open University Press).

Williams, Raymond, 1977: Marxism and Literature (Oxford: Oxford University Press).

Open Access. This chapter is distributed under the terms of the Creative Commons Attribution Non-commercial License, which permits any noncommercial use, distribution, and reproduction in any medium, provided the original author(s) and source are credited. 


\section{Part VII Conclusion}

Chapter 21 'Women in Motion' in a World of NationStates, Market Forces, and Gender Power Relations

Des Gasper and Thanh-Dam Truong 
 Gender Power Relations
}

\author{
Des Gasper and Thanh-Dam Truong
}

\begin{abstract}
This chapter provides concluding reflections from a set of nineteen case studies of transnational and intranational migration and mobility. It contrasts the 'sedentary bias' present in policy regimes and associated thought centred on nation-states, where movement is seen as exceptional, including normatively exceptional, with the centrality of movement in the processes of socio-economic change and evolution, particularly those promoted under capitalist systems of economic organization. While market capitalist and nation-state principles of organization differ, they combine in hybrid systems, such as those currently being elaborated in policy regimes for temporary migrant workers, to exploit migrant labour. Many of these arrangements mirror the indentured labour regimes of earlier eras. The chapter presents by contrast a perspective based on principles of human rights and human security that uses a global framework both for understanding and for evaluation and then adds an explicit gender-aware enrichment of that perspective, in order to do justice to the special vulnerabilities and exploitation of women's migrant labour. A human security perspective, in particular, helps to base concern for human rights in an awareness of bodily and emotional needs, of global interconnections, and of the intersecting circumstances in people's everyday lives; but it requires, and lends itself to, gender-enrichment through partnership with insights from feminist theory, as illustrated in the book's various case studies. The systems of the nation-state, market capitalism, and gender power that are discussed in this chapter, that structure the experiences of migrant women workers, are very deeply established. The chapter suggests directions for possible re-cognition, to reduce and counter the invisibility and misframing of migration, and of women and their work; it also suggests priority areas for research and networking following the format employed for the book: linking researchers, policy practitioners and migrant advocates, South-South-North.
\end{abstract}

Keywords: Women's migration, human security, human rights. migration regimes, globalization, women's labour, intersectionality.

\subsection{Themes}

This book reflects the great scale and reach of contemporary migration and its far-reaching impacts, notably the frequently problematic outcomes in terms of quality of life and well-being for many of the more vulnerable migrants, especially women. Mobility is a normal and necessary component in the processes of economic, social and personal development and evolution, and of learning and cultural enrichment (section 2I.2). Yet in a world structured around, firstly, a nation-state system and nationalist principles of identity, mobility - at least the mobility of poor people - is treated as not normal, and it is assumed that migrants do not have to receive normal treat- ment. 'People on the move' was the title of the chapter on migration in the report Human Security Now (CHS 2003). As counterpart to that phrase we take instead 'women in motion' (Oishi 2005) for the title of this concluding chapter, since 'women on the move' has become mostly used as a catchphrase for upward professional mobility, which does not fit the cases addressed in this book.

Contemporary migration is structured, secondly, by the pull of market power and by largely capital-centred policy calculation (section 2I.3). Nowadays ministries of finance and economic affairs often dominate migration policy, not ministries of social welfare or labour. Within these market processes, women's labour is especially in demand. The principles of the capital- 
ist market are fundamentally different from those of the nation-state. ${ }^{1}$ The former is not only open to migration but actively generates it, and current migration is in part a response to greatly increased global and intra-national inequality. ${ }^{2}$ But the two sets of principles are widely combined in hybrid policy regimes which seek to maximize profit while minimizing perceived costs to national identity in richer states. These hybrid regimes draw on migrant labour while minimizing the rights granted (sections 2I.4-2I.6).

Thirdly, central to the investigations in this book, a remarkably high proportion of migrant labour is now women's labour. Around eighty per cent of Indonesia's international labour migrants, for example, are women (Sukamdi 2008); a similar percentage among Burmese workers in factories in Thailand is reported in various studies (Pearson/Kusakabe 20I2: 78). Yet this feature is still relatively little considered in policy

1 This essay adopts the usage 'nation-state' rather than 'nation state'. Historically such terms were originally used to help differentiate between types of state: compared to a city state or empire a nation state was a "sovereign state of which most of the citizens or subjects are united also by factors which define a nation, such as language or common descent" (Oxford Dictionary of English 20IO). However, in the literatures of political science new layers of meaning emerged. In the realist tradition of international relations, the terms nation and state have often come to be used interchangeably. Some lines of work have explored the meaning of this coincidence, its fusion of belonging and governance. In the nation-state an apparatus of governance ('the state') has fused with the society it governs, so that the unit of governance is asserted to be also in important respects an integrated community and body politic: an identity-area and not only a governance-area. Use of only a few terms is inevitably imperfect for describing the many situations possible. In English, 'state' is ambiguous: it sometimes refers to a country and sometimes to its state apparatus, because of the history of partial fusion. 'Nation' too is ambiguous: it sometimes refers to a country but also has strong connotations of cultural community. However, the term 'nation' does not now imply necessarily a relatively full cultural or ethnic unity; any significant degree of shared identity is sufficient, and is typically achieved (despite considerable internal heterogeneity) in important part through distinguishing a 'We' as against a 'They'. The disadvantage of the term 'nation state' then is to convey a too simple picture. The hybrid term 'nation-state' is intended here to better suggest, by its evident artificiality, the social construction of a system of governance which includes both a notion of civic belonging and citizenship and a culture of national feeling and identity, the latter based on (in Benedict Anderson's term) an 'imagined community'. discourse and even in much research on migration. Women's work, whether in formal or informal workplaces or in homes, whether in labour-importing countries or labour-exporting countries, remains to a large extent 'invisible' (section 2I.7). Thus, in addition to the structuring roles of legal and policy regimes and of market forces, structures of gender power are also at play in the huge growth of exploitation of migrant women's labour, as we outlined in the Introduction.

Nowadays, women may even constitute the majority of international migrants, given the scale of demand for their labour in most sectors, reflecting their perceived greater docility because of family commitments, ${ }^{3}$ and especially the demand for their services as care workers, maids, and providers of sexual services (for pleasure, intimacy and emotional wellbeing as well as for biological reproduction). These last three roles and more are combined in the case of arranged foreign brides, as illustrated in chapter 5 . Enormous numbers of women from low-income countries, and especially from South and South-East Asia, now play such roles in richer countries. Many chapters in this book address a new global class of women, who form one of the largest groups of international migrant workers and yet whose labour is not recognized as 'real' 'work' by domestic laws and migration regimes, and who thus work with little protec-

2 Economic calculation is, however, never more than part of the causes of migration. Goldin, Cameron, Balarajan (20II) note that the US mainland has three times the average income and a quarter of the unemployment of the American territory of Puerto Rico, whose residents have the right to emigrate to the mainland - yet the large majority choose not to (p. Ioo). Worldwide, economic analysis alone cannot explain why still relatively few people try to migrate, why emigrants are concentrated among particular social groups and localities, and why even chronically ageing Japan holds out against official in-migration. The relevant costs excluded by the economic analyses include costs of meaning and identity too; thus Goldin, Cameron and Balarajan (20II), using economists' highly restricted notion of welfare admit that their accounting is purely in 'economic and welfare' terms (p. 269.)

3 Of the Burmese women in Thailand interviewed for chapter 4 , three-quarters 'related that they had migrated out of a sense of duty to their parents' (Pearson/Kusakabe 20I2: 58), and many supported younger siblings. They continue their remittances home much longer than their male counterparts, including after marriage (ch. 3). Yet having gone to Thailand to support their families in Burma, many gradually lose their place and social base in Burma but remain rejected outsiders in Thailand and never achieve much security $($ chs 6,7$)$. 
tion and who are disproportionately subject to abuse. In recent times both India and Indonesia, for example, have been led in some cases to stop their citizens taking up contracts abroad as domestic servants until conditions were improved (see, for example, TIP 2010 on one Indonesian proscription on moving to such work in Kuwait). But, as observed by Irianto and Truong in chapter 2, of the 109 articles in Indonesia's 2004 law on the placement and protection of migrant workers abroad, only eight cover protection. Women are disproportionately affected too by the care burdens that remain in the country of origin when men or women leave to work in another country. Largely similar issues arise in much intra-national migration too.

The phrase 'feminization of migration' has become popular to refer to women's increasing statistical share in various migration streams (internal, South-North, South-South). Studies in this book show the importance of the qualitative dimensions, in addition to headcounts: how migration practices bear distinct gendered values, norms and characteristics, the gender-differentiated treatment of migrants, and gendered modes of migration and means of migrant livelihood. That migration's patterns and effects are strongly gendered should be no surprise: gender is not a peripheral decorative feature in social life but a core dimension. Formal migration research has however been dominated by behaviouralist approaches that are preoccupied with surface phenomena and that try to build generalized models about, for example, when people move and the impacts on economic production (for further discussion, see Truong/ Gasper 20IIa, and chapter I in this volume). The spectacular rise in officially measured international remittances, from an estimated US\$3I bn. in 1990 to US\$3I6 bn. in 2009, has understandably attracted attention. What migrants - especially migrant women experience and think has been a lower research priority, so that many of the realities of social life have stayed relatively neglected. Yet according to studies reviewed in one recent survey of global migration (Goldin/Cameron/Balarajan 20II: IO-I2), these new realities include accelerated innovation, including innovation in identities (not least via the movement of brides).

Even Goldin, Cameron and Balarajan's prominent survey still in many ways reflects the slight and unbalanced attention typically given to migrant experience. The lead author, Ian Goldin, earlier a vice-president of the World Bank, heads the Oxford Martin School of futures studies at Oxford University, and evinces throughout the book a sympathy for migrants that re- flects his own family history and personal trajectory, as a progressive émigré South African of East European Jewish background. But the perspective remains the abstracted generalized gaze typical of an economist. Women migrants receive very little specific mention. Only two-thirds of the way through the book and two-thirds of the way through a fifty-page chapter on the impacts of migration focusing overwhelmingly on measured economic impacts - do women migrants at last specifically appear, in one brief mention that they are the most absolutely and relatively disadvantaged participants in labour markets compared to the native workers (p. 194). The treatment of the social costs of outmigration more broadly remains remarkably brief and superficial (e.g. p. 193). In these respects the book is typical of many treatments of migration, which underrate the various aspects of societal reproduction, including the biological, familial, emotional, psychological, and cultural.

The present book has in contrast explored the lifeworlds of migrants, especially migrant women, the impacts on migrants' security and insecurity of the systems of nation-state membership and exclusion and of global market power, and how migrants seek to cope and respond. This concluding chapter reviews and reflects on themes arising from these studies, from a workshop on the draft volume held in Trivandrum in February 20I3, and from wider literatures. ${ }^{4}$ It does not attempt a summary, which has already been offered in chapter I. Instead it essays an interpretation and commentary with reference to key issues, of which some are specific to women migrants and others common to all migration or all international migration. Part of our analysis will locate migrant women's problems within the context of market-dominated development transformations and nation-state systems (sections 2I.2-2I.6); and part will highlight the specific and additional difficulties that millions of migrant women face, and the shifts of cognition and representation that are needed to acknowledge and respond to these, as well as sister shifts needed to respond to the structural forces that affect all migrants (sections 2I.72I.9). Since the opening chapter has theorized gender dimensions in some depth, this closing chapter pays considerable attention to the latter forces too. It seeks to identify causal structures and also their social construction, and thus to indicate some spaces for reform efforts.

4 Our thanks go to all the workshop participants, not least Indu Agnihotri, Ruth Pearson, and Anita Shah, for helpful and thought-provoking contributions. 


\subsection{Migration is Major and Normal but is Treated as Exceptional and Ethically Aberrant}

The 20I0 World Migration Report reported 2I4 million people now living outside their country of birth. Sometimes it is observed that this constitutes only three per cent of the world's population, a modest share that is little or no higher than twenty or a hundred years ago. However, the figure is misleading in several respects, quite apart from the question of the possible and increasing exclusion of many irregular migrants from the statistics. It does not include children who have not themselves emigrated but have been born in a different country from where their parents were born and grew up, or have been left behind and separated from one or both parents who have emigrated. And it does not include other persons who are also strongly involved: the other family members and (former) close associates of the emigrants in their country of origin; people who have moved earlier in their lives but have returned to their country of origin; people who are preparing to emigrate; and others who are strongly affected by emigration, whether in the countries of origin or destination or en route. If we include these groups we talk of a figure several times larger. Beyond this, and much more than in earlier eras, the 'transnational' character of much present-day movement - that so many people retain strong connections with a land (or lands) of personal or family origin, through more frequent visits and communication, cultural exchange and identification, strong family links, and even recurrent switches of place of residence - has profound implications (see, for example, Truong/Gasper 2008b, 20IIb).

The numbers of intra-national migrants are several times higher: estimated at over 300 million in India alone, including a large majority of women migrants (whose primary recorded reason for migration is marriage). Most of the themes that arise in the discussion of international migration - of the economic impacts of remittances and of absences and returns, of the political and psychological impacts of cultural change and interchange, of social strains and endangered social cohesion, of changed gender roles, of the emergence of new identities different from those prior to the move, and more - often apply almost equally in internal migration. The existential gap between Jharkhand and Delhi may well be bigger than that between Delhi and Dallas or Dubai.

In contrast to the scale of movements, much social science and policy has been marked by 'sedentary bias' (Castles 2009): movement from the location where one was born is presumed to be abnormal, in the normative sense too, and especially when we speak of 'location' in terms of the scale of nationstates. Thus migration studies are not treated as a necessary dimension of all social studies but as a minor specialism. Moving between locations, and certainly moving between nation-states, is often presumed to arise from some failing, inadequacy, or sickness in the outmigration location's economy or body politic. In, for example, the leading American philosopher John Rawls's treatise The Law of Peoples, international outmigration is taken as proof that the country of origin's government has failed in its duties (see likewise the work of Rawls's prominent pupil Thomas Nagel [2005]). International migration, in contrast to trade or short-term travel, is thereby in this view excluded from the sphere of matters that governments are morally obligated to regulate amongst themselves by mutual agreement; instead, each government can regulate it as it sees fit. Such a perspective matches the conflation of migration with pathologies of crime and drug smuggling that has arisen in some 'homeland security'-type thinking. Young people's migration for work is likewise often presented as overwhelmingly due to the machinations of traffickers. Huijsmans has analysed the prevailing narratives concerning the movements of young women from Laos to Thailand (Huijsmans 20II; and chapter I9 in this volume). Movement supposedly destroys an idyll of childhood and/or rural residence; and young women are presented as forced to move in order to compensate for their drunken fathers' failure to earn. Huijsmans reports that the young Lao people he studied, not least the girls and young women, often in fact seek to migrate at an early age as a prestige-raising step towards becoming an adult, and that they cope competently with the challenges.

Movement by women is particularly prone to be represented as abnormal. Processes of nation formation have often included the strengthening of an image of women as symbols of family, domesticity, motherhood, and tradition, as counter-poles to Westernization, and as requiring male protection (Chatterjee 1993). Migrant women's lives expose and challenge these hegemonic norms; women who move are then liable to be treated either as trafficked or as perverted and hence as having forfeited their rights (Kapur 20I0).

Movement is a normal part of life and adaptation, as we can see from all human history, implied the World Migration Report 2008; though it was too cau- 
tious to say so openly, and so presented this position as just one possible perspective (IOM 2008; CampilloCarrete/Gasper 20II). Goldin, Cameron and Balarajan state the position openly, after a pointed review of human history. First, the human race is one. We all stem from a core group of perhaps two thousand humans who lived in East Africa a modest 75,000 years ago (Goldin/Cameron/Balarajan 20II: I2); they/we then moved, across the world. Second, 'Migration is not a problem to be solved. It is an intrinsic element of international society and inextricably bound up with globalization itself' (p. 260). Yet while movement is normal, borders make it seem not normal, and lead to special problems for migrants, pushed and pulled by the pressures in the world political economy.

Rawls's liberal justice framework uses the idea of a social contract amongst citizens. It reasons in terms of individuals who are tacitly viewed as members of a nation-state, which is the frame for the social contract, but not as residents of the globe who exist in and through global webs of relationships. Extraordinarily - given its formulation within the USA, a country founded on immigration - the framework excludes migrants and issues of immigration (Gasper 20II). What we can call its Westphalian perspective combines a normative nationalism - moral communities are held to exist only within borders, not across them - with an explanatory nationalism that seeks to explain and allocate responsibility for events within a country's borders exclusively within those borders, as do Rawls and Nagel and the governments of some rich countries. "[R]ich countries that energetically export arms to troubled poor countries whose manufactured and agricultural exports they at the same time firmly restrict through use of tariff and non-tariff barriers, while also drawing away their best educated personnel, yet hold the poor countries overwhelmingly responsible for their failed systems of governance and thereby draw no conclusions of moral obligation for themselves - obligations to help constructively, to cease destructive exports, to open economic opportunities, and to admit more deserving migrants" (Gasper/Truong 20IOa: 345-346). As global economic forces feed into local political conflicts and dynamics, the categories of economic migrant and political refugee merge in many cases, but this is denied in political philosophies grounded on nation-states.

Castles points out that most social science has shared the sedentary bias seen in modern nation-state policies. By the late twentieth century, however, we could no longer plausibly treat the nation as the natural, self-enclosed 'society'-cum-'economy'-cum-'polity' that had been typically assumed in the social sciences since their origins and codification in the eighteenth and nineteenth centuries (Wallerstein et al. 1996). The assumption that the nation-state, an apparatus of rule over a given geographical territory, also represents an economic and sociocultural community and exercises close control in it has come to diverge too far from reality. The present-day scale of flows of messages, ideas, hopes and values, commodities and finance, of longer-term and permanent migrants and refugees, and of short-term visitors, pathogens, weapons, and technologies, has required changes in social sciences' traditional choice of the boundaries of states as the main frame for organizing their attention.

\subsection{Global Interconnectedness and Global Economic Forces}

Methodological nationalism in social science analyses - automatically taking the nation as the appropriate framework - is obsolete. The much discussed 'transnational migration' of the past generation, for example, has involved the maintenance of ongoing intense interactions with the area of origin, including through trade, movements to and fro of persons, cultural relations and exchange of ideas, and much more. It is part of an increased global interconnectedness that generates global-wide streams of 'side effects' that render nationally-enclosed analyses outdated. This book is part of an ongoing passage from a conception of 'international migration' (a definition based on the nation-state as a unit and actor in international relations) to a conception of 'transnational migration' (based on the recognition of a transnational space formed by the trans-boundary activities of a variety of actors, including but not limited to the nation-state). The former conception is associated with a primary focus on the management of aggregate flows between countries (population, goods, finance, skills, etc.). The latter conception tries to grasp the interactions between the global and local dynamics of migration, and requires a multi-pronged approach in research, advocacy, and policy advice. Debates on migration that use an 'international migration' conception often fall into a "North versus South" framework which depicts a geographical divide and a binary opposition of power (North) versus vulnerability (South). More fruitful for dealing with contemporary realities in migration is to study structures, networks, and relationships that cut across national boundaries, including the practices adopted by migrants and their trans-local networks, in 
interaction with different state agencies, employers, migration brokers, and so on.

Kaye (2010) illustrates the interconnectedness by looking at some of the drivers of outmigration from Senegal. Senegalese farmers are out-competed by subsidized foreign produce, and many Senegalese fishermen have been displaced by foreign factory trawlers that exceed their approved catches. Eighty per cent of the country's rice is now imported. European governments see, or acknowledge, no causal connection between these economic patterns and the presence of European Union Frontex ships off the Senegal coast to block attempts at migration, sometimes in canoes, across the ocean to outlying territories that belong to Spain and Portugal (Kaye 20IO: 232-235). Tandian and Bergh's chapter in this volume noted how the Spanish government in 2008 recruited two thousand (again) Senegalese ex-fishery workers on permanent contracts. Kaye quotes the ambassador of Senegal to Spain - 'I think if Spain offered employment contracts in Senegal, it is because somewhere there is the phenomenon of canoes' - and shows us how behind the canoes are the factory trawler boats, the European Union's subsidies to fishers and farmers, and its de facto barriers to many types of processed and manufactured imports.

To draw these connections has been taboo in Northern governments and businesses; no globalwide social impact assessments of policies and programmes are undertaken. Kaye adds that the huge International Organization for Migration (IOM) contains negligible expertise on local development, because its central function has been to shift cheap labour into metropolises when it is required and back again when it is no longer wanted there. Despite IOM's name, forty per cent of its 2009 budget was funded by one country, the USA (Kaye 20I0: 249). The broader picture he presents is of how, being able to rely on a huge reserve labour army - from, for example, the Philippines, thanks partly to the lack of land reform there (Kaye 20I0: 39) - a footloose global capitalism pulls people here and there, whenever convenient to business, and whatever the formal legality.

Intensified global interconnections mean that not only do the actions of the strong impose 'externalities' on the weak worldwide, but also that sometimes and increasingly the weak 'talk back', whether through conscious reactions or through ramifying chains of consequences, such as in the fields of environment, education, and health. Old habits of the strong - imposing negative 'externalities'/'side-effects'/'collateral damage' on the weak - can boomer- ang and damage the strong too. Neglecting the education and care of some groups of international migrant children, within a framework of self-oriented national governance, for example - as in Japan or Thailand, where often the children of foreign workers have had and still have no de facto right to education (chapters 4 and 17) - may eventually lead to sad and disruptive outcomes. So can their exclusion from health care systems, and the roles of social inequalities in the emergence and spread of diseases (Farmer 1996). Undermining of local economies and of the care of children whose parents work abroad can lead eventually to a next generation of economically and psychologically displaced young people whose actions will not remain confined, in execution and effects, by national boundaries. Conflicts can spread, just like disease.

In the longer run, legal exclusion but de facto admission of low-skilled workers creates in some countries an undereducated marginalized underclass. It provides a supply of cheap labour, but can foster a world of associated illegality and criminality - of 'black money', bribes, and marginalized people who lack qualifications - whose existence then serves in the ideological reproduction of a certain sort of system of rule. It isolates a group or groups who are deemed 'other' and can be viewed as dangers: 'they' must 'therefore' be ruled firmly by a tough-minded national elite. The underclass can fulfil the role of scapegoat and be blamed for various social ills in a way that removes criticism from, indeed mobilizes support for, national elites (see chapter 20 by Sandoval-Garcia on these cultural dynamics in Costa Rica, Abella [20I3] on attitudes to migrants in ASEAN, and De Genova [2005]). The politics of securitization of borders in various parts of the world has eroded existing protection systems and promoted xenophobic sentiments. These have in turn encouraged ever more stringent practices of migration management where thinking is in terms of "flows of people" across borders rather than with understanding of persons having their own histories, networks, and contributions.

\subsection{The Attempted Maintenance of Nation-State Projects Through Migration Regimes of 'Temporary' and 'Irregular' Workers}

In many respects global economic forces act in ways that do not respect, and can undermine, a system centred on nation-states. The global system of market 
capitalism causes calculations and decisions to be made in the light of worldwide market alternatives and opportunities. However, while globalist in this regard it is like the system centred on nation-states in another way: it has no inherent respect for universal human rights; its calculations concern profitability. Partnerships between the system of market power and the nation-state system have emerged around the exploitative use of migrant labour (Gasper/Truong 20I0a). Since women's labour too is a space for intensified exploitation, migrant women's labour is such a space par excellence.

A 'migration regime' is a system of regulation of migration that covers far more than formal laws and written regulations. De facto systems of national and international regulation of lower-skilled migrant workers frequently allow additional value to be extracted from these workers through their official rejection as legal migrants. Huijsmans (20II; see also chapter I9), for example, noted that Laos (the Lao People's Democratic Republic) prohibits the recruitment of Lao workers for unskilled work in Thailand, and yet all participants know that this is what the largest group of Lao international migrant workers do. Kusakabe and Pearson in chapter 4 demonstrated the impacts of the migration regime for foreign women workers in Thailand and the human costs of a blinkered approach (see also Doneys 20II; Pearson/Kusakabe 20I2). Negative impacts are partly deliberately discriminatory and partly unintended in countries where economic expansion induces in-migration, particularly to activities which citizens become unwilling to undertake, and yet where national identity is a product in the making or something that is reviving. Many migration regimes are attempting to control a transnational phenomenon that is unavoidable, but are doing so while an exercise in nation-building is still going on. In such situations Mushakoji (20II) warns against attempts to directly enforce universal humanist values in order to defend migrants, for migrant rights will then be reviled as imperialist imposition. He advises instead seeking creative syntheses of humanist values with compatible strands in the national culture.

A migration regime extends across borders, and interfaces with and links to other such regimes, as shown by Irianto and Truong in chapter 2. Many actors are involved in the multi-billion-dollar migration industry, in both its legal and illegal channels, including not only recruitment agents and smugglers and traffickers of persons, but especially the employers and customers who benefit from the low-cost flexible supply of labour power and goods and services. Even
Lao migrants with an 'irregular' status in Thailand are part of a highly regulated system, regulated by the Thai state and Thai employers. Employers prefer illegal low-skilled foreign workers, for they are cheaper, more vulnerable, more flexible and exploitable, and easier to dismiss and expel than legals. Their very 'irregularity' increases the demand for such labour.

Piore (1979) long ago explored this rationale in a North American context. Illegal labour has no rights and no protection; its secretly sanctioned entry brings no admission of the political sin of polluting the motherland/fatherland through an open-door introduction of aliens. Further, such workers have little or no access to social benefits, and so, given that and their low wages, they are obliged to have a high rate of participation in work, often relatively dangerous work (Goldin/Cameron/Balarajan 20II: 206-207). The intensity of this rationale has increased since the I970s as global competition has increased (Chun 2009; Hiemstra 20I0): many employers prefer rightless illegals, who have fewer alternatives also because they have less education and less access to education. The employers pay little or nothing towards the full cost of the social reproduction of their labour force including the costs of bringing up and educating children and caring for the old and the sick. These burdens fall exclusively on the workers and their families, especially the women. But relatively neglected children may eventually disrupt this short-run market logic of cost minimization.

Both 'temporary' and 'irregular' workers are now found worldwide in huge numbers and proportions. For the USA, Goldin, Cameron and Balarajan (20II) cite recent estimates of twelve million irregular workers, who have only a one to two per cent chance of being caught (pp. II7-II9). While border control in the USA has grown enormously, the "percentage of undocumented migrants working on US farms and in low-level service occupations and construction also rose continually" (p. II9). Kaye (20IO) investigates how this form of migration regime is constituted in particular US states, such as in Texas's alliance between business and migrant groups. Border control schemes do not achieve their objectives, and compared to the vast gains realizable potentially for all parties by well handled legitimate migration they are an anachronistic waste of resources, conclude Goldin, Cameron and Balarajan (20II: 2IO). A theatrical apparatus of border checking has been instituted - comparable to the enforcement apparatus in the era of attempted alcohol Prohibition in the USA - which prevents relatively few people from entering (except 
for asylum seekers), and cannot prevent millions of overstayers. 'The [high] regulation/[low] enforcement gap in low-skilled sectors represents a political compromise for governments that face pressure to be "tough on illegal immigration", when key sectors of the economy depend on the low-skilled labour that they provide' (Goldin/Cameron/Balarajan 20II: 252).

Comparable patterns apply, mutatis mutandis, between regions within a continental-size country, India, where huge numbers of workers are controlled and exploited in circuits of temporary and circulating labour, as shown by Mazumdar and Agnihotri in chapter 7 (see also Breman 2009). Internal xenophobia against internal migrants serves as part of a similar social logic of creating and keeping a rightless class to provide cheap labour. An extreme example of such a pattern was apartheid South Africa pre-I994, which even tried to turn itself from a single country into a series of supposedly separate nation-states, most of which would be the 'national homes' of the low-wage labourers, even if many of these had never lived in their supposed 'national home'. Capital was allowed to move freely across the new boundaries, while labour movements were to be strictly controlled. In practice, irregular labour was still plentiful and - because irregular - cheap. The same pattern is seen in contemporary practices in the USA and the European Union.

The form of legal migration now put forward by the governments of most rich countries and the migration management organizations that they support is temporary migration. In effect the model country in the contemporary migration order is the Philippines, whose economy revolves around preparing its workers for recurrent temporary emigration, as relatively cheap, docile, and supposedly short-term labour to fill slots identified by rich importing countries. The Philippines is a demonstrably inferior development model, socially and economically. As a substitute for the sort of land reform and other internal reforms that sustained the economic transformation of many of its neighbours, it recurrently exports its citizens, at considerable personal cost to them and their families and children (see e.g. chapter I2 by Marin and Quesada). ${ }^{5}$ It is not gutted by this brain drain in the same way as a country like Malawi, where the large majority of doctors and nurses have left the country (Goldin/ Cameron/Balarajan 20II: I80), because the Philippines specializes in training extra staff who will then attempt to emigrate for at least some time. Some Filipino doctors even retrain as nurses in order to more readily gain access to the USA.
Many contemporary projects to promote security for citizens within labour-importing countries rest on the insecurity of the lives of an underclass, those in temporary work and irregular work, whose labour power is wanted but who are not wanted as citizens. Much current temporary labour, legal and illegal, is in effect indentured labour (see e.g. Pearson/Kusakabe 2OI2, ch. 2, on the millions of foreign workers in Thailand). The workers are tied to a single employer and a single location for a long period; payment is in part only at the end of the period and subject to a series of conditions. This is the case in Canada's seasonal worker scheme described by Goldin, Cameron and Balarajan (2OII: I32) that seeks to prevent long-term entry; by contrast, a 2008 law allowed foreign graduates of Canadian universities to stay and work for three years, in the hope of then culling the best of them (p. I39). Similarly, Korea and Japan avoid official in-migration, and draw instead on the labour of 'trainees' and students and overstayers (p. I3I). In the Spanish seasonal agricultural work scheme studied by Tandian and Bergh (chapter 3), most of the Senegalese workers quickly 'absconded' to elsewhere in Spain to seek work with better prospects, particularly work with a longer time horizon.

Historically, indentured labour paralleled and then replaced slavery. Not only was it the format used to bring South Asian and East Asian workers to the Americas, South Africa, and elsewhere after the abolition of slavery, but before then: "of all the colonial white immigrants [to the thirteen colonies that became the USA] between 1580 and I775, more than half came as indentured servants who had agreed to provide several years of labor in exchange for passage, food, protection, and eventual landownership" (Kaye 20I0: 127). Nowadays, vast numbers of South Asians, South-East Asians, and Africans working in West Asia are de facto indentured, but, as in many other contemporary cases, they have no path for movement to citizenship - unlike in the American case in the seventeenth and eighteenth centuries.

5 Philippines government induction courses to prepare emigrants for international employment as domestic servants tell them not to expect more than five hours sleep a night, but do not tell them that the contracts they sign in the Philippines will often be replaced by far more unfavourable contracts when they reach their destination (Marin 20I3). 
Table 21.1: Viewpoints in Global Ethics. Source: Adapted from Gasper (2005a).

\begin{tabular}{|c|c|c|c|c|}
\hline \multicolumn{2}{|c|}{ Viewpoints In Global Ethics } & \multicolumn{3}{|c|}{ Extent of Values and Responsibilities With Global Scope } \\
\hline & & Extensive & Modest / Slight & None \\
\hline \multirow{3}{*}{$\begin{array}{l}\text { Are } \\
\text { national } \\
\text { (and regional) } \\
\text { boundaries } \\
\text { ethically } \\
\text { important? }\end{array}$} & Very important & 1. 'Scandinavian' & $\begin{array}{l}\text { 2. 'Inter-nationalist' (which } \\
\text { includes some communi- } \\
\text { tarians) }\end{array}$ & $\begin{array}{l}\text { 3. 'International sceptic' } \\
\text { Plus some communitari- } \\
\text { ans \& post-modernists }\end{array}$ \\
\hline & $\begin{array}{l}\text { Intermediate } \\
\text { importance }\end{array}$ & $\begin{array}{l}\text { 4. 'Solidarist- plural- } \\
\text { ist' }\end{array}$ & $\begin{array}{l}\text { 5. Transnational corporations } \\
\text { with national loyalties/ pri- } \\
\text { orities but some accepted } \\
\text { global duties }\end{array}$ & $\begin{array}{l}\text { 6. Typical domestic corpo- } \\
\text { ration }\end{array}$ \\
\hline & Not important & $\begin{array}{l}\text { 7. Full cosmopoli- } \\
\text { tans ('solidarist- } \\
\text { globalist') e.g. } \\
\text { pure utilitarians }\end{array}$ & $\begin{array}{l}\text { 8. 'Libertarian-minimalist' I: } \\
\text { e.g. transnational corpora- } \\
\text { tions without national loy- } \\
\text { alties but with some } \\
\text { accepted necessary global } \\
\text { duties }\end{array}$ & $\begin{array}{l}\text { 9. 'Libertarian-minimalist' } \\
\text { II: } \\
\text { 9a Business-only corporati- } \\
\text { ons } \\
\text { 9b Robber-baron businesses }\end{array}$ \\
\hline
\end{tabular}

\subsection{Who Counts? National Versus Market Versus Humanist Frames}

This book has explored the forms of insecurity experienced by "people on the move" (CHS 2003) who straddle different jurisdictions and systems of social protection. The two stances we have just highlighted - a nationalist stance that gives weight only to the interests of citizens of one's own nation, and a marketoriented stance that gives weight only to the expansion of economic profit - represent two of the poles within the political landscape. A more formal analysis helps to clarify this. Table 2I.I uses two dimensions for classification: I. how far is global community - the existence of values and responsibilities of global scope - accepted? and 2. how important are national community and national boundaries deemed to be? Cosmopolitan positions hold that: all humanity is the reference group in ethical discussions, some important common values apply across humanity, and some responsibilities exist across all humanity. In full cosmopolitanism $(\# 7)$, an extensive set of values is deemed universally appropriate and to be promoted. In contrast, 'international scepticism' ( $\left.\#_{3}\right)$ holds that countries do and should pursue only their own interests. These sceptics concerning inter-national morality are, however, believers in intra-national morality (unlike position \#9b). In contrast, libertarian-minimalist positions (\#9 especially) first assign no special priority to national boundaries: individuals and their liberties are all that matter worldwide, not nations/states, which must not interfere with those liberties; and second, libertar- ian-minimalists deny having significant responsibilities to almost any others, not only to foreigners.

The formal analysis reveals more positions besides the three corner positions $(3,7,9)$ that we have mentioned. 'Scandinavian' positions combine strong national feelings and strongly felt global obligations $\left(\#_{I}\right)$. Position 2 is an 'inter-nationalism': while countries are the primary units, held together internally as established communities, a community of countries is held to have emerged to some degree, for and through the regulation of their interactions; and this inter-national community produces agreements which must be respected. In a solidarism-pluralism variant of cosmopolitanism (\#4; Dower 1998), global-wide concerns and obligations are emphasized but with acceptance of considerable variation in values and behaviour between settings. And towards the bottom right of the table are a range of positions held by business actors $(5,6,8)$, that represent variants around the full 'libertarian-minimalist' category (9a, 9b). Market perspectives can seek to turn almost everything into a commodity, including human life, human organs, the human genome, even (in position $9 \mathrm{~b}$ ) legal rulings and police services. But other market-based perspectives include a greater acknowledgement of the prudence and/or appropriateness of accepting certain elements of obligation in relation to compatriots or even to all fellow humans (positions 5, 6, 8).

In the era when Europeans wanted to spread out and trade as they wished, in China, India, and the Americas, they put forward cosmopolitan doctrines which gave people a natural right to move in this way. 
Francesco de Vitoria (I492-I546), considered by many to be the founder of international law, wrote that "[i]t was permissible from the beginning of the world, when everything was in common, for anyone to set forth and travel wheresoever he would." Similar ideas appeared in the works of other great jurists of the time, including Hugo Grotius (1583-1645), Samuel von Pufendorf (I634-I692), and Christian Wolff (I679-I754), who argued that the state possessed a duty to allow the transit (and sometimes residence) of migrants (Goldin/ Cameron/Balarajan 20II: 42).

By the late nineteenth century in Europe passports had come to be seen as feudal relics, only still used internally by feudal states such as Russia. In I892, the Institute of International Law declared that free entry was the norm and should only be curtailed for special and very weighty reasons (Goldin/Cameron/Balarajan 20II: 7I). However, passports re-emerged in the run-up to the First World War, and by the I93os the norm had been reversed. The Netherlands refused to admit Jews in the 1930s unless they could prove that they faced an "immediate danger to life" (p. 83). This principle is now widely applied by rich countries. The ranking of the liberal principles of securing individual freedom and allowing individual endeavour versus the nationalist principles of restricting rights and responsibilities to only those people within national borders has been inverted. Within liberal countries people have the right to move, and cannot be legally prevented from entering a community by the local community itself, but between countries these rights have disappeared (Goldin/Cameron/Balarajan 20II: 266267). To a full cosmopolitan these are feudal attempts to protect unjust privilege (Carens 1987); and for Goldin et al., given their perspective that all humankind is a relatively new enterprise by two thousand African migrants, 'the earth is one country and all of humanity its citizens' (Goldin/Cameron/Balarajan 20II: 285).

Nowadays, the global neo-liberal governance regime is a hybrid that asserts that national boundaries have high ethical status in respect of people - foreigners will be kept out - but have no status in respect of capital: commodities and finance must flow without hindrance. This version of neo-liberalism is far from textbook nineteenth-century liberalism and market doctrine, and is not a pure position. It is laced with rich-country chauvinism, and aims to marry the possessive individualism of market thinking with the pseudo-communalism of nationalism. Different arrangements are then constructed for: I. drawing on high-skilled workers from poorer countries; 2. making use of but socially excluding low-cost lesser-skilled foreign labour, in those labour-intensive tasks which can- not be relocated to low-wage countries, in particular many tasks in the agriculture, construction, personal services, and care sectors - some in legally approved temporary arrangements and some in formally irregular but tolerated shadow zones; and 3. marginalizing and excluding other groups, both within and outside a country, as part of the ideological legitimation of rule by a national elite. For asylum seekers, "the three Ds" are deployed - the instruments of destitution, detention, and deportation (Hintjens/Kumar/Puri 20II). Overall, the layered system of privilege, exclusion, and deportation has thought-provoking resemblances to what was pioneered by apartheid-era South Africa, and is seen by some as a system of global apartheid (Hintjens/Kumar/Puri 20II; Mine 20II). As with apartheid South Africa, reforming such a system requires looking in a differentiated and empathetic way at the concerns of all parties, taking into account their psychological as well as economic insecurities.

A possibly enlightening parallel emerged in chapter 8 in this volume by Zhu and Lin on China. In this subcontinental-size country, perhaps the largest migration flows for employment in world history have been under way during the past generation. There have been very high average income differentials between the main in-migration areas, mostly in the coastal provinces, and the main outmigration areas, mainly in the interior. The majority of migrants do not make a once-for-all transfer to in-migration areas. They continue moving to and fro, and/or plan to return eventually to their area of origin (if not necessarily to their place of origin), for reasons of family loyalty, sentiment, access to land, and/or lack of access to many registration-based rights and privileges in the place of in-migration, but also because of lack of access to stable urban employment. A large proportion of urban jobs are in rapidly changing sectors in which firms' workloads fluctuate markedly, and lay-offs are as frequent as hirings. From their own studies of internal migrants and review of many related studies, Zhu and Lin (p. 167) recommend that "the protection of the rights of migrants should not rely on 'urban citizenship', and the whole society (rather than the destination cities) should bear the responsibility for protecting the rights of all citizens, including female and male migrants, no matter where they live."

The policy in many in-migration countries is now to promote regulated temporary and circular migration and to exclude the migrant 'denizens' from full rights. That stance has been defended (for example by Gerhard Leers, the Netherlands minister for immigration and integration in 20IO-I2) on the grounds that 
rich countries do not wish to have any second-class residents and 'so' insist on having only temporary regulated in-migrants rather than long-term irregular inmigrants. A third option - permanent in-migrants who acquire citizenship - is very largely closed. Principles of reciprocity and solidarity apply amongst citizens, but supposedly 'win-win' deals will be negotiated with non-citizens, such as redundant Senegalese fishermen or young Burmese women seeking to support their struggling families, that take advantage of their marginalized position. In contrast, the proposal for China is to move to a 'whole society' approach with special attention to the interests of temporary and circular migrants, so that they accumulate rights from their years of work that are later transferable elsewhere.

\subsection{A Human Development and Human Security Perspective}

A human development and human security approach, as articulated by, for example, Mahbub ul Haq, instigator of the work on Human Development Reports, attempts to apply a global, humanist perspective both in descriptive and explanatory work and in normative and policy work (UNDP 1990, 1994; Haq 1999). It uses a wide-angle lens that leads us beyond the bounds to analysis conventionally set by national frontiers and disciplinary divisions. At the same time it uses a zoom lens, to look at how particular people actually live and can live: at their opportunities that are attainable and valued through reason - this is the 'human development' reconceptualization of 'development' - and at the risks and pressures to which people's lives are subject within global, transdisciplinary systems of interconnection: the 'human security' focus within the 'human development' agenda (Brauch 2009; Gasper 2005b, 2009, 20I0; Truong/Gasper 20IIb; UNESCO 2008). The concept of human security focuses on 'critical, severe or pervasive threats to the vital interests of human life, livelihood or dignity, where the harm caused can be prevented or mitigated by human action' (Lester 20IO: 322).

A concern with the meanings and sources of people's security and insecurity helps us to think about what matters most in their lives and how they are affected by the intersections of different factors - gender, class, race, religion, sexual identity, age, nationality, chance events - that structure and affect their lives, their opportunities and risks, rises and falls (Leichenko/O’Brien 2008; Gasper 20I3). By situating individuals socially, such an approach becomes less in- dividualistic than unnuanced human rights thinking, while encouraging sensitivity to subjectivities (Burgess 2007; Gasper/Truong, 2005, 20IOb). It strengthens the basis for taking human rights seriously (Oberoi 20I0). By looking at the capability of people and groups to maintain, restore, and promote their own security - 'securitability' (UNDP 2003) - it partners, and helps to set priorities within, work on 'human development'. Reflecting the realities of a transnational and interpenetrated system, it goes beyond the Westphalian conception of states and citizenship. 'Non-citizens are not viewed as non-persons or "outsiders", as they are under the state-centric system of international relations, but as equal citizens in the global community facing interdependent and universally relevant threats' (Edwards/Ferstman 20I0: 40). Overall, it offers a commodious framework that respects the richness of listening-oriented fieldwork about daily living, the style of research seen in nearly all the chapters in this book, and that at the same time connects well with themes of global interconnection. The book has followed this agenda, as well as paying attention to the influence, in combination with other factors, of gender norms, including forms of gender blindness. ${ }^{6}$

Rich countries have sought to enforce a global order of open trade and capital flows, but with close regulation and restriction of flows of people, or to be more exact, of poor people. Some at least amongst their leading decision-makers know that the full logic of economic benefit from free trade applies only when all factors of production can move; but they have calculated that stronger actors can reap most of their own potential benefits without (officially) allowing poorer people to move, and they do not feel inclined to increase the dissatisfaction of some groups in rich countries by openly imposing upon them cultural stresses from immigration in addition to the economic stresses engendered by free trade and free movement of capital. Ignoring the principle of common (shared) security, they have calculated that ghettos of frustration created in pockets such as the driven-out fishing communities of Senegal can be se-

6 Whereas a significant body of work has now appeared that looks at migration in human security terms, the national framing inherent in National Human Development Reports has meant that none of the many such Reports that have explicitly investigated human security have taken migration as a lead theme (Gomez/Gasper/ Mine 2013). In contrast, the Commission on Human Security (CHS 2003) used a global framing and treated migration in detail in its chapter 'People on the Move'; for an evaluation, see Oberoi (20IO). 
questered, or they do not even consider such consequences and the possible knock-on effects. The principle of common security holds instead that no sustained security can be obtained through undermining the security of those with whom one interacts (Lester 20IO; Mushakoji 20II).

The social order in much of Europe and in Japan and perhaps some other countries, their human security in the long run, may also not be sustainable as the proportion of old people rises dramatically and care burdens are not absorbed by succeeding generations (UN Report on Replacement Migration 200I). The widespread pattern of continually increasing orientation to earn, spend, and consume; declining family care of the absolutely and relatively increasingly numerous elderly; and fewer women (let alone men) interested in bearing and caring for families that are on average of replacement size, let alone in caring for the previous generations, while at the same time coping with - or forgoing - the pressures and challenges of paid employment, might constitute in total one of what Daniel Bell (1996) called 'the cultural contradictions of capitalism'. The sheer extent of demographic imbalance in much of Europe and in Japan makes it difficult politically and socially, however, for these countries to swallow the scale of immigration required to counterbalance the consequences of widespread - sexist, individualist, consumerist - cultural proclivities.

Goldin, Cameron and Balarajan propose (20II: 253) that the huge and growing gaps in the market for lower-skilled labour in rich countries cannot be bridged by the various subterfuges of undocumented migration; nor will permanently circulating workforces from South to North, Philippines-style, make sufficient economic or functional sense or be sustainable. For highly-skilled labour, they project that pressures to import will mount, and will collide with domestic resistance, at least in unprepared and fearful low-trust countries. They present a picture of vast potential economic gains from bringing labour to where demand for it exists, and cite World Bank estimates that economic benefits for countries of origin from expanded migration - of which a very large share would be by women - would vastly exceed those from full free trade or doubled international aid (Goldin/ Cameron/Balarajan 20II: I63). Recipient countries, too, could benefit hugely, for example by releasing skilled women into the labour market, as described by Sandoval-Garcia for Costa Rica in chapter 20. Given labour market stratification, the evidence is that most immigrant workers do not compete with domestic la- bour and so do not significantly reduce domestic wages in in-migration countries (Goldin/Cameron/ Balarajan 20II: I66) but do significantly reduce the cost of wage-goods and services.

This sort of economic accounting is not sufficient for understanding the life impacts, including felt impacts and impacts not measured in money terms, for both immigrants and in-migration country residents; and consequently is not sufficient for devising and managing relevant, workable and just policy regimes. Widespread resistance and antipathy to immigrants is common: in Assam, Malaysia, South Africa, and Thailand, for example, not only in Italy, Japan, and the Netherlands; even, as seen in this book, to Nicaraguans in Costa Rica, despite their major contributions to the country's agricultural exports and to freeing its middle-class women (and men) for paid employment. National identity and the nationally specific notion of citizenship are constructed in contrast to marginalized or excluded Others. The contemporary Indian state sometimes demonizes Bangladeshis, former fellowresidents of unpartitioned India, to the extent of periodically shooting some of them along the now partly fenced border as they continue to cross as always (Human Rights Watch 20IO). Their exclusion helps to define something non-Indian, and hence to define 'India' (Kapur 20IO: 200-I). In the Netherlands the principle of shared membership of 'ons land' (our country) conflicts with continuing race-based identification, in which the descendants of immigrants from some countries remain classified as allochtoon (from another soil), generation after generation.

Temporary-migration programmes plus the twilight status of de facto tolerated 'irregulars' seem designed to prevent any impression that a government treats new immigrants better than long-standing residents, but whether they will satisfy traditional residents, when these are exposed to exclusivist ideologies and a perpetual stream of transient foreigners rather than to emergent fellow-citizens, remains questionable. Further, major programmes of this type in the past in Germany and the USA have in reality still largely led to permanent settlement; they on balance discourage return to country of origin since migrants realise they cannot readily come back again (de Haas 20I2). Similarly, felt security is not furthered by the parallel system of de facto tolerated irregular migration, but rather by the building of migrant loyalty to the country of in-migration by providing legal channels for entry and channels for legalization. 


\subsection{A Gender-enriched Human Security Perspective}

Let us review our arguments up to this point. We have identified and contrasted, first, "a nationalist perspective that adopts only the nation as its ethical space, and typically adopts a national frame in explanation too; and second, a capitalist perspective that adopts a global frame in both evaluation and explanation, but with enormous exclusions in concern for poor people" since its measures in evaluation are purchasing power and completed monetary transactions (Gasper/Truong 20IOa: 348-9). We contrast both these with the 'human discourses' fostered in the United Nations system: human development and more especially human rights and human security. These adopt "a global normative frame, in two senses - a comprehensive interest in the contents of people's lives, and a concern for people everywhere, grounded in perceptions of human dignity and fundamental rights" (Gasper/Truong 20I0a: 349). Work on human security in particular combines “'joined-up thinking' in explanation - a tracing through of fundamental interlinkages that cross national borders and conventional disciplinary boundaries - with cosmopolitan 'joined-up feeling' in valuation, giving priority to basic needs everywhere" (ibid.: 349). These human discourses, while open to different versions and emphases, are close partners and are readily and desirably combined. For our purposes, it matters relatively little whether the perspective is elaborated into an ethical viewpoint that corresponds to position I or 4 or 7 in table 2I.I, for each of those positions incorporates extensive values and responsibilities with global scope.

Of central significance for our purposes, by contrast, is that like all the standpoints in social philosophy that we have mentioned so far these discourses are not explicitly gendered. The emphases in human security thinking on human bodies, subjectivities, and human relationships make it a welcoming partner for gender analysis; but while fully relevant to women, there is no special emphasis on the distinctive pressures, discriminations and disadvantages faced by many women, especially women migrants, and how they serve as social and economic 'shock absorbers' (Gasper/Truong 2005). ${ }^{7}$ Yet Kusakabe and Pearson

7 Even an authoritative collection by human rights lawyers on Human Security and Non-Citizens, edited by Alice Edwards and Carla Ferstman, has little to say on women. The 26-page index has no entries for 'women' or 'gender'. (chapter 4), for example, recount how the overwhelmingly female Burmese work force in the Thai border factories they studied face peculiarly harsh workplace conditions and must also struggle and improvise to fulfil the needs of social reproduction (material, generational, cultural), including care work, cooking, economic support of a wider family, and especially the bearing and upbringing of small children. Support from the state (whether Thai or Burmese) and from employers is almost entirely absent. Kusakabe (2013) notes with irony how employers recurrently used the phrase 'We treat workers like family', as an attempted justification for employees' lack of enforceable formal rights and being always on call for more work rather than having fixed maximum working hours. The women improvise responses using community groups, hired services, and family members, in addition to their own efforts; for example, paying a 'baby agent' who transfers a batch of sedated babies back to their mothers' home places in Burma. None of these means is highly satisfactory, stable and sustainable, so the methods of coping change frequently.

Women's relative invisibility within discussions of international relations and social justice is unacceptable. This volume and its predecessor (Truong/Gasper 20IIb) attempt to contribute in countering lack of gender awareness in regard to migration. They try to describe, explain and evaluate the gendered structures of intra- and especially inter-national migration and to identify directions for countering the major injustices, both those common to all migrants and those especially affecting women. While many of women migrants' problems and needs are the same as men's, some are distinctive, though those too can be fruitfully addressed if we harness and enrich the human discourses in order to advance women's rights, security and development, rather than seek to build separate approaches.

For decades, the framework for international migration studies (as well as that of refugee studies) has reflected mainly the experiences of men of productive age, while the framework of human trafficking has predominated in representations of the experience of young and unmarried women. In recent years, especially around and since the High-Level Dialogue on International Migration and Development initiated by former UN Secretary-General Kofi Annan (2006), there has been growing recognition of the increased presence of women in migration streams - now at parity with men's - and of the factors behind it. We must go further though, to undo biased assumptions linked to gender that have been built into research concepts 
and methods of data collection and interpretation. The biases have important consequences for policy choices in matters related to migration. Invisibility, misrecognition, and inappropriate framing of gender concerns are key issues for research on and advocacy for social justice in migration.

The Migration, Gender and Social Justice (MGSJ) research project from which this book emerged has adapted Collins's four-facetted 'matrix of domination' designed for Black studies to provide a framework for studying the relations of gender subordination in migration (Collins 2000: 277; Truong/Gasper 20IIa: 4). The four facets, or levels, are as follows. First, the hegemonic level consists of entrenched ruling ideas, including the dominant idea of the bounded nationstate that has enforceable borders and a relatively clear set of norms and rules to determine membership. Cross-border migration has typically been understood in terms of a series of dichotomies: 'economic migrants' versus 'refugees', 'free choice' versus 'force', men as 'autonomous migrants' versus women as 'dependants'. These dichotomies give legitimacy to practices that have consequences for (un)fair treatment. They also fail to show the cumulative effects of intersectionality and the spiral of discrimination caused by multiple inequalities based on gender, ethnicity, and migrant status. Second, the bureaucratic level concerns state structures and the articulation and application of regulations, norms, standards, and procedures for specific groups of migrants, including the use of surveillance practices. ${ }^{8}$ Third, the institutional level concerns how migration institutions (organizations of the state, migrant recruiting agencies, etc.) interact with each other in gendered ways that can (re-)produce the series of dichotomous classifications of people on the move (skilled-unskilled, legal-illegal, autonomous-dependent, etc.) with consequences for the subordination of women as a group of migrants. Fourth, the interpersonal level concerns how the

8 Migrants are affected not only by the framework of classification of identities that separates them from nationals, but also by a hierarchy of identities within the population of foreigners (as we see in chapter 13 on Libya). Though the specific features of this hierarchy of identities may differ according to the particularities of geopolitical contexts, often the management of 'flows' (of people on the move) misframe some groups of migrants and their identities into a 'social problem' that supposedly requires a solution. This misframing can conceal the need to examine dysfunctional aspects of the management of migratory flows by the state and by non-state actors. three facets above interface and are acted out in everyday social interactions in specific contexts: among and between the migrants, the local communities, support groups, and bureaucracies. The framework helps to bring out the practical challenges for advocacy for inclusive citizenship, due to the intersecting forms of subordination and of legal liminality.

The framework helps us also in avoiding overgeneralizations about the relationship between gender and migration. It is essential to recognize the importance of contexts and their particularities, the layers of factors involved, and the interactions of gender with other social statuses (legal identity as migrants; class; race/ethnicity; age). Overgeneralizations hide the various ways in which institutional power dynamics circumscribe the space for women migrants to claim rights. Discussion of social justice in relation to migration needs to be informed by understanding of the locally specific dynamics of migration and of organizational practices and legal regulations. We need also to recognise, besides the material circumstances that drive migration, the patterns of differentiation among migrants, the sense of prestige that people attach to 'being mobile', and the role of social networks in the diffusion of images and norms regarding mobility within and across borders.

Through exploration of the contemporary forms of circular, temporary, and transient migration and their gendered features, the studies in this volume have revealed the multi-layered meanings of 'gender' and their intersectional expression in all stages of migration. The traditional framework for considering women's rights in terms of citizenship may be applicable specifically to immigration (migration for permanent settlement). In other migration forms, the transnational character of power relations as well as their local expressions and affiliated practices of genderbased discrimination need to be analysed as a series of interconnections between different institutions and systems (households, communities, market-based recruitment agencies, relations between sending and receiving states, work placement practices). A new approach to rights is necessary that recognizes the role of multiple actors in multiple locations and that can discern the different aspects of structural vulnerability at each point in the entire migration process and develop a corresponding picture of accountability. The model presented in chapter 2 (table 2.2) is relevant here in combination with the four-part framework just described. ${ }^{9}$ They help us to examine the realities of migrants' lives. 


\subsection{Invisibility and Re-Cognition of Women's Migration: Promoting Human Rights and Security}

The 'invisibility' and misframing of 'migration', migrants, 'gender', and women's work have consequences for social justice, as seen throughout the book. There are great limits to what one can achieve by trying to reform policies, official rules, and actual practices that violate migrants' rights and human security, especially for women migrants, if one does not significantly alter the realm of cognitions about migration (including those we referred to above as 'sedentary bias' and 'the hegemonic level' or nation-centred perspective) and about masculinities and femininities (ideas about appropriate behaviours, roles, and rights for males and females).

The concept of 'invisibility' has arisen in several different ways:

a) statistical invisibility, which leads to the invisibility of women migrants in the eyes of planners, and thus their exclusion from policy attention and from activities for social protection (for example, see chapter 7 on India);

b) institutional invisibility (the fact of having no formal status, or an unauthorized status), which derives from the rigidity of tacit presumptions and institutional settings, and excludes some migrants from programmes that might benefit them (seen in most chapters);

c) strategic invisibility, chosen by migrants in order to evade discriminatory practices by the state or abusive behaviours at inter-group level or both (see, for example, chapters 4, 6, I0);

d) most importantly, invisibility in the sense of being outside the realm of cognition as formal knowledge and sometimes even as tacit knowledge; for example, chapter I4 showed that the girl companions of blind beggars in Senegal and Mali are socially invisible, simply not noticed; more widely, much of the work done by women in caring for dependants and in household management is not perceived as real work.

Cognitive invisibility is the most important, for it underlies statistical and institutional invisibility which

9 The model in chapter 2 can be seen as an elaboration for migration of the questions raised by the 'Institutional Responsibility Matrix' developed by Geof Wood; see, for example, Gough and Wood (2004). then motivate strategic invisibility. Attaining institutional recognition requires re-cognition.

The multiple layers of invisibility have implications for migrants' economic and sociocultural security in their daily lives and in their relationship with agents of the state. Invisibility (including the non-recognition of migrants' diplomas) and misframing (e.g. misuse of the notion of 'family' to license unlimited calls on others' labour) are functional for powerful groups. We are dealing here with social fields of power, not just cognitive error. The struggles for rethinking are not just cognitive struggles.

The social invisibility or scant recognition of much of women's work within a country makes it hard for that country to make credible claims in support of its own women emigrants who do such work - if the country perceives and values their work at all. Countries which treat domestic workers within their borders as not 'workers' have little credibility when seeking to defend such workers against abusive conditions abroad. Indonesia's Domestic Workers Protection Bill, for example, remains unadopted, after years of discussion of the issue. Similarly, countries which treat in-migrants (and their own women workers) badly have less clout when seeking to defend their own outmigrant citizens (especially outmigrant women workers). Cholewinski (20IO) identifies the feminization of migration (meaning here the increased proportion of women) as one reason why migrant rights have not been taken seriously by the governments of in-migration countries, nor sometimes by the countries of outmigration.

Invisibility, screening-out, is an extreme example of misframing. Discussions about domestic labour and domestic workers frequently involve other forms of misframing, such as failure to connect the mass migration of women domestic workers to the ongoing transformation in the organization of social reproduction for affluent groups, especially in rich countries. Persistent misframing can contribute to eventual crisis, which may then provide opportunity for reframing, recognition, and affirmation of certain categories of migrants whose presence and contributions to society have been left invisible.

Invisibility and misframing in terms of systems of classification of work, workers and migrants must be taken on board as issues of social justice. The systems must not be taken as given. They are based on specific knowledge frames which are time-bound and vulnerable to errors and to institutional rigidity. Similarly, the inherited legal approach to women's rights in migration is partly embedded in a dated framework of 
group rights built on the rationale of protecting minority groups and minors.

More widely, tacit social constructions of 'masculinities' and 'femininities' affect subjectivities as well as codified practices, and exercise great influence both on how women, men, and young people become involved in migration processes, and on how policies of social protection are designed. The role frequently accorded to women is that of the human shock absorber, the nurturing human environment for the activities of others. Like shock absorbers and the physical environment they are taken for granted.

The frameworks of human rights - for women, for migrants, and for all persons - are nowadays elaborate and quite clear; but they are not self-enforcing, and their adoption and implementation is highly discretionary and very frequently absent (see, for example, the reviews by Cholewinski 2010 and Lester 2010 for migrant rights). Application of the frameworks to cases of international migration depends on collaboration between nation-states, and thus also on the perceptions of and pressures from the public in those states. Hierarchical relations between nation-states, economic and political agendas, and rigidity in administration make this collaboration ineffective. Parts of civil society play an important role in the defence of migrant rights, but civic actors too are embedded in the national sphere of politics that is influenced by nationalist sentiments that often do not favour such rights. A large number of studies in this volume have documented social processes of 'racialization' or other types of social construction that present migrant workers as inferior (and dangerous) beings. Countering such processes is an essential task for increasing the likelihood of the implementation of legal declarations of migrants' rights. Chapter 20 by Sandoval-Garcia, in particular, describes several relevant avenues for this work.

Cholewinski (20IO) lists, over very many pages, the years of meetings and reports on migrant rights, but can unfortunately provide little evidence of impact. Oberoi (20IO) and Lester (20IO) fear that the meetings are another form of theatre, for the more general conventions on human rights, if taken more seriously, would already accord major protection to migrants. Apart from the power of groups that benefit from the invisibility of migrant workers, Oberoi notes another explanation, another type of invisibility which is produced by the absence of migrant representation. The meetings and negotiations are conducted in closed chambers, with migrants' own representatives excluded. Thus 'in inter-state discussions the world over, agreement is reached that it is the migrant who is to blame for the chaotic state of contemporary migration, it is the migrant who is a terrorist, a queue jumper, a criminal; he or she is barred from the rooms in which migration policy is being discussed' and where rules are established and reinforced that render people on the move marginal and illegal (Oberoi 20IO: 272).

Research and advocacy guided by a human security perspective can help expose what is kept invisible, and so help to strengthen the perceptual, affective, and political basis for giving serious attention to formal human rights. Ethnographic research can present migrants' voices on their experiences of being invisible, of the multiple and interconnected layers of insecurity, and of negotiating recognition (such as successfully achieved by some of the Vietnamese brides in Korea and Taiwan seen in chapter 5). Direct testimony may counteract streams of misrepresentation and poison in parts of the mass media and 'give a voice to some of the migrant women', observe Pearson and Kusakabe (20I2: I76), who themselves use the method to good effect.

These voices also direct attention to the ways in which the control of migrant workers is carried out. Studying migration means studying not only migrants' everyday lives but the systems of creating and controlling borders (legal, social, economic, and cultural) that shape their life-worlds and restrict their agency. This can help to bridge the gap of understanding between a state-centric notion of 'national security' and a notion of how security is produced or undermined locally by social interactions.

Many people fear that the language of security is "a double-edged sword. ...it can label the subjects of this security discourse as threats to security, rather than being victims at risk of insecurity" (Edwards/Ferstman 20IO: 40). A language of 'human security' in particular is sometimes adapted to serve forms of discipline and control over migrant populations. However, similar types of labelling and control have happened for centuries and are not generated by a human security perspective that specifically offers resistance to racialization and related forms of othering and scapegoating. Ensuring the rights of 'people on the move' requires as the first step addressing the forms of structural injustice they face. Human security analysis enters the life-worlds, constraints, opportunities, and subjectivities of all participants and considers how these are interlinked. As illustrated in this book, it can help shift thinking about 'security' from border control towards the notion of positive freedom for 
those who migrate or return. Eve Lester argues thus that "the application of a human security lens to the social and economic rights framework...may serve as a counterweight to the forces of national security and sovereignty that have historically dominated legal and political discourse, often at the expense of justice" (Lester 20IO: 317). Human security analysis is an essential partner to a human rights approach, not a diversion or competitor (Lester 20IO).

The structures, institutional and mental, which we have identified and discussed are not subject to overnight change. Goldin, Cameron and Balarajan, as we saw, closed their book with a cosmopolitan clarion call in respect of free movement. But in terms of next steps they presented a more modest proposal: to create a global migration body that is divorced from the direct control of rich in-migration countries, and that can counter the policy patterns in which party politicians appear largely trapped. They consider that such an international lead agency can coordinate a longrun agenda for increased international migration, given its unavoidability. Reflecting its size and experience, the International Organization for Migration appears to them and to many as the logical choice, if converted into a United Nations agency and thus with an authority beyond the short-term political wishes of rich countries that fund it (Goldin/Cameron/Balarajan 20II: 282). This was the recommendation of the 2005 Global Commission on International Migration; it was blocked by in-migration countries.

The next best next step brokered by Kofi Annan in 2006 - the Global Forum for Migration and Development - is purely a non-binding discussion forum. But Annan framed and launched it within a longer-term perspective and with an attractive boldness of spirit. For Annan, the rationale of the Forum was to gradually build awareness of patterns of interconnectedness and progressively reduce the fears and misperceptions of in-migration countries and more generally. ${ }^{10}$ While the Forum conducts its business in closed chambers it has become a prominent target of attention for civil

10 Annan's 'program logic', as diagnosed by Gasper and Roldan (20II), was as follows: We should go ahead with the Global Forum for Migration and Development, given that: I. We must manage migration, 2. in a context where major disagreements exist, and a heritage of casual, non-thoughtful, non-constructive behaviour; 3 . The alternatives are not feasible at present, whereas 4. GFMD is feasible and 5. can be fruitful since controversial emotive problems require calm, structured communication. This underlying set of ideas is open to critical assessment and possible improvement. society. Migrant organizations, social movements, and migration research bodies monitor, parallel, and lobby the Forum's activities. The spirit is consistent with that in Sen's approach to justice (2009): not a perfectionist model but focused on relevant ameliorations from real starting points. Within such a forum and similar channels, and partnered by pressure from civil society, progress is perhaps possible in some important areas. ${ }^{11}$

\subsection{Next Steps}

We conclude with an indication of some of the key areas for research and networking. Existing work could be deepened by using a human security perspective that incorporates a gender framework as suggested above.

First, transformations of borders: borders are transforming in various ways: physically, the gatekeeping functions to control and exclude migrants are now dispersed across numerous locations, including within the routines of daily life in the countries of in-migration and even the countries of outmigration; legally, there are now huge grey zones of 'legal liminality'; culturally and psychologically, borders of various sorts are being constructed and deconstructed. Illumination of the new meanings and practices of borders is a research priority, to update the conceptual apparatus that we bring to considering migration and mobil-

11 In terms of table 2I.I, different starting points and different potential paths can apply to, and within, different constituencies: businesspeople and workers, politicians and administrators, elites, marginal groups. Countries that are presently strongly marked by business-centred positions $(6,9)$ might gradually move towards positions 5 and 8 , with growing recognition and acceptance of the necessity and appropriateness of various duties that cross national borders (and that apply within national borders too). Roughly speaking, an author like Scheffer $(2007,20 I I)$, reasoning within a world of nation-states and of local communities, proposes a gradual progression of global awareness and trust, moving thus across the top row in the diagram, from 3 to 2 to I. He argues that only by the promotion of healthy local interactions, including a recognition of the historical and geographical strands that have contributed and continue to contribute to the cooperative life in a locality, is the required basis established for more trusting broader interaction. Mushakoji (20II) proposes a fuller trajectory, $3 \rightarrow_{2} \rightarrow_{\mathrm{I}} \rightarrow_{4}$. He is at the same time strongly aware of the dangers residing in positions on the right side of the table, which can grow in reaction to premature attempts to fulfil a cosmopolitan ideal of position 7 . 
ity and thus to reorient subsequent research in a way that does fuller justice to contemporary and emerging systems. The emergence of new forms of female migration, temporary, circular, and transient, and how these forms can produce conditions of insecurity not experienced by settled migrants, needs research and policy attention. The implications of border transformation and female migration for, not least, children (as stay-behinds, or co-migrants, or born during migration, or as returnees) have been noted here in the chapters on Mexico, Mali, and Thailand. The existing group rights approaches (e.g. women's rights, children's rights, indigenous people's rights) to migration seem more applicable to the integration of settled migrants in the host society than to the increasing number of circular, temporary, and transient migrant communities.

Second, South-South migration has already become equal in scale to South-North migration (as conventionally measured) some years ago (UNDP 2009), and is likely to rapidly exceed it. Women are very prominent in such movements. The large majority of the component studies in the MGSJ project and in this book address South-South migration, though the original scheme of work was not formulated in these terms. This trend throws up new questions. However, because of the domination of research agendas by the concerns and perspectives of Northern funders, South-South migration remains relatively speaking less studied.

One of the largest components of especially South-South migration during the coming decades is likely to be induced by climate change, given the greater expected impacts of climate change in tropical and subtropical areas and in low-income countries, the economic dynamism in much of the South, and intensive anti-immigration policy regimes in much of the North (see, for example, McAdam and Saul 20Io). The Bangladesh-India border is a likely example of a major locus of such migration. While there is

\section{References}

Abella, Manolo, 20I3: Contribution by Manolo Abella, former Director of ILO International Migration Program, to AP-MagNet Talkshow \# I: Social Protection for Migrant Workers (March 20I3); at: <http://apmagnet.ilo.org/podcast>.

Annan, Kofi, 2006: The Secretary-General's address to the High-Level Dialogue of the General Assembly of the United Nations on International Migration and Development, New York, I4 September 2006; at: 〈http:// www.un.org/migration/sg-speech.html>. growing research on climate change and migration, relatively little has yet connected closely to the issues of differential impacts on men, women, children, family organization, etc.

Thirdly, for both South-South and South-North movements, and intra-national migration, portability of social protection is a key transformative reform needed to respect the human rights of the migrants whom the global economic system requires and generates. The theme emerges strongly from the case studies in this volume, for example those on China, the Gulf, the Philippines, and Thailand. They reveal the central tension between the mobility of labour and the non-mobility of entitlements for most migrants. For migrants whose movements are temporary, circular, or transient, social protection schemes that can be made portable are vital. For example, Indonesian migrant domestic workers pay for their health and social insurance before departure, but they cannot access this support when in need because of institutional rigidity in the administration of labour migration policy in Indonesia, as well as in the receiving country. Special attention needs to be paid to the particular situations and needs of various categories of women migrants, and to the role of organization of and by migrant workers themselves to engage in campaigns for portable protection and for acquisition and then implementation of accorded rights.

The experience of the MGSJ project and the character of these concluding suggestions underscore the need for the cross-fertilization of ideas between regional research networks, South-South-North. Promoting cooperation, in order to reduce duplication and to avoid research driven by purely theoretical or purely national policy interests without due consideration for gender transformation as an ongoing process integral to migration itself, can help to support a bottom-up strategy of rights-claiming that responds more directly to migrants' needs and aspirations.

Bell, Daniel, 1996: The Cultural Contradictions of Capitalism [20 th anniversary edition] (New York: Basic Books).

Brauch, Hans Günter, 2009: "Human Security Concepts in Policy and Science“, in: Brauch, Hans Günter; Oswald Spring, Ursula; Grin, John; Mesjasz, Czeslaw; KameriMbote, Patricia; Behera, Navnita Chadha; Chourou, Béchir; Krummenacher, Heinz (Eds.): Facing Global Environmental Change: Environmental, Human, Energy, Food, Health and Water Security Concepts (Berlin - Heidelberg - New York: Springer-Verlag): 965-99o.

Breman, Jan, 2009: "The Great Transformation in the Setting of Asia". Public lecture to accept honorary doctorate (The Hague: International Institute of Social Studies). 
Burgess, J. Peter, 2007: Promoting Human Security: Ethical, Normative and Educational Frameworks in Western Europe (Paris: UNESCO).

Campillo Carrete, Beatriz; Gasper, Des, 20II: "Managing Migration in the IOM's World Migration Report 2008”, in: Truong, Thanh-Dam; Gasper, Des (Eds.): Transnational Migration and Human Security (Berlin - Heidelberg - New York: Springer): II7-I32.

Carens, Joseph, 1987: "Aliens and Citizens - the case for open borders", in: The Review of Politics, 49,2: 25I-273.

Castles, Stephen, 2009: "Development and Migration Migration and Development: What Comes First? Global Perspective and African Experiences", in: Theoria, 56, I2I: I-3I.

Chatterjee, Partha, 1993: The Nation and its Fragments (Delhi: Oxford University Press).

Cholewinski, Ryszard, 20I0: "Labour migration management and the rights of migrant workers", in: Edwards, Alison; Ferstman, Carla (Eds.): Human Security and Non-Citizens (Cambridge: Cambridge University Press): 273-3I3.

CHS / Commission on Human Security (2003) Human Security Now, New York. UN Secretary-General's Commission on Human Security.

Chun, Jennifer Jihye, 2009: Organizing at the Margins: The Symbolic Politics of Labor in South Korea and the United States (Ithaca, NY: ILR Press).

Collins, Patricia Hill, 2000: Black Feminist Thought (New York: Routledge).

De Genova, Nicholas, 2005: Working the Boundaries: Race, Space, and "Illegality" in Mexican Chicago (Durham, NC: Duke University Press).

De Haas, Hein, 20I2: "The Migration and Development Pendulum: A Critical View on Research and Policy", in: International Migration, 50(3): 8-25.

Doneys, Philippe, 20II: "En-Gendering Insecurities: The Case of the Migration Policy Regime in Thailand”, in: International Journal of Social Quality, I, 2: 50-65.

Dower, Nigel, 1998: Global Ethics (Edinburgh: Edinburgh University Press).

Edwards, Alison; Ferstman, Carla, 20I0: "Humanising noncitizens: the convergence of human rights and human security", in Edwards, Alison; Ferstman, Carla (Eds.): Human Security and Non-Citizens (Cambridge: Cambridge University Press): 3-46.

Edwards, Alison; Ferstman, Carla (Eds.), 20I0: Human Security and Non-Citizens (Cambridge: Cambridge University Press).

Farmer, Paul, 1996: "Social Inequalities and Emerging Infectious Diseases”, in: Emerging Infectious Diseases, 2,4: 259-269.

Gasper, Des, 2005a: "Beyond The Inter-National Relations Framework: An Essay In Descriptive Global Ethics”, in: Journal of Global Ethics, I,I: 5-23.

Gasper, Des, 2005b: "Securing Humanity - Situating 'Human Security' as Concept and Discourse”, in: Journal of Human Development, 6,2, 22I-245.
Gasper, Des, 2009: "Global Ethics and Human Security", in: Honor, Fagan G.; Munck, Ronaldo (Eds.): Globalization and Security: An Encyclopedia (two vols.) (Westport, CT: Greenwood): Vol.I, I55-I7I.

Gasper, Des, 20I0: “The Idea of Human Security”, in: O’Brien, Karen; St. Clair, Asunción Lera; Kristoffersen, Berit (Eds.): Climate Change, Ethics and Human Security (Cambridge: Cambridge University Press): 23-46.

Gasper, Des, 20II: "International Migration, Well-Being and Transnational Ethics", in: Truong, Thanh-Dam; Gasper, Des (Eds.): Transnational Migration and Human Security: The Migration-Development-Security Nexus: The Migration-Development-Security Nexus (Berlin Heidelberg - New York: Springer): 259-272.

Gasper, Des, 2013: "Concepts of Human Security", in: Martin. Mary; Owen, Taylor (Eds.): The Routledge Handbook of Human Security (London: Routledge).

Gasper, Des; Roldan, Bernice, 20II: "A Chance to Frame the Issues in a Way that Allows You to Move Forward Together"? Kofi Annan's Rhetorical Strategy for The Global Forum on Migration and Development", in: African Journal of Rhetoric, 3: 156-I95.

Gasper, Des; Truong, Thanh-Dam, 2005: "Deepening Development Ethics - From economism to human development to human security", in: European Journal of Development Research, I7,3: 372-384.

Gasper, Des; Truong, Thanh-Dam, 20Ioa: "Movements of the 'We': International and Transnational Migration and the Capabilities Approach", in: Journal of Human Development and Capabilities, II,2: 339-357.

Gasper, Des; Truong, Thanh-Dam, 20Iob: "Development Ethics through the Lenses of Caring, Gender and Human Security”, in: Esquith, Stephen Lawrence; Gifford, Fred (Eds.): Capabilities, Power and Institutions: Towards a More Critical Development Ethics (University Park, PA: Pennsylvania State University Press): 58-95.

Goldin, Ian; Cameron, Geoffrey; Balarajan, Meera, 20II: Exceptional People - How migration shaped our world and will define our future (Princeton, NJ: Princeton University Press).

Gomez, Oscar A.; Gasper, Des; Mine, Yoichi, 2013: Good Practices in Addressing Human Security through National Human Development Reports; Report to Human Development Report Office, UNDP, New York.

Gough, Ian; Wood, Geof (Eds.), 2004: Insecurity and Welfare Regimes in Asia, Africa and Latin America (Cambridge: Cambridge University Press).

Haq, Mahbub ul, I999: Reflections on Human Development (Delhi: Oxford University Press).

Hiemstra,. Nancy, 20IO: "Immigrant 'Illegality' as Neoliberal Governmentality in Leadville, Colorado", in: Antipode, 42, I: 74-IO2.

Hintjens, Helen; Kumar, Richa; Pouri, Ahmed, 20II: "Pro-asylum Advocacy in the European Union: Challenging the State of Exception”, in: Truong, Thanh-Dam; Gasper, Des (Eds.): Transnational Migration and Human Secu- 
rity: The Migration-Development-Security Nexus (Berlin - Heidelberg - New York: Springer): 209-223.

Huijsmans, Roy, 20II: "The Theatre of Human Trafficking: A global discourse on Lao stages", in: International Journal of Social Quality, I,2: 66-84.

Human Rights Watch, 20I0: “Trigger Happy - Excessive Use of Force by Indian Soldiers at the Bangladesh Border", at: 〈http://www.hrw.org/reports/20IO/I2/og/trigger- happy-o> (23 March 20I3).

IOM, 2008: World Migration Report 2008 (Geneva: International Organization for Migration).

Kapur, Ratna, 20I0: Makeshift Migrants and the Law (Delhi: Routledge).

Kaye, Jeffrey. 20I0: Moving Millions - how coyote capitalism fueled global immigration (New York: Wiley).

Kusakabe, Kyoko, 20I3: Commentary at the Final Workshop of research project on Migration, Gender and Social Justice, in Trivandrum, India, February.

Leichenko, Robin; O’Brien, Karen, 2008: Environmental Change and Globalization: Double Exposures (New York: Oxford University Press).

Lester, Eve, 20I0: "Socio-economic rights, human security and survival migrants: Whose rights? Whose security?", in: Edwards, Alison; Ferstman, Carla (Eds.): Human Security and Non-Citizens (Cambridge: Cambridge University Press): 3I4-356.

McAdam, Jane; Saul, Ben, 20I0: "An insecure climate for human security? Climate-induced displacement and international law", in: Edwards, Alison; Ferstman, Carla (Eds.): Human Security and Non-Citizens (Cambridge: Cambridge University Press): 357-403.

Marin, Maria Lourdes S., 20I3: Commentary at the Final Workshop of research project on Migration, Gender and Social Justice, in Trivandrum, India, February.

Mine, Yoichi, 20II: "Migration Regimes and the Politics of Insiders/Outsiders: Japan and South Africa as Distant Mirrors", in: Truong, Thanh-Dam; Gasper, Des (Eds.): Transnational Migration and Human Security: The Migration-Development-Security Nexus (Berlin Heidelberg - New York: Springer): 287-296.

Mushakoji, Kinhide, 20II: "State and Immigrant Diaspora Identity in Contemporary Japan: From a Developmentalist National Ethic towards a Multicultural Development Ethic of Common Human Security”, in: Truong, Thanh-Dam; Gasper, Des (Eds.): Transnational Migration and Human Security: The Migration-Development-Security Nexus (Berlin - Heidelberg - New York: Springer): 297-310.

Nagel, Thomas, 2005: "The Problem of Global Justice", in: Philosophy and Public Affairs, 33, 2: II3-I47.

Oberoi, Pia, 20IO: "Empowering migrants: human security, human rights, and policy", in: Edwards, Alison; Ferstman, Carla (Eds.), 2010: Human Security and Non-Citizens (Cambridge: Cambridge University Press): 227-272.

Oishi, Nana, 2005: Women in Motion: Globalization, State Policies and Labor Migration in Asia (Stanford, CA: Stanford University Press).
Pearson, Ruth; Kusakabe, Kyoko, 20I2: Thailand's Hidden Workforce: Burmese Migrant Women Factory Workers (London: Zed Books).

Piore, Michael, 1979: Birds of Passage: Migrant Labor and Industrial Societies (New York: Cambridge University Press).

Rawls, John, 1999: The Law of Peoples (Cambridge, MA: Harvard University Press).

Scheffer, Paul, 2007: Het Land van Aankomst (Amsterdam: De Bezige Bij).

Scheffer, Paul, 20II: Immigrant Nations (Cambridge: Polity Press).

Sen, Amartya, 2009: The Idea of Justice (London: Penguin).

Sukamdi, 2008: "Indonesia", in: Asia and Pacific Migration Journal, I7, 3-4: 325-334.

TIP, 20Iо: Trafficking in Persons Report 2010 (Washington, DC: U.S. Department of State).

Truong, Thanh-Dam; Gasper, Des, 2008a: "Trans-Local Livelihoods and Connections - Embedding a Gender Perspective into Migration Studies", in: Gender, Technology and Development, I2, 3: 285-302.

Truong, Thanh-Dam; Gasper, Des (Eds.), 2008b: TransLocal Livelihoods and Connections. Special issue on transnational migration and multi-local livelihoods; in: Gender, Technology and Development, I2, 3: 285-507.

Truong, Thanh-Dam; Gasper, Des, 20IIa: "Transnational Migration, Development and Human Security”, in: Truong, Thanh-Dam; Gasper, Des (Eds.): Transnational Migration and Human Security: The Migration-Development-Security Nexus (Berlin - Heidelberg - New York: Springer): 3-22.

Truong, Thanh-Dam; Gasper, Des (Eds.), 2orrb: Transnational Migration and Human Security: The MigrationDevelopment-Security Nexus (Berlin - Heidelberg New York: Springer).

UNDP, 1990: Human Development Report 1990 - Concept and measurement of human development (New York: Oxford University Press).

UNDP, 1994: Human Development Report 1994: - New dimensions of human security (New York: Oxford University Press).

UNDP, 2003: Latvia Human Development Report: 20022003: Human Security (Riga: UNDP; <http://hdr. undp.org/en/reports/national/europethecis/latvia/name, 3I94,en.html>.)

UNDP, 2009: Human Development Report 2009 - Overcoming barriers: human mobility and development (New York: Palgrave).

UNESCO, 2008: Human Security - Approaches and Challenges (Paris: UNESCO).

United Nations, 200I: Replacement Migration: Is It a Solution to Declining and Ageing Populations? (New York: United Nations).

Wallerstein, Immanuel, et al., 1996: Open The Social Sciences - Report of the Gulbenkian Commission on the Restructuring of the Social Sciences (Stanford, CA: Stanford Univ. Press).

Open Access. This chapter is distributed under the terms of the Creative Commons Attribution Non-commercial License, which permits any noncommercial use, distribution, and reproduction in any medium, provided the original author(s) and source are credited. 


\section{Abbreviations}

Abvakabo FNV Algemene Bond van Ambtenaren

Katholieke Bond van Overheidspersoneel

en Federatie Nederlandse Vakbeweging

(Federation of Dutch Trade Unions)

ACHIEVE Action for Health Initiatives (Philippines)

ACMECS Ayeyawady-Chao Phraya-Mekong Economic

Cooperation Strategy

AIDS Acquired Immune Deficiency Syndrome

AIDWA All India Democratic Women's Association

AJ Al-Jazeera English News

ANEJ Agence Nationale pour l'Emploi des Jeunes

(National Agency for Youth Employment)

APPO Assamblea Popular de los Pueblos de

Oaxaca (Popular Assembly of the People of

Oaxaca)

APS Australian Psychological Society

APWLD Asia Pacific Forum on Women, Law and

Development

ARCM Asian Research Center for Migration

ASEAN Association of Southeast Asian Nations

BIT Bureau International du Travail

(International Labour Office)

BT Bacillus thuringiensis (species of bacteria which gives its name to a kind of crop and pesticides)

CARIM Consortium for Applied Research on International Migration

CBCP Catholic Bishops' Conference of the Philippines

CCSS Caja Costarricense de Seguro Social (Costa Rican Social Security Bank)

CEDAW Convention on the Elimination of All Forms of Discrimination Against Women

CEDEM Centre for Ethnic and Migration Studies, University of Liège, Belgium

CEPS Centre for European Policy Studies

CFA Communauté Française d'Afrique (French Community of Africa)

CFA Communauté Financière Africaine (African Financial Community)

CFE Critical Feminist Ethnography

CGIAR Consultative Group on International Agricultural Research

CHS Commission on Human Security

CLAIP Consejo Latinoamericano de Investigación para la Paz (Latin American Council for Peace Research)

COLEF Colegio de la Frontera Norte (The College of the Northern Border)

CONAPO Consejo Nacional de Población (National Population Council)
CONAPRED Consejo Nacional para Prevenir la Discriminación (National Council to Prevent Discrimination)

CPA China Population Association

CRC Convention on the Rights of the Child

CRIM Centro Regional de Investigaciones Multidisciplinarias (Regional Centre for Multidisciplinary Research)

CWDS Centre for Women's Development Studies

DFA

DGME

DNT

DRDA

DREAM

Department of Foreign Affairs Division of Migration and Alien Affairs Denotified Tribes

District Rural Development Agencies Development, Relief, and Education for Alien Minors

ECOSUR El Colegio de la Frontera Sur (The College of the Southern Border)

ECOWAS Economic Community of West African States

EDP Everyday Politics

EMIF-Sur Encuesta sobre Migración en la Frontera Sur (Southern Border Migratory Survey)

EMN European Migration Network

EU European Union

EXIM Export-Import Bank of Thailand

FDW Filipina Domestic Workers

FGDs $\quad$ Focus Group Discussions

FM2 Forma Migratoria 2 (Immigration Form 2)

$\mathrm{FM}_{3} \quad$ Forma Migratoria 3 (Immigration Form 3)

FMP Federación Mujeres Progresistas (Progressive Women's Federation)

FMTF Forma Migratoria de Trabajador Fronterizo (Immigration Form for Frontier Workers)

FMVL Forma Migratoria de Visitante Local (Migratory Form for Local Visitors)

FNV Federatie Nederlandse Vakbeweging (Federation of Dutch Trade Unions)

FRY Foundation for Rural Youth

FTUB Federation of Trade Unions Burma

GCC Gulf Cooperation Council

GDP Gross Domestic Product

GERM Groupe d'Etudes et de Recherches sur les Migrations (Research and Study Group on Migrations)

GMS Greater Mekong Sub-Region

GREFELS Groupe de Recherche Femmes et Lois au Sénégal (Research Group on Women and the Law in Senegal) 


\begin{tabular}{|c|c|c|c|}
\hline $\mathrm{HIN}_{\mathrm{I}}$ & $\begin{array}{l}\text { Hemagglutinin I and Neuraminidase I } \\
\text { (Virus Influenza A-2009) }\end{array}$ & MGNREGS & $\begin{array}{l}\text { Mahatma Gandhi National Rural } \\
\text { Employment Guarantee Scheme }\end{array}$ \\
\hline HIV & Human Immunodeficiency Virus & MOE & Ministry of Education \\
\hline \multirow[t]{2}{*}{ HIV-AIDS } & Human Immunodeficiency Virus-Acquired & MOI & Ministry of Interior \\
\hline & Immune Deficiency Syndrome & MOL & Ministry of Labour \\
\hline ICPD & $\begin{array}{l}\text { International Conference on Population } \\
\text { and Development }\end{array}$ & MoLSW & $\begin{array}{l}\text { Ministry of Labour and Social Welfare (Lao } \\
\text { PDR) }\end{array}$ \\
\hline \multirow[t]{2}{*}{ ICRtoP } & $\begin{array}{l}\text { and Development } \\
\text { International Coalition for the }\end{array}$ & MOU & Memorandum of Understanding \\
\hline & Responsibility to Protect & NAFTA & North American Free Trade Agreement \\
\hline ID & Identification Document & NATO & North Atlantic Treaty Organization \\
\hline IDRC & $\begin{array}{l}\text { International Development Research } \\
\text { Centre (Canada) }\end{array}$ & NCEUS & $\begin{array}{l}\text { National Commission for Enterprises in the } \\
\text { Unorganised Sector }\end{array}$ \\
\hline IDWN & International Domestic Workers' Network & NCRL & National Commission on Rural Labour \\
\hline ILC & International Law Conference & NCT & National Capital Territory \\
\hline ILO & International Labour Office & NGO & Non-Governmental Organization \\
\hline \multirow[t]{3}{*}{ ILO-IPEC } & International Labour Office's International & NICs & Newly Industrialized Countries \\
\hline & Programme on the Elimination of Child & NL & The Netherlands \\
\hline & Labour & NSS & National Sample Survey \\
\hline IMI & $\begin{array}{l}\text { International Migration Institute (University } \\
\text { of Oxford) }\end{array}$ & NSSO & National Sample Survey Office \\
\hline \multirow[t]{3}{*}{ INDH } & Initiative Nationale pour le Développement & NYT & New York Times News \\
\hline & Humain (National Initiative for Human & OBCs & Other Backward Classes/Castes \\
\hline & Development) & OEC & Office of Education Council \\
\hline INEC & $\begin{array}{l}\text { Instituto Nacional de Estadística y Censos } \\
\text { (National Institute of Statistics and Census) }\end{array}$ & OECD & $\begin{array}{l}\text { Organisation for Economic Co-operation } \\
\text { and Development }\end{array}$ \\
\hline \multirow[t]{2}{*}{ INEGI } & $\begin{array}{l}\text { Instituto Nacional de Estadística y } \\
\text { Geografía (National Institute of Statistics }\end{array}$ & OFWs & Overseas Filipino Workers \\
\hline & and Geography) & POEA & Philippine Overseas Employment \\
\hline \multirow[t]{2}{*}{ INM } & Instituto Nacional de Migración (National & & Administration \\
\hline & Migration Institute) & PPS & Probability Proportional to Size (sampling \\
\hline $\mathrm{IOM}$ & International Organization for Migration & & technique) \\
\hline \multirow[t]{2}{*}{ IPEC } & International Programme on the & PRC & People's Republic of China \\
\hline & Elimination of Child Labour & RTI & Respiratory Tract Infection \\
\hline \multirow{3}{*}{$\begin{array}{l}\text { IPSR } \\
\text { IRENE }\end{array}$} & Institute for Population and Social Research & RtoP & Responsibility to Protect \\
\hline & International Restructuring Education & & \\
\hline & Network Europe & SARS & Severe Acute Respiratory Syndrome \\
\hline IRP & Integrated Resource Package & SC & Scheduled Castes \\
\hline \multirow{4}{*}{$\begin{array}{l}\text { ISA } \\
\text { ISDS } \\
\text { ISS }\end{array}$} & Institute of Asian Studies & SEGEPLAN & Secretaría de Planificación y Programación \\
\hline & Institute for Social Development Studies & & (Guatemalan Secretariat of Planning and \\
\hline & International Institute of Social Studies of & & Programming) \\
\hline & Erasmus University Rotterdam & SPA & Social Protection in Asia \\
\hline \multirow[t]{2}{*}{ IUF } & $\begin{array}{l}\text { International Union of Food, Agricultural, } \\
\text { Hotel, Restaurant, Catering, Tobacco and }\end{array}$ & SRE & $\begin{array}{l}\text { Secretaría de Relaciones Exteriores (Foreign } \\
\text { Ministry of Mexico) }\end{array}$ \\
\hline & Allied Workers' Associations & SRH & Sexual and Reproductive Health \\
\hline \multirow[t]{2}{*}{ IUSSP } & International Union for the Scientific Study & SRT & Social Representations Theory \\
\hline & & ST & Scheduled Tribes \\
\hline \multirow{2}{*}{$\mathrm{km}$} & \multirow{2}{*}{ kilometres } & STD & Sexually Transmitted Disease \\
\hline & & STI & Sexually Transmitted Illness \\
\hline Lao PDR & Lao People’s Democratic Republic & STyPS & Secretaría de Trabajo y Previsión Social \\
\hline LGBT & Lesbian, Gay, Bisexual, and Transgender & & \\
\hline LPN & Labour Rights Promotion Network & TDRI & Thailand Development Research Institute \\
\hline \multirow[t]{2}{*}{ LUTRENA } & Programme to combat the trafficking of & TG & The Guardian News \\
\hline & $\begin{array}{l}\text { children for labour exploitation in West } \\
\text { Africa and Central Africa (ILO) }\end{array}$ & TICW & $\begin{array}{l}\text { Mekong Project to Combat Trafficking in } \\
\text { Children and Women }\end{array}$ \\
\hline MAFE & Migrations between Africa and Europe & TIP & Trafficking in Persons \\
\hline MBC & Most Backward Castes & TPS & Temporary Protected Status \\
\hline MFA & Ministry of Foreign Affairs & TSR & Theory of Social Representations \\
\hline
\end{tabular}




\begin{tabular}{|c|c|c|c|}
\hline TWC2 & Transient Workers Count Too & UNHCR & $\begin{array}{l}\text { United Nations High Commissioner for } \\
\text { Refugees }\end{array}$ \\
\hline UAE & United Arab Emirates & UNIAP & United Nations Inter-Agency Project \\
\hline UCI & University of California, Irvine & UNICEF & United Nations Children's Fund \\
\hline UCR & University of Costa Rica & UNIFEM & United Nations Development Fund for \\
\hline UCW & Understanding Children's Work (project) & & Women \\
\hline UK & United Kingdom & UN Women & United Nations Entity for Gender Equality \\
\hline UN & United Nations & & and the Empowerment of Women \\
\hline \multirow{3}{*}{ UNAM } & Universidad Nacional Autónoma de México & UPR & Usual Place of Residence \\
\hline & (National Autonomous University of & UPSS & Usual Status Principal+subsidiary workers \\
\hline & Mexico) & USA & United States of America \\
\hline \multirow[t]{2}{*}{ UNCTOC } & United Nations Convention on & USD & United States Dollar \\
\hline & Transnational Organized Crime & USSR & Union of Soviet Socialist Republics \\
\hline UNDP & United Nations Development Programme & & \\
\hline UN-ESCAP & $\begin{array}{l}\text { United Nations Economic and Social } \\
\text { Commission for Asia and the Pacific }\end{array}$ & WHO & World Health Organisation \\
\hline UNESCO & $\begin{array}{l}\text { United Nations Educational, Scientific and } \\
\text { Cultural Organization }\end{array}$ & YCOWA & Yaung Chi Oo Workers Association \\
\hline
\end{tabular}




\section{Biographies of Contributors}

Indu Agnihotri (India) is a professor and the director of the Centre for Women's Development Studies (CWDS), the Indian Council of Social Science Research. She holds a Ph.D. from Jawaharlal Nehru University, and has a keen interest in the following areas: Gender and History; the Women's Movement in India; Curriculum development in Women's Studies. Her publications include: "Globalization, Resistance and Change: Reflections on South Asian Women's Experiences”, in: Bhatia, Manjeet; Bhanot, Deepali; Samanta, Nirmalya (Eds.): Gender Concerns in South Asia: Some Perspectives (Jaipur: Rawat Publications, 2008); "Women's Movement and Governance: Issues and Challenges", in: Mishra-Panda, Smita (Ed.): Engendering Governance Institutions: State, Market and Civil Society (New Delhi: Sage, 2008); (co-author with Indrani Mazumdar): "Dusty Trails and Unsettled Lives: Notes on Women's Labour Migration in Rural India”, in: Indian Journal of Gender Studies, I6,3 (2009): 375-399; (co-author with Vina Mazumdar): "Changing Terms of Political Discourse: Women's Movement in India, I970s-I990s”, in: Oommen, T.K. (Ed.): Social Movements II: A Reader, Concerns of Equity and Security (New Delhi: Oxford University Press, 20Io); (coauthor with Vina Mazumdar): "Democracy, Freedom and Development: The Struggle for Women's Emancipation in India”, in: Bijayalakshmi, Nanda (Ed.) Understanding Social Inequality: Concerns of Human Rights, Gender and Environment (New Delhi: Macmillan, 20IO); (co-author with Indrani Mazumdar, Neetha N. Pillai): "Gender and Migration in India", in: The Report of the National Workshop on Internal Migration and Human Development in India (New Delhi: UNESCO/UNICEF, 20II); at: <http:// www.unicef.org/india/Migration_VOL2_v3.pdf>.

Address: Prof. Dr. Indu Agnihotri, 25, Bhai Vir Singh Marg (Gole Market) New Delhi - II ০o০I, India.

Email: <indu@cwds.ac.in>, <indu@cwds.org>.

Website: 〈www.cwds.org>.

Sylvia I. Bergh (Sweden) is Senior Lecturer in Development Management and Governance at the International Institute of Social Studies (ISS), Erasmus University Rotterdam. She obtained an MA (First Class Honours) in Arabic and International Relations from the University of St Andrews in Scotland, followed by an M.Phil. in Modern Middle Eastern Studies from the University of Oxford. After a two-year posting with the World Bank in Washington DC and in Morocco, she undertook doctoral research on local governance in Morocco, including grass-roots and transnational migrants' associations, rural-urban migration, and return migration, earning a D.Phil. in Development Studies from the University of Oxford. She also has extensive consultan- cy experience, including for the United Nations Development Fund for Women (UNIFEM) involving an evaluation of the Gender-Responsive Budgeting Programme in Morocco, for Dutch non-governmental organizations. She has a keen interest in the research-policy nexus. Among her key publications are: "Assessing the Scope for Partnerships Between Local Governments and Community-Based Organizations: Findings from Rural Morocco" in: International Journal of Public Administration, 33,I2-I3 (2010): 740-75I; "Introduction: Researching the effects of neoliberal reforms on local governance in the Southern Mediterranean", in: Mediterranean Politics, I7,3 (20I2): 303-32I; "'Inclusive' Neoliberalism, Local Governance Reforms and the Redeployment of State Power: The Case of the National Initiative for Human Development (INDH) in Morocco", in: Mediterranean Politics, I7,3 (20I2): 4IO-426; "Governance Reforms in Morocco - Beyond Electoral Authoritarianism?", in: Kadhim, Abbas (Ed.): Governance in the Middle East and North Africa: A Handbook (London: Routledge, 20I2).

Address: Dr. Sylvia I. Bergh, International Institute of Social Studies, P.O. Box 29776, 2502 LT The Hague, The Netherlands.

Email: <bergh@iss.nl>.

Website: <www.iss.nl/bergh>.

Codou Bop (Senegal) is a scholar and activist on women's rights and human rights. A member of the African Feminist Forum, she is also linked to many feminist movements in the region and at the international level. Based in Dakar, Senegal, she serves as the Coordinator for the Groupe de Recherche sur les Femmes et les Lois au Senegal (GREFELS). For the last two decades she has worked on sexuality, sexual orientation, women with disability, citizens' rights, migrations and trafficking in women, women's rights in customary and religious laws, and gender violence justified by customs or religion. She holds a doctorate in Sciences of Information from the University of Paris II Assas Sorbonne, France. She has published widely on a variety of themes, including: women's reproductive health and sexuality; homophobia; women's access to land; gender-based violence; migration and citizenship. Her latest publications include: (co-author with Fatou Sow): Notre Corps, Notre Santé, Un livre sur la santé et la sexualité des femmes en Afrique Subsaharienne (Paris-Budapest-Torino: L'Harmattan, 2004); "Roles and Position of Women in Sufi Brotherhoods in Senegal", in: Journal of the American Academy of Religion, 73,4 (2005): I099-III9; "I killed her because she disobeyed me in wearing this new hairstyle: Gender-Based violence, Law, and Impunity in Senegal”, in: Burril, Emily 
S.; Roberts, Richard L.; Thornberry, Elizabeth (Eds.): Domestic Violence and the Law in Colonial and Postcolonial Africa (Athens, Ohio: Ohio University Press, 20Io).

Address: Dr. Codou Bop, PO Box 15275, Dakar, Fann, Senegal.

Email:<codoubop@orange.sn>,<codou.bop@gmail.com>. Website: 〈www.grefels.com>.

Susan Bibler Coutin (USA) is Professor in the Departments of Criminology, Law and Society and Anthropology at the University of California, Irvine (UCI), where she is also Associate Dean of the Graduate Division. She holds a Ph.D. in sociocultural anthropology from the University of California, Irvine. Her research has examined legal and political advocacy by and on behalf of Central American immigrants in the US. Her publications include: Nations of Emigrants: Shifting Boundaries of Citizenship in El Salvador and the United States (Ithaca: Cornell University Press, 2007); "Confined Within: National Territories as Zones of Confinement”, in: Political Geography, 29,4 (2010): 200208; "Falling Outside: Excavating the History of Central American Asylum Seekers", in: Law \& Social Inquiry, 36,3 (20II): 569-596; "Legal Exclusion and Dislocated Subjectivities: The Deportation of Salvadoran Youth from the United States", in: Squire, Vicki. J. (Ed.): The Contested Politics of Mobility: Border Zones and Irregularity (London: Routledge, 20II): I69-I83.

Address: Prof. Dr. Susan Bibler Coutin, University of California, Irvine, 5300 Social and Behavioral Sciences Gateway, Irvine, CA 92697-7050, USA.

Email: <scoutin@uci.edu>.

Website: <htp://clsc.soceco.uci.edu/>.

Maria C. DeVargas (Colombia/Spain) has extensive field experience on development projects from 1994 through her work with non-governmental organizations, the academic community, and the private sector. She holds a BA in Psychology from the Universidad de los Andes in Bogotá, Colombia; a specialization in Socio-Cognitive Psychotherapy from University of Barcelona, and an MA in Development Studies with a specialization in the Politics of Alternative Development from the International Institute of Social Studies. Her research interest and previous work focus on themes of agency, gender, social change, resilience, and sustainable livelihoods. She has worked for more than two years as Researcher and Project Officer for the IDRC-ISS project Migration, Gender and Social Justice at the International Institute of Social Studies, Erasmus University Rotterdam. In addition she also provides research assistance for other projects and teaching assistance for MA courses at the International Institute of Social Studies.

Address: Ms Maria C. DeVargas, International Institute of Social Studies, P.O. Box 29776, 2502 LT The Hague, The Netherlands.

Email: <mcdevargas@yahoo.com>, <devargas@iss.nl>. Website: <www.iss.nl>.

Stefania Donzelli (Italy) is a Ph.D. candidate at the International Institute of Social Studies (ISS), Erasmus University
Rotterdam. Her main research project focuses on migration, feminism, and social movements. She received her BA with distinction from the Faculty of Political Sciences, University of Bologna (2007). During that study period, she received an overseas scholarship to study for one year at the Universidad Nacional Autónoma of México (UNAM). In 2009 she graduated with distinction from the ISS, after completing an MA in Politics of Alternative Development. Her MA thesis on feminist representations of rape won the ISS MA Research Award and was published as a working paper. Currently she is working as a research assistant.

Address: Ms Stefania Donzelli, International Institute of Social Studies, P.O. Box 29776, 2502 LT The Hague, The Netherlands.

Email:<donzelli@iss.nl>.

Website: <www.iss.nl>.

Des Gasper (United Kingdom/The Netherlands) works at the International Institute of Social Studies (ISS), Erasmus University Rotterdam, on topics in public policy analysis, discourse analysis, development ethics, human development, and human security. After studies in economics, international development, and policy analysis at the Universities of Cambridge and East Anglia, he worked for many years in Southern Africa before coming to ISS. In recent years his empirical focus has been on migration, and increasingly also on climate change. Selected publications: The Ethics of Development-From Economism to Human Development (Edinburgh: Edinburgh University Press, 2004); "What is the Capability Approach? Its Core, Rationale, Partners and Dangers", Journal of Socio-Economics, 36,3 (2007): 335-359; (co-author with Thanh-Dam Truong): "Movements Of The 'We': International and Transnational Migration and the Capabilities Approach", in: Journal of Human Development and Capabilities, II,2 (2010): 339357; "Development Ethics - Why? What? How? A formulation of the field", in: Journal of Global Ethics, 8, I (20I2):II7-I35; "Climate Change - The Need For A Human Rights Agenda Within A Framework Of Shared Human Security", in: Social Research: An International Quarterly of the Social Sciences, 79,4 (20I2): 983-IOI4.

Address: Prof. Dr. Des Gasper, International Institute of Social Studies, P.O. Box 29776, 2502 LT The Hague, The Netherlands.

Email: <gasper@iss.nl>.

Website: <www.iss.nl/gasper>.

Aster Georgo Haile (Eritrea) conducted the empirical research for this chapter in the context of her MA thesis at the International Institute of Social Studies (ISS) of Erasmus University Rotterdam. In 20II, she graduated from the ISS with an MA in Development Studies, specializing in Women, Gender, and Development. Currently, she is a graduate student in the Africana Studies Department at the University at Albany, State University of New York.

Address: Ms Aster Georgo Haile, Africana Studies BA II5, I400 Washington Avenue, The University at Albany, Albany, New York I2222, USA.

Email: <astageorgo@yahoo.com>. 
Jeff Handmaker (United Kingdom/USA) is a senior lecturer in Law, Human Rights, and Development at the International Institute of Social Studies (ISS) of Erasmus University Rotterdam and an Honorary Senior Research Fellow in the School of Law at the University of the Witwatersrand in South Africa. Before joining the ISS in 2007 , he studied law and was called to the English bar in 1995. He obtained a Ph.D. in the Sociology of Law from Utrecht University. From the early I990s he worked for the South African organization Lawyers for Human Rights and from 2000 he was based in The Hague as a freelance consultant, trainer, and researcher for projects mainly in Southern Africa and the Middle East. He has published scholarly work on human rights, refugee law, and civic-state interactions to hold states accountable to their international legal obligations, with a primary geographical focus on South Africa. His publications include: (co-editor with Lee Anne de la Hunt, Jonathan Klaaren): Advancing Refugee Protection in South Africa, (New York, Oxford: Berghahn, 2008); Advocating for Accountability: Civic-State Interactions to Protect Refugees in South Africa (Antwerp: Intersentia, 2009): "Public Interest Litigation for Refugees in South Africa and the Potential for Structural Change", in: South African Journal of Human Rights, 27,I (20II): 65-8I.

Address: Dr. Jeff Handmaker, International Institute of Social Studies, P.O. Box 29776, 2502 LT The Hague, The Netherlands.

Email: <handmaker@iss.nl>.

Website: <www.iss.nl/handmaker>.

Roy B. C. Huijsmans (The Netherlands) is lecturer in Children and Youth Studies at the International Institute of Social Studies (ISS) in The Hague, The Netherlands <http:// blog.eur.nl/iss/cys/>. His research interests cover questions concerning children and young people in the context of development. This includes work on young people and migration which he has studied in relation to gender and generation, migration regimes, constructs of childhood and youth, rural transformation, migration discourses, and intra-household dynamics. He has written on this topic in the context of the EU and South-East Asia. His publications include: "Child Migration and Questions of Agency", in: Development and Change, 42,5 (20II): I307-I32I; "The Theatre of Human Trafficking: A global discourse on Lao stages", in: International Journal of Social Quality, I,2 (2012): 66-84.

Address: Dr. Roy B. C. Huijsmans, International Institute of Social Studies, P.O. Box 29776, 2502 LT The Hague, The Netherlands.

Email: <r.b.huijsmans@gmail.com>,<Huijsmans@iss.nl>.

Website: <www.iss.nl>.

Sulistyowati Irianto (Indonesia) is Professor of the Anthropology of Law at the Faculty of Law, University of Indonesia. She holds Master's degrees in the Anthropology of Law from Leiden University and the University of Indonesia, and a Doctoral degree on the same subject from the University of Indonesia. She is chair of the Centre for Women and Gender Studies, University of Indonesia, and has been a board member of the International Commission on Legal Pluralism since 2006, and she teaches on "Legal Anthropol- ogy" and "Women and Law". She has strong interests in the fields of legal pluralism and gender and the law. Her latest research projects include: Access to Justice and Global Migration: Stories of Indonesian Women Domestic Migrant Workers in the United Arab Emirates (2008-20II); Negotiating and Contesting Inheritance Law: Socio-Legal Position of Indonesian Moslem Women (2009-20I2). Among her major publications are: (co-editor with Shidarta Sakirno): Penelitian Hukum: Konstelasi dan Refleksi (Legal Research Methods: Constellation and Reflection) (Jakarta: Yayasan Obor, 20Iо); Akses Keadilan dan Migrasi Global: Kisah Perempuan Indonesia Pekerja Domestik di Uni Arab Emirates (Access to Justice and Global Migration: Stories of Indonesian Women Domestic Migrant Workers in the United Arab Emirates), (Jakarta: Yayasan Obor, 20II); "The Changing Socio-Legal Position of Women in Inheritance: A Case Study of Batak Women in Indonesia dalam”, in: Hayami, Yoko; Koizumi, Junko; Songsamphan, Chalidaporn; Tosakul. Ratana (Eds.): The Family in Flux in Southeast Asia: Institution, Ideology, and Practice (Kyoto-Chiang Mai: Kyoto University Press - Silkworms Books, 20I2).

Address: Prof. Dr. Sulistyowati Irianto, University of Indonesia, Faculty of Law, UI Campus Depok I6424 - Indonesia.

Email: <sulis_irianto@yahoo.com>.

Website: 〈www.ui.ac.id/id/profile/page/struktur-ui/sau>.

Thu Hong Khuat (Vietnam) is the founder and Co-Director of the Institute for Social Development Studies (ISDS), a non-governmental research organization located in Hanoi, Vietnam. She has a BA in Psychology from Moscow State University in the former Union of Soviet Socialist Republics (USSR), and a Ph.D. in Sociology from the Institute of Sociology, Hanoi. Before establishing ISDS, she worked for the Institute of Sociology, Vietnam Academy of Social Sciences for sixteen years and for United Nations Development Programme (UNDP) as a gender specialist from 2000 to 200 . Her major fields of study include gender, sexuality, reproductive and sexual health, and HIV/AIDS. Recent publications on migration include: (co-editor with Le Bach Duong): Market Transformation, Migration and Social Protection in a Transitioning Vietnam (Hanoi: World Publisher, 2008); (co-author with Danièle Bélanger, Kayoko Ueno, Emiko Ochiai): "From Foreign Trainees to Unauthorized Workers: Vietnamese Migrant Workers in Japan", Asian and Pacific Migration Journal, 20,I (20II): 3I-53.

Address: Dr. Thu Hong Khuat, Institute for Social Development Studies, Suite 225, CT5 Building, Tran Van Lai Street, Me Tri-My Dinh Area, Pham Hung Road, Hanoi, Vietnam. Email: <hongisds@gmail.com>.

Website: <www.isds.org.vn>.

Kyoko Kusakabe (Japan/Thailand) is Associate Professor of Gender and Development Studies, School of Environment, Resources, and Development, Asian Institute of Technology, Thailand. Her research focuses on gender issues in mobility in the Greater Mekong Subregion and she studies the effect of regional economic integration on women's work and employment. In 20I2-20I3 she was a visiting professor at the Paris Institute of Political Studies 
(Sciences Po). She is a member of the Programme Oversight Panel for the Consultative Group on International Agricultural (CGIAR) Research Programme on Aquatic Agricultural Systems. She has carried out empirical work in Thailand, Laos, and Cambodia, and has a special interest in women in trans-border trade. Her recent publications include: (co-author with Prak Sereyvath, Ubolratana Suntornratana, Napaporn Sriputinibondh): "Gendering border spaces: Impact of open border policy between CambodiaThailand on small-scale women fish traders" in: African and Asian Studies, 7,I (2008): I-I7; (co-author with Ruth Pearson): "Transborder Migration, Social Reproduction and Economic Development: A Case Study of Burmese Women Workers in Thailand”, in: International Migration, 48,6 (2010): I3-43; (co-author with Ruth Pearson): "Who Cares? Gender, Reproduction, and Care Chains of Burmese Migrant Workers in Thailand", in: Feminist Economics, I8,2 (2012): I49-I75; (co-author with Ruth Pearson): Thailand's Hidden Workforce: Burmese Migrant Women Factory (London: Zed Books, 20I2); Gender, Roads and Mobility in Asia (Rugby, Warwickshire: Practical Action Publishing, 20I2).

Address: Prof. Dr. Kyoko Kusakabe, Asian Institute of Technology - Gender and Development Studies, School of Environment, Resources, and Development P.O. Box 4, Klong Luang, Pathumthani I2I20, Thailand.

Email:<kyokok@ait.asia>.

Website: <www.serd.ait.ac.th/pages/peopleinfo.php?id=I6>.

Bach Duong Le (Vietnam) is the Director of the Institute for Social Development Studies (ISDS), an independent research and advocacy institute based in Hanoi, Vietnam. Previously, he worked as senior researcher for the Institute of Sociology and the Institute for South-East Asian Studies of the Vietnam Academy for Social Sciences. He has consulted for key donors and international organizations including the World Bank, International Labour Office (ILO), and United Nations Development Programme (UNDP), as well as many international non-governmental organizations (NGOs). His major areas of research include migration, development studies, and sexuality. He earned his Ph.D. in sociology from the State University of New York at Binghamton in 1998. Recent publications on migration include: (co-author with Nguyen Thanh Liem): From Villages to Cities: Impact of Migration on Sending and Receiving Areas in Vietnam (Hanoi: Youth Publisher, 20II); (co-editor with Khuat Thu Hong): Market Transformation, Migration and Social Protection in a Transitioning Vietnam (Hanoi: World Publisher, 2008); (co-author with Danièle Bélanger, Tran Giang Linh): "Marriage Migrants as Emigrants" Asian Population Studies, 7,2 (2011:): 89-105.

Address: Dr. Bach Duong Le, Institute for Social Development Studies, Suite 225, CT5 Building, Tran Van Lai Street, Me Tri-My Dinh Area, Pham Hung Road, Hanoi, Vietnam. Email: <duonglb@gmail.com>.

Website: 〈www.isds.org.vn>.

Liyue Lin (China) is a Lecturer at the School of Geography, Fujian Normal University in China. She is currently working on the mobility patterns and social protection of rural-ur- ban migrants in China. She earned her B.Sc. in geography and her M.Sc. and Ph.D. in human geography from Fujian Normal University. She has published several papers in leading demographic journals in China as well as in international journals, and has presented papers at several international conferences, including: (co-author with $\mathrm{Yu} \mathrm{Zhu):}$ "The diverse housing needs of rural to urban migrants and policy responses in China: Insights from a survey in Fuzhou", in: IDS Bulletin, 4I,4 (20IO): I2-2I; "An analysis on the factors affecting social insurance participation of the floating population based on a survey in six cities of Fujian Province" (in Chinese), in Population and Economics, No. 3 (2009): 89-95; "Housing conditions of the floating population under the status of circulation: A case study of Fujian Province" (in Chinese), in: Population Research, 32,3 (2008): 48-56.

Address: Dr. Liyue Lin, School of Geography, Fujian Normal University, Fuzhou, Fujian Province 350007, People's Republic of China.

Email: <lly3o@I63.com>.

Maria Lourdes S. Marin (Philippines) is the Executive Director of Action for Health Initiatives (ACHIEVE), Inc., a Philippines-based organization working on migration, gender, and health issues. She is a trainer, writer, and programme specialist on issues related to migration, gender, sexuality, and HIV and AIDS. She has been involved in health and migration work since 2000 . She is also actively engaged in Lesbian, Gay, Bisexual, and Transgender (LGBT) rights advocacy, both nationally and internationally. Some of her publications include: Women and Migration: The Mental Health Nexus-A Research on Individual and Structural Determinants of Stress and Mental Health Problems of Filipino Women Migrant Domestic Workers (Quezon City: Action for Health Initiatives [ACHIEVE Inc.], 20II); (co-author with Amara Quesada): Unveiling HIV Vulnerabilities: Filipino Women Migrant Workers in the Arab States (Quezon City: Action for Health Initiatives [ACHIEVE, Inc.], 2009); (co-author with Lia van der Ham): Addressing Stress and Psychosocial Issues of Women Migrant Domestic Workers: An Intervention Framework (Quezon City: Action for Health Initiatives [ACHIEVE, Inc.], 20II).

Address: Ms Maria Lourdes S. Marin. Action for Health Initiatives (ACHIEVE), Inc., I62-A Scout Fuentebella Ext., Quezon City, IIO3 Philippines.

Email: <achieve_caram@yahoo.com>.

Website: <www.achieve.org.ph>.

Indrani Mazumdar (India) is a senior researcher at the Centre for Women's Development Studies (CWDS), the Indian Council of Social Science Research. She holds an MA in History from Delhi University. Her selected publications include: Women Workers and Globalization: Emergent Contradictions in India (Kolkata: Stree, 2007); "Public-Private Partnership in Integrated Child Development Services: Privatisation vs. Universalisation", in: Labour File, 6,4-5 (2008); 2008: "Women's Unpaid Labour in Neo-liberal India", The Indian Historical Review, 35, 2; "Missing the Wood for the Trees, The Human Development Report 
2009", in: Women's Equality, I (2010); (co-author with Indu Agnihotri, Neetha N. Pillai): Gender and Migration in India, in: Report of the National Workshop on Internal Migration and Human Development in India (New Delhi: UNESCO UNICEF, 20II); at: <http://www.unicef.org/india/Migration_VOL2_v3.pdf $>$.

Address: Dr. Indrani Mazumdar, 25, Bhai Vir Singh Marg (Gole Market), New Delhi - II oooI, India.

Email: <indu@cwds.ac.in>, <indu@cwds.org>.

Website: 〈www.cwds.org>.

Cecilia Menjívar (USA) is Cowden Distinguished Professor in the School of Social and Family Dynamics at Arizona State University. Her research has examined social aspects of migration, including social networks, gender and intergenerational relations, families across borders, and religion and religious communities, focusing on the effects of immigration laws on these spheres. Though most of her work has centred on Guatemalans, Hondurans and Salvadorans in the USA, recently she has conducted research on Mozambican and Russian migration, examining the effects of migration on non-migrants. She is the author of: Enduring Violence: Ladina Women's Lives in Guatemala (Berkeley: University of California Press, 20II); Fragmented Ties: Salvadoran Immigrant Networks in America (Berkeley: University of California Press, 2000).

Address: Prof. Dr. Cecilia Menjivar, School of Social and Family Dynamics, Program in Sociology, Arizona State University, Tempe, AZ 85287-370I, USA.

Email:<menjivar@asu.edu>.

Website: <www.asu.edu>.

Claudia Mora (Chile) holds a Ph.D. in Sociology and is currently a faculty member in the Department of Sociology at Universidad Alberto Hurtado in Santiago, Chile, where she conducts social research and teaches on gender and social stratification, migration, and globalization. Her projects have explored Latin American intraregional migration, specifically the labour market insertion of Peruvian migrants in Chile, social exclusion, and migrants' citizenship. Her latest project inquires into the gender and social class dynamics of exclusion in the labour market through a qualitative approach to the understanding of gender/class categories underlying workers' trajectories in Chile. Most recent publications include: "Global Inequalities-Local Hierarchies: "Peruvian Migrants' Labor Niches and Occupational Mobility in Chile", in: Rehbein, Boike (Ed.): Globalization and Inequality in Emerging Societies (Basingstoke: Palgrave Macmillan, 20II); (co-author with Nicola Piper): "Notions of Rights and Entitlements Among Peruvian Female Workers in Chile" in: Diversities Journal, I3,I (20II); (co-author with Ignacio Madero): "Capital Social e Inclusión Laboral: Una aproximación a las trayectorias de ascendencia laboral de migrantes Peruanos en Chile”, in: Polis [En linea], 29 (20II). She is a member of the Social and Political Theory Laboratory, Lab_TSP, Chile.

Address: Prof. Dr. Claudia Mora, Universidad Alberto Hurtado, Departamento de Sociología, Cienfuegos 46, Santiago, Chile.
Email: <cmora@uahurtado.cl>.

Website: <www.sociologia.uahurtado.cl>.

Ruth Pearson (United Kingdom) is Professor of International Development at the University of Leeds. Her research over some thirty years has been centred on women's work in the global economy, focusing recently on migrant workers and gendered globalization. She has undertaken empirical work in Latin America, including Mexico, Argentina, Bolivia, and Cuba, as well as in Thailand and Europe. She has a particular interest in the intersection of women's productive and reproductive roles and its implications for understanding globalization and crisis in the contemporary economy. She is Associate Editor of the Oxfam journal Gender and Development. Her recent publications include: "Beyond Women Workers: Gendering Corporate Social Responsibility”, in: Third World Quarterly, 28,4 (2007): 73I749; (co-author with Kyoko Kusakabe): “Transborder Migration, Social Reproduction and Economic Development: A Case Study of Burmese Women Workers in Thailand”, in: International Migration, 48,6 (20IO): I3-43; (co-author with Anitha Sundari, Linda McDowell): "Striking lives: Multiple narratives of South Asian women's employment, identity and protest in the UK, in: Ethnicities March, 2-22 (20I2); (co-author with Kyoko Kusakabe): "Who Cares? Gender, Reproduction, and Care Chains of Burmese Migrant Workers in Thailand", in: Feminist Economics, I8,2 (20I2): I49I75; (co-author with Kyoko Kusakabe): Thailand's Hidden Workforce: Burmese Migrant Women Factory Workers (London - New York: Zed Books).

Address: Prof. Dr. Ruth Pearson, University of Leeds, Centre for Global Development, School of Politics and International Studies, Woodhouse Road, Leeds, LS2 9JT, UK. Email: <r.pearson@leeds.ac.uk>.

Kamonwan Petchot (Thailand) holds an MA in Development Studies, majoring in Human Rights, Development, and Social Justice from the International Institute of Social Studies (ISS) of Erasmus University Rotterdam, where she has conducted research on rights to education for migrant children in Thailand. She is currently serving as a consultant to the Asia Pacific Forum on Women, Law and Development (APWLD) in an action entitled "Grounding the Global" which aims to enhance women's human rights in the Asia-Pacific region by engaging with regional and international mechanisms.

Address: Ms Kamonwan Petchot, I45, Moo 3, Tombon Tamiram, Amphur Muang, Phattalung Province 93000, Thailand.

Email: <k.petchot@gmail.com>.

Amara Quesada-Bondad (Philippines) has been the Programme Officer of Action for Health Initiatives, Inc. (ACHIEVE) since 200I. She graduated with a Bachelor of Arts degree in Public Administration from the University of the Philippines-Diliman. She has so far earned twelve units in Master of Science in Bioethics from the College of Medicine in the University of Philippines-Manila. She has extensive experience in conducting action research on the sexual and reproductive health issues of Overseas Filipino Work- 
ers (OFWs) in destination countries, including HIV vulnerability and mandatory HIV testing among migrant workers. She has conducted numerous seminars and workshops on $\mathrm{HIV}$, gender and sexuality, human rights, and migration issues for various groups, civil society organizations, government departments, and academic institutions. She has conducted skills building workshops on participatory action research, facilitation, and advocacy skills. Among her publications are: (co-author with Maria Lourdes S. Marin): Unveiling HIV Vulnerabilities: Filipino Women Migrant Workers in Arab States (Quezon City: Action for Health Initiatives [ACHIEVE, Inc.], 2008); (co-author with Lisa Garcia): Fit to Work?: Consequences of Mandatory Health Testing Among Overseas Filipino Worker (Quezon City: Action for Health Initiatives [ACHIEVE, Inc.], 2008); (coauthor with Carolyn I. Sobritchea, Dino Alberto Subingsubing): Health of our Heroes: Access to Sexual and Reproductive Health Services and Information of Women Migrant Domestic Workers (Quezon City: Action for Health Initiatives [ACHIEVE, Inc.], 20Io).

Address: Ms Amara Quesada-Bondad, Action for Health Initiatives (ACHIEVE), Inc., I62-A Scout Fuentebella Ext., Quezon City, II03, Philippines.

Email: <mara.quesada@gmail.com>.

Website: <www.achieve.org.ph>.

Martha Luz Rojas-Wiesner (Colombia/Mexico) has been senior researcher in the area of Society, Culture, and Health at El Colegio de la Frontera Sur (ECOSUR) in Tapachula, Chiapas since 1998. She conducts studies on female migration on Mexico's southern border. In particular, she has studied the mechanisms of social exclusion affecting Guatemalan women in Mexico. She has focused on the impact of exclusion on their daily lives and the circumstances that make their attempts to register and obtain regular status in Mexico very challenging. Some of her recent publications are: (co-author with Hugo Angeles Cruz): "Gendered migrations in the Americas: Mexico as country of origin, destination, and transit", in: Piper, Nicola (Ed.): New Perspectives on Gender and Migration. Livelihood, rights and entitlements (New York-London: Routledge-UNRISD, 2008): 189-245; "Migration and education in border regions. The case of Central American migrants in Chiapas, Mexico, a pending issue", in: Higher Education and Society I5,2 (2OIO): I33-I6I; (co-author with Hugo Angeles Cruz): "Female migration and rights: the situation of Guatemalan migrants in Mexico", in: Jorge Martinez Pizarro (Ed.): A collection of essays on population and human rights Latin America (Rio de Janeiro: American Association of Population, 2OII): 22I-249.

Address: Dr. Martha Luz Rojas-Wiesner, Carretera Antiguo Aeropuerto km 2.5 s/n, C.P. 30700, Tapachula, Chiapas, México.

Email: <mrojas@ecosur.mx>.

Website: <www.ecosur.mx>.

Carlos Sandoval-García (Costa Rica) obtained his Ph.D. in Cultural Studies at the University of Birmingham, UK. He is a professor in the Media Studies School and in the Institute for Social Research, both at the University of Costa
Rica. He has been working on the relationship between migration, rights, and justice. Currently he is editor of the $A n$ uario de Estudios Centroamericanos (<www.anuario. ucr.ac.cr >). He is a member of a number of migrant rights initiatives. His books published in English include: Threatening Others. Nicaraguans and the Formation of National Identities in Costa Rica (Athens, Ohio: Ohio University Press, 2004); Shattering Myths on Immigration and Emigration in Costa Rica (Lanham, Md.: Lexington Books, 20II).

Address: Prof. Dr. Carlos Sandoval-García, Instituto de Investigaciones Sociales, Universidad de Costa Rica, Apartado Postal 4920-60, Ciudad Rodrigo Facio, San José, Costa Rica.

Email: <carlos.sandoval@ucr.ac.cr>.

Website: 〈www.iis.ucr.ac.cr〉.

Serena Eréndira Serrano Oswald (Mexico) is an academic, lecturer, clinical therapist, and consultant. She is a postdoctoral research fellow in Sociology and Gender at the Regional Centre for Multidisciplinary Research (CRIM), National Autonomous University of Mexico (UNAM). She holds a Ph.D. in Social Anthropology (UNAM), an M.Sc. in Social Psychology (LSE), an MFT in Systemic Family Therapy (CRISOL Institute), a BA (Hons) in Political Studies and History (SOAS), and a professional diploma in translation and interpreting (Institute of Linguists, UK). She lectures on psychology, social sciences, and humanities in public and private universities (UNAM; UAEM; UVM; CEPS; CESNAV; Crisol) and has collaborated on several research projects. She has thirty peer-reviewed publications on gender, social representations, identities, peace, motherhood, regional development, and migration. An active feminist and leader of young people, she is vice-president of the Mexican Association of Regional Development (AMECIDER-RSAI). Among her major publications are: "The impossibility of Securitizing Gender vis à vis Engendering Security", in: Brauch, Hans Günter et al. (Eds.), 2009: Facing Global Environmental Change (Heidelberg: Springer): II5I-II64; (co-author with Fátima Flores Palacios): "Process analysis of the impact of HIV/AIDS and its representations in seropositive people in Mexico", in: Journal of Research in Peace, Gender and Development, I3,2 (2012): 304-310; "Social Representations Theory: A Potential for Gender Sensitive Latin American Social Science Regional Studies", and: "Engendered Identities in San Martín Tilcajete: A Case Study", in: Sánchez Almanza, Adolfo (Ed.): El futuro del desarrollo regional Iberoamericano: Posicionamiento Mundial y Estrategias (Mexico: AMECIDER-UNAM, IIEc, 2OI2). She has translated several books, book chapters, and articles into English and Spanish.

Address: Dr. Serena Eréndira Serrano Oswald, CRIMUNAM Av. Universidad s/n, Circuito 2, Col. Chamilpa, Cuernavaca, Morelos, Mexico CP 62210

Email: <sesohi@hotmail.com>.

Website: 〈www.crim.unam.mx>.

Karin Astrid Siegmann (Germany) is a Senior Lecturer in Labour and Gender Economics at the International Institute of Social Studies (ISS) of Erasmus University Rotter- 
dam in The Hague, The Netherlands. She holds a Ph.D. in Agricultural Economics. For the past decade, her research has been concerned with the intersection of global economic processes with local labour markets, stratified by varying degrees of formality of work and gender, as well as other axes of identity. Her work has identified gendered labour dimensions in a number of critical fields such as international migration, global production networks, and financial crises. The geographical focus of her work has been South Asia, and Pakistan in particular. Her major publications include: (co-author with J. Lee Pegler, Sietze Vellema): "Labour in Globalized Agricultural Value Chains", in: Helmsing, A.H.J.; Vellema, Sietze (Eds): Value Chains, Social Inclusion and Economic Development: Contrasting Theories and Realities (Milton Park-New York: Routledge, 20II); "Strengthening whom? The role of international migration for women and men in Northwest Pakistan", in: Progress in Development Studies, I0,4 (2010): 345-36I; (coauthor with Susan Thieme): "Coping on women's back: social capital vulnerability links though a gender lens”, in: Current Sociology, 58,5 (2010): 715-737.

Address: Dr. Karin Astrid Siegmann, International Institute of Social Studies, P.O. Box 29776, 2502 LT The Hague, The Netherlands.

Email: <siegmann@iss.nl>.

Website: <www.iss.nl/siegmann>.

Giulia Sinatti (Italy/United Kingdom) joined the International Institute of Social Studies (ISS), Erasmus University Rotterdam as a Research Fellow in 20II. She has a background in sociology and holds a Ph.D. in Comparative Urban and Local Studies from the University of Milan-Bicocca (2006). She has previously also worked at the Institut Fondamental d'Afrique Noire (Senegal), London School of Economics, and Goldsmiths College (United Kingdom). Her research is concerned with patterns of migrant mobility and their local effects in sending and receiving societies, with a particular focus on migrant transnationalism and its relation to social integration in countries of residence and to transformations in countries of origin. She has spent many years researching migration between Africa and Europe, covering migrant communities from West and East Africa established in different countries of destination. She strives for her work to be policy-relevant and regularly collaborates with policymakers in national governments and international agencies. Her work has focused on various topics, including: migrant identification and belonging; diaspora formation, nationalism and transnationalism; migration-development linkages; diaspora engagement in homeland development and peace-building; return and circular migration; cohabitation and conflict in ethnically diverse societies. Some of her recent publications include: "Mobile Transmigrants' or 'Unsettled Returnees'? Myth of Return and Permanent Resettlement among Senegalese Migrants”, in: Population, Space and Place, I7,I (20II): I53-I66; (co-author with Sandra Paola Alvarez Tinajero): Migration for Development: A Bottom-up Approach: A Handbook for Practitioners and Policymakers (Brussels: European Commission UNDP Brussels Office, 20I2).
Address: Dr. Giulia Sinatti, International Institute of Social Studies, P.O. Box 29776, 2502 LT The Hague, The Netherlands.

Email: <sinatti@iss.nl>, <giulia.sinatti@yahoo.it>. Website: <www.iss.nl>.

Aly Tandian (Senegal) obtained a Ph.D. in Sociology at the University of Toulouse 2-Le Mirail, in France where he also taught for several years in the Sociology Department. He has conducted postdoctoral research at the Center for Ethnic and Migration Studies (CEDEM) at the University of Liège in Belgium. Since 2006, he has been teaching and research professor in Sociology at the University Gaston Berger where he leads the Study and Research Group on Migration and Social Phenomena (Groupe d'Etudes et de Recherches sur les Migrations \& Faits de Sociétés [GERM]). $\mathrm{He}$ is an Associated Researcher with the Centre for Anthropology (Centre d'Anthropologie, EHESS-CNRS) in Toulouse, scientific partner of CEDEM, member of the Transatlantic Forum on Migration and Integration (USA), and a member of the Consultative Committee of the ACP Observatory on Migration in Brussels. His recent publications include: "Barça ou Barsaax (Aller à Barcelone ou mourir): le désenchantement des familles et des candidats à la migration”, in: DIASPORAS, Histoire et Sociétés, No. 9 (2007): I24-I37; "Las technologias de la information y la comunicacion: in: Relaciones Internacionales, I4,I4 (20IO): 75-92.

Address: Dr. Aly Tandian, Département de Sociologie, Coordonnateur du GERM \& Faits de Sociétés, Université Gaston Berger de Saint-Louis BP 575I Saint-Louis, Sénégal. Email: <Aly.Tandian@ugb.edu.sn>.

Website: <www.germ.sn/>.

Thanh-Dam Truong (Vietnam/The Netherlands) is Associate Professor in Women/Gender and Development Studies at the International Institute of Social Studies (ISS) of Erasmus University Rotterdam. One of the first scholars to have provided an academic analysis of the problem of sex tourism in South-East Asia from the perspective of international political economy, she has published widely on subjects such as human development, gender aspects of research, international migration, human trafficking and organized crime, and the gender dimensions of transition. Her work has been translated into several languages (Dutch, Japanese, Indonesian, and Spanish). Her current work addresses the intersection between transnationalized human security, development ethics, and the ethics of care. Some recent publications on the theme of migration include: "Governance and Poverty in Sub-Saharan Africa: Rethinking Best Practices in Migration Management”, in: International Social Science Journal, 58,190 (2006): 697-7I4; (co-editor with Des Gasper): "Trans-local Livelihoods and Connections: Embedding a Gender Perspective into Migration Studies", Special Issue, Gender, Technology and Development, I2,3 (2008); "Feminist Knowledge and Human Security: Bridging Rifts through the Epistemology of Care", in: Young, Brigitte; Scherrer, Christopher (Eds.): Gender Knowledge Networks in International Political Economy (BadenBaden: Nomos, 2010): I60-I82; (co-author with Amrita Chhachhi): "Gender, poverty, and social justice", in: R.A. 
Denemark (Ed.), The International Studies Encyclopedia (Malden, MA: Wiley-Blackwell, 20IO): 2732-275I; (co-editor with Des Gasper): Transnational Migration and Human Security: The Migration-Security-Development Nexus (Heidelberg: Springer, 20II).

Address: Dr. Thanh-Dam Truong, International Institute of Social Studies, P.O. Box 29776, 2502 LT The Hague, The Netherlands.

Email: <Truong@iss.nl>.

Website: <www.iss.nl>.

Antoinette Vlieger (The Netherlands) completed a Master's degree in both Dutch law and international law. In addition, she completed a minor degree (propedeuse) in cultural anthropology and the sociology of the non-Western world. She followed one year of courses in Arabic and the politics of the Middle East, in economics (including development economics), and in language studies, focusing on argumentation theory. She worked on corporate law for several years before she returned in 2005 to the University of Amsterdam. Since then, she has lectured on corporate law, introduction to law, argumentation theory, contract law and penal law from meta-legal perspectives, and liability law. Since December 2006 she has worked on a research project within the Hugo Sinzheimer Institute of Labour Law. In $201 \mathrm{I}$ she publicly defended her doctoral dissertation. Her main publications include: "Sharia on domestic workers: legal pluralism and strategic maneuvering in Saudi Arabia and the Emirates", in: Journal for Islamic Law and Culture, I2,2 (2010): I66-I82; "Dienstbodes in Saoedi-Arabië; intersectionaliteit en toegang tot het recht", in: Recht der Werkelijkheid 32,2 (201I): 47-64; "Domestic Workers in Saudi Arabia and the Emirates: Trafficking Victims?", in: International Migration, 50,6 (2012): I80-I94; Domestic workers in Saudi Arabia and the Emirates: a Socio-Legal Study on Conflicts (New Orleans: Quid Pro Books, 20I2).

Address: Dr. Antoinette Vlieger, University of Amsterdam, Oudemanhuispoort 4-6, IOI2 CN Amsterdam, The Netherlands.

Email:<A.R.Vlieger@uva.nl>.

Website: <www.antoinettevlieger.nl>.
Yu Zhu (China) is Professor in the School of Geography and Director of the Centre for Population and Development Research, Fujian Normal University in China. He is also Chair of the International Union for the Scientific Study of Population's (IUSSP) Scientific Panel on the Impact of Internal Migration and Urbanization in Developing Countries; Chair of Asia and Pacific Migration Research Network, Member of the International Advisory Board of UN Habitat State of the World's Cities Report 20I2/20I3, Member of the first International Advisory Group of the International Organization for Migration (IOM) Research and Training Centre; Council Member of China Population Association, Member of the China Population Association's (CPA) Committee on Migration and Urbanization; and Deputy Director of the Committee on Population Geography, the Geographical Society of China. He received his Ph.D. from the Demography Programme at the Australian National University, and his research interests straddle the two disciplines of demography and human geography, focusing on issues relating to migration and urbanization. His recent international publications include: "The settlement intention of China's floating population in the cities: Recent changes and multifaceted individual-level determinants", in: Population Space and Place, I6,4 (2010): 253267; Urban Population-Development-Environment Dynamics in the Developing World: Case Studies and Lessons Learned (Paris: Committee for International Cooperation in National Research in Demography, 2009); "China's floating population and their settlement intention in the cities: Beyond the Hukou reform”, in: Habitat International, 3I,I (2007): 65-76; "Patterns of population and employment changes in Shanghai in the I990s: A zonal analysis with international comparisons", in: International Development Planning Review, 28,3 (2006): 287-309.

Address: Prof. Dr. Yu Zhu, School of Geography, Fujian Normal University, Fuzhou, Fujian Province 350007, People's Republic of China.

Email: <zhuzoo@fjnu.edu.cn>.

Website: <http://geo.fjnu.edu.cn/teacher_info.asp?keyno= I078>. 


\section{Index}

\section{A}

abortion 78, 79, 230, 23I, 234, 236

Abu Dhabi 3I, 39, 43, 298

access to education

liminal legality and migrant

children 3I3, 3I4

access to justice 29I, 293, 299, 300,

$$
303,304
$$

concept of 297,299

domestic workers 297-299

Acquired Immune Deficiency Syn-

drome (AIDS)/ Human Immunodeficiency Virus (HIV) 95, I82, I88, 233, 238, 242

Advancing the Rights of Migrant Women in Latin America and the Caribbean project 352,356

advocacy (see also social movements)

I9-22, 205, 229, 23I, 233, 244, 275,

28I, 285, 286, 288, 352, 36I, 370, 380

in/visibility of migrants 205-207

Nicaraguan migrants in Costa Rica

352, 356, 36I

Peruvian migrants in Chile 28I, 282, 285

political intersectionality 244

research and advocacy $352,356,380$, $38 \mathrm{I}$

sexual and reproductive health

(SRH) 229, 230

Wahhabism movement 297

women's movement I24-I26, I30,

I3I, I39, I46, I49, 243, 244

African Charter on the Rights and Wel-

fare of the Child, 1999274

agricultural labour 53-57, I33, I36, I42, I44, I78-I80, 20I

agricultural migration 48, 53-57, 63,

I33, I42, I78, 2OI, 22I, 265, 309, 374

agriculture $48,5 \mathrm{I}-53,55,56,63, \mathrm{I} 26$,

I29, I32, I33, I4O, I42, I44, I45, I48,

I73, I78, I80, 267, 376

Ajia no hanayome (brides from

Asia) 89

Al Jazeera English 243, 25I, 253-256, 259

alebrije I8O-I8I, I85

allochtoon 378

Amnesty International 35

Annan, Kofi 379

anti-immigration policy regimes 384 anti-trafficking policy 333,338

Arab Declaration of Human

Rights 298

Arendt, Hannah 259, 295, 300, 304

Asia Pacific Mission for Migrants 235

asistencialismo 360

Association of Southeast Asian Nations (ASEAN) 337

asylum seekers II, 248, 249, 255, 329, 374,376

Australia 357

\section{B}

Baan Naam 335, 336, 339, 342-346

Bacillus thuringiensis (BT) I42

Bamako 267, 268, 270, 27I

Bangkok Declaration on Irregular Migration of April 1999337

Bangladesh 378, 384

Bedouin culture 37

begging $266,268,270-276$

circular migrations 267-273

multiple conditions of disability and migration 270, $27 \mathrm{I}$

behaviouralist approaches 369

Beijing Plan of Action, 199532

beru 220

biological reproduction 71, 78, 90, 97, IOO, 368

bokk 2I9

bonded labour I43

Boonyaratkalin, Sonthi 82

border factories

regulation and control of migrant

factory workers in Thailand 73-77

boroom kër 220, 222

boroom sarret 22I

Bourdieu, Pierre 243, 257

Bracero Programme (I944-I964) I78, I79

breadwinner I07, I08, 216, 2I7, 219,

$$
335,338
$$

Burma (see Myanmar)

C

Calcutta I08

Cambodia 307, 3II

Campeche 199, 200, 204

Canada 195

capitalism I28 care centres 95

care chain 33, 70, 88, 106, I07, 217

care for elderly 94

care provision $32,83,90,92,97,98$

care regimes 3I, 32, 9I

caste hierarchies (India) I38-I4O

Catholic Bishops' Conference of the Philippines (CBCP) 230

Central American Jesuit Migration Service 352

Centre for Population and Development Research at Fujian Normal University 157

Centre for Women's Development Studies (CWDS) I24, I26, I33, I34, I36, I37, I39, I4I, I42, I45-I49

Chad 246

Chiapas I94, I95, I98-200, 202, 204

child beggars 274, 275

child care provision I4, 32, 6I, 70, 80, 82, 92, I07, I09, 29I, 293

child labour 274, 3II, 3I5, 320

child labour migration 265, 266, 274

child migrants/migration 266

challenges of accessing education in

Thailand 309-32I

legal and institutional frameworks

for protection in Mali and

Senegal 273-277

child trafficking $265,273-276$

childcare 92, 93

Thailand $80,8 \mathrm{I}$

Chile

Catholic Church 286, 287

civic agency 287,288

civil society organizations 28I, 285288

Immigration Department 282

migration policy and

role of NGOs 282, 285-289

Peruvian migration to $28 \mathrm{I}, 282,286-$

289, 326-328

China $74,338,375-377$

Department of Construction and

Housing of Fujian Province I57

Department of Education of Fuzhou

Municipality I57

Departments for Labour and Social

Insurance of Fujian Province 157 
Fujian Provincial Population and Family Planning Commission 157 internal migrant population 153 Ministry of Construction 156 Ministry of Finance 156 People's Bank of China I56 Rural Cooperative Medical Schemes I66

China, migration policy developing a clear legal and institutional framework I68, I69

Fujian Province and women migrants 156-169

policy suggestions and approaches for the protection of women migrants' rights I67-169 progress in migrants' rights protection within the current urban-centred and residence-based approach $154-156$ survival-oriented to a developmentoriented approach shift I68 principle of the hukou $153-155, \mathrm{I} 58$, I62-I64, I67, I68

women migrants' rights and aspects of gender differences I54, I57-I62 women migrants' complex and diverse migration flows I62-I67

Chosnjok brides 89

circular migration I37, I39, 265

begging 267-273

longer duration 139

shorter duration 139

citizenship 7I, 282, 284, 285, 288, 295, $296,327,328$

concept of $9,3 \mathrm{I} 2$

connections between social and definition of 283,299

globalized world 282, 283, 286

restrictiveness of citizens'

inclusion 283,284

rights 73

rights and social justice 284, 285

Saudi and Emirati Employers 300302

Thai 74

types of 295,296

civic actors 282, 286, 288, 289

translators 286

civic agency 287,288

civil citizenship 293

concept of 302-304

domestic workers 299, 300

civil movement 302

civil society I9, 33, 35, 9I, IOO, 205,

208, 227, 230, 23I, 267, 275, 28I,

285-288, 328, 382

organizations 28I, 285-288

class 380

cognitive invisibility $38 \mathrm{I}$ collective memory 360

colonialism 29

colonization 266

commercially arranged transnational marriage (CATM) 88

earning pofits, and constructing

modernity 94-97

reproductive bargaining

process 97-IOO

social reproduction perspective 89 -

9I

Committee on the Rights of Migrant

Workers 285

common security 378

community work $352,360,36 \mathrm{I}$

complicit masculinity 258

Condet 39, 40

Confucian family 88, 9I-93, 97

Confucian family ideology 87

Confucian family welfare model 89 , 97

Confucian values Ioo

contemporary migration $367,374,382$

Convention Concerning Decent Work for Domestic Workers II7

Convention on the Elimination of All Forms of Discrimination against Women (CEDAW) 32, 274

Convention on the Elimination of All Forms of Racial Discrimination (I965) 284

Convention on the Protection of the Rights of All Migrant Workers and Members of Their Families (1990) 283, 284, 286

Convention on the Rights of the Child (CRC), 1989 274, 284, 308, 328

cosmopolitan identity 359

cosmopolitanism 9, 22, 359, 36I, 375

Costa Rica 378

Constitutional Court 35I, 356

General Division of Migration and

Alien Affairs (DGME) 354-356

Political Constitution 355

Public Security System (Caja Costarricense de Seguro Social

(CCSS)) 356,358

Social Security reports 354

Costa Rica, immigration policy 20II census 357

absence of recognition of

interdependences 357-359

analytical, normative, and transla-

tion research 354-357

anti-immigrant hostility $357-359$

challenges and evaluation 36r, 362

Migration and Alien Affairs Law,

2010 35I, 354, 355

Migration Police 356
Nicaraguan migrants as threatening others 353,354

Regulations of Alien Affairs 356 scope and limitations of social researchers and social activists to intervene 35I, 352

seeking cosmopolitanism-from-

below 359-36I

critical feminist ethnography I74, I77 cultural identity 7, 87, 203

Cytotec 236

\section{D}

daaras 274

daily/weekly commuters I39

Dakar 50, 55, 220-223, 266-272, 274, 275

decent work I3, 3O, 3I, 43, 48, II7, 283, 300,310

demographic crisis Ioo

denotified tribes (DNT), India I43

development

reconceptualization 377

Development, Relief, and Education for Alien Minors (DREAM) 326

disability 266, 267, 269, 270, 276

district rural development agencies (DRDAs), India I43

domestic labour I06

domestic labour/work 47, 48, 5I-53, 57-63, 106

Filipino men's and Filipina women's experience in the Netherlands Io6II7

gender identity IIO-II3 gender politics of social equality $3{ }^{\mathrm{I}}-$ 33

Hong Kong, Singapore, and Qatar and the implications for workers'

SRH 23I-234

intersection of class, race, and gender II3-II6 production of migrant identities I07, I08

race as social division 108 role in industrial society 105-IO7 Senegalese women with irregular status in Spain 57-64

Sexual and Reproductive Health

(SRH) and structural

vulnerability $230-234$

domestic workers

access to justice 297-299

citizenship of 295,296

civil citizenship 299, 300

facing conflicts 293

female migrants in United Arab

Emirates 29I-304, 325, 326 
female migrants in Saudi

Arabia 29I-304, 325-328

Indonesian migrants in the United

Arab Emirates 30, 3I, 33, 34, 36-39,

4I-43

legal status in Hong Kong, Singa-

pore, and Qatar 232, 233

Dubai 43, 294, 296, 298

Dubai Court of Cassation 296

E

East Africa 37I

East Asian capitalism IoO

East Asian family-based welfare regime transnational marriage 87, 9I-94

East Asian Miracle 88

Economic Community of West African States (ECOWAS)

Declaration to fight against Trafficking in Persons (200I) 274

economic migrants 4, I35, I94, I96, 20I, 202, 329, 380

ECOSUR (El Colegio de la Frontera Sur (The College of the Southern Border)), Mexico I99

egalitarianism $\mathrm{I} 75$

Egypt 249, 254, 296, 297, 328

El Salvador 329

embodied labour 32

employment agencies changing political economy of migration 338,339

Laos 335, 338, 346

Enlightenment 9

environmental change 178,238

equality $6,7,9$, IO, 3I, 32, 93, I25, I30, I39, I68, I89, 215

Ethiopia 292

ethnic cleansing 24I

ethnic identity $3 \mathrm{I} 5$

ethnicity I2, I7, 6I, 73, 76, 89, 90, IOO, I54, I99, 206, 208, 22I, 224, 229, 230, 233, 243-245, 380

European Migration Network (EMN) $5 \mathrm{I}$

European Union (EU) I2, 48, 357 border control 259

debates on migration and citizenship 9

externalization of migration

controls 248

Libya 247,248

migration control policies 255

regime of migration control 259

Schengen Agreement 50

Senegalese migration 50-53

Everyday Politics (EDP) 195, 205

in/visibility as a form of 205-208

external border regime I2

\section{F}

family labour I27, I8I

family welfare 89, 9I, 97

female identity I26, I87

female migrants (see women migrants)

feminine I5, 30, I06, IIO-II4, II6, II7, I76, 246, 256, 336, 342

femininities 4 , 9, III, II2, 242, 38I, 382

femininity I06, I07, III, II2, 346

Feminist Critical Ethnography

Social Representations Theory

(SRT) I76, I77

feminist research 5, 6, 8, I82

feminization of migration $369,38 \mathrm{I}$

feminization of survival 30

focus group discussions (FGDs) 39, 234,237

formal statelessness 328,329

fosterage 265

Foucault, Michel 3, 34

Foundation for Rural Youth (FRY) 308

France 50, 216

Fujian Provincial Population and Family Planning Commission, China 157

G

Gaddafi, Muammar 247, 248, 250256,258

gender

feminist approaches $3-5$ social structure and structuring process 8,9

gender-enriched perspective on human security 379-384

gender equality $6,7,9,33,53,88$, 9I, 92, I26

gender identity 8, 3I, 34, I06, I07, I09, II2-II4, I9O, 203, 2I6, 2I8

domestic work IIO-II3

gender inequalitiy 106, I07, I33

gendering macro-view on labour migration I3O-I34, I47, I48

gendering meso-level view on labour migration $\mathrm{I} 34-\mathrm{I} 36, \mathrm{I} 48$

gender justice I06, II6, II7

gender relations

intersectionality and hegemonic

masculinity $2 \mathrm{I} 8$

transnational families $2 \mathrm{I} 7,224$

gender research 4, 9, 34

labour migration 34

gender regime 90

genocides 24I

Germany 378

Ghana 246

global care chain 33,70

global ethics 375
Global Forum on International Migration and Development II

global hypergamy 87

global migration $238,369,383$

globalization 6, 30, 69, 37I

citizenship 282-286

goorgoorlu 220

governmentality concept 3,34

graduated sovereignty 76

Greater Mekong Subregion

(GMS) 333, 334, 337

gross domestic product (GDP)

India $\mathrm{I} 33, \mathrm{I} 48$

Thailand 307

Guardian, The 243, 25I, 253-256, 260

Guatemala

women migrants at Mexico's southern border 194-208

Gulf Cooperation Council (GCC) 30, $33,34,36,39$

$\mathrm{H}$

HiNi virus 238

Habermas, Jürgen 174

health care 203, 228, 230, 23I, 237, 249, 270, 285, 3ОI, 3IO, 3I2, 3I $4,327,328$, $344,356,372$

health control international migration 227,228

hegemonic femininity IO7, III, 337

hegemonic gender identities concept and context 107

hegemonic masculinity I06-IO8, IIO, III, II 4,2 I 7, 223, 224, 245, 246, 255, $256,258,334,346$

concept of I07, 2I8

heterosexual family 107

High-Level Dialogue on International Migration and Development, 2006379

Ho Chi Minh City 94, 95

Hong Kong 30, 33, 236

domestic workers from the

Philippines 228, 23I-237

Family Planning Programme 233

Filipina domestic workers 234

Identification Card (ID) 236

Occupational Health and Safety

Ordinance 232

Race Discrimination Bill 232

Racial Discrimination

Ordinance 237

Sex Discrimination Ordinance 232

horticulture 55

hukou principle (China) I53-I55, I58, I62-I64, I67, I68

human development 377, 379

Human Development Report of I994 II, I2, 377 
human life with dignity 259

human reproduction 88,89 , I00

human rights I74, I93, 284, 286, 292, $373,377-379,382,383$

regime of 326

Human Rights Commission

Universal Periodic Review of 2009298

human rights law 283

Human Rights Watch 293

human security 4, II, I2, 238, 24I-244,

248, 25I, 257

gender-enriched perspective 379 -

384

international migration $377-384$

social justice $\mathrm{I} 74, \mathrm{I} 75$

Human Security Now report 24I, 367

human trafficking 5, I2, I96, I97, 266,

$267,273,275,308,333,334,379$

UN definition of 274

humanitarian intervention 250, 255

\section{I}

identity card (ID) 33, 5I, 202, 236, 3I7

identificatory projection 359

identity construction I06, 244, 250

identity document 77, 8I, I97, $20 \mathrm{I}$

identity formation 6

in/visibility 204

Everyday Politics (EDP) 205-208

understanding strategic 203-205

India 292, 375, 384

agrarian crisis I24

constitution, I950 I38

denotified tribes (DNT) I43

district rural development agencies

(DRDAs) I43

gross domestic product (GDP) I33, I48

Mahatma Gandhi National Rural

Employment Guarantee Scheme

(MGNREGS) I44

National Industrial Classification

(NIC) I42

National Rural Employment Guar-

antee Act, 2005 I29

National Sample Survey (NSS) I23,

I24, I28, I29, I3I-I33, I37, I38, I44

National Sample Survey Office I26,

I27

other backward classes/castes

(OBCs) I39, I4O, I43

Scheduled Castes (SC) I34, I38-

I40, I43, I45

Scheduled Tribes (ST) I34, I38-I40, I43, I45
India, migration policy $\mathrm{I} 45$

caste hierarchies I38-I40

changes in women's migration I4O-

I49

gendering macro-view on labour

migration $\mathrm{I} 30-\mathrm{I} 34, \mathrm{I} 47$, I48

gendering meso-level view on labour

migration $\mathrm{I} 34-\mathrm{I} 36, \mathrm{I} 48$

macro-survey I23, I24

typology of migration I36-I40

Indonesia 292, 293, 294, 384

Domestic Workers' Protection

Bill 35

Law No. 39/2004 on the Placement and Protection of Indonesian Man-

power Abroad 34-36, 39

national law on labour migration

and domestic work 34-36

New Order of Suharto 34

Provincial Parliament of

Yogyakarta 35

women migrant domestic workers

in the United Arab Emirates 30, 3I, $34-36,38-43$

industrialization 32, 33, 91, 303, 304

information and communications technology (ICT) 9I, 96

Institute for Population and Social Research (IPSR) 82

Institute for Social Research at the University of Costa Rica 352

Institute of Asian Studies (ISA) 82

institutional discrimination 228, 230

institutional invisibility $38 \mathrm{I}$

intercontinental migration 2I6, 2I8

intergenerational care 88-92, I00

International Conference on Population and Development (ICPD), Report, Cairo 1994228

International Development Research Center (IDRC) IX, XI, XII, 29, 49, 69, 87, I23, I24, I53, I57, I59, I60, I93, I99, 200, 228, 265, 28I, 35I, 352

International Labour Conference (ILC) II7

International Labour Organization (ILO) 48, 274, 284, 285, 296, 307, 3II, 334, 335, 339

Convention I8I on Private Employment Agencies (1997) 339

Convention 97 on Migration for

Employment (1949) 338

Convention Concerning Decent

Work for Domestic Workers 29, 30, 37

International Programme on the Elimination of Child Labour 3I5 international legal norms

international migration 284-286,

$289,338,339,362$

protection of child migrants in Mali

and Senegal 273-277

international migration

adult blind beggars 267

Burmese migrant women workers in

Thailand $70-83$

Burmese migrant workers in Samut

Sakhon 3I2-3I5, 3I8, 3I9, 325, 327

children of migrants in Thailand and

challenges of accessing

education 309-32I, 325

circular migrations for

begging 267-273

citizenship in a globalized

world 282-286

Costa Rica debate and Nicaraguan

migrants $35 \mathrm{I}-362$

different regulatory regimes 284 -

286

factors facilitating or precluding migrants' mobilization 326,327

female migrant domestic workers in

Saudi Arabia 29I-304, 325-328

female migrant domestic workers in

United Arab Emirates 29I-304, 325, 326

Filipino men's and Filipina women's experience with domestic work in the Netherlands I06-II7

global interconnectedness and global economic forces 37I, 372

health control 227,228

Indonesian migrant domestic workers in the United Arab Emirate 30,

3I, 33, 34, 36-39, 4I-43

international legal regimes 282,362 irregular status I06, I08-II7 irregular status of Senegalese women in Spain 48, 49, 5I, 52, 57-62, 64 Lao-Thai migration in the middle Mekong Valley and the role of employment agencies 334-346

Latin America 28I

Malian girls and young women from rural and peri-urban areas to Dakar (Senegal) 266-276

national versus market versus humanist frames 375-377

Peruvian migration to Chile 28I, 282, 286-289, 326-328

Senegalese migrants 2I6, 2I8-224 Senegalese women migrants' economic and social situation in Spain $47-64$ 
SRH situations of domestic workers from the Philippines in Hong Kong, Singapore, and Qatar 228, 230-238 transnational marriage and the East Asian welfare regime in Taiwan, South Korea, and Vietnam 88-Ioo transnational mobility 5, 6 treated as exceptional and ethically aberrant 370, 37I

West Africa 265-269, 273, 274, 276

Wolof migrants 2I6, 219, 22I, 224

International Organization for Migration (IOM) 30, 246, 308, 315, 372

intersectionality (concept of) IO6, 2I7, 2I $8,223,230,243,244,257$

key concept to the study of male experiences in migration 224

masculinities 243-246

meso-dimension 250

Sexual and Reproductive Health

(SRH) and structural

vulnerability 228-230

intra-national migration I5, I6, I78, I79, 369, 370, 384

intraregional migration 28I, 282

invisibility

cognitive $38 \mathrm{I}$

concept of $38 \mathrm{I}, 382$

institutional $38 \mathrm{I}$

multiple layers $38 \mathrm{I}, 382$

social $38 \mathrm{I}$

statistical $38 \mathrm{I}$

strategic $38 \mathrm{I}$

women migrants 204

women's migration $38 \mathrm{I}-384$

irregular immigration status $372-374$

Filipino men and Filipina woman in

the Netherlands I06, I08-II7

Guatemalan migrant workers in

Mexico 208

Senegalese women in Spain 48, 49,

5I, 52, 57-62, 64

Thailand 82

irregular short-term migrant I37, I39

Islamic brotherhoods 219, 223

Islamic education 274

Islamic gentrification 39

Islamic law 296

Italy $33,216,248,249,378$

\section{$\mathrm{J}$}

Jakarta 39

Japan $33,88,372,378$

migrant sex workers 78

jus sanguinis 9

jus soli 9

\section{K}

Kafala system 34, 36, 37, 38, 232

khulwa (gender segregation)

concept 299, 304

knowledge migrants 286

Kuwait 294

\section{L}

La Carpio community/project 352

La Gaceta daily 356

labour law 297, 299, 303

labour market $48,50-52,54,60-64$

labour migration I24, I26-I34, I36I38, I42, I44-I49

Burmese workers in Thailand $77-8 \mathrm{I}$

India I30-I49

qualitative gender research 34

Labour Rights Promotion Network (LPN) 3I4, 3I5, 3I8

Laos 307, 3II, 373

emergence of a migration

regime 337-339

employment agencies $335,338-340$, 342-346

Memorandum of Understanding

(MoU) on Employment

Cooperation 337-339

migration in the middle Mekong

Valley 334-346

Lebanon 294

legal culturalism $30 \mathrm{I}$

legal identity 3I, 380

legal liminality (see liminal legality)

legal non-existence concept 3I3

legal sociology 292

legal status 3I2, 3I 3

developing a clear framework in

China I68, I69

migration regime in Laos 337-339

migrant domestic workers in Hong

Kong, Singapore, and Qatar 232,

233

national law on labour migration

and domestic work in

Indonesia 34-36

national law on labour migration

and domestic work in United Arab

Emirates (UAE) 34-39

liberalism 376

Libya

Friendship, Partnership and Cooper-

ation Treaty, 2008248

migration regime 246-249

rentier state 245

transnational mass migration 247

Libya, conflict/war, 20II

media and the creation of human insecurity and information 25I-257 media narratives 255 media representations and construction of masculinities of sub-Saharan

African migrants 242-259

liminal legality IX, 9, IO, I7, I9-2I, I89, 282, 293, 300, 304, 3I2, 3I8, 320,

$32 \mathrm{I}, 329,380,383$

concept I9, 3I2, 3I3

domestic workers 300, 304, 325, 326

experience of migrant children in

the Thai education system 3I8-32I,

325

migrant children and

education 327,328

migrant children's access to

education 3I3, 3I4

Peruvian migrants and 282, 326

socio-legal perspective Io

transnational context IO

vulnerability 3I2, 3I3

livelihood

multiple conditions of disability and migration for begging 270, $27 \mathrm{I}$

long-distance commuters $\mathrm{I} 37$

long-term migrant I37, I39, 285

longue durée 5

\section{M}

Mae Sot (Thai province of Tak) $72-83$

Mae Tao Clinic 78, 79, 8I

Mahatma Gandhi National Rural Employment Guarantee Scheme

(MGNREGS), India I44

Mahbub ul Haq 377

mahram 299

Malaysia 30, 33, 34, 378

male femininities IO7, IIO, II2, II4, II6

male migrants I5, I9, 2I, 82, I06, I08, IIо, II6, I33, I34, I37, I38, I58, I59, I6I-I64, I67, I69, 203, 2I6, 2I7,

$265,333-335,340,34 \mathrm{I}, 343,346,376$ masculinity and the limitations of male privilege 343-346

San Martín Tilcajete, Mexico I79,

I80

transnational families, intersection-

ality, and hegemonic

masculinity 2I7, 2I8, 223, 224

vulnerability of 333,334

Mali 246, 384

migration of girls and young women

from rural and peri-urban areas to

Dakar 266-276

Malta 249

manhood 2I7-222

marginalized masculinities 246, 256, $25^{8}$

marriage migration I27, I28, I29

literature on 89

Marxist theory $30 \mathrm{I}$ 
masculine hegemonic power IOO masculine identity IIO

masculinities 4, 9, I9, I07, I88, 216, 242, 245, 246, 25I, 252, 256, 257 , $334-336,38$ I, 382

construction of 335,336

intersectionality concept $243-246$

limitations of male privilege 343 , 346

sub-Saharan black African migrants

and the Libya war, 20II 242-259

mass migration 247

Mauritania 267

mbaraan 222

mbokk 2I9

media representations

construction of masculinities of sub-

Saharan black African migrants and

the Libya war, 20II 242-259

medium-term migration I37-I39

memory

socio-historical construction 360

Mexico 73, 384

ECOSUR (El Colegio de la Frontera

Sur) 199

EMIF-Sur survey (Encuesta sobre

Migración en la Frontera Sur (Southern Border Migratory Survey) I99

Guatemalan women migrants I94208

Migratory Form for Frontier Workers (FMTF) 197

Migratory Form for Local Visitors

(FMVL) 197

National Institute of Migration's Re-

gional Delegation 198

National Migration Institute

(INM) 198

national security 197

National Security Council I98

National Survey on

Discrimination 198

Mexican Revolution 178

South Beta Group of Migrant

Protection 198

Southern Border Migratory

Survey 199

Zapatista movement 195

Mexico City I99

Mexico, migration policy

Bracero Programme (I944-

I964） I78, I79

gender and woodcarving in San

Martín Tilcajete I77-I8I

male migration in San Martín

Tilcajete I79, I80

Mexican Experiences of Immigra-

tion study, I994 I89

Mexican Women and the Other

Side of Immigration study I89
USA I78, I79, 329

women migration in San Martín

Tilcajete I8I-I90

migrant advocacy (see advocacy)

migrant children 20,80-82, I55, 275, 308

education and liminal legality 327 , 328

education in Samut Sakhon 3I4-3I8

liminal legality and the Thai educa-

tion system 3I8-32I

liminal legality and access to

education 3I3, 3I4

providing education in

Thailand 308, 309

Thai policy 3II

migrant domestic work

literature on 295, 296

migrant for family care I39

migrant identity

domestic work 107, I08

race and gender relationship I08

migrant labour organization 34

migrant men (see male migrants)

migrant safety $333,334,337,338,340$, 343,346

migrant vulnerability 2I, 70, II4, I30, I58, 203, 208, 238, 242, 248, 276,

$286,333,337,338,345,346$

Burmese migrant women

workers 70,73

concept 4, II, 257

domestic workers 62, IO9, II4, 228

employment and income 158

female migrants 343

gendered differences 242,346

intersectionality and 244, 245, 266,

285

irregular immigration status II4

liminal legal status $3 \mathrm{I} 2,3 \mathrm{I} 3,328$

Malian guides of beggars 273,275 , 285

North versus South 37I

masculinity and 2I, 334, 337

migrant students $3 \mathrm{I} 5$

Netherlands IO9, II4

sexual and reproductive health

(SRH) 230, 238

structural vulnerability $228-230,380$

violent conflicts $243,245-249$

workers 13,36

migrant women (see women migrants)

migrants for family care $\mathrm{I} 38$

migration business Io

migration chains $6,8, \mathrm{I} 2$

migration crisis 253,255

migration management $195,337,338$, 372

migration process 5 , IO migration regime $249,259,283,285$, $286,288,326,328,368,373,384$

Lao 337-339

Libya 246-249

nation-state projects and temporary

and irregular workers $372-374$

migration research $4-6,369,383$

future tasks 383,384

Sexual and Reproductive Health

(SRH) 228-23I, 233-238

migration streams 369

migration theories/approaches

behaviouralist 369

conceptualization 3-5

development paradigms and

gender I26-I30

feminist approaches $3-5$

feminist critique of 335

gender impacts 3-5

human development and human se-

curity perspective $377-384$

New Economics of Labour 2I7, 2I8

state-centric 5

structural inequality, vulnerability

and North-South relations 4

transnational 5, 6

migration typology

caste hierarchies in India I38-I40

developing of $\mathrm{I} 36-\mathrm{I} 38$

Migration, Gender and Social Justice

(MGSJ) research project 380,384

Migratory Form for Frontier Workers

(FMTF) I97

Migratory Form for Local Visitors

(FMVL) 197

migratory movements

complexity of 265

misrecognition concept 327

mobility $367,380,383,384$

Morocco 52, 54, 292

mujeridades 190

murder of migrants 198

Myanmar 307, 3II

migrant women workers in

Thailand 70

migrant workers in Samut

Sakhon 3I2-3I5, 3I8, 3I9, 325, 327

\section{$\mathrm{N}$}

Nasser, Gamal Abdel 247

nation

definition 4

National Domestic Workers Alliance, USA 29

national identity $34,368,373,378$

National Industrial Classification

(NIC), India I42

national labour movements II7 
National Sample Survey (NSS), India I23, I24, I28, I29, I3I, I33, I37, I38, I44

national security 194, 196, I98, 208, 308-3II, 3I4, 382

nationalism Io, 359, 37I, 376

nationality $9,36,38,74,76,80,82$, II6, I89, 233, 243, 285, 308, 3I3, 3I 5, 32I, $356,359,377$

nationality verification process 74,75

nation-state $3,5,6$, II, 22, 28I-285, 288, $368-374,380,382,383$ usage 368

\section{NATO}

humanitarian intervention 250

Libya conflict, 20 II 249,250

Navetanat system (Senegal) 267

neo-liberalism 376

Nepal 292

Netherlands I05, 206, 376, 378

Filipino men's and Filipina women's experience with domestic

work I06-II7

migrant domestic workers'

experiences 108, I09

migrants with irregular status I06, IO8-II7

paid labour market Io9

New Economics of Labour Migration theory 2I7, 2I 8

New York Times 243, 25I, 253-256, 260

Newly Industrialized Countries (NICs) in Asia 73

Nicaragua 378

Niger river 270

Nigeria 246

non-governmental organizations

(NGOs) 5, 57, 72, 8I, 233, 257, 275, 282, 285-289, 294, 297, 308, 309, $3 \mathrm{I} 4,3 \mathrm{I} 5,326,327,356,360,362$

North American Free Trade Agreement (NAFTA) I94, I96

$\mathrm{O}$

Oaxaca I77-I79, I89

Obama administration 329

Office of Education Council (OEC)

Education Provision for Disadvantaged Children 308

Oman 42

Onchocerciasis 266

Organisation for Economic Co-operation and Development

(OECD) 50, 52

organized crime I2, I94, I97, 273

other backward classes/castes (OBCs), India I39, I40, I43
Pakistan 296

pan-Arabism 247

patriarchal family I 30

permanent migration $\mathrm{I} 36$

permanent migratory circulation $\mathrm{I} 42$

permanent settlement paradigm I27, I28, I47

personal security $272,273,276$

Philippines 292-294, 384

Catholic Bishops' Conference of the

Philippines (CBCP) 230

hegemonic masculinity of urban

middle-class men 107

political refugees 329

Poo, Ai-Jen 29

Portugal 372

postcolonial theory $30 \mathrm{I}$

postmodernism $30 \mathrm{I}$

post-structuralism 355

privi-legium concept 295, 304

probability proportional to size

(PPS) 157

proliferation of weapons of mass destruction $\mathrm{I2}$

projective identification 358

Protocol to Prevent, Suppress and Punish Traffic in Persons Especially Women and Children 273

Protocol to the African Charter on Human and Peoples' Rights on the Rights of Women in Africa, 2003274

public community 300, 303, 304

public sociology 22, 352

Q

Qatar

Filipina domestic workers 228, 23I235, 237

Interior Ministry 233

kafala system 232

Sponsorship Law, I963 232

Quintana Roo I99, 200, 203

$\mathrm{R}$

race $3,7,76,89$, I00, I06, I07, II6, II7, 2I6, 2I $8,232,243,245,380$

Rak Thai Foundation 3 I5

Rawls, John 370, 37I

Reagan Administration 353

reproductive bargain $14,70,83,89,94$, IOO

commercially arranged transnational marriage (CATM) 97-100 concept of 90

reproductive care labour 92 reproductive health $23 \mathrm{I}, 234,238$

definition of 228, 230, 23I

Responsibility to Protect (RtoP)

principle I2, 24I, 242, 248, 257, 259

right to education 308,309 , 3II, 32I

right to have rights approach 259

river blindness $266,267,270,276$

rural-to-urban migration 30, I26, I44, I48

Russia 376

\section{S}

Samut Sakhon Educational Service Area 3I5

Samut Sakhon province (Thailand) 309, 3II, 3I2, 3I4-3I6, $3 \mathrm{I} 8$

SARS 238

Saudi Arabia 30, 39

female migrant domestic

workers 29I-304, 325-328

Governor's Office in Riyadh 294

Human Rights Commission $30 \mathrm{I}$

labour law 297, 30I

legal systems 297

National Society for Human

Rights 298

Saudi Basic Governance 298

Universal Periodic Review of 2009298

Save the Children 3I5

Scheduled Castes (SC), India I34, I38I40, I43, I45

Scheduled Tribes (ST), India I34, I38, I39, I4O, I43, I45, I48

securitability 377

segmented assimilation $3 \mathrm{I} 2$

Senegal 372

challenges to manhood and emerg-

ing masculinities 22I-224

emigration 216

Labour Directorate 49

markers of manhood and migrants

within their transnational

families 2I8-22I

migration of Malian girls and young women from rural and peri-urban areas to Dakar 266-276

Ministry of the Interior 49

National Youth Employment

Agency 49

Navetanat system 267

Structural Adjustment

Programme 50

Wolof 2I6, 219, 22I, 224

women migrants' economic and social situation in Spain 47-64

settled migrants 384

sexual abuse 202 
Sexual and Reproductive Health

(SRH) I8

domestic workers and structural vulnerability $230-234,238$ individual problems and intersecting power relations $234-238$ perspective of intersectionality and structural vulnerability 228-230 sexual ethics 229 sexual exploitation 308 sexual harassment 76 sexual health 228 sexual identity 3I, 377 sexual industry $3 \mathrm{II}$ sexual labour 8

sexual orientation 17 sexual politics 187 sexual services $8,265,368$

sexual violence $206,244,246,273,293$ sexuality 90, 97, I00, II5, I88, 218, 227, 230, 23I, 233-235, 238, 337

Sexually Transmitted Diseases (STDs) 233

Sharia court 298

Sharia/Islamic law 292, 296-298, 30I, 302

short-term migrants I27, I3I-I37

short-term seasonal migrants I37, I39

Singapore $30,33,88$ domestic Filipina workers 228, 23I234, 236, 237

slavery $29,2 \mathrm{I} 8,374$

social citizenship 302-304

social equality $3 \mathrm{I}$

social factory 3 I, 32, 39

social identity 228,355

social imaginaries $352,357,358$

Nicaraguan migrants in Costa

Rica 353, 354, 357-359

social inclusion

concept of 283

social invisibility $38 \mathrm{I}$

social justice 3, 4, 9-I2, I7, I9-2I, II7, I74-I76, I80, I8I, I87, I89, 2I5, 276, $283,284-288,379-38$ I all-affected principle II human security I74, I75 humanity principle Io migration needs 380 reflexive and dialogical approach Io social movements 8, IO, I2, II7, I25,

I94, 207, 253, 297, 302, 326, 329, 383

social policy 89 , Iо०

social positioning $89,97,99$, I00

social representations

virility $\mathrm{I} 88$
Social Representations Theory

(SRT) $\mathrm{I} 74, \mathrm{I} 76$

concept I75, I76

Feminist Critical Ethnography I76, I77

social reproduction 8, 70, 7I, 89, 90, 9I, 93, I00

commercially arranged transnational marriage (CATM) 89-9I

crisis in Vietnam 92-94

social rights 326

social stratification 282,283

societal integration 167

societal reproduction 369

Somalia 292

South Africa 378

South Korea 33

arranged transnational marriage in

the context of the East Asian welfare regime 88,89 , 9I, 92-100

South-South migration 384

Spain 216, 372

agricultural work scheme, process

and outcomes 53-57

Contingente de Trabajadores

Extranjeros 53

Foreigners Acts 52-54

labour market 53,6I

legislation for seasonal workers 54 , 55

Ministry of Labour 64

Ministry of Youth 55

Moroccan migration 52, 64

National Agency for Youth Employment (ANEJ) 55

National Commission for Manage-

ment and Monitoring of Job

Offers 55

Plan Estratégico de Ciudadanía e Integración (Strategic Plan for Citizenship and Integration), 2007-2010 64 Senegalese women migrants' economic and social situation 47-64 welfare system 52

Work Departments and Provincial

Labour Inspectorate 54

Sri Lanka 292

state security $24 \mathrm{I}$

statistical invisibility $38 \mathrm{I}$

strategic invisibility $38 \mathrm{I}$

stratification 282,283

structural inequality vulnerability 4

structural vulnerability 228-230, 238

domestic workers and Sexual and

Reproductive Health (SRH)

problems $230-234,238$

Sexual and Reproductive Health

(SRH) and intersectionality 228 230

subordinated masculinity 258
sub-Saharan Africans' migrants media representations of construction of masculinities in the Libya conflict, 20II 242-259

Sudan 296

Suharto, Haji Mohamed 34

symbolic violence 25I, 257, 258

concept 243

media representations of the Libyan

Conflict, 20II 249-25I

$\mathrm{T}$

Tabasco 195, I99

Taiwan 33

arranged transnational marriage in the context of the East Asian welfare regime 88,89 , 9I, 92, 94-IOO

talibés 274

temporary legality 3I3

temporary migration I24, I27, I33, I36, I37, I47

Temporary Protected Status

(TPS) 329

temporary workers $372-374$

terrorism I2

Thailand 372, 373, 378, 384

administration of labour migration

policy 3IO, 3II

Burmese migrant women

workers $70-83$

childcare $80,8 \mathrm{I}$

children of migrants and challenges

of accessing education 309-32I, 325

creating 'cheap labour' for export

industries $73-76$

economic situation 82

Education for All Cabinet Resolution of 2005 308, 3I5

expansion of economy and large national demand for labour 307

Foreign Employment Acts 309

gross domestic product (GDP) 307

Immigration Act 1979309

irregular migrant workers 82

Labour Protection Act of 1998309 Labour Rights Promotion Network

(LPN) 3I $4,3 \mathrm{I} 5,3 \mathrm{I} 8$

memoranda of understanding

(MOU) with neighbouring

countries 7I, 74, 3II

migrant children policy 3II migrant labour in Samut Sakhon

Province 3II, 3I2

migration in the middle Mekong

Valley 334-346

Ministry of Education (MOE) 3II, 3I5, 316

Ministry of the Interior (MOI) 3II, 315,320 , 
Ministry of Labour (MOL) 3IO, 3I4, 3I5, 3I7

Mon-Thai community 3I5

policy on labour migration 309-3I2

providing education to migrant

children 308, 309

regulation and control of migrant

factory workers $73-77$

restricting women migrant workers'

mobility 76,77

Royal Thai Government 337

Royal Thai Police 3I5

Special Economic Zone in Mae

Sot 75

Yaung Chi Oo Workers Association

(YCOWA) 72

Thailand Development Research Institute (TDRI) 82

tileño I79, I86, I90

Trachoma 266

transnational care $2 \mathrm{I} 7$

transnational cooperation 34

transnational crime 196, 273, 276

transnational economy of care 33

transnational families $17,20,34,43$,

$89,90,100,218,22 \mathrm{I}-224$

challenges to manhood for Senega-

lese migrants 22I-224

Confucian (East Asian) family 88-

92, 100

gender relations 217,224

intersectionality and hegemonic

masculinity 2I7, 2I $8,223,224$

markers of manhood for Senegalese

migrants 2I8-22I

Spain and Morocco 52, 53

Spain and Senegal 59

study/research of 215-2I7

transnational migration regime $3 \mathrm{I}$,

34

transnational father 223

transnational health challenges 238

transnational justice Io

transnational labour markets 339

transnational labour migration 3I, 35,

43

transnational labour movements II7

transnational marriages 89, 9I, 94, 96,

IOO

definition 89, 90

East Asian family-based welfare

regime 9I-94

social reproduction and the repro-

ductive bargain 90, 9I

Taiwan, South Korea, and Vietnam

and the East Asian welfare

regime 88-IOO transnational migration/migrants (see also international migration) 5,6 , 9, IO, I7, 20, 2I, 43, 48, 64, I75, 2I6, 2I9, 22I, 223, 224, 287, 288, 354

conception of $37 \mathrm{I}$

West African 2I9

women $\mathrm{IO} 7$

transnational migratory practices $2 \mathrm{I} 6$

transnational mobility 5, 6

transnational motherhood 2I7

transnational relations

equality and social justice

implications $2 \mathrm{I} 5$

transnational reproductive labour $7 \mathrm{I}$

transnational spaces $2 \mathrm{I} 7,288$

transnationalism 34, 216, 359

Tunisia 249

$\mathrm{U}$

Understanding Children's Work (UCW) 274

United Arab Emirates (UAE) I2, I3, 20, 29-45, 29I-306, 328

Federal Law No. 8 on labour 34, $36-38$

female migrant domestic

workers 29I-304, 325, 326

Immigration Office 38

Indonesian migrant domestic

workers 30, 3I, 33, 34, 36-39, 4I- 43

Kafala system $34,36-38$

labour law 296

legal systems 296, 297

Ministry of the Interior 298

national law on labour migration

and domestic work 34-39

United Kingdom 206

United Nation Children's Fund (UNICEF) 308

United Nations (UN)

human security 4

Human Security Now report 24I

Responsibility to Protect (RtoP)

principle 24I, 242, 248, 257, 259

Security Council 248

United Nations Charter II

United Nations Children's Fund (UNICEF) 274

United Nations Convention on Transnational Organized Crime (UNCTOC) 273

Protocols on Human Trafficking and Human 196

United Nations Development Fund for Women (UNIFEM) 335

United Nations Development Programme (UNDP)

Human Development Report of I994 II, I2
United Nations Educational, Scientific and Cultural Organization

(UNESCO) 4, I80

'Education for All' campaign 308

United States of America (USA) 33, I95, 327, 357, 372, 378

debates on migration and

citizenship 9, IO

Deferred Action programme and refugees from El Salvador 329

National Domestic Workers

Alliance 29

Universal Declaration of Human

Rights (I948) 284

urban- and residence-based approach I53, I55, I62

urban citizenship 153

urban integration $\mathrm{I} 53, \mathrm{I} 67$

urban migration $\mathrm{I} 45$

68

urbanization I26, I73, 266

usual place of residence (UPR) I23, I27, I3I-I33

V

Vietnam 74

Agricultural Decision No. IO in I988 93

arranged transnational marriage in

the context of the East Asian welfare regime 88,89 , 9I-IOO

Chinese Codes 92

Civil Codes 92, 93

Doi Moi reform 93

Family Law 92-94

Hong Duc Code 92

household contract-based system

(khoan ho) 93

rural sector 92-94

social reproduction crisis $\quad 92-94$

virility $\mathbf{I} 88$

\section{W}

Waiji/dalu Xinniang (foreign/mainland brides) in Taiwan 89

war crimes 24I

wasta concept 302, 303

welfare regimes I6, 87, 88, 9I, 93, I00 gender 90

Wenner-Gren Foundation for Anthropological Research 352

West Africa international migration 265-267, 269, 273, 274, 276

Wolof 2I6, 2I9, 22I, 224

women migrants/migration 6-9, I24, I64, 369, 370, 379-38I, 384

changes in India I40-I49

Everyday Politics (EDP) 205-208 
Fujian Province (China) I56-I69 gender equality and rights 6-8

living in situations of invisibility 204 in/visibility of 203-205

invisibility and re-cognition $38 \mathrm{I}-384$ policy suggestions and approaches for the protection of rights in China I67-I69 rights and aspects of gender differences in China I57-I62

San Martín Tilcajete, Mexico I8II9O

women's movement I24-I26, I28-I3I, I37, I39, I46, I49

woodcarving I73, I74, I77, I80, I8I, I86, I88- 90

World Bank 339, 378

World Health Organization (WHO) 229

World Heritage Site I80

World Migration Report 370

World Social Forum II

$\mathrm{X}$

xenophobia 4, 199, 358-360, 372, 374

Y

Yaung Chi Oo Workers Association

(YCOWA), Thailand 72

Z

Zapatista movement 195

Zapotec language $\mathrm{I} 77$

Zapotec origin 177

Zapotec world outlook I89 


\section{Hexagon Series on Human and Environmental Security and Peace (HESP)}

This book series includes monographs and edited volumes that cross scientific disciplines and develop common ground among scientists from the natural and social sciences, as well as from North and South, addressing common challenges and risks for humankind in the $2 \mathrm{I}^{\text {st }}$ century.

The 'hexagon' represents six key factors contributing to global environmental change three nature-induced or supply factors: soil, water and air (atmosphere and climate), and three human-induced or demand factors: population (growth), urban systems (habitat, pollution) and rural systems (agriculture, food). Throughout the history of the earth and of homo sapiens these six factors have interacted. The supply factors have created the preconditions for life while human behaviour and economic consumption patterns have also contributed to its challenges (increase in extreme weather events) and fatal outcomes for human beings and society. The series covers the complex interactions among these six factors and their often extreme and in a few cases fatal outcomes (hazards/disasters, internal displacement and migrations, crises and conflicts), as well as crucial social science concepts relevant for their analysis.

Further issues related to three basic areas of research: approaches and schools of environment, security, and peace, especially in the environmental security realm and from a human security perspective, will be addressed. The goal of this book series is to contribute to a fourth phase of research on environmental security from a normative peace research and/ or human security perspective. In this series, the editor welcomes books by natural and social scientists, as well as by multidisciplinary teams of authors. The material should address issues of global change (including climate change, desertification, deforestation), and its impacts on humankind (natural hazards and disasters), on environmentally-induced migration, on crises and conflicts, as well as for cooperative strategies to cope with these challenges either locally or in the framework of international organizations and regimes.

From a human-centred perspective, this book series offers a platform for scientific communities dealing with global environmental and climate change, disaster reduction, human, environmental and gender security, peace and conflict research, as well as for the humanitarian aid and the policy community in national governments and international organizations.

The series editor welcomes brief concept outlines and original manuscripts as proposals. If they are considered of relevance, these proposals will be peer-reviewed by specialists in the field from the natural and the social sciences. Inclusion in this series will also require a positive decision by the publisher's international editorial conference. Prior to publication, the manuscripts will be assessed by the series editor and external peer reviewers.

Mosbach, Germany, May 2013

Hans Günter Brauch, Free University of Berlin and AFES-PRESS

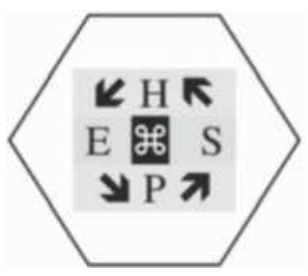




\section{Hexagon Series on \\ Human and Environmental Security and Peace (HESP)}

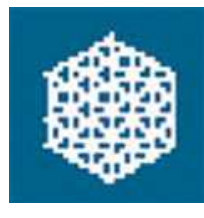

Edited by

\section{Hans Günter Brauch, Free University of Berlin, UNU-EHS and AFES-PRESS}

Vol. I: Hans Günter Brauch, P. H. Liotta, Antonio Marquina, Paul Rogers, Mohammad El-Sayed Selim (Eds.): Security and Environment in the Mediterranean - Conceptualising Security and Environmental Conflicts. With Forewords by the Hon. Lord Robertson, Secretary General of NATO, and the Hon. Amre Moussa, Secretary General of the League of Arab States (Berlin - Heidelberg - New York: Springer, 2003).

ISBN: 978-3-540-40I07-0 (Print)

ISBN: 978-3-642-55854-2 (Online)

DOI I0.I007/978-3-642-55854-2

Vol. 2: Hillel Shuval, Hassan Dweik (Eds.): Water Resources in the Middle East: IsraelPalestinian Water Issues - from Conflict to Cooperation (Berlin - Heidelberg New York: Springer-Verlag, 2007).

ISBN: 978-3-540-69508-o (Print)

ISBN: 978-3-540-69509-7 (Online)

DOI I0.I007/978-3-540-69509-7

Vol. 3: Hans Günter Brauch, Úrsula Oswald Spring, Czeslaw Mesjasz, John Grin, Pál Dunay, Navnita Chadha Behera, Béchir Chourou, Patricia Kameri-Mbote, P.H. Liotta (Eds.): Globalization and Environmental Challenges: Reconceptualizing Security in the $2 I^{s t}$ Century (Berlin - Heidelberg - New York: Springer-Verlag, 2008). ISBN : 978-3-540-75976-8 (Print)

ISBN : 978-3-540-75977-5 (Online)

DOI I0.I007/978-3-540-75977-5

Vol. 4: Hans Günter Brauch, Úrsula Oswald Spring, John Grin, Czeslaw Mesjasz, Patricia Kameri-Mbote, Navnita Chadha Behera, Béchir Chourou, Heinz Krummenacher (Eds.): Facing Global Environmental Change: Environmental, Human, Energy, Food, Health and Water Security Concepts (Berlin - Heidelberg - New York: Springer-Verlag, 2009).

ISBN: 978-3-540-68487-9 (Print)

ISBN: 978-3-540-68488-6 (Online)

DOI I0.1007/978-3-540-68488-6

Vol. 5: Hans Günter Brauch, Úrsula Oswald Spring, Czeslaw Mesjasz, John Grin, Patricia Kameri-Mbote, Béchir Chourou, Pal Dunay, Jörn Birkmann (Eds.): Coping with Global Environmental Change, Disasters and Security - Threats, Challenges, Vulnerabilities and Risks (Berlin - Heidelberg - New York: Springer-Verlag, 20II).

ISBN: 978-3-642-I7775-O (Print)

ISBN: 978-3-642-I7776-7 (Online)

DOI I0.I007/978-3-642-I7776-7 
Vol. 6: Thanh-Dam Truong, Des Gasper (Eds.): Transnational Migration and Human Security: The Migration - Development - Security Nexus. Hexagon Series on Human and Environmental Security and Peace, vol. 6 (Heidelberg - Dordrecht London - New York: Springer, 20II).

ISBN 978-3-642-I2756-4 (Print)

ISBN 978-3-642-I2757-I (Online)

DOI I0.1007/978-3-642-I2757-I

Vol. 7: Úrsula Oswald Spring (Ed.): Water Resources in Mexico. Scarcity, Degradation, Stress, Conflicts, Management, and Policy. Hexagon Series on Human and Environmental Security and Peace, vol. 7 (Heidelberg - Dordrecht - London - New York: Springer, 20II).

ISBN: 978-3-642-0543I-O (Print)

ISBN 978-3-642-05432-7 (Online)

DOI I0.I007/978-3-642-05432-7

Vol. 8: Jürgen Scheffran; Michael Brzoska; Hans Günter Brauch; Peter Michael Link; Janpeter Schilling (Eds.): Climate Change, Human Security and Violent Conflict: Challenges for Societal Stability. Hexagon Series on Human and Environmental Security and Peace, vol. 8 (Berlin - Heidelberg - New York: Springer-Verlag, 20I2).

ISBN: 978-3-642-28625-4 (Print)

ISBN 978-3-642-28626-I (Online)

DOI I0.I007/978-3-642-28626-I

Vol. 9: ThanhDam Truong, Des Gasper, Jeff Handmaker, Sylvia I. Bergh, (Eds.): Migration, Gender and Social Justice - Perspectives on Human Insecurity. Hexagon Series on Human and Environmental Security and Peace, vol. 9 (Heidelberg - Dordrecht - London - New York: Springer-Verlag, 2013).

ISBN: 978-3-642-280II-5 (Print)

ISBN 978-3-642-280I2-2 (Online)

DOI I0.I007/978-3-642-280I2-2

\section{In Planning}

Vol. Io: Hans Günter Brauch, Úrsula Oswald Spring, John Grin, Jürgen Scheffran (Eds.): Sustainability Transition and Sustainable Peace Handbook. Hexagon Series on Human and Environmental Security and Peace Io (Heidelberg - New York - Dordrecht - London: Springer-Verlag, 20I4).

Vol. II: Czeslaw Mesjasz: Stability, Turbulence or Chaos? Systems Thinking and Security. Hexagon Series on Human and Environmental Security and Peace, vol. II (Berlin Heidelberg - New York: Springer-Verlag, 20I4).

Authors or editors who would like to have their publication project considered for inclusion in this series should contact both the series editor:

PD Dr. phil. habil. Hans Günter Brauch, Alte Bergsteige 47, 7482I Mosbach, Germany

Phone: 49-626I-I29I2 FAX: 49-626I-I5695

Email afes@afes-press.de

http://www.afes-press.de and http://www.afes-press-books.de/html/hexagon.htm

and the publisher:

Dr. Christian Witschel, Editorial Director, Earth Sciences, Geosciences Editorial, Springer-Verlag Tiergartenstraße I7, 69I2I Heidelberg, Germany

Email Christian.Witschel@springer.com

http://www.springer.com

Springer: 〈http://www.springer.com/series/8090>

AFES-PRESS: 〈http://www.afes-press-books.de/html/hexagon.htm> 


\section{SpringerBriefs in}

\section{Environment, Security, Development and Peace}

Editor:

Hans Günter Brauch, Free University Berlin, Germany

SpringerBriefs in Environment, Security, Development and Peace (ESDP) present concise summaries of cutting-edge research as well as innovative policy perspectives. The series focuses on the interconnection of new and nontraditional global environmental and development challenges facing humankind that may pose dangers for peace and security in the Anthropocene era of earth history. SpringerBriefs in ESDP publish monographs as well as edited volumes of topical workshops that are peer-reviewed by scholars from many disciplines and from all parts of the world. SpringerBriefs in ESDP will give more "voice" and "visibility" to scientists and innovative political thinkers in developing countries.

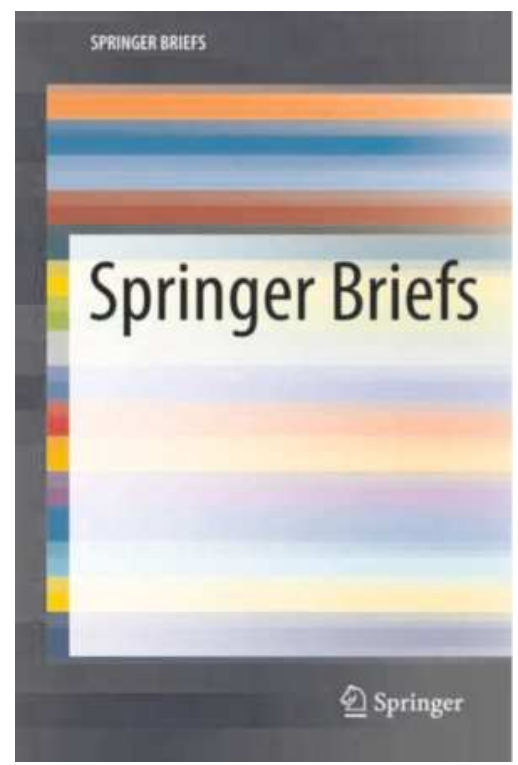

The books will be published 8 to 12 weeks after acceptance. Featuring compact volumes of 50 to 125 pages (approx. 20,000- 70,000 words), the series covers a wide scope of policy-relevant issues from policy-oriented, to professional and academic perspectives.

SpringerBriefs in ESDP address the "conceptual quartet" among the four research research programmes in the social sciences focusing on Environment, Security, Development and Peace as well as the "consilience" between the natural and the social sciences that try to initiate debates and to provide multi-, inter- and transdisciplinary knowledge relevant for coping with the multiple projected impacts of global environmental change.

- Timely reports of state-of-the art analyses (e.g. from earth systems science or analysis, geoecology) and policy assessments dealing with the global challenges facing humankind in the $21^{\text {st }}$ century

- SpringerBriefs in ESDP bridges between new research results offering snapshots of hot and/or emerging topics, literature reviews and in-depth case studies

Briefs will be published as part of Springer's eBook collection, with millions of users worldwide. In addition, Briefs will be available for individual print and electronic purchase. Briefs are characterized by fast, global electronic dissemination, standard publishing contracts, easy-to-use manuscript preparation and formatting guidelines, and expedited production schedules.

Interested? Please send your proposal to:

PD Dr. habil. Hans Günter Brauch

Alte Bergsteige 47, 74821 Mosbach, Germany

hg.brauch@onlinehome.de

Your proposal should consist of the following items: Title, Author(s) information, Abstract, 5 Keywords (would be used when searching your topic on Google or Amazon), Manuscript delivery date, estimated number of pages, concise outline (ca. 200 words), Table of contents. Please allow 1-2 months for the peer review process. 


\section{SpringerBriefs in Environment, Security, Development and Peace}

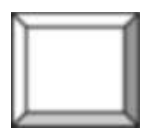

Edited by

Hans Günter Brauch, Free University of Berlin, UNU-EHS and AFES-PRESS

Vol. I: Mely Caballero-Anthony, Youngho Chang and Nur Azha Putra (Eds.): Energy and Non-Traditional Security (NTS) in Asia. SpringerBriefs in Environment, Security, Development and Peace, vol. I (Heidelberg - Dordrecht - London - New York: Springer-Verlag, 20I2).

Vol. 2: Mely Caballero-Anthony, Youngho Chang and Nur Azha Putra (Eds.): Rethinking Energy Security in Asia: A Non-Traditional View of Human Security. SpringerBriefs in Environment, Security, Development and Peace, vol. 2 (Heidelberg Dordrecht - London - New York: Springer-Verlag, 20I2).

Vol. 3: Philip Jan Schäfer: Human and Water Security in Israel and Jordan. SpringerBriefs in Environment, Security, Development and Peace, vol. 3 (Heidelberg - Dordrecht London - New York: Springer-Verlag, 2013).

Vol. 4: Gamal M. Selim: Euro-American Approaches to Arms Control and ConfidenceBuilding Measures in the Middle East: A Critical Assessment from the South. SpringerBriefs in Environment, Security, Development and Peace, vol. 4 - Mediterranean Studies Subseries No. I (Heidelberg - Dordrecht - London - New York: Springer-Verlag, 20I3).

Vol. 5: Charlène Cabot: Climate Change and Security Risks in Africa. A Case Study of Farmer-Herder Conflicts over Natural Resources in Côte d'Ivoire, Ghana, and Burkina Faso. SpringerBriefs in Environment, Security, Development and Peace, vol. 5 - (Heidelberg - Dordrecht - London - New York: Springer-Verlag, 20I3).

Vol. 6: Lourdes Arizpe, Cristina Amescua: Anthropological Perspectives on Intangible Cultural Heritage. SpringerBriefs in Environment, Security, Development and Peace, vol. 6 (Heidelberg - Dordrecht - London - New York: Springer-Verlag, 2013).

Vol. 7: Ebru Gencer: Natural Disasters and Risk Management in Urban Areas: A Case Study of the Istanbul Metropolitan Area. SpringerBriefs in Environment, Security, Development and Peace, vol. 7 - Mediterranean Studies Subseries No. 2 (Heidelberg - Dordrecht - London - New York: Springer-Verlag, 2013).

Vol. 8: Selim Kapur, Sabit Erşahin (Eds.): Soil Security for Eco-system Management SpringerBriefs in Environment, Security, Development and Peace, vol. 8 - Mediterranean Studies Subseries No. 3 (Heidelberg - Dordrecht - London - New York: Springer-Verlag, 20I3).

Vol. 9: Zairina Othman, Sity Daud, Rashila Ramli: Human Security and Peace in ArchipelagicSoutheast Asia. SpringerBriefs in Environment, Security, Development and Peace, vol. 9, ASEAN Studies Subseries No. I (Heidelberg - Dordrecht - London New York: Springer-Verlag, 20I4).

Vol. Io: Nur Azha Putra, Aulalia Han (Eds.): Governments Responses to Climate Change: Selected Examples from Asia-Pacific. SpringerBriefs in Environment, Security, Development and Peace, vol. Io - ASEAN Studies Subseries No. I (Heidelberg Dordrecht - London - New York: Springer-Verlag, 20I4).

Vol. II: Sara Hellmüller, Martina Santschi (Eds.): Is Local Beautiful? Peacebuilding between International Interventions and Locally Led Initiatives. SpringerBriefs in Environment, Security, Development and Peace, vol. II - Peace and Security Studies Subseries No. I. (Heidelberg - Dordrecht - London - New York: Springer-Verlag, 20I4). 
Vol. I2: Úrsula Oswald Spring, Hans Günter Brauch, Keith G. Tidball (Eds.): Expanding Peace Ecology: Security, Sustainability, Equity and Peace: Perspectives of IPRA's Ecology and Peace Commission. SpringerBriefs in Environment, Security, Development and Peace, vol. I2 - Peace and Security Studies Subseries No. 2 (Heidelberg Dordrecht - London - New York: Springer-Verlag, 20I4).

Vol. 13: Lourdes Arizpe: Beyond Culture: Conviviability and the Sustainable Transition. SpringerBriefs in Environment, Security, Development and Peace, vol. I3 (Heidelberg - Dordrecht - London - New York: Springer-Verlag, 20I4).

Vol. I4: Liliana Rivera-Sánchez, Fernando Lozano-Ascencio (Eds.): The Practice of Research on Migration and Mobilities. SpringerBriefs in Environment, Security, Development and Peace, vol. I4 - Migration Studies Subseries No. I (Heidelberg Dordrecht - London - New York: Springer-Verlag, 20I4).

Vol. I5: Yongyuth Chalamwong - Naruemon Thabchumpon (Eds.): Livelihood Opportunities, Labour Market, Social Welfare and Social Security in Temporary Sheltered and Surrounding Communities. SpringerBriefs in Environment, Security, Development and Peace, vol. I5 - Migration Studies Subseries No. 2 (Heidelberg - Dordrecht - London - New York: Springer-Verlag, 20I4).

Vol. I6: Suwattana Thadaniti (Ed.): The Impact of Displaced People's Temporary Shelters on their Surrounding Environment. SpringerBriefs in Environment, Security, Development and Peace, vol. I6 - Migration Studies Subseries No. 3 (Heidelberg Dordrecht - London - New York: Springer-Verlag, 20I4).

Vol. I7: Premjai Vungsiriphisal and Dares Chusri (Eds.): Royal Thai Government Policy and Donor, INGO/NGO and UN Agency Delivery of Humanitarian Assistance for Displaced Persons from Myanmar. SpringerBriefs in Environment, Security, Development and Peace, vol. 17 - Migration Studies Subseries No. 4 (Heidelberg Dordrecht - London - New York: Springer-Verlag, 20I4).

Vol. I8: Ben Harkins, Nawita Direkwut, Aungkana Kamonpetch (Eds.): Resettlement of Displaced Persons on the Thai-Myanmar Border - Executive Summary and Recommendations. SpringerBriefs in Environment, Security, Development and Peace, vol. I8 - Migration Studies Subseries No. 5 (Heidelberg - Dordrecht - London - New York: Springer-Verlag, 20I4).

Authors or editors who would like to have their publication project considered for inclusion in this series should contact both the series editor:

PD Dr. phil. habil. Hans Günter Brauch, Alte Bergsteige 47, 7482I Mosbach, Germany

Phone: 49-626I-I29I2 - FAX: 49-626I-I5695 - Email: afes@afes-press.de

http://www.afes-press.de and http://www.afes-press-books.de

and the publisher:

Dr. Johanna Schwarz, Editor, Earth Sciences, Geosciences Editorial, Springer-Verlag Tiergartenstraße I7, 69I2I Heidelberg, Germany

Email: Johanna.Schwarz@springer.com and http://www.springer.com

Springer: 〈http://www.springer.com/series/10357>

AFES-PRESS: <http://www.afes-press-books.de/html/SpringerBriefs_ESDP.htm> 


\section{Springer Briefs on Pioneers in Science and Practice (PSP)}

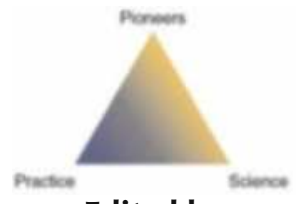

Edited by

\section{Hans Günter Brauch, Free University of Berlin, UNU-EHS and AFES-PRESS}

Vol. I: Arthur H. Westing: Arthur H. Westing: Pioneer on the Environmental Impact of War. SpringerBriefs on Pioneers in Science and Practice No. I - presented by Hans Günter Brauch (Heidelberg - New York - Dordrecht - London: Springer-Verlag, 2013).

Vol. 2: Rodolfo Stavenhagen: Pioneer on Indigenous Rights. Springer Briefs in Pioneers in Science and Practice No. 2 - presented by Ursula Oswald Spring (Heidelberg - Dordrecht - London - New York: Springer-Verlag, 20I3).

Vol. 3: Rodolfo Stavenhagen: The Emergence of Indigenous Peoples. Springer Briefs on Pioneers in Science and Practice, vol. 3, Subseries with Texts and Protocols, vol. I (Heidelberg - New York - Dordrecht - London: Springer-Verlag, 20I3).

Vol. 4: Rodolfo Stavenhagen: Peasants, Culture and Indigenous Peoples: Critical Issues. Springer Briefs on Pioneers in Science and Practice, vol. 4, Subseries with Texts and Protocols, vol. 2 (Heidelberg - New York - Dordrecht - London: Springer-Verlag, 20I3).

Vol. 5: Johan Galtung: Pioneer of Peace Research. SpringerBriefs on Pioneers in Science and Practice No. 5 - presented by Dietrich Fischer [Switzerland] (Heidelberg - New York - Dordrecht - London: Springer-Verlag, 20I3).

Vol. 6: Dieter Senghaas: Pioneer of Peace and Development Research. SpringerBriefs on Pioneers in Science and Practice No. 6 - presented by Michael Zürn (Heidelberg New York - Dordrecht - London: Springer-Verlag, 20I3).

Vol. 7: Chadwick Alger: Pioneer in the Study of the Political Process and on NGO Participation in the United Nations. Springer Briefs on Pioneers in Science and Practice No. 7 - presented by Carolyn Stephenson (Heidelberg - New York - Dordrecht London: Springer-Verlag, 20I4).

Vol. 8: Chadwick F. Alger: The UN System and Cities in Global Governance. Springer Briefs on Pioneers in Science and Practice No. 8. Subseries Texts and Protocols No. 3 (Heidelberg - New York - Dordrecht - London: Springer-Verlag, 20I4).

Vol. 9: Chadwick F. Alger: Peace Research and Peacebuilding. Springer Briefs on Pioneers in Science and Practice No. 9. Subseries Texts and Protocols No. 4 (Heidelberg New York - Dordrecht - London: Springer-Verlag, 20I4).

Vol. Io: Lourdes Arizpe: Lourdes Arizpe Schlosser: A Mexican Pioneer in Anthropology. Springer Briefs on Pioneers in Science and Practice No. IO - presented by Margarita Velázquez Gutiérrez (Heidelberg - New York - Dordrecht - London: SpringerVerlag, 20I4).

Vol. II: Lourdes Arizpe: Migration, Women and Social Development: Key Issues. Springer Briefs on Pioneers in Science and Practice No. II. Subseries Texts and Protocols No. 5 (Heidelberg - New York - Dordrecht - London: Springer-Verlag, 20I4).

Vol. I2: Lourdes Arizpe: Culture, Diversity and Heritage: Major Studies. Springer Briefs on Pioneers in Science and Practice No. I2. Subseries Texts and Protocols No. 6 (Heidelberg - New York - Dordrecht - London: Springer-Verlag, 20I4). 
Vol. I3: Arthur H. Westing: Texts on Environmental and Comprehensive Security. SpringerBriefs on Pioneers in Science and Practice No. I3 - Subseries Texts and Protocols No. 7 (Heidelberg - New York - Dordrecht - London: Springer-Verlag, 20I4).

Vol. I4: Klaus von Beyme: Pioneer in the Study of Political Theory and Comparative Politics. SpringerBriefs on Pioneers in Science and Practice No. I4 - Presented by Rainer Eisfeld (Heidelberg - New York - Dordrecht - London: Springer-Verlag, 2013).

Vol. I5: Klaus von Beyme: On Political Culture, Culture, Art and Politics. SpringerBriefs on Pioneers in Science and Practice No. 15 - Subseries Texts and Protocols No. 7 (Heidelberg - New York - Dordrecht - London: Springer-Verlag, 20I4).

Vol. I6: Samir Amin: Pioneer on the Rise of the South - Presented by Dieter Senghaas. SpringerBriefs on Pioneers in Science and Practice No. I6 (Heidelberg - New York - Dordrecht - London: Springer-Verlag, 20I4).

Authors or editors who would like to have their publication project considered for inclusion in this Springer Briefs in PSP series should contact both the series editor:

PD Dr. phil. habil. Hans Günter Brauch, Alte Bergsteige 47, 7482I Mosbach, Germany Phone: 49-626I-I29I2 - FAX: 49-626I-I5695 - Email afes@afes-press.de http://www.afes-press.de and http://www.afes-press-books.de and the publisher:

Dr. Johanna Schwarz, Editor, Earth Sciences, Geosciences Editorial, Springer-Verlag Tiergartenstraße 17, 6912I Heidelberg, Germany

Email: Johanna.Schwarz@springer.com and http://www.springer.com

Springer: 〈http://www.springer.com/series/I0970>

AFES-PRESS: <http://www.afes-press-books.de/html/SpringerBriefs_PSP.htm> 